\title{
PERFIL ESPECTROGRÁFICO DA HIPERNASALIDADE DE FALA DE MULHERES PORTADORAS DE FISSURA PALATINA
}

\begin{abstract}
Dissertação apresentada ao Programa de Pós-Graduação Interunidades em Bioengenharia (Escola de Engenharia de São Carlos - Faculdade de Medicina de Ribeirão Preto - Instituto de Química de São Carlos) da Universidade de São Paulo, como parte dos requisitos para obtenção do Título de Mestre em Bioengenharia.
\end{abstract}

Orientadora: Profa. Dra. Maria Inês Pegoraro-Krook

São Carlos

2003 


\title{
Dedico este trabalho aos Meus Amados Pais:
}

\author{
Lourdes Leite Melo Vieira \& Rui de Souza Vieira
}

A quem devo a vida,

O apoio incondicional em todos os momentos de minha caminhada,

A pessoa que sou e a que eu virei a ser.

A eles, que são meu exemplo de honestidade, responsabilidade, respeito e esforço.

Com eles aprendi o valor da vida, da confiança, do trabalho e da educação.

O que sempre me impressionou foi o amor que sempre tiveram à escola e a crença de que nos tornamos melhores e cidadãos dignos pelo processo educacional. Sem dúvida, isto é possível, mas não suficiente.

A abnegação dos pais ou dos cuidadores de uma criança, primando por seu caráter e para que ame seu próximo como a si mesmo, como fizeram meus pais, são fatores igualmente importantes, senão imprescindíveis.

Aprendi com meus pais que Educação é muito mais que ir ao colégio...

É fazer do mundo uma escola;

E de cada planta ou animal;

De cada ser humano: rico ou pobre, doutor ou analfabeto:

Um professor.

E a todos, devotar respeito.

Meus Pais,

Muito, Muito Obrigada!

Aos Senhores dedico este trabalho. 


\title{
Agradecimentos Especiais:
}

\begin{abstract}
À Profa. Dra. Maria Inês Pegoraro-Krook, minha Orientadora e Amiga, agradeço a liberdade de agir e o estímulo inestimável em minha trajetória profissional, bem como o apoio e as palavras certas nos momentos decisivos.

Nunca me deu o peixe; sempre me impulsionou a pescar...
\end{abstract}

Ao Prof. Dr. José Carlos Pereira, a quem admiro a humildade e o espírito de luta. Estendeu-me a mão, colocou-me diante da estrada e disse: ande. Sempre pude contar com seu apoio. Seu respeito e sua consideração com quem sabe menos (às vezes, muito menos, como eu), tornaram inegáveis e atingíveis meu crescimento pessoal e profissional. Contigo experenciei que aprender dói, é um caminho árduo, mas se torna possível com companheirismo, esforço e dedicação. Especialmente, quando se quer abrir um novo caminho e uma nova mentalidade...

Ao Prof. Dr. Plínio Almeida Barbosa, apoio constante nas horas mais difíceis. Mesmo com toda a sabedoria que possui, nunca furtou-se de sentar-se ao lado, pegar no "mouse" e realizar seu dom: ensinar. Sua humildade e dedicação são incomensuráveis.

À Profa. Dra. Lídia Cristina Teles-Magalhães, minha sempre professora, exemplo de vida e, acima de tudo: Amiga... Agradeço-lhe a oportunidade de estar sempre compartilhando sua pessoa, sua família, a profissão e o desenvolvimento acadêmicocientífico. Contigo aprendi que é preciso ser um ser humano completo, desenvolver-se em todas as áreas e que nada, nada vale sem Amor... 


\section{Agradecimentos}

A Deus, presença constante em minha vida... minha fonte inesgotável de alento e coragem...

Aos meus irmãos: Ivan e Joice por todo carinho, fraternidade, torcida e por terem agüentado firmes meus estresses...

Aos Amigos de todas as horas e de muitas formas:

Ana Cristina Musa Minervino-Pereira, Josiane Fernandes Denardi,

Luciana Mara de Oliveira Andrade, Marcos K. Magalhães e Pablo Arantes

À equipe Projeto Flórida/Prótese de Palato do HRAC/USP: Érika, Homero, Luciano, Teresa e Simone pela amizade e apoio, de diversas maneiras...

Aos Professores do Programa Interunidades Bioengenharia/USP, aos Amigos Aparecida (Parê), Daniel, Maira, Marcelo Rosa e Mori por toda atenção, carinho e companheirismo, à querida secretária Janete e ao Serviço de Biblioteca da EESC

Ao Hospital de Reabilitação de Anomalias Craniofaciais (HRAC/USP) pelo espaço, seus diversos setores/equipes: Unidade de Ensino e Pesquisa (UEP), Centro de Processamento de Dados (CPD), Central de Agendamento, Recursos Humanos, Fotografia, Pós-Graduação... Destes locais há uma lista infindável de nomes de pessoas que mais do que na pesquisa, ajudaram-me a crescer como ser humano... foram mais que profissionais, foram amigos...

Ao Laboratório de Fonética e Psicolingüística do Instituto de Estudos da Linguagem da Universidade de Campinas (LAFAPE/IEL/UNICAMP), pelo apoio na análise dos dados e pelo exemplo de crescimento cooperativo.

Ao Laboratório de Fonética HRAC/USP, pelos 3 anos e 8 meses de convivência diária... Onde aprendi muito; vivi medos, angústias e alegrias; fiz inúmeras descobertas... Compartilhei idéias, ideais, e, especialmente, a amizade. Cresci. A suas paredes brancas e seu silêncio... meu profundo e irrestrito agradecimento. Sem janelas, ajudou-me a abrir portas...

Ao apoio financeiro da Fundação de Amparo à Pesquisa do Estado de São Paulo (FAPESP)

A todas as participantes: pacientes e não pacientes do HRAC/USP - meu Muito Obrigada! 
Esta minha representação do corpo humano vai ser tão clara que é como se você tivesse o próprio homem à frente; e isto porque, se você deseja conhecer as partes do homem, anatomicamente, você, ou seu olho, precisa vê-lo de diferentes ângulos, considerando-o de baixo, de cima e dos lados, fazendo-o girar e procurando a origem de cada membro... Por isso os meus desenhos, valendo-se de todos os recursos possíveis, o farão conhecer todas as partes, e cada uma delas de três pontos de vista diferentes.

Leonardo da Vinci (grifos meus) 


\section{RESUMO}

VIEIRA, J. M. (2003). Perfil espectrográfico da hipernasalidade de fala de mulheres portadoras de fissura palatina. Dissertação (Mestrado) - Programa de Pós-Graduação Interunidades Bioengenharia (EESC/FMRP/IQSC), Universidade de São Paulo, São Carlos, 2003.

A hipernasalidade de fala é um distúrbio da ressonância nasal, freqüentemente encontrada em portadores de fissura palatina com disfunção velofaríngea. Constitui-se de uma nasalidade imprópria e excessiva dos sons exclusivamente orais, que pode ser analisada pela espectrografia, que decompõe o sinal de fala em três dimensões de análise: freqüência, tempo e intensidade, gerando um gráfico, o espectrograma. Assim, o objetivo do presente estudo é investigar as características espectrográficas da hipernasalidade de fala de mulheres portadoras de fissura palatina e comparar os achados com os resultados da nasometria e da avaliação perceptivo-auditiva de suas emissões de fala. Contou-se com a colaboração de 30 mulheres sem comprometimentos de fala e do trato vocal, 5 portadoras de fissura palatina não operada e 21 portadoras de fissura palatina operada, na faixa etária de 18 a 40 anos de idade. Emitiram as vogais [a] e [ẽ] sustentadas, separadamente e dentro de uma frase-veículo diante do nasômetro e de um gravador digital. Estas amostras de fala foram avaliadas perceptivoauditivamente, determinadas suas nasalâncias e características formânticas. Foram encontradas as seguintes características espectrográficas: inserção de formantes nasais e antiformantes dentre os formantes orais nas emissões nasalizadas/hipernasalizadas. Não houve correspondência direta desses achados com a nasometria nem com a avaliação perceptivo-auditiva e nem destas entre si.

Palavras-chave: fissura palatina; disfunção velofaríngea; hipernasalidade de fala; espectrografia; formante. 


\section{ABSTRACT}

VIEIRA, J. M. (2003). Spectrographic profile of the speech hipernasality cleft palate women. M.Sc. Dissertation - Programa de Pós-Graduação Interunidades Bioengenharia (EESC/FMRP/IQSC), Universidade de São Paulo, São Carlos, 2003.

Speech hypernasality is a nasal resonance's disorder, come across often in cleft palate persons with velopharingeal disfuction. It is an inappropriate and excessive nasality just oral sounds, that can be analyzed for spectrograph (decompose speech signal in three dimensions: frequency, time and intensity, generating the spectrogram). Hence, this dissertation has the objective of investigating speech hipernasality spectrographic cues of the cleft palate women and to compare the findings with the nasometry results and auditory perceptual evaluation of the speech issues. Thirty women without speech and of the vocal tract problems, 5 cleft palate women no operated and 21 operated (18 to 40

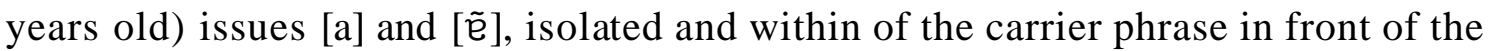
nasometer and digital record. After auditory perceptual evaluation, nasalances and formants cues it was possible to verify nasal formants and antiformants among oral formants in the nasalized/hipernasalyzed issues and don't have correspondency this findings with the nasometry neither with the auditory perceptual evaluation neither themselves.

Kaywords: cleft palate; velopharyngeal dysfuction; speech hipernasality; spectrograph; formant. 


\section{LISTA DE FIGURAS}

Figura 1 Visão sagital do fechamento velofaríngeo (BZOCH, 1997).

Tipos de FVF: A: transverso ou coronal; B: circular; C:

Figura 2 circular com Anel de Passavant; D: Sagital; : palato mole; :palato posterior da faringe (adaptado de Cassel e Elkadi, 1995).

Figura 3 segundo a classificação de Spina et al. (1972): (a) unilateral; (b) bilateral - adaptado de Uemeoka (2003).

Figura 4

Esquema representativo das fissuras transforame incicivo, segundo a classificação de Spina et al. (1972): (a) unilateral; (b) bilateral - adaptado de Uemeoka (2003).

Esquema representativo das fissuras pós-forame incicivo,

Figura 5 segundo a classificação de Spina et al. (1972): (a) total; (b) parcial - adaptado de Uemeoka (2003).

Figura 6 Posicionamento da participante para a captação das amostras de fala para este estudo.

Tela do programa computacional Multi-Speech: A: janela apresentando o sinal acús tico de uma vogal oral /a/ sustentada;

Figura 7 B: janela apresentando espectrograma do mesmo sinal acústico da janela anterior, vinculada a ela (note as barras verticais na mesma posição em ambas janelas).

Janelas do programa computacional Multi-Speech: A: janela apresentando o sinal acústico de uma vogal oral /a/ sustentada em torno do ponto considerado mais estável da emissão; B:

Figura 8 janela apresentando espectrograma do mesmo sinal acústico da janela anterior, vinculada a ela (note as barras verticais na mesma posição em ambas janelas); $\mathrm{C}$ : janela apresentando em (a) representação do mesmo ponto do sinal acústico pela FFT e (b) representação do mesmo ponto do sinal acústico por LPC.

Figura 9 Configuração do espectrograma.

Figura 10 Configuração da análise FFT.

Figura 11 Configuração da análise LPC. 


\section{LISTA DE GRÁFICOS}

Gráfico 1 Box plot dos valores média e desvio-padrão de nasalância nos 3 grupos estudados.

73

Gráfico 2 Box plot dos valores mínimo, máximo, mediana e quartis de nasalância nos 3 grupos estudados.

Gráfico 3 Comportamento da aplicação da $A N O V A$ no $\mathrm{F}_{1} / \mathrm{f}_{1}$ em relação às vogais oral e nasal para os 3 grupos estudados.

Gráfico 4 Comportamento da aplicação da ANOVA no $\mathrm{F}_{2} / \mathrm{f}_{2}$ em relação às vogais oral e nasal para os 3 grupos estudados.

Gráfico 5 Comportamento da aplicação da $A N O V A$ no $\mathrm{F}_{3} / \mathrm{f}_{3}$ em relação às vogais oral e nasal para os 3 grupos estudados.

Comportamento da mediana, mínimo e máximo dos 3

Gráfico 6 formantes iniciais para cada um dos 3 grupos estudados quanto à vogal oral.

Comportamento da mediana, mínimo e máximo dos 3

Gráfico 7 formantes iniciais para cada um dos 3 grupos estudados quanto à vogal nasal.

Gráfico 8

Comportamento das diferenças entre os formantes da mesma vogal para os 3 grupos estudados. 


\section{LISTA DE TABELAS}

Tabela 1 Formantes da vogal [a], segundo estudo de Jesus (1999).

Tabela 2 Distribuição das participantes nos 3 grupos estudados e sua faixa etária, com média ( $\bar{X})$ e desvio-padrão (DP).

Caracterização do tipo de fissura nos grupos de portadoras de fissura palatina deste estudo; idade(s) no(s) reparo(s)

Tabela 3 cirúrgico(s), tempo e número de reparos cirúrgicos e presença de palatoplastia secundária com retalho faríngeo no grupo de PFR.

Achados da avaliação fonoaudiológica específica dos grupos

Tabela 4 de PFA e de PFR quanto à inteligibilidade e à hipernasalidade de fala, à articulação compensatória e à produção vocal.

Resultados da aplicação estatística da correlação pelo

Tabela 5 coeficiente de Spearman $\left(\mathrm{r}_{\mathrm{s}}\right)$ para as classificações da ressonância nasal determinadas por 3 examinadoras sobre a vogal oral [a] dos 3 grupos estudados $(\mathrm{p}=0,05)$.

Percentual (\%) de concordância nas respostas das

Tabela 6 examinadoras para as classificações da ressonância nasal determinadas por 3 examinadoras sobre a vogal oral [a] dos 3 grupos estudados.

Resultados da aplicação estatística da correlação pelo

Tabela 7 coeficiente de Spearman $\left(\mathrm{r}_{\mathrm{s}}\right)$ para as classificações da ressonância nasal determinadas entre as 3 examinadoras sobre a vogal oral [a] dos 3 grupos estudados $(p=0,05)$.

Percentual (\%) de concordância nas respostas inter-

Tabela 8 examinadoras para as classificações da ressonância nasal de fala determinadas por 3 examinadoras sobre a vogal oral [a] dos 3 grupos estudados.

Tabela 9

Descritores estatísticos das nasalâncias (\%) para as vogais

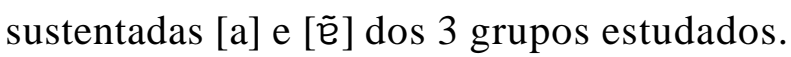

Descritores estatísticos das freqüências formantes $(\mathrm{Hz})$ para as

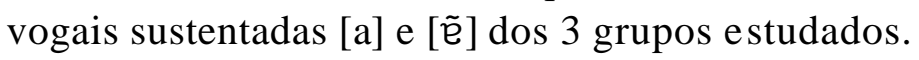

Tabela 10

Tabela 11 Valores de média e desvio-padrão da diferença nas regiões de formante para cada vogal e grupo estudados. 


\section{LISTA DE ABREVIATURAS, SIGLAS E SÍMBOLOS}

\begin{tabular}{|c|c|c|}
\hline ppvv & $=$ & pregas vocais \\
\hline $\bar{X}$ & $=$ & média \\
\hline $\mathrm{A} / \mathrm{D}$ & $=$ & analógico/digital \\
\hline CEP & $=$ & Comitê de Ética em Pesquisa \\
\hline $\mathrm{CON}$ & $=$ & grupo controle \\
\hline CSL & $=$ & Computerized Speech Laboratory \\
\hline DSP & $=$ & digital signal processing \\
\hline DVF & $=$ & disfunção velofaríngea \\
\hline EVF & $=$ & esfíncter velofaríngeo \\
\hline $\mathrm{F}_{0}$ & $=$ & freqüência fundamental \\
\hline $\mathrm{F}_{1}$ & $=$ & primeiro formante \\
\hline$f_{1}$ & $=$ & primeiro formante com atuação do antiformante/formante nasal \\
\hline $\mathrm{F}_{2}$ & $=$ & segundo formante \\
\hline$f_{2}$ & $=$ & segundo formante com atuação do antiformante/formantenasal \\
\hline $\mathrm{F}_{3}$ & $=$ & terceiro formante \\
\hline $\mathrm{f}_{3}$ & $=$ & terceiro formante com atuação do antiformante/formante nasal \\
\hline FFT & $=$ & Fast Fourier Transform \\
\hline FVF & $=$ & fechamento velofaríngeo \\
\hline HRAC & $=$ & Hospital de Reabilitação de Anomalias Craniofaciais \\
\hline IEL & $=$ & Instituto de Estudos da Linguagem \\
\hline LAFAPE & $=$ & Laboratório de Fonética Experimental e Psicolingüística \\
\hline LPC & $=$ & Linear Predictive Coding \\
\hline PB & $=$ & português brasileiro \\
\hline PDS & $=$ & processamento digital de sinais \\
\hline PFA & $=$ & grupo de portadoras de fissura palatina aberta \\
\hline
\end{tabular}




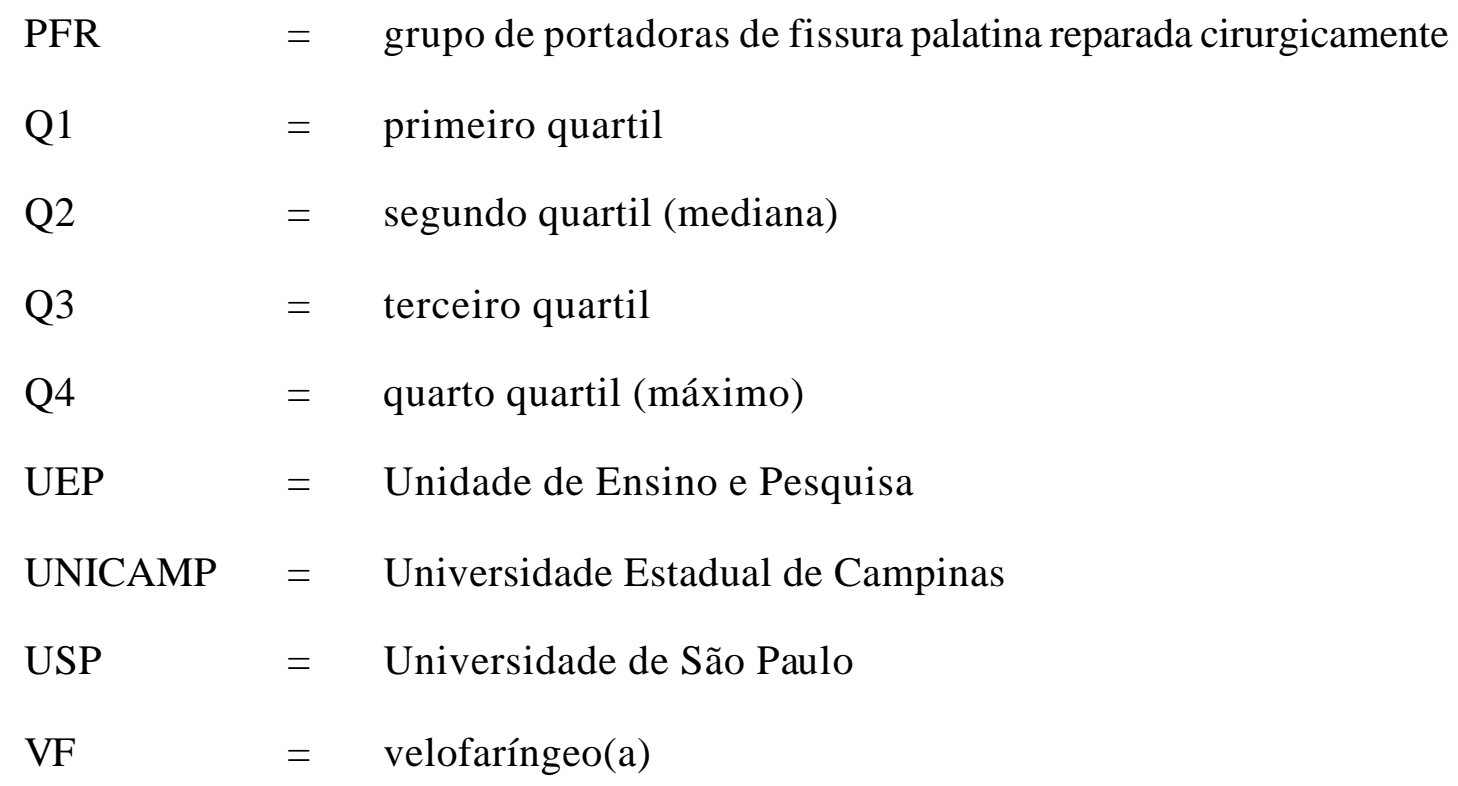




\section{SUMÁRIO}

RESUMO X xiii

ABSTRACT $\quad x v$

1 INTRODUÇÃO

1.1 Objetivos 5

2 REVISÃO DE LITERATURA

2.1 A fala 9

2.2 A fala e o trato vocal 10

2.3 A fala e o esfíncter velofaríngeo (EVF) 12

2.4 A fala do portador de fissura palatina $\quad 15$

2.4.1 A fissura de lábio e/ou de palato 16

2.4.2 A produção de fala do portador de fissura palatina 19

2.5 A fala na DVF: hipernasalidade $\quad 20$

2.6 A nasalidade $\quad 24$

2.7 O trato nasal $\quad 27$

2.8 Os formantes e a nasalidade/hipernasalidade $\quad 30$

2.9 A nasalidade/hipernasalidade pela espectrografia 36

2.9.1 A espectrografia 36

2.9.1.1 A espectrografia digital $\quad 37$

2.9.2 A espectrografia e a nasalidade/hipernasalidade $\quad 39$

2.10 A avaliação da hipernasalidade $\quad 42$

2.10.1 A avaliação nasométrica da hipernasalidade de fala 43

2.10.2 A avaliação perceptivo-auditiva da hipernasalidade $\quad 44$

3 METODOLOGIA 45

$\begin{array}{ll}3.1 \text { Participantes } & 47\end{array}$ 
3.2 Aplicação do protocolo de entrevista e de avaliação fonoaudiológica específica

3.3 Amostras de fala

3.4 Equipamentos para captação, armazenagem e análise instrumental das amostras de fala

3.5 Procedimentos para captação, armazenagem e análise instrumental das amostras de fala

3.6 Procedimentos da avaliação perceptivo -auditiva das amostras de fala

3.7 Procedimentos da análise estatística 58

\section{RESULTADOS}

61

4.1 Participantes

63

4.2 Aplicação do protocolo de entrevista e de avaliação 66 fonoaudiológica específica

4.3 Avaliação perceptivo-auditiva das amostras de fala

67

4.4 Análise instrumental das amostras de fala

4.4.1 Nasometria

4.4.2 Espectrografia

4.4.3 Análises FFT e LPC

4.5 Comparação entre a avaliação percpetivo-auditiva e a análise instrumental

5 DISCUSSÃO

89

6 CONCLUSÕES

6.1 Outras conclusões

7 SUGESTÕES

REFERÊNCIAS

APÊNDICES

APÊNDICE A - Termo de consentimento livre e esclarecido apresentado às portadoras de fissura palatina. 
APÊNDICE B - Termo de consentimento livre e esclarecido apresentado às participantes do grupo controle.

APÊNDICE C - Protocolo de entrevista e de avaliação 125 fonoaudiológica específica.

APÊNDICE D - Protocolo para anotações das examinadoras que realizaram a avaliação perceptivo - auditiva da emissão da vogal oral /a/ sustentada emitida pelas participantes dos 3 grupos estudados.

APÊNDICE E - Descrição dos achados do quadro fonêmico dos grupos PFA e PFR.

APÊNDICE F - Tabela com os valores de nasalância e de freqüências formantes de cada participante deste estudo.

APÊNDICE G - Forma de onda das emissões das vogais [a] e [ẽ] sustentadas (A) e seu respectivo espectrograma (B) da participante com protocolo número 01 do grupo $\mathrm{CON}$.

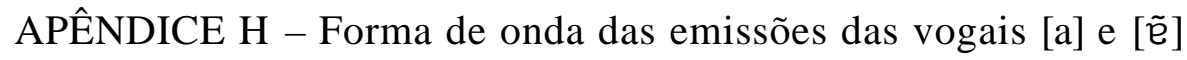
sustentadas (A) e seu respectivo espectrograma (B) da participante com protocolo número 02 do grupo $\mathrm{CON}$.

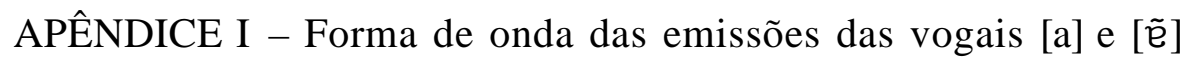
sustentadas (A) e seu respectivo espectrograma (B) da participante com protocolo número 03 do grupo $\mathrm{CON}$

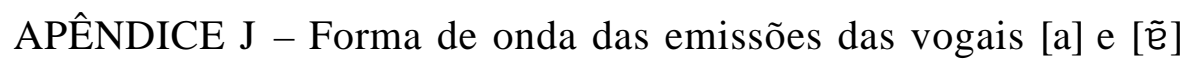
sustentadas (A) e seu respectivo espectrograma (B) da participante com protocolo número 04 do grupo $\mathrm{CON}$.

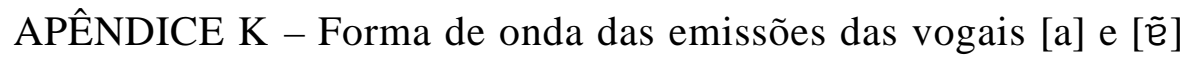
sustentadas (A) e seu respectivo espectrograma (B) da participante com protocolo número 05 do grupo $\mathrm{CON}$.

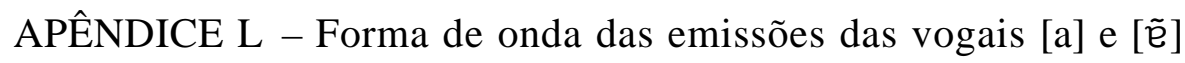
sustentadas (A) e seu respectivo espectrograma (B) da participante com protocolo número 06 do grupo $\mathrm{CON}$.

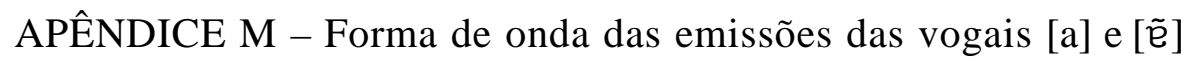
sustentadas (A) e seu respectivo espectrograma (B) da participante com protocolo número 07 do grupo $\mathrm{CON}$.

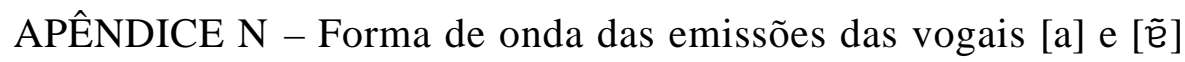
sustentadas (A) e seu respectivo espectrograma (B) da participante com 143 protocolo número 08 do grupo $\mathrm{CON}$. 
APÊNDICE O - Forma de onda das emissões das vogais [a] e [ $\tilde{e}]$ sustentadas (A) e seu respectivo espectrograma (B) da participante com 144 protocolo número 09 do grupo CON.

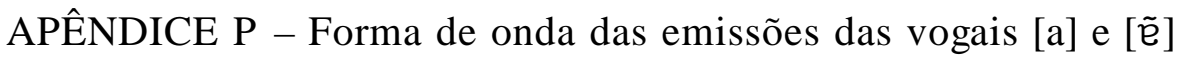
sustentadas (A) e seu respectivo espectrograma (B) da participante com 145 protocolo número 10 do grupo $\mathrm{CON}$.

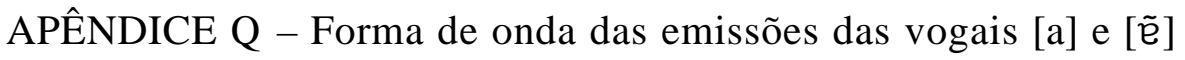
sustentadas (A) e seu respectivo espectrograma (B) da participante com protocolo número 11 do grupo $\mathrm{CON}$.

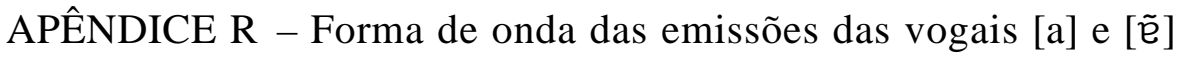
sustentadas (A) e seu respectivo espectrograma (B) da participante com protocolo número 12 do grupo $\mathrm{CON}$.

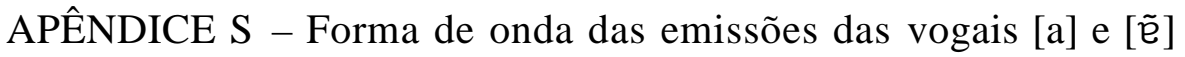
sustentadas (A) e seu respectivo espectrograma (B) da participante com protocolo número 13 do grupo $\mathrm{CON}$.

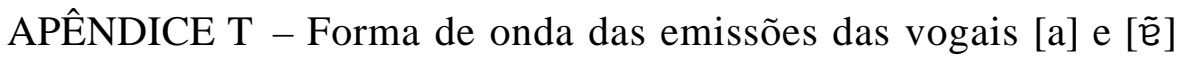
sustentadas (A) e seu respectivo espectrograma (B) da participante com protocolo número 14 do grupo CON.

APÊNDICE U - Forma de onda das emissões das vogais [a] e [ẽ] sustentadas (A) e seu respectivo espectrograma (B) da participante com protocolo número 15 do grupo $\mathrm{CON}$.

APÊNDICE V - Forma de onda das emissões das vogais [a] e [ẽ] sustentadas (A) e seu respectivo espectrograma (B) da participante com protocolo número 16 do grupo $\mathrm{CON}$.

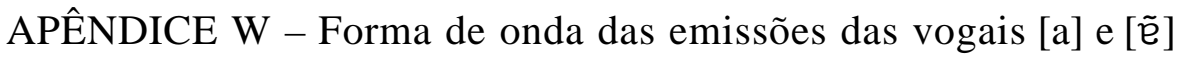
sustentadas (A) e seu respectivo espectrograma (B) da participante com protocolo número 17 do grupo CON.

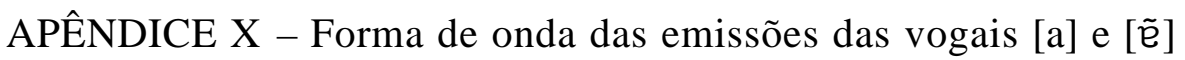
sustentadas (A) e seu respectivo espectrograma (B) da participante com protocolo número 18 do grupo $\mathrm{CON}$.

APÊNDICE Y - Forma de onda das emissões das vogais [a] e [ẽ ] sustentadas (A) e seu respectivo espectrograma (B) da participante com protocolo número 19 do grupo $\mathrm{CON}$.

APÊNDICE Z - Forma de onda das emissões das vogais [a] e [ẽ ] sustentadas (A) e seu respectivo espectrograma (B) da participante com 155 protocolo número 20 do grupo $\mathrm{CON}$. 


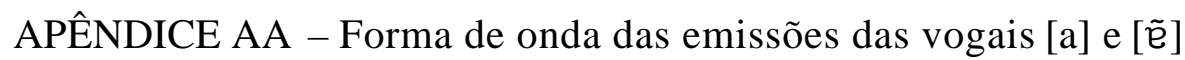
sustentadas (A) e seu respectivo espectrograma (B) da participante com protocolo número 21 do grupo $\mathrm{CON}$.

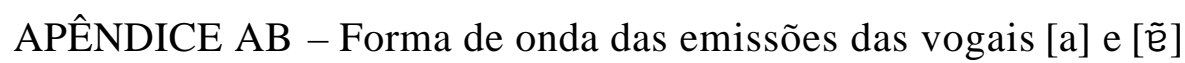
sustentadas (A) e seu respectivo espectrograma (B) da participante com protocolo número 22 do grupo $\mathrm{CON}$.

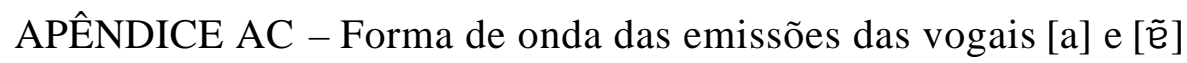
sustentadas (A) e seu respectivo espectrograma (B) da participante com protocolo número 23 do grupo $\mathrm{CON}$.

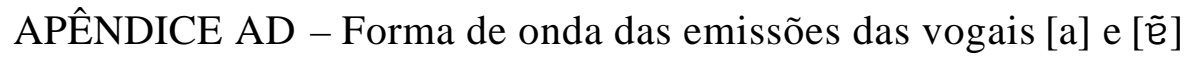
sustentadas (A) e seu respectivo espectrograma (B) da participante com protocolo número 24 do grupo CON.

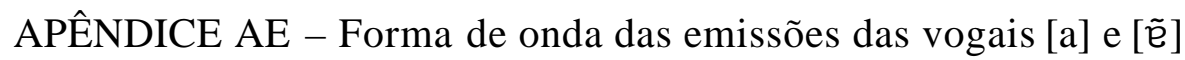
sustentadas (A) e seu respectivo espectrograma (B) da participante com protocolo número 25 do grupo $\mathrm{CON}$.

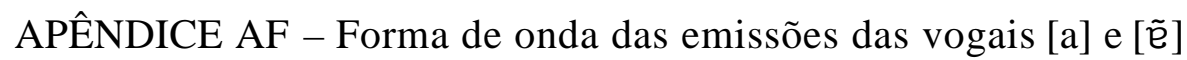
sustentadas (A) e seu respectivo espectrograma (B) da participante com protocolo número 26 do grupo $\mathrm{CON}$

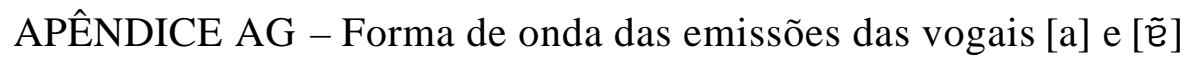
sustentadas (A) e seu respectivo espectrograma (B) da participante com protocolo número 27 do grupo $\mathrm{CON}$

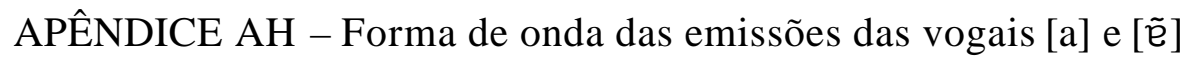
sustentadas (A) e seu respectivo espectrograma (B) da participante com protocolo número 28 do grupo $\mathrm{CON}$.

APÊNDICE AI - Forma de onda das emissões das vogais [a] e [ẽ ] sustentadas (A) e seu respectivo espectrograma (B) da participante com protocolo número 29 do grupo $\mathrm{CON}$.

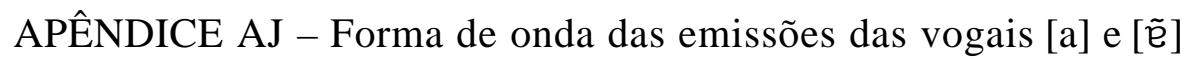
sustentadas (A) e seu respectivo espectrograma (B) da participante com protocolo número 30 do grupo $\mathrm{CON}$.

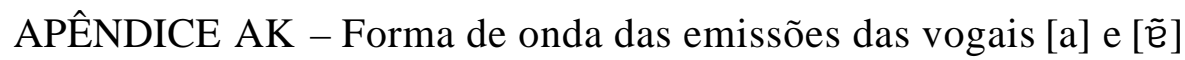
sustentadas (A) e seu respectivo espectrograma (B) da participante com protocolo número 01 do grupo PFA.

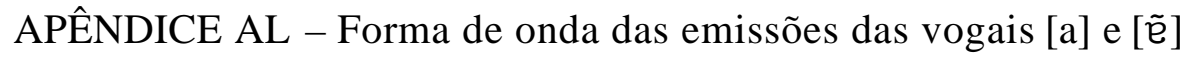
sustentadas (A) e seu respectivo espectrograma (B) da participante com protocolo número 02 do grupo PFA. 


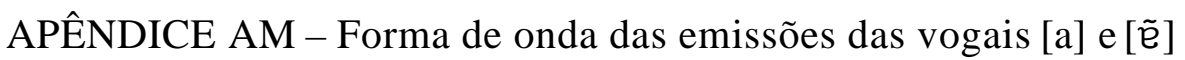
sustentadas (A) e seu respectivo espectrograma (B) da participante com 168 protocolo número 03 do grupo PFA.

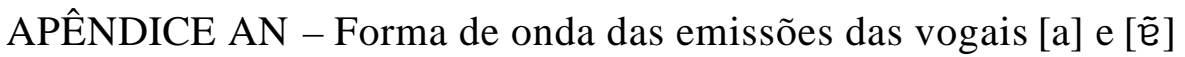
sustentadas (A) e seu respectivo espectrograma (B) da participante com 169 protocolo número 04 do grupo PFA.

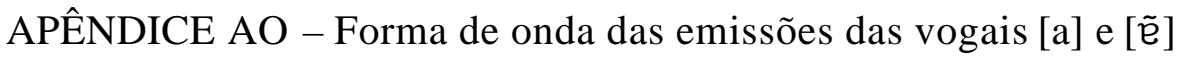
sustentadas (A) e seu respectivo espectrograma (B) da participante com protocolo número 05 do grupo PFA

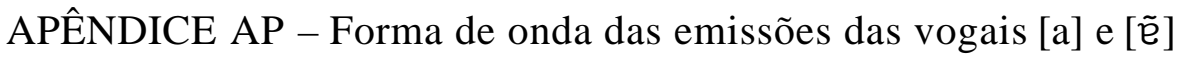
sustentadas (A) e seu respectivo espectrograma (B) da participante com protocolo número 01 do grupo PFR

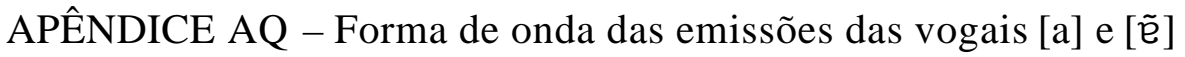
sustentadas (A) e seu respectivo espectrograma (B) da participante com protocolo número 02 do grupo PFR.

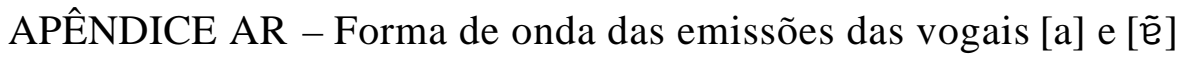
sustentadas (A) e s eu respectivo espectrograma (B) da participante com protocolo número 03 do grupo PFR.

APÊNDICE AS - Forma de onda das emissões das vogais [a] e [ẽ] sustentadas (A) e seu respectivo espectrograma (B) da participante com protocolo número 04 do grupo PFR.

APÊNDICE AT - Forma de onda das emissões das vogais [a] e [ẽ] sustentadas (A) e seu respectivo espectrograma (B) da participante com protocolo número 05 do grupo PFR.

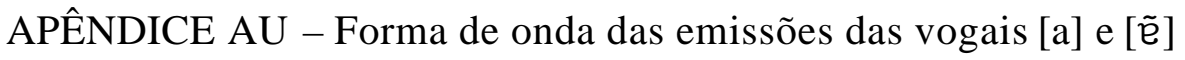
sustentadas (A) e seu respectivo espectrograma (B) da participante com protocolo número 06 do grupo PFR.

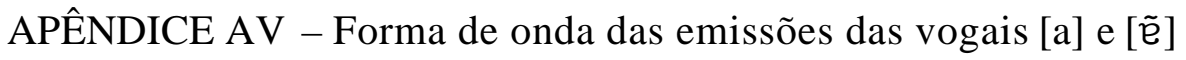
sustentadas (A) e seu respectivo espectrograma (B) da participante com protocolo número 07 do grupo PFR.

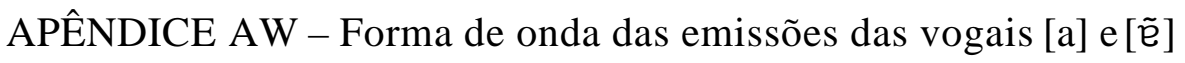
sustentadas (A) e seu respectivo espectrograma (B) da participante com 178 protocolo número 08 do grupo PFR.

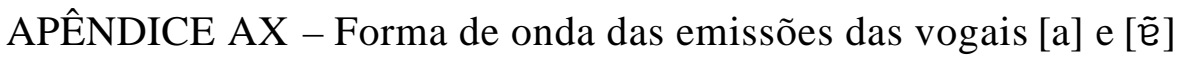
sustentadas (A) e seu respectivo espectrograma (B) da participante com 179 protocolo número 09 do grupo PFR. 


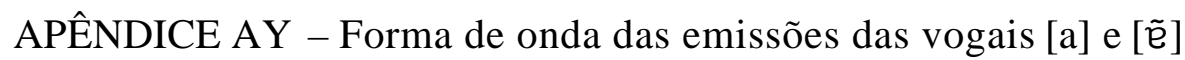
sustentadas (A) e seu respectivo espectrograma (B) da participante com protocolo número 10 do grupo PFR.

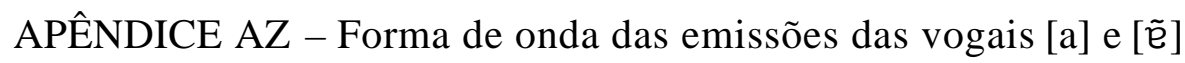
sustentadas (A) e seu respectivo espectrograma (B) da participante com protocolo número 11 do grupo PFR

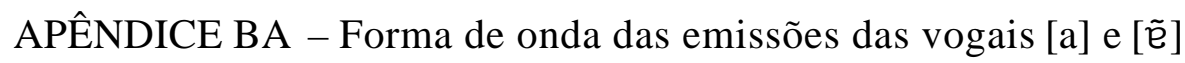
sustentadas (A) e seu respectivo espectrograma (B) da participante com protocolo número 12 do grupo PFR.

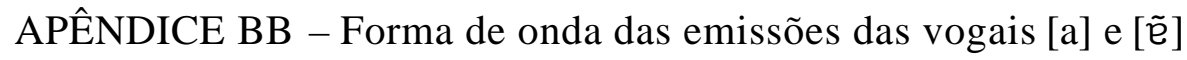
sustentadas (A) e seu respectivo espectrograma (B) da participante com protocolo número 13 do grupo PFR.

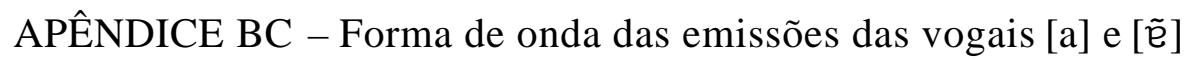
sustentadas (A) e seu respectivo espectrograma (B) da participante com protocolo número 14 do grupo PFR

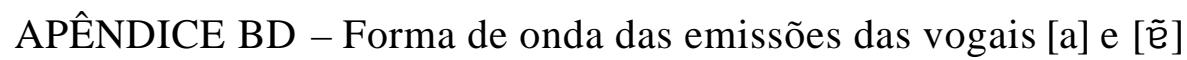
sustentadas (A) e seu respectivo espectrograma (B) da participante com protocolo número 15 do grupo PFR

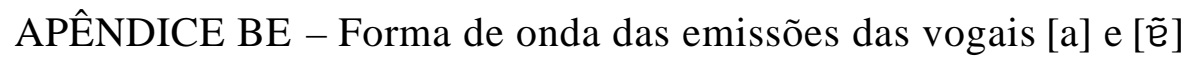
sustentadas (A) e seu respectivo espectrograma (B) da participante com protocolo número 16 do grupo PFR.

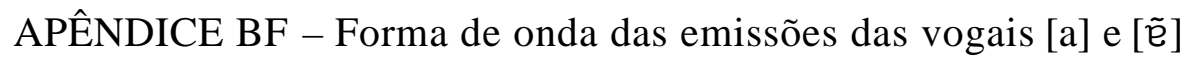
sustentadas (A) e seu respectivo espectrograma (B) da participante com protocolo número 17 do grupo PFR.

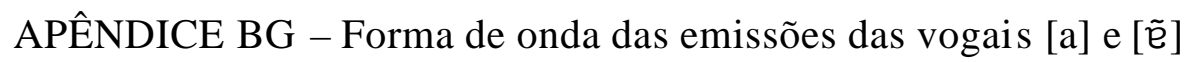
sustentadas (A) e seu respectivo espectrograma (B) da participante com protocolo número 18 do grupo PFR.

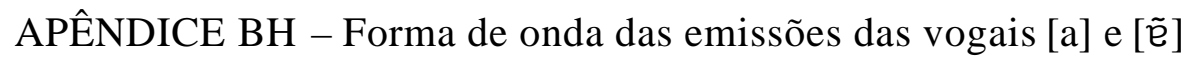
sustentadas (A) e seu respectivo espectrograma (B) da participante com protocolo número 19 do grupo PFR.

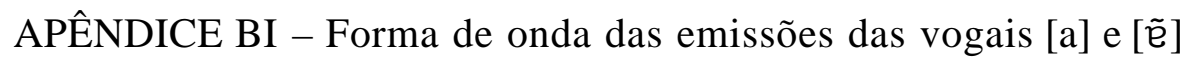
sustentadas (A) e seu respectivo espectrograma (B) da participante com protocolo número 20 do grupo PFR.

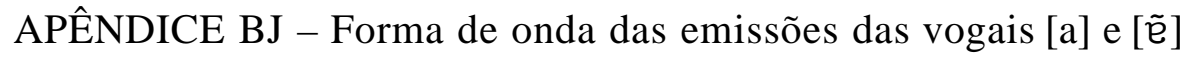
sustentadas (A) e seu respectivo espectrograma (B) da participante com protocolo número 21 do grupo PFR. 
APÊNDICE BK - Análises FFT e LPC das emissões das vogais [a]

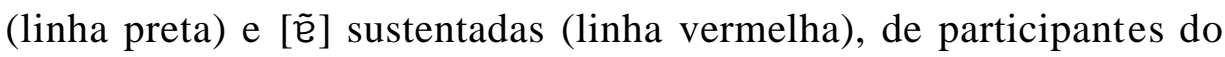
grupo CON.

APÊNDICE BL - Análises FFT e LPC das emissões das vogais [a]

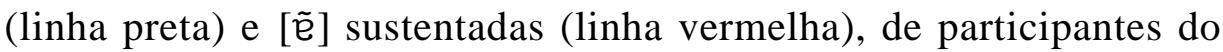
grupo PFA.

APÊNDICE BM - Análises FFT e LPC das emissões das vogais [a]

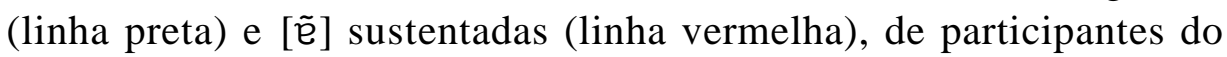
198 grupo PFR.

APÊNDICE BN - Tabela comparativa dos resultados entre a avaliação perceptivo-auditiva e a análise instrumental na emissão da vogal oral [a] para os 3 grupos estudados.

ANEXOS

ANEXO A - Ofício no . 072/2002 do Comitê de Ética em Pesquisa (CEP) do HRAC/USP.

ANEXO B - Classificações da inteligibilidade de fala e da 208 ressonância de fala, segundo Pegoraro-Krook, 1995.

ANEXO C - Visão nasoendoscópica do retalho faríngeo (PRÓTESE DE PALATO/HRAC/USP, 2003). 


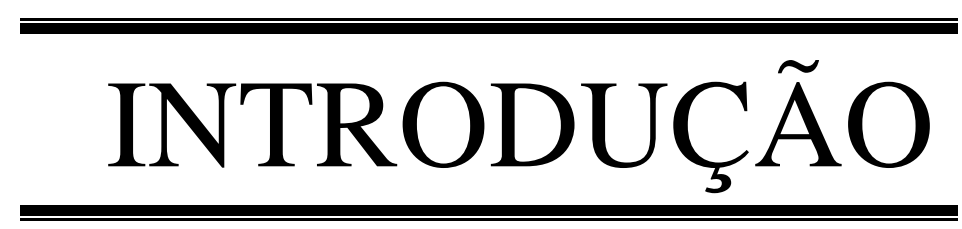




\section{INTRODUÇÃO}

A fala é a possibilidade humana de exprimir pensamentos por meio de sons articulados. É a transformação do mundo interior humano e sua percepção do meio externo em oralidade.

Para que se constitua plenamente, além do quê dizer e de tudo o que isto envolve, como a linguagem, por exemplo, é imprescindível um aparato físico suficiente. Ou seja, o sistema nervoso, a audição, o sistema respiratório, a laringe e as regiões supraglóticas (a faringe, as cavidades oral e nasal, bem como os órgãos fonoarticulatórios) têm de estar anátomo-fisiologicamente adequados.

Dentre os prejuízos anátomo-fisiológicos que podem acometer as regiões supraglóticas, há aqueles que atingem o palato mole/duro em virtude de fissura palatina congênita.

Esta fissura surge pela não junção das lâminas palatinas entre a oitava e a décima segunda semana de gestação. Ela propicia a comunicação entre as cavidades oral e nasal, ocasionando saída acústica para os sons da fala por ambas cavidades, simultaneamente.

Os sons da fala que deveriam ser emitidos apenas pela cavidade oral vêm carregados de uma nasalidade imprópria, denominada hipernasalidade. Esta hipernasalidade também persiste naqueles falantes que realizaram cirurgia para fechamento da fissura palatina, porém, indesejavelmente permaneceram com o palato mole curto ou apresentaram deficiência em seu movimento e/ou das paredes faríngeas, impossibilitando a separação entre as cavidades oral e nasal durante a produção dos sons orais. 
Tal separação é o resultado da atuação concomitante das estruturas do mecanismo velofaríngeo: movimento para cima e para trás do palato mole, anteriorização da parede posterior da faringe e mesialização de suas paredes laterais.

Quando as condições anatômicas e/ou funcionais do palato mole e/ou das paredes da faringe estão prejudicadas, ocorre a disfunção velofaríngea. Esta disfunção, tanto por insuficiência (falta de tecido) ou incompetência (déficit na contração muscular dos tecidos), pode ocorrer mesmo após a correção cirúrgica do palato. Em relação à acústica da fala, a disfunção velofaríngea resulta em hipernasalidade, pois permite que ondas acústicas provenientes da cavidade nasal componham indevidamente os sons que deveriam ser exclusivamente orais.

Um dos primeiros métodos para se analisar a fala acusticamente foi a espectrografia, que provê um gráfico, o espectrograma, representativo de três dimensões de análise: freqüência, tempo e intensidade, potencialmente capaz de fornecer informações acerca da hipernasalidade, ainda mais considerando-se que há poucos estudos envolvendo espectrografia e hipernasalidade, especialmente na fala de mulheres.

Mais do que estudos espectrográficos e hipernasalidade há estudos espectrográficos e nasalidade. Em geral, estes apontam que as ondas acústicas provenientes da cavidade nasal resultam em freqüências formantes mais baixas que nas emissões orais.

Será que o comportamento espectrográfico encontrado para a nasalidade seria o mesmo que para a hipernasalidade? E como seria a relação disto tudo com omecanismo velofaríngeo?

Além de se perceber a hipernasalidade auditivamente, um método objetivo de a quantificar sempre foi procurado. É o que se constata diante de pesquisas com o nasômetro, que fornece o índice denominado nasalância - uma porcentagem da relação das energias acústicas nasal e oral.

A divulgação da espectrografia e demais métodos de análise acústica vocal ocorre cada vez mais, devido ao advento do processamento digital de sinais e a popularização de máquinas computacionais. Portanto, é inevitável e imprescindível o aprofundamento técno-científico dos interessados, estudiosos e clínicos da fala-o que 
engloba aqueles que lidam com a hipernasalidade proveniente da fissura palatina, para que com conhecimento, discernimento e segurança conduzam adequadamente sua atuação clínica e/ou científica.

\subsection{Objetivos}

Investigar as características espectrográficas da hipernasalidade de fala de mulheres portadoras de fissura palatina e comparar os achados com os resultados da nasometria e da avaliação perceptivo-auditiva de suas emissões de fala. 


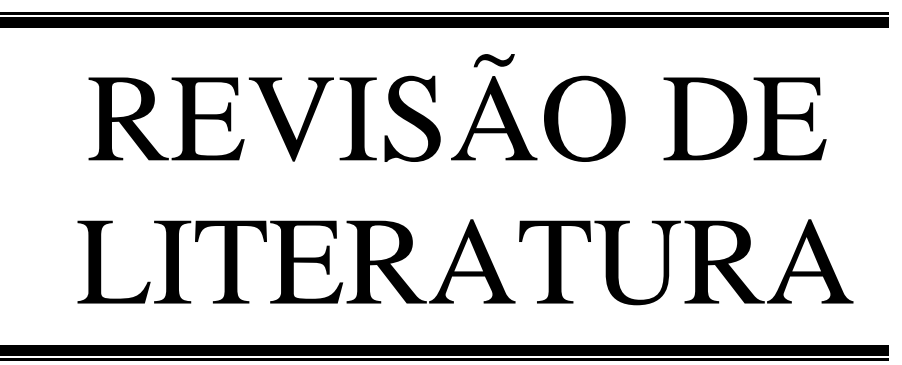




\section{REVISÃO DE LITERATURA}

\subsection{A fala}

A fala é uma face visível da linguagem humana. É a expressão do pensamento por meio de palavras sonorizadas. É, portanto, o som da essência do que passa no interior do homem e que flui para o espaço.

\section{(...) Os sons têm um poder inexorável sobre nossas emoções. Eles nos dispõem em nossa tristeza ou em nossa melancolia, em nossas alegrias, euforias, e nossas raivas e indiferenças... Com o som é que nossas almas estão afinadas. (CRITELLI, 1996: 64-5).}

A fala é, ainda, a realização da comunicação oral, uma entre as diversas formas de comunicação. É uma habilidade humana, modalidade complexa da linguagem simbólica, dependente da integração do sistema nervoso central, da audição, do sistema respiratório, da laringe e das cavidades supraglóticas (PEGORARO-KROOK, 1995).

Do ponto de vista fisiológico-acústico, a fala tem origem na vibração das pregas vocais, provocada pelo ar expirado dos pulmões, produzindo um som (voz) que será modelado pelos articuladores (lábios, bochechas, mandíbula, dentes, palato duro, palato mole, paredes faríngeas) e ressonadores (faringe, cavidades oral e nasal), que compõem o trato vocal. São os ressonadores que contribuem grandemente para a qualidade, a riqueza e a intensidade da voz (BOONE e McFARLANE, 1994). 


\subsection{A fala e o trato vocal}

A teoria acústica da produção da fala, criada por Gunnar Fant em 1960 ${ }^{1}$, embasa os estudos em Fonética Acústica e Experimental, quanto à abordagem na formulação do conhecimento sobre a fala. É um modelamento do trato vocal em sua realização, difundido e aceito pelos estudiosos da área, apesar de não responder pela produção de todos os sons vocais gerados em todas as línguas, para os quais também se recorre a outras abordagens como a teoria dos sistemas dinâmicos (JOHNSON, 1997b, 1997c; KELSO, 1995; KENT e READ, 1992).

Contudo, é inegável sua aplicação às vogais e seu valor por tudo que possibilitou sobre elas. É uma válida aproximação teórica do trato vocal humano. Acerca desta teoria, há relatos de diversos autores (BARBOSA, 2003; COLEMAN JR., 1963; FUJIMURA, 1990; FUJIMURA e ERICKSON, 1997; JOHNSON, 1997c; KENT, 1993; 1997; KENT e READ, 1992; PICKETT, 1980; SEIKEL et al., 2000).

Considerando um trato vocal saudável, a vibração das pregas vocais (ppvv) constitui fonte de energia sonora para as vogais. Esta energia sonora é modificada ao percorrer o trato vocal - ação que constitui a função transferência modelada nas teorias sobre a produção da fala. Neste momento, considere trato vocal a extensão da glote (espaço entre as ppvv), até os lábios.

O som produzido pela vibração das ppvv pode ser decomposto em várias freqüências $^{2}$ : uma fundamental (F0) e suas múltiplas (harmônicas), como propõe a série matemática de Fourier.

Ao passar pelo trato vocal, o som gerado pelas ppvv terá algumas freqüências com amplitudes aumentadas, enquanto outras serão amortecidas. Isto ocorrerá de acordo com a configuração do trato vocal que origina regiões de ressonância ${ }^{3}$ que, ao vibrar em frequiência próxima a algum harmônico do som complexo, amplifica-o - o que não ocorre com os harmônicos com freqüências diferentes da freqüência natural ${ }^{4} \mathrm{de}$ vibração dessas regiões.

\footnotetext{
${ }^{1}$ FANT, G. (1960). The Acoustics Teory of Speech, The Haugue: Mouton.

${ }^{2}$ Freqüência é o número de ciclos por segundo, ou seja, $\mathrm{F}=1 / \mathrm{T}$, onde $\mathrm{F}$ é a frequiência e $\mathrm{T}$ o período.

${ }^{3}$ Ressonância é a capacidade que um corpo tem de vibrar na mesma freqüência de uma fonte geradora, aumentando a amplitude desta frequiência.

${ }^{4}$ Freqüência natural é a vibração específica gerada por um corpo, dependente de sua massa e densidade.
} 
Esta frequiência natural de vibração denomina-se formante. Há infinitos formantes, assim como há infinitos harmônicos.

Os formantes não geram energia sonora, apenas modificam-na. E como esta modificação acontece seletivamente, ou seja, há amplificação de algumas freqüências e amortecimento de outras, o trato vocal comporta-se como um filtro (acústico).

As características acústicas do trato vocal, que são impressas no som originado na glote, estão diretamente relacionadas ao seu comprimento e a sua largura. Estas dimensões variam de acordo com o sexo e a idade do falante. Por exemplo, o homem tem um trato vocal em torno de $17,5 \mathrm{~cm}$ de comprimento, enquanto a mulher em torno de $15 \mathrm{~cm}$ e a criança de 8 a $10 \mathrm{~cm}$ de comprimento. A largura varia em toda a sua extensão, tendo-se várias seções transversais. Visto desta forma, o trato vocal parece um tubo, essencialmente acústico como af irmou Peterson (1959), cujas relações entre suas dimensões e propriedades físicas podem ser tratadas matematicamente.

Como o trato vocal não é um tubo estático, pois o movimento dos articuladores que o compõe lhe confere um aspecto dinâmico, especialmente a língua, o comprimento e as seções transversais alteram-se. Estas alterações são responsáveis pelos diferentes sons vocálicos. Portanto, ainda de acordo com Peterson (1959), a natureza dos sons vocálicos pode vir de considerações do mecanismo vocal.

O movimento da língua, ao estreitar ou ampliar espaços nas seções transversais do tubo, cria constrições. E, em última instância, é a relação destas constrições com o comprimento do trato vocal que determina regiões de ressonância - os formantes.

A altura da língua é determinante para a composição do primeiro formante $\left(\mathrm{F}_{1}\right)$, o qual varia inversamente à altura da língua, enquanto seu deslocamento no eixo horizontal, no sentido ântero-posterior, está associado ao segundo formante $\left(\mathrm{F}_{2}\right)(\mathrm{KENT}$ e READ, 1992; PICKETT, 1980). Segundo Pickett (1980), em geral a localização e o espaçamento entre os formantes, a partir do terceiro formante $\left(F_{3}\right)$, são mais estritamente correlacionados com o comprimento do trato vocal.

Os formantes, resultantes, portanto, de diferentes formas do trato vocal, caracterizam as vogais (LADEFOGED, 2001), constatando-se em diversos trabalhos que os valores de freqüência dos três primeiros formantes são suficientes para definir a 
identidade de uma vogal (BEHLAU et al., 1988; JOHNSON, 1997c; KENT, 1993; 1997; KENT e READ, 1992; PICKETT, 1980; SCHWARTZ, 1968).

A relação entre os três formantes iniciais é constante para a produção de cada vogal (para um mesmo locutor, emitindo-a sob as mesmas condições e no mesmo contexto de produção), e constitui uma das formas em que a audição humana percebe um som vocálico em particular (FUCCI e LASS, 1999).

Quanto maior o trato vocal, menores são as médias das freqüências formantes (PICKETT, 1980). O efeito do arredondamento ou da protrusão labial é sempre abaixar os valores das freqüências de todos os formantes (FANT, 1958).

Os formantes das mulheres têm valores de frequiência mais altos que os dos homens pelo comprimento do trato vocal feminino ser menor que o do masculino (FANT, 1958; PICKETT, 1980).

Inicialmente, a forma utilizada para a análise dos formantes vocálicos era por meio da espectrografia. Após o advento do processamento digital de sinais, surgiu outra técnica para analisá-los, a LPC (Linear Predictive Coding), mais confiável quando utilizada sobre o espectro da FFT (Fast Fourier Transform). Adiante explicar-se-á melhor cada um destes procedimentos.

\subsection{A fala e o esfíncter velofaríngeo (EVF)}

Para uma produção de fala satisfatória, além de uma correta articulação, um dos aspectos mais importantes que devem ser considerados é o equilíbrio perfeito da ressonância oro-nasal (PEGORARO-KROOK, 1995).

Essa ressonância é adequada para os sons orais quando suas ondas acústicas são radiadas apenas pela cavidade oral, não passando pela cavidade nasal. E isso só é possível pelo funcionamento adequado do esfíncter velofaríngeo: elevação e posteriorização do palato mole em direção à faringe, mesialização das paredes laterais da faringe e anteriorização de sua parede posterior (MOON e KUEHN, 1997), como mostrado sagitalmente na Figura 1. 


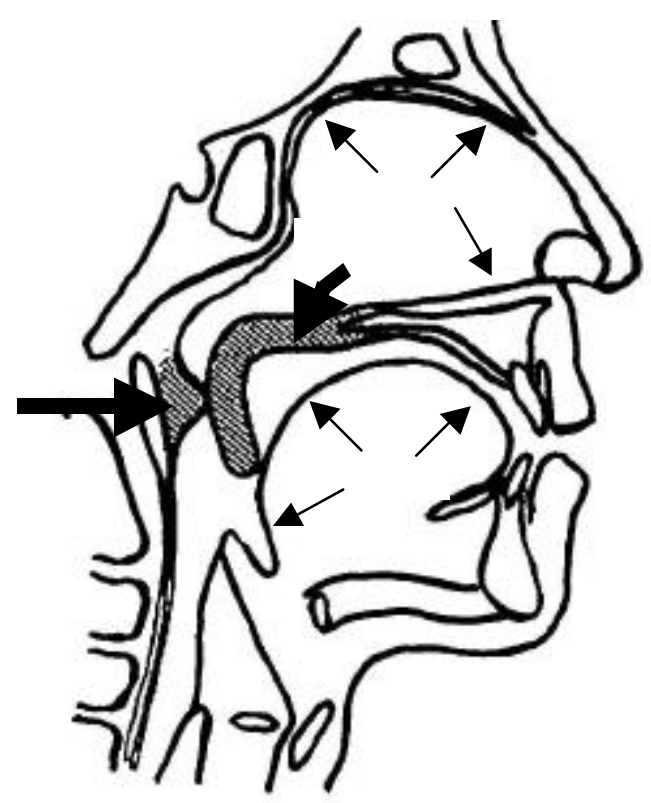

Figura 1 - Visão sagital do fechamento velofaríngeo (BZOCH, 1997).

Há 3 tipos de fechamento velofaríngeo (FVF) (Figura 2): 1) transverso ou coronal, em que há movimento acentuado do palato mole; 2) circular, em que há equilíbrio no movimento das estruturas envolvidas, podendo ocorrer, ainda, a presença de uma saliência muscular na parede posterior da faringe, denominada Anel de Passavant; 3) sagital, em que há movimento principalmente das paredes laterais da faringe (PEGORARO-KROOK, 1998). 

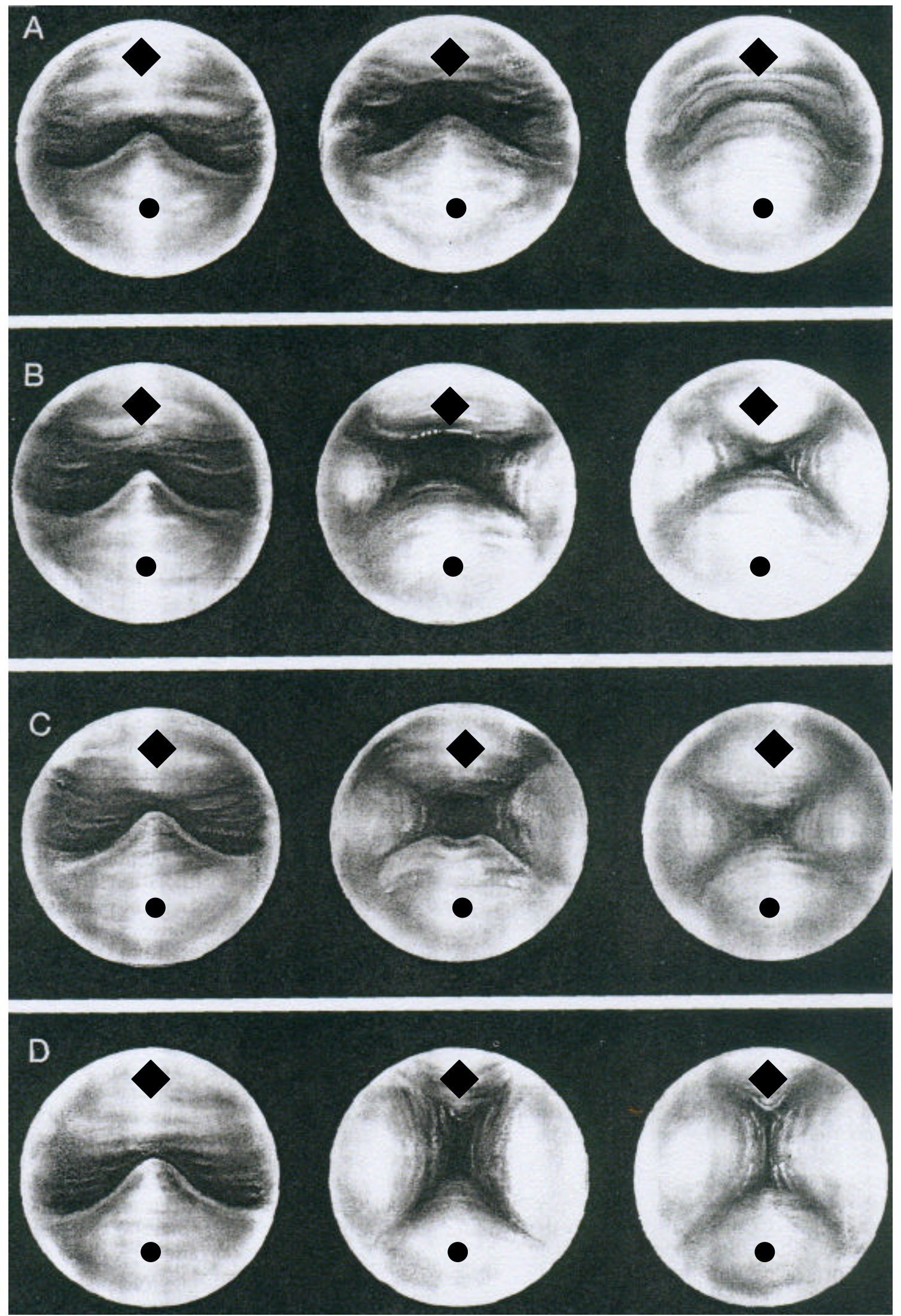

Figura 2-Tipos de FVF: A: transverso ou coronal; B: circular; C: circular com Anel de Passavant; D: Sagital; : palato mole; parede posterior da faringe (adaptado de Cassel e Elkadi, 1995). 
Pode ocorrer uma falha no movimento do esfíncter velofaríngeo, acoplando as cavidades oral e nasal e, conseqüentemente, prejudicando a fala na produção dos sons orais.

Esse acoplamento pode ser em virtude de uma ausência parcial ou total do palato, fissura palatina não-reparada, ou ainda, pela existência de um palato curto, congênito ou por reparação cirúrgica ineficiente ou, ainda, pela ressecção total ou parcial do palato, devido a neoplasias malignas. Nesse caso, em que há falta de tecido, constitui-se o distúrbio orgânico denominado insuficiência velofaríngea. Por outro lado, se esse acoplamento das cavidades oral e nasal ocorrer de forma assistemática, decorrente da falta de mobilidade das paredes faríngeas e/ou do palato mole, está-se diante do distúrbio funcional denominado incompetência velofaríngea, que pode estar presente nas desordens neurológicas congênitas ou adquiridas, nos casos de fissura submucosa ou de fissura palatina reparada adequadamente, do ponto de vista anatômico (BOONE e McFARLANE, 1994; LESSA, 1996; PEGORARO-KROOK, 1995; PICCOLI, 1998; TABITH Jr., 1997; TRINDADE e TRINDADE Jr., 1996).

A incompetência e a insuficiência velofaríngeas constituem a disfunção velofaríngea (DVF).

Conforme Moon e Kuehn (1997), alterações na posição da mandíbula com mudanças na freqüência e/ou intensidade de fala podem aplicar forças ao palato mole e, conseqüentemente, em sua atuação quanto ao mecanismo velofaríngeo, por estar coordenado com outros articuladores. Além da mandíbula, destacaram a participação da língua em caso de DVF, pois ela atuaria na tentativa de se evitar que ondas acústicas invadissem o trato nasal em caso de articulação de sons orais.

\subsection{A fala do portador de fissura palatina}

Antes de se escrever sobre a fala, propriamente dita, do portador de fissura palatina, faz-se necessário alguma explanação acerca da fissura lábio-palatina. 


\subsubsection{A fissura de lábio e/ou de palato}

A fissura é uma fenda que pode atingir os lábios, o palato mole e/ou duro; ou ainda, outra região da face. A fissura de palato pode ocorrer isolada ou associada com a fissura de lábio (SHPRINTZEN, 1995).

Origina-se no período embrionário, entre a oitava e a décima segunda semana gestacional, em que não há a fusão dos processos palatinos (CAPELOZZA FILHO e SILVA FILHO, 1992; MODOLIN e CERQUEIRA, 1997), que devem se encontrar na linha média, fundirem-se entre si e com a porção óssea do septo nasal, o vômer (SHPRINTZEN, 1995).

Esta ausência de fusão dos processos palatinos pode ser em virtude de medicamentos, defensivos agrícolas (agrotóxicos e herbicidas) e a consangüinidade dos pais (FRASER, 1970). Há que se considerar, ainda, a inexistência de um fator causal específico, mas sim agentes de categoria genética ou ambiental. Trinta por cento dos casos de fissura de lábio e/ou de palato são atribuídas ao fator genético, ao passo que o restante deve-se ao ambiente extra-uterino: infecções viróticas, epilepsia, drogas anticonvulsivas, deficiência nutricional, irradiação ionizante, estresse emocional, fumo, alcoolismo e idade dos pais na concepção. O mais provável é a causa ser de origem multifatorial, ou seja, das interações entre as variantes genéticas e os fatores teratogênicos extragenéticos (CAPELOZZA FILHO e SILVA FILHO, 1992; MODOLIN e CERQUEIRA, 1997).

O estudo de Souza-Freitas (1974) indicou o risco de 0,1\% de pais não portadores de fissura de lábio e/ou de palato gerarem uma criança com esta má-formação, enquanto que este risco aumenta para 4,5\% em um segundo filho, quando estes mesmos pais já conceberam um filho com fissura. No caso de um dos pais ser portador de fissura de lábio e/ou de palato, há o risco de $2 \%$ de terem um filho com a mesma deformidade, ao passo que este risco também cresce, agora para $15 \%$, se já tiverem um filho com fissura. De acordo com Menegotto e Salzano (1991), que estudaram o histórico familiar de 741 nascimentos de crianças portadoras de fissura de lábio associadas ou não à fissura de palato e sem síndromes associadas, de 115 nascidos com fissura de palato isolada e de igual número de recém-nascidos controles, 17,3\% dos recém-nascidos portadores de fissura de lábio associadas ou não à fissura de palato e sem síndromes associadas tinham 
casos de fissura na família, enquanto que os controles tinham $0,5 \%$ de casos de fissura na família; e, ainda, nestes portadores de fissura, 2,9\% de seus parentes também apresentavam fissura, enquanto que $1,6 \%$ dos pais a possuíam.

Todas as raças, etnias, sexos e classes sócio-econômicas podem ser acometidas por fissuras de lábio e/ou de palato.

No estudo de Neel (1958), a raça amarela é a mais susceptível de seu aparecimento, ou seja, 1 ocorrência a cada 373 nascimentos. Natsume et al.(1984), também encontram maiores ocorrências de fissura na raça amarela, só que 1 a cada 498 nascimentos. A raça negra, segundo Iregbulem (1982) tem a menor ocorrência, isto é, 1 caso a cada 2.070 nascimentos. Valores intermediários são encontrados para a raça branca, a saber: de acordo com Nagen et al. (1968), na cidade de Bauru/SP/Brasil, há 1 caso de fissura a cada 650 nascimentos; o estudo de Souza-Freitas (1974) revelou 1 ocorrência a cada 700 nascimentos, mesma estimativa encontrada por Johnson (1987) para o Brasil, ou seja, o nascimento de 1 criança com algum tipo de fissura orofacial a cada 700 nascimentos. A revisão de literatura feita por Peterson-Falzone et al. (2001) indicou que a fissura labiopalatina encontra-se entre as malformações craniofaciais mais comuns, com uma freqüência entre 1:500 e 1:700 nascimentos.

As fissuras que envolvem o lábio têm maior frequiência sobre homens, enquanto que as fissuras isoladas de palato têm maior freqüência em mulheres (ÅBYHOLM, 1978; FRASER, 1960; GREENE, 1964, 1968; MODOLIN e CERQUEIRA, 1997).

Seguindo a classificação de Spina et. al. (1972), que toma como ponto de partida o forame incisivo, local de junção na formação de toda a região lábio-palatina, as fissuras podem ser assim agrupadas:

- Grupo I (Figura 3), das fissuras pré-forame incisivo: unilaterais (direita/esquerda, total/parcial, conforme atingem ou não a arcada alveolar); bilaterais (total/parcial); medianas (total/parcial); 


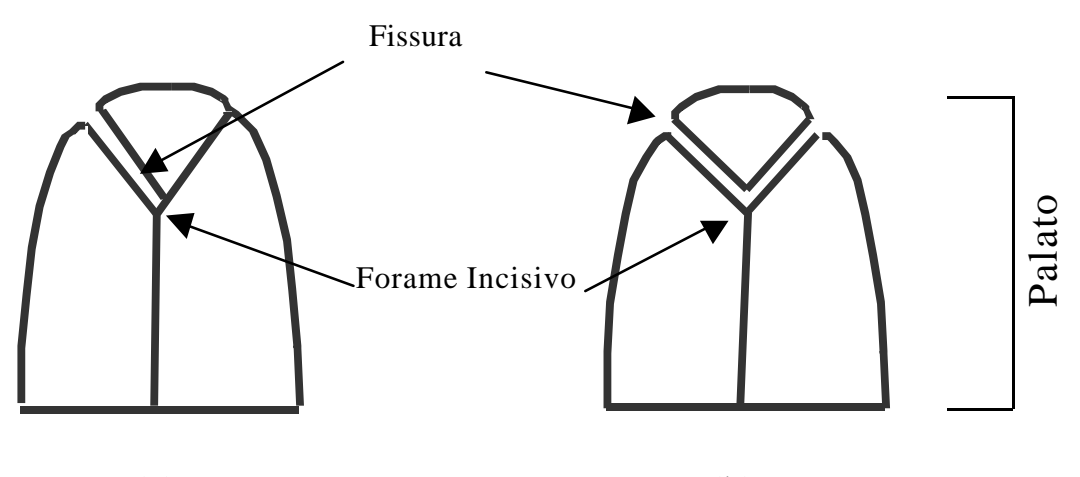

(a)

(b)

Figura 3 - Esquema representativo das fissuras pré-forame incisivo, segundo a classificação de Spina et al. (1972): (a) unilateral; (b) bilateral - adaptado de Uemeoka (2003).

- Grupo II (Figura 4), das fissuras transforame incisivo: unilaterais (direita/esquerda); bilaterais;

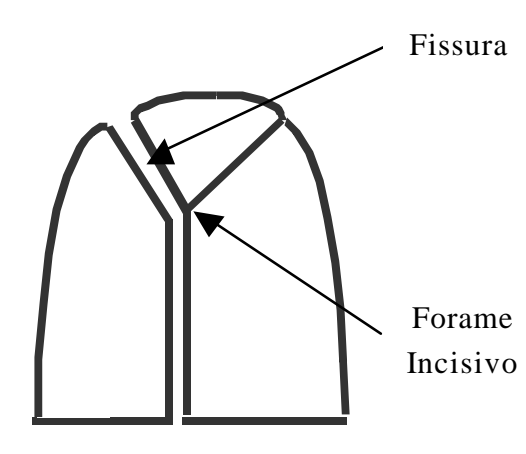

(a)

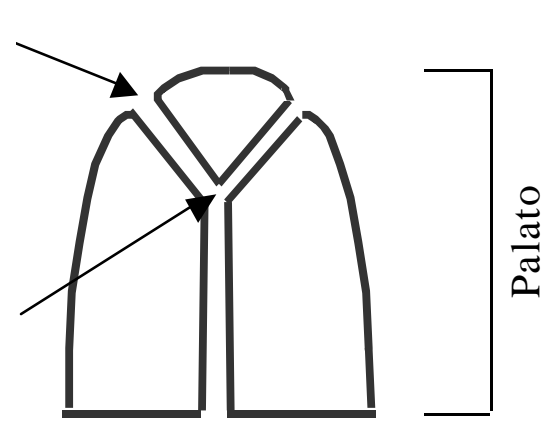

(b)

Figura 4-Esquema representativo das fissuras transforame incisivo, segundo a classificação de Spina et al. (1972): (a) unilateral; (b) bilateral - adaptado de Uemeoka (2003). 
- Grupo III (Figura 5), das fissuras pós-forame incisivo total/parcial;

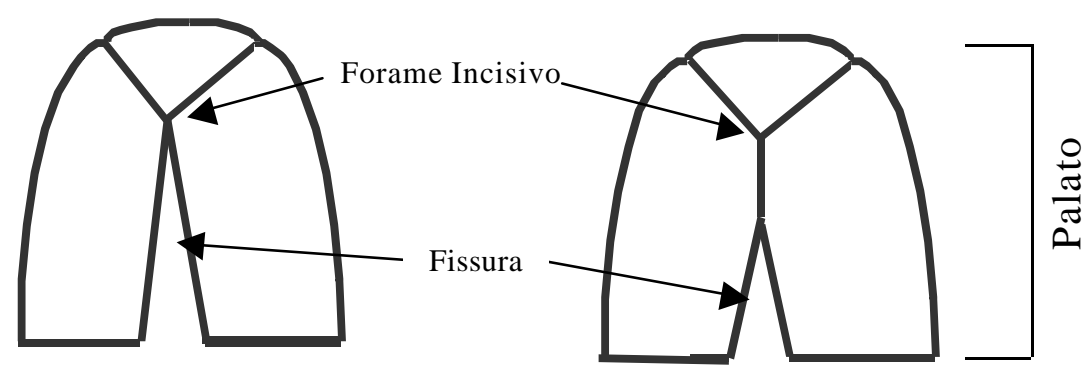

(a)

(b)

Figura 5-Esquema representativo das fissuras pós-forame incisivo, segundo a classificação de Spina et al. (1972): (a) total; (b) parcial-adaptado de Uemeoka (2003)

- Grupo IV, fissuras raras da face: oblíquas, transversais, do lábio inferior, do nariz, etc.

As fissuras pré-forame incisivo dizem respeito àquelas que atingem os lábios e/ou a arcada dentária, ao passo que as fissuras transforame incisivo atingem todo o lábio e todo o palato e as pós-forame incisivo atingem somente o palato mole ou entendem-se por toda a porção posterior do palato duro.

Ainda há uma variação da fissura palatina denominada submucosa. Nesta fissura, a comunicação entre cavidades nasal e oral não é visível, pois existe uma mucosa cobrindo a fissura, isto é, a não fusão óssea e muscular dessa região, que pode ou não ocasionar problemas de fala (DI NINNO e GENARO, 1998; SHPRINTZEN, 1995).

\subsubsection{A produção de fala do portador de fissura palatina}

O portador de fissura de lábio, apenas, não traz em si a iminência de problemas de fala. Apesar de se reconhecer que os lábios participem efetivamente da articulação de diversos sons e que seu movimento de protrusão, especialmente, altera a configuração do trato vocal e, por conseguinte, isto possa ser refletido acusticamente, não se destacam 
problemas de fala desta ordem nem abordagens clínico-científicas desta natureza, nos casos com lábio operado.

Por outro lado, se houver fissura palatina isoladamente ou acompanhando uma fissura de lábio, freqüentemente surgem problemas articulatórios de fala. O surgimento destes problemas decorre do tempo de convivência do portador de fissura de palato com sua fissura. Ou seja, se não tiver condições anátomo-fisiológicas para uma produção de fala adequada, é um forte candidato a desenvolver uma fala com comprometimentos articulatórios, que podem ir de distúrbios articulatórios simples (omissão, substituição e/ou distorção dos sons da língua) às articulações compensatórias (golpe de glote, plosiva faríngea, plosiva dorso médio palatal, fricativa faríngea, fricativa posterior), que são posteriorizações do ponto articulatório que o portador de fissura palatina faz na tentativa de aproximar o máximo possível das emissões orais do falante não portador desta fissura (AMARAL e GENARO, 1996; GOLDING-KUSHNER, 1995; SELL et al., 1994; WITZEL, 1995). Conforme Capelozza Filho e Silva Filho (1992), são freqüentes, também, problemas articulatórios dento-oclusais, conseqüentes da atresia lateral e ântero-posterior do arco dentário, sendo as consoantes mais freqüentemente afetadas as fricativas /s/, /z/, /f/, /v/ e as plosivas linguo-alveolares /t/ e /d/. E acrescentam que, às vezes, discrepâncias sagitais extremas entre os arcos dentários impedem o posicionamento do lábio inferior e dente superior na produção normal do /f/ e do /v/ e podem restringir a aproximação dos lábios para a produção das bilabiais /p/, $/ \mathrm{b} / \mathrm{e} / \mathrm{m} /$.

Contudo, o que mais estigmatiza o portador de fissura palatina com produção de fala inadequada, é o distúrbio de ressonância de fala, denominado hipernasalidade, conseqüente da DVF, o que o faz, pejorativamente, ser chamado de fanho ou fanhoso.

\subsection{A fala na DVF: hipernasalidade}

A DVF leva a uma ressonância nasal excessiva denominada hipernasalidade, pois a abertura do esfíncter velofaríngeo muda as características acús ticas do trato vocal pelo acoplamento das cavidades oral e nasal (BOONE e McFARLANE, 1994; BRADLEY, 1997; CURTIS, 1970; LESSA, 1996), sendo um fenômeno perceptivo 
(HENNINGSSON, 1988) e o problema de fala mais freqüentemente associado com a fissura palatina (WITZEL, 1995).

D’ Antonio e Scherer (1995) definem hipernasalidade como a percepção da ressonância nasal irregular durante a produção de vogais, desde que estas não sejam baixas ou não estejam acompanhando consoantes nasais.

Ou em outras palavras, como para Seikel et al. (2000), a hipernasalidade referese a uma excessiva, lingüisticamente inapropriada, ressonância nasal, decorrente da ausência de um fechamento velofaríngeo adequado durante os sons não-nasais na produção da fala.

Não acomete apenas portadores de fissura palatina, mas também qualquer pessoa que tenha tido seu palato removido parcial ou totalmente, como nas ressecções em virtude de tumores malignos ou que o tenha paralisado em conseqüência de traumatismos que afetem a inervação deste local.

No caso dos portadores de fissura palatina, de acordo com Hardin-Jones et al. (1993), McWilliams e Musgrave (1970), McWilliams et al. (1990), Morris (1973), Skolnick (1975) e Vandemarck e Hardin (1985), o grau de nasalidade é influenciado pelo tamanho da fissura palatina, pelas época e técnica do reparo cirúrgico e por vários fatores morfo-fisiológicos, como o tamanho e a mobilidade do palato mole.

Fletcher (1977) registra que a hipernasalidade é tipicamente identificada como uma conseqüência de trauma desenvolvimental ou de distúrbio das estruturas velofaríngeas.

Hirschberg (1986) afirma que, em geral, déficits estruturais como um palato mole curto ou uma nasofaringe profunda, distúrbios funcionais como desordens articulatórias e limitações dinâmicas, ou s eja, uma pobre mobilidade do palato mole ou um movimento mínimo das paredes laterais da faringe, são causas para a disfunção velofaríngea e para a hipernasalidade.

Uma vez havendo a hipernasalidade, há emissão de ar pelo nariz, que pode ser audível ou não, e reduzida pressão intra-oral (GOLDING-KUSHNER, 1995; SELL et al., 1994; WITZEL, 1995), na articulação dos sons consonantais. Algumas vezes, podese perceber não um fluxo de ar saindo pelo nariz, mas um ruído turbulento semelhante a 
um ronco, que, por sua vez, pode ocorrer isoladamente ou acompanhando a emissão de ar nasal (SELL et al., 1994).

Carney e Morris (1971) investigaram os correlatos estruturais da nasalidade entre portadores e não portadores de fissura palatina, que apresentavam distúrbio de nasalidade. Em cada um destes 2 grupos, participaram 10 falantes, sendo que os portadores de fissura palatina já haviam realizado cirurgia, não usavam próteses obturadoras nem tinham retalho faríngeo em seu palato. Todos jovens adultos e sem problemas auditivos gravaram em fita magnética e em filme cinefluorográfico suas emissões de 5 vogais (/i/, /å/, /a/, /Ë/ e /u/) isoladamente, em contexto silábico consoante plosiva surda/vogal/consoante plosiva surda, também isoladamente e conectados em um texto de 47 sílabas. Da cinefluorografia retiraram medidas da: 1) constrição velar; 2) constrição faríngea; 3) constrição oral e 4) abertura entre os incisivos. Estas medidas apresentaram-se semelhantes entre os grupos, nos diferentes contextos lingüísticos; em geral, os participantes sem fissura de palato apresentaram maior constrição velar ( 0 a 5,50 mm) que os portadores de fissura palatina ( 0 a 4,50 mm). A severidade da nasalidade, julgada por 65 ouvintes, não foi sistematicamente relacionada a nenhuma das medidas investigadas. A determinação do tamanho da constrição velar para a nasalidade variou de indivíduo para indivíduo, o que impossibilitou sua relação com a severidade da nasalidade. Os indivíduos com nasalidade e portadores de fissura palatina apresentaram maior nasalidade, em média, nas vogais altas que nas baixas, enquanto que nos falantes com nasalidade e não portadores de fissura palatina aconteceu o inverso. A relação entre a severidade da nasalidade entre vogais isoladas e na fala conectada foi baixa. Como a vogal /a/, em geral, é julgada a menos nasalizada e a que apresenta maior espaço na constrição velar dentre as vogais, questionam sua validade na avaliação da relação da constrição velar com a severidade da nasalidade para falantes nasais portadores de fissura de palato. E, por fim, viram que pode ser mais significativo investigar as combinações das medidas estruturais que cada uma, isoladamente, em relação à severidade da nasalidade. Os autores usaram o termo nasalidade e não hipernasalidade, o que foimantido, apesar de ser perceptível tratar-se do distúrbio da ressonância nasal (hipernasalidade).

Kummer et al. (1992) propuseram-se a determinar se existia correlação entre as várias características perceptivas da hipernasalidade e da emissão de ar nasal e a extensão da insuficiência velofaríngea (VF). Vinte e oito indivíduos foram selecionados 
(faixa etária de 2,8 a 23,4 anos de idade, $\overline{\mathrm{X}}=6,1$ anos), possuíam histórico de fissura de lábio e/ou palato, fissura de palato submucosa ou insuficiência velofaríngeacongênitae compuseram 3 grupos: um com hipernasalidade sem emissão de ar nasal audível (8 componentes), outro com hipernasalidade com emissão de ar nasal audível (10 componentes) e, por fim, um sem hipernasalidade e com emissão de ar nasal audível (10 componentes). Todos os participantes foram submetidos a uma avaliação de fala (avaliação articulatória de palavras isoladas e fala espontânea foram incluídas) e à videofluoroscopia. A hipernasalidade foi observada na amostra de fala espontânea, enquanto que a articulação e a emissão de ar nasal ou o ronco nasal foram avaliados em palavras isoladas e na fala espontânea. Houve significância estatística tanto para abertura velofaríngea $(\mathrm{p}=0,005)$ quanto para movimento das paredes laterais da faringe ( $\mathrm{p}=0,0029)$, entre os grupos com hipernasalidade (com e sem emissão de ar nasal audível) e o grupo com emissão de ar nasal audível, apenas. Segundo os autores, a hipernasalidade, com ou sem emissão de ar nasal audível, pode ocorrer com uma pequena abertura VF, contudo seus resultados levaram-nos a acreditar que a hipernasalidade pode ser primariamente associada com uma abertura VF relativamente grande. Sugeriram, ainda, que a abertura VF é menor em casos de emissão de ar nasal audível que para hipernasalidade, apesar de esta, ainda, poder ocorrer em pequena abertura VF. Entre os grupos com hipernasalidade, com e sem emissão de ar nasal audível, não houve significância estatística.

Zuleta et al. (1997) delinearam as configurações laríngeas e do EVF de indivíduos portadores de fissura palatina pela observação clínica, fibroscopia rígida e flexível. Contaram com 9 participantes, falantes do Português Brasileiro (PB) (5 homens e 4 mulheres, na faixa etária de 16 a 33 anos de idade), operados: 3 portadores de fissura transforame incisivo à direita; 2 portadores de fissura transforame incisivo à esquerda; 1 portador de fissura transforame incisivo bilateral e 3 com fissura pós-forame incompleta. Três nunca fizeram fonoterapia anteriormente ao estudo e 6 haviam feito ( 4 receberam alta e 2 interromperam o tratamento fonoterápico). Destaca-se que, pela avaliação perceptivo -auditiva vocal, os participantes apresentaram pouca alteração de pitch e loudness, enquanto a ressonância e o ataque vocal indicaram ter necessidade de maior atenção. Seus achados demonstraram que os sons articulados com mecanismo compensatório apresentaram maiores diferenças ( gap) no FVF, ao passo que estes foram mínimos na articulação fonêmica adequada. Finalizaram argumentando que a 
valorização da singularidade fisiológica e dos achados individuais convergem para uma melhor abordagem terapêutica, protética e cirúrgica.

Conforme Pulkkinen et al. (2001), a morfologia orofacial de portadores de fissura palatina muda com a idade por causa das intervenções cirúrgicas e do crescimento, com conseqüências sobre a fala e a produção vocal. Afirmam, também, que as alterações de fala associadas com a incompetência velofaríngea incluem hipernasalidade e emissão de ar nasal.

\subsection{A nasalidade}

Froeschels (1957) discutiu o termo nasalidade baseado na fisiologia envolvida. Considerando que o termo nasalidade vem do Latimnasus (nariz), parece ser adequado utilizá-lo para as impressões acústicas de uma fala que a apresenta de forma anormal (usando sua própria forma de narrativa). Porém, cientificamente, o questionamento do termo persiste, ao se considerar que "algo anormal está passando pelo nariz" ser uma definição imprecisa. Mesmo na fala sem comprometimentos, pelas impressões acústicas, pode-se perceber que "algo está passando pelo nariz". Então, o termo nasalidade pode ser usado para as condições ditas normais e anormais. O padrão da normalidade pode ser o referencial para os achados acústicos anormais da nasalidade. As características fisiológicas sugerem que o termo nasalidade é peculiar aos sons nasais $/ \mathrm{m} /, \mathrm{n} / \mathrm{e} / 3 /$, bem como das vogais que se avizinham deles. Independente de normal ou anormal, a nasalidade pode ser ouvida, vista (exemplifica com a laringoscopia) ou sentida (pela colocação dos dedos sobre o nariz, que vibra nas emissões com presença de nasalidade). Visto assim, a nasalidade como um achado fisiológico, presente em todos os falantes e em sons intrinsecamente nasais, o autor argumenta que o termo é impróprio para designar achados patológicos. Nos casos em que as características acústicas peculiares aos sons nasais aparecem em todos os sons vocalizados, notadamente nas vogais, também há a nomeação nasalidade aberta ou rinolalia aberta. Não concorda com o termo "aberta”, pois é justamente a condição de abertura entre as cavidades oral e nasal que caracteriza os sons nasais e, também, constituem a nasalidade. Sugere o termo hiper-rinolalia para a fala comprometida, em 
que os sons vocais carregam consigo o som característico apenas dos sons nasais. E a hiporrinolalia que, por outro lado, significaria a ausência total ou parcial de sons nasais.

Curtis, em 1970, definiu que, fisiologicamente, a nasalização está relacionada com uma simples ação valvular, que controla o acoplamento entre a porção oro-faríngea do trato vocal e a cavidade nasal. Desde que a cavidade nasal não mude em termos de forma e de volume, uma tendência seria assumir que suas características acústicas de ressoador ou de sistema de transmissão fossem constantes. Contudo, não é o que revela a análise acústica do sinal, que medeia os eventos fisiológicos e perceptivos. Uma explicação poderia vir do modelo de ressonador duplo Helmholtz ${ }^{5}$, que considera, especialmente, a cavidade oro-faríngea, onde uma protuberância da língua a divide em dois volumes, em que cada cavidade do trato vocal, incluindo a cavidade nasal, tem características próprias de ressonância, que agem independentemente umas das outras. Pode incluir anti-ressonâncias, que tenderiam a cancelar a radiação de energia em uma região de freqüência em particular e, também, incluir ressonâncias, que tenderiam a produzir uma concentração de energia em uma determinada região do espectro. Assim, há o indicativo de que a cavidade nasal emite uma freqüência em torno de 250 a $300 \mathrm{~Hz}$ e a existência de uma anti-ressonância, aproximadamente, na freqüência da oitava mais alta. Porém, todo esse comportamento mostrou-se dependente de qual vogal está se tratando, de características individuais do falante e prejudicado pela observação dos efeitos isolados das variáveis atuantes em um processo complexo, além da pobre resolução de energia dos métodos espectrográficos para análise acústica, utilizados até então. Mesmo o sistema de ressonância da cavidade nasal possuindo características próprias, não age independentemente no resultado acústico das emissões vocais das quais participa, estando em interação com as demais cavidades do trato vocal, inclusive dependendo do grau de acoplamento entre as cavidades nasal e oro-faríngea. Outra explicação das ressonâncias do trato vocal seria dividindo-o em sistemas em forma de cilindro, que estariam conectados, aplicando analogias dinâmicas da teoria elétrica de transmissão em linha. Desta forma, reafirma-se a interdependência da ressonância da cavidade nasal e se justifica as diferenças espectrais obtidas para cada vogal nasalizada. Este autor registrou, ainda, que a literatura sobre desordens da fala e da voz

\footnotetext{
${ }^{5}$ Sobre esta questão de modelamento do trato vocal sugiro: STEVENS, K. (1999). Basic acoustics of vocal tract resonators, cap. 3, 2a . Edição, Acoustic Phonetics, Massachusetts: Massachusetts Institute of Technology, p.127-202.
} 
freqüentemente refere-se a uma "ressonância nasal", de forma a parecer que existe uma ressonância nasal constante, independente do restante do trato vocal. O autor afirmou a necessidade de se esclarecer como variações fisiológicas e acústicas da nasalização podem ser percebidas da mesma forma, o que também não quer dizer que a percepção da nasalidade seja uniforme e invariante. E, portanto, a característica perceptiva da nasalidade não pode ser tomada como indicativo de uma constância física.

Segundo Camara Jr. (1970), há dois contextos no PB em que podem surgir a nasalização, para a qual usa o termo nasalação: em nível fonológico para fazer a distinção entre palavras (por exemplo, junta/juta, cinto/cito, lenda/leda) ou em nível fonético, apenas, simplesmente pela antecipação do falante em abaixar o véu palatino para a emissão da consoante na sílaba seguinte (por exemplo, ano, cimo, uma, etc.), sem função distintiva.

Back (1973) discutiu se as vogais nasais do PB são ou não fonemas. Explicou que para alguns elas constituem apenas alofones ${ }^{6}$ das respectivas orais, enquanto que para outros, são fonemas, tanto quanto as orais. Como existem vogais nasais que não são condicionadas por c onsoante nasal, concluiu que o sistema vocálico do PB possui 12 vogais, ou seja, 7 orais e 5 nasais, de forma exaustiva, pois assim é possível explicar todos os fatos da língua portuguesa (do Brasil), e coerente, por esclarecer sobre a rima e os alomorfes ${ }^{7}$ ora com vogal oral, ora com vogal nasal. Finaliza afirmando que as vogais orais não se opõem ao seu par nasal por terem distribuição diferente.

Abaurre et al. (1996) atém-se não à nasalidade distintiva do PB, mas à nasalidade fonética, que se manifesta de forma diferente em diferentes dialetos do PB, por processo de assimilação. Com esta finalidade, analisaram 4.624 dados deste tipo de nasalidade em relação a todas as vogais do PB. Encontraram que se a vogal estiver em sílaba tônica, a nasalização acontece quase categoricamente, porém isto não é observado na juntura de palavra. A nasalização também é percebida em vogal diante de consoante nasal palatal. E, por fim, a região geográfica é determinante para a descrição do processo de nasalização: em Recife e em Salvador, nasalizam mais, enquanto que em

\footnotetext{
${ }^{6}$ Segundo o próprio autor, dois ou mais sons são alofones entre si, quando jamais ocorrem no mesmo ambiente (a não ser como variantes livres) (p.299).

7 Alomorfe é a representação alternativa e diferente, estudada no campo da morfologia, dependente do contexto fônico, que não implica significados diferentes (BORBA, 1971; LYONS, 1979; LOPES, 1989). Exemplo: o plural em português pode ser realizado, dentre as possibilidades existentes, com acréscimo de -s ou -es (alomorfes) e continuam significando plural: casa/casas, mar/mares.
} 
São Paulo e em Porto Alegre, nasalizam menos; o Rio de Janeiro fica com nível de nasalização entre estes dois extremos.

Ladefoged (2001) afirmou que as vogais serão nasalizadas se o palato mole estiver abaixado, propiciando que parte do fluxo aéreo escape através do nariz. Sendo possível colocar o diacrítico [ ] sobre qualquer vogal para indicar que ela está nasalizada. Segundo ele, vogais deste tipo são comumente chamadas vogais nasais.

\subsection{O trato nasal}

Na seção 2.2, considerou-se como trato vocal o trajeto da glote aos lábios, com o esfíncter velofaríngeo (EVF) constituído. Porém, ao abaixar o palato mole e se relaxar as paredes faríngeas, a cavidade nasal é agregada ao tubo vocal original, aumentando o domínio do trato vocal.

Relatos de Barbosa, (2003); Coleman Jr., (1963); Fujimura, (1990); Fujimura e Erickson, (1997); Johnson, (1997d); Kent, (1993, 1997); Kent e Read, (1992) fornecem conhecimentos a respeito da cavidade nasal.

O trato nasal tem cerca de $12,5 \mathrm{~cm}$ de comprimento no homem adulto. É dividido em dois canais, um à direita e outro à esquerda da cavidade nasal, separado pelo septo, simetricamente, o que possibilita o funcionamento acústico do nariz como uma cavidade única. Sua riqueza em tecidos lhe confere uma propriedade de amortecimento sobre o som. A existência do septo nasal e a disposição dos tecidos sobre ele, formando as coanas, aumenta consideravelmente sua superfície, apresentando área maior que algumas constrições do restante do trato vo cal.

A cavidade nasal tem uma frequiência natural de vibração que, semelhante ao restante do trato vocal, é capaz de amplificar ou amortecer frequiências geradas na glote.

Quando o som radiado é puramente nasal, um /m/, por exemplo, os lábios estão selados e a cavidade nasal é a única saída do som. Como a cavidade oral está fechada, ela retém energia sonora, abafando algumas freqüências. Surgem, então, os antiformantes. 
Vê-se que a cavidade nasal contribui com formantes e antiformantes sobre a energia sonora.

Com este ponto de vista, no caso das vogais, não há, realmente, vogais nasais, mas sim nasalizadas, pois a radiação do seu som não ocorre apenas pelo nariz, porém concomitantemente pela cavidade oral.

Lindqvist e Sundberg (1972), defendem que além do nariz, os sinus nasais maxilares (um de cada lado de cada narina) e frontais (dois, acima do trato nasal), também colaboram para a composição acústica da nasalidade.

Maeda (1982), utilizando a síntese de fala e o modelo acústico do trato vocal incluindo a cavidade nasal, investigou os correlatos acústicos para a nasalização de vogais. Propôs-se a encontrar a característica acústica da nasalidade que fosse independente da vogal e alguma explicação para a característica de nasalização dependente da vogal. As características acústicas das vogais nasalizadas puderam ser calculadas pela magnitude do acoplamento entre as cavidades oral e nasal e esta mesma magnitude foi investigada para resultar na relação entre o efeito acústico (modificação no espectro vocálico) e o efeito perceptivo -auditivo (percepção subjetiva do grau de nasalização). Em cima deste raciocínio, encontrou que os efeitos acústicos e perceptivo auditivos do acoplamento nasal para as vogais /i/, /u/ e /a/ francesas dependeram de qual vogal se tratava. Uma característica de nasalização que pareceu independente do tipo vocálico foi a suavização espectral na região do primeiro e segundo formantes, ou seja, de 200 a $2000 \mathrm{~Hz}$. Apesar de não ter conseguido definir matematicamente uma medida que refletisse esta suavização espectral, acreditou que ela seria uma explicação para a variação, independentemente da vogal, do grau subjetivo de nasalização vocálica.

Stevens et al. (1987) registram que o acoplamento entre as cavidades oral e nasal, gerando presença de nasalidade, ocorre durante a fala na produção de vogais sob algumas condições: 1) acoplamento permanente entre as cavidades por problemas anatômicos ou funcionais; 2) vogais na vizinhança de sons nasais; 3) distinção fonêmica entre vogais nasais e não nasais em algumas línguas como o Francês, o Português e o Gujarati. Levantam a possibilidade de limitações na compreensão da contribuição do trato nasal para a função transferência incorporada na teoria acústica da produção de vogais, pelo modelamento não levar em conta, por exemplo, as áreas dos sinus nasais. Defendem um detalhamento das áreas participantes às propriedades acústicas nasais 
para um modelamento e teorização mais precisos sobre a produção de vogais nasalizadas. Pelo acoplamento oro-nasal, há a inserção de formantes nasais em torno de freqüências baixas (300-400 Hz) e uma queda no valor do primeiro formante das vogais baixas quando comparadas à sua reprodução não nasalizada. Realizaram experimentos com manipulações da impedância nasal, ou seja, da abertura noesfíncter velofaríngeoe, então, graduando a área de acoplamento entre as cavidades oral e nasal, usando o sintetizador Klatt e apresentando estas produções acústicas (pares de palavras com vogais /i/, /a/ e /u/ nasalizadas e não nasalizadas), para ouvintes. Perceberam que o ajuste no grau de acoplamento entre as cavidades, para conferir uma nasalidade diferencial entre vogais nasalizadas e não nasalizadas, depende de qual vogal se trata e, ainda, que mudanças espectrais no $\mathrm{F}_{2}$ são responsáveis pela percepção de nasalização. $\mathrm{Na}$ busca de um traço comum entre todas as vogais nasalizadas e que constitua em si a nasalidade propriamente, viram uma correlação entre o espectro de vogais nasalizadas que apresentam maior largura de banda em $\mathrm{F}_{1}$ que seu par não nasalizado, como se a nasalidade acrescentasse 2 picos: um acima de $F_{1}$ e outro abaixo dele, dependendo da vogal considerada, sendo a distância entre o $F_{1}$ e este pólo adicional na faixa de 200 a 400 Hz. E mais, vêem a necessidade de se atrelar os e studos espectrais à percepção do nervo auditivo, visto que parece ser a distância entre os picos espectrais que confere a percepção da nasalidade pelo ouvinte.

Folkins (1988) afirma que as características de filtro do trato nasal não dependem do tamanho do espaço VF, mas sim da relativa impedância acústica entre as cavidades oral e nasal. E, ainda, que são as variações das secções transversais de área e não o tamanho absoluto das constrições que determinam as freqüências ressonantes. Os gestos de abertura para as articulações orais podem neutralizar uma inabilidade estrutural para reduzir a impedância nasal. Este autor cita Kent (1966) ${ }^{8}$, que usou próteses para produzir orifícios circulares na região VF em 6 portadores de fissura palatina. Após um período, alguns deles demonstraram ausência de hipernasalidade para vogais abertas mesmo em orifícios iguais a $113 \mathrm{~mm}^{2}$. O autor ainda usou a cinefluoroscopia para documentar que os falantes sistematicamente abriram os lábios, a mandíbula e a língua mais ordenadamente para interagir com os aumentos de tamanho

\footnotetext{
${ }^{8}$ KENT, L. (1966). The effects of oral-to-nasal coupling on the peceptual, physiological, and acoustical characteristics of vowels. Unpublished Ph.D. dissertation, University of Iowa apud FOLKINS, J.W. (1988). Velopharyngeal nomenclature: incompetence, inadequacy, insufficieny, and dysfunction. Cleft Palate J, v.25, n.4, p.413-6.
} 
do esfíncter VF. Este mesmo estudo foi citado por Curtis $(1970)^{9}$, que afirmou ainda, que ele pôde demonstrar que esta variação no acoplamento foi acompanhada pelo esperado aumento da nasalidade, como percebido e a valiado pelos ouvintes, porém não pôde demonstrar uma variação consistente associada às características espectrais.

Retornando às elaborações de Folkins (1988), este afirma que o comprometimento da fala está relacionada a uma interação entre estrutura e função e não é benéfico rotular ambos como causas isoladas. Destaca que a avaliação da interação entre fatores estrutural e motor deve ser regra central na avaliação da fala.

\subsection{Os formantes e a nasalidade/hipernasalidade}

House e Stevens (1956) afirmam que o acoplamento entre a cavidade nasal e o trato vocal durante a produção de vogais resulta em aumento na largura de banda do F1, em redução no nível de amplitude geral dos formantes, em introdução de antiressonância, em eliminação do $\mathrm{F}_{3}$, em irregularidades nos formantes altos, em possível inserção de picos espectrais adicionais e que a percepção da nasalidade mostrou-se mais ligada à magnitude das propriedades espectrais dos sons analisados que ao tamanho da área acoplada.

Coleman Jr. (1963) estudou o efeito no espectro acústico e nas percepções da qualidade vocal nasal de quatro vogais, causado por aumentos sistemáticos no tamanho da abertura velofaríngea em um colaborador sem comprometimentos do trato vocal. As vogais /i/, / / /, /a/ e /u/ foram emitidas isoladamente com aberturas velofaríngeas redimensionadas nove vezes. Estas aberturas foram construídas em próteses orais removíveis, que apresentavam um prolongamento em direção à parede posterior da faringe (bulbo), onde as aberturas eram feitas. O colaborador escolhido foi um homem adulto, sem problemas de fala, habituado neste tipo de experimento e capaz de produzir vogais sustentadas em níveis fixos de pitch, as quais foram produzidas em uma frequiência fundamental de $120 \mathrm{~Hz}$, sempre após uma apresentação de um tom puro,

9 KENT, L. (1966). The effects of oral-to-nasal coupling on the peceptual, physiological, and acoustical characteristics of vowels. Unpublished Ph.D. dissertation, University of Iowa apud CURTIS, J.F. (1970). The acoustics of nasalized speech. Cleft Palate J, v.7, p.380-96. 
também de $120 \mathrm{~Hz}$, como referência, em uma intensidade vocal confortável para o emissor. Este foi posicionado diante de um microfone condensado, que estava a 8 polegadas em frente aos seus lábios, em plano horizontal e dentro de uma sala acusticamente tratada. Para eliminar a variabilidade intra-sujeito, foi solicitado ao emissor que repetisse 3 vezes cada vogal sustentada. Além da análise do espectro acústico de cada vogal, por meio da espectrografia (Sona-Graph, Kay Elemetric Company), falantes nativos do inglês americano, em uma sala de aula, fizeram o julgamento perceptivo-auditivo das vogais, diante de 2 alto-falantes. O pesquisador encontrou mudanças acústicas assistemáticas e não diretamente relacionadas ao tamanho da abertura velofaríngea. Em /a/, houve um aumento na largura de banda de todos os formantes e uma queda na freqüência do $F_{3}$. Estas mudanças nem sempre ocorreram em todas 3 produções da mesma vogal, no mesmo tamanho de abertura velofaríngea, sugerindo a não correlação das mudanças acústicas com a abertura velofaríngea. Tanto as mudanças no espectro acústico, quanto no julgamento dos ouvintes aconteceram quando a abertura velofaríngea foi aumentada para $0,50 \mathrm{~cm}$ e para $1,20 \mathrm{~cm}$ de diâmetro, indicando graus críticos do acoplamento a cústico no trato vocal deste sujeito em particular. Constatou, com base nas 3 repetições de cada vogal sob as mesmas condições, que há variabilidade nas emissões de um mesmo falante, com mesma abertura velofaríngea e com a mesma vogal, tanto no espectro acústico quanto na avaliação perceptivo-auditiva. Afirmou que a altura e a posição da curvatura da língua, o grau de constrição labial e o tamanho da abertura das narinas para o exterior determinaram a relação de impedância entre as cavidades oral e nasal. Se reduzirem a impedância para a entrada da cavidade nasal, a qualidade vocal nasal é intensificada. Ea percepção destas mudanças sobre a nasalidade é diferente no caso de as vogais nasais serem produzidas por falantes com estruturas orais adequadas ou com fissura palatina.

Schwartz (1968) observou as características do espectro (representação gráfica da freqüência versus intensidade relativa), das vogais /i/, /u/, /æ/ e /a/, nas condições de fechamento velofaríngeo completo e com uma abertura de $3,7 \mathrm{~cm}^{2}$, sendo as curvas nasais adaptadas e modificadas de resultados obtidos através do uso de um sintetizador de fala eletrônico. Teceu algumas considerações a respeito das características nasais das referidas vogais nasalizadas. Destac ou que a característica mais comumente notada é a redução da intensidade do $F_{1}$. A magnitude desta redução depende de qual vogal se trata. Este efeito redutor é consequiência da adição das características de amortecimento 
das superfícies das paredes da cavidade nasal. Uma segunda característica correntemente registrada é a presença de uma anti-ressonância no espectro vocálico. Uma anti-ressonância ou queda da intensidade de uma porção do espectro é um fenômeno acústico que ocorre quando um tubo (assim como a cavidade oro-faríngea)é acoplado a um tubo ramificado (como a cavidade nasal). Para a vogal /a/ nasal, a antiressonância pode ser vista em $2400 \mathrm{~Hz}$, onde há a eliminação do $\mathrm{F}_{3}$. Uma terceira característica do espectro nasal é a presença de harmônicos reforçados nas frequiências em que a energia não é normalmente esperada. Estas freqüências reforçadas, que constituem ressonâncias extras, podem ser consideradas as ressonâncias da cavidade nasal. Tanto a localização da freqüência e a magnitude da redução de energia de uma anti-ressonância, quanto às posições de freqüência e de amplitude relativas de ressonâncias extras variam de acordo com a vogal, com o falante e com o tamanho da abertura velofaríngea. A quarta característica do espectro nasal é a mudança nas posições relativas da freqüência dos formantes. Uma mudança deste tipo é esperada desde que o acoplamento da cavidade nasal efetivamente mude as dimensões da cavidade oro-faríngea. O autor afirma que vogais isoladas nasais, no mínimo, apresentarão uma destas quatro características. Afirma, ainda, que a diferença básica entre vogais nasais e não-nasais está na intensidade das harmônicas e não na freqüência destas, pois a modificação não ocorre em nível laríngeo (glótico), mas sim no acoplamento entre as cavidades oral e nasal. Desta forma, destaca que clínicos que trabalham com problemas de nasalidade podem obter medidas objetivas da nasalidade a partir de medições das intensidades das harmônicas. Sugere, então, um escore de diferença espectral (SDS: spectrum difference score), em dB, que é a soma da diferença da intensidade relativa de cada harmônica. Coloca uma questão, não concluída até então: se todas as quatro características descritas são igualmente importantes para a percepção da nasalidade. Sugere, portanto, que pode ser tentada a alteração seletiva da intensidade de várias porções do espectro da vogal nasal, enquanto se estuda o efeito de cada manipulação sobre a avaliação da severidade por ouvintes.

Em 1970, Fant, ao discorrer sobre sons nasais e nasalização, afirmou que a nasalização vocálica ocorre, via de regra ou mais freqüentemente, em vogais posicionadas entre duas consoantes nasais. Em posições átonas, a nasalidade assimilada pode vir combinada com um curto ou completa ausência do intervalo sonoro do murmúrio nasal de uma consoante nasal, em que a nasalização vem da característica 
maior da presença de um fonema nasal. Elucida que as vogais nasais, tal como ocorre em Francês, são produzidas em posições específicas da língua (o articulador), em adição ao elemento de nasalização. A nasalização não é fácil de ser estudada, devido às características intrínsecas do falante, do próprio som que está sendo nasalizado e o tipo e o grau do acoplamento nasal. Um certo grau de nasalização é provavelmente um atributo esperado para algumas vogais orais, em que o véu palatino tende a abaixar durante sua emissão, como em [a]. Esta nasalização seria uma compensação para a posição neutra da língua (o articulador), associada a uma ampla região faríngea ou a um aumento do volume após o ponto de ár ea mínima de corte transversal, senão a qualidade vocálica corresponderia a uma vogal schwa $([\S])^{10}$ e não [a]. Nesta mesma publicação, sua análise de vogais russas, emitidas por um sujeito russo, de 38 anos de idade, mais suas observações em emissões por síntese e a construção de circuitos analógicos, a nasalização teve como característica mais consistente a redução da intensidade do $\mathrm{F}_{1}$, que também justifica a anti-ressonância e o aumento da largura de banda dos formantes. No estudo da vogal [a], emitida apenas por via oral, isto é, sem acoplamento entre as cavidades oral e nasal, encontrou $F_{1}=630 \mathrm{~Hz}, F_{2}=1070 \mathrm{~Hz}$ e $F_{3}=2400 \mathrm{~Hz}$. Ao comparar estes achados dispostos graficamente com aqueles obtidos com uma área de acoplamento entre as cavidades oral e nasal de $0,16 \mathrm{~cm}^{2}$, constatou um vale e um nível reduzido em $\mathrm{F}_{3}$, a ocorrência de um formante nasal em $2000 \mathrm{~Hz}$ e uma anti-ressonância entre este e $F_{3}$. No caso de extrema abertura do trato nasal tanto em nível de seu acoplamento com a orofaringe $\left(2,6 \mathrm{~cm}^{2}\right)$, quanto das narinas, encontrou antiformante somente abaixo de $\mathrm{F}_{2}$, resultando em um nível muito (termo do autor) baixo do $\mathrm{F}_{2}$. Este efeito foi mais acentuado quando se diminuiu a área do corte transversal na entrada da cavidade oral, semelhante ao que acontece quando o véu palatino abaixa e encontra a língua. Percebeu que houve variações no valor de $F_{1}$ diretamente relacionadas ao tamanho das áreas oro-naso-faringe e das narinas, as quais manipulou.

Em 1980, Pickett relatou que, na fala comprometida em que o indivíduo é portador de uma fissura de palato ou tem seu véu palatino curto ou com movimento deficiente, pode ocorrer extrema nasalização de todos os sons da fala. Um efeito desta extrema nasalização foi verificar que $\mathrm{F}_{1}$ torna-se mais amplo e com menor pico quando comparado ao $\mathrm{F}_{1}$ de vogais exclusivamente orais, pelo amortecimento da ressonância

\footnotetext{
${ }^{10}$ Fonema presente em línguas como o Inglês, por exemplo, o a de about; não existe em Português Brasileiro, mas conforme BUENO (2000), é semelhante ao seu e átono no final das palavras.
} 
formante pela menor energia através da abertura dentro do trato nasal. Afirmou que outra mudança é a aplicação de picos de ressonância negativos para a resposta do trato vocal. Estas ressonâncias negativas são chamadas zeros, ou seja, são anti-ressonâncias. Em vez de reforçar e amplificar o espectro na e próximo à freqüência ressonante, uma anti-ressonância seletivamente absorve o som, tanto que ele acentuadamente reduz a amplitude dos componentes na e próximo à freqüência anti-ressonante. Em adição, para cada zero há um formante extra. A quantidade destes efeitos depende da quantidade de abertura entre o trato oro-faríngeo e o trato nasal. Isto é, os efeitos da nasalização sobre o espectro dependem da quantidade de acoplamentos entre os dois tratos. Portanto, a quantidade de acoplamento afeta as posições de freqüência dos zeros e dos formantes extras. O efeito total sobre o espectro é complexo, mas há dois efeitos gerais: 1) os efeitos da nasalização sobre $F_{1}$ são reduzir sua amplitude e movê-lo para uma região de frequiência mais alta, cerca de $50 \mathrm{~Hz}$ a $100 \mathrm{~Hz}$; 2) o acoplamento nasal pode, ainda, causar zeros nas regiões do $\mathrm{F}_{2}$ e do $\mathrm{F}_{3}$, o que freqüentemente reduz os picos destes formantes ou completamente suaviza-os.

Em sua dissertação, Glass (1984) caracterizou e quantificou as consoantes nasais e vogais nasalizadas do Inglês Americano, além de delinear sistemas de detecção automática destes mesmos sons. Para isto, contou com a colaboração de 3 homens e 3 mulheres, falantes nativos do inglês americano, na faixa etária de 20 a 40 anos de idade, que emitiram 1200 palavras, das quais mensurou-se a duração, a energia e as características espectrais dos sons nasais. Seus achados revelaram que a propriedade acústica mais robusta de uma consoante nasal é uma constante baixa frequiência de ressonância, que domina o espectro. Enquanto que para uma vogal nasalizada é a presença de uma ressonância extra na região do $\mathrm{F}_{1}$, acima ou abaixo dele, dependendo da altura da vogal. Ao medir a força da ressonância relativa extra do $F_{1}$ e uma quantidade de tempo da vogal, é possível determinar graus relativos de nasalização.

Båvegård et al. (1993) afirmam que o detalhamento sobre a nasalidade em vogais depende do grau de nasalização e das suposições sobre a estrutura da cavidade nasal, como a influência dos sinus nasais.

Krakow e Huffman (1993) destacam a análise espectral como uma ferramenta para o estudo da nasalização, visto a facilidade e a forma não-invasiva de se fazer gravações em áudio. Colocam que a variabilidade do trato nasal entre os falantes 
contribui para a dificuldade que se tem para fazer generalizações sobre a interação das cavidades oral e nasal quando acopladas. Em geral, há constantes mudanças na freqüência e na largura de banda dos formantes vocálicos, especialmente $F_{1}$ e há formantes adicionais e antiformantes no espectro-tais mudanças variam de vogal para vogal.

Maeda (1993) escreve que o acoplamento da cavidade nasal ao trato oral para /a/ provoca uma divisão e uma suavização do pico de seu $F_{1}$, por ação do formante nasal. Para ele, é provável que o limite de abertura velofaríngea esteja de acordo com a posição da língua. A língua em posição alta resulta em pouco espaço para o abaixamento velar, então há menor abertura VF, relativamente.

Johnson (1997d) relata que as frequiências antiformantes em vogais nasalizadas são uma função do grau de acoplamento entre a cavidade nasal e a faringe. E que, mesmo não havendo complexidade articulatória na produção de vogais nasalizadas, elas se apresentam mais complexas acústica e perceptivamente que as vogais orais.

Seara (2000) analisou acústica e perceptivamente vogais e consoantes nasais do $\mathrm{PB}$, em termos de freqüência, de intensidade formântica e de duração, em contextos tônicos e átonos no interior de vocábulos. Contou com a colaboração de 5 falantes nativos do $\mathrm{PB}$, homens na idade de 22 a 48 anos de idade. Realizou as análises acústicas: espectrografia, FFT e LPC, por meio do programa Computadorized Speech Lab (CSL), modelo 4300B, da Kay Elemetrics. Constatou que quando o /a/ foi nasalizado, houve surgimento de baixas freqüências próximas a $\mathrm{F}_{1}$ (freqüência média de $250 \mathrm{~Hz}$ ), a qual determinou formante nasal; presença de anti-ressonância na região entre $700 \mathrm{~Hz}$ e $1200 \mathrm{~Hz}$; aumento na largura de banda de $F_{1}$ e $F_{3}$ (o que justificou como possível conseqüência do aparecimento de formantes nasais). Percebeu que um aumento em frequiência dos formantes da vogal nasal átona leva a uma maior aproximação dessa vogal à átona oral, inferindo que isto seria uma explicação para a vogal oral átona ter sido percebida como nasal nos experimentos perceptivo -auditivos, quando dobrada sua duração e em isolamento. 


\subsection{A nasalidade/hipernasalidade pela espectrografia}

\subsubsection{A espectrografia}

A espectrografia é um método instrumental objetivo para avaliar o resultado acústico de uma emissão vocal (BALL, 1993; BUDER, 2000; CALLOU e LEITE, 1990; FANT, 1958; FARMER, 1984; FRY, 1979; KOENIG et al., 1946; HANAYAMA et al., 2001; LADEFOGED, 1982; PICKETT, 1980; RUSSO e BEHLAU, 1993). Segundo Pinho e Camargo (2001), a espectrografia revolucionou os estudos de voz e de fala por fornecer sua representação tridimensional em um gráfico de dois eixos, no qual a freqüência é representada no eixo vertical, o tempo no eixo horizontal e a intensidade é visível pela variação de tonalidade (preto, cinza e branco) ou de cores. Recentemente, o uso de modelos e de sistemas computadorizados tem aumentado a eficiência e a aplicabilidade da espectrografia (BALL, 1993; CALLOU e LEITE, 1990).

A análise acústica da voz por meio da espectrografia permite a decomposição da onda sonora, visualizando-se as concentrações de energia em áreas de freqüência, os formantes (CALLOU e LEITE, 1990).

O espectrógrafo, que possibilita a espectrografia, é um instrumento que mais tem sido usado recentemente para estudos sobre as desordens de fala e de linguagem, segundo Farmer (1997).

Com base nos relatos de Barbosa (2003), Fant (1958) e Kent e Read (1992), dados históricos e conceituais sobre espectrografia serão abordados a seguir.

No ano de 1936, os Laboratórios de Telefonia Bel1 ${ }^{11}$ publicaram seu importante trabalho sobre as técnicas de representação/descrição da fala espectrográfica. Um ano mais tarde, a publicação do livro "Visible Speech" marca uma nova era na fonética experimental.

\footnotetext{
${ }^{11}$ Fazia parte deste laboratório nesta época os pesquisadores Potter, Kopp e Green. Outro importante laboratório destacado nesta época foi o Laboratórios Haskins, composto pelos pesquisadores Cooper, Delattre e Liberman.
} 
As expectativas em torno da espectrografia eram altas. Esta técnica foi considerada, nos termos de Fant (1958), um poderoso método para desenvolver estudos objetivos dos elementos essenciais da substância-sonora como contidos na onda de fala.

Em meados dos anos de 1940, foi produzido comercialmente o primeiro espectrógrafo chamado "Sonagraph”, fabricado pela Kay Electric Company. Tinha limitações técnicas para representação/descrição de sons fracos.

O primeiro lingüista a fazer uso do som espectrográfico foi M. Joos.

O espectrógrafo foi desenvolvido possibilitando visualizar como as concentrações de energia de determinadas regiões de frequiência mudam com o passar do tempo. Compreendia os seguintes passos:

- transdução da amostra de fala por um microfone, assim que as variações de pressão aérea do sinal acústico são colocados dentro da forma de variações de tensão elétrica;

- conversão do sinal elétrico, para registro sobre o tambor magnético do espectrógrafo;

- conversão do sinal armazenado em sinal elétrico, para análise como um espectrograma;

- filtragem do sinal, para que a energia em várias regiões de freqüência pudessem ser armazenadas;

- amplificação do sinal elétrico e sua manutenção através de uma agulha marcadora;

- os fluxos de corrente elétrica pela agulha marcadora queima um papel, especialmente tratado, localizadamente. $O$ procedimento de queima escurece o papel proporcionalmente ao fluxo através da agulha, resultando no espectrograma.

\subsubsection{A espectrografia digital}


Na década de 70, houve o desenvolvimento do processamento digital de sinais (PDS ou da sigla em inglês, DSP: digital signal processing), especialmente dos sinais de fala, o que trouxe novas possibilidades de análise de voz e de fala, além de aprimorar as existentes. $\mathrm{O}$ fato de armazenar o sinal de fala permitiu que a forma de onda fosse exibida, medida e editada.

Conforme Farmer (1997), o desenvolvimento do processamento digital de sinais ou a habilidade para conversão analógico-digital (A/D) dos sinais para análise tem produzido uma mudança radical na espectrografia.

Por ação do PDS, o sinal de fala pode ser digitalizado ${ }^{12}$, sendo possível gerar espectrogramas, similarmente ao espectrógrafo. O espectro assim gerado, pode ainda, ser analisado simultaneamente com aqueles gerados pela aplicação direta da transformada rápida de Fourier (FFT: Fast Fourier Transform) e da predição linear (LPC: Linear Predictive Coding).

Os espectrogramas em tempo real exibem a forma espectrográfica instantaneamente na tela do computador, podendo ser impressos.

A espectrografia por computador é consideravelmente flexível, possibilitando mudar o tipo de análise, a extensão das freqüências, as escalas temporais, os tamanhos de banda de freqüência efetivos e outros parâmetros. Mesmo que anteriormente se pudesse operar algumas dessas mudanças, atualmente são vantajosas as combinações praticáveis.

Além das afirmações anteriores, Kent e Read (1992) afirmaram que a extração das medidas de tempo e de freqüência pelo movimento dos cursores sobre a tela do computador é mais fácil, rápida e precisa do que sobre o espectrograma impresso. Assim, a impressão do espectrograma ficaria destinada, apenas, à documentação.

Percebe-se que as principais vantagens são decorrentes da interação com o dispositivo eletrônico, não na natureza da análise em si.

Caso se queira ver o quão muda o sinal espectrográfico no tempo, é mais indicado usar uma análise em banda-larga $( \pm 300 \mathrm{~Hz})$. Porém, se a expectativa é ver

\footnotetext{
${ }^{12}$ Digitalizar é converter um sinal analógico (contínuo) em uma representação digital (discreta) (KENT e READ, 1992).
} 
melhor resolução em freqüência, ou s eja, com a possibilidade de visualização da $\mathrm{F}_{0}$, é viável utilizar uma análise em banda-estreita $( \pm 45$ ou $60 \mathrm{~Hz})$.

\subsubsection{A espectrografia e a nasalidade/hipernasalidade}

Em 1958, Hattori et al. determinaram que os principais traços da nasalização de vogais são: 1) há uma ressonância abafada em torno de $250 \mathrm{~Hz}$; 2) há o aparecimento de uma anti-ressonância em torno de $500 \mathrm{~Hz}$; 3) entre os formantes surgem componentes fracos e difusos (em comparação com seu par oral). Este terceiro traço ocorre em certas regiões de freqüência, apesar de variarem de vogal para vogal e de pessoa para pessoa, além de carregar informações sobre a posição da língua durante o fechamento oral, sendo afetado pelos antiformantes. Definiram antiformante como a região de freqüência característica onde os componentes são anulados pela anti-ressonância. Em geral, a nasalização é caracterizada por um realce em componentes de baixa freqüência ou pelo aparecimento de uma faixa de freqüência na porção inferior do espectrograma. No caso da vogal /a/, encontraram que o $\mathrm{F}_{3}$ em torno de $2500 \mathrm{~Hz}$ está atenuado, quando esta vogal está intensamente nasalizada, o que pode ser em virtude da atenuação da ressonância laringo-faríngea pela inclinação do véu palatino.

Dickson (1962) realizou um estudo na tentativa de delinear correlatos espectrográficos da nasalidade e investigar as possíveis diferenças entre homens adultos: falantes com e sem problemas de nasalidade e portadores de fissura de palato com hipernasalidade.

Segundo Behlau et al., 1988, o estudo de formantes das vogais de uma língua é a análise mais frequiente obtida com o espectrógrafo de som. Mesmo nesta época já existindo técnicas como a LPC, extraíram as freqüências formantes pelo valor mediano da região de freqüências, reconhecendo que esta forma de leitura do formante não era ideal nem suficiente, mas afirmaram desconhecer melhores formas para isto. Estes mesmos autores realizaram uma análise espectrográfica das 12 vogais do $\mathrm{PB}$, isoladas e sustentadas, o mais naturalmente possível, emitidas por 90 indivíduos brasileiros da cidade de São Paulo: 30 homens e 30 mulheres na faixa etária de 18 a 45 anos de idade e 30 crianças (15 de cada sexo), entre 8 e 12 anos de idade. Fez-se o registro das emissões dentro de uma sala acústica, em fitas magnéticas, que foi posteriormente 
analisado pelo espectrógrafo V.I., modelo 700, em banda-larga. Com auxílio de uma transparência milimetrada sobre o ponto médio da extensão da região das faixas de energia, determinaram a freqüência média de cada formante. Calcularam, ainda, as proporções entre os 3 primeiros formantes e as intensidades relativas de cada formante ( $F_{1}$ de maior amplitude foi a referência da qual subtraíram-se os valores de $F_{2}$ e $F_{3}$ ). No que diz respeito às emissões femininas da vogal oral, central, baixa, aberta /a/, obtiveram $\mathrm{F}_{1}=956 \mathrm{~Hz}( \pm 132,52), \mathrm{F}_{2}=1634 \mathrm{~Hz}( \pm 240,57)$ e $\mathrm{F}_{3}=2721 \mathrm{~Hz}( \pm 297,31)$; para a vogal nasal, central, média, aberta /ã/, obtiveram $\mathrm{F}_{1}=817 \mathrm{~Hz}( \pm 77,59), \mathrm{F}_{2}=1642$ $\mathrm{Hz}( \pm 169,58)$ e $\mathrm{F}_{3}=2764 \mathrm{~Hz}( \pm 184,20)$. Observaram que houve acentuada atenuação da intensidade de todos os formantes da vogal /ã/ em relação à vogal /a/, devido às antiressonâncias e aos formantes nasais, que retiram energia acústica dos formantes vizinhos.

Boone e McFarlane (1994) e Bradley (1997) destacaram a possibilidade de uso da espectrografia como um instrumento para medir ou verificar o julgamento clínico da hipernasalidade.

Hong et al. (1997) investigaram a relação entre obstrução nasal e nasalidade em indivíduos que padeciam de sintomas de obstrução nasal causados por pólipos nasais.

Em sua dissertação, Jesus (1999) teve o objetivo de depreender as características acústicas das vogais relacionadas à nasalidade, a partir de estudos espectrográficos com as vogais /a/, /i/ e /u/ orais, nasais e nasalizadas em portadores e não portadores de fissura de palato. Foram 10 participantes (5 homens e 5 mulheres) no grupo não portador de fissura palatina, na faixa etária de 20 a 37 anos de idade ( $\bar{X}=27$ anos) e 10 participantes no grupo portador de fissura palatina o perada ( 5 homens e 5 mulheres, 6 com fissura de lábio associada à fissura palatina e 4 com fissura de palato, apenas), com variados graus de nasalidade, na faixa etária de 17 a 27 anos de idade ( $\bar{X}=21,5$ anos). As vogais anteriormente citadas constituíram 18 palavras dissílabas, de modo que o contexto fonético propiciasse a ocorrência de vogais orais, nasais (quando pertenciam a sílabas com $/ \mathrm{m} /$ ou $/ \mathrm{n} /$ ) ou nasalizadas (quando precediam $/ \mathrm{m} /$ ou $/ \mathrm{n} /$ ), lidas aleatoriamente dentro da frase "diga pra ela". Tais vogais, orais e nasais, também foram lidas isoladamente. Em sala acusticamente tratada, as leituras foram registradas em gravador digital, amostradas a $44,1 \mathrm{kHz}$ e quantizadas a 16 bits. Para a análise acústica, utilizou-se o SoundScope, da GW Instruments, versão 2.17. Os 
resultados do estudo desta autora mais relevantes para a presente pesquisa seguem na tabela seguinte ${ }^{13}$.

Tabela 1 - Formantes da vogal /a/, segundo estudo de Jesus (1999).

\begin{tabular}{|c|c|c|c|c|c|c|c|c|c|c|c|c|c|c|c|c|}
\hline \multirow{4}{*}{ 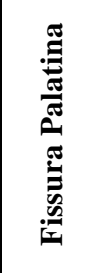 } & \multicolumn{16}{|c|}{ Vogal /a/ } \\
\hline & \multicolumn{8}{|c|}{ Isolada } & \multicolumn{8}{|c|}{ Contexto fonético (cata, canta, cana) } \\
\hline & \multicolumn{4}{|c|}{ Oral } & \multicolumn{4}{|c|}{ Nasal } & \multicolumn{4}{|c|}{ Oral } & \multicolumn{4}{|c|}{ Nasal } \\
\hline & $\mathbf{F}_{1}$ & $F_{2}$ & $\mathbf{F}_{3}$ & Fn & $F_{1}$ & $\mathbf{F}_{2}$ & $\mathbf{F}_{3}$ & Fn & $\mathbf{F}_{1}$ & $F_{2}$ & $\mathbf{F}_{3}$ & Fn & $F_{1}$ & $\mathbf{F}_{2}$ & $\mathbf{F}_{3}$ & Fn \\
\hline 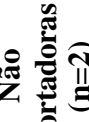 & 904 & 1399 & 2669 & - & $343^{*}$ & 1370 & 3183 & - & 829 & 1537 & 2305 & - & 622 & 1449 & 2596 & - \\
\hline 窇 & 962 & 1563 & 2693 & 656 & 516 & 1188 & 2648 & 218 & 1014 & 1581 & 2673 & $625^{*}$ & 444 & 1488 & 2641 & $2051^{*}$ \\
\hline
\end{tabular}

Formante Nasal

*Resultado obtido com uma participante, apenas

Para as participantes não portadoras de fissura, a vogal/a/ nasal apresentou antiressonâncias e formantes nasais abaixo de $\mathrm{F}_{1}$; em relação à oral, o valor do $\mathrm{F}_{1}$ foi menor, indicando menor abertura (oral), além de menor $\mathrm{F}_{2}$ e maior $\mathrm{F}_{3}$. Quanto às portadoras de fissura palatina, em contexto fonético, a vogal nasal apresentou menor valor em $\mathrm{F}_{1} \mathrm{em}$ relação a sua correlata oral, bem como diminuição em $F_{2}$ e menores intensidades. Comparativamente, $\mathrm{F}_{1}$ da vogal oral /a/ apresentou-se mais alto para as portadoras de fissura, indicando que esta vogal é produzida com maior abertura (oral) no grupo de portadoras de fissura, além de ter ocorrido aumento de $\mathrm{F}_{3}$ e significativa menor intensidade de $\mathrm{F}_{2}$. Afirma que para uma análise completa da nasalidade, a espectrografia deve ser um instrumento somado a outras avaliações. E, ainda, afirma que a nasalidade em casos patológicos não é determinada apenas pelo grau de inadequação VF, mas é influenciada pela resistência bucal, pelas condições anatômicas da cavidade nasal, pelo tempo de abertura/fechamento do palato e pela variabilidade de falante para falante.

Casal et al. (2002) afirmaram que a espectrografia apresenta características acústicas relevantes para a dimensão articulatória, além de poder ser útil para avaliar resultados terapêuticos ou em estudos comparativos intergrupos com portadores de

${ }^{13}$ Tabela retirada do Anexo VIII da dissertação de Jesus (1999). 
anomalias craniofaciais e que há poucos estudos de análise espectrográfica com portadores de fissura de palato.

Jesus (2002) realizou um estudo fonético da nasalidade em falantes normais, descrevendo as vogais nasais do PB, acusticamente. Para isto, contou com a participação de 10 falantes adultos, na faixa etária de 20 a 37 anos de idade $(\bar{X}=27$ anos), sendo 5 de cada sexo. Gravou, de cada falante, emissões de vogais isoladas e em 18 palavras contendo as vogais /a/, /i/ e /u/ orais, nasais e nasalizadas pela consoante /m/ ou /n/ na sílaba seguinte, inseridas em uma frase de referência. As gravações foram realizadas em sala acústica e plataforma digital, com ganho de nível de gravação em $-12 \mathrm{~dB}$. As vogais foram analisadas quanto à freqüência e à intensidade relativa dos quatro primeiros formantes e sua duração, utilizando espectrograma, oscilograma e análises FFT e LPC (esta quando possível), do programa computadorizado de análise vocal SoundScope. Centrando-se nas emissões femininas, para cujas vozes utilizou um filtro de $300 \mathrm{~Hz}$, a autora encontrou para a vogal oral /a/ isolada ${ }^{14}$, as seguintes médias para os formantes (sucedidas por sua intensidade relativa): $F_{1}=904 \mathrm{~Hz}(-2 \mathrm{~dB}) ; \mathrm{F}_{2}=$ $1399 \mathrm{~Hz}(-2 \mathrm{~dB}) ; \mathrm{F}_{3}=2669 \mathrm{~Hz}(-10 \mathrm{~dB})$. Para sua correlata nasal, a qual representou [ç], determinou: $F_{1}=343 \mathrm{~Hz}(-15 \mathrm{~dB}) ; F_{2}=1370 \mathrm{~Hz}(-16 \mathrm{~dB}) ; F_{3}=3183 \mathrm{~Hz}(-14 \mathrm{~dB})$. Diante das emissões femininas, concluiu, para estas duas vogais, que a vogal nasal apresentou menor $F_{1}$ que a vogal oral, menor freqüência de $F_{2}$ e maior de $F_{3}$. Houve, também, significativa redução da intensidade de $F_{1}, F_{2}$ e $F_{3}$, além da presença de antiressonância e formantes nasais abaixo de $\mathrm{F}_{1}$, quando encontrados.

\subsection{A avaliação da hipernasalidade}

Além da avaliação clínica perceptivo-auditiva da hipernasalidade, pode-se contar com uma medida objetiva da ressonância de fala, o parâmetro nasalância, obtido pelo exame denominado nasometria. 


\subsubsection{A avaliação nasométrica da hipernasalidade de fala}

Como ressaltaram Kataoka et al., 2001, várias técnicas instrumentais são utilizáveis por clínicos para medir a severidade da hipernasalidade como, por exemplo, a nasometria.

Parece consenso reconhecer a dificuldade em aplicar e confiar plenamente na avaliação perceptivo - auditiva de ouvintes, pela divergência de experiências dos clínicos, devido às diferenças individuais entre os ouvintes (KATAOKA et al., 1996; 2001), o que estimula que pesquisadores busquem medidas objetivas, por meio de parâmetros quantitativos.

Diversos estudos preocuparam-se em propor uma avaliação quantitativa da hipernasalidade de fala, propondo parâmetros e/ou equipamentos (CHOI et al., 2001; FLETCHER, 1970; KATAOKA et al., 1996), sempre buscando sua correlação com a análise qualitativa, ou seja, com a avaliação perceptivo-auditiva da hipernasalidade de fala e, algumas vezes, aprofundando-se nas análises estatísticas (KATAOKA et al., 1996; 2001).

Como afirmaram Dalston et al. (1991), a nasometria é um instrumento apropriado para avaliar as emissões de falantes com suspeita de prejuízo no mecanismo velofaríngeo.

E, de acordo com Dalston (1997), há inúmeros estudos que utilizam a nasometria para a avaliação da nasalidade: hiponasalidade em emissões repletas de fonemas nasais ou hipernasalidade em emissões exclusivamente compostas por fonemas orais ou para ver ambos desvios de nasalidade ou, ainda, a habilidade do mecanismo de abertura e de fechamento velofaríngeo em emissões equilibradamente compostas por fonemas orais e nasais. Para cumprir este intento, o próprio programa fornece textos e sentenças com as referidas composições fonêmicas que, em outros países, cujos nativos não têm o Inglês como língua materna, há adaptações.

\footnotetext{
${ }^{14}$ Vê que os mesmos valores de formantes apresentados são iguais ao do seu grupo controle feminino em 1999, com a ressalva de que naquela ocasião mencionou que contou com a colaboração de 2 mulheres e neste estudo de 2000 com 5 mulheres.
} 
Os diversos usuários deste equipamento, ou seja, do Nasômetro, preocupam-se com valores de referência e buscam determiná-lo (LEWIS et al., 2000; SEAVER et al., 1991; SUGUIMOTO e PEGORARO-KROOK, 1995; WATTERSON et al., 1999), nos mais variados contextos lingüísticos, faixas etárias e para ambos os sexos.

\subsubsection{A avaliação perceptivo-auditiva da hipernasalidade}

Mesmo reconhecendo-se todos o s benefícios que uma avaliação objetiva por via instrumental fornece, o registro espectrográfico ou nasométrico, por exemplo, como bem afirmou Fant (1958), há que se considerar que não há substituição da transcrição aural, ou como se diz hoje, é preciso um a análise conjunta com a avaliação perceptivo auditiva, com o que corrobora Seaver et al. (1991) - visto que nenhuma forma de análise é absoluta ou conclusiva por si só. 


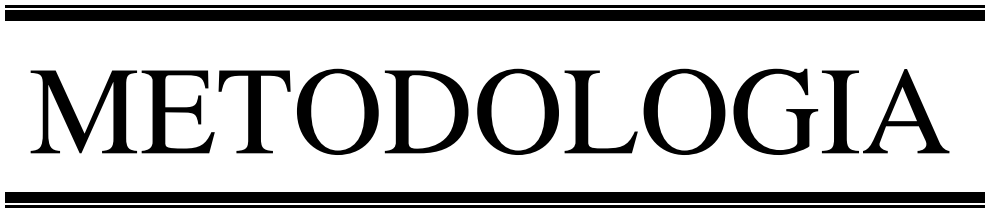




\section{METODOLOGIA}

\subsection{Participantes}

Por estarem condizentes com os critérios de seleção, contou-se com a colaboração de 57 indivíduos do sexo feminino, na faixa etária de 18 a 40 anos de idade, após seu aceite e assinatura do Termo de Consentimento Livr e e Esclarecido (Apêndices A e B), devidamente submetido e aprovado pelo Comitê de Ética em Pesquisa do Hospital de Reabilitação de Anomalias Craniofaciais - Universidade de São Paulo (HRAC/USP), câmpus de Bauru, local de desenvolvimento do estudo (Ofício $\mathrm{n}^{\circ}$. 072/2002-UEP-CEP, Anexo A).

As participantes foram distribuídas em 3 grupos:

1) Grupo controle, denominado $\mathrm{CON}$;

2) Grupo de portadoras de fissura palatina aberta, denominado PFA;

3) Grupo de portadoras de fissura palatina reparada cirurgicamente, denominado PFR.

Cabe ressaltar que, conforme Minervino-Pereira (2000), optou-se pela terminologia portadora de fissura palatina e não fissurada, pois como advoga o referido estudo, o termo fissurada é estigmatizante e não condiz com o estado daquela que já realizou a cirurgia reparadora do palato. A expressão portadora de fissura palatina abarca tanto aquela que passou por tal cirurgia, quanto aquela que ainda passará, uma vez que remete à sua condição genética e não morfo-anatômica, apenas. 
Além do aceite e da assinatura do termo de consentimento livre e esclarecido, as participantes deveriam enquadrar-se em alguns critérios, com a finalidade única e exclusiva de delimitação de variáveis.

Para composição do CON, os critérios foram:

1) Não apresentarem fissura palatina;

2) Não apresentarem disfunção velofaríngea (DVF);

3) Não estarem fazendo uso de quaisquer drogas (aqui incluem-se os medicamentos), que alterem a performance vocal;

4) Não serem consumidoras freqüentes de bebida alcoólica;

5) Não apresentarem alterações das vias aéreas superiores no dia do exame, tais como: resfriado, gripe, rinite, alergia, sinusite, alterações vocais, etc., e nem comprometimentos vocais e/ou do trato vocal, especialmente da cavidade nasal;

6) Serem falantes nativas do português brasileiro;

7) Não apresentarem problemas de voz e de fala;

8) Não estarem em pleno fluxo menstrual, grávidas ou na menopausa.

Para composição dos PFA e PFR, os critérios foram:

1) Ser portadora de fissura palatina congênita e isolada:

a) não operada: membro do grupo de PFA;

b) operada: membro do grupo de PFR;

2) Apresentarem ressonância de fala hipernasal, portanto, com DVF;

3) Não estarem fazendo uso de quaisquer drogas (aqui incluem-se os medicamentos), que alterem a performance vocal;

4) Não serem consumidoras freqüentes de bebida alcoólica; 
5) Não apresentarem alterações das vias aéreas superiores no dia do exame, tais como: resfriado, gripe, rinite, alergia, sinusite, alterações vocais, etc., e nem comprometimentos vocais e/ou do trato vocal, especialmente da cavidade nasal;

6) Serem falantes nativos do português brasileiro;

7) Não estarem em pleno fluxo menstrual, grávidas ou na menopausa..

Para ambos os grupos, a condição auditiva só foi excludente a partir do relato da participante sobre sua audição e de seu desempenho auditivo durante a conversação, levando a avaliadora a determinar sua audição insuficiente e inadequada para a execução dos procedimentos do estudo.

O HRAC/USP recebe diariamente clientes de todo o Brasil, agendados para os atendimentos de acordo com a necessidade e as possibilidades de ambos. Em virtude disto, as participantes portadoras de fissura palatina encontravam-se em rotina ambulatorial e foi apenas acrescentado o atendimento para este estudo, após auxílio do Centro de Processamento de Dados e da Central de Agendamento do referido hospital. Desta forma, além do não aceite da cliente, a execução deste esteve sujeita a faltas, além de respeitar imprevistos de horários de outros atendimentos, sempre priorizando seu tratamento.

\subsection{Aplicação do protocolo de entrevista e de avaliação fonoaudiológica específica}

Aplicou-se o protocolo de entrevista e avaliação fonoaudiológica específica (Apêndice C), composto de identificação, verificação dos critérios de inclusão no estudo (item caracterização), levantamento das características de produção de fala e de voz.

No aspecto produção de fala, a inteligibilidade foi avaliada como normal ou com prejuízo leve, leve para moderado, moderado, moderado para severo ou severo, de acordo com Pegoraro-Krook (1995) (Anexo B). Também conforme esta autora, a ressonância foi classificada como normal ou com hipernasalidade leve, moderada ou severa e ainda, aberta ou fechada (Anexo B). 


\subsection{Amostras de fala}

As amostras de fala constituíram-se da emissão da vogal oral sustentada [a] e da

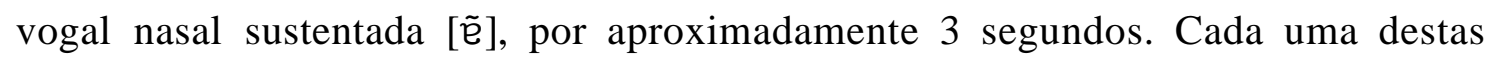
voeegais foi emitida dentro da frase-veículo “A vogal___é baixa.”, coletando-se uma única emissão para cada tipo vocálico.

Solicitou-se que cada participante realizasse suas emissões em níveis confortáveis de intensidade e de freqüência vocais, o mais próximo possível de sua fala habitual.

\subsection{Equipamentos para captação, armazenagem e análise} instrumental das amostras de fala

1) Gravador digital Sony, modelo DTC-690;

2) Microfone de cabeça, condensado/unidirecional ATM73a, da Audio-technica;

3 ) Pré-amplificador de microfone dbx, modelo 760X;

4) Nasômetro 6200-3, da Kay Elemetrics Corp., composto por um programa instalado em um computador pentium Byte On, um suporte de captação munido de microfones e uma interface externa entre este suporte e o computador;

5) Computador IBM PC 100 para edição das amostras gravadas; por meio do programa Creative Sound/WaveStudio, versão 2.0, em monocanal, amostragem de 22050Hz e 16 bits;

6) Computadorized Speech Lab (CSL), modelo 4300B, versão 5.X, da Kay Elemetrics Corp., instalado em computador pentium compatível;

7) Programa Multi-Speech, modelo 3700, versão 2.2, da Kay Elemetrics Corp., instalado em computador pentium compatível.

Ainda sobre o nasômetro há de se fazer algumas considerações: 
O nasômetro é um instrumento não-invasivo, para obtenção de uma medida objetiva da nasalidade, denominada nasalância. Esta, por sua vez, é o resultado da seguinte razão numérica: [(energia acústica nasal) $\div$ (energia acústica oral + energia acústica nasal)] x 100. Expressa, portanto, em porcentagem.

\subsection{Procedimentos para captação, armazenagem e análise}

\section{instrumental das amostras de fala}

Para a gravação digital o nível de registro do gravador foi mantido em 5. O ganho do pré-amplificador foi determinado de acordo com a indicação do painel do gravador digital, conforme especificação do seu manual, a fim de garantir níveis de audição e de futura análise acústica satisfatórios.

Simultânea a esta gravação, as mesmas emissões foram captadas pelo nasômetro.

A participante manteve, então, o rosto encostado na placa do nasômetro durante suas emissões (Figura 6). Esta placa foi utilizada conforme adaptação de Dutka (1992). Houve o devido cuidado com a calibração deste equipamento e higienização de sua placa de captação para uso de cada participante.

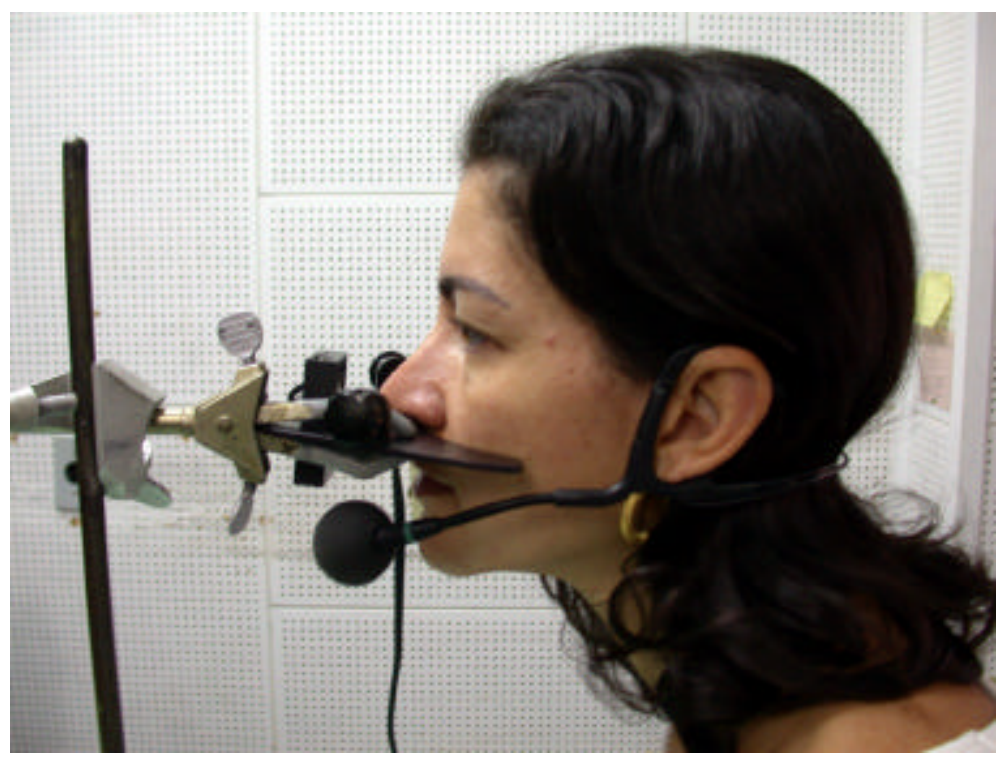

Figura 6-Posicionamento da participante para a captação das amostras de fala para este estudo. 
Obteve-se os valores de nasalância de cada vogal, eliminando-se o início e o fim da emissão, considerando-se a porção mais estável em termos de frequiência e de intensidade vocais.

As amostras de fala gravadas na fita digital foram editadas em um computador, onde cada amostra correspondeu a um arquivo independente, nomeado com o código do grupo e o número da participante. Os procedimentos de edição foram os seguintes: extraiu-se a emissão vocálica da frase-veículo, eliminou-se o início e o fim das emissões, restando a região mais estável em termos de freqüência e de intensidade vocais, com duração mínima de 3 segundos.

A análise espectrográfica foi realizada no Laboratório de Fonética Experimental e Psicolingüística, do Instituto de Estudos da Linguagem, da Universidade Estadual de Campinas (LAFAPE/IEL/UNICAMP), por meio do programa Multi-Speech. Optou-se pela análise na tela do computador pela agilidade em manipular os recursos computacionais, bem como pela melhor definição das imagens na tela que no papel impresso.

A tela do Multi-Speech é composta pela quantidade de janelas que forem necessárias para inserção e/ou exposição de dados. Na janela A carregou-se o sinal da vogal sustentada. Na janela B exibiu-se o espectrograma desta emissão e vinculou-se esta janela à janela $\mathrm{A}$, considerada a janela fonte, para que os cursores movessem-se simultaneamente e se pudesse, portanto, perceber a correspondência entre os trechos. Reproduzindo-se o sinal auditivamente e o acompanhando na tela, determinou-se o ponto mais estável da emissão vocálica (Figura 7).

O trecho, aproximadamente, entre meio segundo abaixo deste ponto e meio segundo acima dele foi novamente selecionado para ocupar toda a janela A. De novo, então, na janela B expôs-se o espectrograma do trecho atual, vinculando esta janela à janela fonte. Assim, analisou-se qualitativamente o espectrograma.

Movendo o cursor sobre o espectrograma seria possível obterem-se valores de frequiências formantes, porém de forma menos precisa e mais subjetiva do que pelas análises concomitantes em FFT e LPC, igualmente fornecidas por este programa, que são mais robustas, específicas e confiáveis na determinação de freqüências formantes. 
Segue-se uma breve explanação sobre estas técnicas de análise com base em Johnson (1997a) e Barbosa (2003).

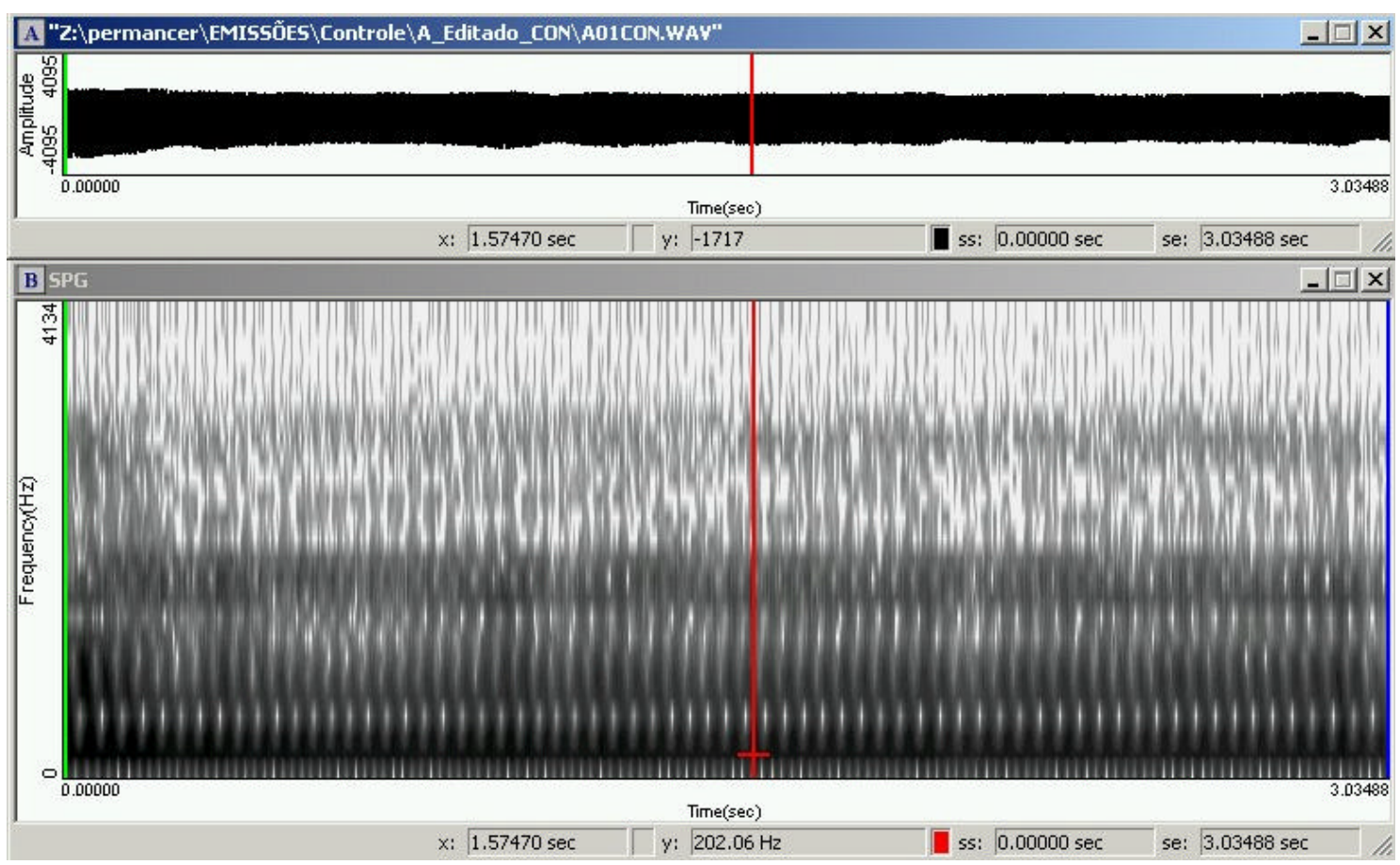

Figura 7 - Tela do programa computacional Multi-Speech: A: janela apresentando o sinal acústico de uma vogal oral [a] sustentada; B: janela apresentando espectrograma do mesmo sinal acústico da janela anterior, vinculada a ela (note as barras verticais na mesma posição em ambas janelas).

Na realidade, pela transformada rápida de Fourier, FFT, determina-se o espectro do sinal vocal, com uma disposição gráfica dos harmônicos, relacionando suas freqüências com suas respectivas amplitudes. Provê a visualização de possíveis regiões de ressonância - os picos de ressonância. Estes são claramente visualizados pela envoltória da análise por predição linear, LPC, capaz de encontrar os picos espectrais. A análise a partir da sobreposição gráfica de ambas técnicas confere maiores chances de precisão aos achados sobre formantes.

Há que se dizer, ainda, que FFT é uma técnica de processamento digital de sinais para cálculo da transformada de Fourier, que, por sua vez, é um método matemático para decompor um sinal em suas componentes espectrais, a saber: freqüência e amplitude, levando em conta suas relações de ortogonalidade. 
LPC é uma técnica que, a partir de uma pequena duração de uma forma de onda acústica, estima as ressonâncias do trato vocal. Usa da autocorrelação para encontrar os componentes de frequiência mais proeminentes no espectro da fala. Como a duração da autocorrelação é menor que um período glotal, não captura a peridiocidade da forma de onda pelo vozeamento, mas sim aquela produzida por ressonâncias formantes. É um método preditivo, porque calcula uma pequena série de coeficientes preditores em uma combinação linear de amostras da forma de onda, possibilitando prever as amplitudes de ressonância de uma forma de onda acústica. Ao se analisar sons nasais/nasalizados reflete tanto a presença de formantes quanto de antiformantes do sinal vocal.

Para que os formantes nasais e os antiformantes fossem obtidos, seria necessária a construção de filtros que permitissem a separação destes dos formantes, o que fugiria ao escopo deste trabalho. Desta maneira, a freqüência formante $\left(F_{n}, F\right.$ maiúsculo, em que n é o número de ordem do formante) pôde ser determinada apenas para a vogal oral [a] do grupo CON. Para as demais amostras vocálicas, as freqüências formantes são denominadas $\mathrm{f}_{\mathrm{n}}$, f minúsculo, em que $\mathrm{n}$ é o número de ordem, justamente para destacar que esta frequiência reflete a atuação do formante oral, do antiformante/formante nasal.

Então, em uma terceira janela, a janela C, exibiu-se as análises FFT e LPC do sinal vocálico no ponto de maior estabilidade em que o cursor foi posicionado. Nesta janela C movia-se o cursor sobre as curvas FFT e LPC rastreando-se os valores em frequiência e, a partir do raciocínio em cima de cada gráfico confrontando-se com o espectrograma, com o que se esperava de valores da freqüência formante para cada região de acordo com a teoria da produção vocálica e com os conhecimentos sobre nasalidade, registrou-se os valores de cada formante. Vide Figura 8. 


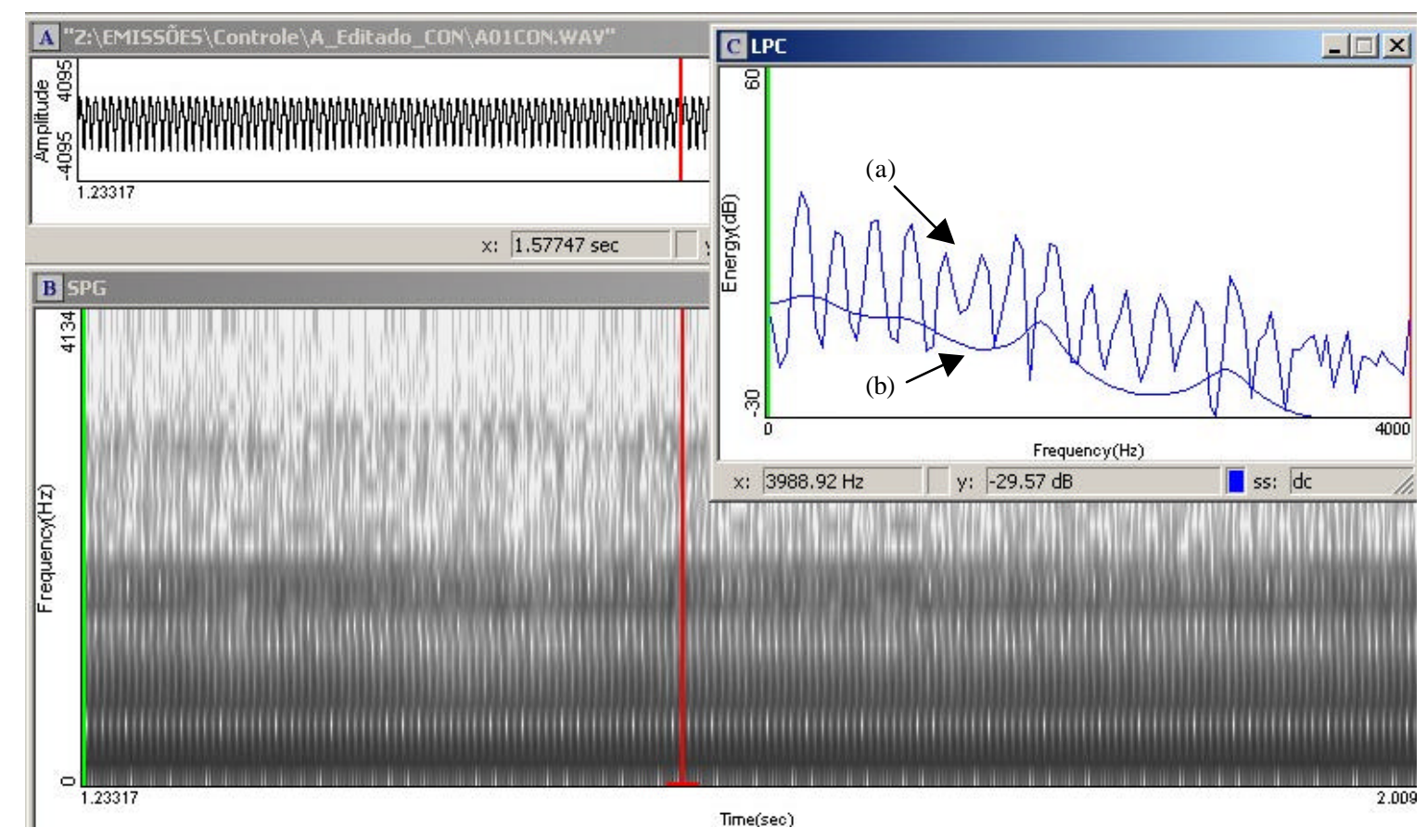

Figura 8-Janelas do programa computacional Multi-Speech: A: janela apresentando o sinal acústico de uma vogal oral [a] sustentada em torno do ponto considerado mais estável da emissão; B: janela apresentando espectrograma do mesmo sinal acústico da janela anterior, vinculada a ela (note as barras verticais na mesma posição em ambas janelas); C: janela apresentando em (a) representação do mesmo ponto do sinal acústico pela FFT e (b) representação do mesmo ponto do sinal acústico por LPC.

Ainda na janela $\mathrm{C}$ foi possível expor o espectro FFT e a envoltória LPC da vogal nasal, para facilitar comparações.

O Multi-Speech proporciona uma tela de resultados do LPC, porém que não foi seguida, visto que o algoritmo pode apresentar valores calculados que não correspondam aos formantes e isto só pode ser checado pelo analista que comparar a envoltória LPC com o espectro FFT. Assim, optou-se como confiável, verdadeira e definitiva esta forma de análise de posicionamento dos cursores sobre os espectros FFT/LPC.

Na Figura 9 pode-se ver a configuração de análise assinalada para o espectrograma: 125 pontos de análise, na faixa de freqüência de $0 \mathrm{~Hz}$ a $4000 \mathrm{~Hz}, \mathrm{com}$ nível de pré-ênfase 0,980, janela Hamming e o gradiente de escurecimento da intensidade determinado a partir do botão Palette. 
Para FFT, a configuração utilizada foi: 512 pontos de análise, nenhum nível de suavização, escala vertical de $-60 \mathrm{~dB}$ a $60 \mathrm{~dB}$, na faixa de freqüência de 0 a $4000 \mathrm{~Hz}$, janela Hamming e nível de pré-ênfase 0,980 (Figura 10).

Para LPC, a configuração foi: cálculo de predição a cada 20 milissegundos, ordem do filtro 24 (houve amostras em que foi necessário usar ordem 22 para melhor curva de análise), escala vertical de $-60 \mathrm{~dB}$ a $60 \mathrm{~dB}$, na faixa de freqüência de 0 a 4000 Hz, janela Hamming, nível de pré-ênfase 0,980 e autocorrelação como método de análise (Figura 11).

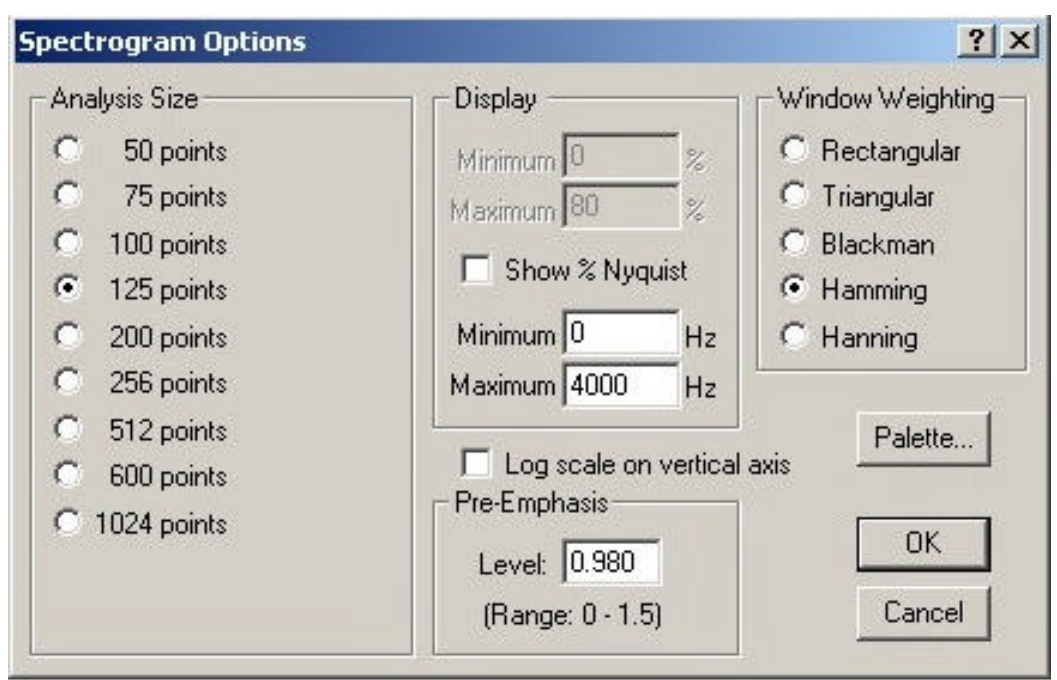

Figura 9 - Configuração do espectrograma.

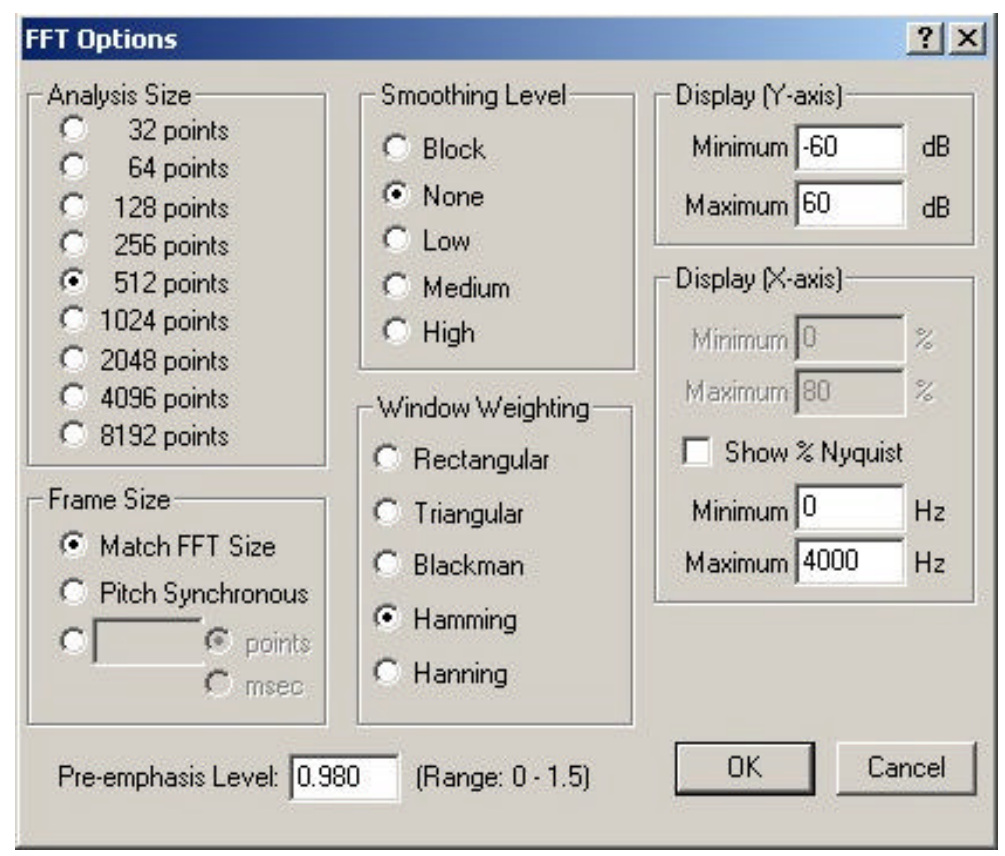

Figura 10 - Configuração da análise FFT. 


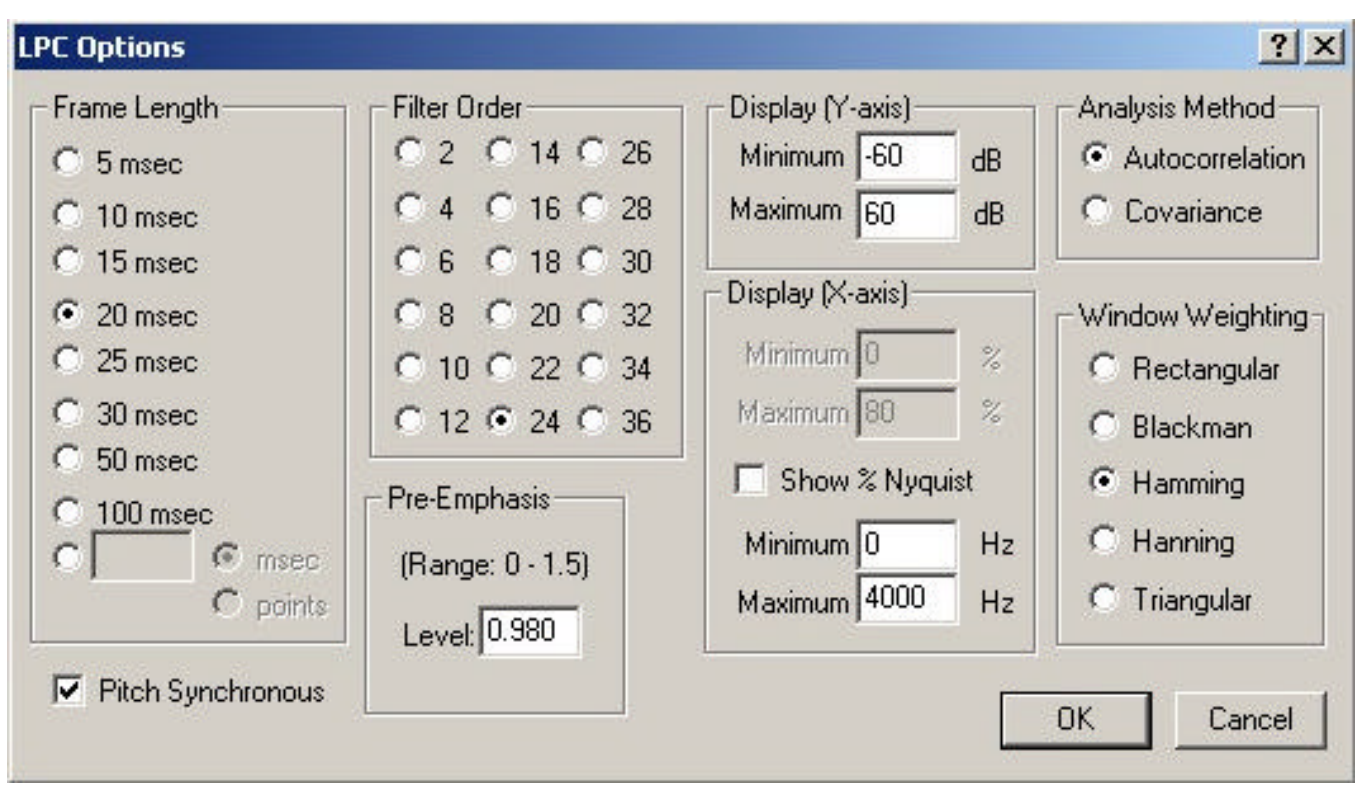

Figura 11 - Configuração da análise LPC.

\subsection{Procedimentos da avaliação perceptivo-auditiva das amostras}

\section{de fala}

No Laboratório de Fonética do HRAC/USP, sala tratada acusticamente, recrutou-se 3 fonoaudiólogas com experiência entre 5 e 6 anos na área de fissura palatina, aptas, portanto, na avaliação perceptivo-auditiva da ressonância e inteligibilidade de fala de portadores dessa má-formação.

Antes da apresentação das emissões das participantes do estudo, explicou-se que a avaliação perceptivo-auditiva deveria ser individual, sem troca de informações entre as profissionais durante os julgamentos.

As mesmas amostras vocálicas analisadas espectralmente foram armazenadas no CSL do Laboratório de Fonética do HRAC/USP.

As 3 examinadoras, juntas, sentaram-se cerca de $1 \mathrm{~m}$ em frente ao alto-falante, munidas dos devidos protocolos para anotações dos seus julgamentos (Apêndice D). Em uma sessão de aproximadamente 2 horas julgaram as emissões vocálicas orais.

Embasadas em sua prática clínica, as examinadoras afirmaram ser difícil a avaliação da ressonância de fala sobre som sustentado, especialmente de [a], em que às vezes, até em indivíduos sem problemas de ressonância nasal, poderia-se detectar 
nasalidade leve. Então, além das categorias normal, hipernasalidade leve, moderada ou severa, acrescentou-se o item "não avaliado", que deveria ser assinalado em caso de impossibilidade de definição sobre a nasalidade e a marcação singular de presença ou ausência de hipernasalidade.

As examinadoras puderam solicitar o aumento do volume de reprodução das emissões, visto que em situação clínica, o objetivo sendo a precisão classificatória da ressonância de fala, além de repetições, aproximam-se ou não dos falantes. O controle na amplificação de acordo com as especificações de qualidade do gravador e a distância fixa do microfone não foram suficientes para padronizar a reprodução. Diante da possibilidade da ausência ou da inadequação da classificação da ressonância de fala, fez-se esta concessão na reprodução das emissões sonoras.

As amostras de fala dos 3 grupos foram misturadas, sendo sua ordem definida aleatoriamente, por sorteio. Houve a repetição de 20 amostras de fala, distribuídas aleatoriamente junto das demais emissões, utilizada para a estatística intraexaminadoras. Para classificação geral da ressonância de fala, a determinação sobre a primeira apresentação foi a considerada, arbitrariamente definida, antes das avaliações perceptivo-auditivas.

Antes de cada amostra de fala a ser julgada, apresentou-se uma emissão de referência, conforme Teles-Magalhães (2002), definida com base perceptivo-auditiva e na certeza de que era uma voz desconhecida das examinadoras da ressonância de fala.

\subsection{Procedimentos da análise estatística}

Na avaliação perceptivo-auditiva, para análise intra-examinadoras, utilizou-se um teste não-paramétrico para duas amostras relacionadas: Wilcoxon matched-pairs signed-ranks test. Desta forma, poderia-se ver se uma performance era "maior que a outra" ou não, em termos das classes selecionadas para análise. No caso deste estudo, os graus de hipernasalidade ou sua presença/ausência. A correlação foi analisada pelo coeficiente de Spearman $\left(\mathrm{r}_{\mathrm{s}}\right)$. 
Nos resultados da nasometria, além da estatística descritiva (média, desviopadrão, mediana, mínimo, máximo e quartis), aplicou-se o teste não-paramétrico Kruskal-Wallis ANOVA by Ranks. Optou-se por testes não-paramétricos pela constituição da nasalância originar-se de uma relação de proporcionalidade e se apresentar em escala percentual.

Também se fez estatística descritiva dos resultados numéricos dos formantes, sobre os quais se usou, ainda, a análise de variância - ANOVA. Quando esta apontava significância estatística, partia-se para o teste Post-hoc Tukey HSD.

Todos os testes foram aplicados em nível de significância de 5\% (p=0,05).

Os procedimentos estatísticos foram aplicados com base em Siegel (1956), Spiegel (1974), Williams (1993) e no Statistica 6.0, da StatSoft, Inc. - programa computacional para análises estatísticas utilizado neste estudo, além de comunicações pessoais com pesquisadores mais experientes. 


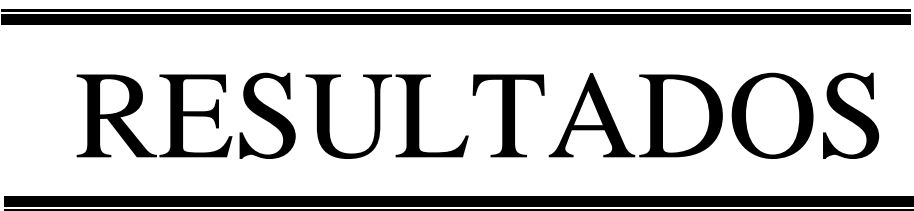




\section{RESULTADOS}

\subsection{Participantes}

Havia o plano inicial de que cada um dos 3 grupos fosse composto por 30 integrantes, para finalidade estatística. Porém, a demanda de adultas portadoras de fissura palatina aberta em busca de cirurgia limitou a composição do grupo de PFA; a aplicação dos critérios de seleção limitou o grupo de PFR; e pela necessidade de uma amostra de fala de referência para a avaliação perceptivo-auditiva, contou-se com a colaboração de mais uma integrante no grupo CON. Assim, a distribuição de participantes (Tabela 2) foi a seguinte: grupo de PFA com 5 participantes, enquanto o de PFR com 21 e o CON com 31 participantes.

Ressalta-se que todos os dados obtidos da amostra de fala de referência não foram computados nos cálculos estatísticos do grupo CON.

No grupo CON, a idade variou de 20 a 40 anos ( $\bar{X}=28$ anos \pm 6 ), enquanto que no de PFA de 22 a 37 anos $(\bar{X}=28$ anos \pm 6$)$ e no grupo de PFR, de 18 a 38 anos $(\bar{X}=$ 25 anos \pm 6 ) - Tabela 2. A participante da amostra de fala de referência tinha 22 anos de idade.

Na Tabela 3 verifica-se que 4 integrantes do grupo de PFA são portadoras de fissura palatina pós-forame incisivo completa e 1 de fissura palatina pós-forame incisivo incompleta. Enquanto que no grupo de PFR, 18 integrantes são portadoras de fissura palatina pós-forame incisivo incompleta e 3 de fissura palatina pós-forame incisivo completa. Ainda neste grupo, 6 mulheres realizaram uma palatoplastia com retalho faríngeo, o que signi fica que a configuração de seu trato vocal tem um prolongamento 
fixo de tecido muscular ligando o palato mole à parede posterior da faringe (Anexo C). Ainda conforme esta tabela, vê-se que o tempo de reparo cirúrgico até a gravação da amostra de fala para este estudo variou de 3 a 21 anos ( $\bar{X}=11$ anos $)$.

Tabela 2 - Distribuição das participantes nos 3 grupos estudados e sua faixa etária, com média $(\bar{X})$ e desvio-padrão (DP).

\begin{tabular}{|c|c|c|c|}
\hline \multirow{2}{*}{$\begin{array}{c}\mathbf{N}^{\mathrm{o}} \text { do } \\
\text { Protocolo }\end{array}$} & \multicolumn{3}{|c|}{ Idade (anos) } \\
\hline & $\begin{array}{c}\text { Grupo CON } \\
(\mathbf{n}=\mathbf{3 0})\end{array}$ & $\begin{array}{c}\text { Grupo de PFA } \\
(n=5)\end{array}$ & $\begin{array}{c}\begin{array}{c}\text { Grupo de PFR } \\
(n=21)\end{array} \\
\end{array}$ \\
\hline 01 & 22 & 24 & 26 \\
\hline 02 & 24 & 30 & 21 \\
\hline 03 & 27 & 27 & 22 \\
\hline 04 & 30 & 22 & 19 \\
\hline 05 & 20 & 37 & 19 \\
\hline 06 & 31 & & 30 \\
\hline 07 & 24 & & 19 \\
\hline 08 & 35 & & 31 \\
\hline 09 & 24 & & 22 \\
\hline 10 & 40 & & 38 \\
\hline 11 & 36 & & 24 \\
\hline 12 & 29 & & 28 \\
\hline 13 & 33 & & 18 \\
\hline 14 & 34 & & 25 \\
\hline 15 & 22 & & 18 \\
\hline 16 & 36 & & 22 \\
\hline 17 & 31 & & 24 \\
\hline 18 & 30 & & 26 \\
\hline 19 & 20 & & 35 \\
\hline 20 & 39 & & 18 \\
\hline 21 & 34 & & 38 \\
\hline 22 & 23 & & \\
\hline 23 & 24 & & \\
\hline 24 & 20 & & \\
\hline 25 & 22 & & \\
\hline 26 & 20 & & \\
\hline 27 & 38 & & \\
\hline 28 & 33 & & \\
\hline 29 & 24 & & \\
\hline 30 & 24 & & \\
\hline$\overline{\mathrm{X}}$ & 28 & 28 & 25 \\
\hline DP & 6 & 6 & 6 \\
\hline
\end{tabular}


Tabela 3 - Caracterização do tipo de fissura nos grupos de portadoras de fissura palatina deste es tudo; idade(s) no(s) reparo(s) cirúrgico(s), tempo e número de reparos cirúrgicos e presença de palatoplastia secundária com retalho faríngeo no grupo de PFR.

\begin{tabular}{|c|c|c|c|c|c|}
\hline $\begin{array}{l}\text { Grupo/ } \\
\mathbf{N}^{\circ} \text { do } \\
\text { Protocolo }\end{array}$ & $\begin{array}{l}\text { Fissura } \\
\text { palatina } \\
\text { pós-forame } \\
\text { incisivo }\end{array}$ & $\begin{array}{l}\text { Idade(s) no(s) } \\
\quad \text { reparo(s) } \\
\text { cirúrgico(s) }\end{array}$ & $\begin{array}{c}\text { Tempo de } \\
\text { cirurgia (anos) da } \\
1^{\mathrm{a}} \text {. cirurgia até a } \\
\text { gravação da } \\
\text { amostra de fala }\end{array}$ & $\begin{array}{l}\text { Número de reparos } \\
\text { cirúrgicos }\end{array}$ & $\begin{array}{c}\text { Presença de } \\
\text { retalho faríngeo }\end{array}$ \\
\hline PFA01 & $\mathrm{C}$ & - & - & - & - \\
\hline PFA02 & $\mathrm{C}$ & - & - & - & - \\
\hline PFA03 & $\mathrm{I}$ & - & - & - & - \\
\hline PFA04 & $\mathrm{C}$ & - & - & - & - \\
\hline PFA05 & $\mathrm{C}$ & - & - & - & - \\
\hline PFR01 & $\mathrm{I}$ & 20 anos & 6 & 1 & - \\
\hline PFR02 & $\mathrm{I}$ & 10 anos e 20 anos & 11 & 2 & - \\
\hline PFR03 & $\mathrm{I}$ & 15 anos e 16 anos & 7 & 2 & - \\
\hline PFR04 & $\mathrm{I}$ & 3 anos e 5 anos & 16 & 2 & - \\
\hline PFR05 & $\mathrm{C}$ & 6 anos; 11 meses & 13 & 1 & - \\
\hline PFR06 & I & $\begin{array}{c}9 \text { anos, } 13 \text { anos, } 19 \\
\text { anos e } 29 \text { anos }\end{array}$ & 21 & 4 & $\operatorname{sim}$ \\
\hline PFR07 & $\mathrm{I}$ & 1 ano;7 meses & 18 & 1 & - \\
\hline PFR08 & $\mathrm{I}$ & 25 anos; 11 meses & 6 & 1 & - \\
\hline PFR09 & I & $\begin{array}{c}1 \text { ano; } 11 \text { meses e } 3 \\
\text { anos; } 2 \text { meses }\end{array}$ & 21 & 2 & - \\
\hline PFR10 & $\mathrm{C}$ & $\begin{array}{c}\text { no HRAC, aos } 35 \\
\text { anos; } 3 \text { meses* }\end{array}$ & - & várias & $\operatorname{sim}$ \\
\hline PFR11 & $\mathrm{I}$ & 18 anos e 21 anos & 6 & 2 & $\operatorname{sim}$ \\
\hline PFR12 & $\mathrm{I}$ & 25 anos & 3 & 1 & - \\
\hline PFR13 & $\mathrm{I}$ & 4 anos; 7 meses & 14 & 1 & - \\
\hline PFR14 & $\mathrm{I}$ & 20 anos & 5 & 1 & - \\
\hline PFR15 & I & $\begin{array}{c}12 \text { anos; } 5 \text { meses e } \\
16 \text { anos; } 1 \text { mês } \\
\end{array}$ & 6 & 2 & $\operatorname{sim}$ \\
\hline PFR16 & $\mathrm{I}$ & 1 ano;5 meses & 21 & 1 & - \\
\hline PFR17 & $\mathrm{C}$ & 20 anos & 4 & 1 & - \\
\hline PFR18 & I & $\begin{array}{c}21 \text { anos; } 10 \text { meses e } \\
22 \text { anos } \\
\end{array}$ & 5 & 3 & - \\
\hline PFR19 & $\mathrm{I}$ & 23 anos e 29 anos & 12 & 2 & $\operatorname{sim}$ \\
\hline PFR20 & $\mathrm{I}$ & 1 ano;6 meses & 17 & 1 & - \\
\hline PFR21 & $\mathrm{I}$ & 31 anos e 34 anos & 7 & 2 & $\operatorname{sim}$ \\
\hline Legenda: & \multicolumn{5}{|c|}{$\begin{array}{l}\text { C = completa } \\
\mathrm{I}=\text { incompleta } \\
* \text { Em seu prontuário hospitalar há apenas relato de que realizou várias cirurgias em } \\
\text { outros serviços. }\end{array}$} \\
\hline
\end{tabular}




\subsection{Aplicação do protocolo de entrevista e de avaliação fonoaudiológica específica}

Nos protocolos aplicados, para todas as participantes houve o preenchimento dos itens identificação e caracterização.

Para o grupo CON foi irrelevante prosseguir com a avaliação dos demais itens, pois era condição sine qua non que estivessem adequados, para sua participação.

Para o grupo de PFA, a inteligibilidade de fala das 5 integrantes deste grupo foi assim classificada: 1 com prejuízo leve, 1 leve para moderado, 2 moderado, 1 moderado para severo. A ressonância de fala prejudicada pela hipernasalidade foi assim classificada: 1 como moderada aberta, 1 moderada fechada, 2 severa aberta e 1 severa fechada. Quatro participantes deste grupo apresentaram distúrbios articulatórios compensatórios, enquanto 1 não os apresentou. A produção vocal foi considerada adequada para todas as participantes deste grupo (Tabela 4).

Quanto ao grupo de PFR, também conforme a Tabela 4, a inteligibilidade de fala apresentou-se normal para 1 participante, com prejuízo leve para 9 participantes, leve para moderado para 8 delas, moderado para 2 e, finalmente, moderado para severo para 1. Quanto à ressonância de fala, a hipernasalidade foi assim classificada: leve aberta para 5 participantes, moderada aberta para 13, moderada fechada para 1 e severa aberta para 2. Em relação à articulação compensatória, 2 participantes deste grupo não a apresentaram, ao passo que 19 a apresentaram (veja detalhes no Apêndice E). Durante a entrevista, 2 participantes apresentaram intensidade vocal diminuída e 1 apresentou quebra de tom, porém tais aspectos vocais não apareceram nas amostras de fala destinadas às análises perceptivo -auditiva nem computadorizada. 
Tabela 4 - Achados da avaliação fonoaudiológica específica dos grupos de PFA e de PFR quanto à inteligibilidade e à hipernasalidade de fala, à articulação compensatória e à produção vocal.

\begin{tabular}{|c|c|c|c|c|}
\hline $\begin{array}{c}\text { Grupo/ } \\
\mathbf{N}^{\circ} \text { do } \\
\text { Protocolo }\end{array}$ & $\begin{array}{l}\text { Grau de prejuízo na } \\
\text { inteligibilidade de fala }\end{array}$ & $\begin{array}{l}\text { Grau de prejuízo da } \\
\text { ressonância de fala - } \\
\text { hipernasalidade }\end{array}$ & $\begin{array}{c}\text { Articulação } \\
\text { compensatória }\end{array}$ & Produção vocal \\
\hline PFA01 & moderada para severa & severa aberta & ausente & adequada \\
\hline PFA02 & leve & moderada fechada & presente & adequada \\
\hline PFA03 & leve para moderada & moderada aberta & presente & adequada \\
\hline PFA04 & moderada & severa aberta & presente & adequada \\
\hline PFA05 & moderada & severa fechada & presente & adequada \\
\hline PFR01 & normal & leve aberta & presente & adequada \\
\hline PFR02 & moderada & moderada aberta & presente & adequada \\
\hline PFR03 & moderada para severa & severa aberta & presente & $\begin{array}{c}\text { intensidade } \\
\text { diminuída }\end{array}$ \\
\hline PFR04 & leve para moderada & moderada fechada & presente & $\begin{array}{c}\text { intensidade } \\
\text { diminuída }\end{array}$ \\
\hline PFR05 & leve & moderada aberta & presente & adequada \\
\hline PFR06 & leve & leve aberta & presente & adequada \\
\hline PFR07 & leve & leve aberta & ausente* & adequada \\
\hline PFR08 & moderada & moderada aberta & presente & adequada \\
\hline PFR09 & leve para moderada & severa aberta & presente & adequada \\
\hline PFR10 & leve & moderada aberta & presente & adequada \\
\hline PFR11 & leve para moderada & moderada aberta & presente & adequada \\
\hline PFR12 & leve para moderada & moderada aberta & presente & adequada \\
\hline PFR13 & leve & leve aberta & presente & adequada \\
\hline PFR14 & leve para moderada & moderada aberta & presente & adequada \\
\hline PFR15 & leve & leve aberta & presente & adequada \\
\hline PFR16 & leve para moderada & moderada aberta & ausente* & adequada \\
\hline PFR17 & leve para moderada & moderada aberta & presente & adequada \\
\hline PFR18 & leve & moderada aberta & presente & quebra de tom \\
\hline PFR19 & leve & moderada aberta & presente & adequada \\
\hline PFR20 & leve para moderada & moderada aberta & presente & adequada \\
\hline PFR21 & leve & moderada aberta & presente & adequada \\
\hline
\end{tabular}

*Não apresentam articulação compensatória, porém outras alterações articulatórias.

\subsection{Avaliação perceptivo-auditiva das amostras de fala}

Pela natureza da avaliação perceptivo-auditiva da vogal oral [a] sustentada, em que cada examinadora atribuiu 1 para ressonância nasal normal, 2 para ressonância hipernasal leve, 3 para ressonância hipernasal moderada, 4 para ressonância hipernasal severa e 5 para não avaliada e, em outra classificação indicando apenas presença/ausência de hipernasalidade, aplicou-se estatística não-paramétrica. 
Pelo Wilcoxon matched-pairs signed-ranks test constatou-se que não houve significância estatística entre a primeira e a segunda avaliações das 3 examinadoras $(\mathrm{p}=0,05)$. Este resultado diante da hipótese inicial $\left(\mathrm{H}_{0}\right)$ de que as duas performances eram iguais indica que esta não pode ser rejeitada. Então a magnitude e a direção dos dados apontaram para o mesmo lado.

A correlação pelo coeficiente de Spearman $\left(\mathrm{r}_{\mathrm{s}}\right)$ indicou significância estatística $(\mathrm{p}=0,05)$ para as 3 examinadoras, à exceção de uma delas na classificação pelos níveis de 1 a 5, supra-citados. Veja detalhes na Tabela 5.

Tabela 5 - Resultados da aplicação estatística da correlação pelo coeficiente de Spearman $\left(\mathrm{r}_{\mathrm{s}}\right)$ para as classificações da ressonância nasal determinadas por 3 examinadoras sobre a vogal oral [a] dos 3 grupos estudados $(p=0,05)$.

\begin{tabular}{cccc}
\hline Examinadora & $\begin{array}{c}\text { Classificação da ressonância nasal } \\
\text { de fala }\end{array}$ & $\mathbf{r}_{\mathbf{s}}$ & $\begin{array}{c}\text { Significância } \\
\text { estatística }\end{array}$ \\
\hline 1 & Em níveis de 1 a 5 & 0,81 & 0,000011 \\
& Presença/ausência de hipernasalidade & 0,90 & 0,000000 \\
\hline 2 & Em níveis de 1 a 5 & 0,70 & 0,000517 \\
& Presença/ausência de hipernasalidade & 0,81 & 0,000010 \\
\hline 3 & Eresença/ausência de hipernasalidade de 1 a 5 & 0,50 & 0,142201 \\
& & 0,34 & 0,023939
\end{tabular}

A análise intra-examinadoras revelou, ainda, que houve maior porcentagem de concordância na classificação de presença/ausência de hipernasalidade de fala do que nos níveis de 1 a 5 na graduação da ressonância nasal de fala. E, também, que a examinadora 1 obteve o maior índice de concordância consigo mesma. Veja a Tabela 6. 
Tabela 6 - Percentual (\%) de concordância nas respostas das examinadoras para as classificações da ressonância nasal determinadas por 3 examinadoras sobre a vogal oral [a] dos 3 grupos estudados.

\begin{tabular}{cccc}
\hline Examinadora & $\begin{array}{c}\text { Classificação da ressonância nasal } \\
\text { de fala }\end{array}$ & $\begin{array}{c}\text { Número de respostas } \\
\text { concordantes } \\
\text { (em 20 possíveis) }\end{array}$ & $\begin{array}{c}\text { \% das respostas } \\
\text { concordantes }\end{array}$ \\
\hline \multirow{2}{*}{$\begin{array}{c}\text { Em níveis de 1 a 5 } \\
2\end{array}$} & Presença/ausência de hipernasalidade & 14 & 70 \\
& Em níveis de 1 a 5 & 19 & 95 \\
\hline 3 & Presença/ausência de hipernasalidade & 18 & 70 \\
& Eresença/ausência de hipernasalidade & 11 & 50 \\
\hline
\end{tabular}

Na comparação das classificações de todas as amotras de fala $(n=56)$, houve significância estatística pelo coeficiente de Spearman $\left(\mathrm{r}_{\mathrm{s}}\right)$, indicando que havia diferenças entre as examinadoras (Tabela 7).

Tabela 7 - Resultados da aplicação estatística da correlação pelo coeficiente de Spearman $\left(\mathrm{r}_{\mathrm{s}}\right)$ para as classificações da ressonância nasal determinadas entre as 3 examinadoras sobre a vogal oral [a] dos 3 grupos estudados $(\mathrm{p}=0,05)$.

\begin{tabular}{cccc}
\hline Examinadora & $\begin{array}{c}\text { Classificação da ressonância nasal } \\
\text { de fala }\end{array}$ & $\mathbf{r}_{\mathbf{s}}$ & $\begin{array}{c}\text { Significância } \\
\text { estatística }\end{array}$ \\
\hline $1 \times 2$ & Em níveis de 1 a 5 & 0,60 & 0,000001 \\
& Presença/ausência de hipernasalidade & 0,60 & 0,000001 \\
\hline $1 \times 3$ & Em níveis de 1 a 5 & 0,37 & 0,004802 \\
\hline & Presença/ausência de hipernasalidade & 0,50 & 0,000012 \\
\hline & Em níveis de 1 a 5 3 & 0,43 & 0,000065 \\
& Presença/ausência de hipernasalidade & 0,54 & 0,000012 \\
\hline
\end{tabular}

As maiores porcentagens de concordância inter-examinadoras aconteceu entre as examinadoras 1 e 2, tanto para a classificação em níveis de 1 a 5 quanto de 
presença/ausência de hipernasalidade da ressonância nasal de fala: $63 \%$ e $80 \%$, respectivamente. Veja detalhes na Tabela 8.

Tabela 8 - Percentual (\%) de concordância nas respostas inter-examinadoras para as classificações da ressonância nasal de fala determinadas por 3 examinadoras sobre a vogal oral [a] dos 3 grupos estudados.

\begin{tabular}{cccc}
\hline Examinadora & $\begin{array}{c}\text { Classificação da ressonância nasal } \\
\text { de fala }\end{array}$ & $\begin{array}{c}\text { Número de respostas } \\
\text { concordantes } \\
\text { (em 20 possíveis) }\end{array}$ & $\begin{array}{c}\text { \% das respostas } \\
\text { concordantes }\end{array}$ \\
\hline $1 \times 2$ & Em níveis de 1 a 5 & 36 & 63 \\
\hline $1 \times 3$ & Presença/ausência de hipernasalidade & 45 & 52 \\
\hline & Em níveis de 1 a 5 & 29 & 77 \\
\hline & Presença/ausência de hipernasalidade & 43 & 57 \\
\hline
\end{tabular}

Diante do que foi exposto:

1. Percebeutse que a classificação pura e simples entre presença/ausência de hipernasalidade de fala foi mais fácil de ser usada do que aquela dos níveis de 1 a 5 de ressonância nasal.

2. Optou-se pelas classificações realizadas pela examinadora 1 para serem comparadas com os resultados instrumentais. 


\subsection{Análise instrumental das amostras de fala}

\subsubsection{Nasometria}

Na Tabela 9 apresenta-se descritores estatísticos dos achados quanto à nasometria. As nasalâncias de cada participante podem ser encontradas no Apêndice F.

Tabela 9 - Descritores estatísticos das nasalâncias (\%) para as vogais sustentadas [a] e [थ̃] dos 3 grupos estudados.

\begin{tabular}{|c|c|c|c|c|c|c|c|c|}
\hline \multirow[b]{2}{*}{ Vogal } & \multirow[b]{2}{*}{ Grupo } & \multicolumn{7}{|c|}{ Nasalância (\%) } \\
\hline & & Mínimo & Q1 & $\begin{array}{c}\text { Q2 } \\
\text { (Mediana) }\end{array}$ & Q3 & $\begin{array}{c}\text { Q4 } \\
\text { (Máximo) }\end{array}$ & $\bar{X}$ & $\begin{array}{l}\text { Desvio- } \\
\text { padrão }\end{array}$ \\
\hline \multirow{3}{*}{ [a] } & $\begin{array}{c}\mathrm{CON} \\
(\mathrm{n}=30)\end{array}$ & 12,40 & 23,97 & 35,69 & 48,56 & 66,18 & 35,62 & 15,30 \\
\hline & $\begin{array}{l}\text { PFA } \\
(\mathrm{n}=5)\end{array}$ & 20,54 & 26,79 & 26,82 & 32,41 & 41,80 & 29,67 & 8,00 \\
\hline & $\begin{array}{c}\text { PFR } \\
(n=21)\end{array}$ & 13,47 & 29,59 & 39,36 & 43,29 & 95,68 & 41,28 & 20,12 \\
\hline \multirow{3}{*}[\tilde{\mathrm{e}}]{} & $\begin{array}{c}\mathrm{CON} \\
(\mathrm{n}=30)\end{array}$ & 5,93 & 36,37 & 46,51 & 60,56 & 82,80 & 47,11 & 22,27 \\
\hline & $\begin{array}{l}\text { PFA } \\
(\mathrm{n}=5)\end{array}$ & 30,15 & 35,92 & 37,09 & 39,81 & 48,09 & 38,21 & 7,00 \\
\hline & $\begin{array}{c}\text { PFR } \\
(\mathrm{n}=21)\end{array}$ & 21,14 & 43,47 & 47,57 & 54,95 & 98,52 & 52,52 & 18,11 \\
\hline
\end{tabular}

Legenda: Q 1, 2, 3 e 4 - divisão por quartis: $25 \%, 50 \%, 75 \%$ e $100 \%$ da amostra.

Para a vogal oral sustentada [a] o menor valor de mínimo de nasalância foi encontrado para o grupo CON $(12,40 \%)$, o que era esperado, visto que é um grupo que tem de emitir sons orais sem traço de nasalidade. Em seguida tem-se o grupo de PFR $(13,47 \%)$ e depois o grupo de PFA $(20,54 \%)$ - o que se justifica pelo palato das integrantes deste grupo estar aberto. Por outro lado, este mesmo grupo apresenta o menor valor de máximos de nasalância $(41,80 \%)$, inclusive menor que o grupo de PFR (95,68\%), o maior valor máximo de nasalância dos 3 grupos, ou seja, maior presença de nasalidade nesta emissão oral. O grupo CON apresenta-se em posição intermediária entre os 2 grupos anteriores $(66,18 \%)$.

Para a emissão da vogal nasal sustentada [ẽ] os valores mínimos de nasalância encontrados foram: 5,93\% para o grupo CON, 21,14\% para o grupo de PFR e 30,15\% para o grupo de PFA. Porém, para os valores máximos, a nasalidade apresenta-se maior para o grupo de PFR $(98,52 \%)$ que para o grupo de PFA $(48,09 \%)$, estando o grupo 
CON, novamente, em posição intermediária $(82,80 \%)$. Numericamente, no grupo CON (palato fechado e adequada atuação do EVF) vê-se que a presença de nasalidade é mais marcante que para o grupo de PFA (palato aberto/DVF).

É intrigante perceber que no grupo CON encontrou-se um valor mínimo de nasalância para [ẽe menor que para [a]. Ou seja, o traço de nasalidade esteve mais presente para a vogal oral que para a nasal. Para os outros 2 grupos, houve um aumento numérico nestes valores mínimos da vogal oral para a nasal - justificado pelo fato de que o traço de nasalidade necessariamente faz parte de sua emissão vocal. $O$ interessante é perceber que há ajustes para a participação da cavidade nasal, que não se limitam à atuação do EVF apenas, visto que na ausência do palato o traço de nasalidade aumentou o valor mínimo de nasalância - caso do grupo de PFA. Os valores máximos crescem, numericamente, da vogal oral para nasal nos 3 grupos estudados. E o mesmo raciocínio para o comportamento de crescimento dos valores mínimos de nasalância para o grupo de PFA também serve para seu valor máximo.

Partindo-se para medidas centrais na emissão da vogal oral, vê-se que a maior média no valor de nasalância é do grupo de PFR $(\bar{X}=41,28 \% \pm 20,12)$, que também possui o maior desvio-padrão, seguido do grupo $\operatorname{CON}(\overline{\mathrm{X}}=35,62 \% \pm 15,30)$ e do grupo de PFA ( $\overline{\mathrm{X}}=29,67 \% \pm 8,00)$. Novamente, é possível perceber que mesmo com o palato aberto, o traço de nasalidade não se apresenta mais saliente no grupo de PFA, como esperado.

A mesma análise realizada para a vogal oral nos 3 grupos serve para a emissão da vogal nasal. Ou seja, a maior média é do grupo de PFR $(\bar{X}=52,52 \% \pm 18,11)$, seguida do grupo CON ( $\bar{X}=47,11 \% \pm 22,27)$ e do grupo de PFA ( $\bar{X}=38,21 \% \pm 7,00)$.

E, mais uma vez, o aumento nos valores de média denotam a presença do traço de nasalidade detectado na nasalância na passagem de uma vogal oral para uma nasal, não só para o grupo $\mathrm{CON}$, mas sim independentemente se o palato está aberto/DVF (caso do grupo de PFA) ou fechado/DVF (grupo de PFR).

Na emissão da vogal oral, o desvio-padrão demonstrou que a maior variabilidade foi do grupo de PFR e a menor do grupo de PFA. Na emissão da vogal nasal, a maior 
variabilidade foi do grupo CON e a menor do grupo de PFA. Como este grupo mostrou a menor variabilidade em ambas vogais, isto pode refletir suas restrições anátomofuncionais, enquanto a maior variabilidade em [a] do grupo de PFR e em [ $\tilde{e}]$ do grupo CON podem significar a variabilidade na abertura do EVF e sua relação com os demais articuladores.

O comportamento da média e do desvio-padrão das amostras vocais dos 3 grupos pode ser visualizado no Gráfico 1, a seguir.

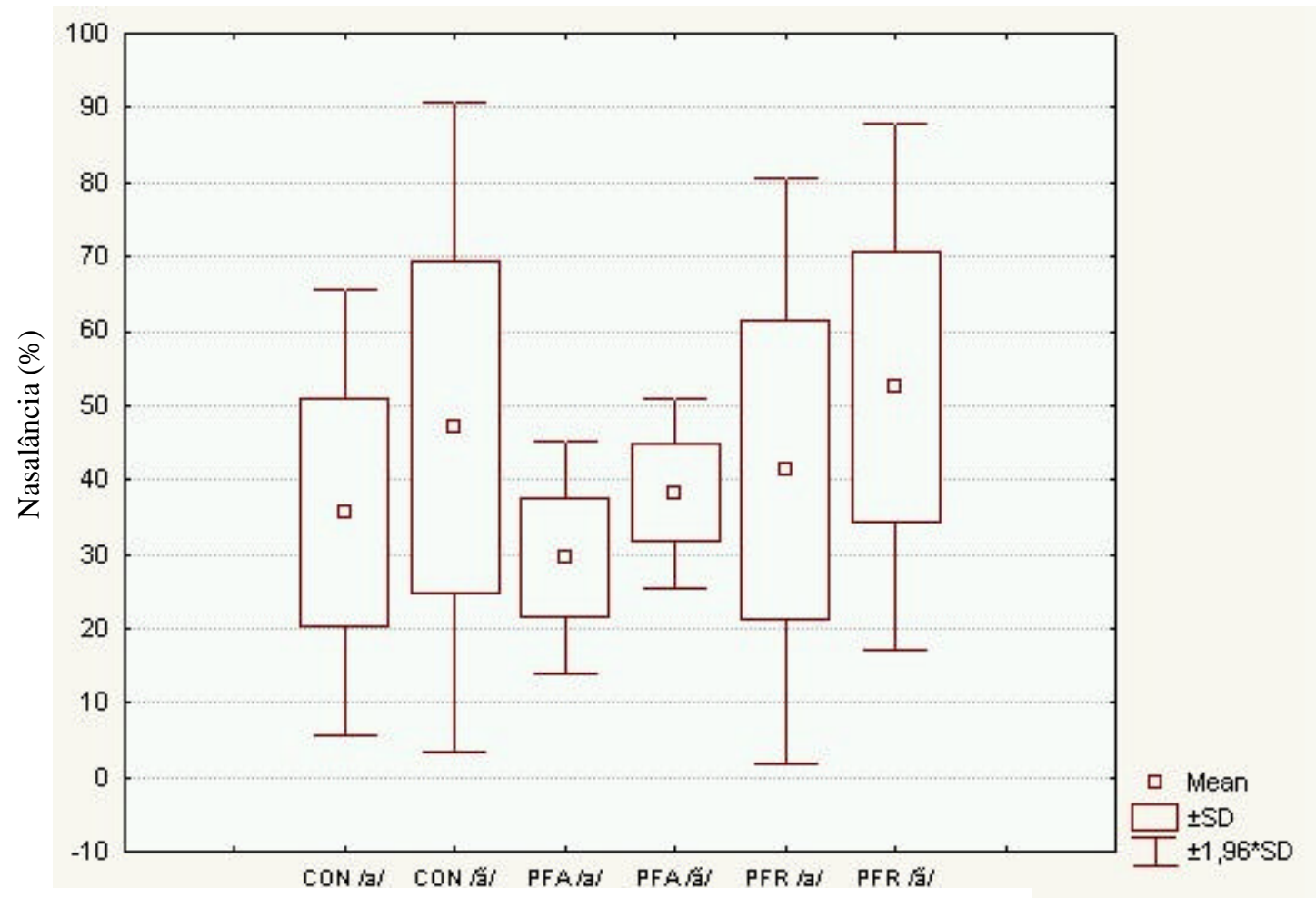

Onde se lê Mean, leia média; e onde se lê $\mathrm{SD}$, leia desvio-padrão.

Gráfico 1 - Box plot dos valores média e desvio-padrão de nasalância nos 3 grupos estudados.

Ainda quanto às medidas centrais, vê-se que a mesma análise aplicada para ambas vogais em ambos grupos continua valendo para a mediana. Isto é, a maior mediana nos valores de nasalância para a vogal oral foi do grupo de PFR $(39,36 \%)$, seguida do grupo CON $(35,69 \%)$ e do grupo de PFA $(26,82 \%)$. Na emissão da vogal nasal, respectivamente, as medianas foram: 47,57\%, 46,51\% e 37,09\%. E, então, continua-se com o mesmo questionamento: como com palato aberto o traço de nasalidade é menos detectado que com o palato fechado e, ainda, havendo crescimento numérico de [a] para [ẽ] no grupo de PFA, há indícios de diferenças na percepção e 
produção do traço de nasalidade para as participantes deste grupo. Aprofundar nesta linha de raciocínio leva a uma revisão até do conceito/entendimento de nasalidade em geral e inclusive dentro da fala classificada como hipernasal. Pois é como se dentro da hipernasalidade houvesse uma variação da nasalidade inerente ao som/fonema nasal.

Toda esta explanação sobre os descritores estatísticos mínimo, máximo, mediana, primeiro/terceiro quartis pode ser visualizada no Gráfico 2.

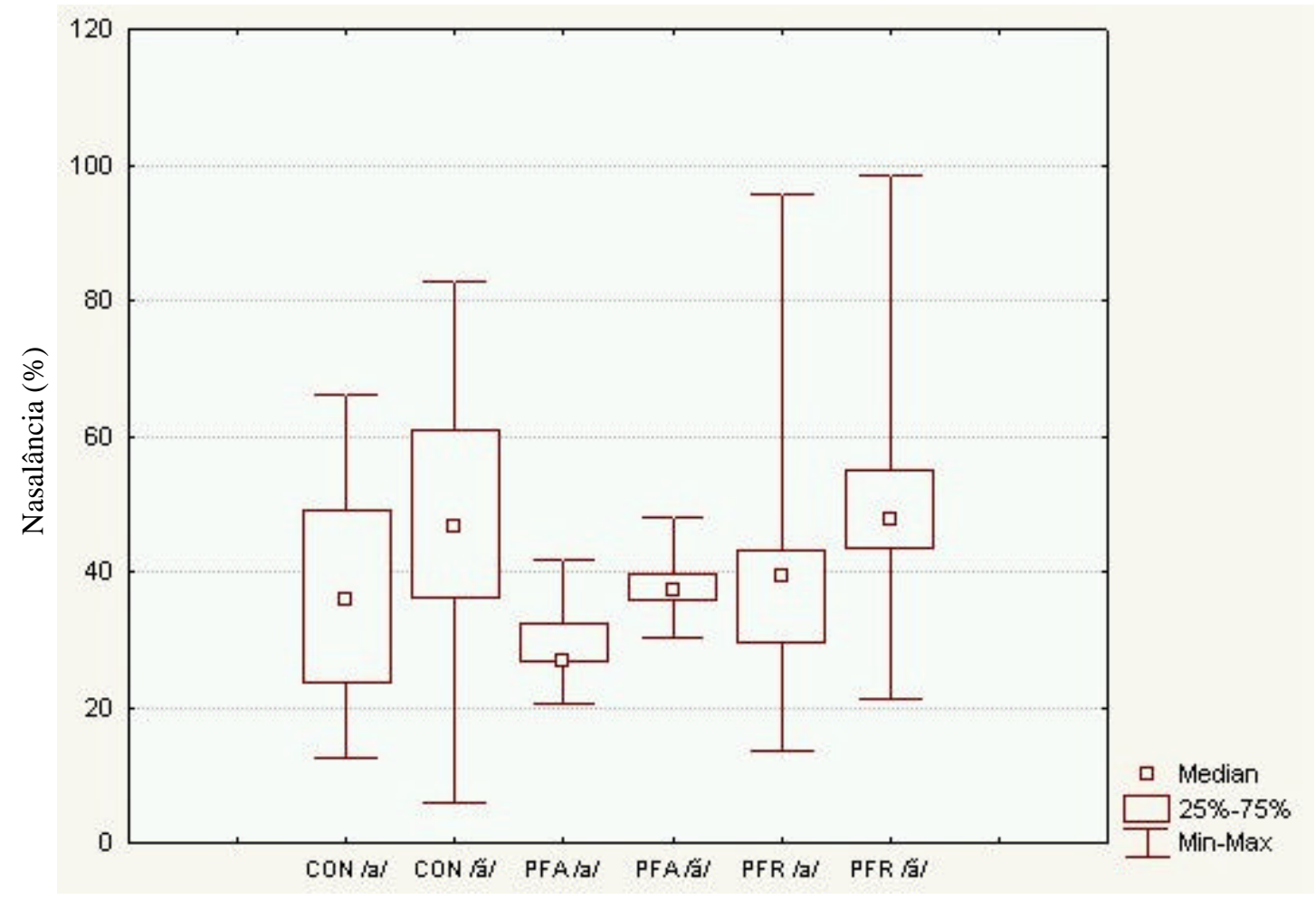

Onde se lê Median, leia mediana; e onde se lê Min-Max, leia mínimo-máximo.

Gráfico 2 - Box plot dos valores mínimo, máximo, mediana e quartis de nasalância nos 3 grupos estudados.

Aplicou-se o teste não-paramétrico Kruskal-Wallis ANOVA by Ranks no contexto vogal oral para analisar as variâncias intragrupos. Como $\mathrm{H}(2, \mathrm{~N}=56)=$ 1,548299 e p=0,4611, verificourse que não houve significância estatística, ou seja, a nasalância não indica diferenças entre os grupos estudados para esta vogal. Houve a mesma verificação para a vogal nasal, em que $H(2, N=56)=3,475045$ e p=0,1760. Assim, pode-se pensar que a variabilidade do traço de nasalidade na emissão dessas vogais é semelhante nos 3 grupos, não sendo possível diferenciá-los. 


\subsubsection{Espectrografia}

Pelos espectrogramas (Apêndices de G a BJ) foi possível visualizar o comportamento formântico das emissões das vogais [a] e [ẽe sustentadas dos 3 grupos estudados.

Tal visualização permitiu determinar o ponto sobre o qual as análises FFT e LPC seriam realizadas, partindo-se da estabilidade do traçado.

A espectrografia digital permitiu, pelo posicionamento do cursor sobre as regiões dos formantes, inspecionar as frequiências neles contidas. Porém, esta forma de análise é mais dependente da "mão" do avaliador do que as técnicas de análise FFT e LPC, além do que impossibilita marcar com precisão onde ocorre um formante, devido à atuação dos filtros, visto que se utilizou uma análise em banda-larga.

Assim, à espectrografia coube a análise qualitativa das amostras de fala do presente estudo, pois precedendo às análises FFT e LPC, gerava expectativas dos futuros achados, bem como provia subsídios para compatibilizá-los.

Seus gradientes de coloração permitiram perceber as regiões de atuação dos formantes nasais e dos antiformantes para as vogais nasais e nasalizadas das participantes deste estudo.

Porém, há que se fazer duas observações importantes:

1) o avaliador tem de ter certeza que definiu o nível de coloração adequadamente, visto que escolhas indevidas podem levar à interpretação de que um determinado formante não existe, quando na realidade não se deu condições reais para que aparecesse;

2) a análise do espectrograma na tela pode ser mais clara e confiável, visto que a versão impressa está sujeita às características do equipamento para impressão. 


\subsubsection{Análises FFT e LPC}

Como explicado na seção 3.5, pelas análises FFT e LPC foi possível determinar

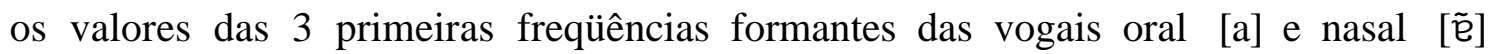
sustentadas, para todos os grupos.

Nos Apêndices de BK a BM é possível comparar as envoltórias FFT/LPC de ambas as vogais para cada participante. É interessante notar os deslocamentos dos picos dos formantes e as suavizações em virturde do traço de nasalidade.

Os valores numéricos das regiões de formantes foram coletados e serão apresentados a seguir.

Para o grupo CON, F (onde n é o número do formante) corresponde aos formantes orais da vogal oral [a] sustentada. Para a vogal nasal [ẽ], também sustentada, deste grupo e ambas as vogais dos outros dois grupos, a denominação das 3 primeiras freqüências formantes foi $\mathrm{f}_{\mathrm{n}}$, por representar não só a presença dos formantes orais, mas também dos nasais e refletir a atuação dos antiformantes.

No caso das vogais nasais é comum verificar em estudos da área a denominação de formante nasal para o primeiro formante detectado no sinal vocálico. Porém, esta freqüência não é resultado apenas da inserção da cavidade nasal no trato vocal, mas a interação deles (e isto implica formantes orais da cavidade oral e antiformantes - novas regiões formadas pela atual configuração do trato vocal, que "aprisionam" energia no sistema). Compreende-se que o fato de surgir um formante não detectado antes, na ausência da participação do nariz e que surge após sua consideração, poderia-se diretamente afirmar que este formante é nasal. Contudo, por conta de enxergar o sistema interativamente, tal distinção não será feita aqui. Caso o objetivo fosse determinar o formante nasal, lançar-se-ia mão de filtros que separassem formantes orais, nasais e antiformantes, o que foge ao escopo deste trabalho.

Na Tabela 10 pode-se observar os mesmos descritores estatísticos aplicados anteriormente, agora sobre as freqüências formantes para os grupos estudados em cada amostra vocálica. Para visualização das freqüências formantes de cada participante, dirija-se ao Apêndice F. 
Tabela 10 - Descritores estatísticos das freqüências formantes $(\mathrm{Hz})$ para as vogais

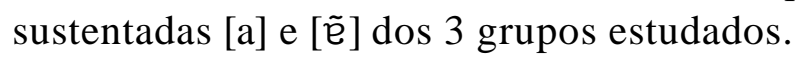

\begin{tabular}{|c|c|c|c|c|c|c|c|c|c|}
\hline \multirow{2}{*}{$\begin{array}{l}\text { Freq. } \\
\text { Form. }\end{array}$} & \multirow[b]{2}{*}{ Vogal } & \multirow[b]{2}{*}{ Grupo } & \multicolumn{7}{|c|}{ Formantes $(\mathrm{Hz})$} \\
\hline & & & Mínimo & Q1 & $\begin{array}{c}\text { Q2 } \\
\text { (Mediana) }\end{array}$ & Q3 & $\begin{array}{c}\text { Q4 } \\
\text { (Máximo) }\end{array}$ & $\bar{X}$ & $\begin{array}{l}\text { Desvio- } \\
\text { padrão }\end{array}$ \\
\hline \multirow{6}{*}{$\mathrm{F}_{1} / \mathrm{f}_{1}$} & \multirow{3}{*}{ [a] } & $\begin{array}{c}\mathrm{CON} \\
(\mathrm{n}=30)\end{array}$ & 648 & 893 & 940 & 1016 & 1148 & 946 & 104 \\
\hline & & $\begin{array}{l}\text { PFA } \\
(\mathrm{n}=5)\end{array}$ & 531 & 744 & 744 & 776 & 893 & 737 & 131 \\
\hline & & $\begin{array}{c}\text { PFR } \\
(\mathrm{n}=21)\end{array}$ & 382 & 829 & 978 & 1000 & 1117 & 887 & 196 \\
\hline & \multirow{3}{*}[\tilde{e}]{} & $\begin{array}{c}\mathrm{CON} \\
(\mathrm{n}=30)\end{array}$ & 265 & 384 & 489 & 601 & 720 & 488 & 132 \\
\hline & & $\begin{array}{l}\text { PFA } \\
(\mathrm{n}=5)\end{array}$ & 340 & 468 & 531 & 585 & 659 & 517 & 121 \\
\hline & & $\begin{array}{c}\text { PFR } \\
(\mathrm{n}=21)\end{array}$ & 287 & 436 & 500 & 531 & 680 & 483 & 86 \\
\hline \multirow{6}{*}{$\mathrm{F}_{2} / \mathrm{f}_{2}$} & \multirow{3}{*}{ [a] } & $\begin{array}{c}\mathrm{CON} \\
(\mathrm{n}=30)\end{array}$ & 1436 & 1536 & 1580 & 1623 & 1744 & 1580 & 77 \\
\hline & & $\begin{array}{l}\text { PFA } \\
(\mathrm{n}=4)\end{array}$ & 1404 & 1452 & 1585 & 1723 & 1787 & 1590 & 183 \\
\hline & & $\begin{array}{c}\text { PFR } \\
(\mathrm{n}=21)\end{array}$ & 1148 & 1521 & 1606 & 1670 & 2861 & 1634 & 330 \\
\hline & \multirow{3}{*}[\tilde{e}]{} & $\begin{array}{c}\mathrm{CON} \\
(\mathrm{n}=29)\end{array}$ & 1247 & 1457 & 1521 & 1581 & 1840 & 1533 & 142 \\
\hline & & $\begin{array}{l}\text { PFA } \\
(\mathrm{n}=3)\end{array}$ & 1340 & 1367 & 1393 & 1409 & 1425 & 1386 & 43 \\
\hline & & $\begin{array}{c}\text { PFR } \\
(\mathrm{n}=21)\end{array}$ & 1191 & 1372 & 1585 & 1755 & 2170 & 1589 & 263 \\
\hline \multirow{6}{*}{$\mathrm{F}_{3} / \mathrm{f}_{3}$} & \multirow{3}{*}{ [a] } & $\begin{array}{c}\mathrm{CON} \\
(\mathrm{n}=30)\end{array}$ & 2478 & 2752 & 2858 & 2994 & 3287 & 2863 & 177 \\
\hline & & $\begin{array}{l}\text { PFA } \\
(n=4)\end{array}$ & 2712 & 2912 & 3000 & 3207 & 3765 & 3119 & 452 \\
\hline & & $\begin{array}{c}\text { PFR } \\
(\mathrm{n}=19)\end{array}$ & 1659 & 2548 & 2840 & 2951 & 3212 & 2700 & 385 \\
\hline & \multirow{3}{*}[\tilde{\mathrm{e}}]{} & $\begin{array}{c}\mathrm{CON} \\
(\mathrm{n}=24)\end{array}$ & 2508 & 2896 & 3046 & 3154 & 3702 & 3039 & 255 \\
\hline & & $\begin{array}{l}\text { PFA } \\
(\mathrm{n}=3)\end{array}$ & 2553 & 2787 & 3021 & 3143 & 3265 & 2946 & 362 \\
\hline & & $\begin{array}{c}\text { PFR } \\
(\mathrm{n}=17)\end{array}$ & 2127 & 2925 & 3095 & 3436 & 3702 & 3065 & 421 \\
\hline
\end{tabular}

Legenda: Q 1, 2, 3 e 4 - divisão por quartis: $25 \%, 50 \%$, $75 \%$ e $100 \%$ da amostra; Freq. Form.= frequiências formantes.

Iniciando-se a análise pelos valores de média das frequiências formantes, vê-se que na região do $F_{1} / f_{1}$ há uma redução do seu valor partindo-se da vogal oral para a nasal. Ou seja, de $737 \mathrm{~Hz}( \pm 131)$ para $517 \mathrm{~Hz}( \pm 121)$ no grupo de PFA; de $887 \mathrm{~Hz}$ $( \pm 196)$ para $483 \mathrm{~Hz}( \pm 86)$ no grupo de PFR e de $946 \mathrm{~Hz}( \pm 104)$ para $488 \mathrm{~Hz}( \pm 132)$ no grupo CON. No grupo de PFA esta queda no valor de média ultrapassou $200 \mathrm{~Hz}$ e tanto 
para o grupo de PFR quanto para o grupo CON vai além de $400 \mathrm{~Hz}$. O desvio-padrão demonstrou que para os grupos de PFA e de PFR houve maior variabilidade na emissão da vogal oral do que da vogal nasal, enquanto que para o grupo CON, observou-se o inverso. E, ainda, que na emissão da vogal oral o grupo de PFR apresentou a maior e o grupo CON a menor variabilidade de produção vocálica. Na emissão da vogal nasal, constatou-se o inverso. Ainda analisando-se as médias na emissão da vogal oral, vê-se que o menor valor foi do grupo de PFA, depois do grupo de PFR e, por fim, do grupo CON. Quando esta análise recai sobre a vogal nasal percebe-se que a hierarquia crescente dos 3 grupos, assim: de PFR, CON e de PFA.

Utilizando-se da análise de variância, ANOVA, sobre o $\mathrm{F}_{1} / \mathrm{f}_{1}$ na relação das vogais oral/nasal com os 3 grupos estudados e destes entre si (Gráfico 3), verificou-se a existência de significância estatística $(F(2,106)=3,5029, p=0,03364)$.

Aplicando-se o Post-hoc Tukey HSD, foram estatisticamente diferentes: vogais oral e nasal do grupo CON ( $\mathrm{p}=0,000120)$, do grupo de PFR ( $\mathrm{p}=0,000120)$ e marginalmente diferentes as do grupo de PFA ( $p=0,097618)$.

Quando se comparou os grupos dentro do contexto vogal oral, o grupo CON foi significativamente diferente do grupo de PFA ( $\mathrm{p}=0,018381)$, mas não do PFR $(\mathrm{p}=0,614821)$ nem entre os grupos de PFA e de PFR $(\mathrm{p}=0,219272)$. No contexto nasal, não houve diferença estatística nem entre o grupo CON e o de PFA $(p=0,997831)$ nem entre o grupo CON e o de PFR ( $\mathrm{p}=0$,999992) nem entre o de PFA e o de PFR $(p=0,995626)$.

No que concerne à diferença entre $o F_{1} / f_{1}$ da vogal oral e o da nasal, em que houve queda no valor de média, ANOVA indicou que havia significância estatística ( $\mathrm{F}(2$, 53)=3,2577; $\mathrm{p}=0,04631$ ) entre os 3 grupos e o Post-hoc Tukey HSD apontou que a significância estatística estava entre o grupo de PFA e o CON ( $\mathrm{p}=0,038313)$, apenas. 


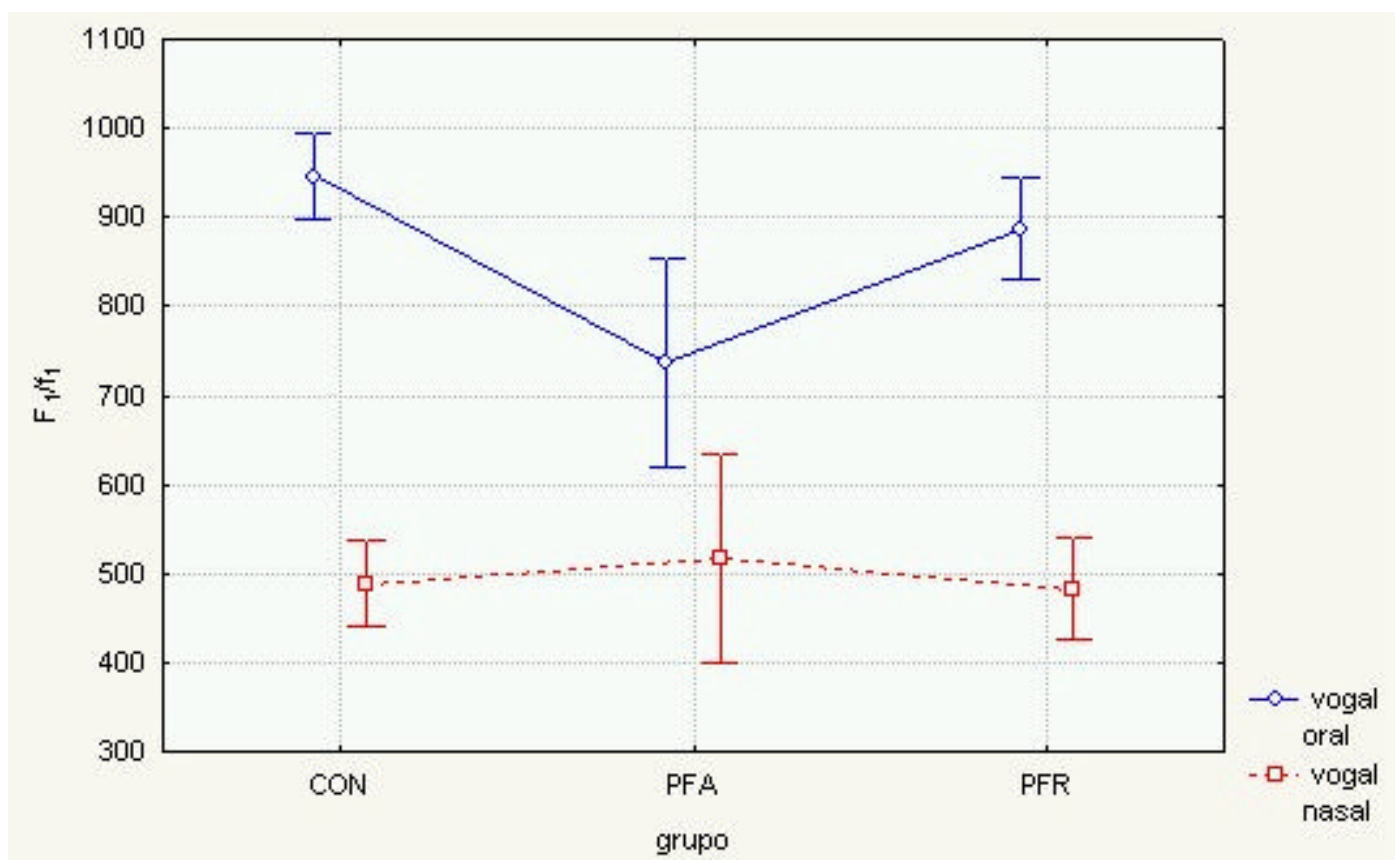

Gráfico 3 - Comportamento da aplicação da $A N O V A$ no $\mathrm{F}_{1} / \mathrm{f}_{1}$ em relação às vogais oral e nasal para os 3 grupos estudados.

Pela média da vogal oral na região do $F_{2} / f_{2}$ pode-se ordenar os grupos de forma crescente, CON, de PFA e de PFR, com os respectivos valores: $1580 \mathrm{~Hz}( \pm 77), 1590 \mathrm{~Hz}$ $( \pm 183)$ e $1634 \mathrm{~Hz}( \pm 330)$. Em relação à vogal nasal, tais valores de média decresceram em torno de $45 \mathrm{~Hz}$ para os grupos CON (1533Hz \pm 142$)$ e de PFR (1589Hz \pm 263$)$, enquanto para o grupo de PFA $(1386 \mathrm{~Hz} \pm 43)$, tal queda esteve em torno de $190 \mathrm{~Hz}$. O desvio-padrão demonstrou que para os grupos de PFA e de PFR houve maior variabilidade na emissão da vogal oral do que da vogal nasal, enquanto que para o grupo CON, observou-se o inverso. E, ainda, que tanto na emissão da vogal oral o grupo de PFR apresentou a maior e o grupo CON a menor variabilidade de produção vocálica. $\mathrm{Na}$ emissão da vogal nasal, a menor variabilidade foi do grupo de PFA e a maior continuou sendo do grupo de PFR. Nesta região do $\mathrm{F}_{2} / \mathrm{f}_{2}$ é possível perceber, pelo número de amostras consideradas para os cálculos estatísticos, a atuação dos antiformantes suprimindo os formantes orais de algumas amostras vocálicas, como evidenciado pelos valores de média/desvio-padrão para a vogal oral que foram calculados sobre um número de 4 amostras vocálicas do grupo de PFA, inicialmente com 5 integrantes. Quando se passou para a vogal nasal, este número diminuiu para 3 amostras neste grupo e no grupo CON, de 30 para 29 amostras vocálicas. 
Pela aplicação da $A N O V A$, não houve significância estatística na região do $\mathrm{F}_{2} / \mathrm{f}_{2}$ (Gráfico 4) na relação entre as vogais oral/nasal e os grupos estudados nem entre estes dentro de cada contexto vocálico $(\mathrm{F}(2,102)=0,46261, \mathrm{p}=0,063095)$.

A respeito da diferença entre $F_{2} / f_{2}$ da vogal oral para a nasal, em que houve queda no valor de média, ANOVA também não acusou significância estatística ( $\mathrm{F}(2$, $50)=1,0086 ; \mathrm{p}=0,37201)$.

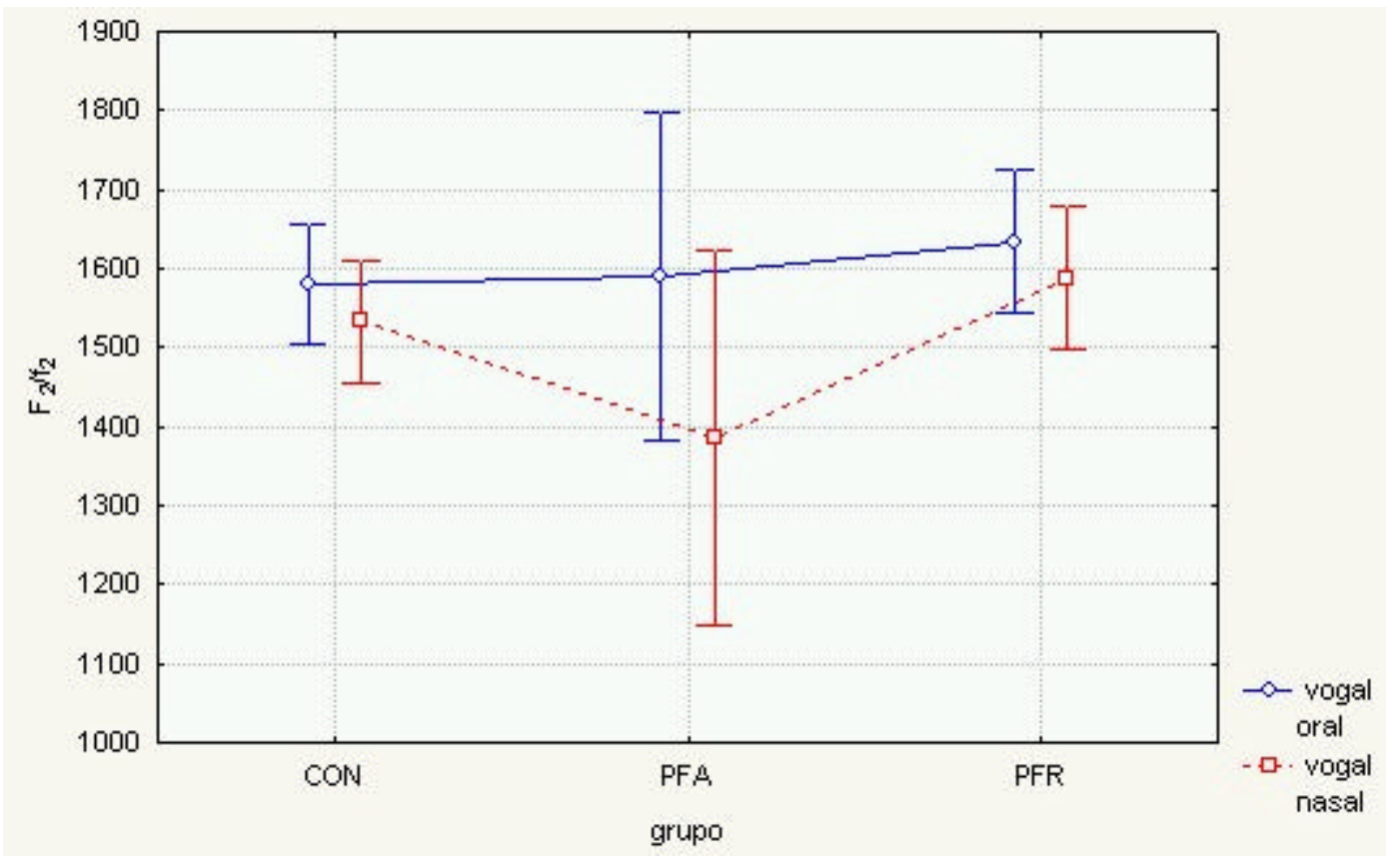

Gráfico 4 - Comportamento da aplicação da ANOVA no $\mathrm{F}_{2} / \mathrm{f}_{2}$ em relação às vogais oral e nasal para os 3 grupos estudados.

$\mathrm{Na}$ região do $\mathrm{F}_{3} / \mathrm{f}_{3}$, houve aumento nos valores de média de 2 grupos estudados, no sentido da vogal oral para a nasal. Este aumento foi da ordem de $170 \mathrm{~Hz}$ para o grupo CON e de $365 \mathrm{~Hz}$ para o grupo de PFR. Para o grupo de PFA, houve redução em torno de $170 \mathrm{~Hz}$. Em [a], a hierarquia crescente dos grupos foi: PFR, CON e PFA, cujos valores foram, respectivamente: $2700 \mathrm{~Hz}( \pm 385), 2863 \mathrm{~Hz}( \pm 177)$ e $3119 \mathrm{~Hz}( \pm 452)$. A mesma descrição para [ẽ] foi: PFA, CON e PFR, com os respectivos valores: $2946 \mathrm{~Hz}$ ( \pm 362$), 3039 \mathrm{~Hz}( \pm 255)$ e $3065 \mathrm{~Hz}( \pm 421)$. O desvio-padrão demonstrou que para os grupos CON e de PFR houve maior variabilidade na emissão da vogal nasal do que da vogal oral, enquanto que para o grupo PFA, observou-se o inverso. Para ambas as vogais, a menor variabilidade na emissão ocorreu para o grupo $\mathrm{CON}$, mas a maior variabilidade na vogal oral foi do grupo de PFA, enquanto na vogal nasal foi do grupo 
de PFR. De forma geral, foi na região do $\mathrm{F}_{3} / \mathrm{f}_{3}$ que os 3 grupos apresentaram os maiores valores de desvio-padrão. Mais uma vez, possivelmente, é a atuação dos antiformantes que suprime o $f_{3}$ de 1 integrante do grupo de PFA e de 2 integrantes do grupo de PFR na emissão de [a]. Quando da emissão nasal, ou seja, em [ẽ $], 2$ integrantes do grupo de PFA e 4 do grupo de PFR deixaram de apresentar o $f_{3}$, o que também aconteceu para 6 integrantes do grupo CON.

Na região do $\mathrm{F}_{3} / \mathrm{f}_{3}$, por meio da $A N O V A$ (Gráfico 5), verificou-se significância estatística marginal $(\mathrm{F}(2,91)=2,4658, \mathrm{p}=0,09060)$ nas relações entre as vo gais oral e nasal e os grupos estudados, e entre estes em cada contexto vocálico.

O Post-hoc Tukey HSD acusou diferença estatística apenas entre as vogais oral e nasal do grupo de PFR ( $\mathrm{p}=0,009010)$.

Em relação à diferença entre o $F_{3} / f_{3}$ da vogal oral para a nasal, em que houve aumento no valor de média, a ANOVA apontou que havia significância estatística $(\mathrm{F}(2,38)=3,9603 ; \mathrm{p}=0,02740)$ entre os 3 grupos e o Post-hoc Tukey HSD indicou que a significância estatística estava entre o grupo de PFA e de PFR ( $p=0,033158)$, apenas.

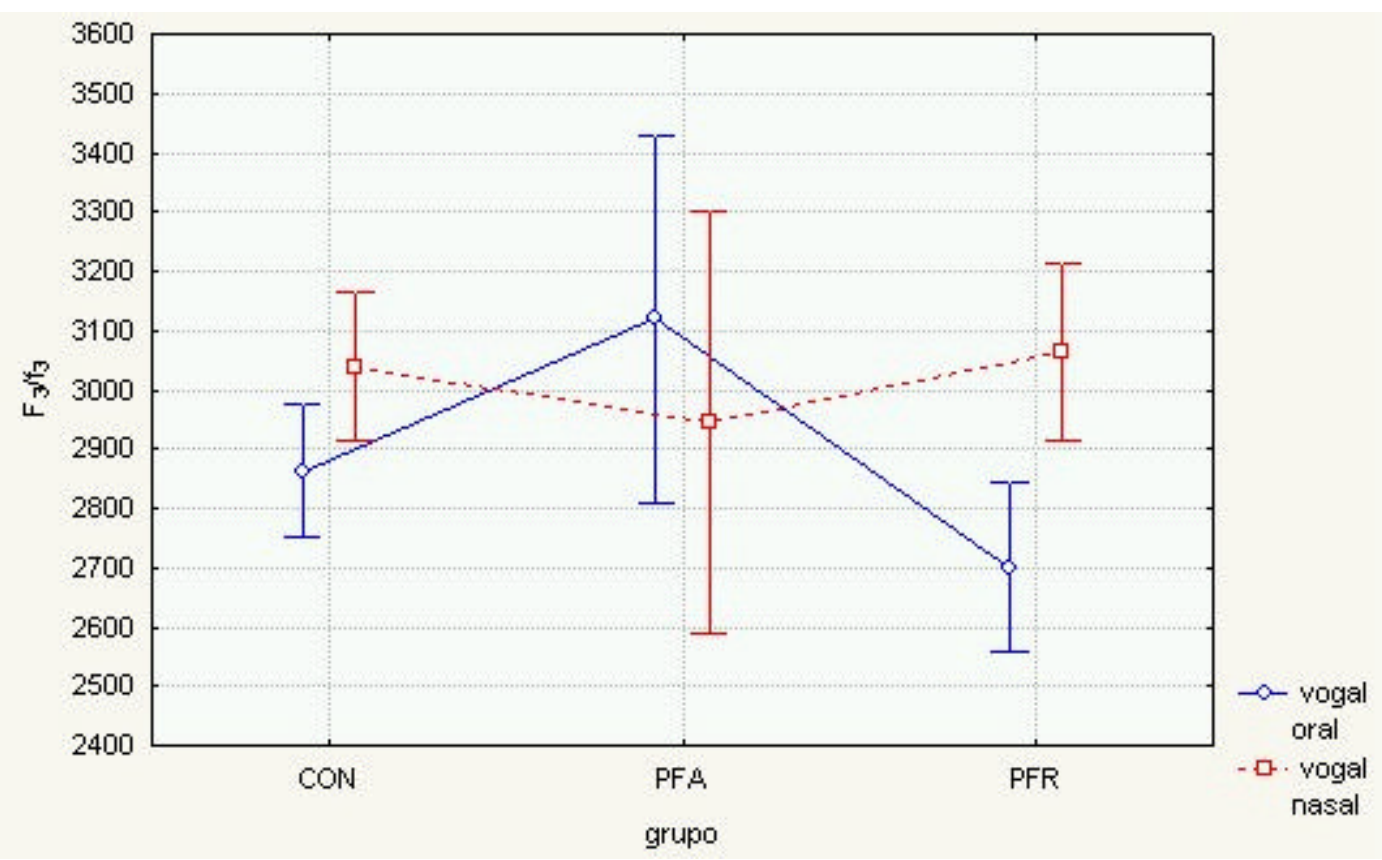

Gráfico 5 - Comportamento da aplicação da $A N O V A$ no $\mathrm{F}_{3} / \mathrm{f}_{3}$ em relação às vogais oral e nasal para os 3 grupos estudados. 
Quanto aos valores de mínimo e máximo encontrados na emissão de cada vogal, para cada grupo nas 3 regiões de formantes analisadas, o que chamou a atenção foi a extensão encontrada. A extensão encontrada na região do $\mathrm{F}_{1} / \mathrm{f}_{1}$ para [a] foi de $362 \mathrm{~Hz}$ para o grupo de PFA, $500 \mathrm{~Hz}$ para o grupo CON e $735 \mathrm{~Hz}$ para o grupo de PFR; para [ẽ] foi de $319 \mathrm{~Hz}$ para o grupo de PFA, $393 \mathrm{~Hz}$ para o de PFR e $455 \mathrm{~Hz}$ para o CON. $\mathrm{Na}$ região do $\mathrm{F}_{2} / \mathrm{f}_{2}$ a extensão para [a] foi de $308 \mathrm{~Hz}$ para o CON, $383 \mathrm{~Hz}$ para o grupo de PFA e $1713 \mathrm{~Hz}$ para o de PFR; enquanto para [ẽe] foi de $85 \mathrm{~Hz}$ para o grupo de PFA, $593 \mathrm{~Hz}$ para o CON e $979 \mathrm{~Hz}$ para o de PFR. Para a região do $\mathrm{F}_{3} / \mathrm{f}_{3}$ a extensão encontrada para [a] foi de $809 \mathrm{~Hz}$ para o CON, $1053 \mathrm{~Hz}$ para o grupo de PFA e $1553 \mathrm{~Hz}$ para o de PFR; enquanto para [ẽ] foi de $712 \mathrm{~Hz}$ para o grupo de PFA, $1194 \mathrm{~Hz}$ para o CON e $1575 \mathrm{~Hz}$ para o de PFR.

$\mathrm{Na}$ região do $\mathrm{F}_{1} / \mathrm{f}_{1}$, assim como ocorreu para as médias, as medianas decresceram da vogal oral em comparação à vogal nasal: de $744 \mathrm{~Hz}$ para $531 \mathrm{~Hz}$ no grupo de PFA, de $940 \mathrm{~Hz}$ para $489 \mathrm{~Hz}$ no grupo CON e de $978 \mathrm{~Hz}$ para $500 \mathrm{~Hz}$ no grupo de PFR. Para a região do $\mathrm{F}_{2} / \mathrm{f}_{2}$ as medianas também delinearam queda, menor que para o $F_{1} / f_{1}$, mas ainda assim, na mesma comparação entre as vogais oral e nasal: de $1580 \mathrm{~Hz}$ para $1521 \mathrm{~Hz}$ no grupo CON, de $1585 \mathrm{~Hz}$ para $1393 \mathrm{~Hz}$ no grupo de PFA e $1606 \mathrm{~Hz}$ para $1585 \mathrm{~Hz}$ no grupo de PFR. E, por fim, assim como na média, na região do $\mathrm{F}_{3} / \mathrm{f}_{3}$ houve aumento nos valores de mediana no sentido vogal oral para nasal: de 2858 $\mathrm{Hz}$ para $3046 \mathrm{~Hz}$ no grupo CON, de $2840 \mathrm{~Hz}$ para $3095 \mathrm{~Hz}$ no grupo de PFR e de 3000 para $3021 \mathrm{~Hz}$ no grupo de PFA.

O comportamento desses últimos descritores estatísticos mencionados pode ser visualizado nos Gráfico 6 e 7, a seguir. 


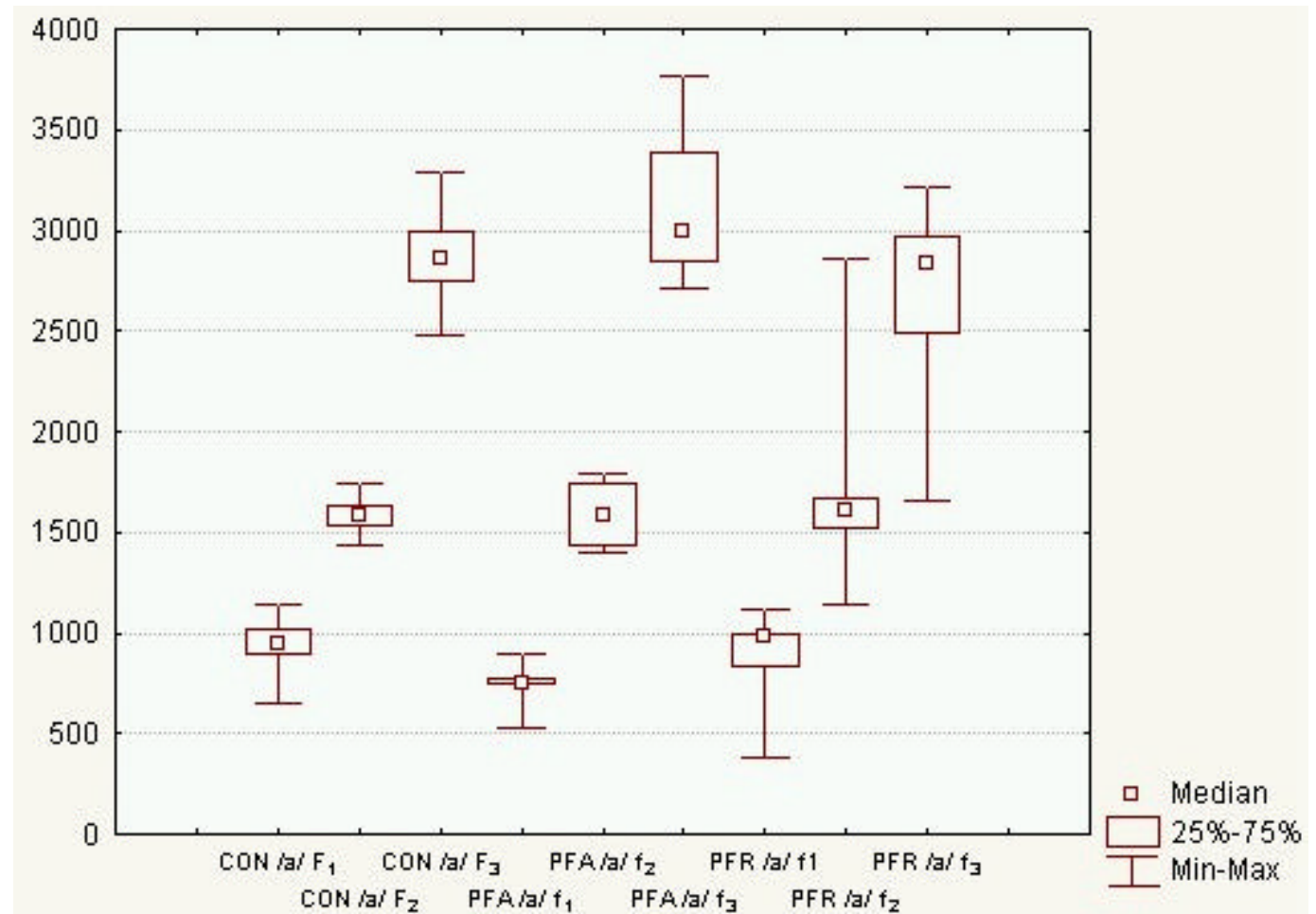

Onde se lê Median, leia mediana; e onde se lê Min-Max, leia mínimo-máximo.

Gráfico 6 - Comportamento da mediana, mínimo e máximo dos 3 formantes iniciais para cada um dos 3 grupos estudados quanto à vogal oral.

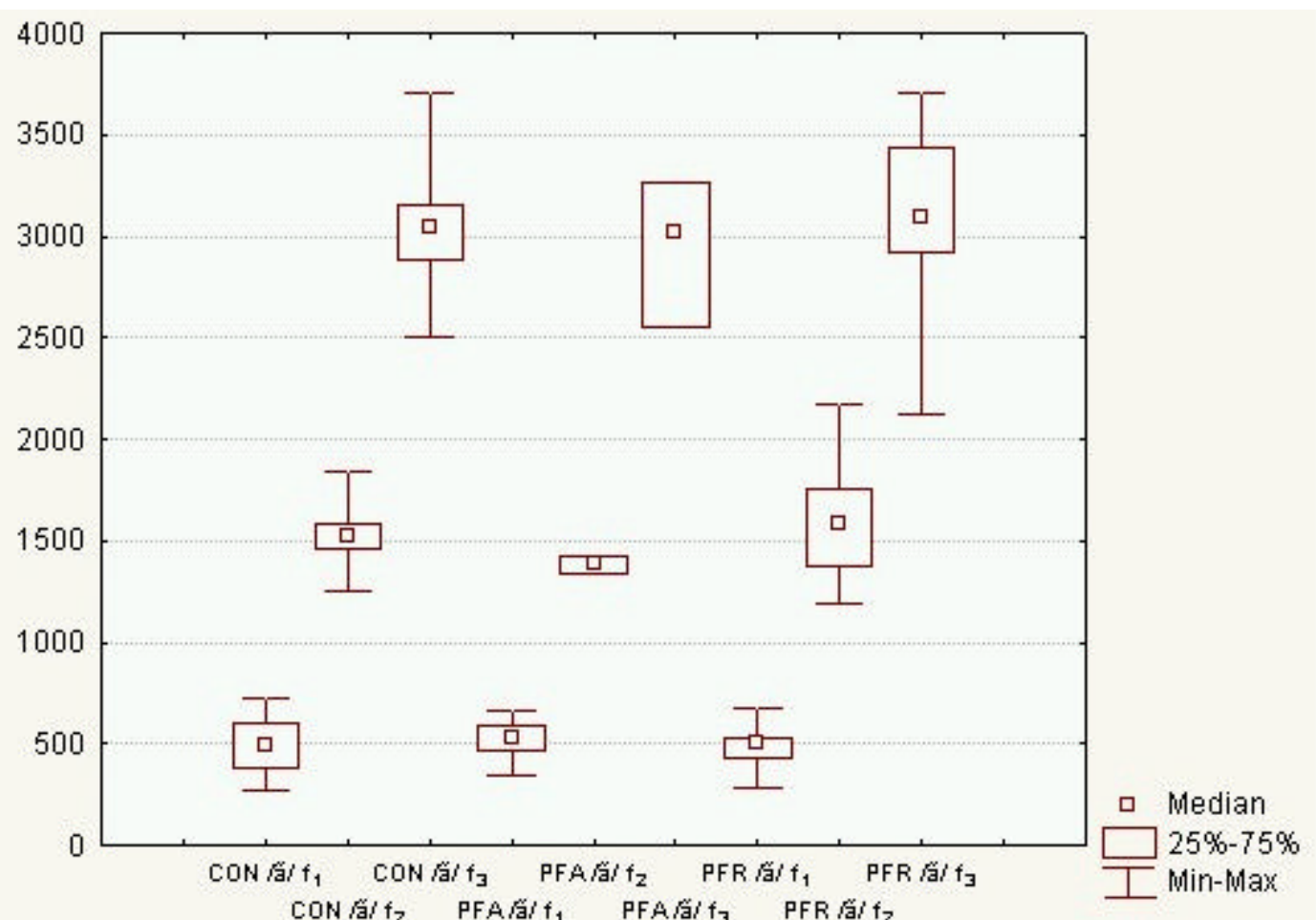

Onde se lê Median leia mediana; e onde se lê Min-Max, leia mínimo-máximo.

Gráfico 7 - Comportamento da mediana, mínimo e máximo dos 3 formantes iniciais para cada um dos 3 grupos estudados quanto à vogal nasal. 
Investigou-se, também, as diferenças entre as regiões de formantes para uma mesma vogal (Tabela 11 e Gráfico 8), com o intuito de traçar paralelos entre estas diferenças e a percepção auditiva ${ }^{15}$.

Tabela 11 - Valores de média e de desvio-padrão da diferença nas regiões de formante para cada vogal e grupo estudados.

\begin{tabular}{|c|c|c|c|}
\hline \multirow{2}{*}{$\begin{array}{l}\text { Região de } \\
\text { formantes }\end{array}$} & \multirow{2}{*}{ Grupo } & \multicolumn{2}{|c|}{ Formantes (Hz) } \\
\hline & & $\bar{X}$ & Desvio-padrão \\
\hline $\mathrm{F}_{2}[\mathrm{a}]-\mathrm{F}_{1}[\mathrm{a}]$ & $\mathrm{CON}(\mathrm{n}=30)$ & 634 & 102 \\
\hline \multirow{2}{*}{$\mathrm{f}_{2}[\mathrm{a}]-\mathrm{f}_{1}[\mathrm{a}]$} & PFA $(n=4)$ & 801 & 220 \\
\hline & $\operatorname{PFR}(n=21)$ & 747 & 278 \\
\hline $\mathrm{F}_{3}[\mathrm{a}]-\mathrm{F}_{2}[\mathrm{a}]$ & $\mathrm{CON}(\mathrm{n}=30)$ & 1284 & 179 \\
\hline \multirow{2}{*}{$\mathrm{f}_{3}[\mathrm{a}]-\mathrm{f}_{2}[\mathrm{a}]$} & PFA $(n=4)$ & 1976 & 869 \\
\hline & PFR (n=19) & 1123 & 323 \\
\hline \multirow{3}{*}{$\mathrm{f}_{2}[\tilde{e}]-\mathrm{f}_{1}[\tilde{\mathscr{e}}]$} & $\mathrm{CON}(\mathrm{n}=29)$ & 1045 & 204 \\
\hline & PFA $(n=3)$ & 922 & 101 \\
\hline & $\operatorname{PFR}(\mathrm{n}=21)$ & 1106 & 280 \\
\hline \multirow{3}{*}{$\mathrm{f}_{3}[\tilde{e}]-\mathrm{f}_{2}[\tilde{e}]$} & $\mathrm{CON}(\mathrm{n}=24)$ & 1557 & 391 \\
\hline & $\operatorname{PFA}(\mathrm{n}=3)$ & 2035 & 915 \\
\hline & PFR (n=17) & 1513 & 489 \\
\hline
\end{tabular}

No que concerne à vogal oral, os valores de média da região entre o $F_{2} / f_{2}$ e o $\mathrm{F}_{1} / \mathrm{f}_{1}$ para cada grupo foram: CON igual a $634 \mathrm{~Hz}( \pm 102)$, PFA $801 \mathrm{~Hz}( \pm 220)$ e PFR $747 \mathrm{~Hz}( \pm 278)$; e entre o $\mathrm{F}_{3} / \mathrm{f}_{3}$ e o $\mathrm{F}_{2} / \mathrm{f}_{2}: \mathrm{CON}$ igual a $1284 \mathrm{~Hz}( \pm 179)$, PFA $1976 \mathrm{~Hz}$ $( \pm 869)$ e PFR $1123 \mathrm{~Hz}( \pm 323)$.

No contexto nasal, para a região entre o $\mathrm{f}_{2}$ e o $\mathrm{f}_{1}$ as médias foram: no grupo CON igual a $1045 \mathrm{~Hz}( \pm 204)$, no grupo de PFA $922 \mathrm{~Hz}( \pm 101)$ e no de PFR $1106 \mathrm{~Hz}( \pm 280)$;

\footnotetext{
15 Baseado na afirmação de que é a constante distância entre os formantes que confere a identidade vocálica, independente se o trato vocal é adulto feminino/masculino ou infantil (FUCCI e LASS, 1999) ao qual se pode estender para anátomo -fisiologicamente adequado ou não.
} 
e entre o $f_{3}$ e o $f_{2}$ : para o CON $1557 \mathrm{~Hz}( \pm 391)$, para o de PFA $2035 \mathrm{~Hz}( \pm 915)$ e para o de PFR $1513 \mathrm{~Hz}( \pm 489)$.

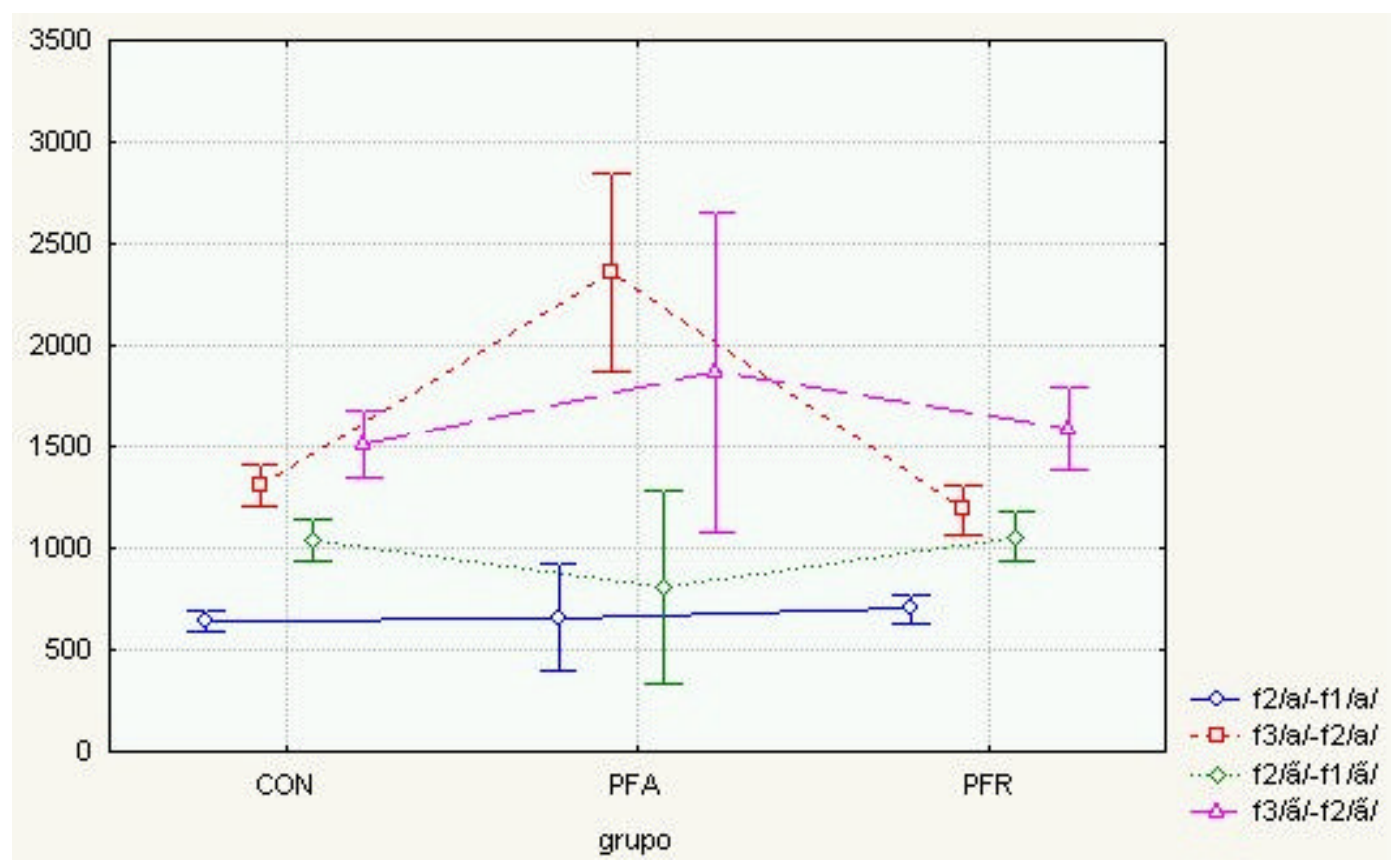

Gráfico 8 - Comportamento das diferenças entre os formantes da mesma vogal para os 3 grupos estudados.

\subsection{Comparação entre a avaliação perceptivo-auditiva e a análise instrumental}

Tentou-se estabelecer correlações entre a avaliação perceptivo-auditiva, a nasalância e as características formânticas, a partir da tabela do Apêndice BN.

Nesta tabela, dos parâmetros referentes à vogal oral [a] sustentada em cada grupo, ordenou-se pela classificação da hipernasalidade ausente, depois presente, de acordo com a examinadora 1 , do menor para o maior valor de nasalância e do $F_{1} / f_{1}$.

A emissão vocálica de 7/30 (23\%) das integrantes do grupo CON foi classificada com hipernasalidade presente. Destas, quando da classificação em níveis de hipernasalidade, houve aquelas as quais não foi possível classificar $(n=3)$ e aquelas com hipernasalidade leve $(n=2)$ ou moderada $(n=2)$. Há, ainda, uma emissão vocálica classificada com hipernasalidade ausente/moderada. 
Nas emissões classificadas com hipernasalidade ausente, os valores de nasalância foram de $12,40 \%$ a 57,83\%. Nas emissões com hipernasalidade presente os valores estiveram entre $16,20 \%$ e 55,23\%. Não foi possível determinar, desta maneira, faixas de nasalância que correspondessem à hipernasalidade ausente ou presente. Mas é interessante notar que o maior valor de nasalância $(66,18 \%)$ corresponde àquela emissão classificada com hipernasalidade ausente/moderada.

Quanto à região do $F_{1}$, a classificação hipernasalidade ausente corresponde u à faixa de $648 \mathrm{~Hz}$ a $1042 \mathrm{~Hz}$, enquanto a hipernasalidade presente, de $925 \mathrm{~Hz}$ a $1148 \mathrm{~Hz}$ e a ausente/moderada a $1085 \mathrm{~Hz}$. Este valor está na faixa de 1042 a $1148 \mathrm{~Hz}$, na qual estão as emissões com hipernasalidade presente/ressonância nasal não avaliada.

Em relação à diferença entre a região do $F_{2}$ e do $F_{1}$ da vogal oral $\left(F_{2}-F_{1}\right)$, hipernasalidade ausente corresponde u à faixa de $522 \mathrm{~Hz}$ a $937 \mathrm{~Hz}$; de hipernasalidade presente de $442 \mathrm{~Hz}$ a $596 \mathrm{~Hz}$ e a ausente/moderada a $627 \mathrm{~Hz}$.

$\mathrm{Na}$ diferença entre as regiões do $\mathrm{F}_{3}$ e do $\mathrm{F}_{2}\left(\mathrm{~F}_{3}-\mathrm{F}_{2}\right)$, a hipernasalidade ausente correspondeu à faixa de $925 \mathrm{~Hz}$ a $1681 \mathrm{~Hz}$; hipernasalidade presente de $1123 \mathrm{~Hz}$ a 1602 $\mathrm{Hz}$ e ausente/moderada a $1181 \mathrm{~Hz}$.

No delineamento de faixas de correspondência percepção auditiva (método subjetivo) e os resultados objetivos (nasalância e $F_{1}, F_{2}-F_{1}$ e $F_{3}-F_{2}$ ), o par com fronteiras (relativamente) mais precisas foi a avaliação perceptivo-auditiva e a diferença do $\mathrm{F}_{2}-\mathrm{F}_{1}$.

No grupo de PFA houve uma emissão vocálica classificada com hipernasalidade ausente (e grau normal) e 4 com hipernasalidade presente (graus: 1 não avaliado, 2 hipernasalidade severa e 1 hipernasalidade moderada).

A nasalância da hipernasalidade ausente foi de 30,15\%, enquanto que a presente esteve na faixa de $35,92 \%$ a 48,09\% (da hipernasalidade presente e não avaliada foi o valor de $35,92 \%)$.

Na região do $\mathrm{f}_{1}$, a hipernasalidade ausente tem o valor de $893 \mathrm{~Hz}$, enquanto a hipernasalidade presente esteve na faixa de $531 \mathrm{~Hz}$ a $776 \mathrm{~Hz}$. 
A diferença $\mathrm{f}_{2}-\mathrm{f}_{1}$ para hipernasalidade ausente foi de $575 \mathrm{~Hz}$ e da hipernasalidade presente esteve na faixa de $660 \mathrm{~Hz}$ a $1043 \mathrm{~Hz}$. É interessante notar que a emissão com hipernasalidade presente com grau não avaliado tem ausência do $f_{2}$.

$\mathrm{Na}$ diferença do $\mathrm{f}_{3}-\mathrm{f}_{2}$ esta mesma emissão com ausência do $\mathrm{f}_{2}$ teve o valor de $3021 \mathrm{~Hz}$, enquanto que a emissão com hipernasalidade ausente tem o valor de $1244 \mathrm{~Hz}$ e a hipernasalidade presente esteve na faixa de $1276 \mathrm{~Hz}$ a $2361 \mathrm{~Hz}$ e teve uma ausência do $f_{3}$.

Apesar de ter pequena amostra, o grupo de PFA apresentou limites de correspondência mais claro entre as avaliações, quando se compara a hipernasalidade ausente/presente, a nasalância, of $f_{1}$ e a diferença do $f_{2}-f_{1}$.

No grupo de PFR 6/21 (28\%) das emissões vocálicas foram classificadas com hipernasalidade ausente e ressonância nasal normal. A faixa de nasalância correspondente foi de 13,47\% a 47,16\%. Para hipernasalidade presente, esta faixa foi de $27,75 \%$ a $95,68 \%$.

Na região do $f_{1}$ a hipernasalidade ausente esteve nas emissões que estão na faixa de $893 \mathrm{~Hz}$ a $1117 \mathrm{~Hz}$, enquanto a hipernasalidade presente esteve na faixa de $382 \mathrm{~Hz}$ a $1085 \mathrm{~Hz}$.

A diferença $\mathrm{f}_{2}-\mathrm{f}_{1}$ esteve concentrada entre $489 \mathrm{~Hz}$ e $1755 \mathrm{~Hz}$ ( 5 emissões de 489 $\mathrm{Hz}$ a $628 \mathrm{~Hz}$ e 1 emissão em $1755 \mathrm{~Hz}$ ), para a classificação hipernasalidade ausente e entre $575 \mathrm{~Hz}$ e $1096 \mathrm{~Hz}$ para a classificação hipernasalidade presente.

$\mathrm{Na}$ diferença $\mathrm{f}_{3}-\mathrm{f}_{2}$, a hipernasalidade ausente esteve na faixa de $1075 \mathrm{~Hz}$ a 1489 $\mathrm{Hz}$ (em 1 emissão há ausência do $\mathrm{f}_{3}$ ) e a hipernasalidade presente na faixa de $511 \mathrm{~Hz}$ a $1712 \mathrm{~Hz}$ (em 1 emissão há ausência do $\mathrm{f}_{3}$ ).

É interessante notar que das 6 emissões vocálicas classificadas com hipernasalidade ausente, 5 corresponderam a participantes que possuíam retalho faríngeo (Tabela 3).

Desta análise, construiu-se a Tabela 12. 
Tabela 12 - Correspondência entre a avaliação perceptivo-auditiva e a análise instrumental na emissão da vogal oral [a] para os 3 grupos estudados.

\begin{tabular}{|c|c|c|c|c|c|}
\hline \multirow{3}{*}{ Hipernasalidade } & \multirow{3}{*}{ Grupo } & \multicolumn{4}{|c|}{ Faixa da vogal oral [a] sustentada } \\
\hline & & \multirow{2}{*}{ Nasalância (\%) } & \multicolumn{3}{|c|}{ Formantes $(\mathbf{H z})$} \\
\hline & & & $\mathbf{F}_{1} / \mathbf{f}_{\mathbf{1}}$ & $F_{2}-F_{1}$ ou $f_{2}-f_{1}$ & $F_{3}-F_{2}$ ou $f_{3}-f_{2}$ \\
\hline \multirow{3}{*}{ Ausente } & $\mathrm{CON}(\mathrm{n}=23)$ & 12,40 a 57,83 & 648 a 1042 & 522 a 937 & 925 a 1681 \\
\hline & $\operatorname{PFA}(n=1)$ & 30,15 & 893 & 575 & 1244 \\
\hline & PFR $(n=6)$ & 13,47 a 47,16 & 893 a 1117 & $\begin{array}{c}489 \text { a } 628, \text { mais } \\
1 \text { emissão de } \\
1755\end{array}$ & 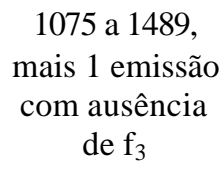 \\
\hline \multirow{3}{*}{ Presente } & $\mathrm{CON}(\mathrm{n}=7)$ & 16,20 a 55,23 & 925 a 1148 & 442 a 596 & 1123 a 1602 \\
\hline & PFA $(n=4)$ & 35,92 a 48,09 & 531 a 776 & 660 a 1043 & $\begin{array}{c}\text { Ausente, 1276, } \\
2361 \text { e } 3021\end{array}$ \\
\hline & $\operatorname{PFR}(n=15)$ & 27,75 a 95,68 & 382 a 1085 & 575 a 1096 & $\begin{array}{c}511 \text { a } 1712, \\
\text { mais } 1 \text { emissão } \\
\text { com ausência } \\
{\operatorname{de~} f_{3}}\end{array}$ \\
\hline
\end{tabular}

Comparando-se os 3 grupos, a partir da tabela anterior, não é possível estabelecer fronteiras claras e definidas para a hipernasalidade ausente e presente e sua relação com a nasalância, a região do $F_{1} / f_{1}$ e as diferenças entre $o F_{2} / f_{2}$ e o $F_{1} / f_{1}$ e entre $o$ $\mathrm{F}_{3} / \mathrm{f}_{3}$ e o $\mathrm{F}_{2} / \mathrm{f}_{2}$. 


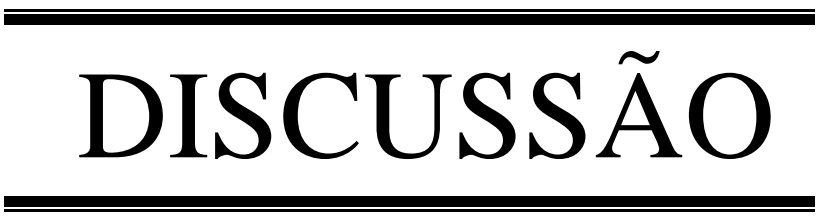




\section{DISCUSSÃO}

A espectrografia demonstrou ser uma ferramenta versátil na análise acústica vocal, especialmente da nasalidade. É inegável que tal versatilidade é um reflexo de o espectrógrafo, atualmente, ser um programa computacional, que confere maior eficiência e aplicabilidade à espectrografia (Ball, 1993; Callou e Leite, 1990).

A inspeção do espectrograma sobre a tela do computador poupou tempo e foi mais fácil que no espectrograma impresso, como relataram Kent e Read (1992), ainda mais considerando que a qualidade e a satisfação gerados pelos dispositivos e suprimentos de impressão de imagens podem ser restritos e comprometedores. Estes autores afirmaram, também, que há precisão na extração das medidas de tempo e de freqüência pelo movimento dos cursores sobre a tela do computador. Isto é questionável, visto que não se tem um controle fino sobre o posicionamento do cursor, além do que se tem faixas onde se encontram os formantes, notadamente na análise em banda larga. E como bem reconheceram Behlau et al. (1988), a leitura do formante pelo valor mediano da região de freqüências não é ideal nem suficiente.

Na visão de Boone e McFarlane (1994) e Bradley (1997), pela espectrografia poderia-se medir ou verificar o julgamento clínico da hipernasalidade. Medir é um tanto complexo, pois não é possível isolar a nasalidade ou a hipernasalidade. O traço de nasalidade, seja ele inerente ao som articulado ou resultado de uma ressonância nasal excessiva, lingüisticamente inapropriada e presente em sons não-nasais hipernasalidade (SEIKEL et al. 2000), manifesta-se sobre todo o espectro vocálico.

Neste caso, a verificação seria mais plausível, pois a espectrografia revela regiões claras, esbranquiçadas, quando usados gradientes de coloração em branco/preto, 
equivalentes aos antiformantes e formantes nasais inexistentes na contraparte vocálica exclusivamente oral.

Segundo Hattori et al. (1958), em geral, a nasalização é caracterizada por um realce em componentes de baixa frequiência ou pelo aparecimento de uma faixa de frequiência na porção inferior do espectrograma. Neste estudo, esta afirmação não foi, via de regra, constatada. Talvez pela falta de experiência da pesquisadora, pelos recursos do programa computacional utilizado (que varia de fabricante para fabricante) ou pelo tipo (sustentada) e qualidade ([a] e [ẽe]) da amostra vocálica. As vogais em contextos lingüísticos, que levassem em conta a tonicidade silábica, a vizinhança consonantal, a duração segmental poderiam propiciar análises mais dinâmicas e evidentes do comportamento formântico.

Enxergando um valor, sobretudo qualititativo no uso da espectrografia, notadamente a digital, largamente difundida nos dias atuais, reconhece-se que ela deve ser somada a outras avaliações para uma análise completa da nasalidade - idéia também defendida por Jesus (1999).

Aqui, estas outras avaliações foram, no âmbito da análise acústica, o uso das técnicas FFT e LPC, que geralmente fazem parte do pacote dos programas computacionais destinados à análise acústica vocal, e à nasometria, além da primordial e insubstituível avaliação perceptivo-auditiva - apesar da dificuldade de a caracterizar e estabelecer parâmetros claros, definidos e precisos, pois é decorrente da saúde auditiva, da experiência clínica e de processos psico-físico-lingüísticos não totalmente desvendados.

No estudo de Behlau et al. (1988) para a vogal [a] do PB, isolada, de mulheres $(n=30)$ adultas e saudáveis foram encontrados os valores médios do $F_{1}=956 \mathrm{~Hz}$ $( \pm 132,52)$, do $F_{2}=1634 \mathrm{~Hz}( \pm 240,57)$ e do $F_{3}=2721 \mathrm{~Hz}( \pm 297,31)$. Na dissertação de Jesus (1999), as mulheres ( $n=2)$ apresentaram para a mesma vogal as médias do $F_{1}=904$ $\mathrm{Hz}$, do $F_{2}=1399 \mathrm{~Hz}$ e do $F_{3}=2669 \mathrm{~Hz}$. Em seu artigo de 2002, Jesus divulgou os mesmos valores para um número de 5 mulheres. No presente estudo, os resultados do grupo CON podem ser comparados aos anteriores, visto ser constituído por mulheres sem comprometimentos morfo-funcionais para fala/voz: $F_{1}=946 \mathrm{~Hz}( \pm 104), F_{2}=1580$ $\mathrm{Hz}( \pm 77)$ e $\mathrm{F}_{3}=2863 \mathrm{~Hz}( \pm 177)$. Veja que os valores encontrados estão (muito) 
próximos daqueles citados nos estudos anteriores, especialmente os de Behlau et al. (1988), que possui o mesmo número de amostras vocálicas aqui analisadas. Chama a atenção, ainda, a variabilidade expressa pelo desvio-padrão, que é compatível entre os dois estudos.

Jesus (1999) encontrou para as mulheres portadoras de fissura palatina operada $(n=5)$ e sem palatoplastia secundária: $F_{1}=962 \mathrm{~Hz}, F_{2}=1563 \mathrm{~Hz}, F_{3}=2693 \mathrm{~Hz}$ e Fnasal= $656 \mathrm{~Hz}$. Para as mulheres portadoras de fissura palatina operada (PFR, n=21) deste estudo, obteve-se: $\mathrm{f}_{1}=887 \mathrm{~Hz}, \mathrm{f}_{2}=1634 \mathrm{~Hz}$ e $\mathrm{f}_{3}=2700 \mathrm{~Hz}-$ valores próximos aos de Jesus. Porém, não se evidenciou o Fnasal, porque no procedimento de Jesus, quando a envoltória LPC não detectava a região que a envoltória FFT mostrava-se saliente, ou seja, LPC delineava um vale e a FFT um cume, posicionava o cursor sobre a harmônica mais proeminente e conseguia seu valor de freqüência. Desta forma, adquiriu o formante nasal. $\mathrm{O}$ referido procedimento não foi aqui adotado, porque se acreditou que o formante nasal só poderia ser realmente determinado com a aplicação de filtragens nas quais se pudesse isolar os formantes orais e a atuação dos antiformantes - não envolvida neste trabalho.

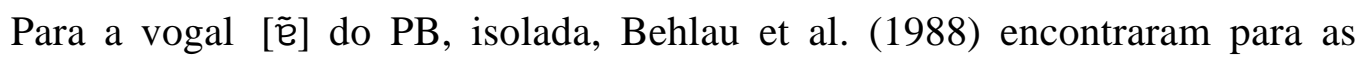
anteriormente referidas mulheres: $F_{1}=817 \mathrm{~Hz}( \pm 77,59), F_{2}=1642 \mathrm{~Hz}( \pm 169,58)$ e $F_{3}=$ $2764 \mathrm{~Hz}( \pm 184,20)$. Jesus $(1999,2002)$ apresentou: $F_{1}=343 \mathrm{~Hz}, F_{2}=1370 \mathrm{~Hz}$ e $F_{3}=$ $3183 \mathrm{~Hz}$. Os valores do grupo CON do presente estudo foram: $F_{1}=488 \mathrm{~Hz}( \pm 132), F_{2}=$ $1533 \mathrm{~Hz}( \pm 142), F_{3}=3039 \mathrm{~Hz}( \pm 255)$. Vê-se que há discrepância no valor de $F_{1}$ entre este estudo e o de Behlau et al., mas não em relação ao de Jesus. Talvez isto possa ser justificado pela forma de análise acústica comum com esta última: associação entre espectrografia, FFT e LPC e o fato de Behlau et al. terem medido o valor da freqüência formante no ponto médio do seu espectrograma.

Jesus (1999) obteve para as emissões de [ẽ] das portadoras de fissura palatina: $\mathrm{F}_{1}=516 \mathrm{~Hz}, \mathrm{~F}_{2}=1188 \mathrm{~Hz}, \mathrm{~F}_{3}=2648 \mathrm{~Hz}$ e Fnasal= $218 \mathrm{~Hz}$. O grupo de PFR deste estudo apresentou: $f_{1}=483 \mathrm{~Hz}( \pm 86), f_{2}=1589 \mathrm{~Hz}( \pm 263)$ e $f_{3}=3065 \mathrm{~Hz}( \pm 421)$. Há proximidade nos achados, à exceção do Fnasal. 
Não se deparou com estudos espectrográficos com portadoras de fissura palatina não operada, apenas nem em comparação com a nasometria e/ou avaliação percpetivoauditiva.

Em estudos envolvendo as características formânticas das vogais orais/nasais do PB e a percepção auditiva tem-se o estudo de Seara (2000). Contudo, a diferença nos procedimentos para avaliação perceptivo-auditiva, como a manipulação de sintetizadores de fala, inviabilizou comparações.

Para os 3 grupos estudados, CON, de PFA e de PFR, houve redução no valor do $\mathrm{F}_{1} / \mathrm{f}_{1}$ de [a] em relação à [ẽ ]. Esta redução em torno de $400 \mathrm{~Hz}$ para os grupos $\mathrm{CON}$ e de PFR, aproxima seus desempenhos que são diferentes do grupo de PFA, cuja redução acercou-se de $200 \mathrm{~Hz}$. Se a determinação do $F_{1}$ tem estrita relação com a constrição na cavidade oral formada entre a altura da língua (para a qual contribui a mandíbula) e o palato (Kent e Read, 1992; Pickett, 1980), em que constrições menores resultam em valores do $F_{1}$ maiores, a existência do palato para os grupos CON e de PFR concedelhes a possibilidade da maior redução de [a] para [ẽe que para o grupo de PFA. Ainda assim, este grupo mostra variação entre [a] e [ẽ], seja, vê-se que há mudança na inserção da nasalidade, mesmo com o palato estando aberto, indicando a contribuição de outro(s) articulador(es) - com significância estatística marginal - evidenciando que não só a atuação do palato e do EVF é responsável pelo traço de nasalidade. Para o qual, notadamente, a altura da língua/mandíbula (Moon e Kuehn, 1997) e quiçá algum movimento das paredes faríngeas contribuem para o combate à DVF. Isto também pode fundamentar a diferença significativa estatisticamente das vogais oral/nasal para o grupo de PFR (palato fechado/DVF). A redução do $F_{1} / f_{1}$ de [a] para [ẽ ] sendo estatisticamente significante entre o grupo CON e o de PFA, apenas, evidencia as diferenças extremas entre estes grupos: presença do palato/sem DVF e ausência do palato/DVF.

Permanecendo nas considerações sobre o $\mathrm{F}_{1} / \mathrm{f}_{1}$, viu-se maior variabilidade, pelo desvio-padrão, dos grupos de PFA e de PFR para a vogal [a] que para [ẽ], enquanto para o grupo CON ocorreu o inverso. Provavelmente isto é reflexo da variabilidade anatômico-funcional daqueles grupos; para o grupo $\mathrm{CON}$ talvez haja maior variabilidade nos graus de liberdade na movimentação destas mesmas estruturas para a 
vogal nasal, pois como afirmam Moon e Kuehn (1997), alterações na posição da mandíbula com mudanças na frequiência de fala podem aplicar forças ao palato mole e, conseqüentemente, em s ua atuação quanto ao mecanismo VF, por estar coordenado com outros articuladores. Contudo, como este desvio-padrão de $132 \mathrm{~Hz}$ da vogal nasal não é tão distante do desvio-padrão de $104 \mathrm{~Hz}$ da vogal oral, pode-se especular, ainda, que esta variabilidade nos graus de liberdade na movimentação das estruturas envolvidas possa responder pela observação das avaliadoras perceptivo-auditivas ao relatarem a experiência clínica em encontrar presença de nasalidade leve em emissões orais de falantes sem problemas na ressonância nasal, o que corrobora com a afirmação de Fant (1970) em que um certo grau de nasalização é provavelmente um atributo esperado para algumas vogais orais, em que o véu palatino tende a abaixar durante sua emissão, como em [a]. Esta nasalização seria uma compensação para a posição neutra da língua, associada a uma ampla região faríngea ou a um aumento do volume após o ponto de área mínima de corte transversal, senão a qualidade vocálica seria da vogal schwa ([§]) e não [a].

Pelas médias do $\mathrm{F}_{1} / \mathrm{f}_{1}$ para [a] viu-se que a do grupo de PFA é menor que do PFR que, por sua vez, é menor que do CON. Isto equivale dizer que o palato aberto/DVF permite maior atuação das propriedades nasais que tendem a reduzir o valor do $F_{1}$, denotando uma suavização espectral (HOUSE e STEVENS, 1956; MAEDA, 1982, 1993; KRAKOW e HUFFMAN, 1993; PICKETT, 1980; STEVENS et al., 1987).

A significância estatística entre as vogais oral e nasal dentro de cada grupo estudado, confirma que mesmo em situação de palato aberto/DVF (PFA) tanto quanto fechado/DVF (PFR), a emissão das vogais é diferente: língua/mandíbula não ocupam as mesmas posições, reforçando a idéia de que a hipernasalidade é diferente e independente da nasalidade inerente à vogal nasal. É como se houvesse a nasalidade da vogal e a nasalidade em virtude da DVF. Isto remete ao registro de Curtis (1970) de que a literatura sobre desordens da fala e da voz freqüentemente refere-se a uma "ressonância nasal", de forma a parecer que existe uma ressonância nasal constante, independente do restante do trato vocal.

Quando da análise da vogal nasal para esta região do $\mathrm{F}_{1} / \mathrm{f}_{1}$, o menor valor médio é do grupo de PFR, do qual o grupo CON está (bem) próximo e o grupo de PFA possui 
o maior valor. A proximidade entre os valores de média dos grupos de PFR e CON para esta vogal, pode ser justificada pela existência do palato e, ao menos, alguma atuação semelhante do EVF.

$\mathrm{Na}$ região do $\mathrm{F}_{2} / \mathrm{f}_{2}$ como não houve significância estatística entre as vogais oral e nasal para cada grupo estudado nem na redução do seu valor de [a] para [̃̃], não há diferença significativa no deslocamento ântero-posterior da língua, responsável pelo $\mathrm{F}_{2}$ (Kent e Read, 1992; Pickett, 1980), tanto em relação à qualidade vocálica ([a] e [ẽ ] quanto para as condições palato fechado/sem DVF (CON), palato fechado/DVF (PFR) e palato aberto/DVF (PFA). Independente da significância estatística, o declive do $F_{2} / f_{2}$ de [a] para [ẽ] é compatível com os achados de Jesus (2002), que observou menor freqüência nesta região decorrente da nasalização.

Ainda nesta região de $\mathrm{F}_{2} / \mathrm{f}_{2}$, sendo a maior variabilidade em [a] dos grupos de PFA e de PFR, indica que o movimento ântero-posterior da língua é maior para aquelas com DVF, na tentativa de impedimento que as ondas acústicas invadam o trato nasal durante a articulação de sons orais, conforme destacaram Maeda (1993) e Moon e Kuehn (1997). O que não é necessário acontecer em [ẽ], onde as melhores condições anátomo-fisiológicas do grupo $\mathrm{CON}$ justificam sua maior variabilidade e a menor variabilidade dos demais grupos.

Veja que no aspecto variabilidade, de acordo com o desvio-padrão e com a qualidade vocálica (oral/nasal), o grupo CON sempre está em posição antagônica aos grupos de PFA e de PFR que, neste aspecto apresentam-se juntos. Ou seja, no movimento vertical $\left(\mathrm{F}_{1} / \mathrm{f}_{1}\right)$ e no horizontal $\left(\mathrm{F}_{2} / \mathrm{f}_{2}\right)$ da língua há mais variações em [a] para os grupos com DVF, que precisam remediar a hipernasalidade, enquanto que no grupo CON estes movimentos da língua ocorrem mais para a vogal nasal.

Diante da nasalidade na emissão vocal, evidenciando a inserção de antiressonâncias (HOUSE e STEVENS, 1956; KRAKOW e HUFFMAN, 1993; SCHWARTZ, 1968) e a atuação de antiformantes na região do F2 (CURTIS, 1970; FANT, 1970; PICKETT, 1980; STEVENS et al., 1987) ou em sua vizinhança (SEARA, 2000), houve o desaparecimento deste formante em 2 amostras vocálicas do grupo de PFA e em 1 do grupo CON. O que também aconteceu na região do $f_{3}$ para 1 integrante 
do grupo de PFA e de 2 integrantes do grupo de PFR, compatível com as afirmações de House e Stevens (1956), Pickett (1980) e Schwartz (1968).

Para Coleman Jr. (1963), Fant (1970) e Hattori et al. (1958), a nasalização leva a uma queda na freqüência do $F_{3}$. Entretanto, comparando-se a vogal oral à sua contraparte nasal, quanto ao $\mathrm{F}_{3} / \mathrm{f}_{3}$ houve aumento em seu valor de freqüência para os 2 dos grupos estudados, com o que corrobora os achados de Jesus (1999, 2000). Este aumento foi menor para o grupo CON do que para o grupo de PFR, o que pode estar vinculado à presença do palato, pois como colocam Hattori et al. (1958), o F3 está relacionado com a ressonância laringo-faríngea pela inclinação do véu palatino e Pickett (1980) afirma que, em geral, a localização e o espaçamento entre os formantes, a partir do $\mathrm{F}_{3}$, são mais estritamente correlacionados com o comprimento do trato vocal.

Pelo desvio-padrão, para ambas as vogais, a menor variabilidade do $F_{3} / f_{3}$ ocorreu para o grupo CON, mas a maior variabilidade na vogal oral foi do grupo de PFA, enquanto na vogal nasal foi do grupo de PFR. Isto faz pensar que a região do $\mathrm{F}_{3} / \mathrm{f}_{3}$ tem relação com a atuação/existência do EVF. Veja que na situação palato aberto/DVF a emissão da vogal oral sofre mais variações na tentativa de remediar a hipernasalidade; enquanto que na condição palato fechado/DVF há mais variações na emissão da vogal nasal - comportamento semelhante ao do grupo CON, que tem palato fechado/sem DVF.

Como, de forma geral, foi na região do $\mathrm{F}_{3} / \mathrm{f}_{3}$ que os 3 grupos apresentaram os maiores valores de desvio-padrão, é interessante notar que esta maior variabilidade na região de $\mathrm{F}_{3} / \mathrm{f}_{3}$ pode ter uma relação direta com o tamanho e o funcionamento do EVF. A presença do palato parece fazer toda a diferença para a região $d F_{3} / f_{3}$, pois seu resultado foi significativo em ambas vogais nas condições palato fechado/sem DVF e fechado/DVF e não sofreu conseqüências em caso de DVF pela ausência do palato.

É intrigante ver que nesta região de $f_{3}$ houve significância estatística entre a vogal oral e a nasal apenas para o grupo de PFR e não se poder inferir algo, visto que para os outros grupos não houve significância estatística.

As grandes extensões (diferenças entre mínimo e máximo) nas regiões formânticas podem significar erro na análise computadorizada ou refletir a variabilidade inerente à diversidade de falantes, tratos vocais (incluindo a cavidade nasal) e emissões 
vocálicas (COLEMAN Jr., 1963; JESUS, 1999; KRAKOW e HUFFMAN, 1993; SCHWARTZ, 1968). Há que se lembrar, ainda, que outras estruturas podem estar atuando quanto à nasalização como os sinus nasais, citados por Båvegård et al. (1993), Lindqvist e Sundberg (1972) e Stevens et al. (1987).

Diante da constatação de que não foi possível estabelecer fronteiras claras e definidas para a ausência, presença ou graus de hipernasalidade com características formânticas ${ }^{15}$, fica evidente a necessidade de mais estudos que considerem a largura de banda, que relacionem as faixas de atuação dos formantes e a audição humana, inclusive lidando não apenas com os valores em frequiências dos formantes, mas com seus parâmetros de amplitude/intensidade e energia - dando-se especial atenção às escalas e suas relações com os aspectos de produção e percepção sonora. Estudos deste tipo podem trazer resposta ao questionamento que Schwartz fez em 1968 indagando se todas as características resultantes da nasalização, especialmente as que ele encontrou (vide p.28-29) são importantes para a percepção da nasalidade. Ou, ainda, estes estudos podem aprofundar os achados de Seara (2000), que percebeu que um aumento em freqüência dos formantes da vogal nasal átona leva a uma maior aproximação dessa vogal à átona oral, inferindo que isto seria uma explicação para a vogal átona ter sido percebida como nasal nos experimentos perceptivo-auditivos, quando dobrada sua duração e em isolamento - o que também pode explicar a percepção de nasalidade em emissões orais de falantes sem DVF.

A nasometria, mesmo largamente difundida no meio científico (DALSTON et al., 1991, 1997; KATAOKA et al., 2001; LEWIS et al., 2000; SEAVER et al., 1991; SUGUIMOTO e PEGORARO-KROOK, 1995; WATERSON et al., 1999), não se mostrou eficaz para diferenciar a nasalidade dos 3 grupos estudados ao emitirem a vogal [a] sustentada, não sendo possível traçar paralelos sobre os seus achados nasométricos, a percepção auditiva e as características formânticas.

Isto abre espaço para o estudo desde a forma de coleta do sinal de fala pelo nasômetro e suas relações de captação da energia acústica e a energia dos formantes,

\footnotetext{
15 A única ressalva é o indício de algum limite na percepção da nasalidade ao se verificar que uma emissão de [a] do grupo CON, classificada com hipernasalidade ausente e moderada, tem o valor do $F_{1}$ em $1085 \mathrm{~Hz}$, estando este valor na faixa de $925 \mathrm{~Hz}$ a $1148 \mathrm{~Hz}$ que correspondeu à classificação hipernasalidade presente.
} 
especialmente em presença de nasalização. Revisão e reflexões sobre a arquitetura do equipamento, de captação e de processamento do sinal de fala e sua eficácia são igualmente pertinentes.

$\mathrm{O}$ que foi descrito e discutido até aqui torna profundamente compreensível a afirmação de Johnson (1997d) de que mesmo não havendo complexidade articulatória na produção de vogais nasalizadas, elas se apresentam mais complexas acústica e perceptivamente que as vogais orais.

Tal complexidade também se estende à terminologia referente à nasalidade, especialmente quando se tenta fazer conexões entre os conhecimentos lingüístico, articulatório, acústico e a ressonância nasal de fala, notadamente em caso de distúrbio.

Os sons nasais não estão presentes em todas as línguas e a nasalização nem constitui traço distintivo entre as palavras, como é para o PB, registrado por Camara Jr. (1970), que inclusive usa o termo nasalação e se manifesta diferentemente pelos vários estados brasileiros (Abaurre et al., 1996). Back (1973) reconhece a existência de vogais nasais enquanto fonemas e Ladefoged (2001) as define pela passagem de fluxo aéreo pelo nariz, nasalizando-as, pelo abaixamento do palato mole. Porém, bem coloca Curtis (1970) que a nasalização é decorrente de uma ação valvular, o que envolve as paredes faríngeas (MOON e KUEHN, 1997), que controla o acoplamento oro-faríngeo com a cavidade nasal. E, principalmente pelos achados aqui apresentados quanto ao grupo de PFA, em que os efeitos da nasalização mostram-se diferentes, ao menos na região do $f_{1}$,

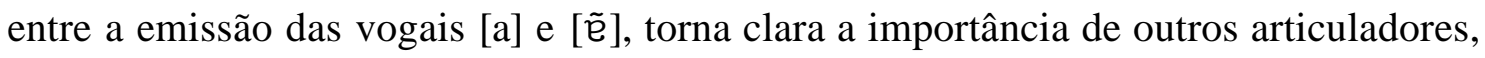
fundamentalmente a língua e, por conseguinte a mandíbula (MOON e KUEHN, 1997), pois mesmo possuindo características próprias, a cavidade nasal não age independentemente, mas em interação com as demais cavidades do trato vocal (CURTIS, 1970). Como para Maeda (1993) a língua em posição alta restringe o espaço velar, havendo menor abertura VF, relativamente, pode-se justificar a diferença signficante entre as vogais oral/nasal para o grupo de PFR na região do $f_{3}$. Ou, ainda, a participação da língua poderia ser explicada pelo modelo de ressoador duplo Helmholtz (Curtis, 1970).

A variabilidade do trato vocal, incluindo o nariz, entre os falantes, dificultando generalizações acerca da interação do acoplamento oro-nasal (KRAKOW e 
HUFFMAN, 1993) e a possibilidade de participação de outras estruturas como os sinus nasais (BÅVEGÅRD et al.,1993; LINDQVIST e SUNDBERG, 1972; STEVENS et al., 1987) leva à reflexão sobre as diversas configurações apresentadas pelos portadores de fissura palatina: amplitude da fissura quando não operada, presença de retalho faríngeo, profundidade da orofaringe, formatos da cavidade nasal, além da mobilidade do palato e de toda a musculatura orofacial envolvida, sem desatrelar os fatores estrutural e motorcomo ressaltou Folkins (1988), e suas conseqüências formânticas e perceptivo-auditivas (5/6 das participantes com retalho faríngeo foram classificadas sem hipernasalidade).

A variabilidade dos achados formânticos, da avaliação perceptivo-auditiva e da nasometria reforçam a variabilidade entre os falantes e de emissões vocálicas como as encontradas por Coleman Jr. (1963), Fant (1970), Jesus (1999) e Schwartz (1968). Para Carney e Morris (1971), é a variabilidade do tamanho da constrição velar para a nasalidade que impossibilita sua relação com a severidade da nasalidade. E para Folkins (1988) não é o tamanho do espaço VF, mas a relativa impedância acústica entre as cavidades oral e nasal e as variações das seções transversais de área e não o tamanho absoluto das constrições que imprimem as características acústicas do trato nasal nas emissões das quais participa. Vê-se que mais estudos sobre a dinâmica vocal para a nasalização são necessários.

Pela diferença estatística encontrada para as vogais oral e nasal nos grupos de PFA e de PFR, mesmo que marginalmente para o primeiro, evidencia que há a nasalidade inerente ao som nasal e uma imprópria lingüisticamente, a hipernasalidade, sendo pertinentes discussões como a proposta por Froeschels (1957).

Indo de encontro à afirmação de Casal et al. (2002) de que a espectrografia apresenta características acústicas interessantes para a dimensão articulatória, além de ser útil para estudos comparativos intergrupos com portadores de anomalias craniofaciais e que há poucos estudos de análise espectrográfica com portadores de fissura palatina, espera-se que o presente estudo tenha fornecido alguma contribuição para os conhecimentos desta área. 


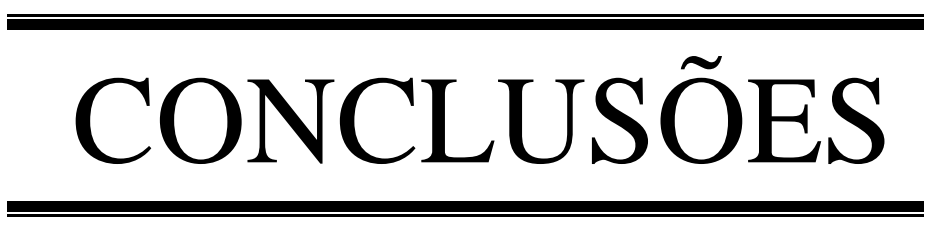




\section{CONCLUSÕES}

Foram encontradas as seguintes características espectrográficas da hipernasalidade de fala de mulheres portadoras de fissura palatina: inserção de formantes nasais e antiformantes dentre os formantes orais, especialmente na vizinhança do $F_{1}$, chegando, em alguns casos, a suprimir o $F_{2}$ e/ou o $F_{3}$, havendo diferenças entre as portadoras de fissura palatina com palato aberto e com palato operado nas emissões da vogal oral [a] ou da nasal [e]. Não houve correspondência direta desses achados com a nasometria nem com a avaliação perceptivo-auditiva e nem destas entre si.

\subsection{Outras conclusões}

Diante da nasalização vocálica do [a], pode-se generalizar que há:

- Abaixamento da freqüência do $\mathrm{F}_{1}$;

- Manutenção ou desaparecimento do $\mathrm{F}_{2}$;

- Aumento do valor de freqüência ou desaparecimento do $\mathrm{F}_{3}$;

- Surgimento e atuação de formantes extras: formante nasal e antiformantes.

Quanto à espectrografia na análise de formantes:

- É eficaz quando associada a outras técnicas como FFT/LPC;

- Requer prática. 


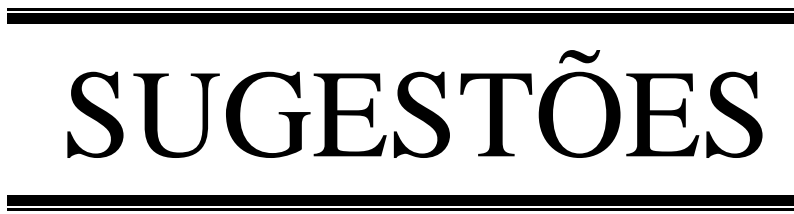




\section{SUGESTÕES}

Além das sugestões de outros estudos colocadas na Discussão, sugere-se ainda:

- Estudo sobre outros parâmetros como a duração, a amplitude/intensidade, a energia dos formantes e sua relação com a audição humana;

- Percepção da nasalidade em vogais sustentadas nasais e em contexto silábico, comparando à sua contraparte oral;

- Estudos sobre as configurações do trato oral com o uso de próteses de palato ou dentária, das propriedades acústicas destas e suas conseqüências formânticas;

- Estudo comparativo da envoltória LPC no par vocálico oral/nasal expondo as regiões de suavização, vales e proeminências;

- Investigação de como se mantém a identidade vocálica nos casos em que, diante da nasalização, há o desaparecimento do $\mathrm{F}_{2}$ e/ou do $\mathrm{F}_{3}$;

- Associação de análise acústica dos formantes e articulação pela cinefluoroscopia;

- Revisão da literatura e proposta de índices, escores ou quantificadores de nasalidade com base nos formantes e suas relações;

- Aprofundamento na teoria e no modelamento do trato vocal com a inserção da cavidade nasal, considerando os sinus nasais e a dinâmica interativa do sistema. 


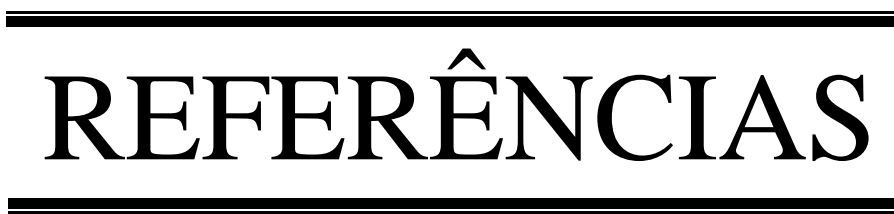




\section{REFERÊNCIAS}

ABAURRE, M.B.M.; PAGOTTO, E.G.; LIMA, S.C.L. (1996). Nasalização no Português do Brasil. In: KOCH, I.G.V. (org.). Gramática do Português Falado, vol. VI: Desenvolvimentos, Campinas: Editora da Unicamp/FAPESP, p.495-526.

ÅBYHOLM, FE. (1978). Cleft lip and palate in norwegian population. II. A numerical study of 1555 CLP - patients admitted for surgical treatment. Scand J Plast Reconstr Sug; 12:35-43.

AMARAL, A.S.; GENARO, K.F. (1996). Análise da fala em indivíduos com fissura lábiopalatina operada. Pró-Fono; 8: 36-46.

BACK, E. (1973). São fonemas as vogais nasais do português??. Construtura: Revista de Lingüística, Língua e Literatura, Curitiba: FTD, ano 1, n.4, p.297-317.

BALL, M.J. (1993). Phonetics for Speech Pathology, 2a . edição, Whurr Publishers Ltd: Londres, , 302p.

BARBOSA, P.A. (2003). Comunicação Pessoal (durante a análise das amostras de fala e em cursos ministrados), Prof. Dr., Foneticista Docente do Laboratório de Fonética e Psicolingüística do Instituto de Estudos da Linguagem da Universidade de Campinas (LAFAPE/IEL/UNICAMP).

BÅVEGÅRD, M; FANT, G.; GAUFFIN, J.; LILJENCRANTS, J. (1993). Vocal tract sweeptone data and model simulations of vowels, laterals and nasals. Q. Prog. Status Rep., Speech Transm. Lab., R. Inst. Technol. Stockh, v.4, p.43-76.

BEHLAU, M.S.; PONTES, P.A.; GANANÇA, M.M.; TOSI, O. (1988). Análise espectrográfica de formantes das vogais do português brasileiro. Acta Awho, v.7, n.2, p.74-85.

BOONE, D.R. \& McFARLANE, S.C. (1994). A Voz e a Terapia Vocal, 5a . edição, Artes Médicas: Porto Alegre, Tradução: Sandra Costa, , 300p.

BORBA, F. da S. (1971). Pequeno Dicionário de Lingüística Moderna, Iniciação Científica, v.31, São Paulo: Editora Nacional e Editora da Universidade de São Paulo, p.100. 
BRADLEY D. (1997). Congenital and acquired velopharyngeal inadequacy. In: Bzoch $\mathrm{KR}$, editor Communicative disorders related to cleft lip and palate. $4^{\mathrm{Th}}$ ed., Texas: ProEd;. p.223-43.

BUDER, E.H. (2000). Acoustic Analysis of Voice Quality: A Tabulation of Algorithms 1902-1990, cap. 9, In: KENT, R.D. \& BALL, M. Voice Quality Measurement, Singular: Canadá, , 492p.

BUENO, S. (2000). Minidicionário Inglês-Português/Português-Inglês, São Paulo: FTD, 959p.

BZOCH, K.R. (1997). Clinical assessment, evaluation, and management of 11 categorical aspects of cleft palate speech disorders. In:

Communicative disorders related to cleft lip and palate., 4a. ed., USA: Pro-ed, p.261311 .

CALLOU, D. \& LEITE, Y. (1990). Iniciação à Fonética e à Fonologia, Jorge Zahar Editor: Rioi de Janeiro, 125p.

CAMARA JR., J.M. (1970). As vogais e as consoantes portuguesas, cap.5, In: Limitada, p.29-42. Estrutura da Língua Portuguesa, Petrópolis, RJ: Editora Vozes

CAPELOZZA FILHO, L.; SILVA FILHO, O.G. da. (1992). Fissuras lábio-palatais. In: Petrelli E, coordenador Ortodontia para fonoaudiologia. Curitiba: Lovise; p.195-240.

CARNEY, P.J.; MORRIS, H.L. (1971). Structural correlates of nasality. Cleft Palate J., v.8, Jul., p.307-21.

CASAL, C.; DOMÍNGUES, C.; FERNÁNDEZ, A.; SARGET, R.; MARTÍNEZCELDRÁN, E.; SENTÍS-VILALTA, J.; GAY-ESCODA, C. (2002). Spectrographic measures of the speech of Young children with cleft lip and cleft palate. Folia Phoniatr Logop, v.54, p.247-257.

CASSEL, M.D.; ELKADI, H. (1995). Anatomy and physiology of the palate and velopharyngeal structures, cap.3. In: Shiprintzen, R.J; Bardach, J. Cleft palate speech management a multidisciplinary approach, USA: Mosby. p.50.

CHOI, H-S.; PARK, Y-J.; KIM, K-M. (2001). Devising an objective nasal vibration test for nasal resonatory disorders. Journal of Voice, v.15, n.2, p.220-30.

COLEMAN JR., R.O. (1963). The effect of changes in width of velopharyngeal aperture on acoustic and peceptual properties of nasalized vowels. A dissertation submitted to the graduate school in partial fulfillment of the requirements for the degree Doctor of Philosophy - Field of Speech Pathology, Northwestern University, Evanston, Illinois, August 1963.

CRITELLI, D.M. (1996). O falar da linguagem. In: OLIVEIRA, S.L.; PARLATO, E.M.; RABELLO, S. (org.). O falar da linguagem, Série Linguagem. São Paulo: Lovise, p.63-7.

CURTIS, J.F. (1970). The acoustics of nasalized speech. Cleft Palate J, v.7, p.380-96. 
D'ANTONIO, L.L. \& SCHERER, N.J. (1995). The Evaluation of Speech Disorders Associated with Clefting, cap. 10, In: SHPRINTZEN, R.J. \& BARDACH, J. Cleft Palate Speech Management: A Multidisciplinary Approach, Mosby: Estados Unidos da América, 380p.

DALSTON, R.M. (1997). The use of nasometry in the assessment and remediation of velopharyngeal inadequacy, In: BZOCH, K.R. Communicative disorders related to cleft lip and palate, 4a. ed., USA: Pro-ed, p.331-46.

DALSTON, R.M.; WARREN, D.W.; DALSTON, E.T. (1991). Use of nasometry as a diagnostic tool for identifying patients with velopharyngeal impairment. Cleft Palate Craniofacial Journal, v.28, n.2, April, p.184-9.

DICKSON, D.R. (1962). An acoustical study of nasality. J. Speech Hearing Res., v.5, p.103-11.

DI NINNO, C.Q. de M. S. \& GENARO, K.F. (1998). Fissura de palato submucosa. Pró-fono: revista de atualização científica, v.10, n.2, set., p.28-33.

DUNN, H.K. (1950). The calculation of vowel resonances, and an electrical vocal tract. The Journal of the Acoustical Society of America, v.22, n.6, Nov.,p.740-53.

DUTKA, J. (1992). Evaluation of a modified procedure for use of Kay Elemetric's Nasometer for nasometric assessment of children younger than five years of age. [Thesis of Master, University of Florida], 59p.

FANT, G. (1958). Modern instruments and methods for acoustic studies of speech. Suécia: Acta Polytechnica Scandinavica, 81p.

FANT, G. (1970). Nasal sounds and nasalization, cap. 2.4, In: Acoustic theory of speech production, 2a.ed., Paris: Mouton, p.139-161.

FARMER, A. (1984). Spectrography, cap. 2, In: CODE, C. \& BALL, M., Experimental Clinical Phonetics: Investigatory Techniques in Speech Pathology and Therapeutics, Croom Helm: Grã-Bretanha, 254p.

(1997). Spectrography, cap.2, In: BALL, M.J. \& CODE, C. Instrumental clinical phonetics, 1a. Ed., EUA: Singular Publishing Group Inc.; p.22-63.

FLETCHER, S.G. (1970). Theory and instrumentation for quantitative measurement of nasality. Cleft Palate J., v.7, p.601-9.

(1977). Cleft lip and palate research: an undated state of the art. Section V. Resonance and phonation. Cleft Palate J., v.14, n.4, Oct., p.313-20.

FOLKINS, J.W. (1988). Velopharyngeal nomenclature: incompetence, inadequacy, insufficiency, and dysfunction. Cleft Palate J., 25(4): 413-6.

FRASER, F.C. (1960). Some experimental and clinical studies on the causes of congenital clefts of the palate and the lip. Arch Pediatr, 77:151-6. 
FRASER, F.C. (1970). The genetics of cleft lip and palate. Am J Hum Genet; 22:33652.

FROESCHELS, E. (1957). Nariz e nasalidade. Archives of Otolaryngology, v.66, Dec., p.629-33.

FRY, D.B. (1979). Acoustic analysis: the sound spectrograph, cap.9, In: . The physics of speech, Londres: Cambridge University Press, p.89-

110.

FUCCI, D.J.; LASS, N.J. (1999). Acoustics of Speech Production, Cap.5. Fundamentals of Speech Science, USA: Allyn and Bacon, p.129-160.

FUJIMURA, O. (1990). Methods and goals of speech production research. Language and Speech, v.33, n.3, p.195-258.

FUJIMURA, O.; ERICKSON, D. (1997). Acoustic Phonetics, Cap.3. In: HARDCASTLE, W. \& LAVER, J. (editores). The Handbook of Phonetic Sciences, Londres: Blackwell Publishers. p.65-115.

GLASS, J.R. (1984). Nasal consonants and nasalized vowels: an acoustic study and recognition experiment. (Dissertação de mestrado em Ciência e Engenharia Elétrica no Massachusetts Institute of Technology), 151p.

GREENE, J.C. (1964). Epidemiologic study of cleft lip and cleft palate in four states. $J$ Am Dent Assoc; 68:387-404.

$76: 1350-6$.

(1968). Epidemiologic research: 1964-1967. J Amer Dent Assoc;

GOLDING-KUSHNER, K.J. (1995). Treatment of articulation and resonance disorders associated with cleft palate and VPI, cap. 16, In: SHPRINTZEN, R.J. \& BARDACH, J. Cleft Palate Speech Management: A Multidisciplinary Approach, Mosby: Estados Unidos da América, p.327-51.

HANAYAMA, E.M. et al. (2001). Ressonância Nasal, cap. 4, In: PINHO, S.M.R. Tópicos em Voz, Guanabara Koogan: Rio de Janeiro, 154p.

HARDIN-JONES, M.A. et al. (1993). Long-term speech results of cleft palate patients with primary palatoplasty. Cleft Palate Craniofac J; 30:55-63.

HATTORI, S.; YAMAMOTO, K.; FUJIMURA, O. (1958). Nasalization of vowels in relation to nasals. J. Acous. Soc.Amer., v.30, p.267-74.

HENNINGSSON, G. (1988). Impairment of Velopharyngeal Function in Patients with Hypernasal Speech: a clinical and cineradiographic study, from the Department of Logopedics and Phoniatrics and from the Department of Oral Radiologia, Karolinska Institutet, Stockholm, Sweden, 553p.

HIRSCHBERG, J. (1986). Velopharyngeal insufficiency. Folia Phoniatr, 38:221-76. 
HONG, K.H., KWON, S.H. e JUNG, S.S. (1997). The assessment of nasality with a nasometer and sound spectrography in patients with nasal polyposis, OtolaryngologyHead and Neck Surgery, 117(4): 343-348, Oct.

HOUSE, A.S. \& STEVENS, K.N. (1956). Analog studies of the nasalization of vowels. Journal of Speech and Hearing Disorders, v.21, n.2, June, p.218-32.

IREGBULEM, L.M. (1982). The incidence of cleft lip and palate in Nigeria. Cleft Palate J, 19:201-5.

JESUS, M. de S. V. (1999). Estudo fonético da nasalidade vocálica em falantes normais e com fissura de palato: enfoque acústico. [Dissertação apresentada ao Programa de Pós-graduação em Letras: Estudos Lingüísticos,da UFMG], 178p.

(2002). Estudo fonético da nasalidade vocálica. In: REIS, C., org. Estudos em fonética e fonologia do Português. Belo Horizonte, FALE - UFMG. (Série Estudos Lingüísticos, v.5). p.205-223.

JOHNSON, K. (1997a). Digital signal processing, Cap.2. In: Acoustic and Auditory Phonetics, USA: Blackwell Publishers Inc. p.22-48.

(1997b). The acoustic theory of speech production: deriving schwa, Cap.4. In: Acoustic and Auditory Phonetics, USA: Blackwell Publishers Inc. p.63-90.

(1997c). Vowels, Cap.5. In: Acoustic and Auditory Phonetics, USA: Blackwell Publishers Inc. p.91-109.

(1997d). Nasals and Laterals, Cap.8. In:Acoustic and Auditory Phonetics, USA: Blackwell Publishers Inc. p.141-160.

JOHNSON, P.E. (1987). Surgical repair of cleft lip and palate. In: Pirruccelo FW, editor. Cleft lip and Palate. Springfield: Charles C. Thomas; p.69-100.

KATAOKA, R.; MICHI, K.; OKABE, K.; MIURA, T.; YOSHIDA, H. (1996). Spectral properties and quantitative evaluation of hypernasality in vowels, Cleft PalateCraniofacial Journal, 33(1): 43-50, Jan.

KATAOKA, R.; WARREN, D.W.; ZAJAC, D.J.; MAYO, R.; LUTZ, R.W. (2001). The relationship between spectral characteristics and perceived hypernasality in children, Journal of the Acoustical Society of America, 109(5): 2181-2189, May.

KELSO, J.A.S. (1995). Dynamic Patterns: the self-organization of brain and behavior, Massachusets: Massachusetts Institute of Technology, 334p.

KENT, L. (1966). The effects of oral-to-nasal coupling on the peceptual, physiological, and acoustical characteristics of vowels. Unpublished Ph.D. dissertation, University of Iowa apud CURTIS, J.F. (1970). The acoustics of nasalized speech. Cleft Palate J, v.7, p.380-96.

KENT, R.D. (1993). Vocal Tract Acoustics. Journal of Voice, v.7, n.2, p.97-117. 
KENT, R.D. (1997). Acoustic Phonetics, Cap. 9. In: Speech Sciences, San Diego: Singular. p.329-67.

KENT, R.D.; READ, C. (1992). The acoustic analysis of speech, San Diego, California, Singular Publishing Group. Inc. N páginas ou especificar os capítulos-foi usado o 2: p.13-40.

KOENIG, W. et al. (1946) The Sound Spectrograph, cap. 4, In: FRY, D.B. Acoustic Phonetics: A course of basic readings, Cambridge University Press: Grã-Bretanha, 1976, 469p.

KRAKOW, R.A.; HUFFMAN, M.K. (1993). Instruments and techniques for investigating nasalization and velopharyngeal function in the laboratory: an introduction. In: HUFFMAN, M.K.; KRAKOW, R.A. (eds.). Phonetics and phonology: nasals, nasalization, and the velum, v.5, San Diego, Califórnia: Academic Presss, Inc..

KUMMER, A.W.; CURTIS, C.; WIGGS, M.; LEE, L.; STRIFE, J.L. (1992). Comparison of velopharyngeal gap size in patients with hypernasality, hypernasality and nasal emission, or nasal turbulence (rustle) as the primary speech characteristic. Cleft Palate J., 29(2):152-6.

LADEFOGED, P. (1982). A Course in Phonetics, 2a . edição, Harcourt Brace Jovanovich: Estados Unidos da América, , 300p. (2001). A course in Phonetics, 4a.ed., USA: Harcourt College Publishers.

LESSA, S. (1996). Insuficiência Velofaringeana, cap. 27, In: ZANINI, S.A. et al. Tratamento das Fissuras Labiopalatinas, 2a . edição, Revinter: Rio de Janeiro, 344p.

LEWIS, K.E.; WATTERSON, T.; QUINT, T. (2000). The effect of vowels on nasalance scores. Cleft Palate Craniofacial Journal, v.37, n.4, July, p.130-5.

LINDBLOM, B.E.; LUBKER, J.F.; PAULI, S. (1977). An acoustic-perceptual method for the quantitative evaluation of hypernasality. J Speech Hear Res, v.20, n.3, Sep., p.485-96.

LINDQVIST, J. \& SUNDBERG, J. (1972). Acoustic properties of the nasal tract. STLQPSR, v.1, p.13-7.

LOPES, E. (1989). Fundamentos da Lingüística Contemporânea, São Paulo: Cultrix, p.156-7.

LYONS, J. (1979). Introdução à Lingüística Teórica, trad.: Rosa Virgínia Mattos e Silva e Hélio Pimentel, São Paulo: Cia. Editora Nacional/Editora da Universidade de São Paulo, p.192.

MAEDA, S. (1982). Acoustic cues of vowel nasalization: a simulation study. Comunicação feita no 104 Encontro da Sociedade Acústica da América, Orlando/Flórida, Novembro, p.27-36.

MAEDA, S. (1993). Acoustics of vowel nasalization and articulatory shifts in French nasal vowels. In: HUFFMAN, M.K.; KRAKOW, R.A. (eds.). Phonetics and phonology: 
nasals, nasalization, and the velum, v.5, San Diego, Califórnia: Academic Presss, Inc., 1993.

McWILLIAMS, B.J.; MORRIS, H.L.; SHELTON, R.L. (1990). Instrumental for assessing the velopharyngeal mechanism. In: McWILLIAMS, B.J.; MORRIS, H.L.; SHELTON, R.L. (editores). Cleft palate speech. Philadelphia: Decker, p.163-90.

McWILLIAMS, B.J.; MUSGRAVE, R.H. (1970). Diagnosis of speech problems in patients with cleft palate. Br Commun Disord, 5:26-32.

MENEGOTTO, B.G.; SALZANO, F.M. (1991). Clustering of malformations in the families of South American oral cleft neonates. Cleft Palate Craniofac J., 28(4)?373-7.

MINERVINO-PEREIRA, A.C.M. (2000). Auto-conceito e auto-estima em indivíduos comfissura lábio-palatina: influência do tipo de fissura e do tempo de convivência com a mesma. [Dissertação de Mestrado apresentada no HRAC/USP, em Distúrbios da Comunicação Humana].

MODOLIN, M.L.A.; CERQUEIRA, E.M.M. (1997). Etiopatogenia. In: Altmann EBC, organizadora, Fissuras labiopalatinas. 4 ed, Carapicuíba: Pró-Fono; p. 25-30.

MOON, J.B.; KUEHN, D.P. (1997) Anatomy and Physiology of Normal and Disordered Velopharyngeal Function for Speech, cap. 2, In: BZOCH, K.R. Communicative Disorders: Related to Cleft Lip and Palate, $4^{\mathrm{a}}$. edição, Pro-ed: Texas, $580 \mathrm{p}$.

MORRIS, H.L. (1973). Velopharyngeal competence and primary cleft palate surgery, 1960-1971: a critical review. Cleft Palate J; 10:62-71.

NAGEN FILHO, H. et al. (1968). Contribuição para o estudo da prevalência das más formações congênitas lábio-palatais na população escolar de Bauru. Rev Fac Odont São Paulo; 6:111-28.

NATSUME, N.; SUZUKI, T.; AOKI, K.; MAKINO, S.; MIZUTANI, J.; KAWAI, T. (1984). Epidemiologic studies on cleft lip and/or palate. I. The classification of cleft types in the general population. Aichi Gakuin Daigaku Shiga; 22:455-60.

NEEL, J.V. (1958). A study of major congenital defects in japanese infants. Am J Hum Genet; 10:398-445.

PEGORARO-KROOK, M.I. (1995). Avaliação da fala de pacientes que apresentam inadequação velofaríngea e que utilizam prótese de palato. São Paulo. 130p. [Tese (Doutor) - Universidade Federal de São Paulo - Escola Paulista de Medicina].

PEGORARO-KROOK, M.I. (1998). Comunicações pessoais, durante as aulas da disciplina e estágio supervisionado "Fissura Lábio-Palatina", do Curso de Fonoaudiologia da Faculdade de Odontologia de Bauru da Universidade de São Paulo (FOB/USP).

PETERSON, G.E. (1959). Vowel formant measurements, Journal of Speech and Hearing Research, v.2, n.2, June, p.173-83. 
PETERSON-FALZONE, S.J.; HARDIN-JONES, M.A.; KARNEL, M.P. (2001). Cleft Palate Speech, Third Edition, St. Louis: Mosby, chapter 1, p.1-30.

PICKETT, J.M. (1980). The sounds of speech communication: a primer of acoustic phonetics and speech perception. Baltimore: University Park Press, 249p.

PICCOLI, E.M.H. (1998). Fissura Lábio-palatina: Considerações na Prática Clínica, cap. 7, In: PINHO, S.M. Tratando os Distúrbio da Voz, Guanabara Koogan: Rio de Janeiro, 128p.

PINHO, S.M. \& CAMARGO, Z. (2001). Introdução à Análise Acústica da Voz e da Fala, cap. 2, In: PINHO, S.M.R. - Tópicos em Voz, Guanabara Koogan: Rio de Janeiro, $154 \mathrm{p}$.

PRÓTESE DE PALATO, Setor de (2003). Arquivo de fotos, setor do HRAC/USP.

PULKKINEN, J., HAAPANEN, M.L.; LAITINEN, J.; RANTA, R. (2001). Velopharyngeal function from the age of three to eight years in cleft palate patients, Folia Phoniatrica et Logopaedica, 53(2): 93-98, Mar-Apr.

RUSSO, I.; BEHLAU, M. (1993). Percepção da Fala: Análise Acústica do Português Brasileiro, Lovise: São Paulo, 57p.

SCHWARTZ, M.F. (1968). The acoustics of normal and nasal vowel production. Cleft Palate J., v.5, p.125-140.

SEARA, I.C. (2000). Estudo acústico-perceptual da nasalidade das vogais do português brasileiro. Florianópolis. 271p. [Tese (Doutor) - Universidade Federal de Santa Catarina].

SEAVER, E.J.; DALSTON, R.M.; LEEPER, H.A.; ADAMS, L.E. (1991). A study of nasometric values for normal nasal resonance. Journal of Speech and Hearing Research, v.34, Aug., p.715-21.

SEIKEL, J.A.; KING, D.W.; DRUMRIGHT, D.G. (2000). Physiology of articulation, cap.8, In: . Anatomy and physiology: for speech, language, and hearing, 2a.ed., San Diego, Califórnia: Singular Publishing Group, p.357-90.

SELL, D.; HARDING, A.; GRUNWELL, P. (1994). A screening assessment of cleft palate speech (Great Ormond Street Speech assessment), European Journal of Disorders of Communication, v.29, n.1, p.1-15.

SERVIÇO DE BIBLIOTECA/EESC/USP (2002). Diretrizes para elaboração de dissertações e teses na EESC-USP, $3^{\mathrm{a}}$. Ed., 59p.

SHPRINTZEN, R.J. (1995). A new perspective on clefting, cap.1, In: SHPRINTZEN, R. J. \& BARDACH, J., Cleft Palate Speech Management: a multidisciplinary approach, USA: Mosby, p.1-15.

SIEGEL, S. (1956). Nonparametric Statistics for the behavioral sciences, USA: McGRAW-HILL BOOK COMPANY, 312p.. 
SPIEGEL, M.R. (1974). Estatística, 7ª Ed., Brasil: McGRAW-HILL DO BRASIL, Ltda., Tradução: Pedro Cosentino, Revisão: Carlos José Pereira de Lucena, 580p..

SKOLNICK, M.L. (1975). Velopharyngeal function in cleft palate. Clin Plast Surg; 2:285-97.

SPINA, V.; PSILLAKIS, J.M.; LAPA, F.S.; FERREIRA, M.C. (1972). Classificação das fissuras lábio palatais: sugestões de modificação. Rev Hosp Clin Fac Med, São Paulo; 27:5-6.

SOUZA-FREITAS, J.A. de. (1974). Centro de Pesquisa e Reabilitação de Lesões Lábio-Palatais. Bauru: Hospital de Reabilitação de Anomalias Craniofaciais, Universidade de São Paulo.

STEVENS, K.N.; FANT, G.; HAWKINS, S. (1987). Some acoustical and perceptual correlates of nasal vowels, In: R. Channon \& L. Shockey (eds.), For Ilse Lehiste, p.24154, Dordrecht, Holanda: Foris.

SUGUIMOTO, M.L.C.P.; PEGORARO-KROOK, M.I. (1995). Avaliação nasométrica em adultos normais falantes do português brasileiro. Pró-fono Revista de Atualização Científica, v.7, n.2, p.03-07.

TABITH Jr., A. (1997). O Esfíncter Velofaríngeo, Distúrbios da Comunicação Humana, São Paulo, 8(2): 135-50, jun.

TELES-MAGAlHÃeS, L.C. (2002). Comunicação Pessoal, Profa. Dra., Docente do Curso de Fonoaudiologia da Faculdade de Odontologia de Bauru da Universidade de São Paulo (FOB/USP).

TRINDADE, I.E.K.; TRINDADE Jr., A.S. (1996). Avaliação Funcional da Inadequação Velofaríngea, cap. 26, In: ZANINI, S.A. et al. Tratamento das Fissuras Labiopalatinas, $2^{a}$. edição, Revinter: Rio de Janeiro, , 344p.

UEMEOKA, E. (2003). Slides de sua palestra sobre Fissura Lábio-Palatina, fonoaudióloga do HRAC/USP.

VANDEMARK, D.R.; HARDIN, M.A. (1985). Longitudinal evaluations of articulation and velopharyngeal competence of patients with pharyngeal flaps. Cleft Palate $J$, 22:163-72.

WATTERSON, T.; LEWIS, K.E.; FOLEY-HOMAN, N. (1999). Effect of stimulus length on nasalance scores. Cleft Palate Craniofacial Journal, v.36, n.3, May, p.243-47.

WILliAMS, B. (1993). Biostatistics, 5ª Ed., Great Britain: Chapman \& Hall, 201p..

WITZEL, M.A. Communicative impairment associated with clefting, cap. 8, In: SHPRINTZEN, R.J. \& BARDACH, J. (1995). Cleft Palate Speech Management: A Multidisciplinary Approach, Mosby: Estados Unidos da América, p.137-66.

ZULETA, P.P.B.; FERREIRA, L.P.; CRESPO, C. (1997). Estudo das configurações laríngeas e do esfíncter velofaríngeo de indivíduos com fissura labiopalatina. Pró-fono: revista de atualização científica, 9(2):22-30. 


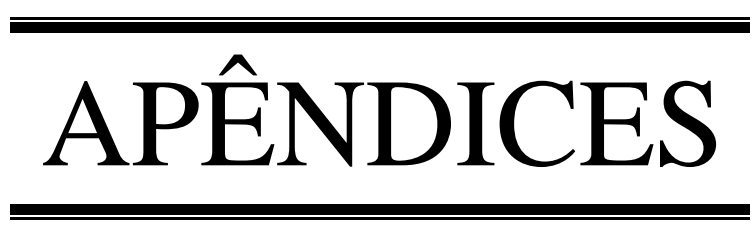


APÊNDICE A - Termo de consentimento livre e esclarecido apresentadoàs portadoras de fissura palatina.

TERMO DE CONSENTIMENTO LIVRE E ESCLARECIDO

para participação na pesquisa:

"PERFIL ESPECTROGRÁFICO DA HIPERNASALIDADE DE FALA DE MULHERES PORTADORAS DE FISSURA PALATINA"

$$
\mathrm{Eu},
$$

, portador do $\mathrm{RG}^{\circ}$.

residente na cidade de

, Estado de , matriculado noHRAC sob

o $\mathrm{RG} \mathrm{n}^{\circ}$. , concordo em participar do estudo "Perfil Espectrográfico da Hipernasalidade de Fala de Mulheres Portadoras de Fissura Palatina", realizando a entrevista/avaliação fonoaudiológica específica, as emissões da vogal oral sustentada[a]

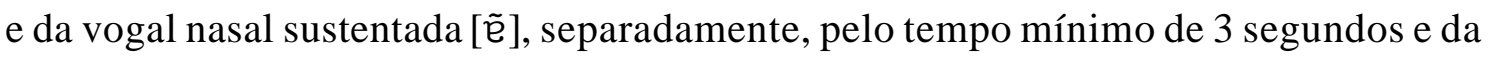
leitura do texto "Hoje é dia de feira" ou da contagem de números de 1 a 20. As emissões serão registradas via microfone em um gravador digital e em um computador. $\mathrm{O}$ objetivo deste estudo é investigar as características espectrográficas da hipernasalidade de fala de mulheres portadoras de fissura palatina e comparar os achados com os resultados da nasometria e da avaliação perceptivo -auditiva de suas emissões e avaliar o valor clínico da espectrografia para a análise da ressonância da fala excessivamente nasal.

Declaro ter sido informada que o procedimento acima não é invasivo, sendo realizado em um único retorno meu ao HRAC-USP, não causará nenhum dano à minha saúde física e mental posteriormente e estarei colaborando para os conhecimentos da ressonância de fala.

Estou ciente que a minha participação é voluntária e tenho o direito de não aceitar colaborar para esse estudo, sem a necessidade de expor as razões e sem comprometer meu tratamento no HRAC-USP.

Estou ciente, também, que minhas emissões vocálicas constituirão um banco de dados que poderá ser utilizado em outros estudos posteriormente.

Seguem-se assinaturas em duas vias de igual teor.

Bauru

Assinatura da Paciente

Fga. Jussara Melo Vieira

Pesquisadora Responsável

Grupo:
Profa. Dra. Maria Inês Pegoraro-Krook

Orientadora Responsável

Protocolo $\mathrm{N}^{\mathrm{o}}$ : 
APÊNDICE B - Termo de consentimento livre e esclarecido apresentado às participantes do grupo controle.

TERMO DE CONSENTIMENTO LIVRE E ESCLARECIDO

para participação na pesquisa:

"PERFIL ESPECTROGRÁFICO DA HIPERNASALIDADE DE FALA DE MULHERES PORTADORAS DE FISSURA PALATINA"

$\mathrm{Eu}$, , portador do $\mathrm{RG} \mathrm{n}^{\circ}$.

residente

à , $\mathrm{n}^{\mathrm{o}}$. , na cidade de

, Estado de , concordo e m participar do

estudo "Perfil Espectrográfico da Hipernasalidade de Fala de Mulheres Portadoras de Fissura Palatina", realizando a entrevista/avaliação fonoaudiológica específica, as

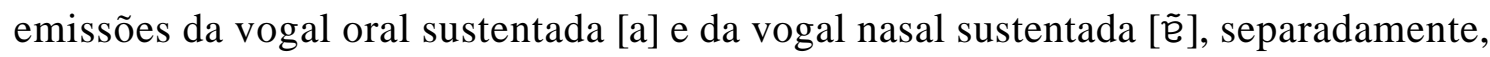
pelo tempo mínimo de 3 segundos e da leitura do texto "Hoje é dia de feira" ou da contagem de números de 1 a 20 . As emissões serão registradas via microfone em um gravador digital e em um computador. O objetivo deste estudo é investigar as características espectrográficas da hipernasalidade de fala de mulheres portadoras de fissura palatina e comparar os achados com os resultados da nasometria e da avaliação perceptivo-auditiva de suas emissões e avaliar o valor clínico da espectrografia para a análise da ressonância da fala excessivamente nasal.

Declaro ter sido informada que o procedimento acima não é invasivo, sendo realizado em uma única visita minha ao HRAC-USP, não causará nenhum dano à minha saúde física e mental posteriormente e estarei colaborando para os conhecimentos da ressonância de fala.

Estou ciente que a minha participação é voluntária e tenho o direito de não aceitar colaborar para esse estudo, sem a necessidade de expor as razões.

Estou ciente, também, que minhas emissões vocálicas constituirão um banco de dados que poderá ser utilizado em outros estudos posteriormente.

Seguem-se assinaturas em duas vias de igual teor.

Bauru, ___________.

Assinatura da Participante

Fga. Jussara Melo Vieira

Pesquisadora Responsável
Profa. Dra. Maria Inês Pegoraro-Krook

Orientadora Responsável

Protocolo $\mathrm{N}^{\mathrm{o}} .:$

Grupo: 
APÊEDICE C - Protocolo de entrevista e de avaliação fonoaudiológica específica.

1 Entrevista

1.1 Identificação

Grupo: 1 ( ) controle2 ( ) PFA 3 ( ) PFR Protocolo $\mathrm{N}^{\circ}$.:

Nome:

$\mathrm{RG}$ :

Idade:

DN:

Data:

Procedência:

Fissura: $\quad 1($ ) ausente

2 ( ) presente: Pós-forame Incisivo:1 ( ) Completo

2 ( ) Incompleto:

1 ( ) aberta

3 ( ) Oculta

2( ) reparada: $\quad 1$ ( ) cirurgia:

2 ( ) prótese: 1 ( ) obturadora com bulbo faríngeo

2 ( ) obturadora sem bulbo faríngeo

3 ( ) ambos

4 ( ) há presença de fístula

obs.:

\subsection{Caracterização}

1 Fuma: $\quad 1$ ( ) não $2($ ) sim

2 Drogas/Medicamentos: 1 ( ) não 2 ( ) sim:

3 Bebida alcoólica: 1 ( ) não 2 ( ) sim: tipo: desde:

freqüência:

4 Alterações nas vias aéreas superiores: 1 ( ) não 2 ( ) sim:

5 Falante nativo do português brasileiro: 1 ( ) não:

6 Queixa vocal/de fala: 1 ( ) não 2( ) sim:

$2($ ) $\operatorname{sim}$

7 Queixa auditiva: 1 ( ) não 2 ( ) sim:

8 Ciclo menstrual: 1 ( ) semana anterior à menstruação

2( ) está menstruada 4 ( ) não está menstruada

3 ( ) ausente:1 ( ) grávida

2 ( ) menopausa

3 ( ) outros:

obs.: 
APÊNDICE C - Protocolo de entrevista e de avaliação fonoaudiológica específica (continuação).

2 Avaliação Fonoaudiológica Específica

2.1 Produção de fala

2.1.1 Inteligibilidade

1 ( ) normal $2($ ) leve $3($ ) leve para moderada $4($ ) moderada

5 ( ) moderada para severa $6($ ) severa $\quad 7$ ( ) muito severa

\subsubsection{Ressonância}

1 ( ) normal $2($ ) mista

3 ( ) Hipernasalidade: 1( ) leve 2( ) moderada 3 ( ) severa 4 ( ) aberta $5($ ) fechada

2.1.3 Distúrbios articulatórios

1 -Compensatórios: 1 ( ) ausentes

$\begin{array}{ll}2 \text { ( ) presentes: } 1 \text { ( ) GG } & \text { 2( ) PDMP } \\ 3 \text { ( ) PF 4 ( ) FF } 5(\text { ) FNP } & 6(\text { ( ) FN } \\ 7 \text { ( ) Outros: } N^{\circ} \text {. de fonemas alterados: } & \end{array}$

\subsection{Produção vocal}

2.2.1 Intensidade

1 ( ) adequada 2( ) aumentada 3 ( ) diminuída 4 ( ) flutuante

2.2.2 Tom

1 ( ) adequado 2( ) acutizado 4 ( ) diplofônico

3 ( ) agravado

2.2.3 Entonação

1 ( ) adequada 2( ) monótona

2.2.4 Ritmo

1 ( ) adequado 2( ) aumentado 3( ) diminuído

2.2.5 Qualidade vocal

1 ( ) adequada

4 ( ) fraca

2 ( ) rouca

5 ( ) tensa

3 ( ) soprosa

4 ( ) outra:

Segundo GRBAS ${ }^{14}$ :
1 = leve
$2=$ moderado
$3=$ severo

14 GRBAS, scale - Comitê para testes de função fonatória da Sociedade Japonesa de Logopedia e Foniatria, Japão. 
APÊNDICE C - Protocolo de entrevista e de avaliação fonoaudiológica específica (continuação).

\subsection{Quadro fonêmico}

\begin{tabular}{|ccc|}
\hline \hline $\mathrm{p}$ & $\mathrm{t}$ & $\mathrm{k}$ \\
$\mathrm{b}$ & $\mathrm{d}$ & $\mathrm{g}$ \\
$\mathrm{m}$ & $\mathrm{n}$ & $\mathrm{c}$ \\
$\mathrm{f}$ & $\mathrm{s}$ & \\
$\mathrm{v}$ & $\mathrm{z}$ & $\mathrm{C}$ \\
& $\mathrm{l}$ & $\lambda$ \\
& $\mathrm{r}$ & $\mathrm{R}$ \\
& $\mathrm{y}$ & \\
\hline \hline
\end{tabular}

africadas:

/t /

$/ \mathrm{d}_{\mathrm{c}} /$

arquifonemas:

$\{R\}$

$\{\mathrm{S}\}$

i

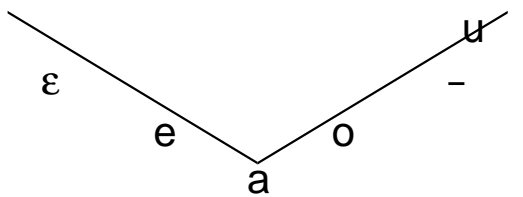

Legenda:

Substituição sistemática

EAN: Emissão de ar nasal audível

PF: Plosiva faríngea

Omissão sistemática

FF: $\quad$ Fricativa faríngea

FV: $\quad$ Fricativa velar

DOL: Distorção oro-lateral

SIGM: Sigmatismo

PROJ: Projeção de língua
GG: Golpe de glote

Substituição assitemática

MF: Mímica facial

$\bigcirc$ Omissão assistemática

MN: Mímica nasal

COART: Coarticulação

FNP: Fricativa nasal posterior

FN: Fricativa nasal

PDMP: Plosiva dorso médio palatal 
APÊNDICE D - Protocolo para anotações das examinadoras que realizaram a avaliação perceptivo-auditiva da emissão da vogal oral [a] sustentada emitida pelas participantes dos 3 grupos estudados.

Examinadora:

$\mathrm{N}^{\mathrm{o}}$ :

Data:

Ressonância:

1-Normal 2-Leve 3-Moderada 4-Severa 5-Não avaliada

\begin{tabular}{|c|c|c|c|}
\hline Amostra de Fala & Hipernasalidade & Ressonância & Observações \\
\hline $\mathrm{A} 01$ & Sim ( ) Não( ) & & \\
\hline A02 & Sim ( ) Não( ) & & \\
\hline A03 & Sim ( ) Não ( ) & & \\
\hline $\mathrm{A} 04$ & Sim ( ) Não ( ) & & \\
\hline $\mathrm{A} 05$ & Sim ( ) Não ( ) & & \\
\hline A06 & Sim ( ) Não ( ) & & \\
\hline A07 & Sim ( ) Não ( ) & & \\
\hline A08 & Sim ( ) Não ( ) & & \\
\hline A09 & Sim ( ) Não ( ) & & \\
\hline A10 & Sim ( ) Não ( ) & & \\
\hline A11 & Sim ( ) Não( ) & & \\
\hline A12 & Sim ( ) Não( ) & & \\
\hline A13 & Sim ( ) Não ( ) & & \\
\hline A14 & Sim ( ) Não( ) & & \\
\hline A15 & Sim ( ) Não（） & & \\
\hline A16 & Sim ( ) Não( ) & & \\
\hline A17 & Sim ( ) Não( ) & & \\
\hline A18 & $\operatorname{Sim}($ ) Não( ) & & \\
\hline A19 & Sim ( ) Não（） & & \\
\hline A20 & Sim ( ) Não（） & & \\
\hline A21 & Sim ( ) Não（） & & \\
\hline A22 & Sim ( ) Não( ) & & \\
\hline$\ldots$ & Sim ( ) Não ( ) & & \\
\hline A76 & Sim ( ) Não ( ) & & \\
\hline
\end{tabular}


APÊNDICE E - Descrição dos achados do quadro fonêmico dos grupos PFA e PFR.

\begin{tabular}{|c|c|c|c|c|c|c|}
\hline GRUPO & $/ \mathrm{p} /$ & $/ \mathrm{t} /$ & $/ \mathrm{k} /$ & $/ \mathrm{b} /$ & $/ d /$ & $/ g /$ \\
\hline \multicolumn{7}{|l|}{ PFA01 } \\
\hline PFA02 & COART GG & COART GG & COART GG & & & COART GG \\
\hline PFA03 & FP & FP & FP & FP & FP & FP \\
\hline PFA04 & MN & MN & COART GG & MN & MN & $\begin{array}{c}\text { MN } \\
\text { COART GG }\end{array}$ \\
\hline PFA05 & $\mathrm{MN}$ & $\mathrm{MN}$ & $\mathrm{PF}$ & $\overline{M N}$ & $\overline{M N}$ & $\mathrm{PF}$ \\
\hline PFR01 & & $\begin{array}{l}\text { ENA } \\
\text { MN } \\
\end{array}$ & & $\begin{array}{l}\text { ENA } \\
\text { MN }\end{array}$ & $\mathrm{MN}$ & \\
\hline PFR02 & $\begin{array}{c}\text { MN } \\
\text { ENA } \\
\text { COART GG }\end{array}$ & $\begin{array}{c}\text { MN } \\
\text { ENA } \\
\text { COART GG }\end{array}$ & $\begin{array}{c}\text { MN } \\
\text { ENA } \\
\text { COART GG }\end{array}$ & $\begin{array}{c}\mathrm{MN} \\
\mathrm{FP}\end{array}$ & COART GG & $\begin{array}{l}\text { MN } \\
\text { FP }\end{array}$ \\
\hline PFR03 & COART GG & COART GG & $\begin{array}{c}\text { COART GG } \\
\text { MN } \\
\end{array}$ & $\begin{array}{l}\text { ENA } \\
\text { MF }\end{array}$ & MN & $\mathrm{MN}$ \\
\hline PFR04 & $\begin{array}{l}\mathrm{MN} \\
\mathrm{FP} \\
\end{array}$ & FP & FP & & & \\
\hline PFR05 & COART GG & COART GG & COART GG & COART GG & COART GG & COART GG \\
\hline PFR06 & COART GG & COART GG & COART GG & COART GG & COART GG & COART GG \\
\hline PFR07 & $\mathrm{RN}$ & $\begin{array}{l}\text { RN } \\
\text { PROJ }\end{array}$ & $\mathrm{RN}$ & RN LEVE & $\begin{array}{c}\mathrm{RN} \\
\text { PROJ }\end{array}$ & $\mathrm{RN}$ \\
\hline PFR08 & COART GG & COART GG & COART GG & COART GG & COART GG & COART GG \\
\hline PFR09 & $\begin{array}{l}\text { ENA } \\
\text { MF }\end{array}$ & $\begin{array}{l}\text { ENA } \\
\text { MF }\end{array}$ & $\mathrm{PF}$ & $\begin{array}{c}\text { ENA } \\
\text { MF } \\
\end{array}$ & $\begin{array}{l}\text { ENA } \\
\text { MF }\end{array}$ & $\begin{array}{l}\mathrm{MF} \\
\mathrm{FP} \\
\end{array}$ \\
\hline PFR10 & FP & & $\begin{array}{c}\text { COART GG } \\
\text { ASSIST } \\
\end{array}$ & & & \\
\hline PFR11 & COART GG & COART GG & COART GG & $\begin{array}{l}\text { FP } \\
\text { MN }\end{array}$ & $\begin{array}{l}\text { FP } \\
\text { MN }\end{array}$ & $\begin{array}{l}\text { MN } \\
\text { FP } \\
\end{array}$ \\
\hline PFR12 & COART GG & COART GG & COART GG & & & \\
\hline PFR13 & & PDMP & & PDMP & PDMP & \\
\hline PFR14 & COART GG & $\begin{array}{c}\text { COART GG } \\
\text { PROJ }\end{array}$ & COART GG & COART GG & $\begin{array}{c}\text { COART GG } \\
\text { PROJ }\end{array}$ & COART GG \\
\hline PFR15 & $\begin{array}{c}\text { COART GG } \\
\text { ASSIST }\end{array}$ & $\begin{array}{c}\text { COART GG } \\
\text { ASSIST }\end{array}$ & & & & \\
\hline PFR16 & $\begin{array}{c}\text { ENA } \\
\text { FP }\end{array}$ & $\begin{array}{c}\text { ENA } \\
\text { FP } \\
\text { RN } \\
\end{array}$ & $\begin{array}{c}\text { ENA } \\
\text { FP } \\
\text { RN } \\
\end{array}$ & $\begin{array}{c}\text { MN } \\
\text { FP } \\
\text { ENA } \\
\end{array}$ & $\begin{array}{c}\text { ENA } \\
\text { FP } \\
\text { RN } \\
\end{array}$ & $\begin{array}{c}\text { ENA } \\
\text { FP } \\
\text { RN } \\
\end{array}$ \\
\hline PFR17 & $\begin{array}{c}\text { COART GG } \\
\text { ASSIST } \\
\text { ORA FP/ENA } \\
\end{array}$ & $\begin{array}{l}\text { COART GG } \\
\text { PROJ }\end{array}$ & COART GG & $\begin{array}{c}\text { ENA } \\
\text { COART GG }\end{array}$ & $\begin{array}{l}\text { COART GG } \\
\text { PROJ }\end{array}$ & $\begin{array}{c}\text { COART GG } \\
\text { ASSIST }\end{array}$ \\
\hline PFR18 & COART GG & COART GG & COART GG & & & \\
\hline PFR19 & COART GG & COART GG & ENA & $\begin{array}{l}\text { MN } \\
\text { ENA } \\
\end{array}$ & $\begin{array}{l}\text { MN } \\
\text { ENA } \\
\end{array}$ & $\begin{array}{l}\text { MN } \\
\text { ENA } \\
\end{array}$ \\
\hline PFR20 & COART GG & $\begin{array}{c}\text { COART GG } \\
\text { PROJ }\end{array}$ & COART GG & $\mathrm{FP}$ & PROJ & \\
\hline PFR21 & & $\begin{array}{c}\text { COART GG } \\
\text { ASSIST }\end{array}$ & COART GG & FP & & \\
\hline
\end{tabular}

Há legenda na página seguinte. 
APÊNDICE E - Descrição dos achados do quadro fonêmico dos grupos PFA e PFR (Continuação).

Legenda:

ASSIST $=$ assistemática $(\mathrm{o})$

SUBST $=$ substituição

$\mathrm{GG}=$ golpe de glote

COART GG = coarticulação com golpe de glote

$\mathrm{FF}=$ fricativa faríngea

COART FF = coarticulação com fricativa faríngea

$\mathrm{PF}=$ plosiva faríngea

$\mathrm{FP}=$ fraca pressão

ENA $=$ emissão nasal audível

$\mathrm{MF}=$ mímica facial

$\mathrm{MN}=$ mímica nasal

$\mathrm{RN}=$ ronco nasal

PDMP = plosiva dorso médio palatal

$\mathrm{FNP}=$ fricativa nasal posterior

DOL $=$ distorção oro-lateral

PROJ = projeção de língua

Observação: esta legenda também é válida para os Apêndices G, H e I, também referentes ao quadro fonêmico das participantes portadoras de fissura palatina. 
APÊNDICE E - Descrição dos achados do quadro fonêmico dos grupos PFA e PFR (Continuação).

\begin{tabular}{|c|c|c|c|c|c|c|}
\hline GRUPO & $/ \mathbf{f} /$ & $/ \mathbf{s} /$ & $/ \mathrm{ch} /$ & $/ \mathrm{v} /$ & $|\mathbf{z}|$ & $/ \mathrm{j} /$ \\
\hline \multicolumn{7}{|l|}{ PFA01 } \\
\hline PFA02 & & $\mathrm{MN}$ & $\mathrm{MN}$ & & & \\
\hline PFA03 & FP & FP & FP & $\mathrm{FP}$ & FP & $\mathrm{FP}$ \\
\hline PFA04 & $\mathrm{MN}$ & $\mathrm{MN}$ & $\mathrm{MN}$ & $\mathrm{MN}$ & $\mathrm{MN}$ & $\mathrm{MN}$ \\
\hline PFA05 & ENA & ENA & ENA & ENA & ENA & $\mathrm{MN}$ \\
\hline PFAUS & $\mathrm{MN}$ & $\mathrm{MN}$ & $\mathrm{MN}$ & $\mathrm{MN}$ & $\mathrm{MN}$ & \\
\hline PFR01 & ENA & FNP & $\mathrm{MN}$ & & FNP & $\mathrm{MN}$ \\
\hline PFR02 & $\begin{array}{l}\mathrm{MN} \\
\mathrm{ENA} \\
\mathrm{MN}\end{array}$ & $\begin{array}{c}\text { ENA } \\
\text { MN } \\
\text { COART FF }\end{array}$ & COART FF & $\begin{array}{l}\text { ENA } \\
\mathrm{MN}\end{array}$ & COART FF & COART FF \\
\hline PFR03 & $\begin{array}{l}\text { ENA } \\
\text { MN }\end{array}$ & $\begin{array}{l}\text { ENA } \\
\text { MN }\end{array}$ & $\begin{array}{l}\text { ENA } \\
\text { MN }\end{array}$ & $\begin{array}{l}\mathrm{MN} \\
\mathrm{FP}\end{array}$ & $\begin{array}{l}\text { ENA } \\
\text { MN }\end{array}$ & $\mathrm{MN}$ \\
\hline PFR04 & $\begin{array}{r}\text { ENA } \\
\text { MN }\end{array}$ & COART FF & FP & & & \\
\hline PFR05 & $\begin{array}{r}\text { ENA } \\
\text { MN }\end{array}$ & $\begin{array}{l}\text { ENA } \\
\mathrm{MN}\end{array}$ & $\begin{array}{r}\text { ENA } \\
\text { MN }\end{array}$ & $\begin{array}{r}\text { ENA } \\
\text { MN }\end{array}$ & & \\
\hline PFR06 & $\mathrm{MN}$ & $\mathrm{MN}$ & & & $\mathrm{MN}$ & \\
\hline PFR07 & $\mathrm{RN}$ & $\begin{array}{c}\mathrm{RN} \\
\mathrm{DOL}\end{array}$ & & $\begin{array}{c}\text { RNLEVE } \\
\text { ASSIST }\end{array}$ & $\begin{array}{l}\mathrm{RN} \\
\mathrm{DOL}\end{array}$ & \\
\hline PFR08 & & FF & $\mathrm{FF}$ & & ENA & \\
\hline PFR09 & $\begin{array}{l}\text { ENA } \\
\text { MF }\end{array}$ & $\begin{array}{c}\text { ENA } \\
\text { MF } \\
\text { FP } \\
\end{array}$ & $\begin{array}{l}\mathrm{FP} \\
\mathrm{MF}\end{array}$ & $\begin{array}{c}\text { ENA } \\
\text { FP } \\
\text { MF } \\
\end{array}$ & $\begin{array}{c}\text { ENA } \\
\text { FP } \\
\text { MF } \\
\end{array}$ & $\begin{array}{c}\text { FP } \\
\text { MF } \\
\text { ENA } \\
\end{array}$ \\
\hline PFR10 & & $\mathrm{FF}$ & $\mathrm{FF}$ & & $\mathrm{FF}$ & FF ASSIST \\
\hline PFR11 & & $\begin{array}{c}\mathrm{FP} \\
\mathrm{MN}\end{array}$ & $\begin{array}{c}\text { FP } \\
\text { ENA }\end{array}$ & & FP & \\
\hline PFR12 & & $\begin{array}{c}\text { COART FF } \\
\text { ASSIST }\end{array}$ & $\begin{array}{c}\text { COART FF A } \\
\text { SSIST } \\
\end{array}$ & & & \\
\hline PFR13 & & & COART FF & & & COART FF \\
\hline PFR14 & FP & FP & FP & FP & FP & FP \\
\hline PFR15 & $\begin{array}{l}\mathrm{MN} \\
\mathrm{LEVE} \\
\end{array}$ & FP & & $\begin{array}{l}\mathrm{MN} \\
\mathrm{LEVE} \\
\end{array}$ & $\begin{array}{c}\text { DISTORÇÃO } \\
\text { LEVE } \\
\end{array}$ & COART FF \\
\hline PFR16 & $\begin{array}{c}\mathrm{MN} \\
\mathrm{FP} \\
\text { ENA } \\
\end{array}$ & $\begin{array}{c}\text { RN } \\
\text { FP } \\
\text { ENA }\end{array}$ & $\begin{array}{c}\text { FP } \\
\text { ENA }\end{array}$ & $\begin{array}{c}\text { MN } \\
\text { FP } \\
\text { ENA }\end{array}$ & $\begin{array}{r}\text { RN } \\
\text { FP } \\
\text { ENA } \\
\end{array}$ & $\begin{array}{c}\text { RN } \\
\text { FP } \\
\text { ENA } \\
\end{array}$ \\
\hline PFR17 & $\begin{array}{l}\mathrm{MN} \\
\text { ENA } \\
\end{array}$ & $\begin{array}{l}\text { MN } \\
\text { ENA }\end{array}$ & $\begin{array}{l}\text { MN } \\
\text { ENA }\end{array}$ & $\begin{array}{l}\text { MN } \\
\text { ENA }\end{array}$ & $\begin{array}{l}\text { MN } \\
\text { ENA }\end{array}$ & $\begin{array}{l}\text { MN } \\
\text { ENA }\end{array}$ \\
\hline PFR18 & ENA & COART FF & FF & & & \\
\hline PFR19 & $\begin{array}{l}\text { MN } \\
\text { ENA } \\
\end{array}$ & $\begin{array}{l}\text { MN } \\
\text { ENA }\end{array}$ & $\mathrm{MN}$ & $\mathrm{MN}$ & $\mathrm{MN}$ & $\mathrm{MN}$ \\
\hline PFR20 & ENA & $\begin{array}{r}\text { ENA } \\
\text { MN } \\
\end{array}$ & $\begin{array}{r}\text { ENA } \\
\text { MN }\end{array}$ & FP & & \\
\hline PFR21 & FP & $\begin{array}{c}\text { FP } \\
\text { MN }\end{array}$ & FP & FP & FP & FP \\
\hline
\end{tabular}


APÊNDICE E - Descrição dos achados do quadro fonêmico dos grupos PFA e PFR (Continuação).

\begin{tabular}{|c|c|c|c|c|c|c|}
\hline GRUPO & /tch/ & $/ \mathrm{dj} /$ & $\{\mathbf{R}\}$ & $\{\mathbf{S}\}$ & $/ \mathbf{r} /$ & $/ \mathbf{l} /$ \\
\hline PFA01 & & PROJ & & & $\begin{array}{c}\text { OMISSÃO } \\
\text { ASSIS } \\
\text { OU } \\
\text { DISTORÇÃO }\end{array}$ & $\begin{array}{l}\text { OMISSÃO } \\
\text { SISTEMÁ- } \\
\text { TICA }\end{array}$ \\
\hline \multicolumn{7}{|l|}{ PFA02 } \\
\hline PFA03 & & & & $\begin{array}{c}\text { COART FF } \\
\text { ASSIST }\end{array}$ & & \\
\hline PFA04 & $\mathrm{MN}$ & $\mathrm{MN}$ & $\mathrm{MN}$ & $\mathrm{MN}$ & & $\begin{array}{c}\text { SUBST POR } \\
\text { /R/ } \\
\end{array}$ \\
\hline PFA05 & $\begin{array}{l}\text { ENA } \\
\mathrm{MN}\end{array}$ & $\begin{array}{l}\text { ENA } \\
\mathrm{MN}\end{array}$ & & ENA & & \\
\hline PFR01 & $\mathrm{MN}$ & $\mathrm{MN}$ & & FNP & & \\
\hline PFR02 & FF & & & COART FF & & \\
\hline PFR03 & $\mathrm{MN}$ & $\mathrm{MN}$ & & & & \\
\hline PFR04 & $\mathrm{MN}$ & & & & & \\
\hline PFR05 & COART GG & COART GG & & & & \\
\hline PFR06 & & & & $\mathrm{MN}$ & & $\begin{array}{c}\text { SUBSTITUI } \\
\text { POR /R/ } \\
\end{array}$ \\
\hline PFR07 & $\mathrm{RN}$ & $\mathrm{RN}$ & & $\begin{array}{c}\text { RN } \\
\text { SIGM }\end{array}$ & & \\
\hline PFR08 & $\mathrm{FF}$ & $\mathrm{FF}$ & & $\mathrm{FF}$ & & $\begin{array}{c}\text { ASSIST POR } \\
\text { /R/ } \\
\end{array}$ \\
\hline PFR09 & $\mathrm{MN}$ & $\mathrm{MN}$ & & $\begin{array}{l}\text { MN } \\
\text { ENA }\end{array}$ & $\mathrm{MN}$ & $\mathrm{MN}$ \\
\hline PFR10 & & & & $\mathrm{FF}$ & & \\
\hline PFR11 & ENA & & & & & $\begin{array}{c}\text { ASSIST POR } \\
\text { /R/ } \\
\end{array}$ \\
\hline PFR12 & COART FF & COART FF & & COART FF & & \\
\hline PFR13 & COART FF & COART FF & & & & \\
\hline PFR14 & $\begin{array}{c}\text { COART GG } \\
\text { ASSIST } \\
\text { ENA } \\
\end{array}$ & COART GG & & COART FF & & \\
\hline \multicolumn{7}{|l|}{ PFR15 } \\
\hline PFR16 & $\mathrm{RN}$ & $\mathrm{RN}$ & $\begin{array}{c}\text { SUBST POR } \\
/ \mathrm{Y} /\end{array}$ & $\mathrm{RN}$ & & \\
\hline PFR17 & COART GG & COART GG & & $\mathrm{MN}$ & & \\
\hline PFR18 & $\mathrm{FF}$ & $\mathrm{FF}$ & & $\mathrm{FF}$ & & $\begin{array}{c}\text { SUBST POR } \\
/ \mathrm{R} /\end{array}$ \\
\hline PFR19 & $\mathrm{MN}$ & $\mathrm{MN}$ & $\mathrm{MN}$ & $\mathrm{MN}$ & & $\begin{array}{c}\text { SUBST POR } \\
\text { /R/ } \\
\end{array}$ \\
\hline PFR20 & ENA & & & & & \\
\hline PFR21 & COART GG & & & FP & & \\
\hline
\end{tabular}


APÊNDICE E - Descrição dos achados do quadro fonêmico dos grupos PFA e PFR (Continuação).

\begin{tabular}{|c|c|c|c|c|c|}
\hline GRUPO & $/ \mathrm{m} /$ & $/ \mathbf{n} /$ & $/ \mathbf{l} /$ & $/ / \mathrm{h} /$ & $/ \mathbf{r} /$ \\
\hline \multicolumn{6}{|l|}{ PFA01 } \\
\hline \multicolumn{6}{|l|}{ PFA02 } \\
\hline \multicolumn{6}{|l|}{ PFA03 } \\
\hline $\begin{array}{l}\text { PFA04 } \\
\end{array}$ & $\mathrm{MN}$ & $\mathrm{MN}$ & MN & $\mathrm{MN}$ & MN \\
\hline \multicolumn{6}{|l|}{ PFA05 } \\
\hline PFR01 & & & $\mathrm{MN}$ & & \\
\hline \multicolumn{6}{|l|}{ PFR02 } \\
\hline \multicolumn{6}{|l|}{ PFR03 } \\
\hline \multicolumn{6}{|l|}{ PFR04 } \\
\hline PFR05 & $\mathrm{MN}$ & & & & \\
\hline \multicolumn{6}{|l|}{$\begin{array}{l}\text { PFR06 } \\
\end{array}$} \\
\hline PFR07 & & PROJ & & & \\
\hline \multicolumn{6}{|l|}{ PFR08 } \\
\hline PFR09 & & & $\mathrm{MN}$ & & \\
\hline \multicolumn{6}{|l|}{ PFR10 } \\
\hline \multicolumn{6}{|l|}{ PFR11 } \\
\hline \multicolumn{6}{|l|}{ PFR12 } \\
\hline \multicolumn{6}{|l|}{ PFR13 } \\
\hline \multicolumn{6}{|l|}{ PFR14 } \\
\hline \multicolumn{6}{|l|}{$\begin{array}{l}\text { PFR15 } \\
\end{array}$} \\
\hline \multicolumn{6}{|l|}{ PFR16 } \\
\hline PFR17 & $\mathrm{MN}$ & & $\begin{array}{c}\text { DISTORÇÃO } \\
\text { ASSIST }\end{array}$ & & $\begin{array}{l}\text { DISTORÇÃO } \\
\text { ASSIST } \\
\text { LEVE }\end{array}$ \\
\hline \multicolumn{6}{|l|}{ PFR18 } \\
\hline \multicolumn{6}{|l|}{ PFR19 } \\
\hline \multicolumn{6}{|l|}{ PFR20 } \\
\hline PFR21 & & & & & \\
\hline
\end{tabular}


APÊNDICE F - Tabela com os valores de nasalância e de freqüências formantes de cada participante deste estudo.

\begin{tabular}{|c|c|c|c|c|c|c|c|c|}
\hline \multirow{2}{*}{ Grupo } & \multicolumn{2}{|c|}{ Nasalância (\%) } & \multicolumn{3}{|c|}{ Formantes (Hz) de [a] } & \multicolumn{3}{|c|}{ Formantes $(\mathrm{Hz})$ de $[\tilde{\mathrm{e}}]$} \\
\hline & [a] & {$[\tilde{\mathbb{E}}]$} & F1/f1 & F2/f2 & F3/f3 & f1 & f2 & $\mathbf{f 3}$ \\
\hline CON01 & 40,09 & 6,01 & 831 & 1706 & 2847 & 388 & 1691 & \\
\hline CON02 & 31,23 & 43,28 & 883 & 1507 & 3002 & 703 & 1493 & 3098 \\
\hline CON03 & 16,34 & 53,67 & 1000 & 1583 & 2869 & 401 & 1391 & \\
\hline CONO4 & 51,22 & 62,71 & 876 & 1525 & 2870 & 603 & 1517 & 3028 \\
\hline CON05 & 57,83 & 46,11 & 965 & 1561 & 2984 & 591 & 1556 & 2829 \\
\hline CON06 & 25,80 & 5,93 & 954 & 1609 & 2678 & 553 & 1633 & 2508 \\
\hline CON07 & 41,31 & 46,91 & 900 & 1441 & 2510 & 319 & 1247 & \\
\hline CON08 & 23,80 & 43,56 & 960 & 1561 & 2846 & 540 & 1581 & 3287 \\
\hline CON09 & 30,88 & 50,07 & 897 & 1527 & 2787 & 578 & 1466 & 2971 \\
\hline CON10 & 16,20 & 82,21 & 1084 & 1586 & 2997 & 329 & 1457 & \\
\hline CON11 & 55,23 & 44,17 & 1042 & 1595 & 3000 & 372 & 1255 & 3457 \\
\hline CON12 & 50,01 & 82,28 & 958 & 1665 & 2927 & 617 & 1542 & \\
\hline CON13 & 15,25 & 63,62 & 1034 & 1690 & 2738 & 478 & 1574 & 3265 \\
\hline CON14 & 24,47 & 17,36 & 971 & 1589 & 2776 & 643 & 1607 & 2829 \\
\hline CON15 & 31,29 & 58,76 & 1135 & 1577 & 2700 & 436 & 1553 & \\
\hline CON16 & 66,18 & 76,30 & 1085 & 1712 & 2893 & 382 & 1840 & 2872 \\
\hline CON17 & 31,65 & 36,81 & 648 & 1585 & 3010 & 436 & 1691 & 2904 \\
\hline CON18 & 40,56 & 73,70 & 984 & 1552 & 3154 & 720 & 1404 & 3702 \\
\hline CON19 & 45,19 & 58,87 & 925 & 1574 & 2872 & 659 & 1521 & 3127 \\
\hline CON20 & 51,44 & 59,98 & 794 & 1563 & 2712 & 382 & 1755 & 2989 \\
\hline CON21 & 12,48 & 30,73 & 851 & 1531 & 2744 & 595 & 1563 & 2914 \\
\hline CON22 & 47,05 & 7,71 & 1148 & 1744 & 3287 & 393 & 1819 & 3117 \\
\hline CON23 & 44,41 & 36,22 & 1042 & 1648 & 2797 & 425 & 1521 & 2776 \\
\hline CON24 & 31,96 & 60,76 & 914 & 1627 & 2808 & 308 & 1521 & 3180 \\
\hline CON25 & 39,41 & 38,20 & 861 & 1457 & 2670 & 500 & & 2595 \\
\hline CON26 & 49,07 & 15,72 & 925 & 1468 & 3042 & 606 & 1489 & 3170 \\
\hline CON27 & 13,30 & 32,16 & 914 & 1436 & 3117 & 638 & 1340 & 3106 \\
\hline CON28 & 52,40 & 82,80 & 1021 & 1595 & 2840 & 265 & 1563 & 3148 \\
\hline CON29 & 12,40 & 59,46 & 893 & 1553 & 2478 & 287 & 1446 & 3063 \\
\hline CON30 & 20,21 & 37,37 & 893 & 1627 & 2946 & 500 & 1414 & 3010 \\
\hline PFA01 & 41,80 & 48,09 & 776 & 1702 & 2978 & 468 & 1425 & \\
\hline PFA02 & 26,79 & 35,92 & 531 & & 3021 & 531 & & 3021 \\
\hline PFA03 & 20,54 & 30,15 & 893 & 1468 & 2712 & 659 & & \\
\hline PFA04 & 26,82 & 37,09 & 744 & 1787 & & 340 & 1340 & 2553 \\
\hline PFA05 & 32,41 & 39,81 & 744 & 1404 & 3765 & 585 & 1393 & 3265 \\
\hline PFR01 & 32,35 & 47,11 & 382 & 1148 & 2010 & 500 & 1457 & \\
\hline PFR02 & 27,75 & 44,88 & 1000 & 1723 & 3000 & 478 & 1659 & 2925 \\
\hline PFR03 & 55,03 & 54,95 & 989 & 1776 & 2606 & 287 & 1968 & \\
\hline PFR04 & 39,73 & 92,08 & 531 & 1627 & 2468 & 361 & 1191 & 3446 \\
\hline PFR05 & 95,68 & 98,52 & 877 & 1634 & 2976 & 574 & 1797 & \\
\hline PFR06 & 41,08 & 56,96 & 1053 & 1627 & 2702 & 436 & 1297 & 2702 \\
\hline PFR07 & 40,75 & 45,53 & 1085 & 1765 & 3021 & 414 & 1510 & 3457 \\
\hline PFR08 & 95,68 & 47,57 & 989 & 1872 & 2489 & 468 & 2170 & 2936 \\
\hline PFR09 & 44,95 & 66,35 & 861 & 1489 & & 542 & 1372 & 2127 \\
\hline PFR10 & 28,89 & 43,74 & 1106 & 2861 & & 404 & 1893 & 3031 \\
\hline PFR11 & 47,16 & 48,54 & 1117 & 1606 & 3095 & 531 & 1404 & 3180 \\
\hline PFR12 & 13,47 & 21,14 & 989 & 1521 & 2904 & 521 & 1340 & 2904 \\
\hline PFR13 & 43,29 & 53,02 & 829 & 1500 & 3212 & 563 & 1521 & 3606 \\
\hline PFR14 & 29,97 & 39,57 & 882 & 1542 & 2606 & 531 & 1840 & 3702 \\
\hline PFR15 & 40,35 & 77,52 & 893 & 1478 & 2840 & 500 & 1212 & 3095 \\
\hline PFR16 & 29,41 & 52,43 & 989 & 1595 & 2723 & 680 & 1595 & 3436 \\
\hline PFR17 & 29,59 & 43,29 & 659 & 1148 & 1659 & 510 & 1755 & \\
\hline PFR18 & 29,18 & 42,81 & 712 & 1670 & 2340 & 446 & 1744 & 2287 \\
\hline
\end{tabular}


APÊNDICE F - Tabela com os valores de nasalância e de freqüências formantes de cada participante deste estudo (Continuação).

\begin{tabular}{|c|c|c|c|c|c|c|c|c|}
\hline \multirow{2}{*}{ Grupo } & \multicolumn{2}{|c|}{ Nasalância (\%) } & \multicolumn{3}{|c|}{ Formantes (Hz) de [a] } & \multicolumn{3}{|c|}{ Formantes $(\mathrm{Hz})$ de $[\tilde{\mathrm{e}}]$} \\
\hline & [a] & {$[\overline{\mathbb{E}}]$} & F1/f1 & F2/f2 & F3/f3 & f1 & f2 & f3 \\
\hline PFR19 & 32,71 & 49,84 & 1031 & 1606 & 2925 & 489 & 1585 & 3127 \\
\hline PFR20 & 39,36 & 33,59 & 670 & 1521 & 2893 & 531 & 1734 & 3138 \\
\hline PFR21 & 30,44 & 43,47 & 978 & 1606 & 2840 & 372 & 1319 & 3000 \\
\hline
\end{tabular}


APÊEDICE G - Forma de onda das emissões das vogais [a] e [ẽe] sustentadas (A) e seu respectivo espectrograma $(\mathrm{B})$ da participante com protocolo número 01 do grupoCON.

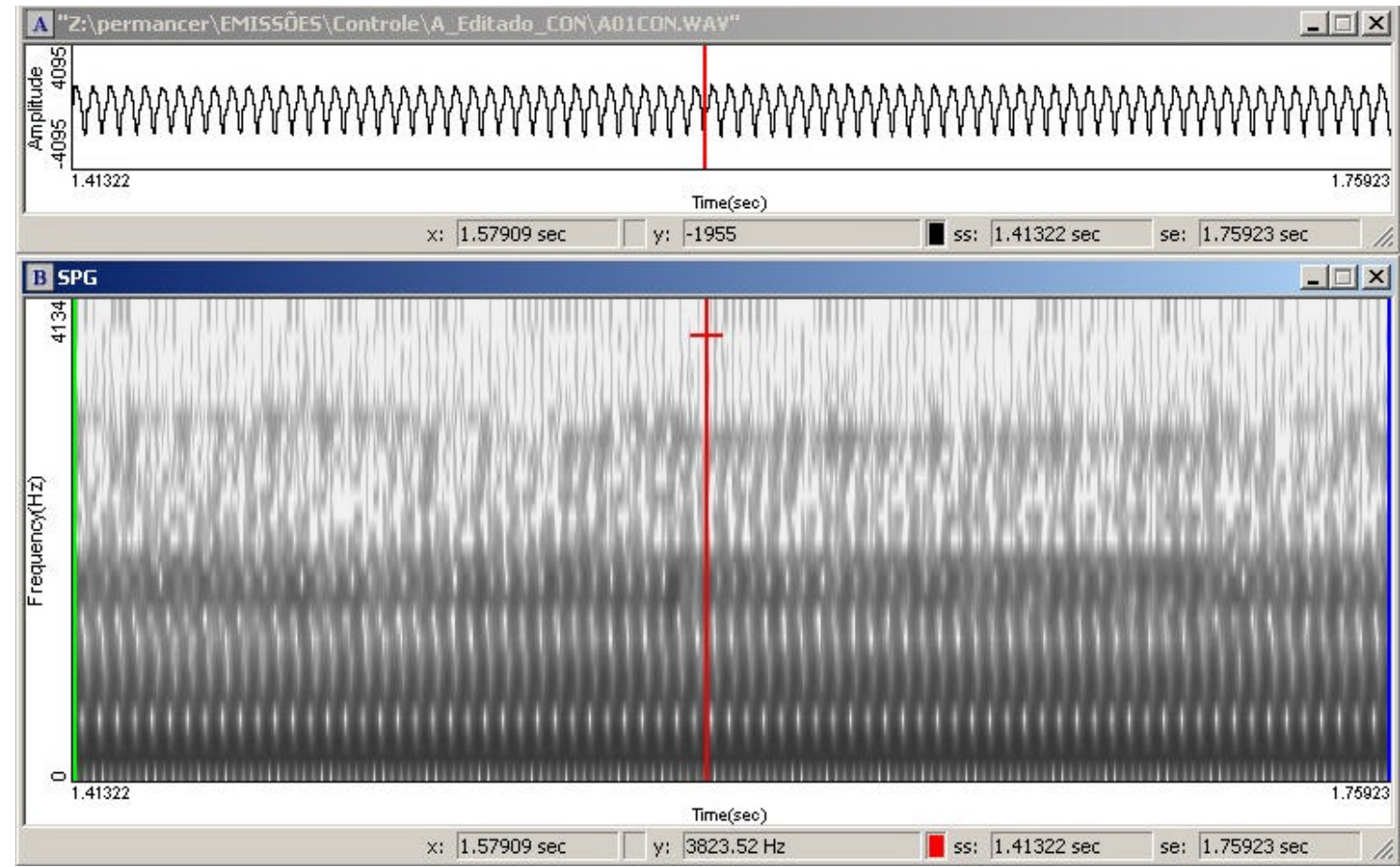

Vogal oral [a] sustentada

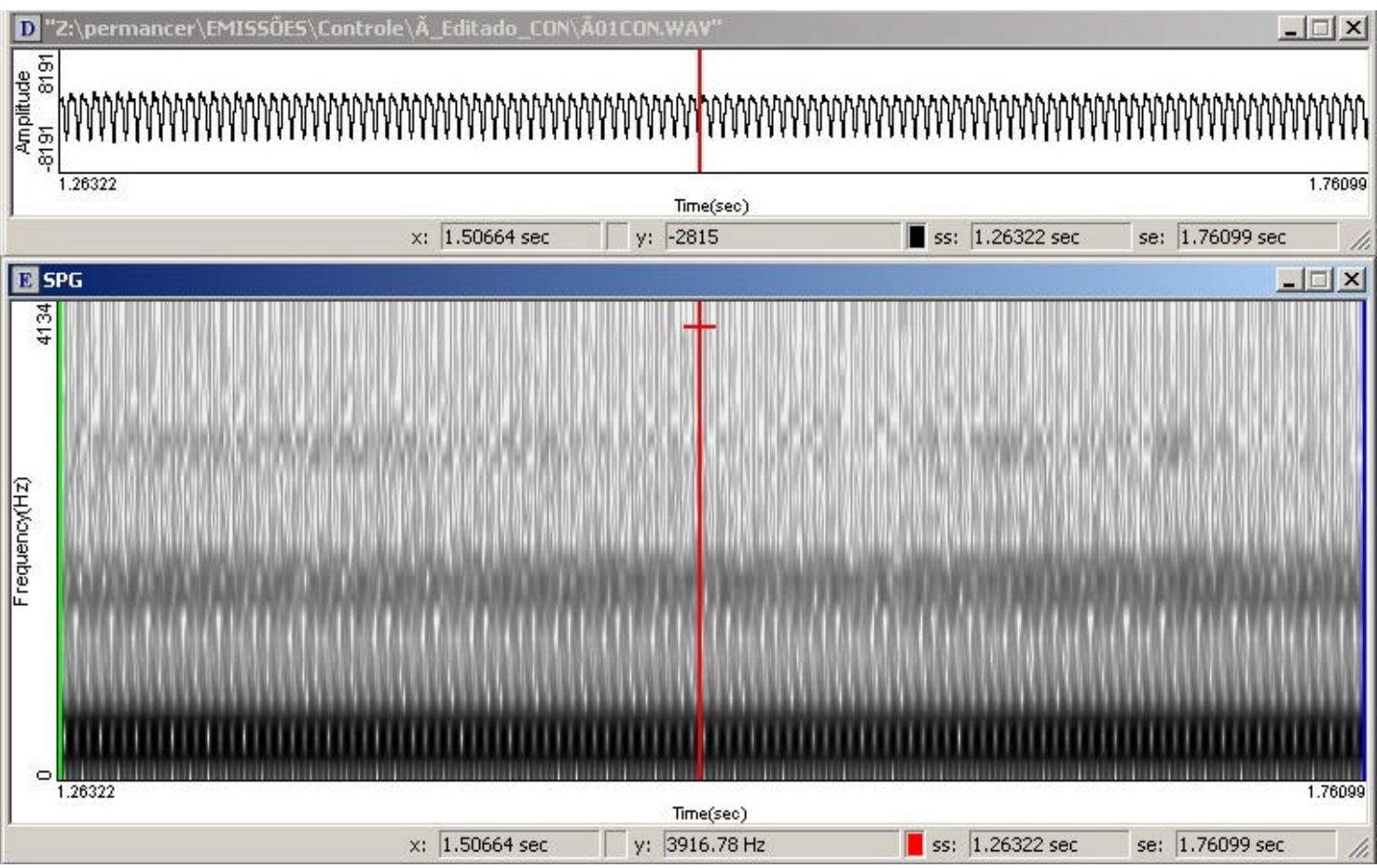

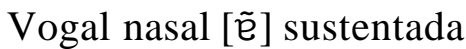


APÊNDICE H - Forma de onda das emissões das vogais [a] e [ẽ] sustentadas (A) e seu respectivo espectrograma $(\mathrm{B})$ da participante com protocolo número 02 do grupo CON.

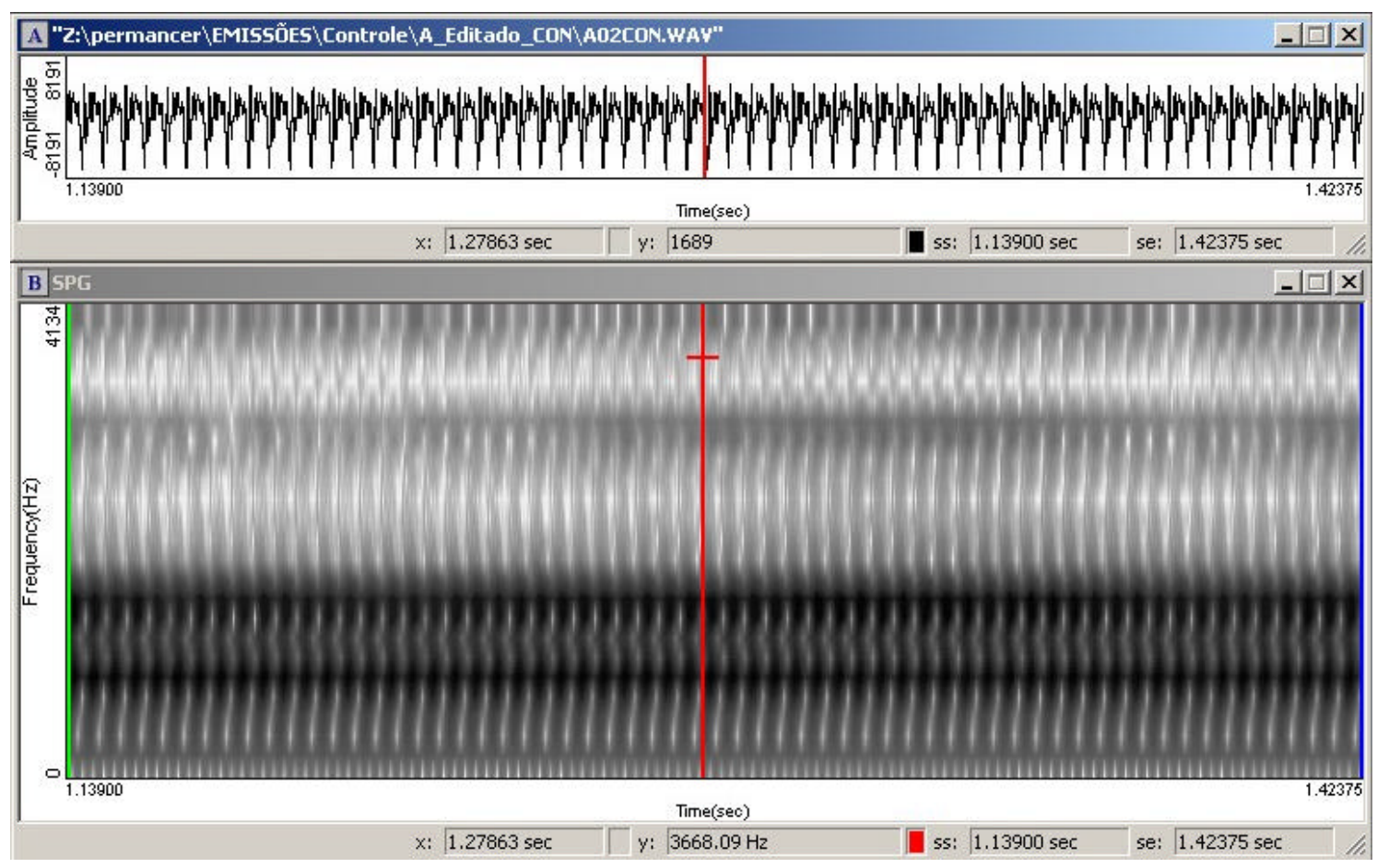

Vogal oral [a] sustentada

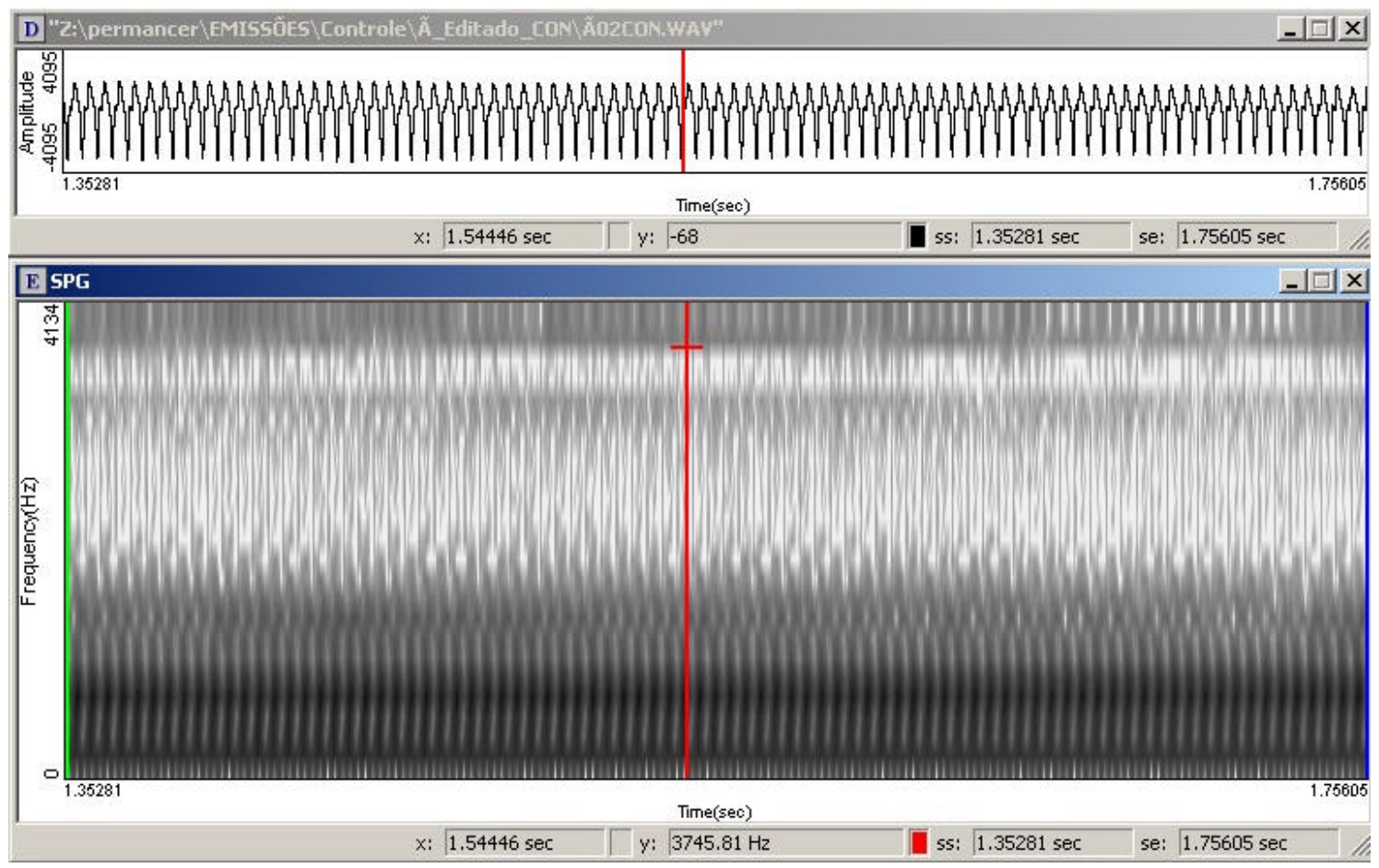

Vogal nasal [ẽ $]$ sustentada 
APÊEDICE I - Forma de onda das emissões das vogais [a] e [ẽ ] sustentadas (A) e seu respectivo espectrograma $(\mathrm{B})$ da participante com protocolo número 03 dogrupoCON.

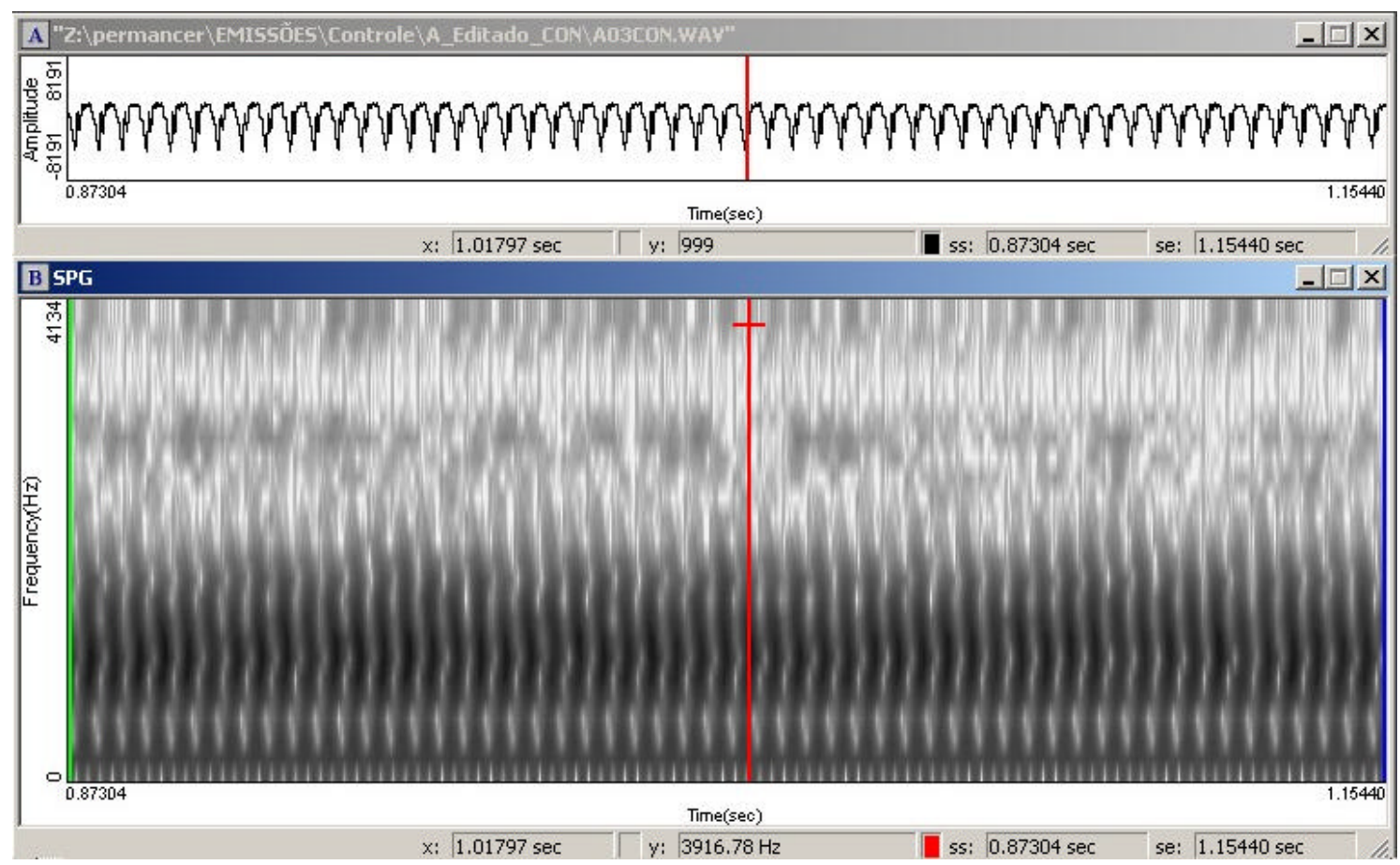

Vogal oral [a] sustentada

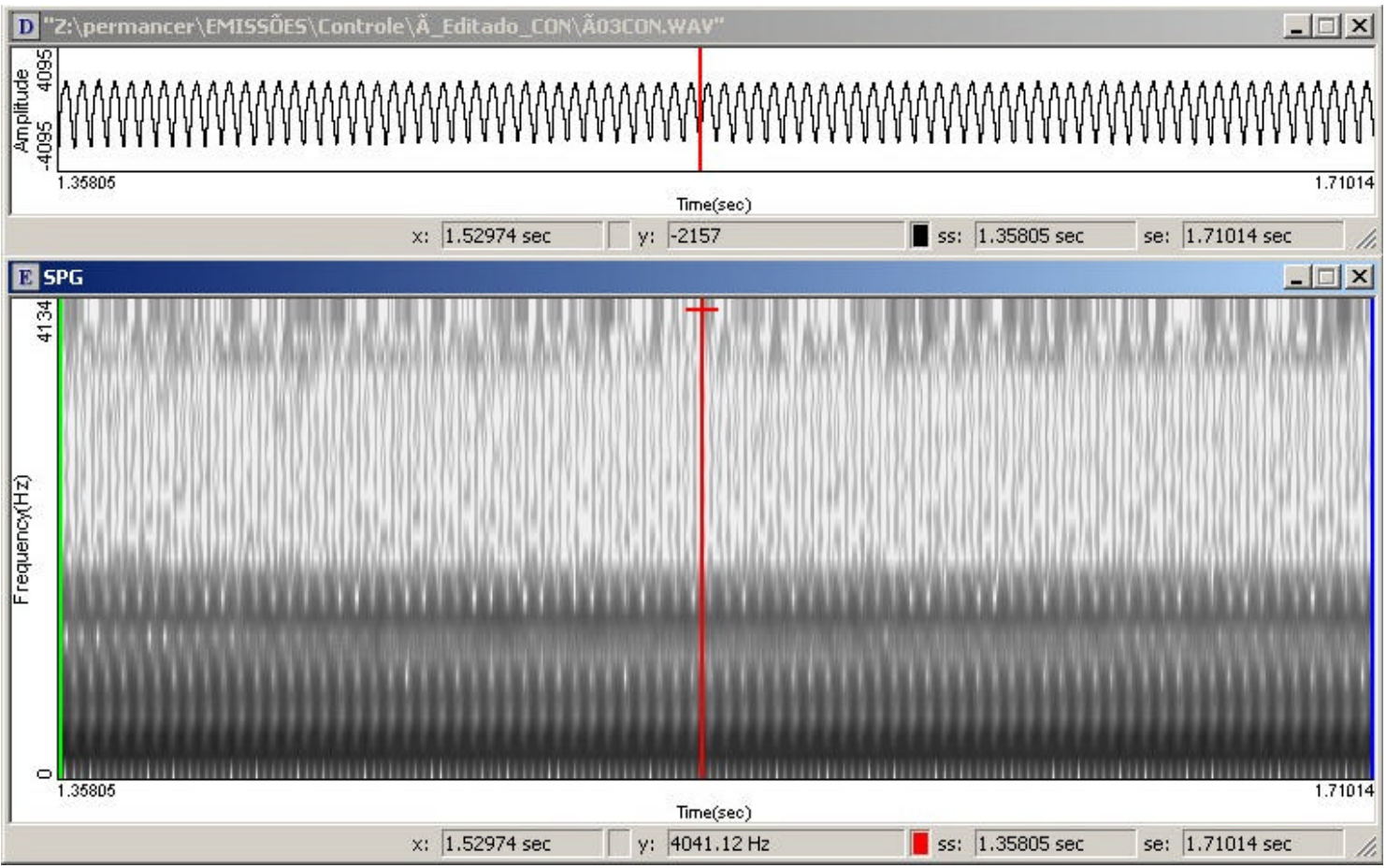

Vogal nasal [ẽ $]$ sustentada 


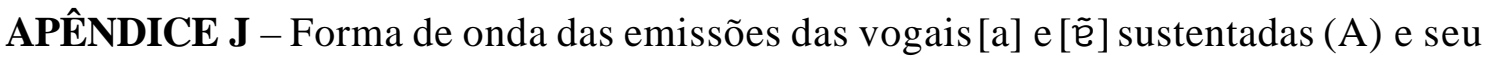
respectivo espectrograma $(\mathrm{B})$ da participante com protocolo número 04 do grupo CON.

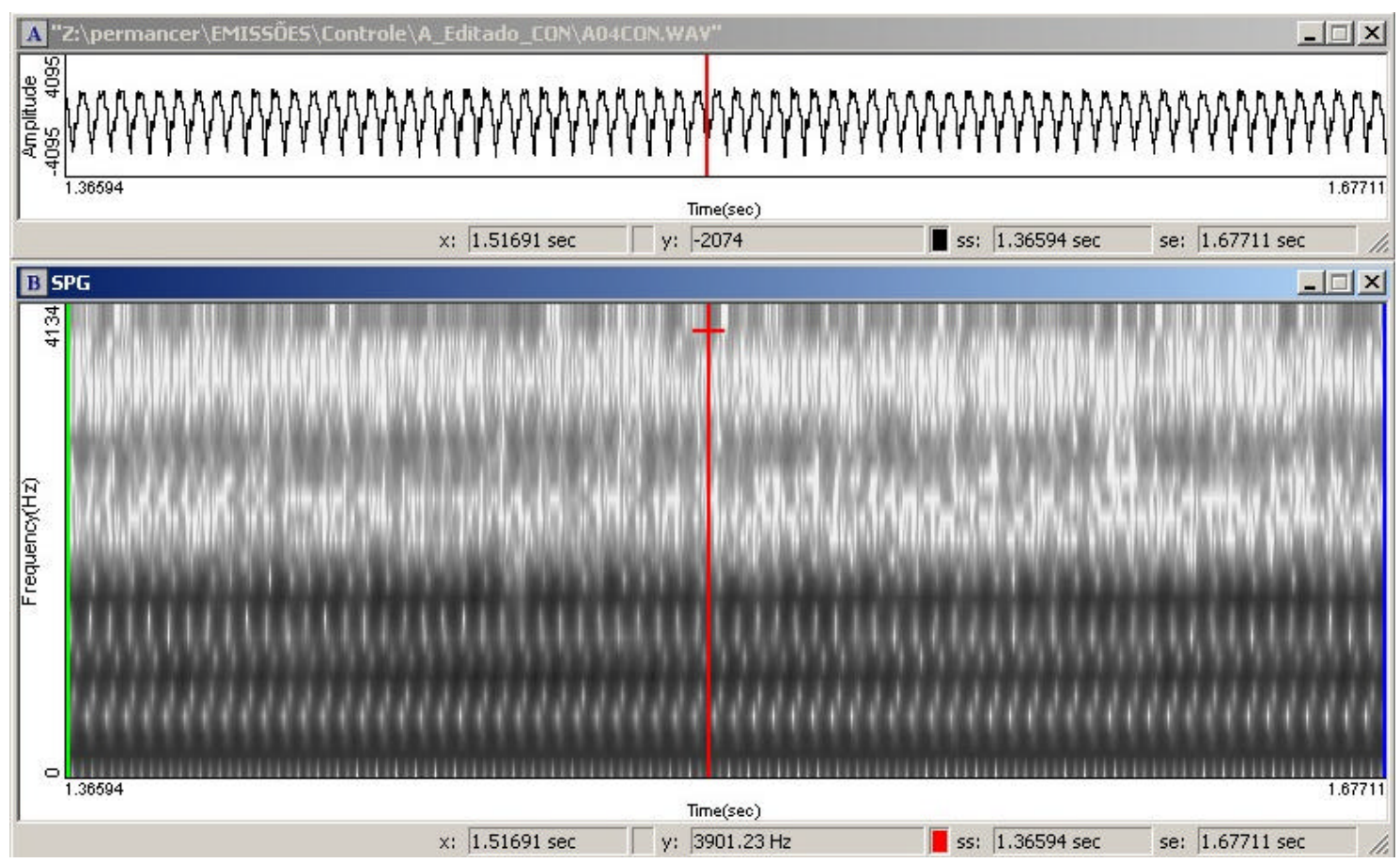

Vogal oral [a] sustentada

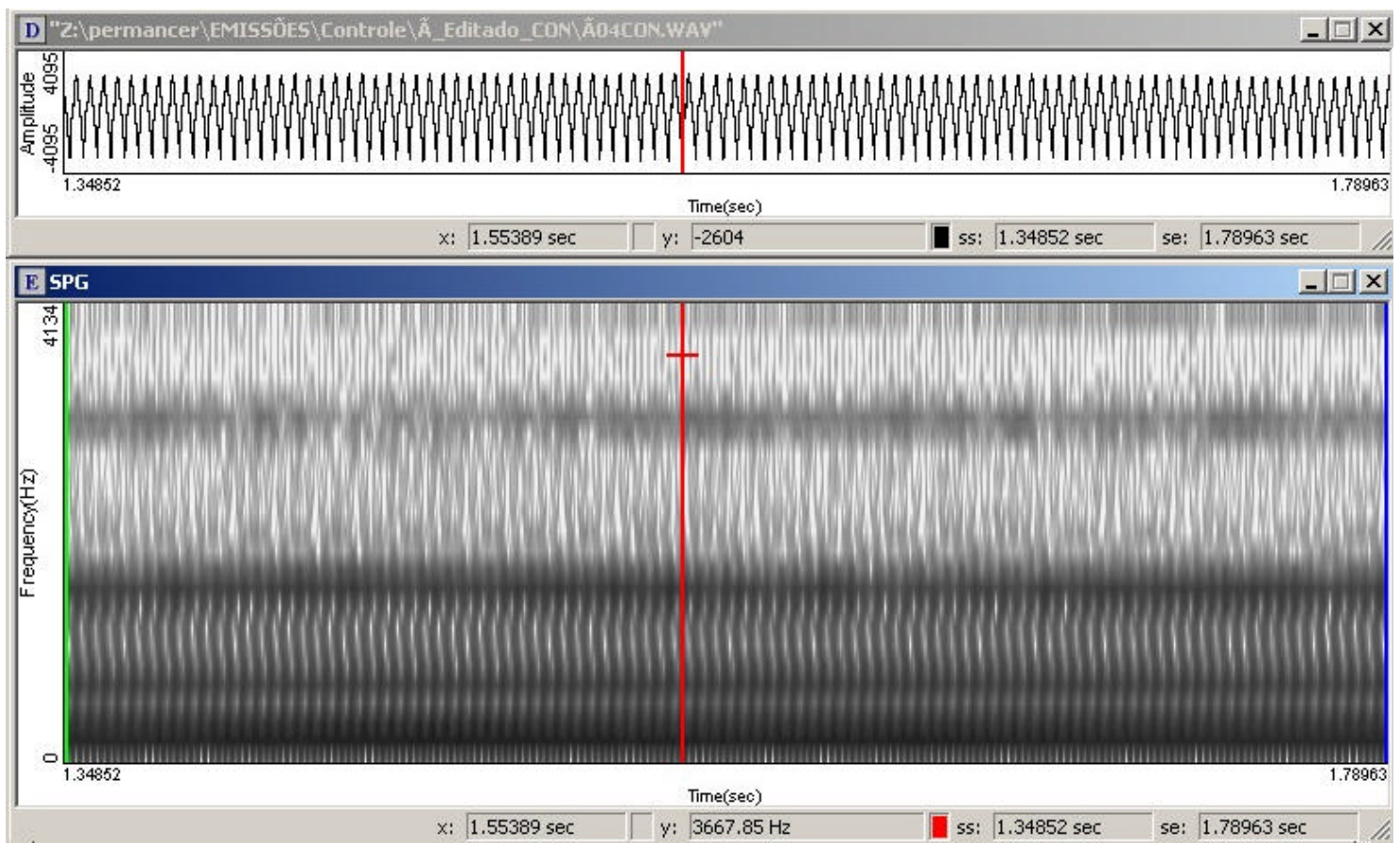

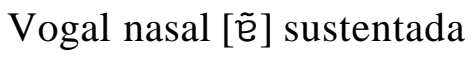


APÊNDICE K - Forma de onda das emissões das vogais [a] e [ẽ ] sustentadas (A) e seu respectivo espectrograma $(\mathrm{B})$ da participante com protocolo número 05 dogrupoCON.

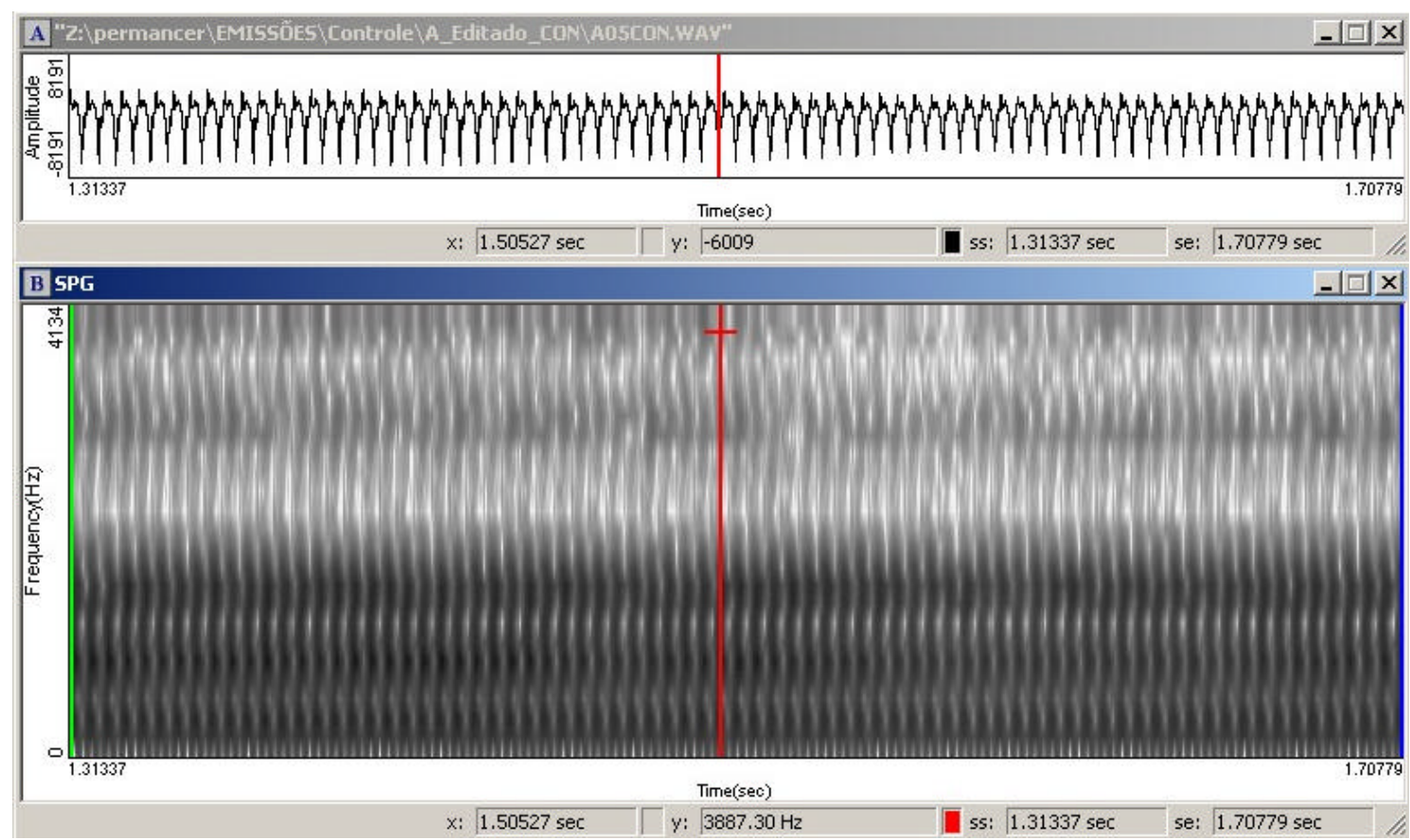

Vogal oral [a] sustentada

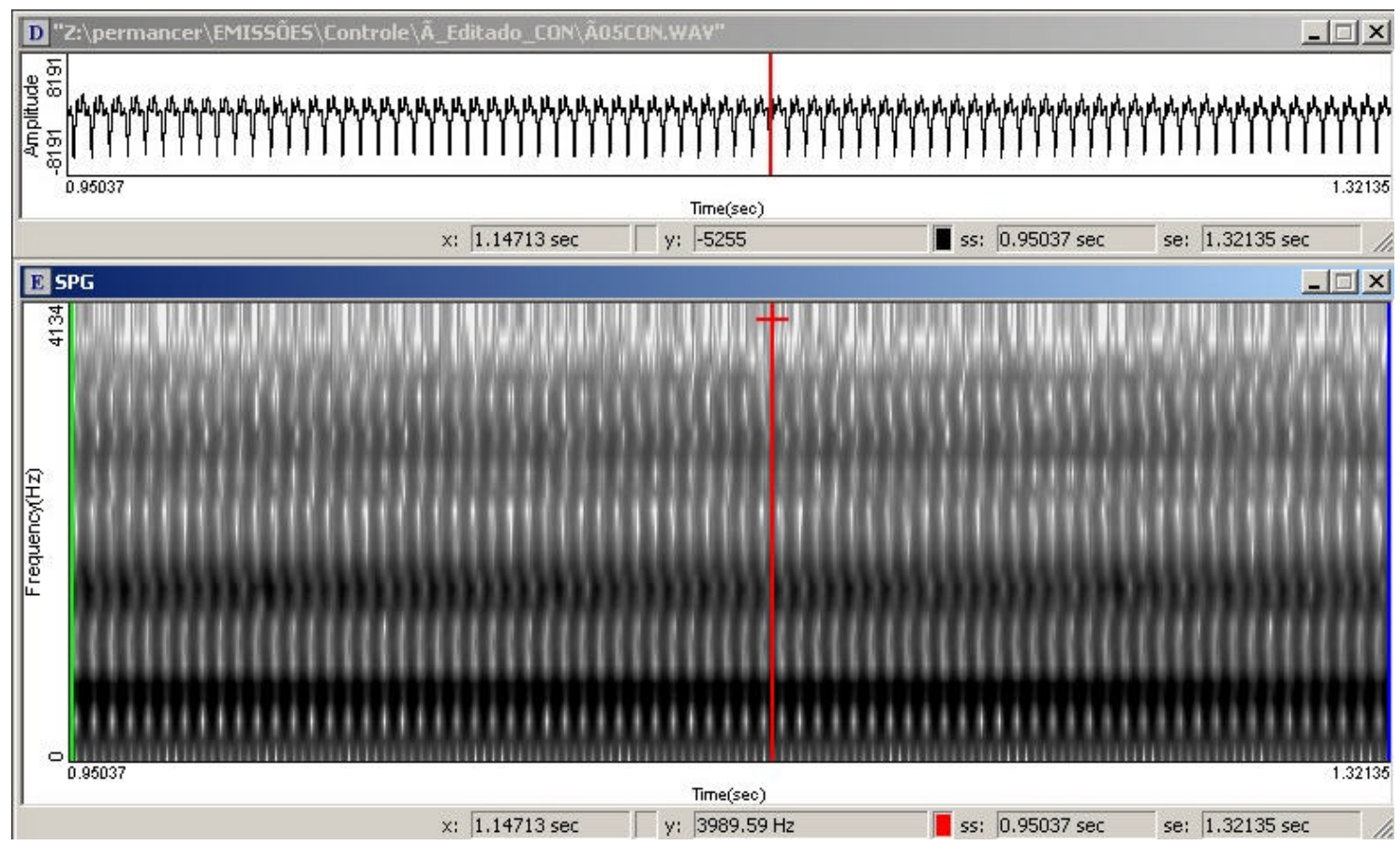

Vogal nasal [ẽ ] sustentada 
APÊNDICE L - Forma de onda das emissões das vogais [a] e [ẽe] sustentadas (A) e seu respectivo espectrograma (B) da participante com protocolo número 06 do grupo CON.

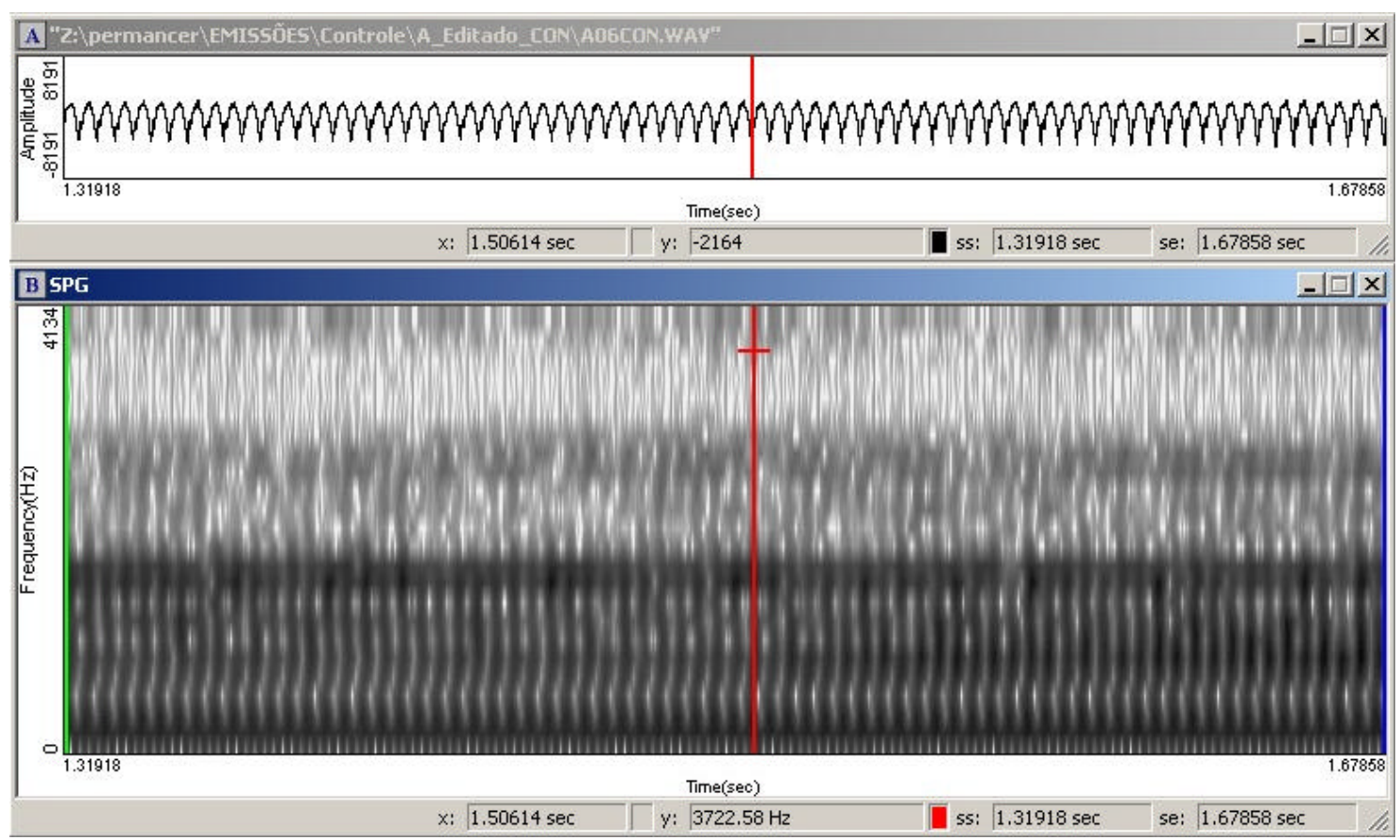

Vogal oral [a] sustentada

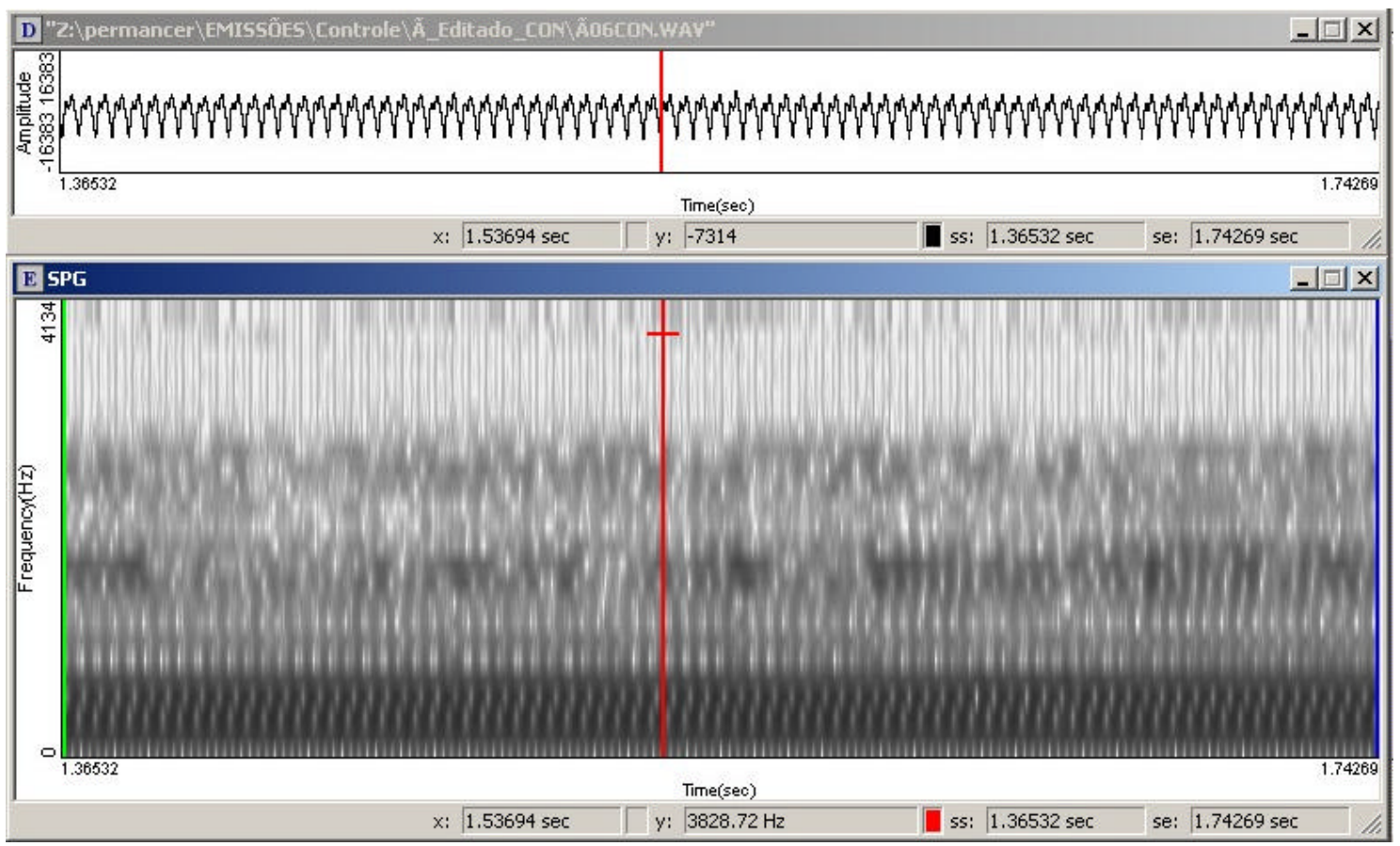

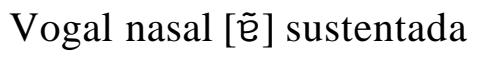


APÊEDICE M - Forma de onda das emissões das vogais [a] e [ẽ] sustentadas (A) e seu respectivo espectrograma $(\mathrm{B})$ da participante com protocolo número 07 do grupo CON.

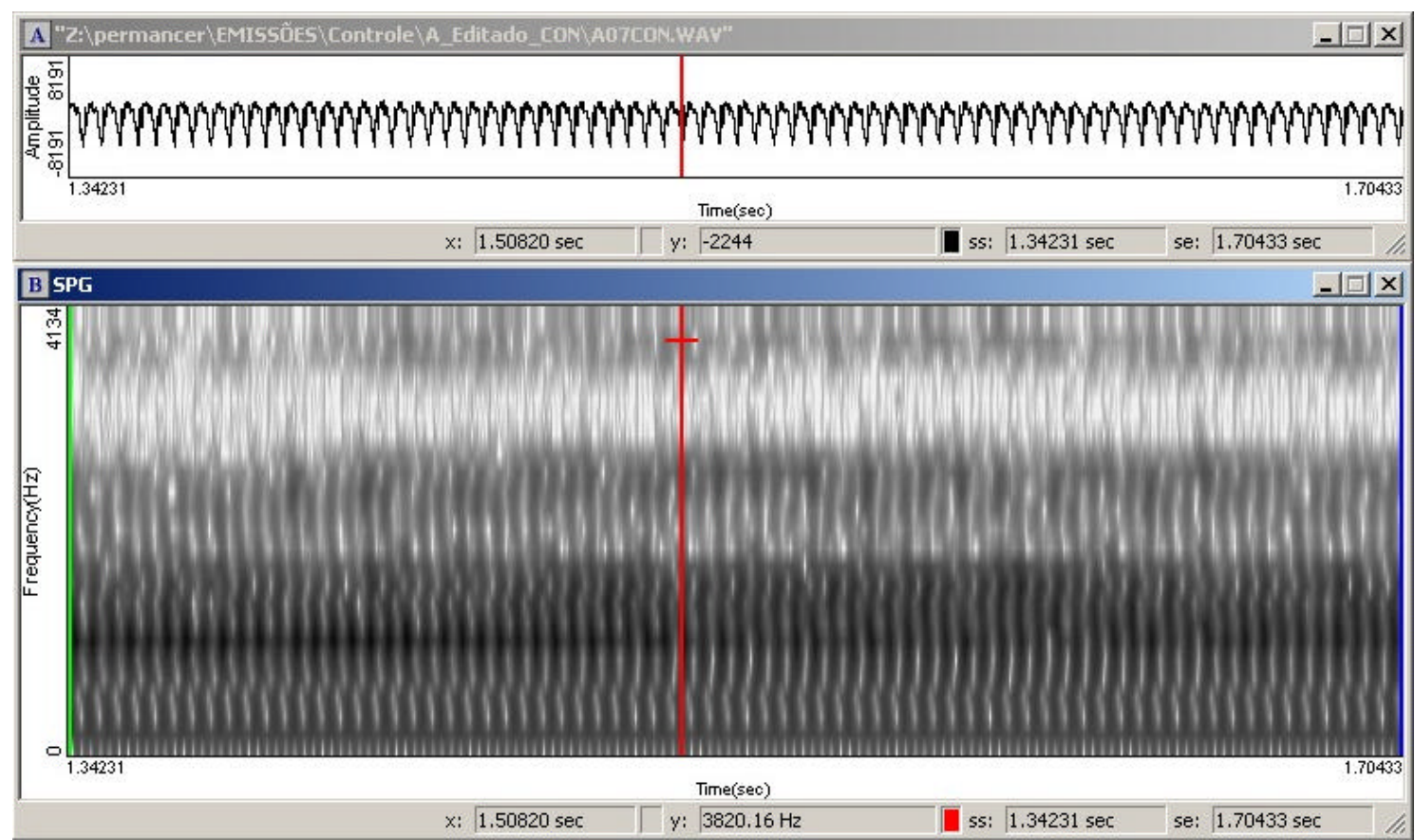

Vogal oral [a] sustentada

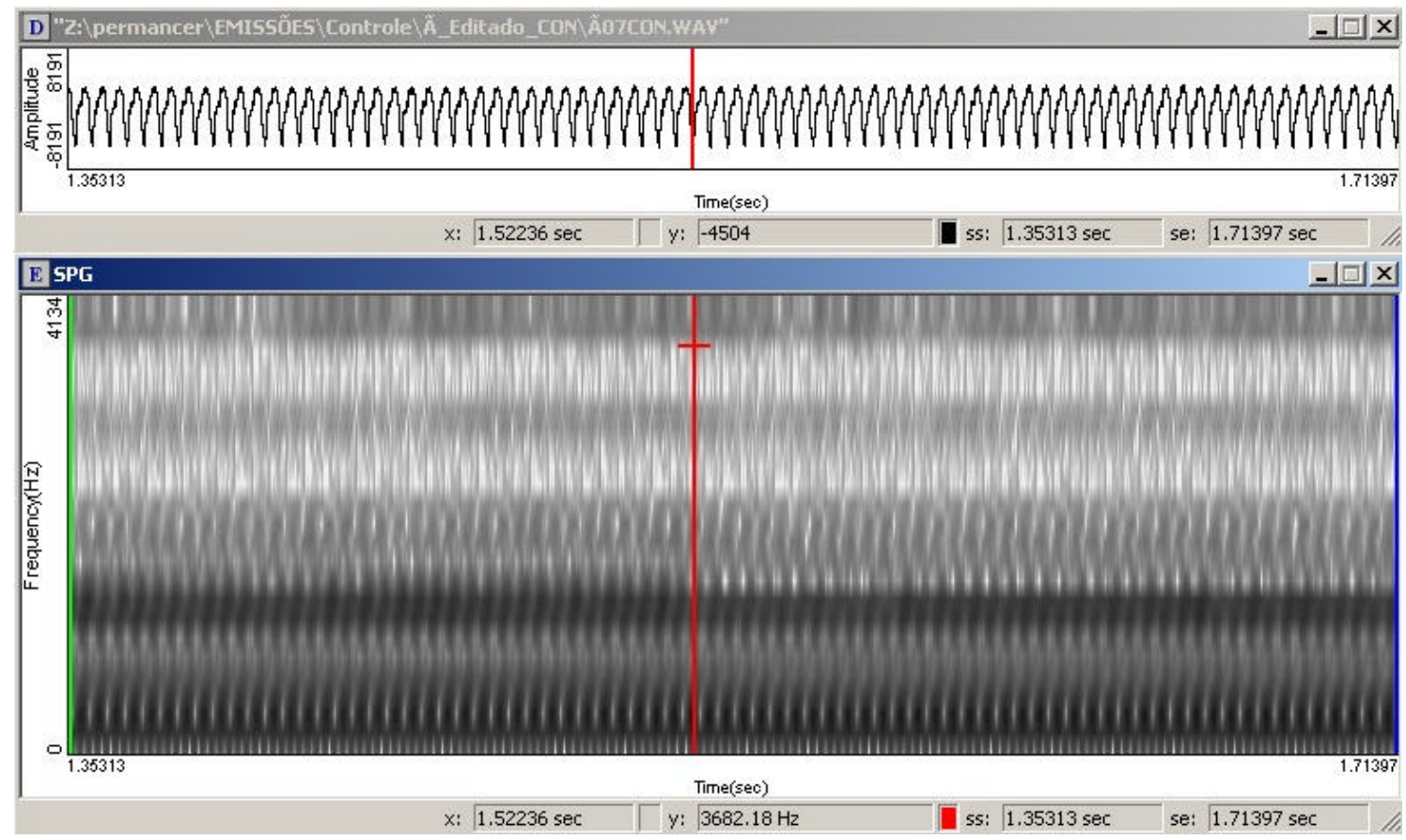

Vogal nasal /ã/ sustentada 
APÊNDICE N - Forma de onda das emissões das vogais [a] e [ẽe] sustentadas (A) e seu respectivo espectrograma (B) da participante com protocolo número 08 do grupo CON.

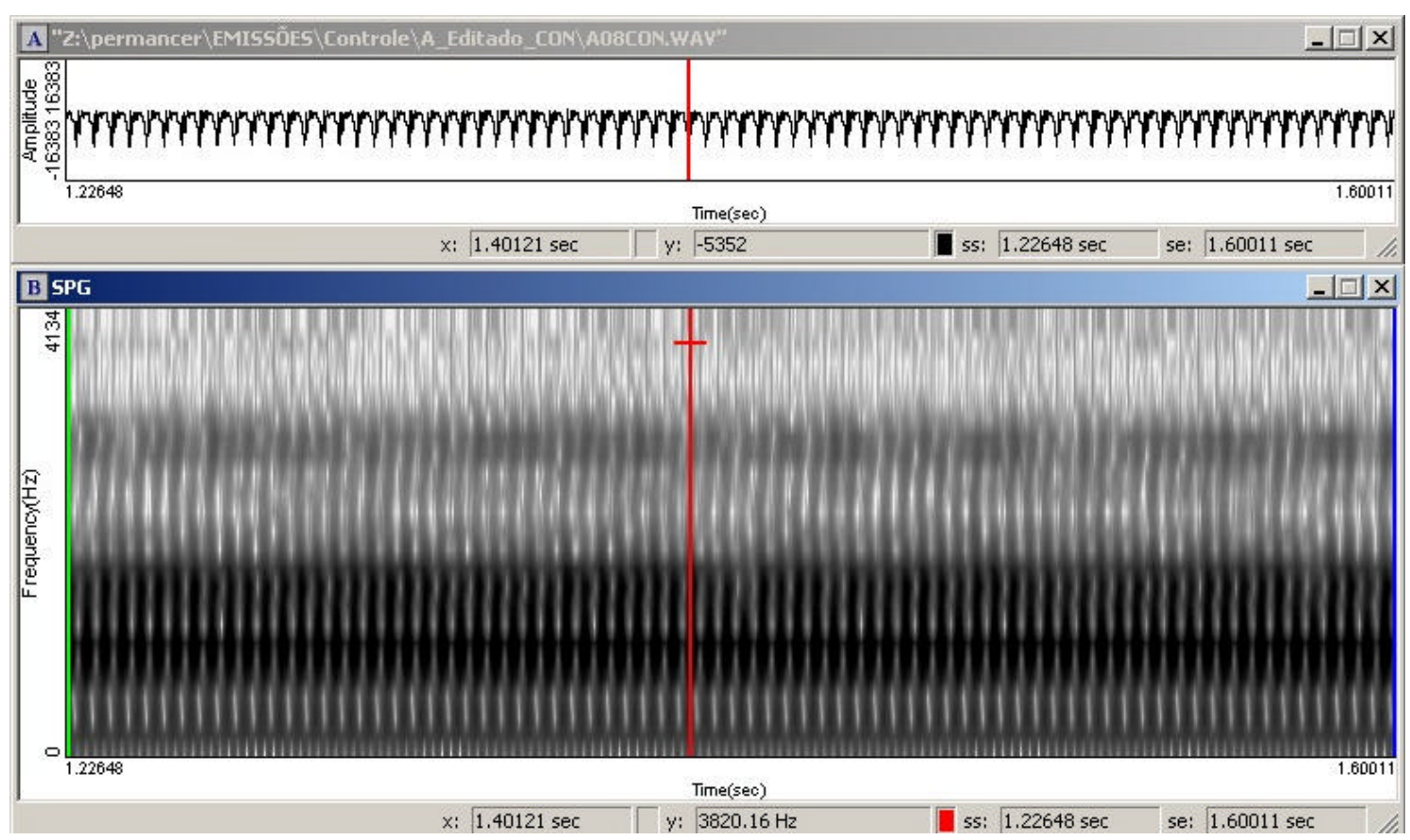

Vogal oral [a] sustentada

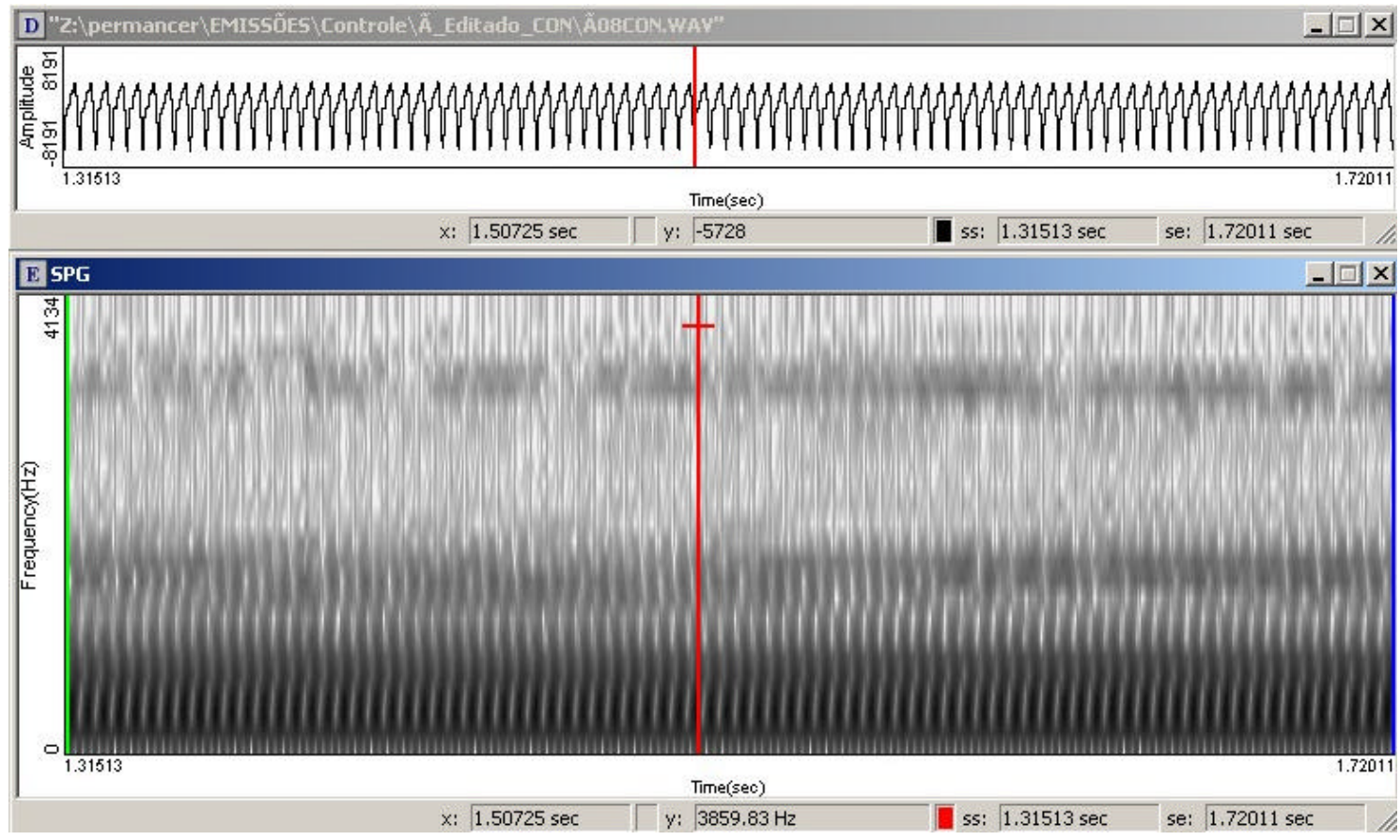

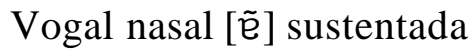


APÊNDICE O - Forma de onda das emissões das vogais [a] e [ẽe] sustentadas (A) e seu respectivo espectrograma (B) da participante com protocolo número 09 do grupo CON.

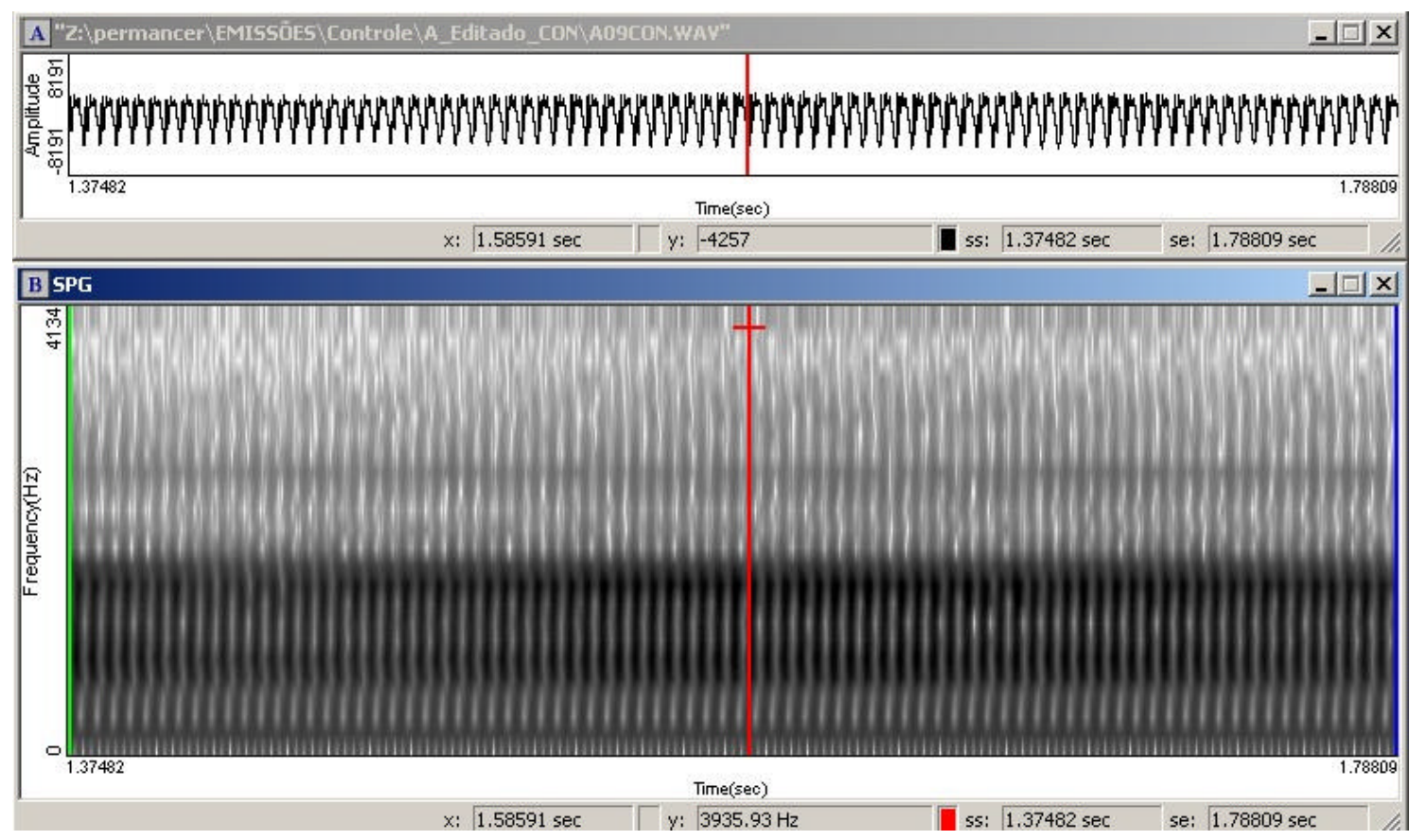

Vogal oral [a] sustentada
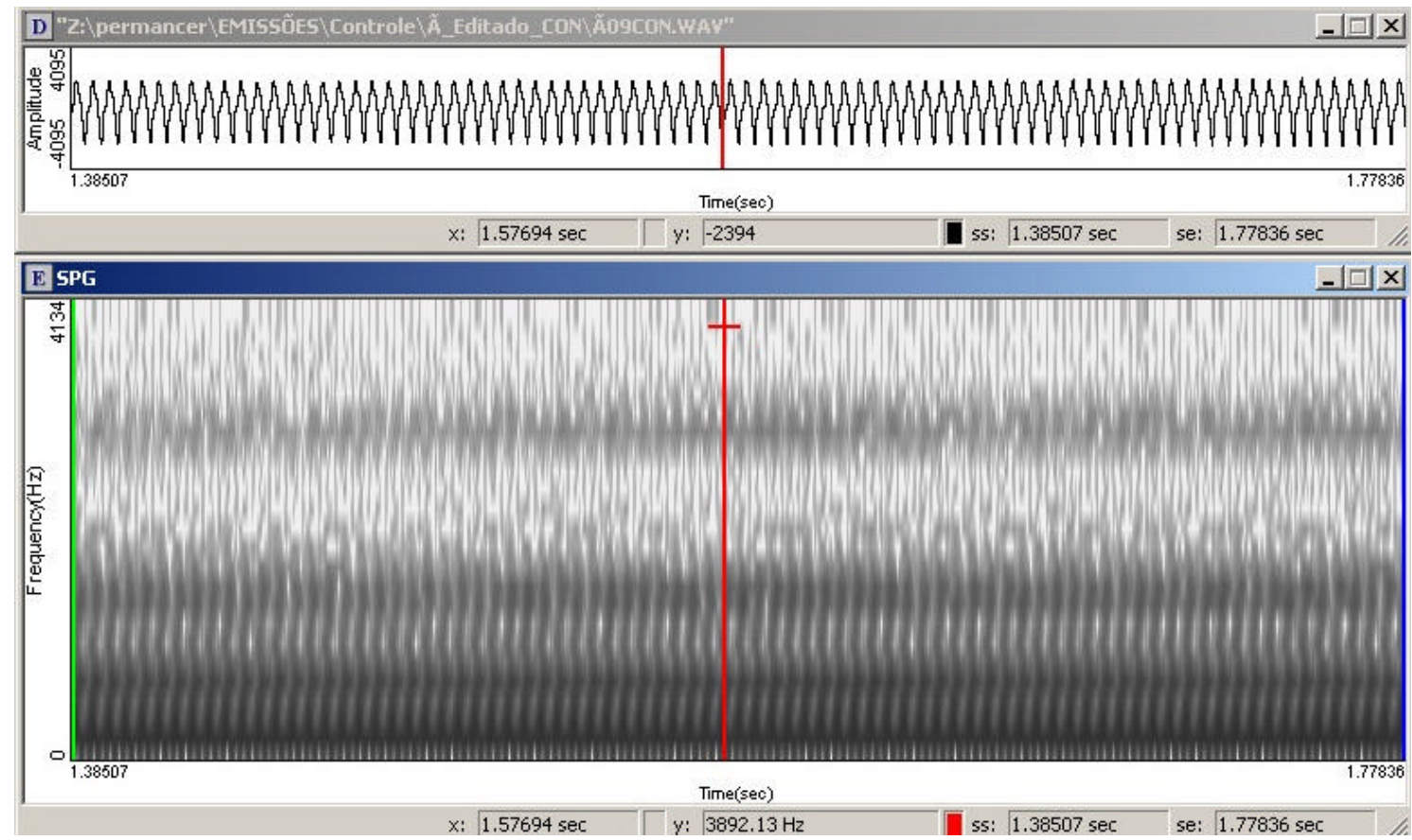

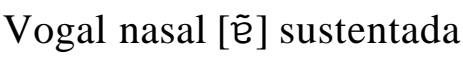




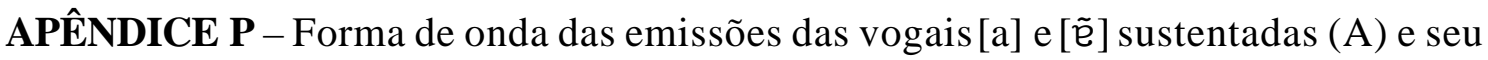
respectivo espectrograma $(\mathrm{B})$ da participante com protocolo número 10 do grupo CON.

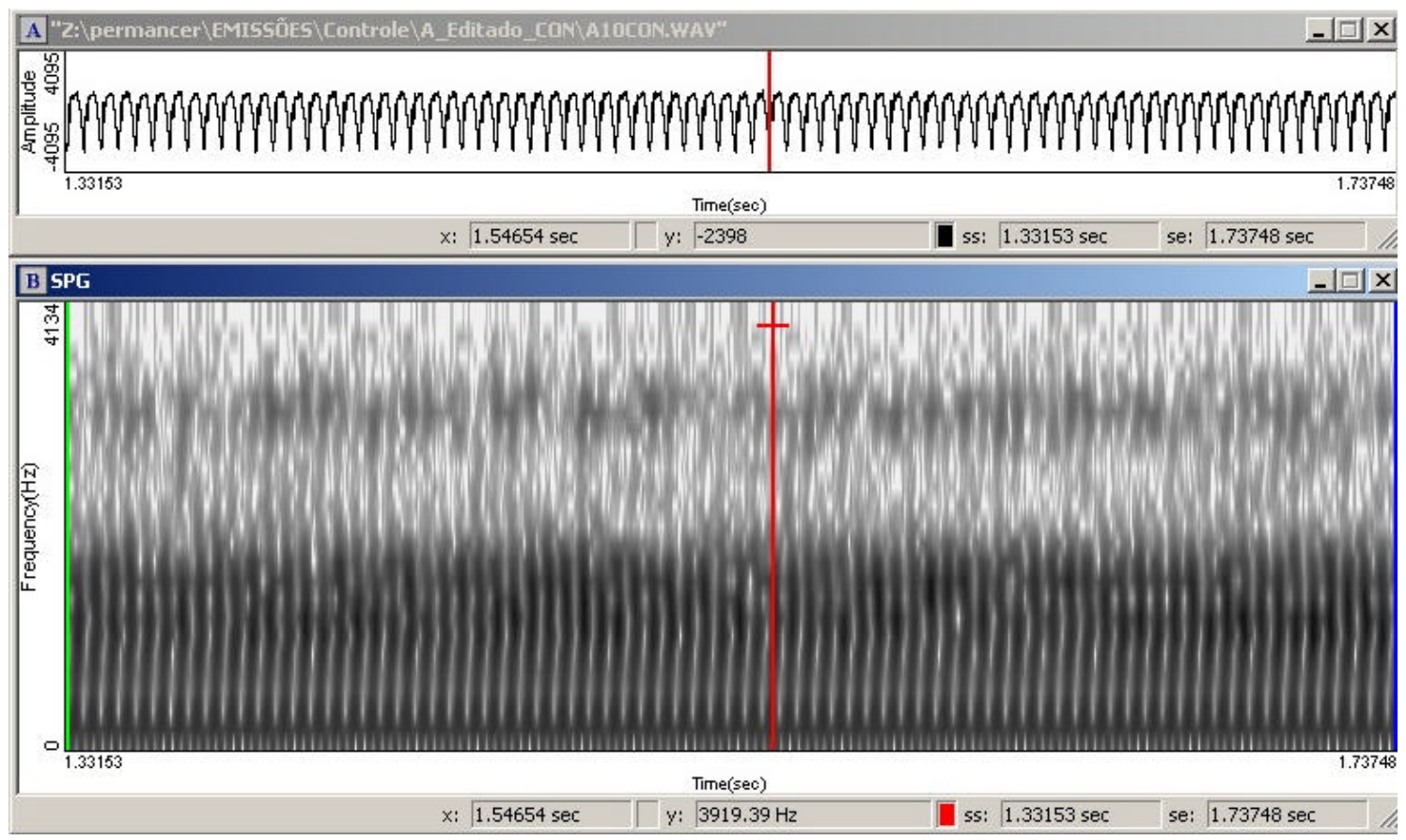

Vogal oral [a] sustentada

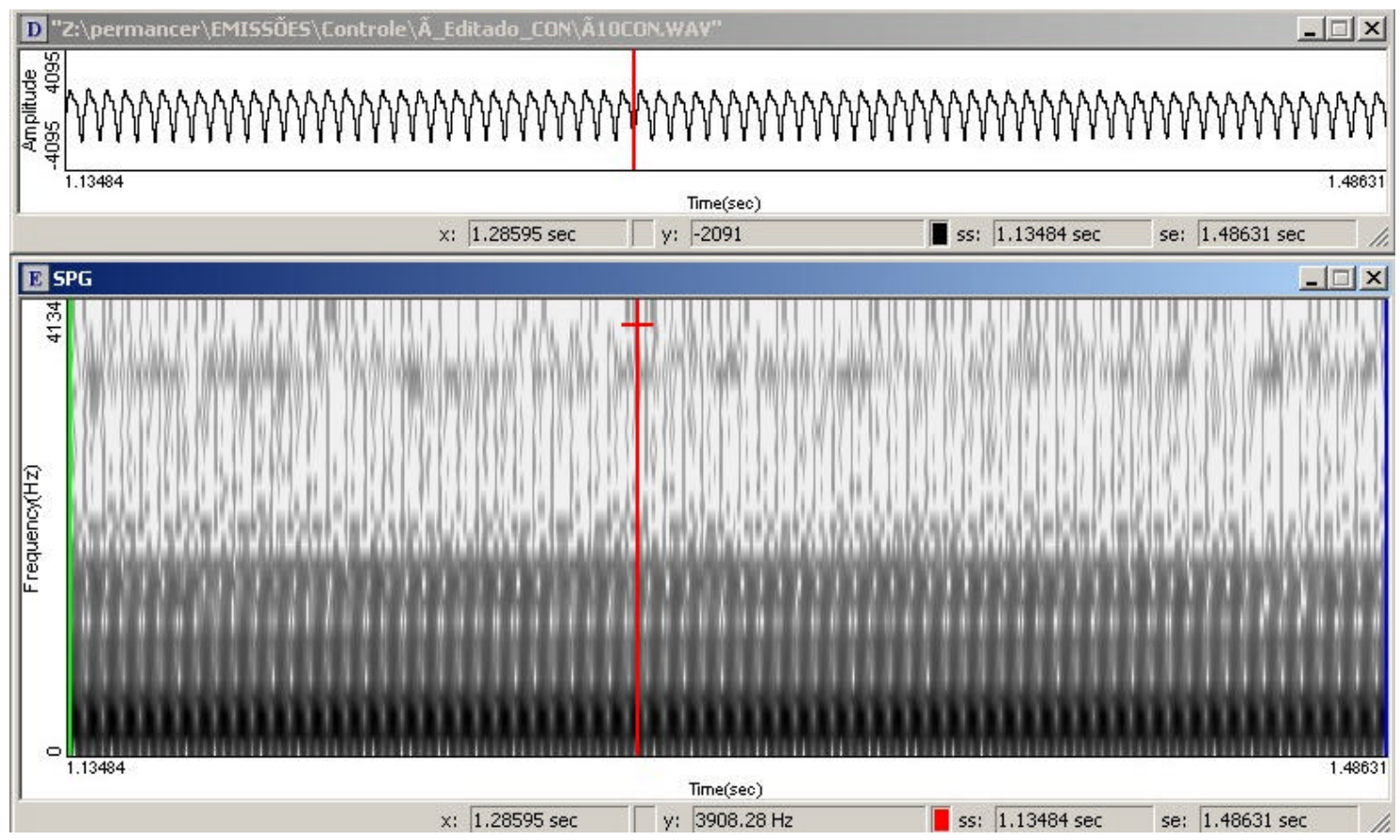

Vogal nasal [ẽ] sustentada 
APÊEDICE Q - Forma de onda das emissões das vogais [a] e [ẽe] sustentadas (A) e seu respectivo espectrograma $(\mathrm{B})$ da participante com protocolo número 11 do grupo CON.

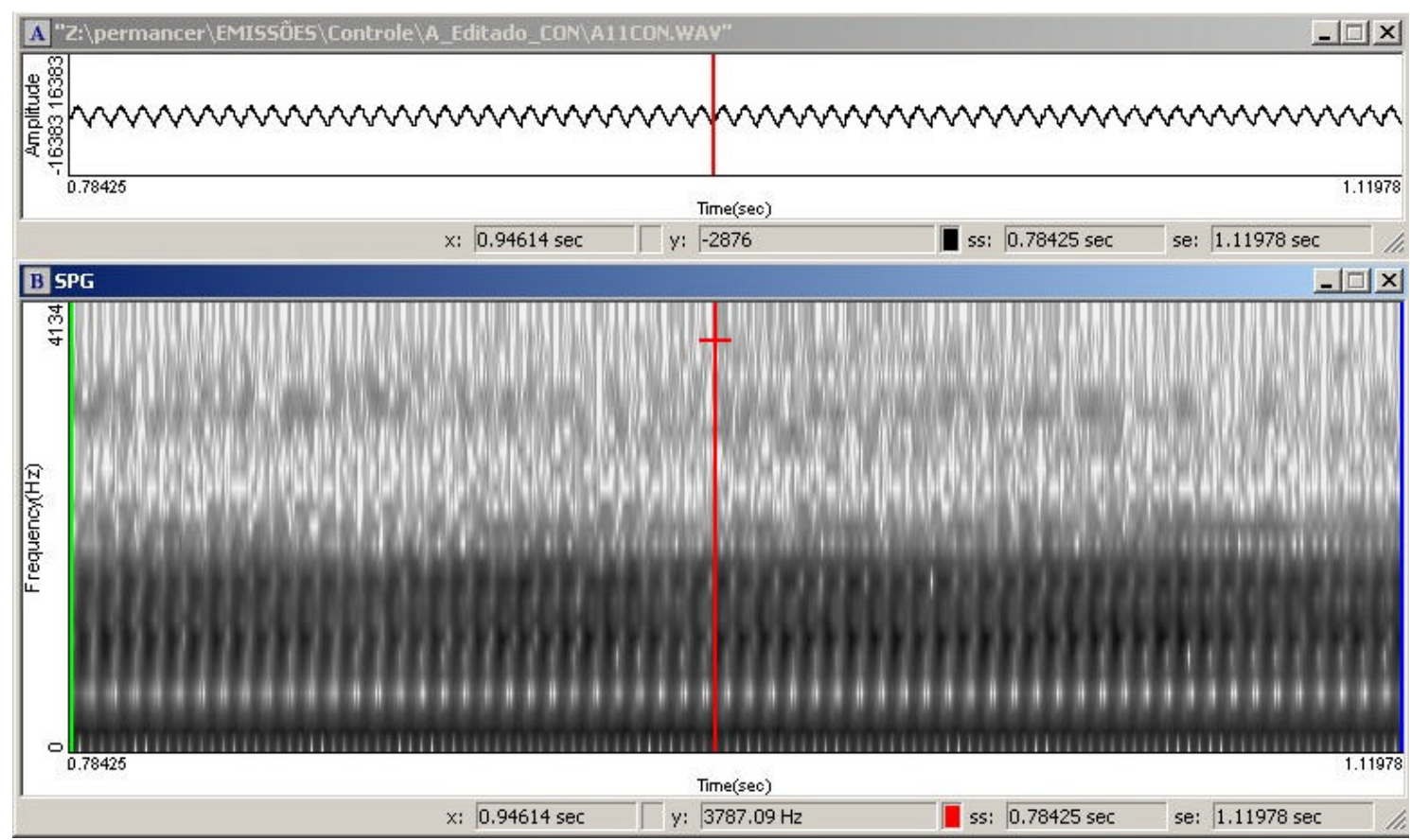

Vogal oral [a] sustentada

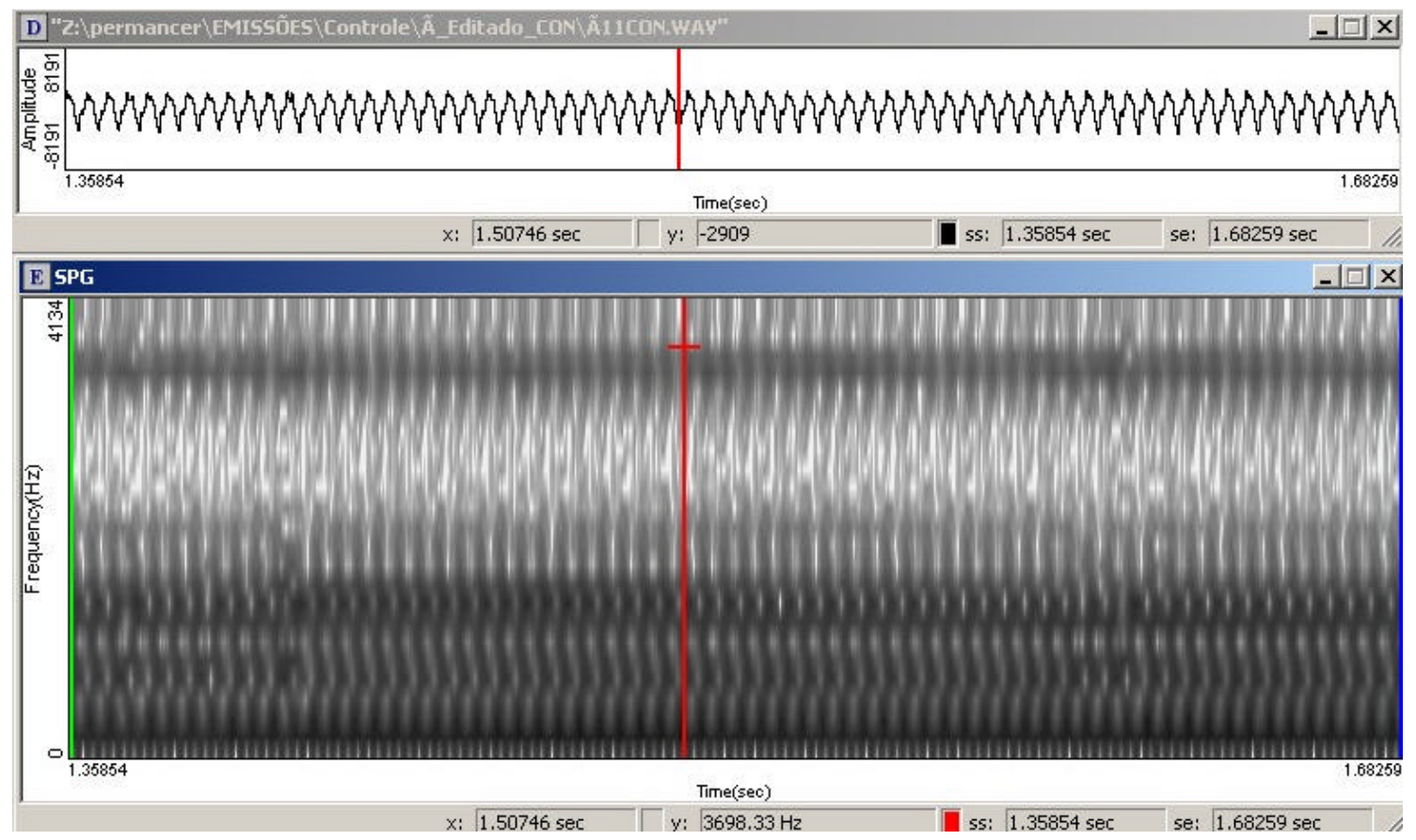

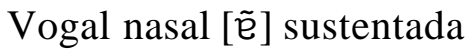


APÊNDICE R - Forma de onda das emissões das vogais [a] e [ẽ ] sustentadas (A) e seu respectivo espectrograma $(\mathrm{B})$ da participante com protocolo número 12 do grupo CON.

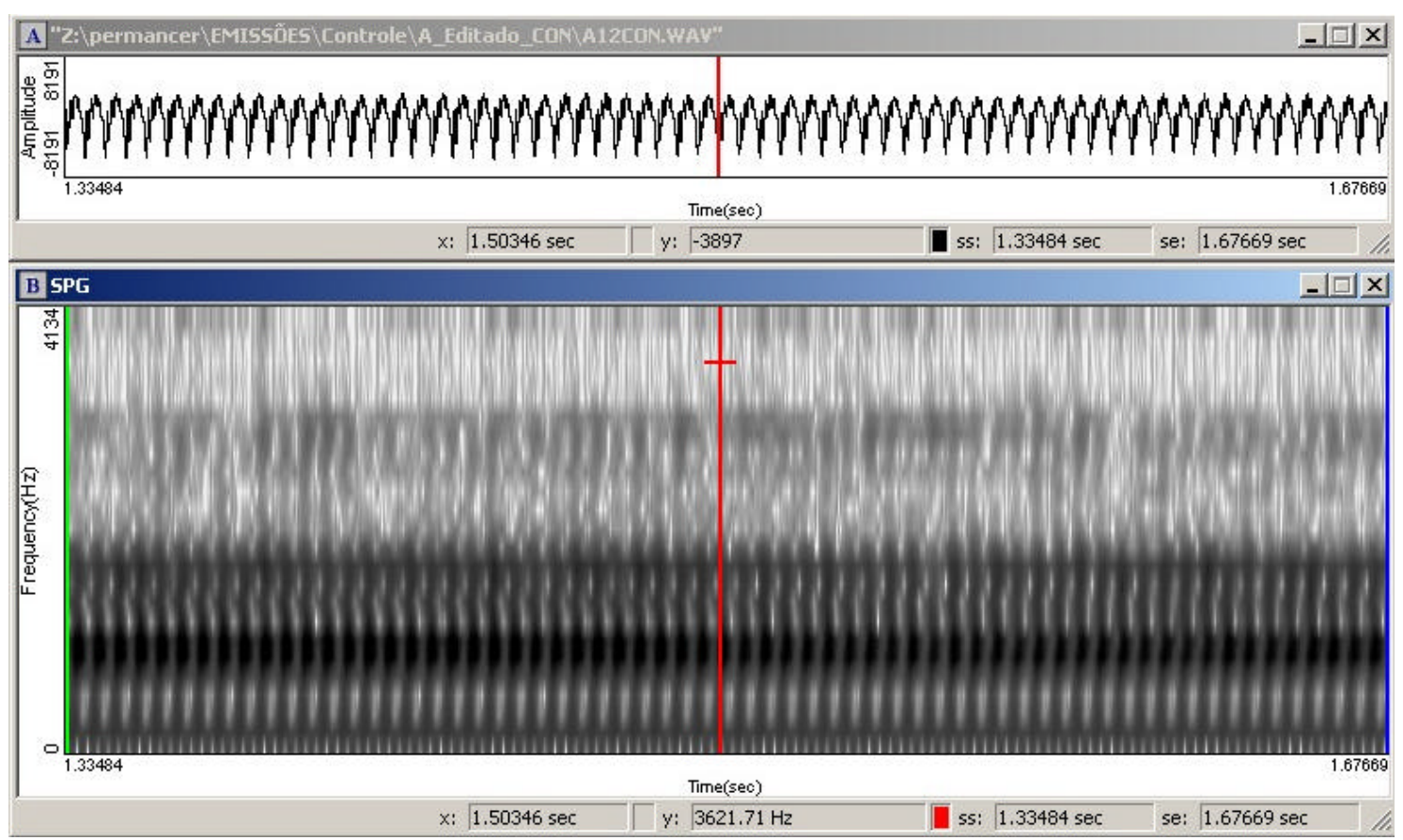

Vogal oral [a] sustentada

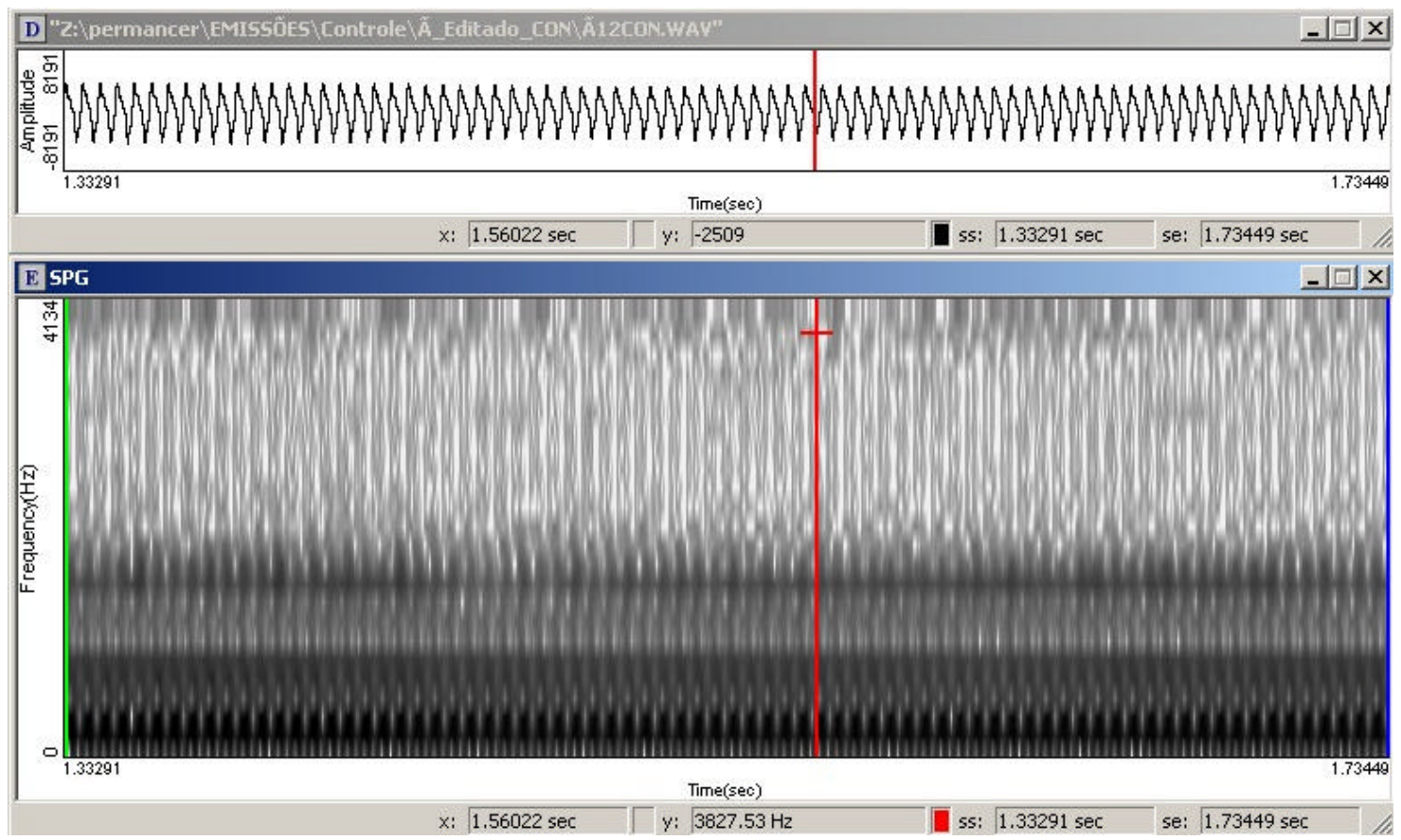

Vogal nasal [ẽ] sustentada 
APÊNDICE S - Forma de onda das emissões das vogais [a] e [ẽ ] sustentadas (A) e seu respectivo espectrograma $(\mathrm{B})$ da participante com protocolo número 13 do grupo CON.

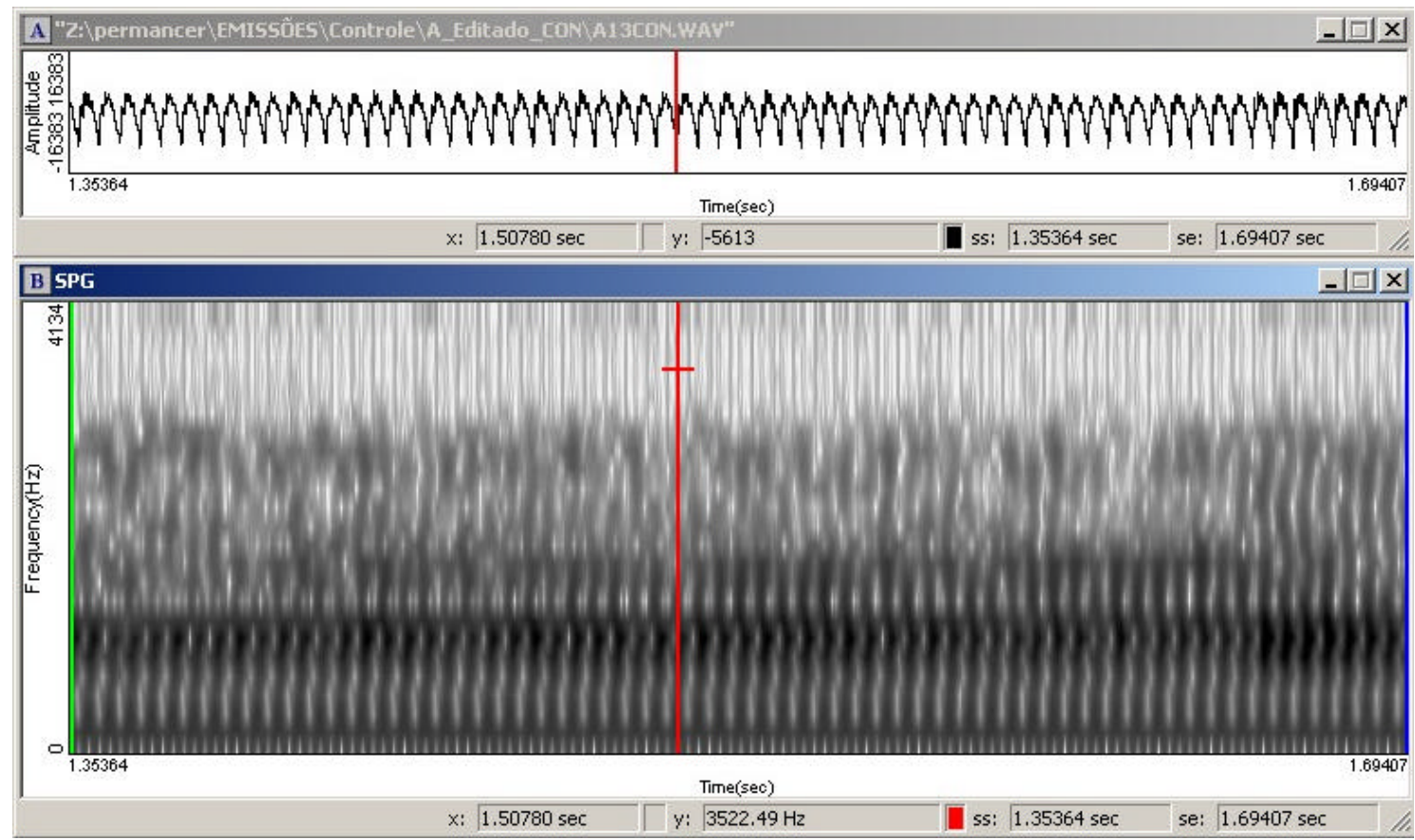

Vogal oral [a] sustentada

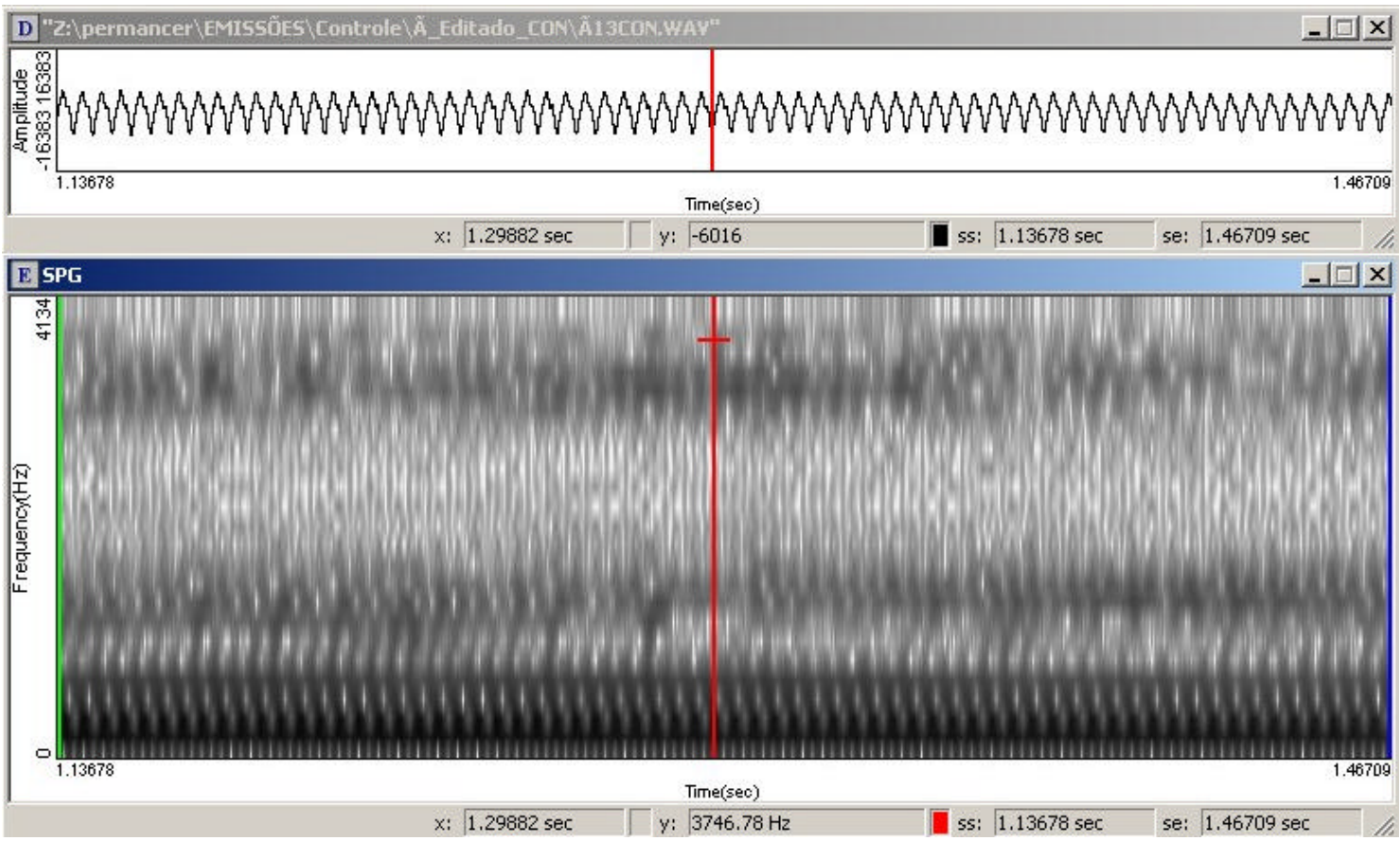

Vogal nasal [ẽ ] sustentada 


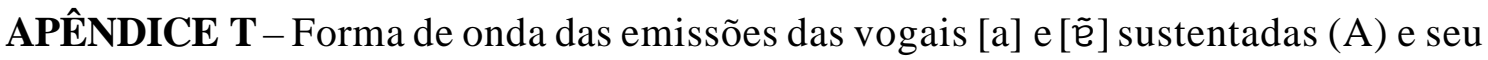
respectivo espectrograma $(\mathrm{B})$ da participante com protocolo número 14 do grupo $\mathrm{CON}$.

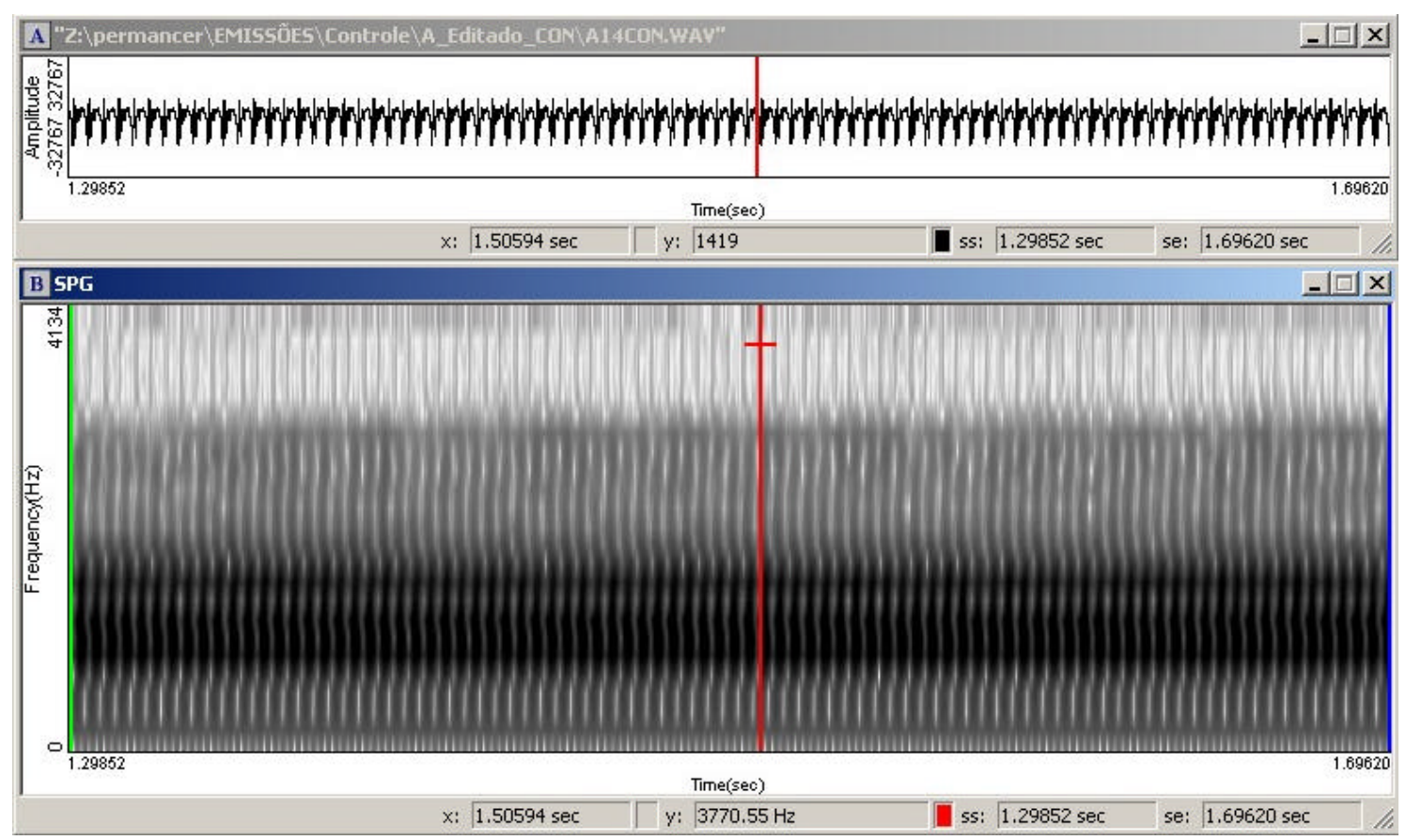

Vogal oral [a] sustentada

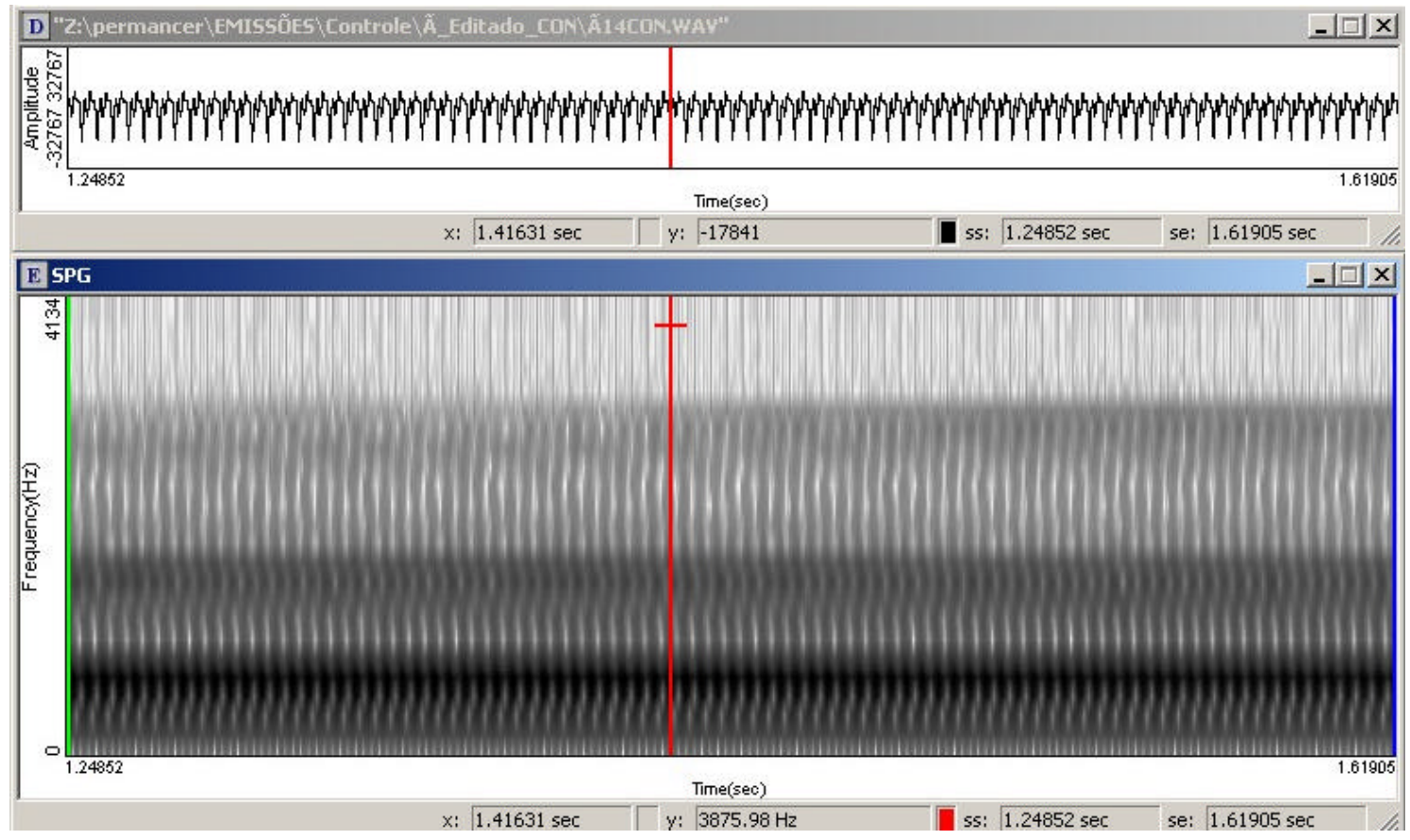

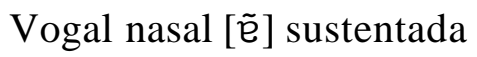


APÊNDICE U - Forma de onda das emissões das vogais [a] e [ẽ ] sustentadas (A) e seu respectivo espectrograma $(\mathrm{B})$ da participante com protocolo número 15 do grupo CON.

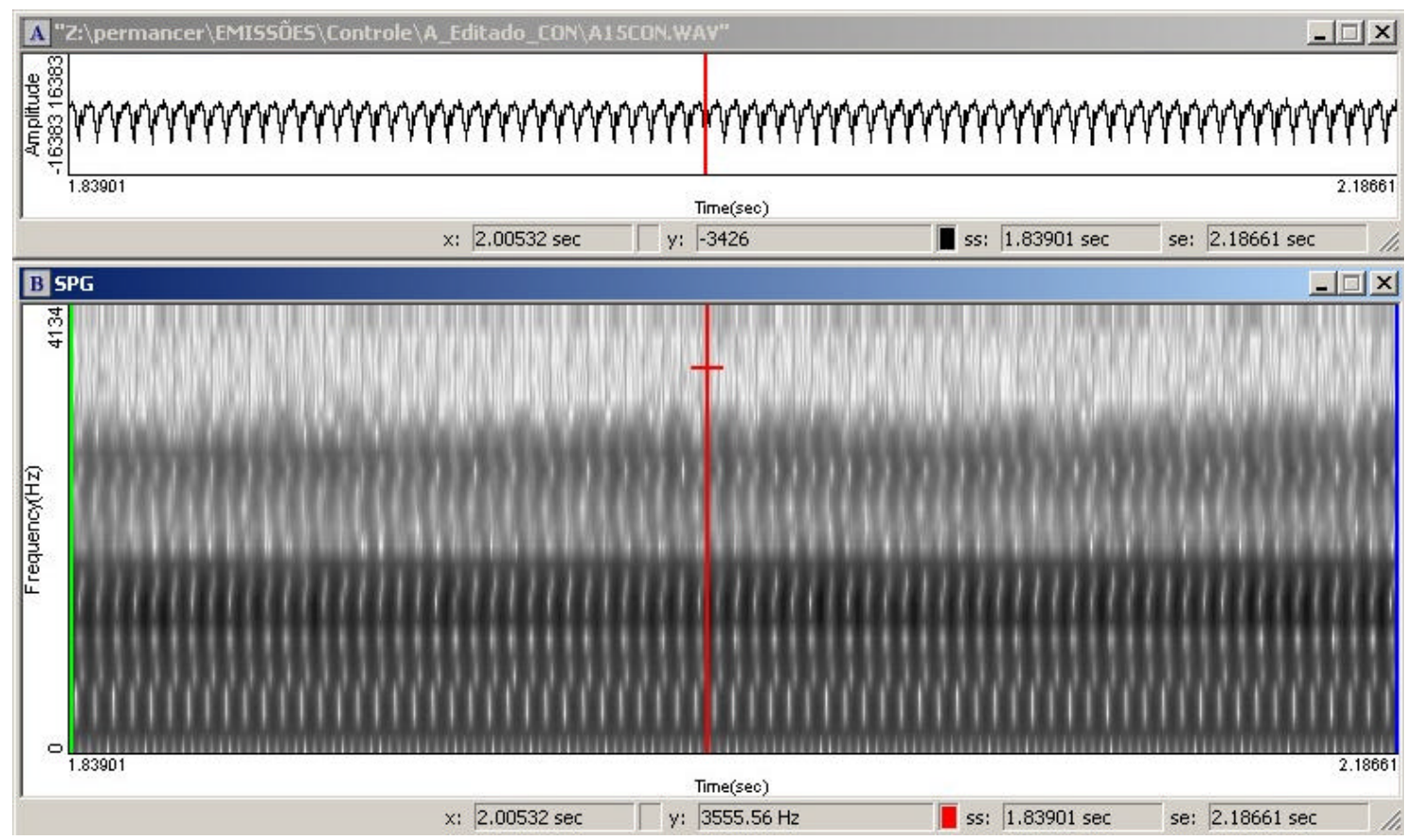

Vogal oral [a] sustentada

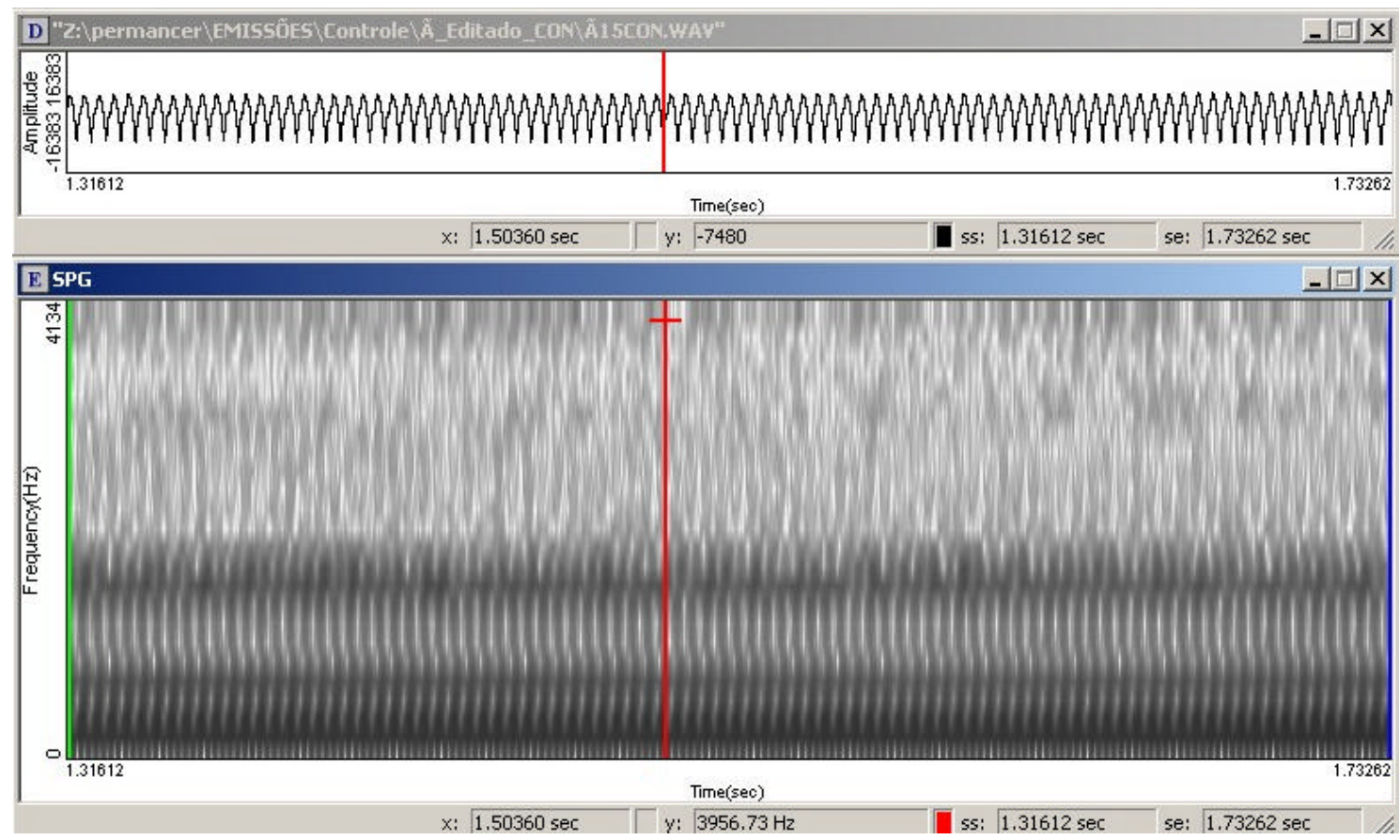

Vogal nasal [ẽ ] sustentada 


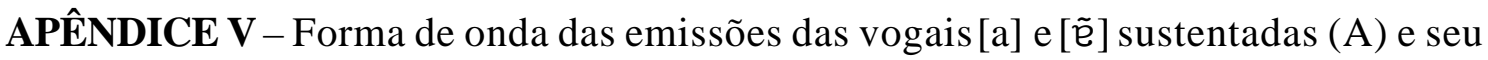
respectivo espectrograma $(\mathrm{B})$ da participante com protocolo número 16 do grupo CON.

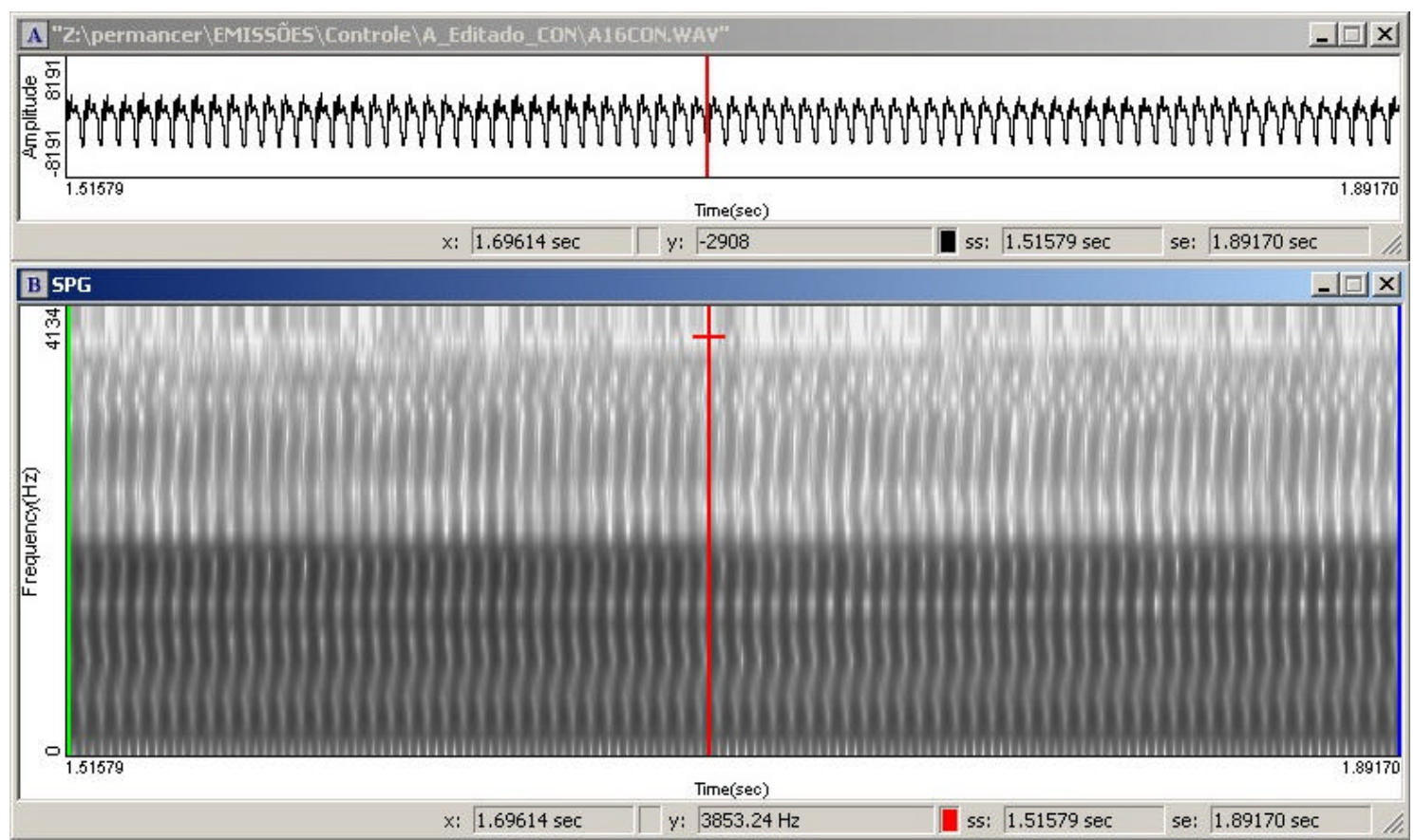

Vogal oral [a] sustentada

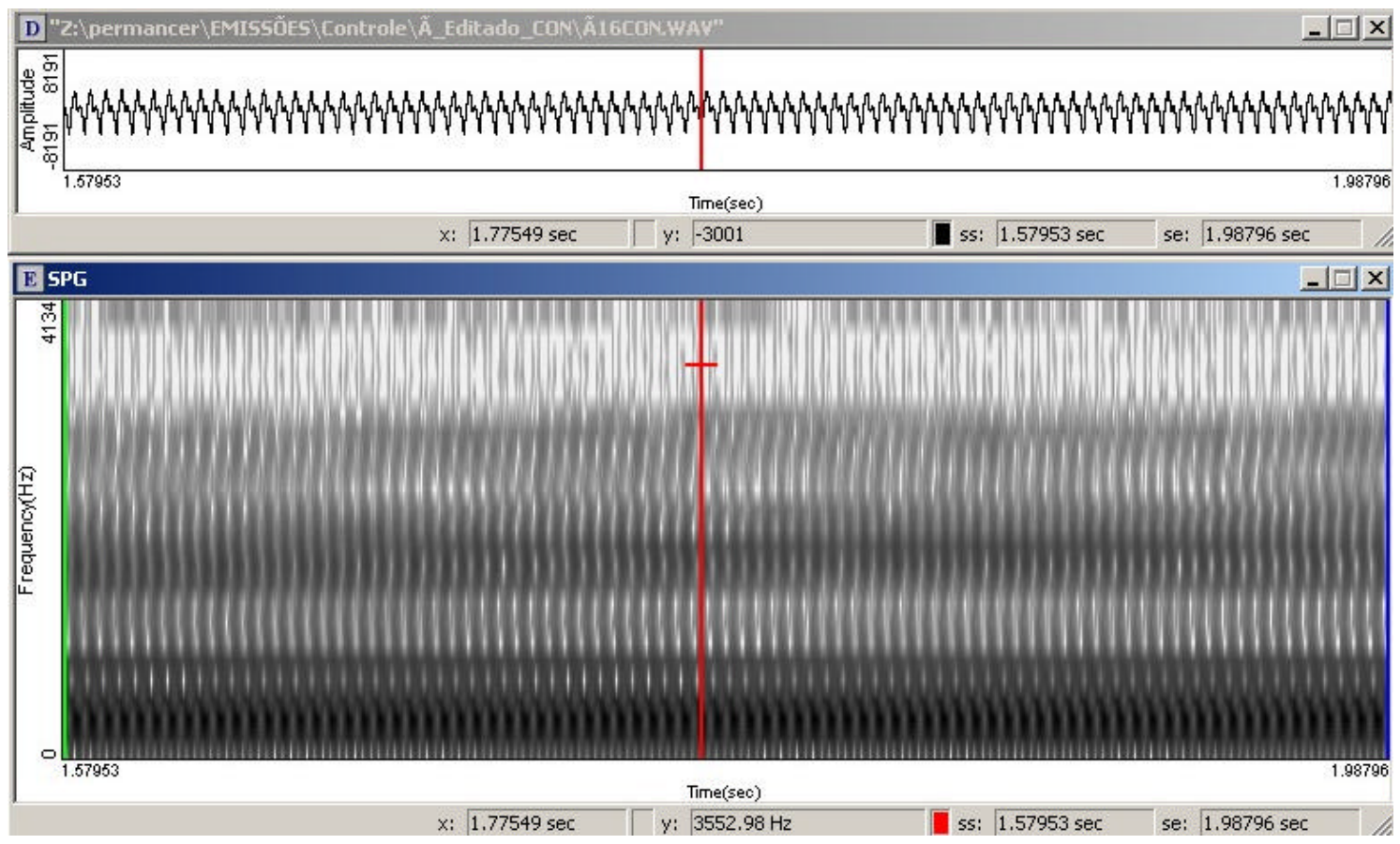

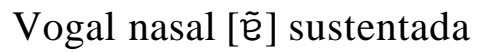


APÊEDICE W - Forma de onda das emissões das vogais [a] e [ẽ] sustentadas (A) e seu respectivo espectrograma $(\mathrm{B})$ da participante com protocolo número 17 do grupo CON.

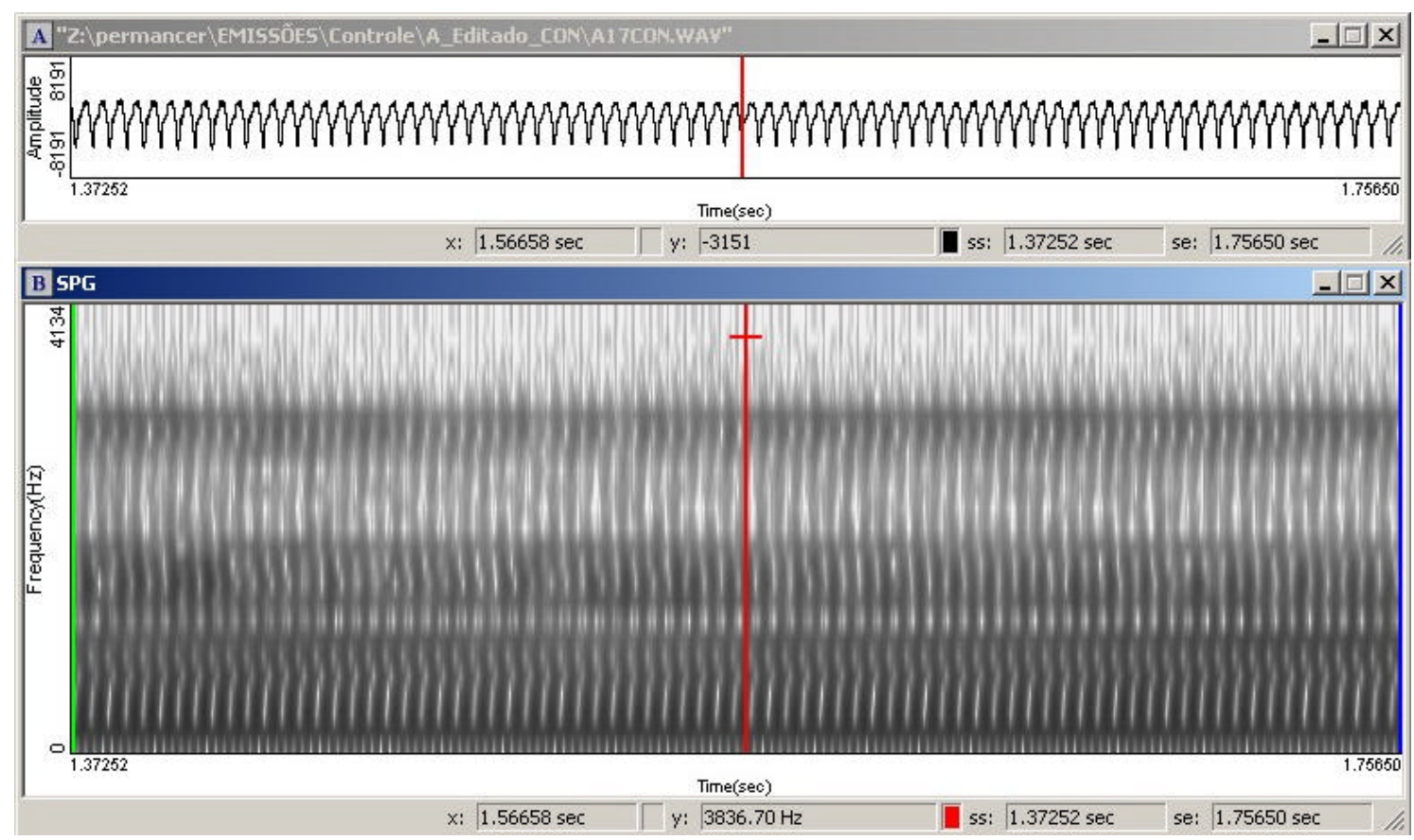

Vogal oral [a] sustentada

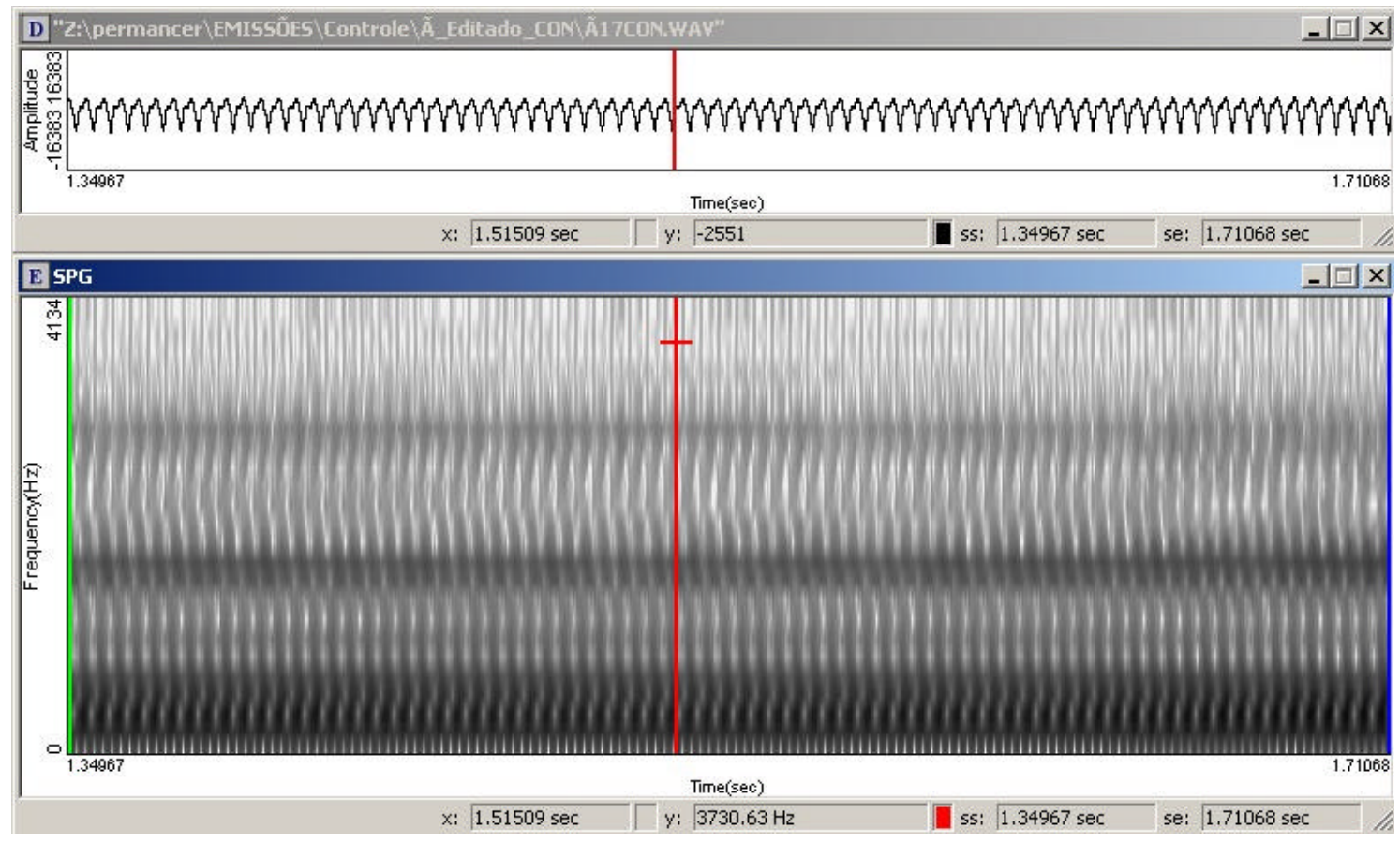

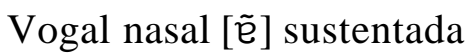




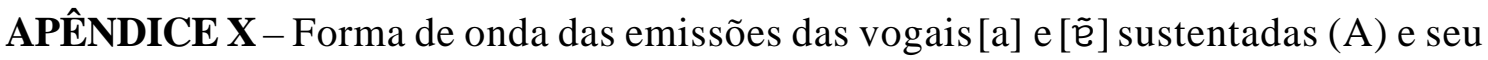
respectivo espectrograma $(\mathrm{B})$ da participante com protocolo número 18 do grupo CON.

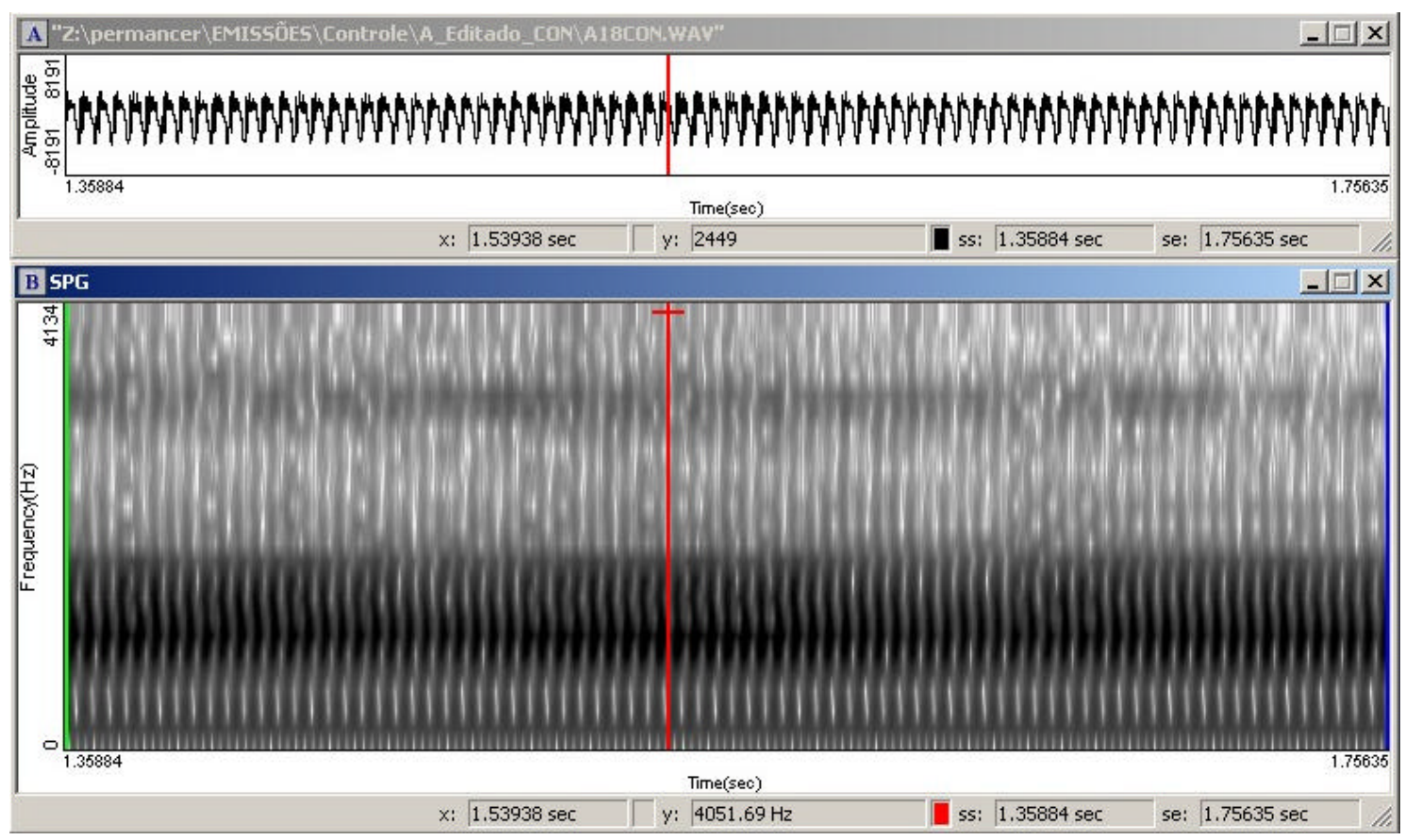

Vogal oral [a] sustentada

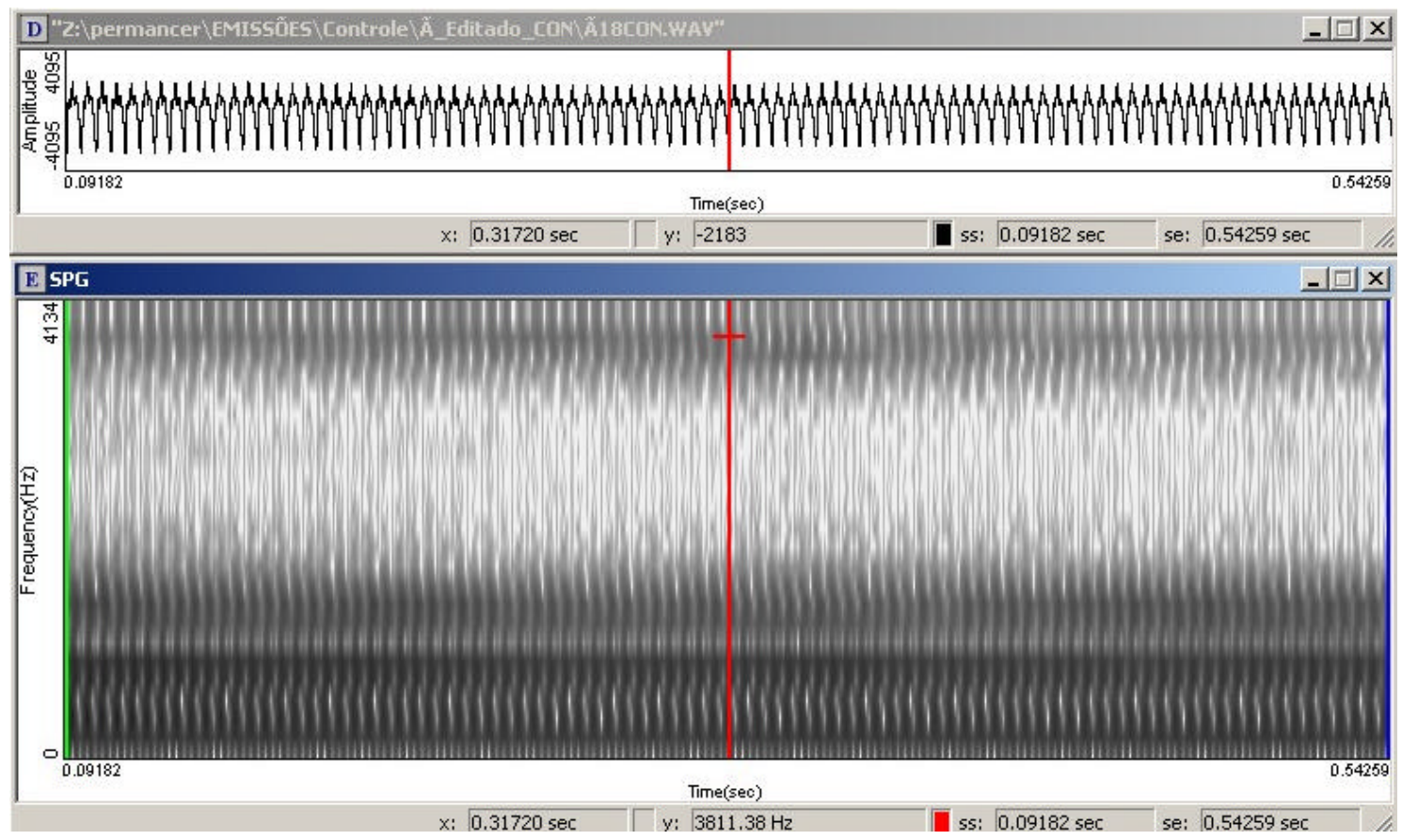

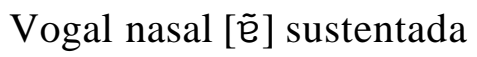


APÊNDICE Y - Forma de onda das emissões das vogais [a] e [ẽe] sustentadas (A) e seu respectivo espectrograma (B) da participante com protocolo número 19 dogrupo CON.

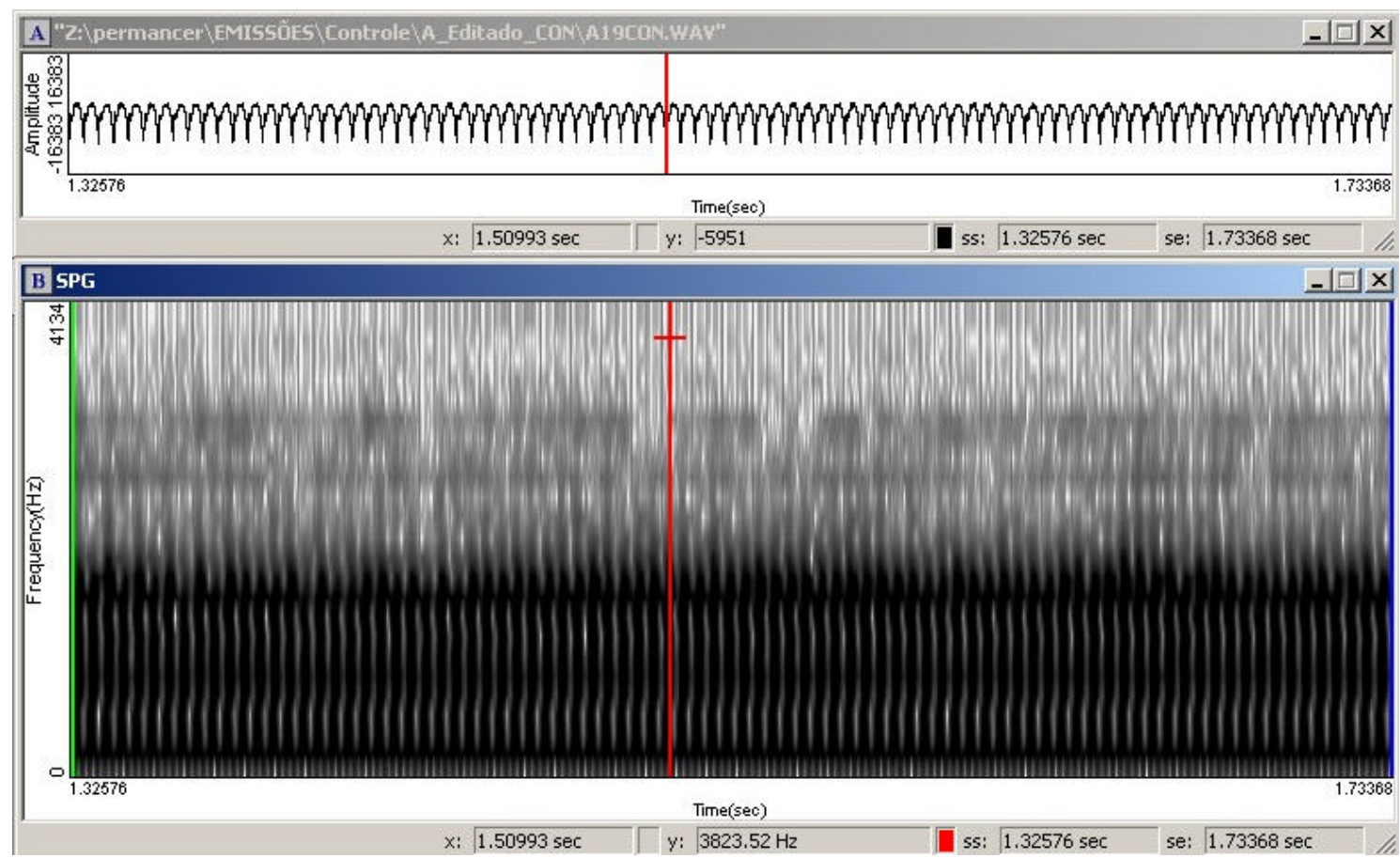

Vogal oral [a] sustentada

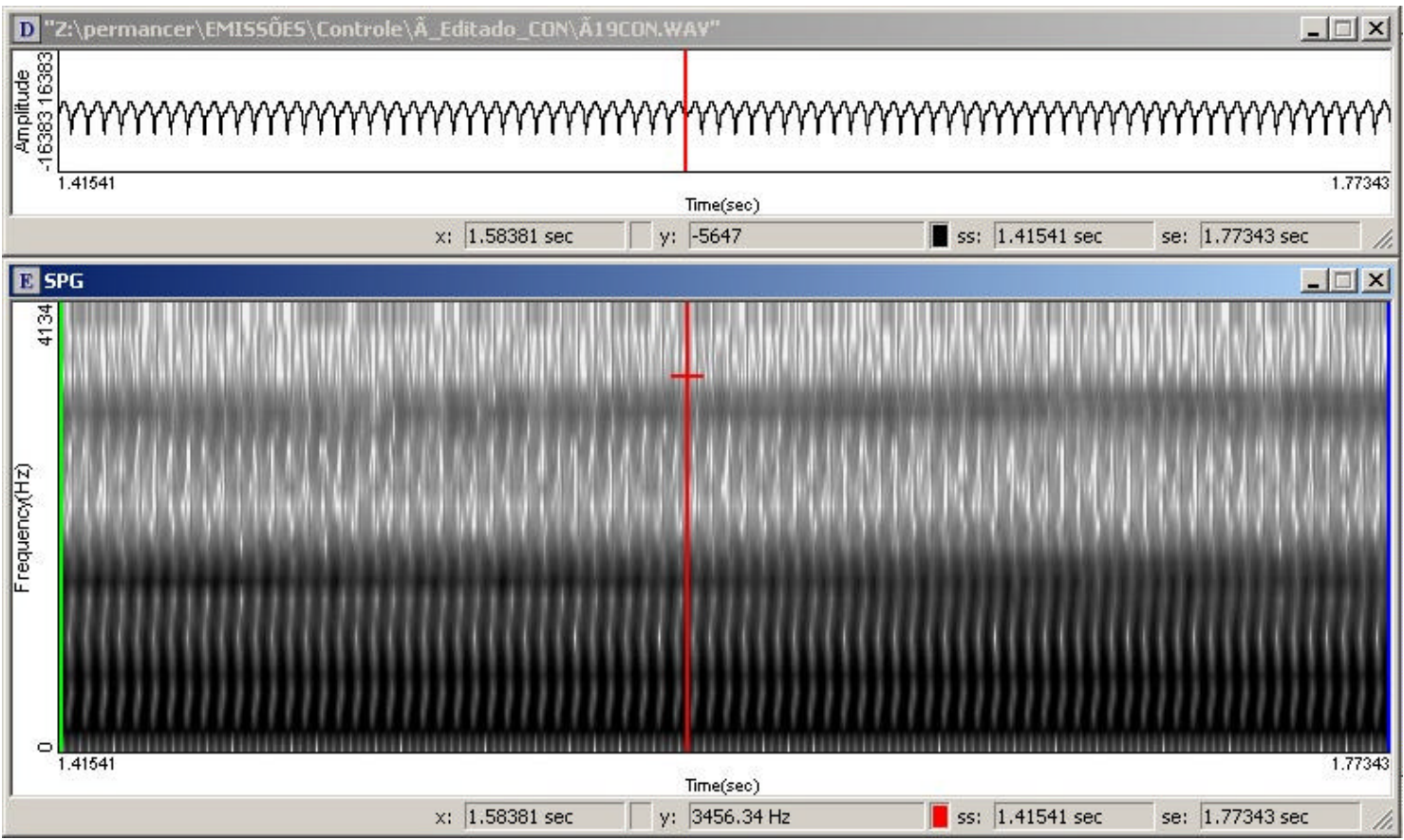

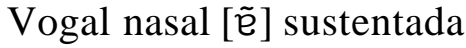




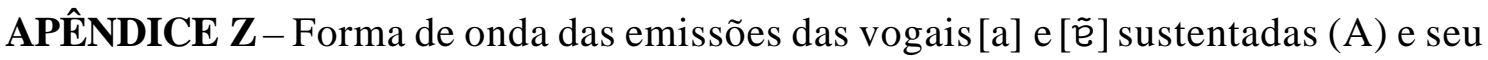
respectivo espectrograma $(\mathrm{B})$ da participante com protocolo número 20 do grupo CON.

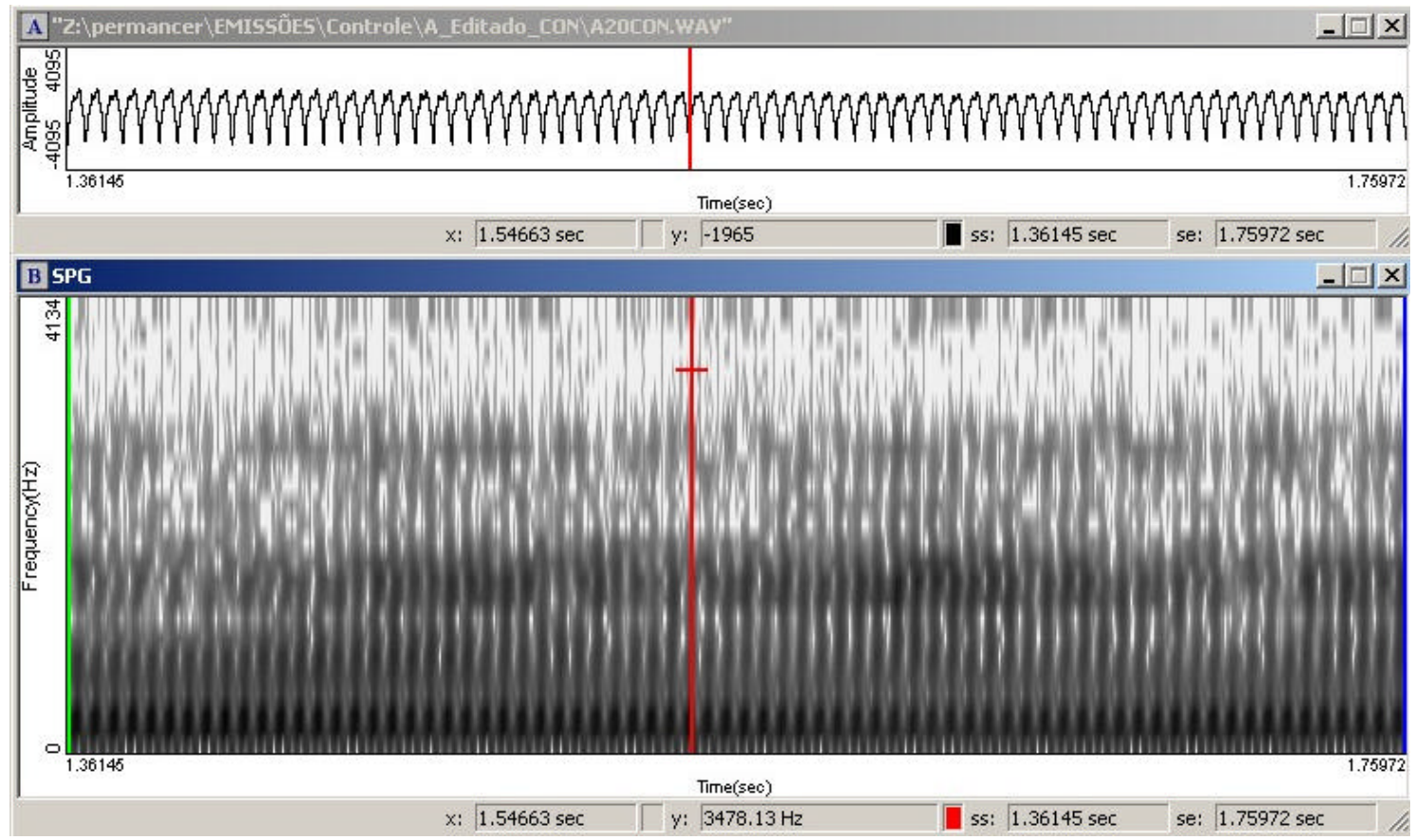

Vogal oral [a] sustentada

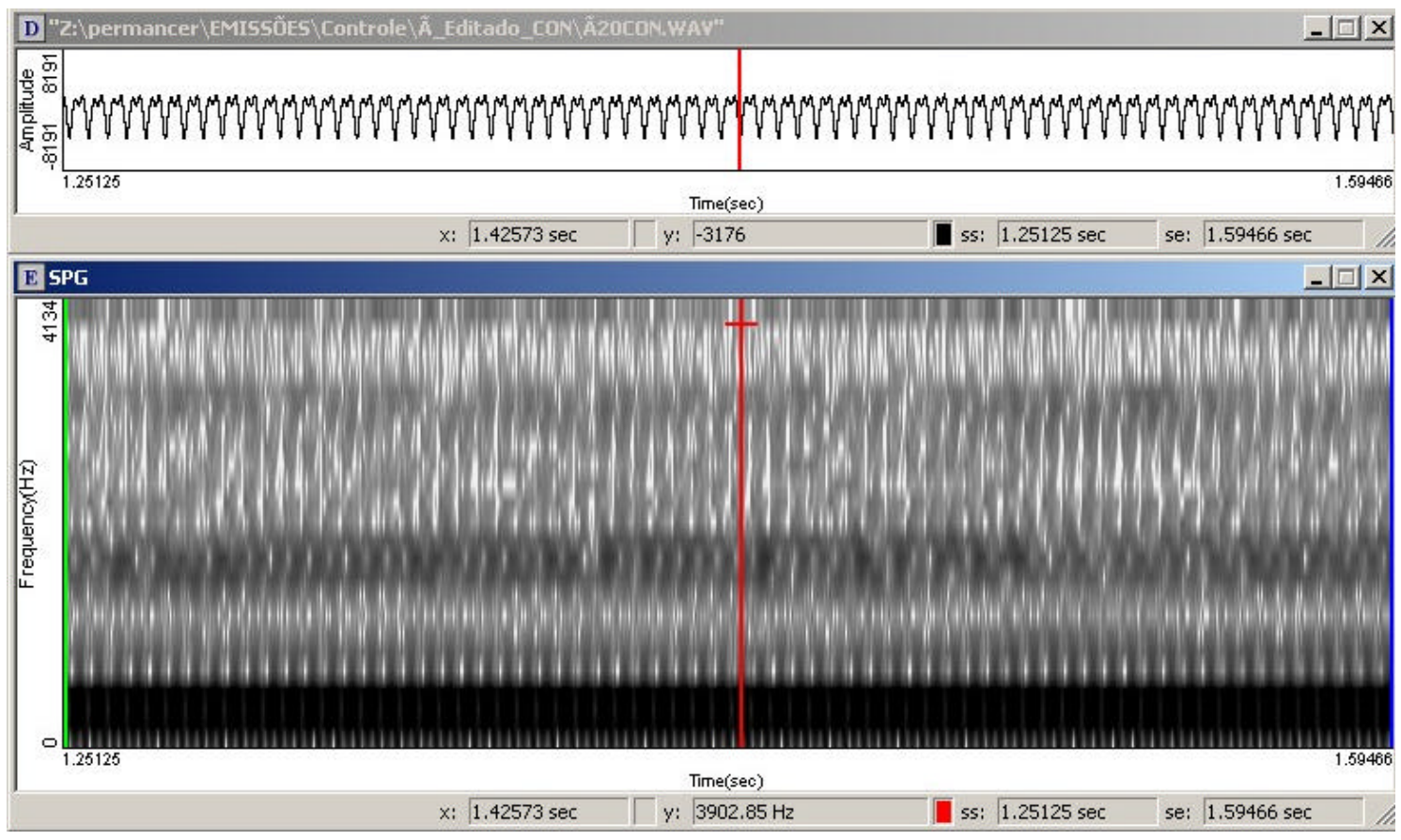

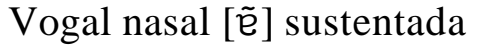


APÊNDICE AA - Forma de onda das emissões das vogais [a] e [ẽ ] sustentadas (A) e seu respectivo espectrograma $(\mathrm{B})$ da participante com protocolo número 21 do grupo CON.

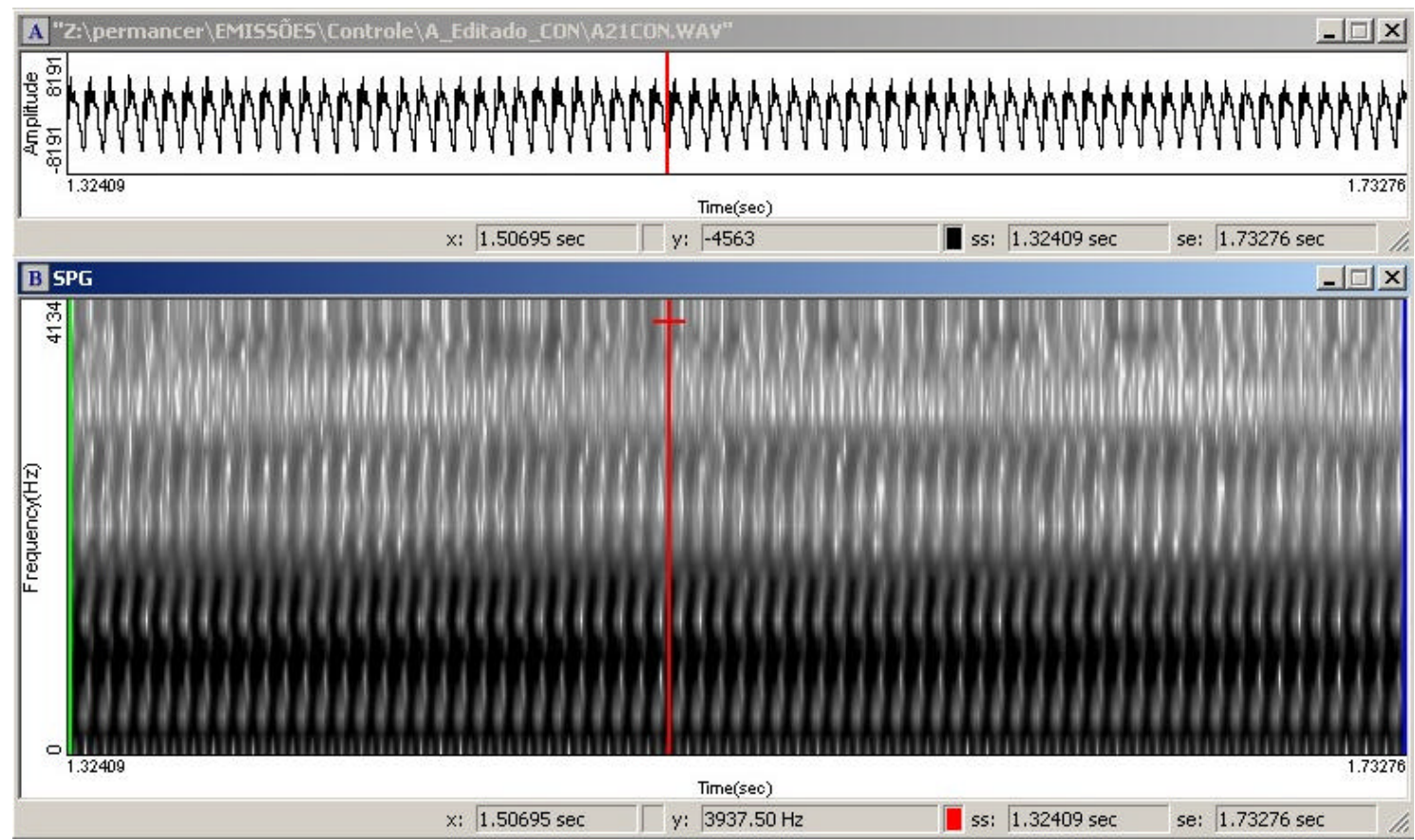

Vogal oral [a] sustentada

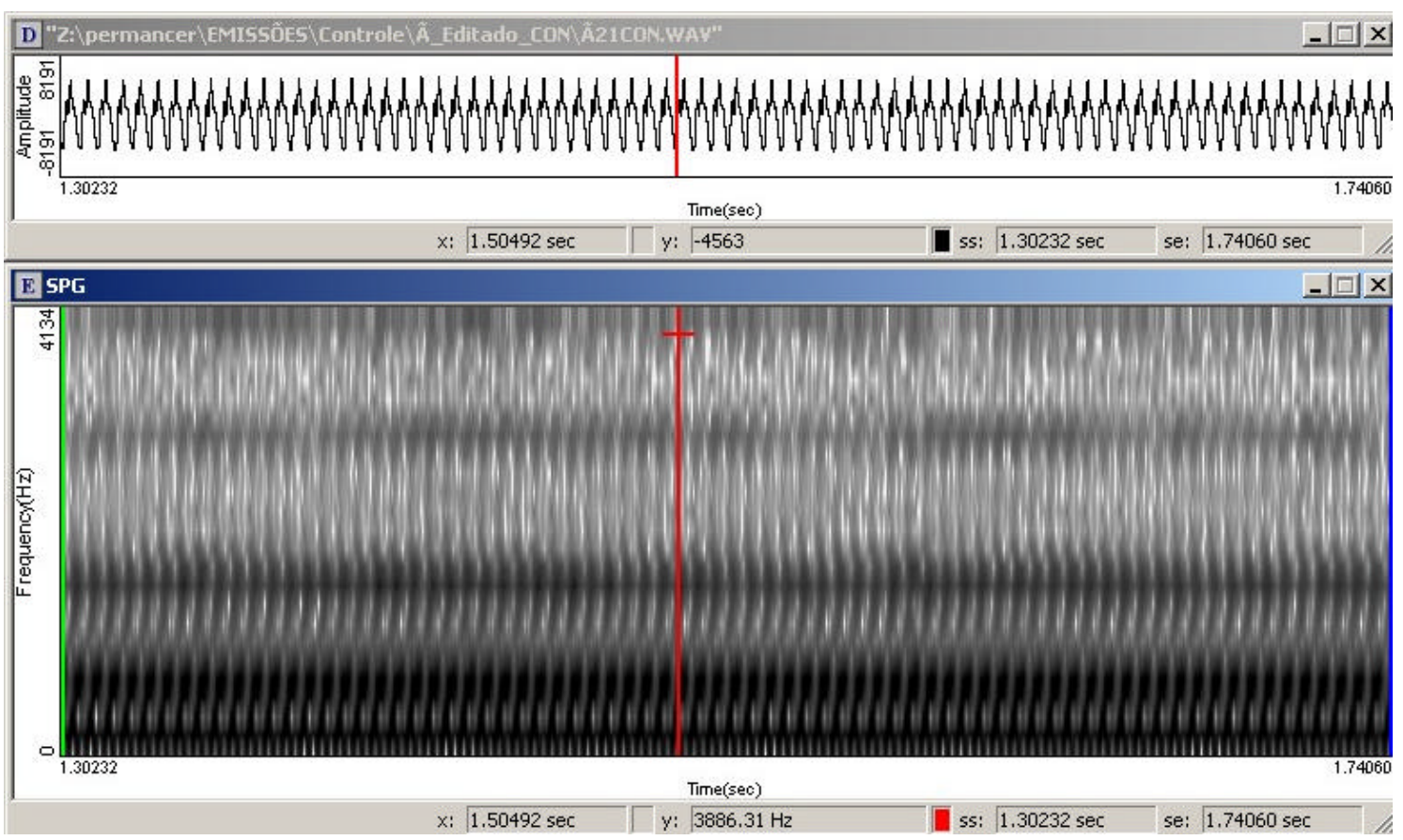

Vogal nasal [ẽ $]$ sustentada 
APÊNDICE AB - Forma de onda das emissões das vogais [a] e [ẽe sustentadas (A) e seu respectivo espectrograma (B) da participante com protocolo número 22 do grupo CON.

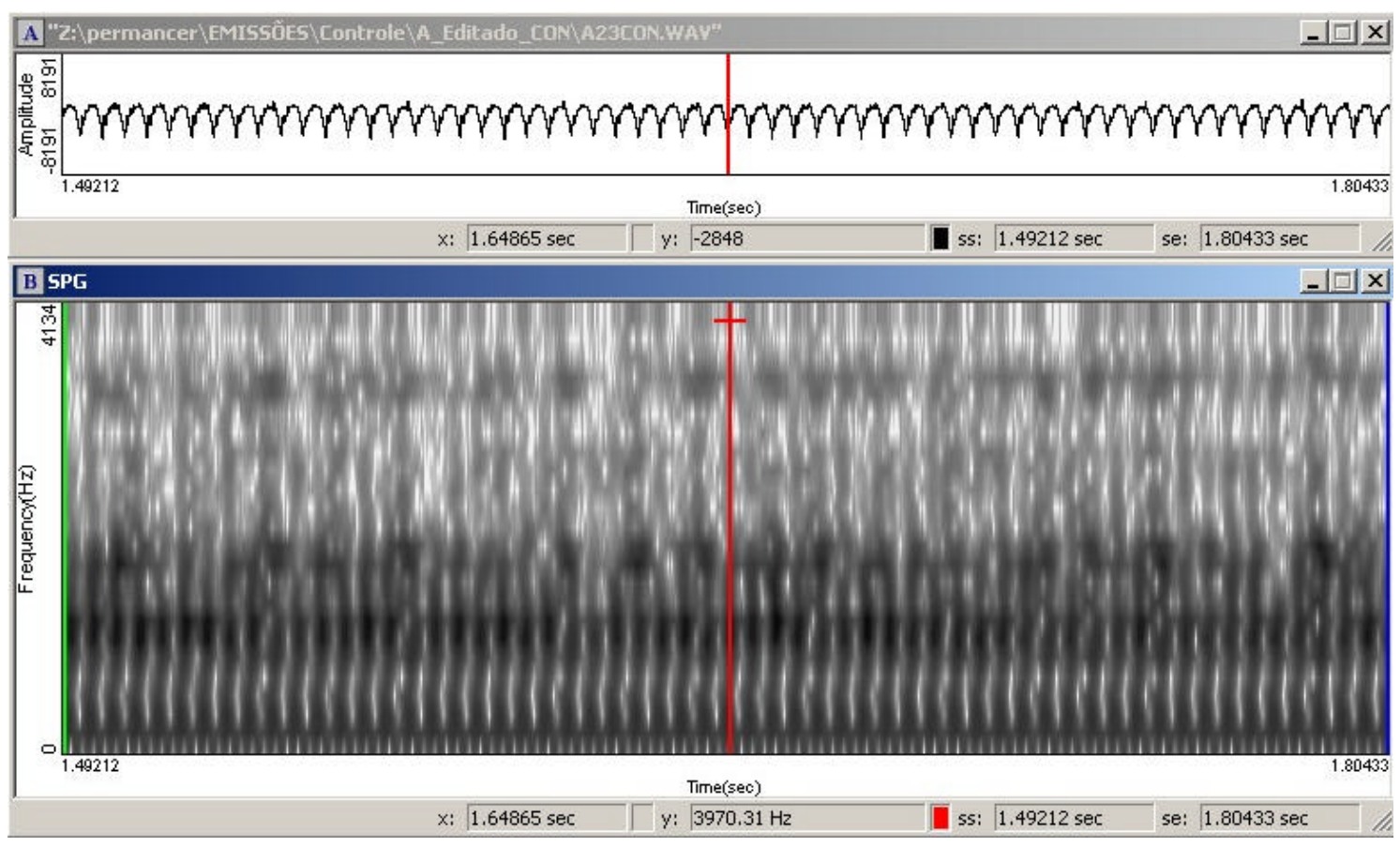

Vogal oral [a] sustentada

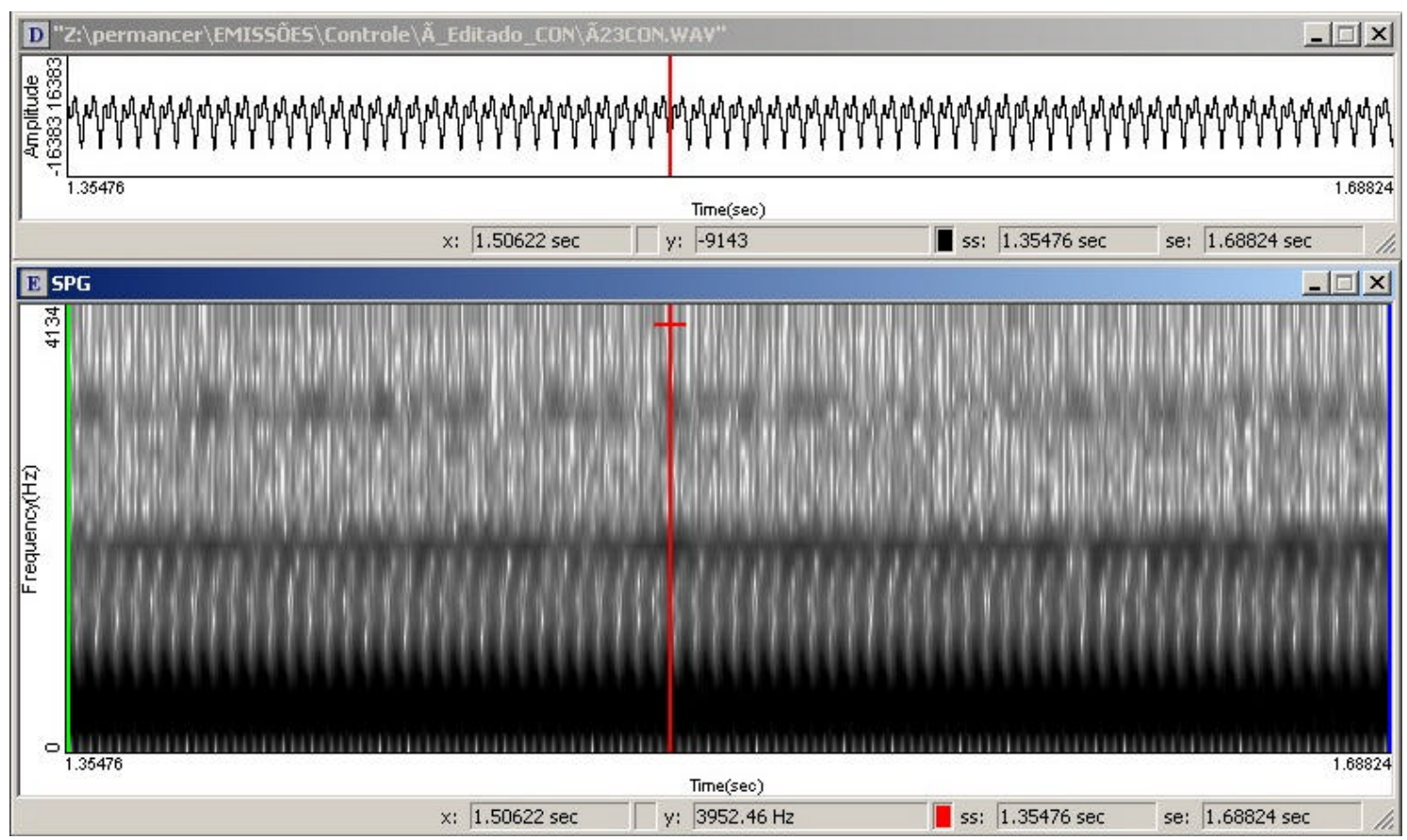

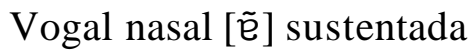


APÊNDICE AC - Forma de onda das emissões das vogais [a] e [ẽ ] sustentadas (A) e seu respectivo espectrograma $(\mathrm{B})$ da participante com protocolo número 23 do grupo CON.

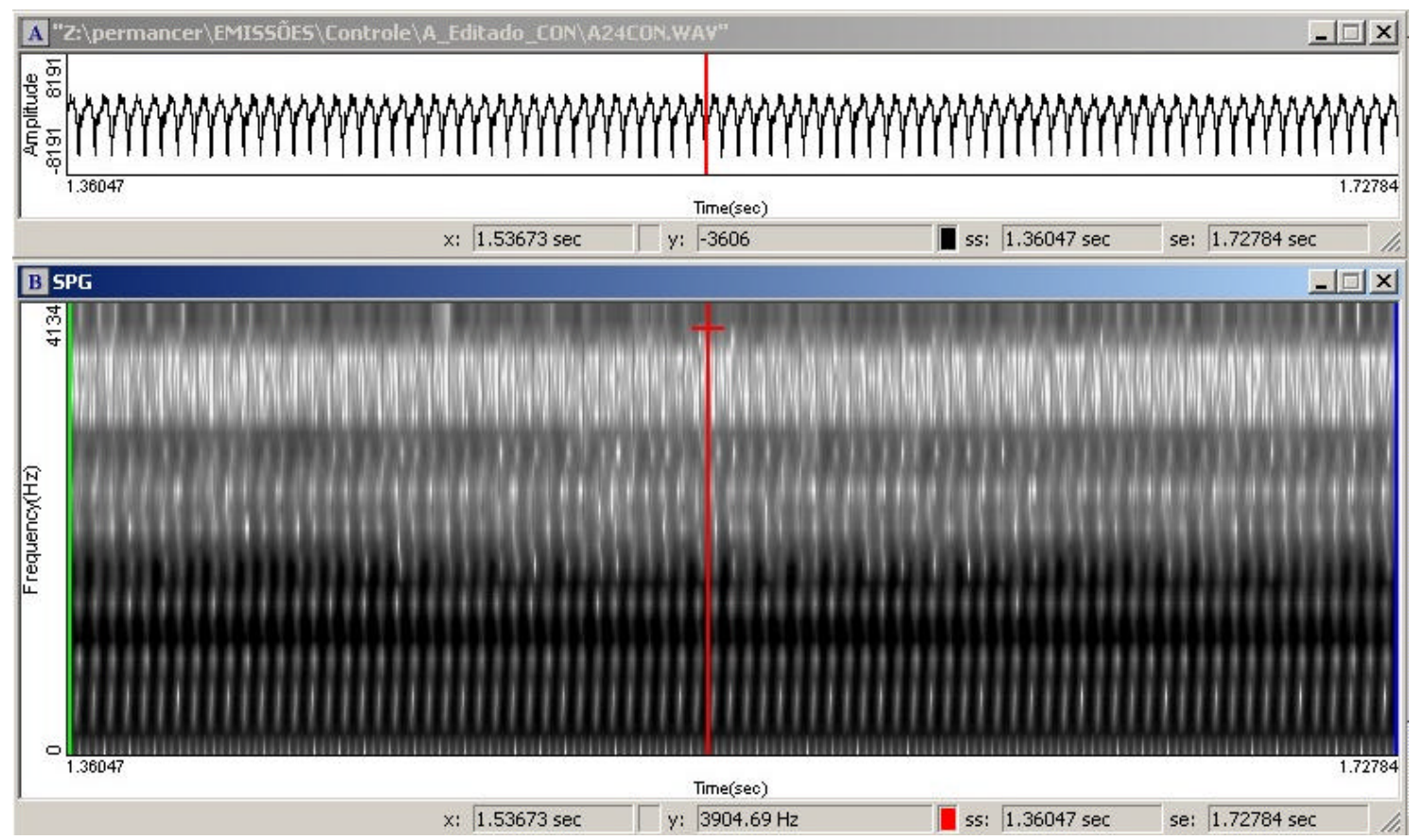

Vogal oral [a] sustentada

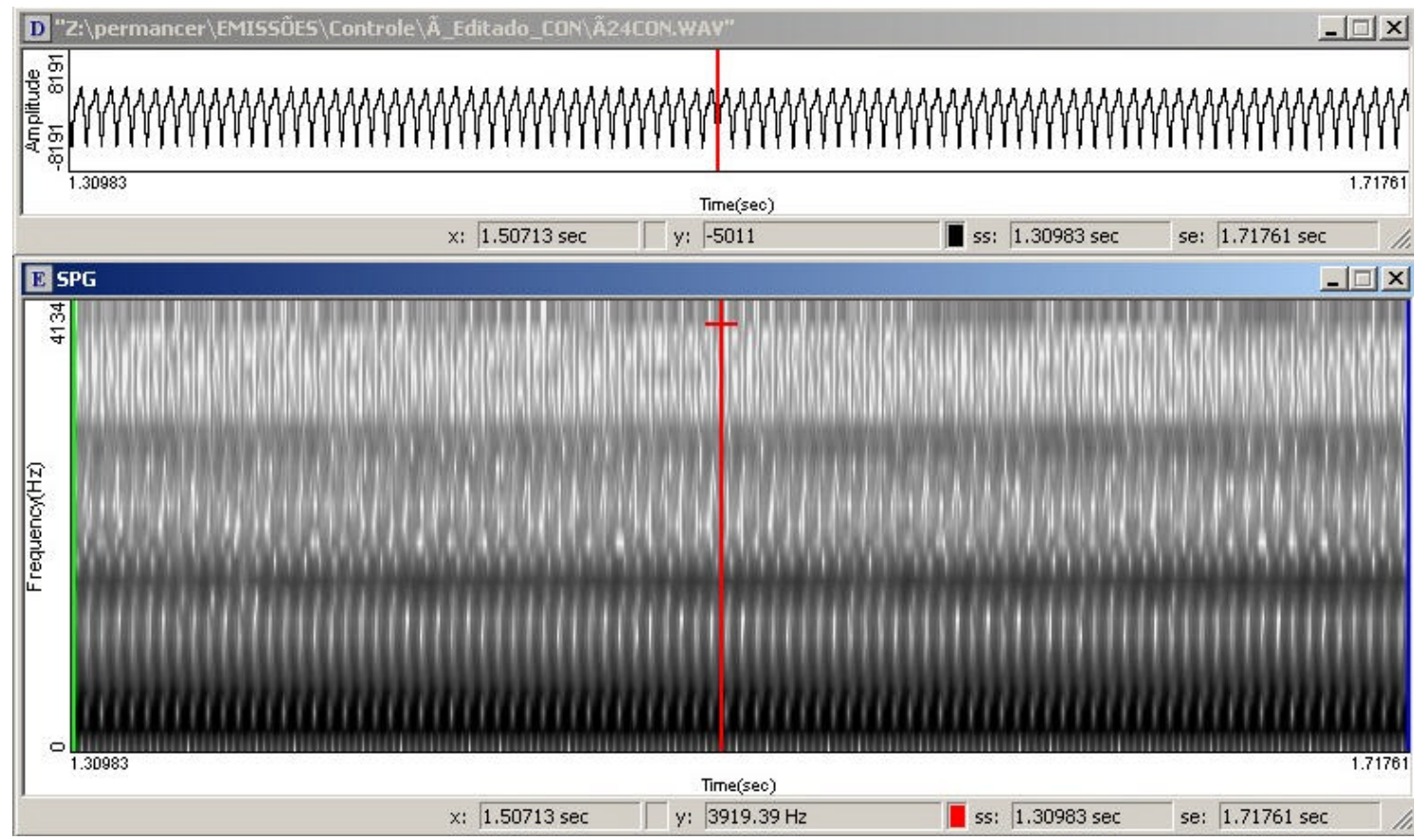

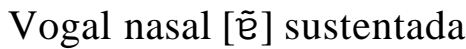


APÊNDICE AD - Forma de onda das emissões das vogais [a] e [ẽ ] sustentadas (A) e seu respectivo espectrograma (B) da participante com protocolo número 24 do grupo CON.

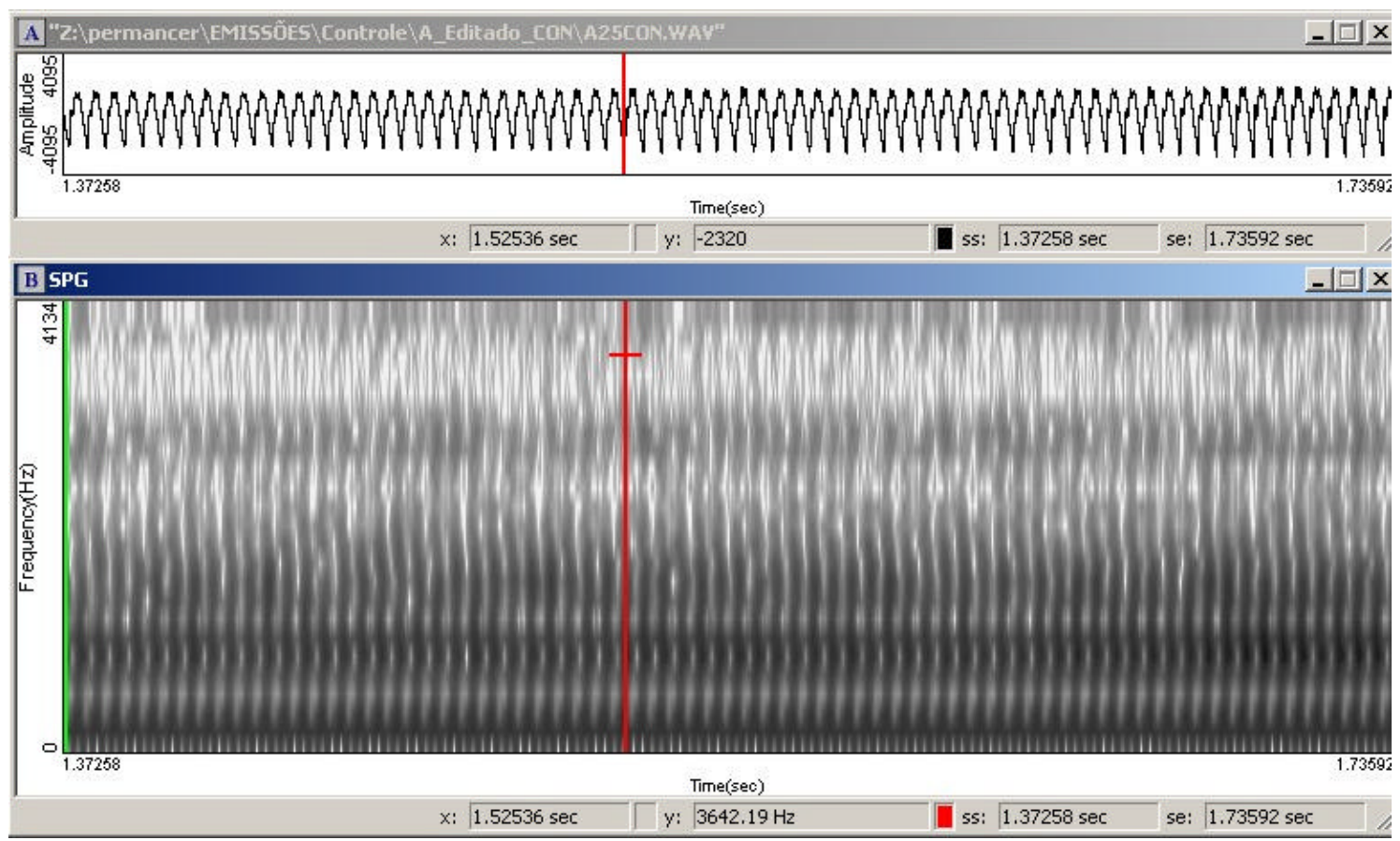

Vogal oral [a] sustentada

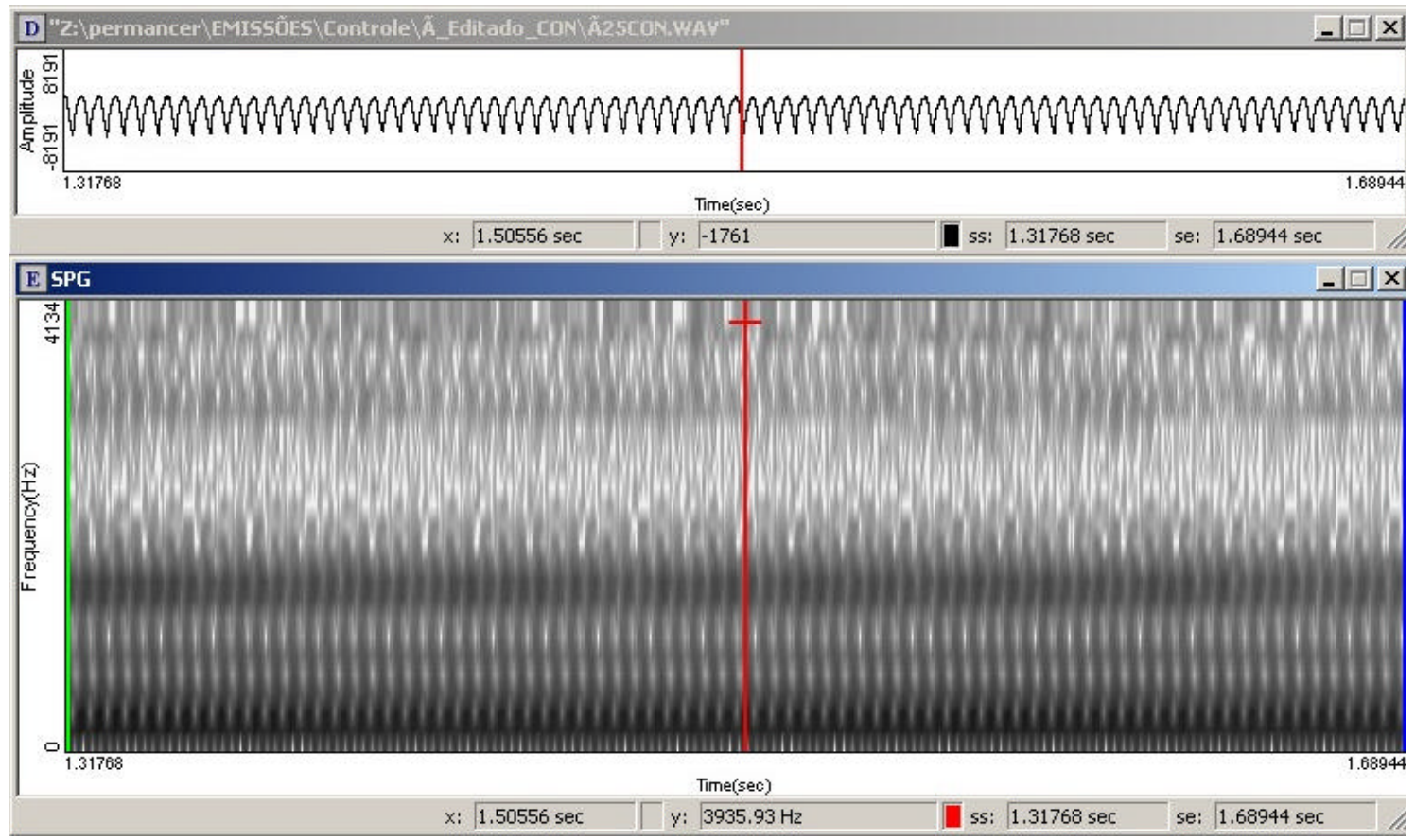

Vogal nasal [ẽ $]$ sustentada 
APÊNDICE AE - Forma de onda das emissões das vogais [a] e [ẽ ] sustentadas (A) e seu respectivo espectrograma $(\mathrm{B})$ da participante com protocolo número 25 do grupo CON.

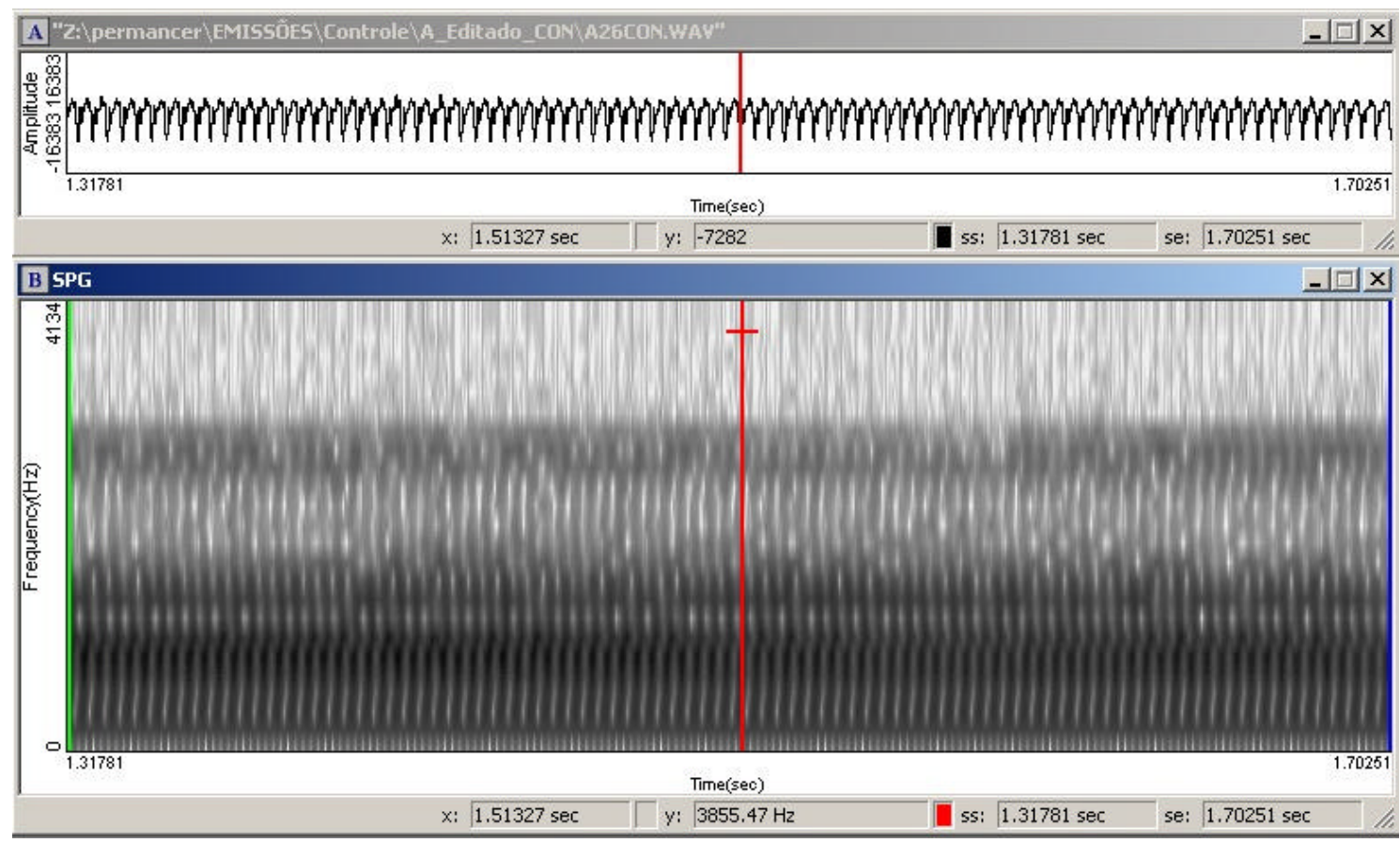

Vogal oral [a] sustentada

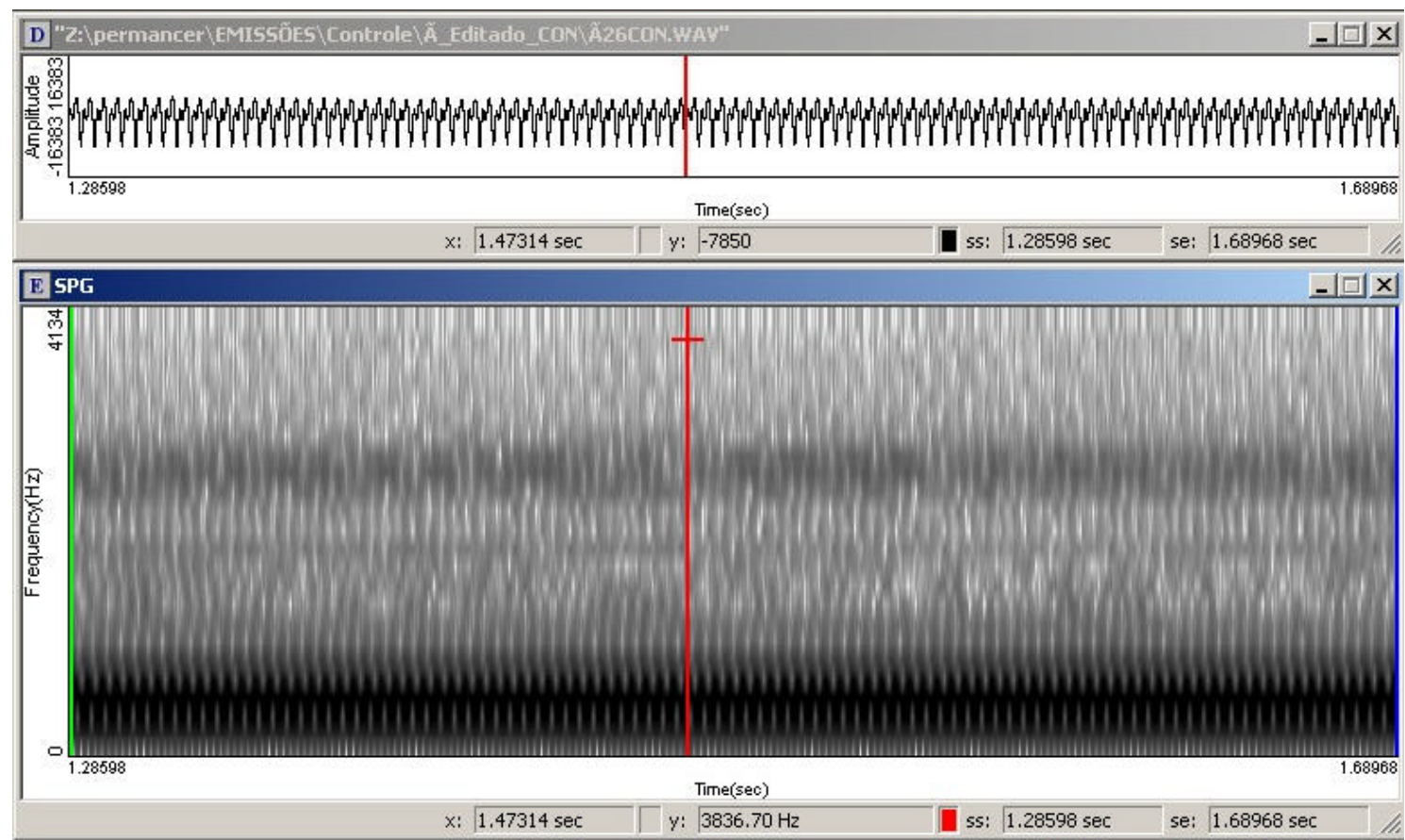

Vogal nasal [ẽ ] sustentada 
APÊNDICE AF - Forma de onda das emissões das vogais [a] e [ẽe sustentadas (A) e seu respectivo espectrograma (B) da participante com protocolo número 26 do grupo CON.

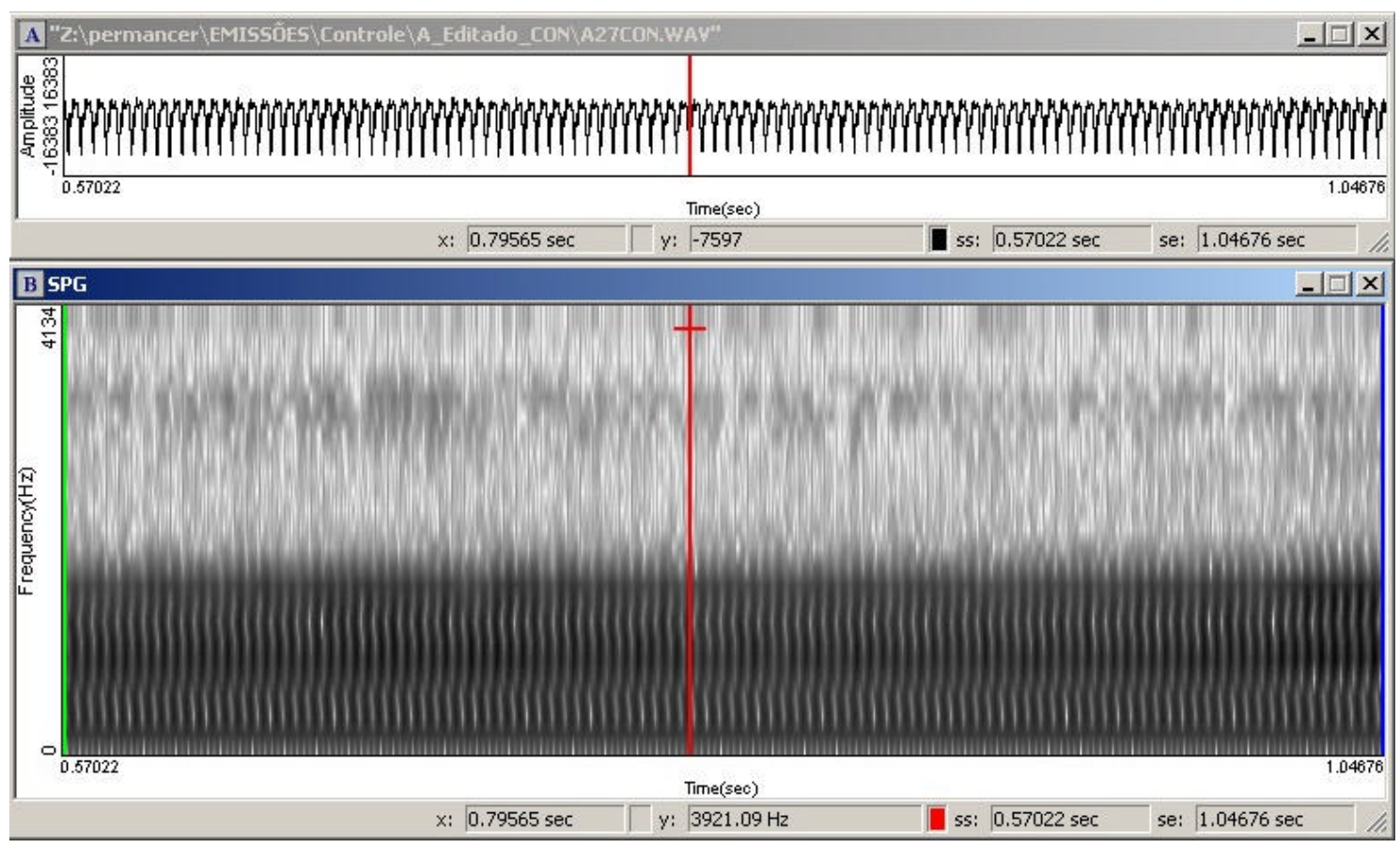

Vogal oral [a] sustentada

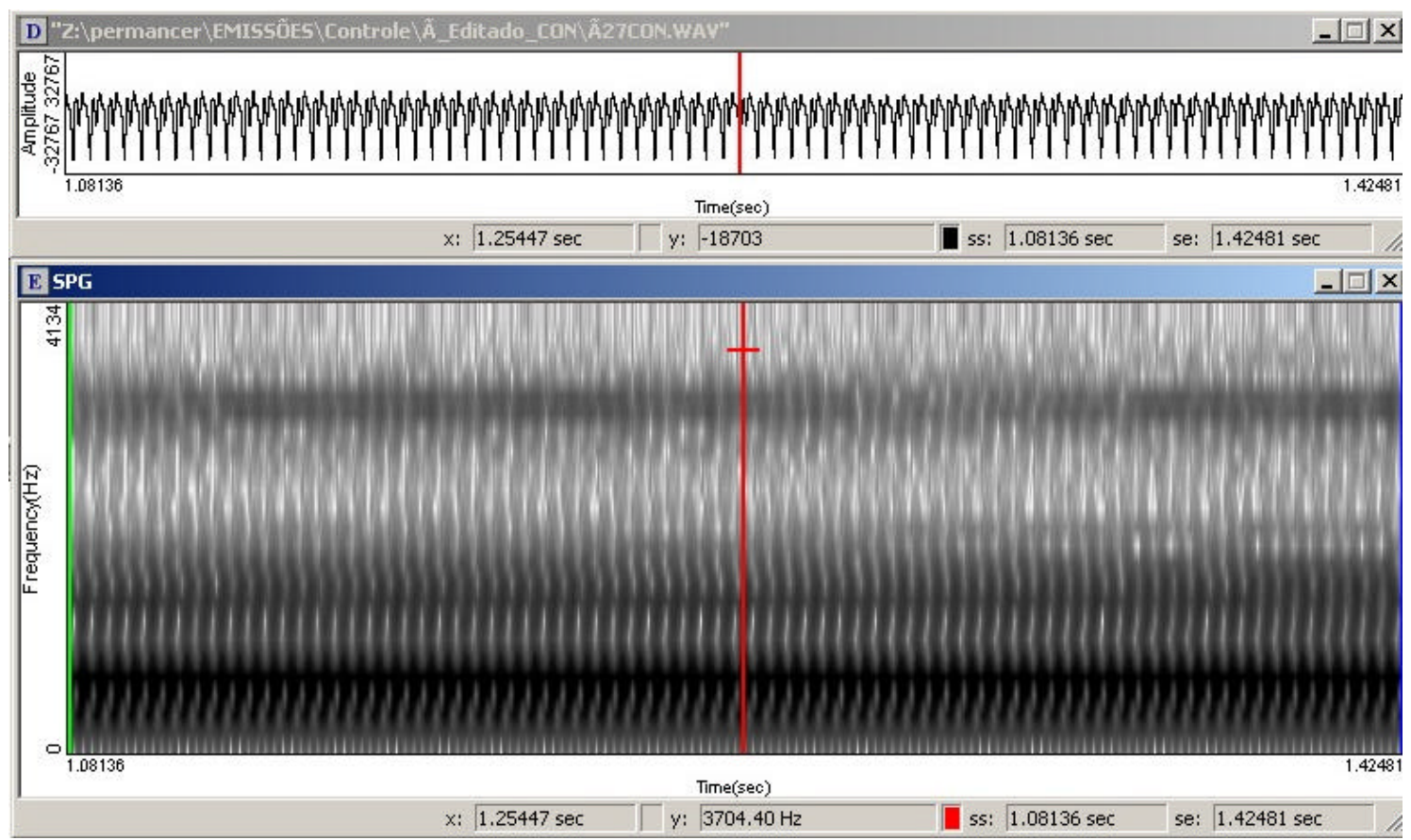

Vogal nasal $[\tilde{e}]$ sustentada 


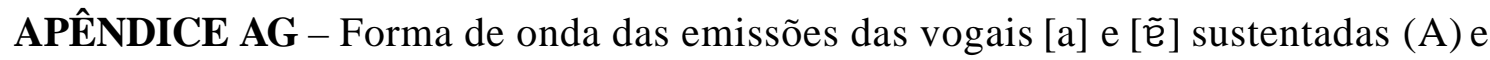
seu respectivo espectrograma (B) da participante com protocolo número 27 do grupo CON.

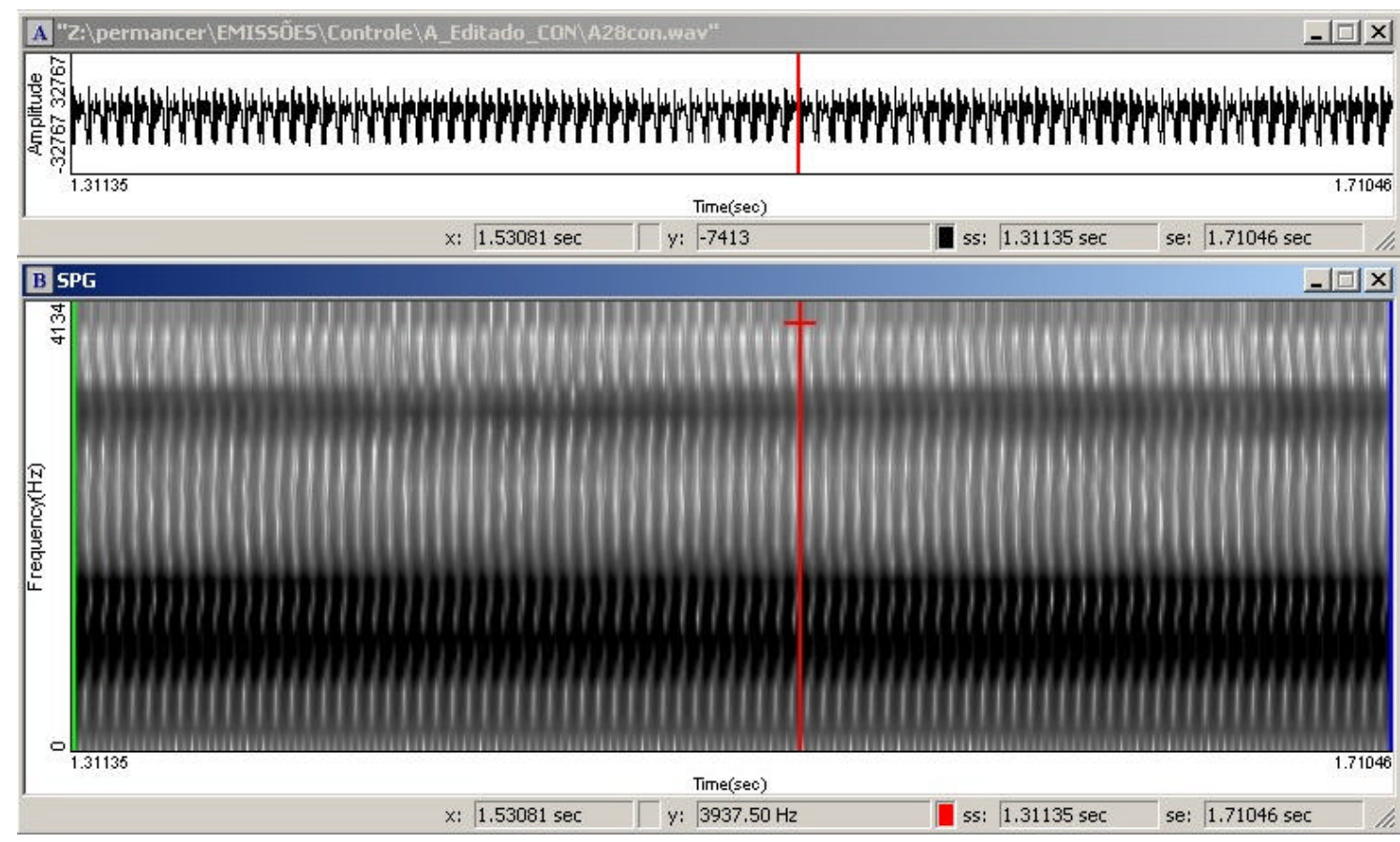

Vogal oral [a] sustentada

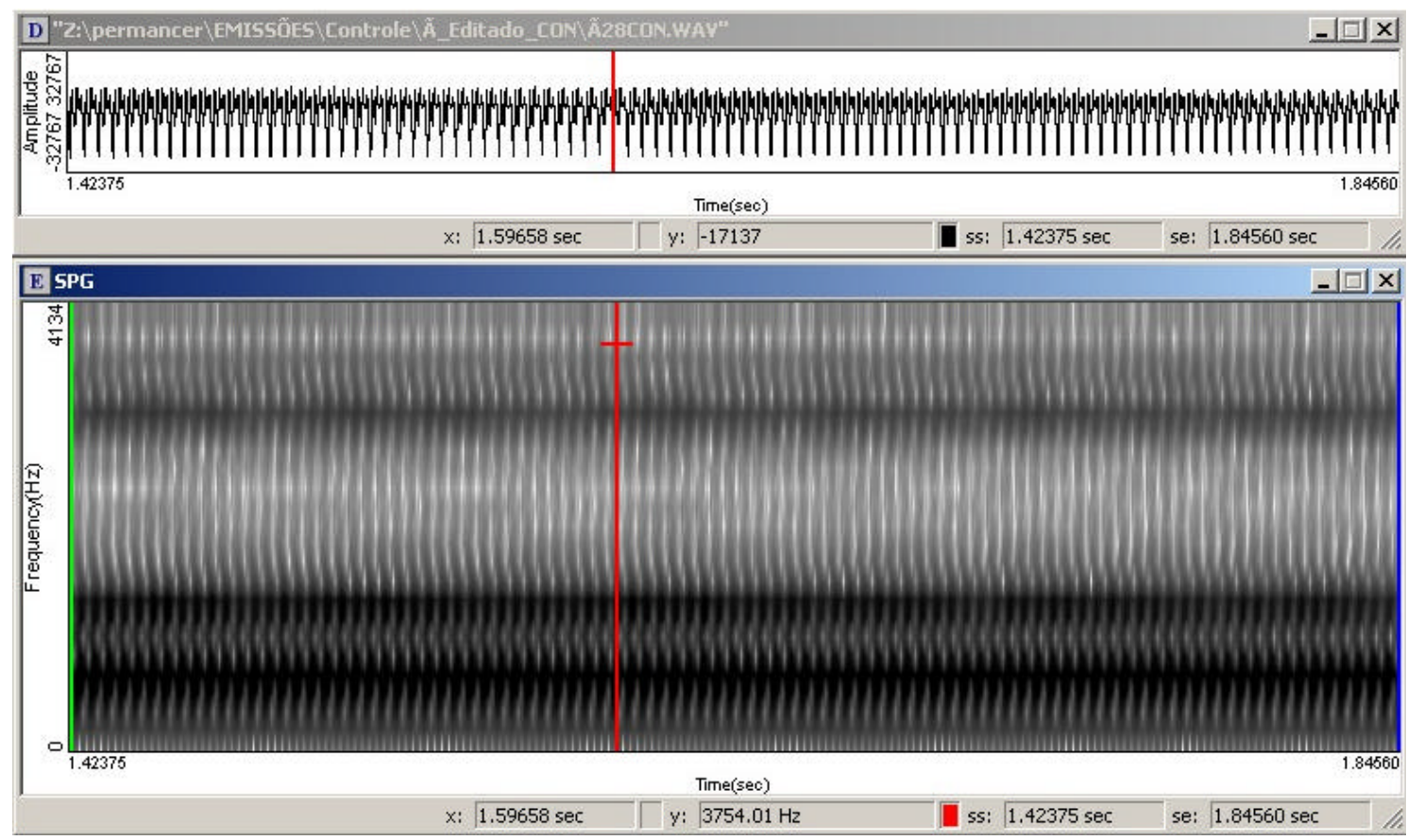

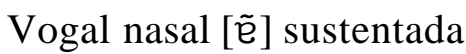


APÊNDICE AH - Forma de onda das emissões das vogais [a] e [ẽ ] sustentadas (A) e seu respectivo espectrograma $(\mathrm{B})$ da participante com protocolo número 28 do grupo CON.

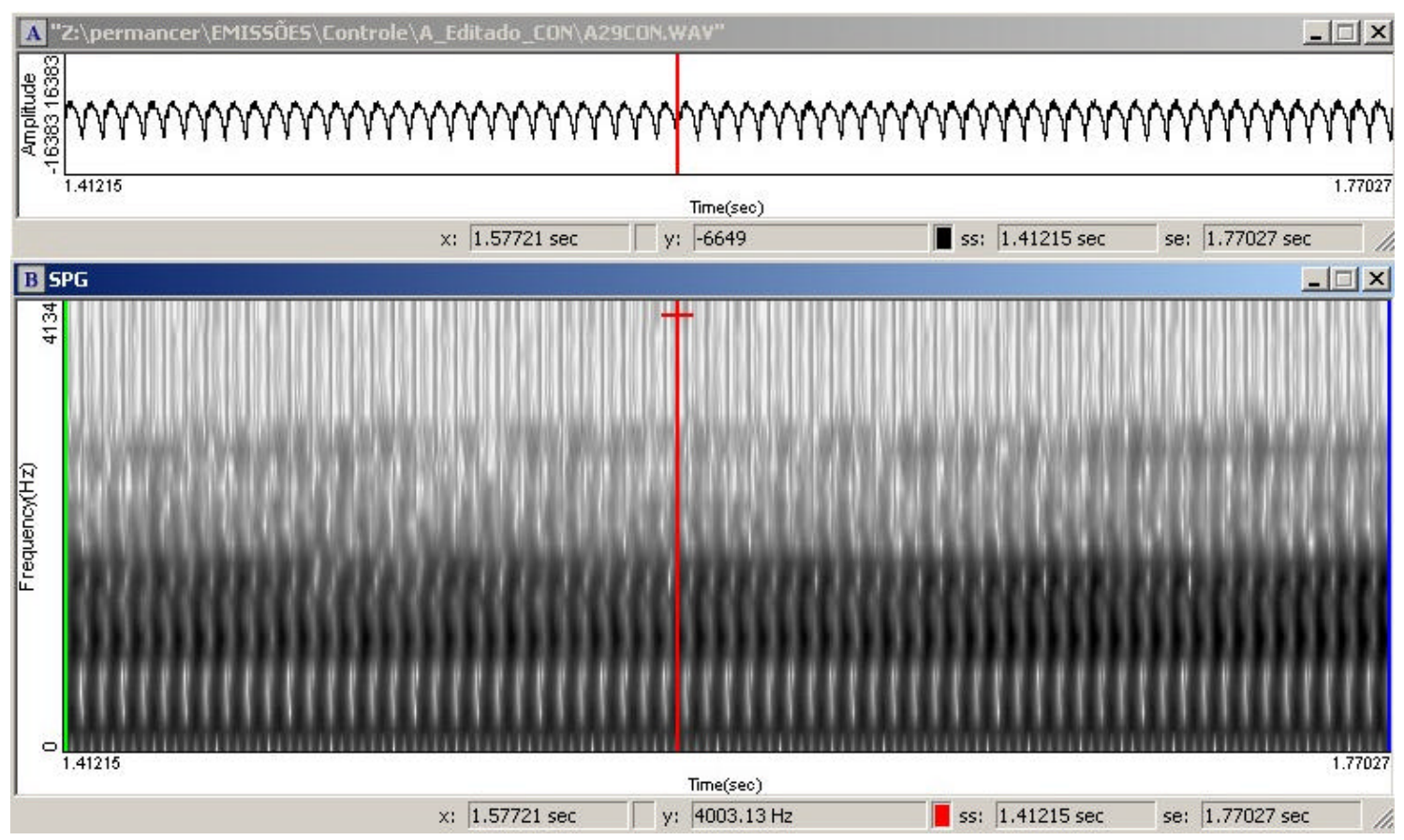

Vogal oral [a] sustentada

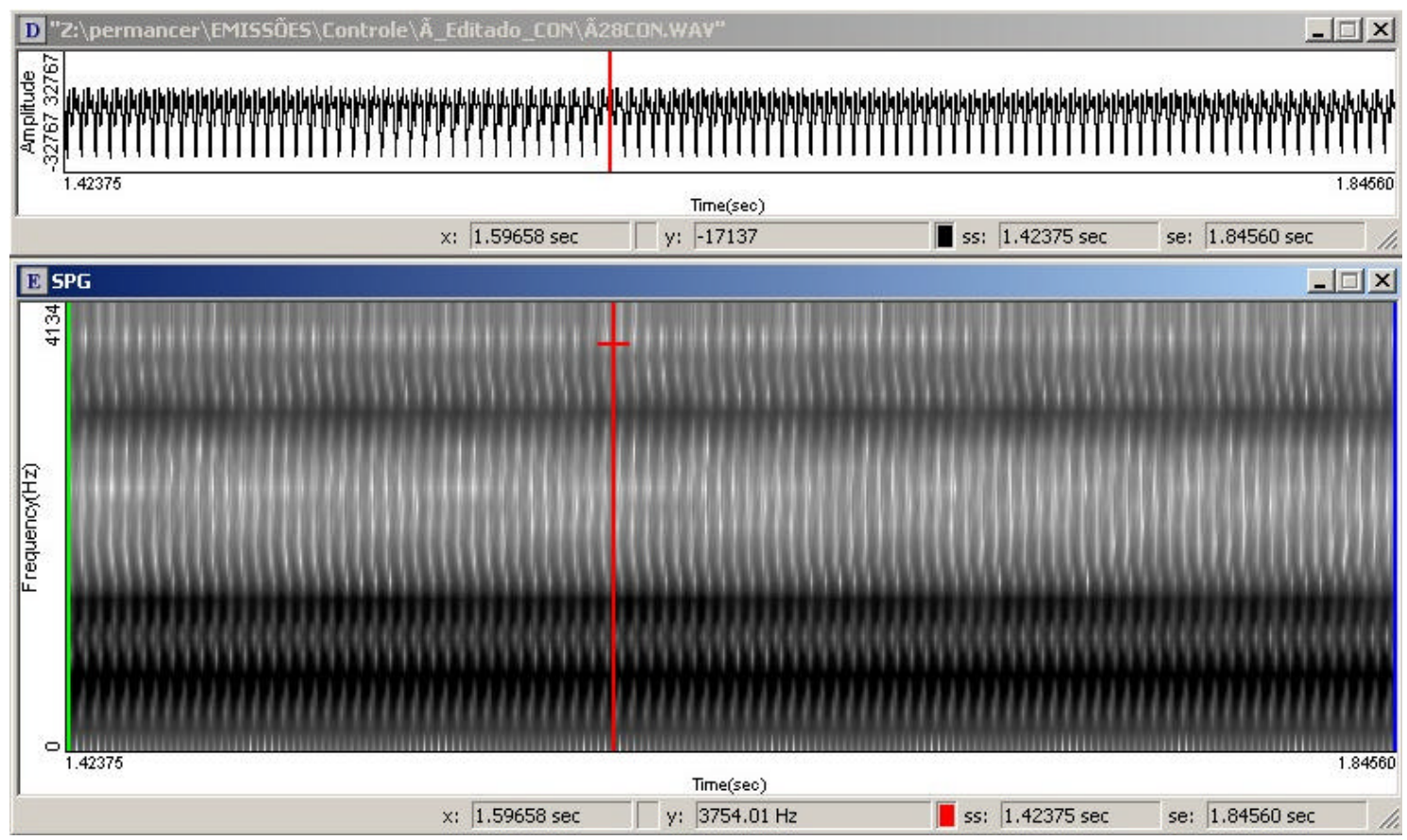

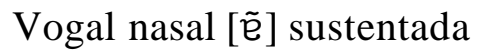


APÊNDICE AI - Forma de onda das emissões das vogais [a] e [ẽ ] sustentadas (A) e seu respectivo espectrograma (B) da participante com protocolo número 29 do grupo CON.

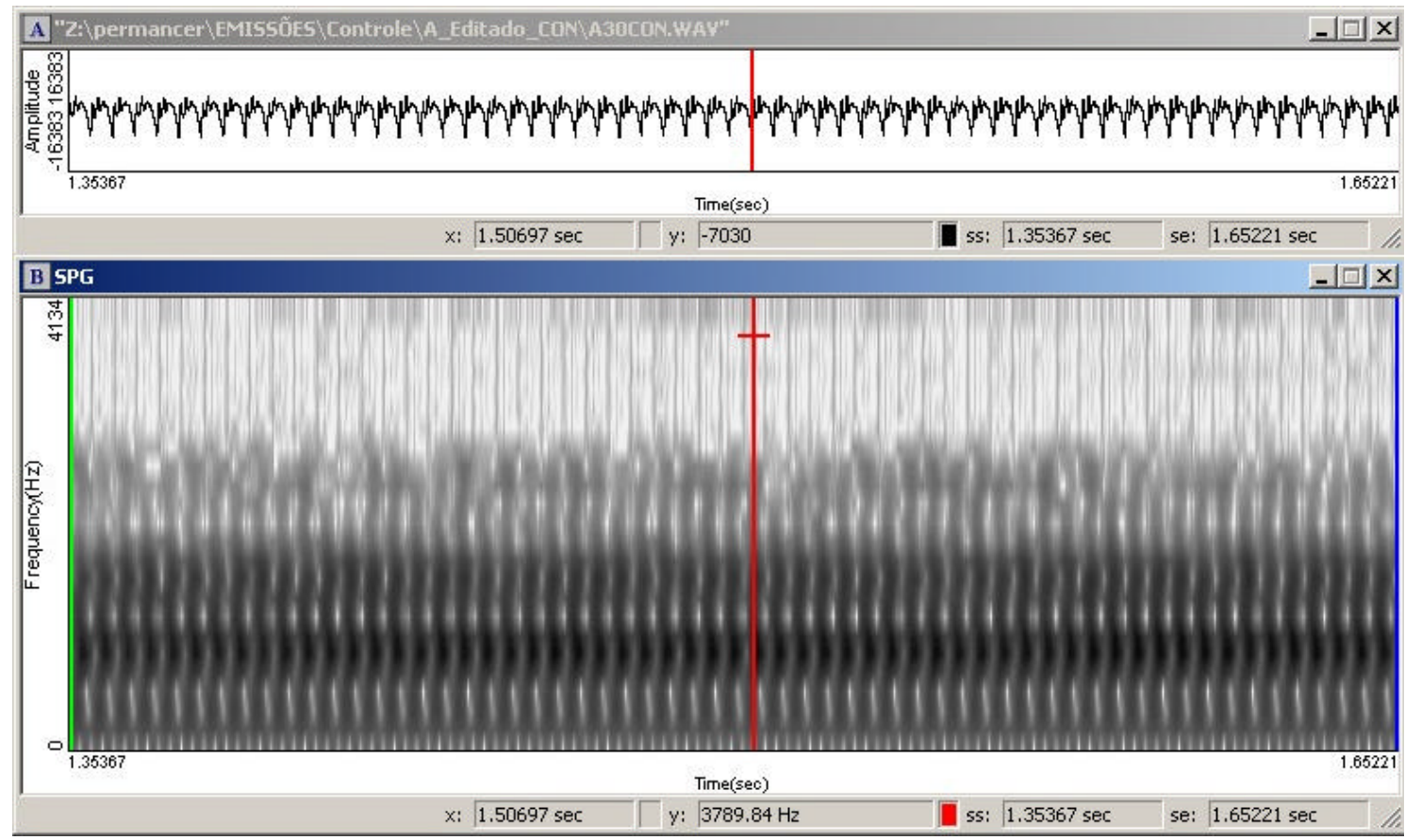

Vogal oral [a] sustentada

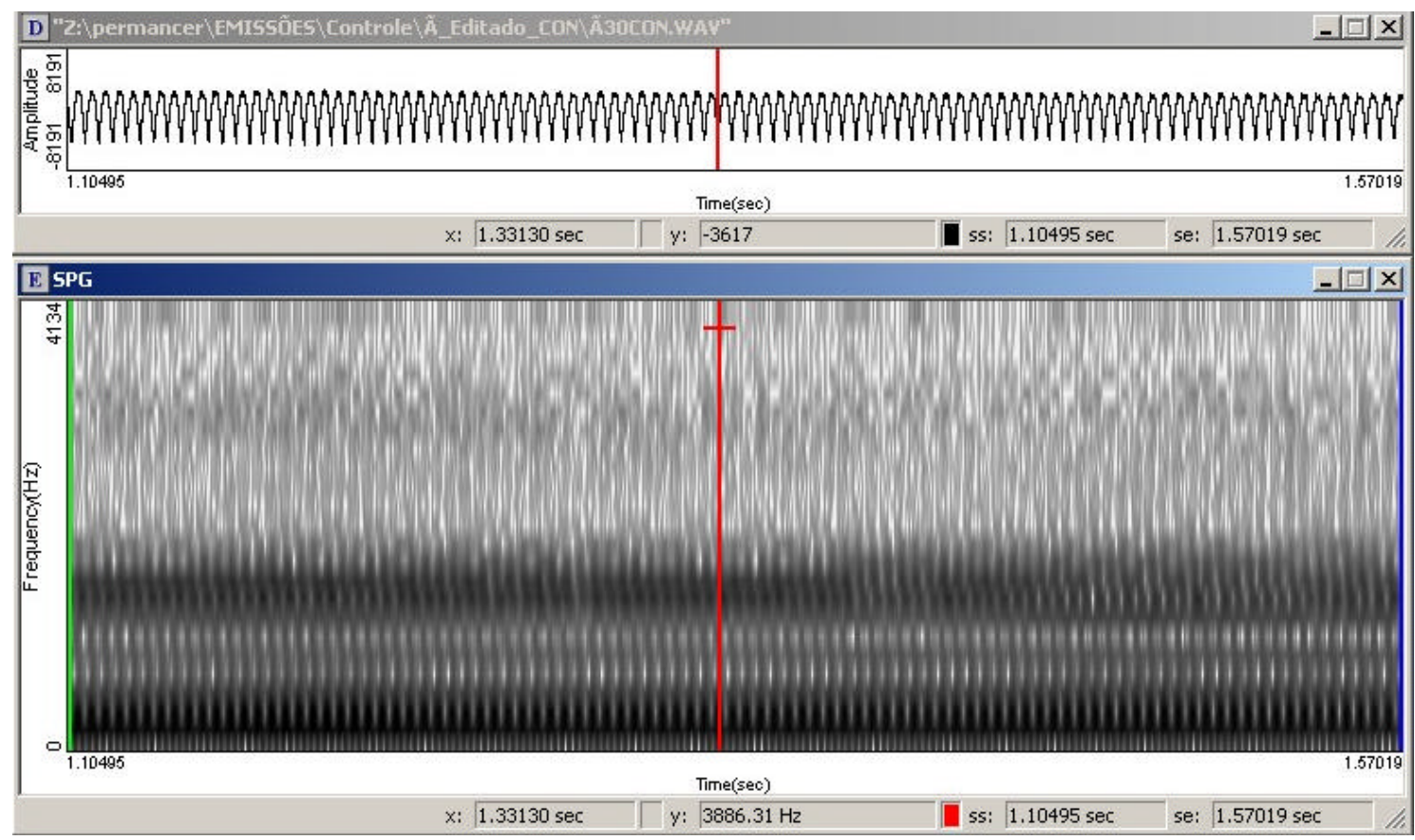

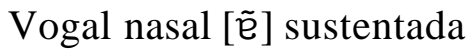


APÊNDICE AJ - Forma de onda das emissões das vogais [a] e [ẽe sustentadas (A) e seu respectivo espectrograma (B) da participante com protocolo número 30 do grupo CON.

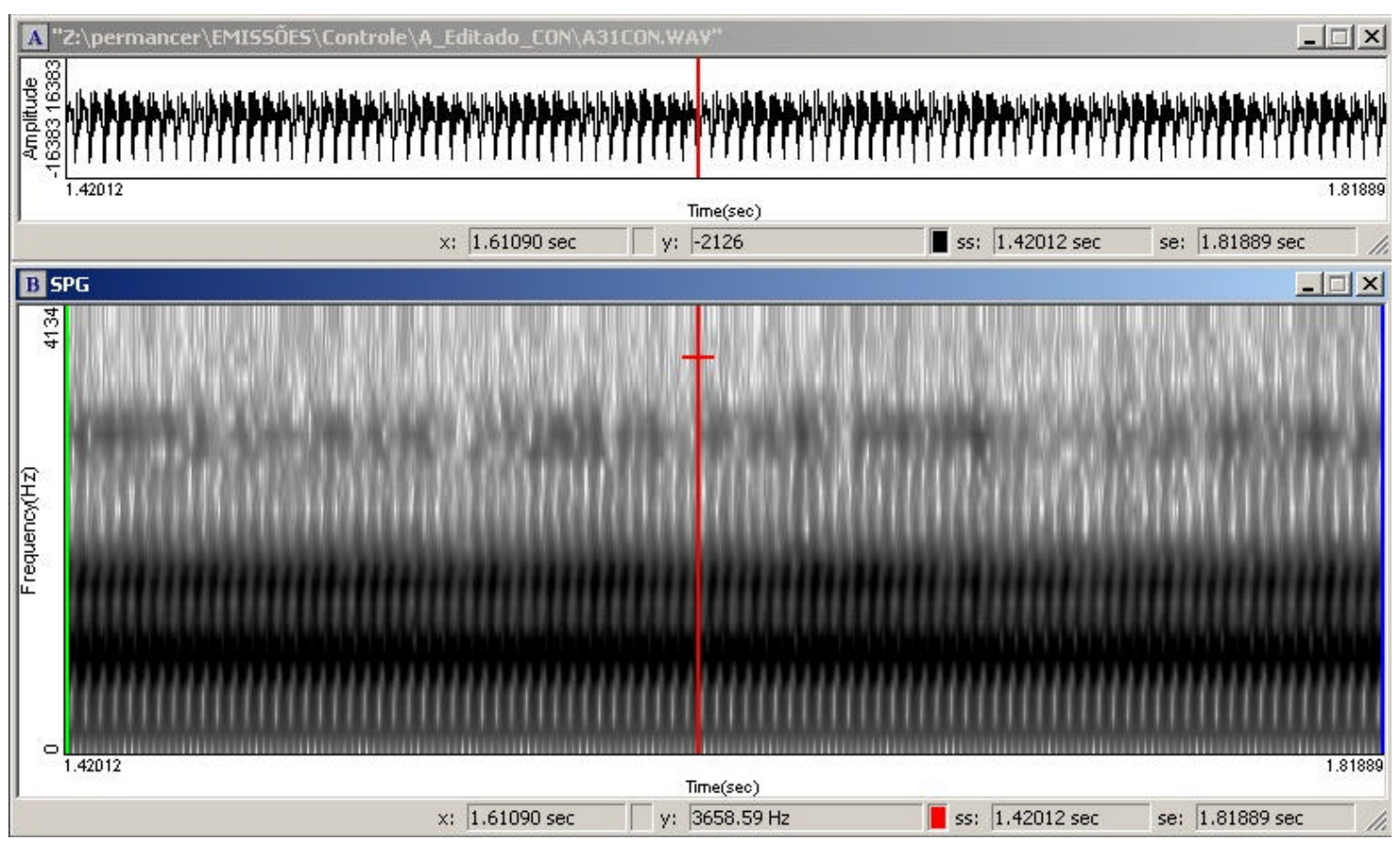

Vogal oral [a] sustentada

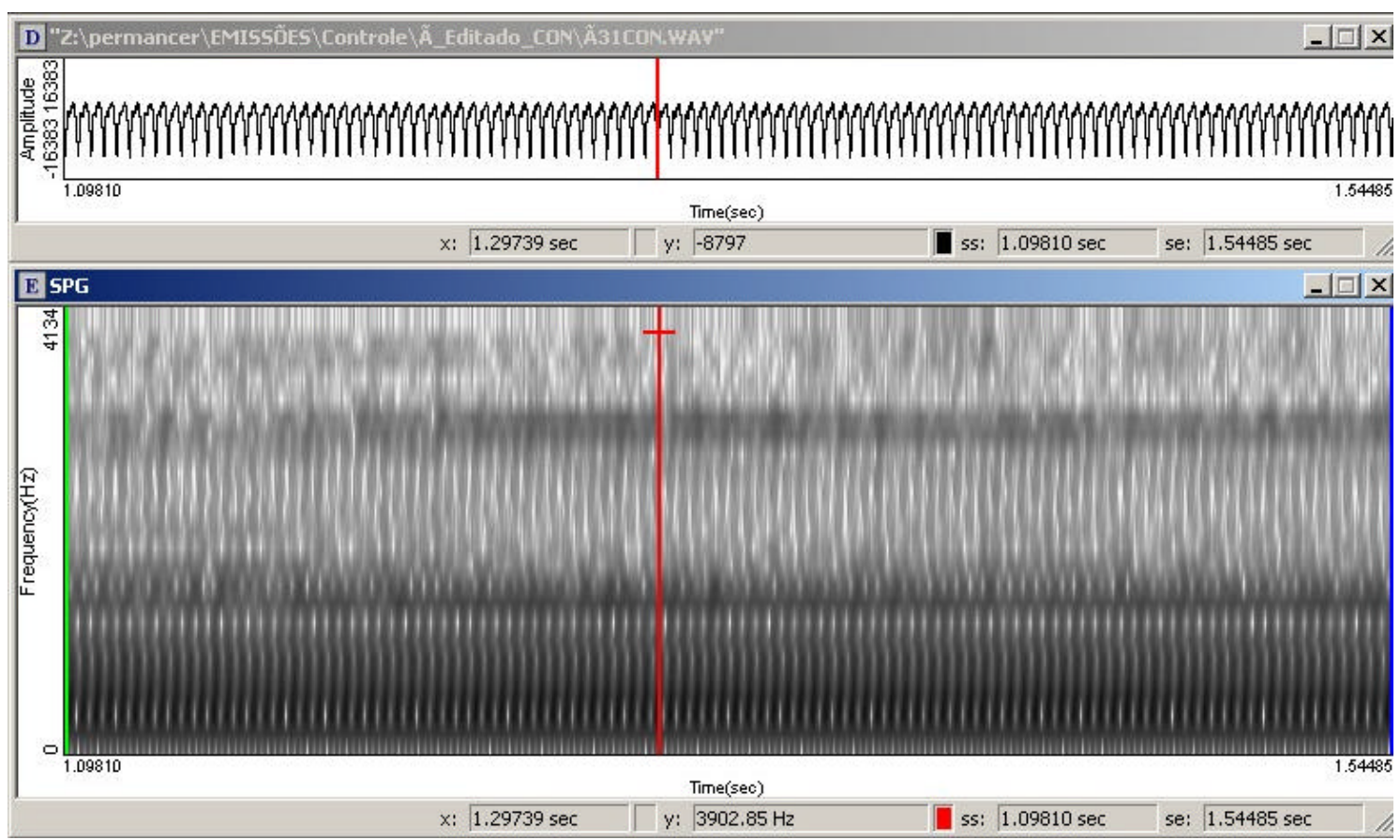

Vogal nasal [ẽ] sustentada 
APÊEDICE AK - Forma de onda das emissões das vogais [a] e [ẽ ] sustentadas (A) e seu respectivo espectrograma $(\mathrm{B})$ da participante com protocolo número 01 do grupo PFA.

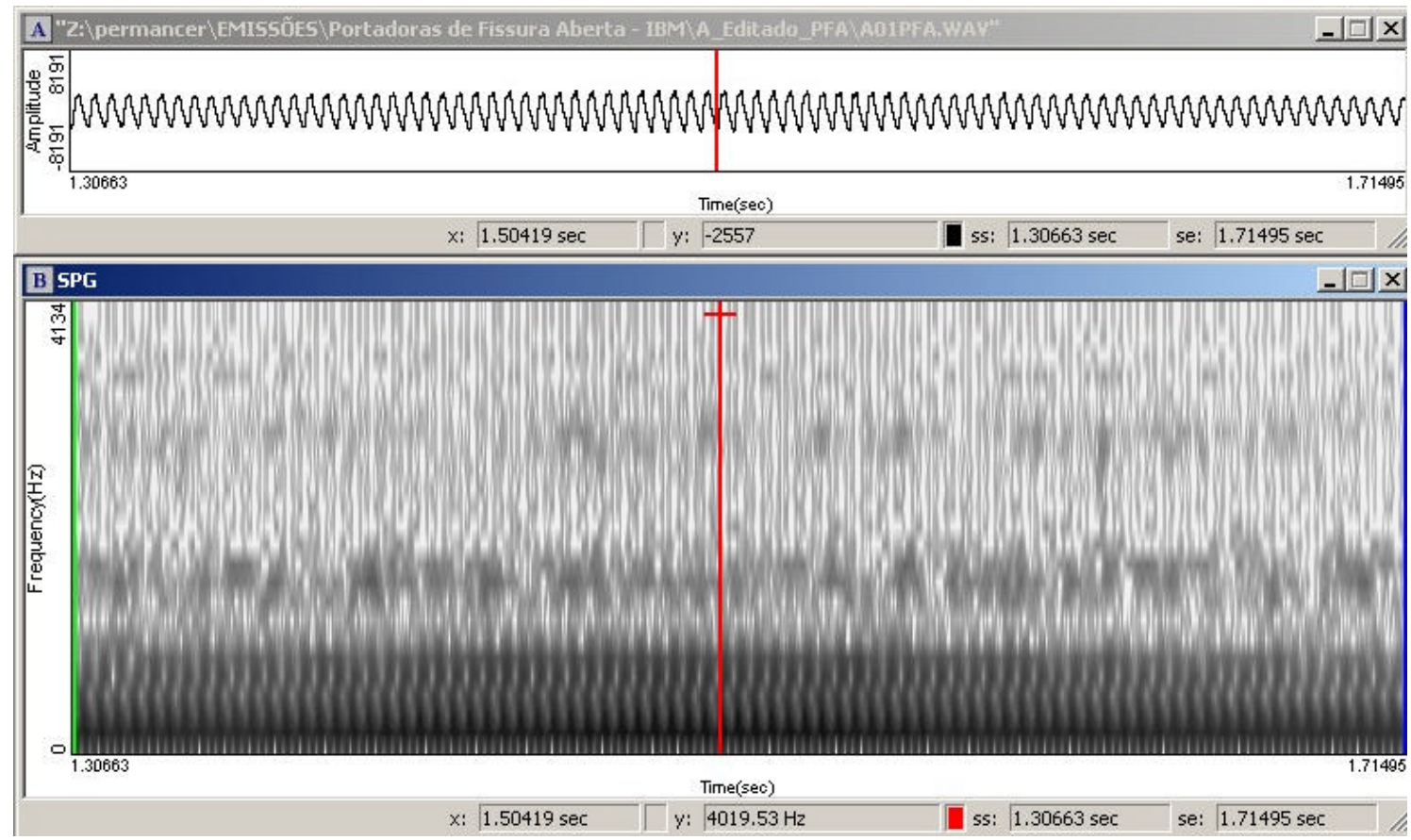

Vogal oral [a] sustentada

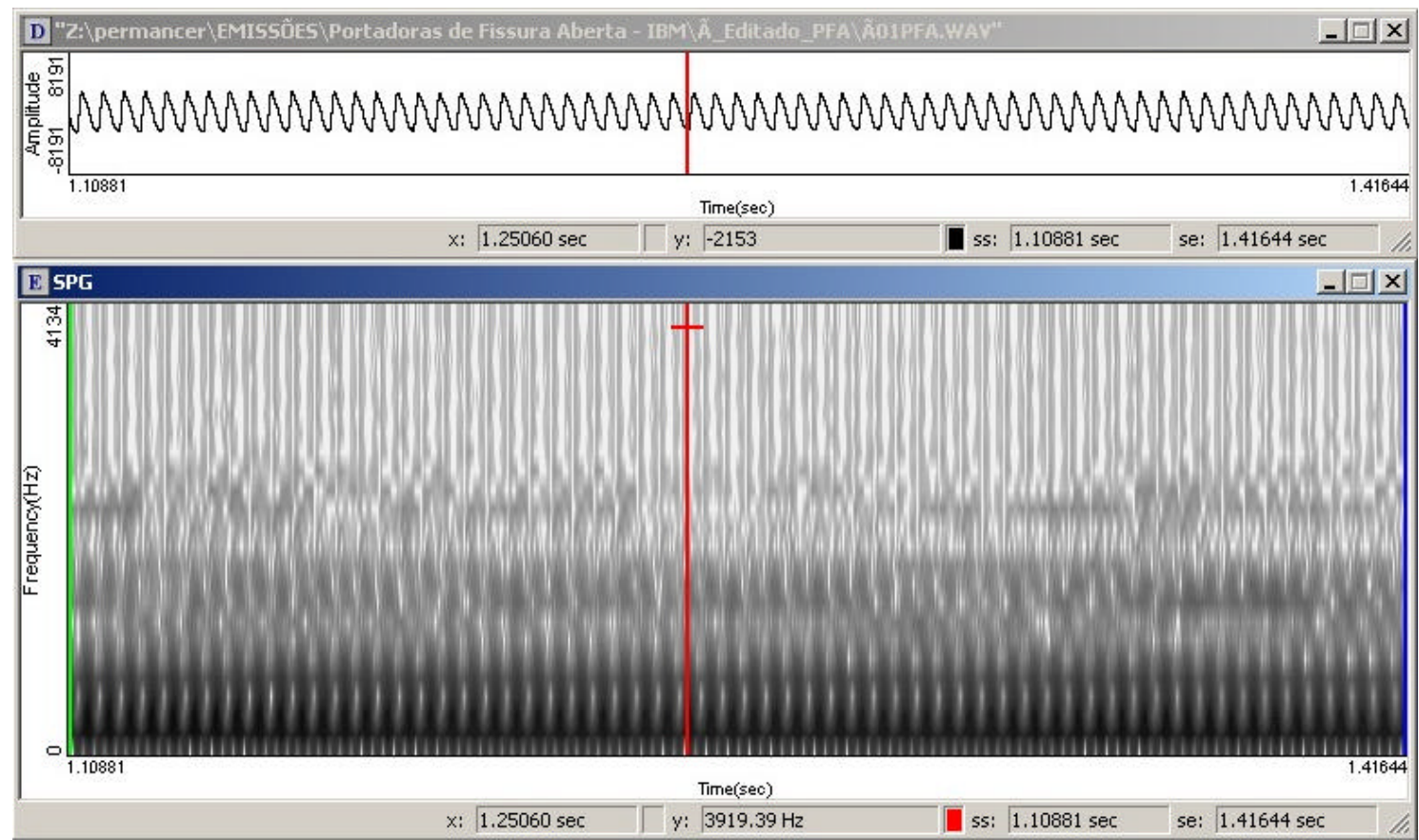

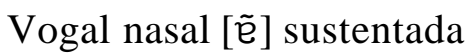


APÊNDICE AL - Forma de onda das emissões das vogais [a] e [ẽe sustentadas (A) e seu respectivo espectrograma (B) da participante com protocolo número 02 do grupo PFA.

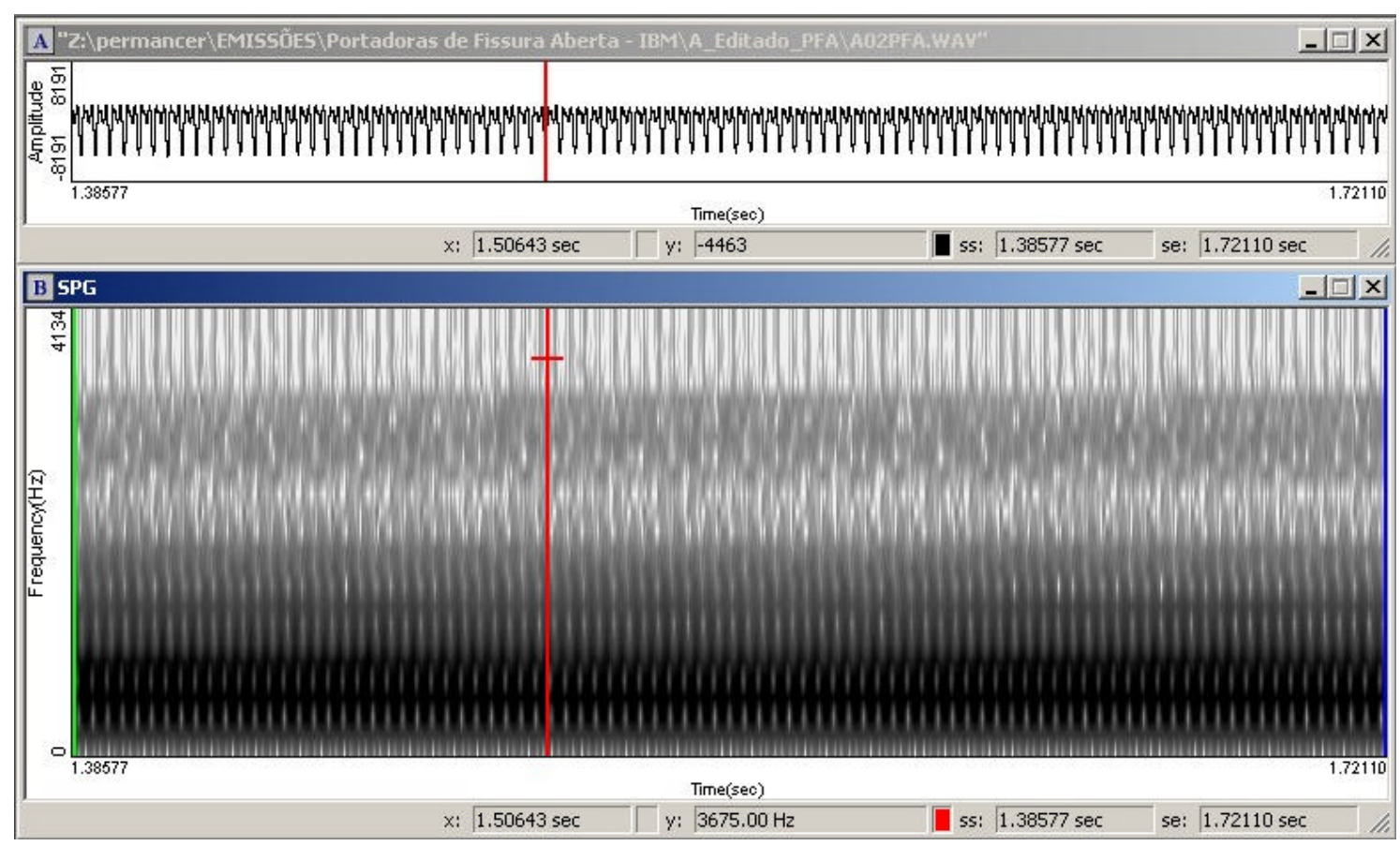

Vogal oral [a] sustentada

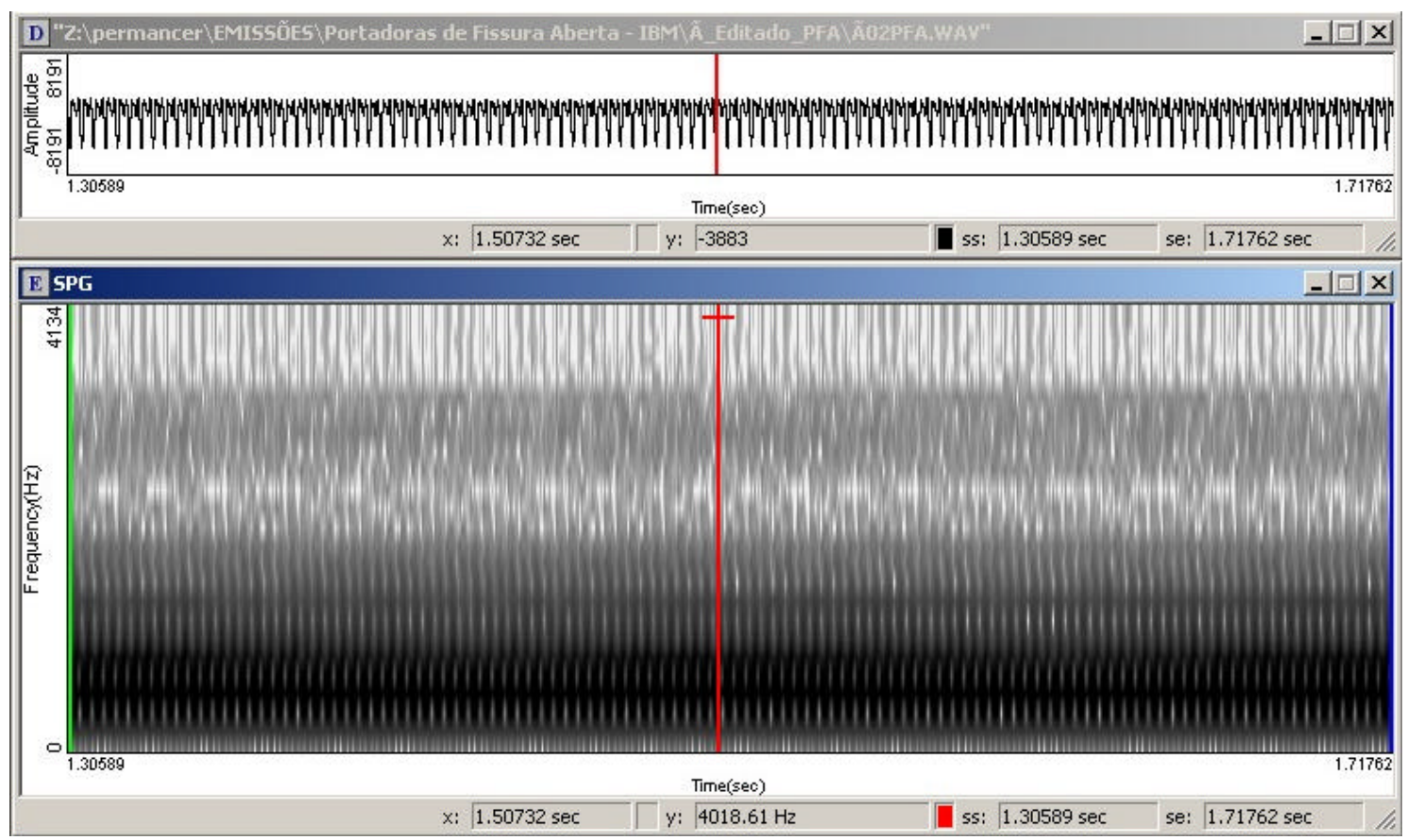

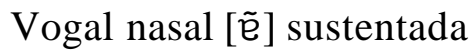


APÊNDICE AM - Forma de onda das emissões das vogais [a] e [ẽ ] sustentadas (A) e seu respectivo espectrograma (B) da participante com protocolo número 03 do grupo PFA.

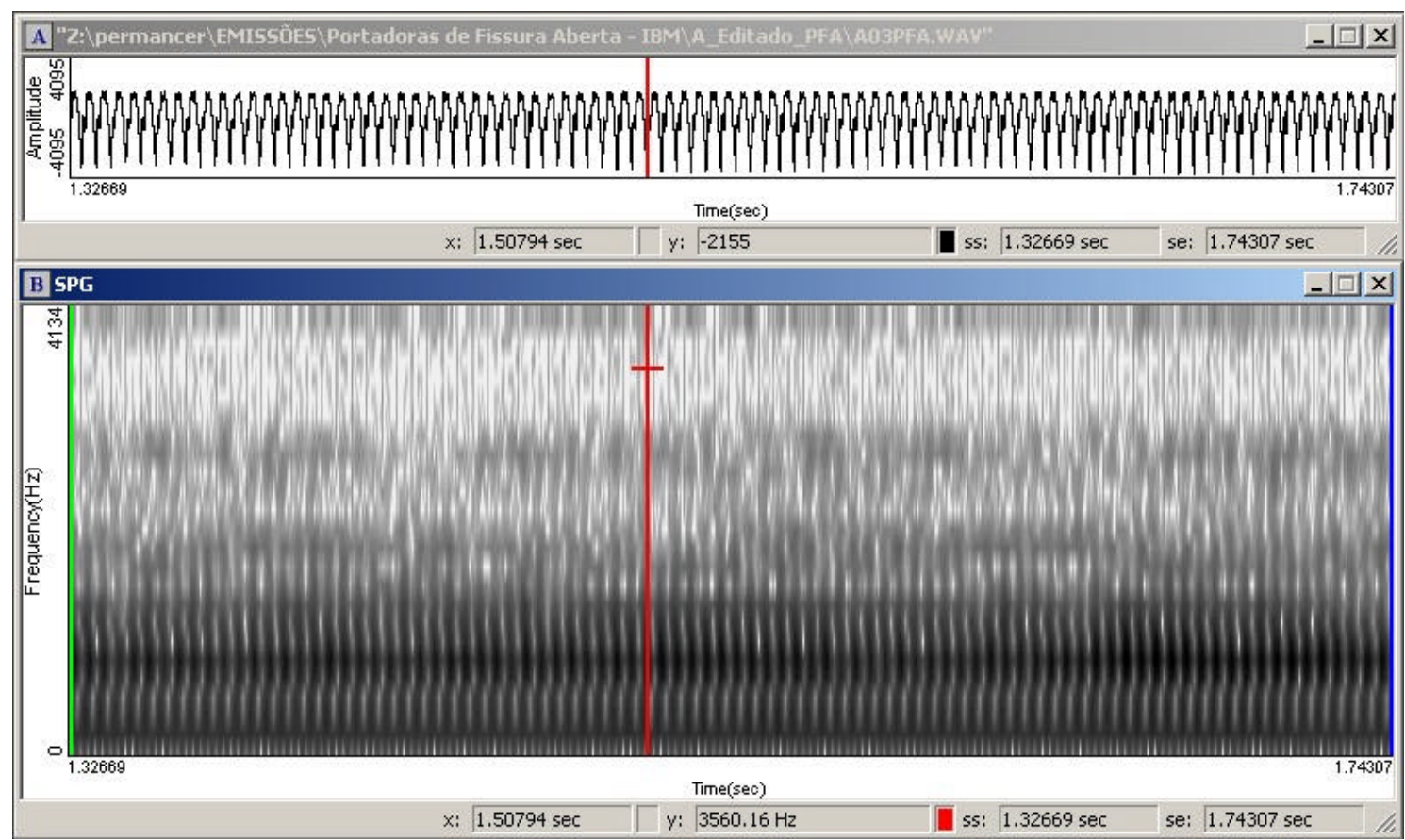

Vogal oral [a] sustentada

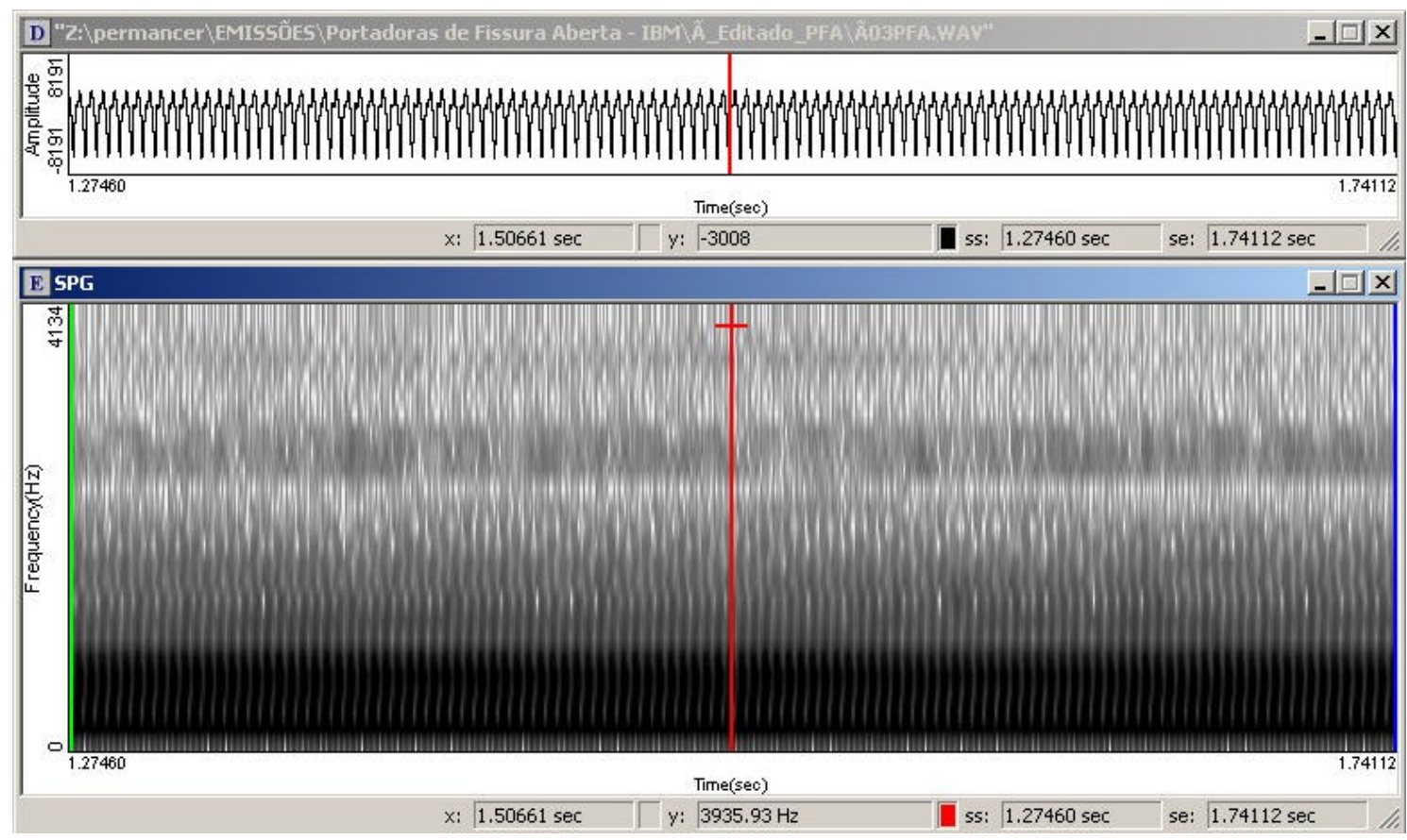

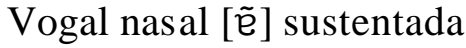


APÊNDICE AN - Forma de onda das emissões das vogais [a] e [ẽ ] sustentadas (A) e seu respectivo espectrograma (B) da participante com protocolo número 04 do grupo PFA.

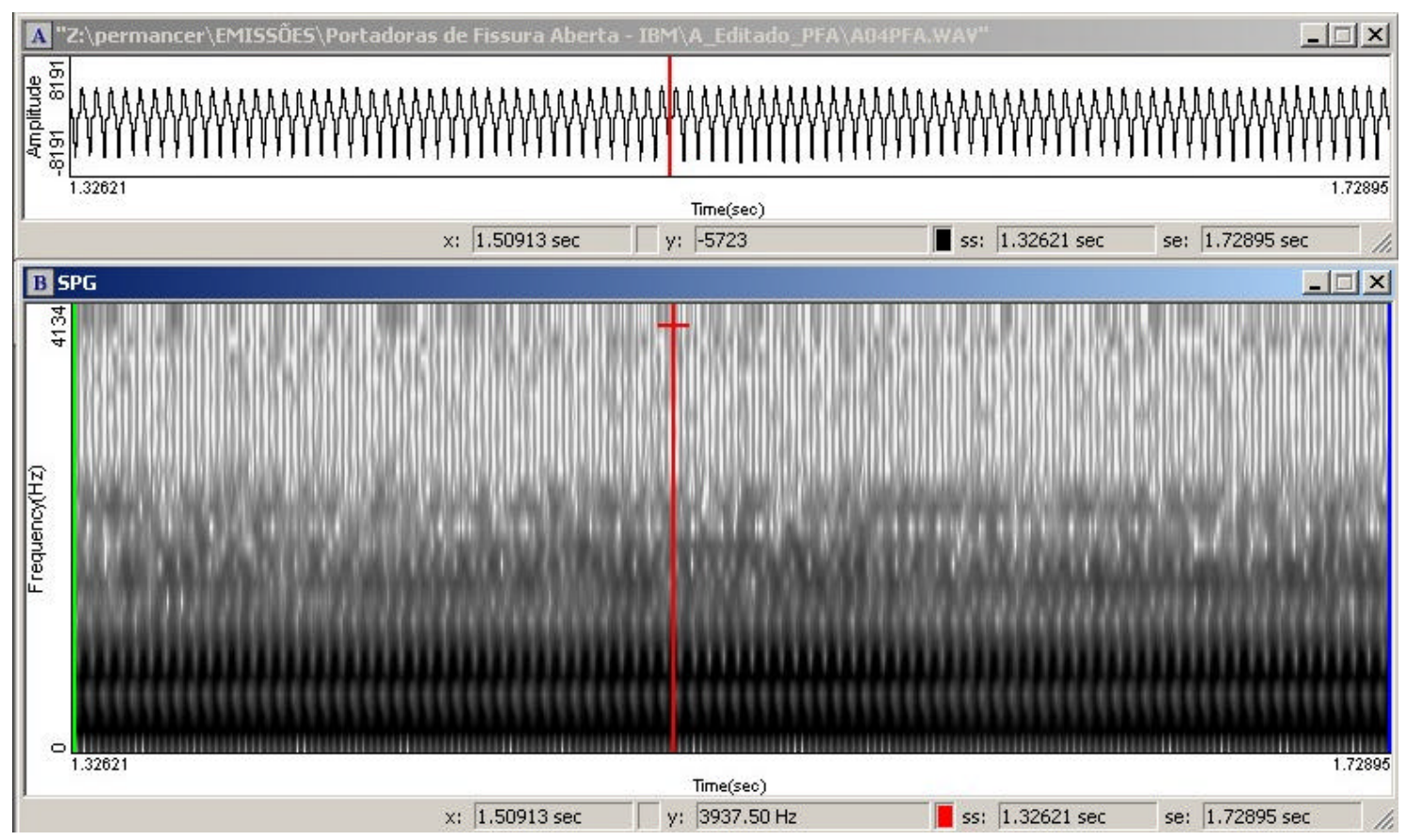

Vogal oral [a] sustentada

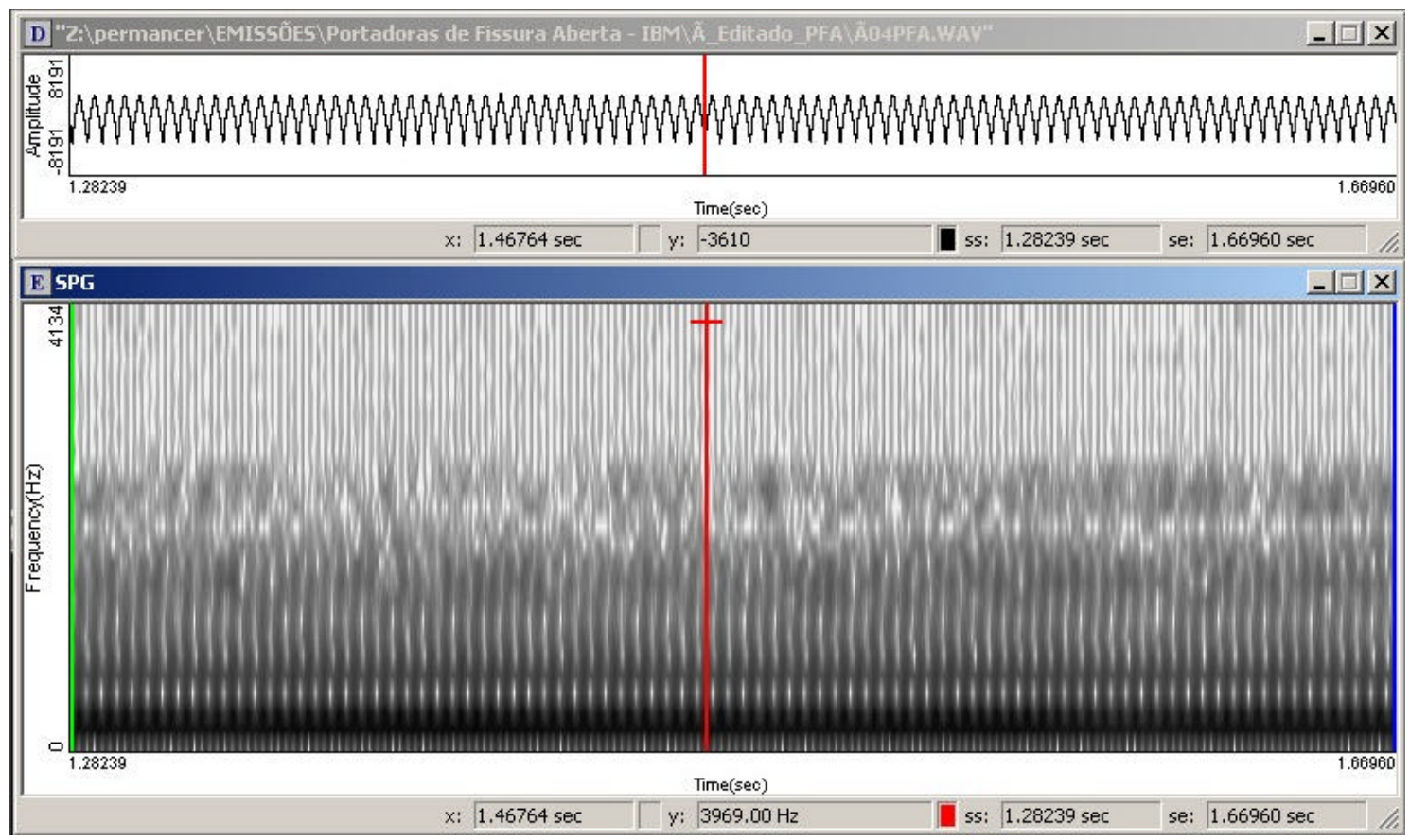

Vogal nasal [ẽ] sustentada 
APÊNDICE AO - Forma de onda das emissões das vogais [a] e [ẽ ] sustentadas (A) e seu respectivo espectrograma $(\mathrm{B})$ da participante com protocolo número 05 do grupo PFA.

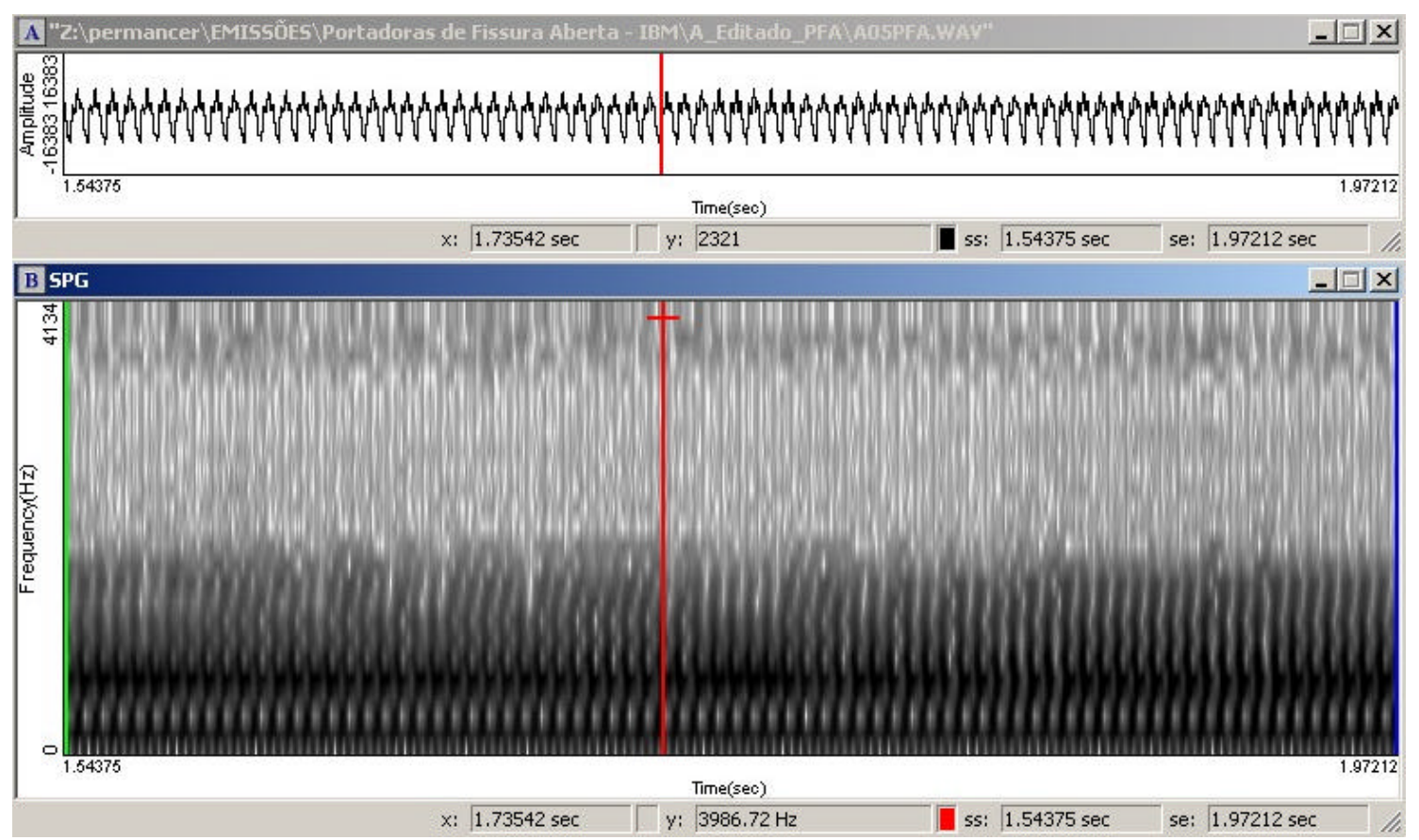

Vogal oral [a] sustentada

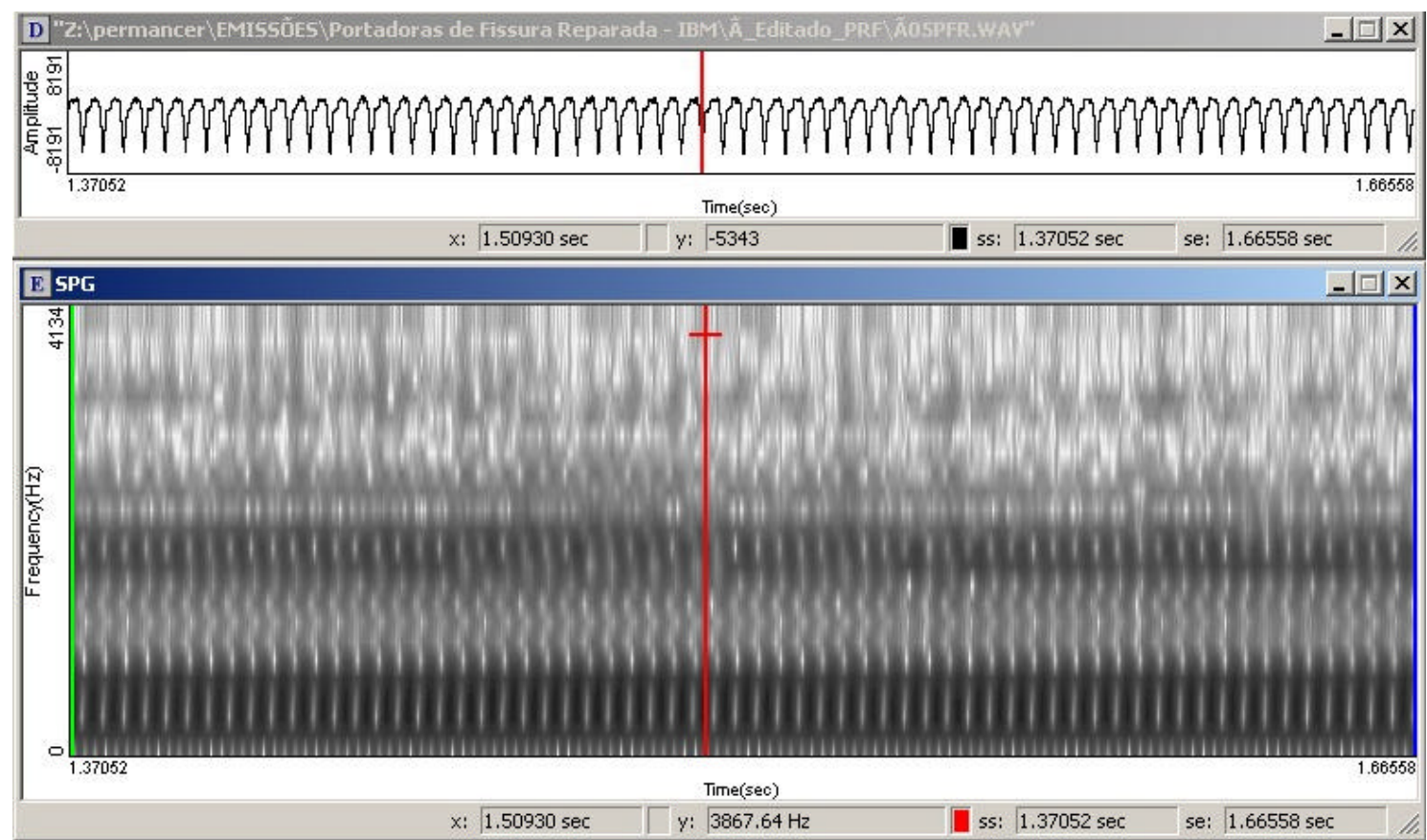

Vogal nasal [ẽe sustentada 
APÊNDICE AP - Forma de onda das emissões das vogais [a] e [ẽe sustentadas (A) e seu respectivo espectrograma (B) da participante com protocolo número 01 do grupo PFR.

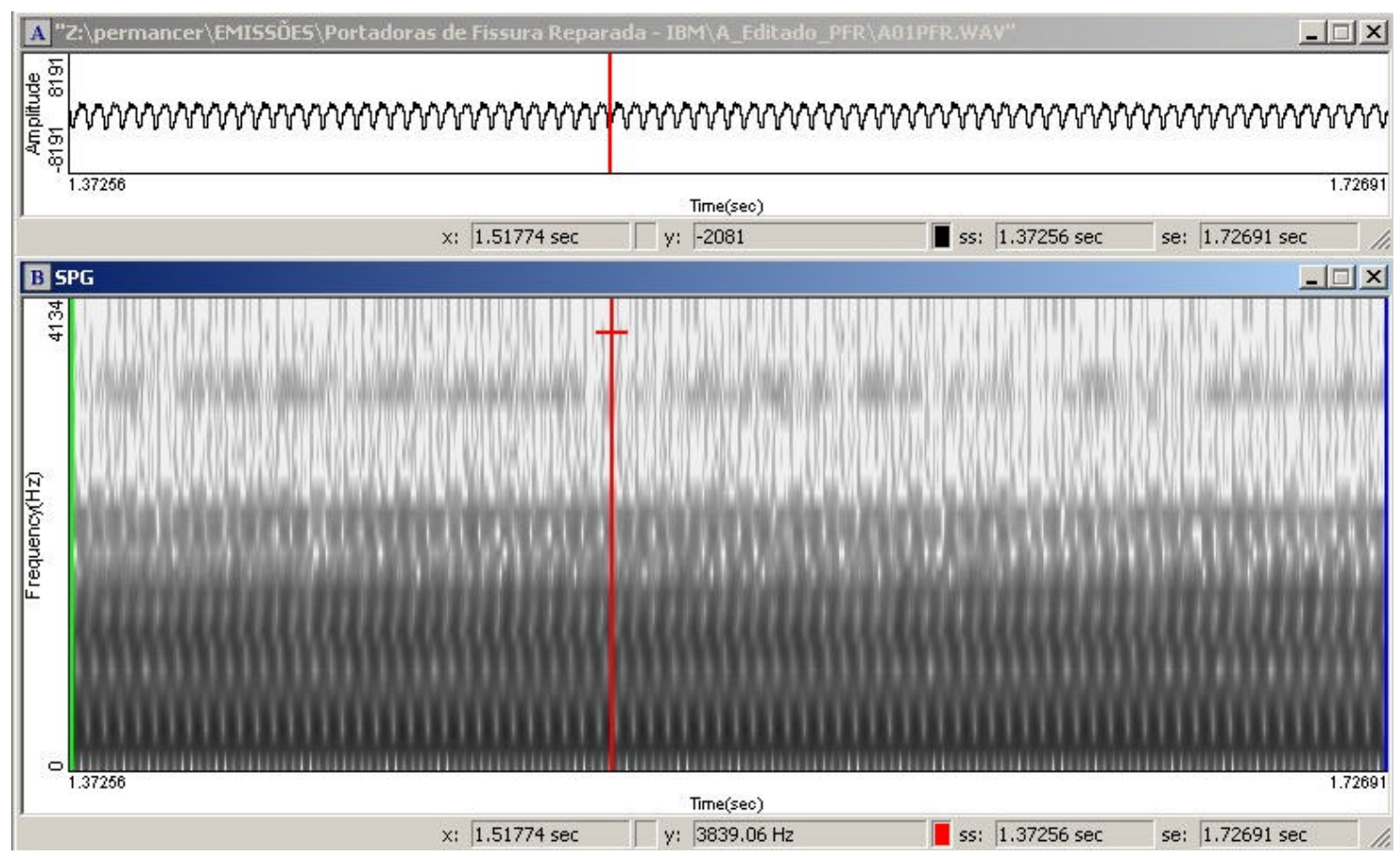

Vogal oral [a] sustentada

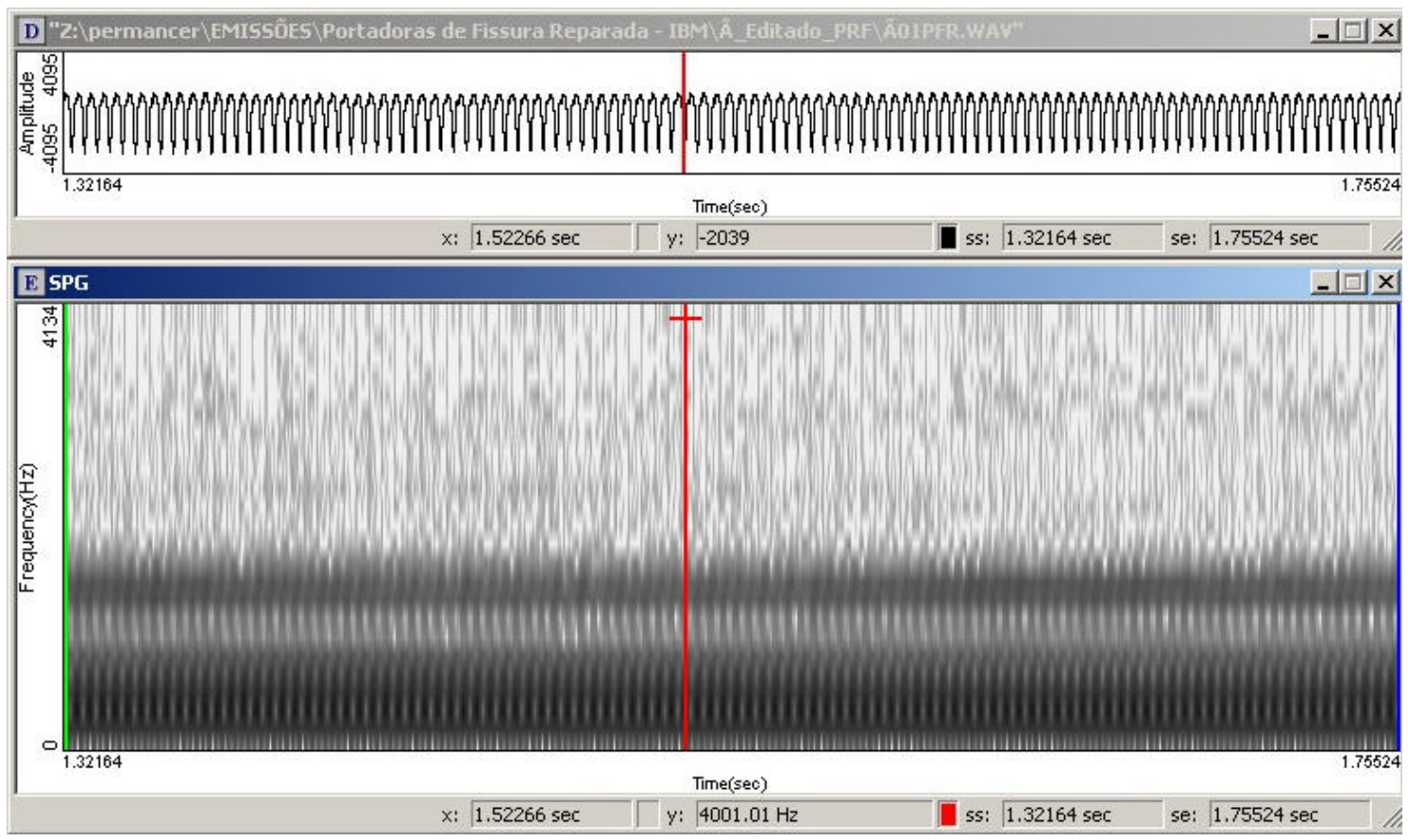

Vogal nasal [ẽ ] sustentada 


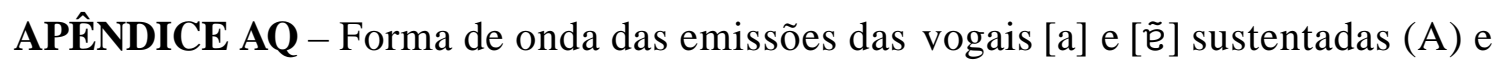
seu respectivo espectrograma (B) da participante com protocolo número 02 do grupo PFR.

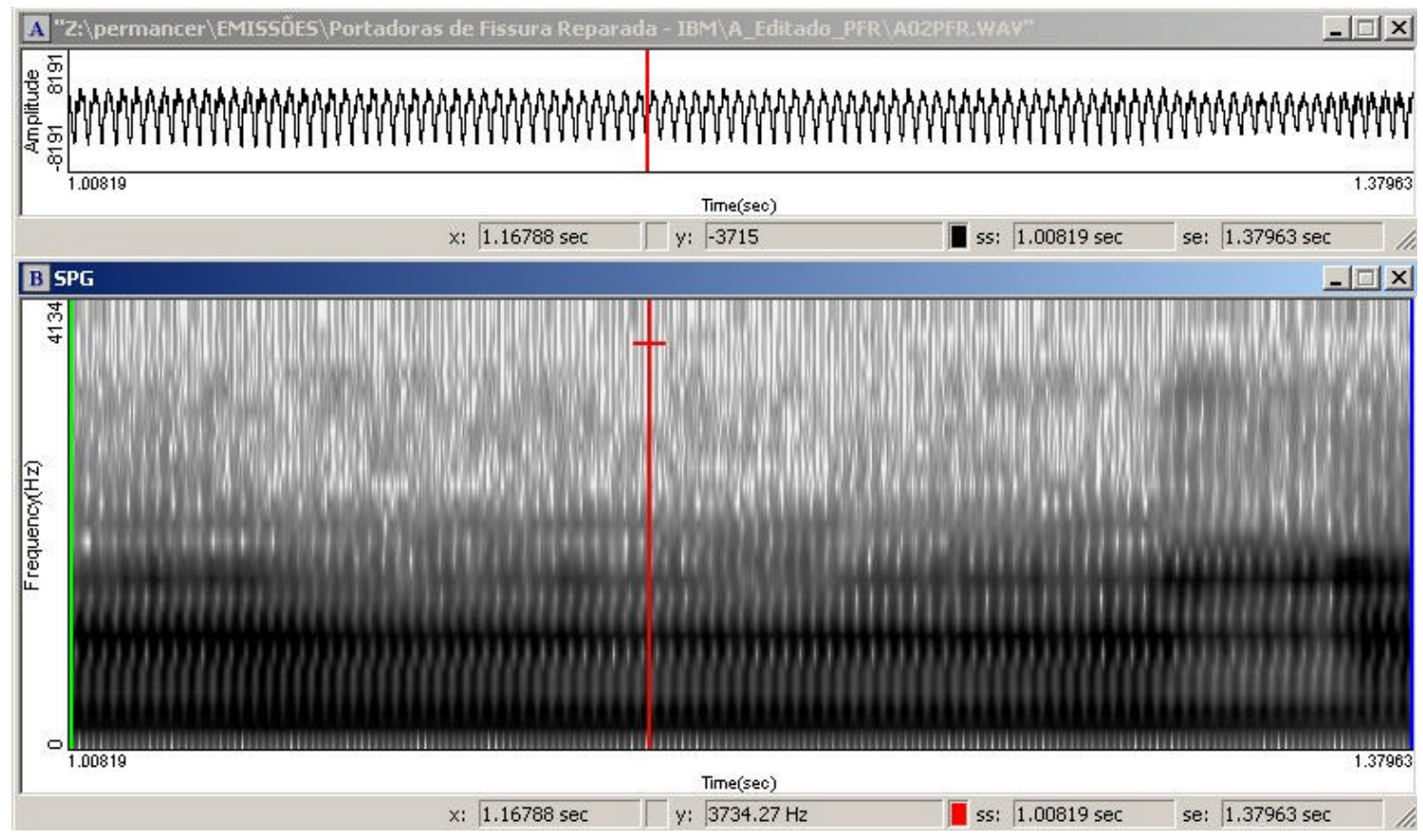

Vogal oral [a] sustentada

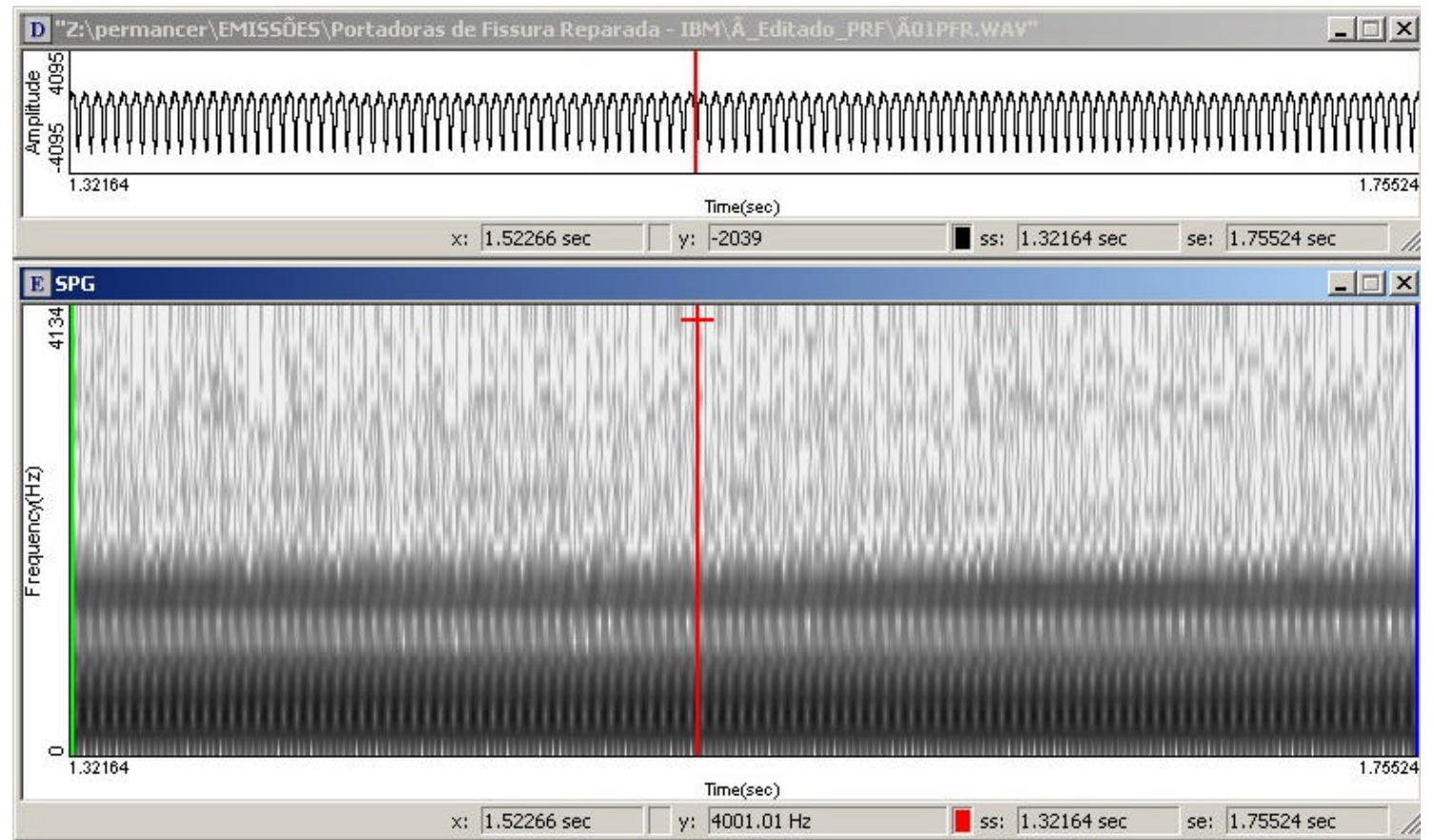

Vogal nasal [ẽe sustentada 
APÊNDICE AR - Forma de onda das emissões das vogais [a] e [ẽ ] sustentadas (A) e seu respectivo espectrograma (B) da participante com protocolo número 03 do grupo PFR.

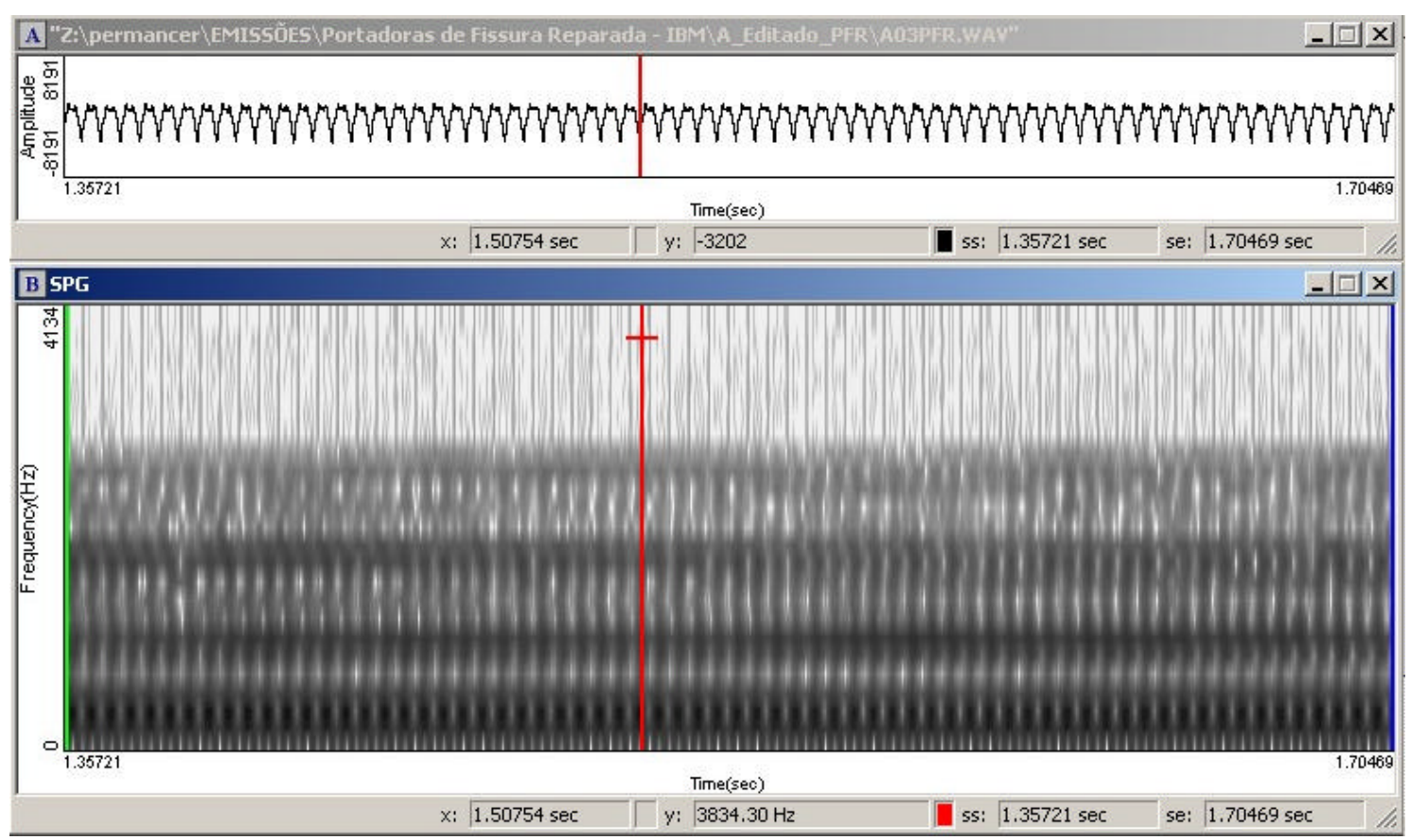

Vogal oral [a] sustentada

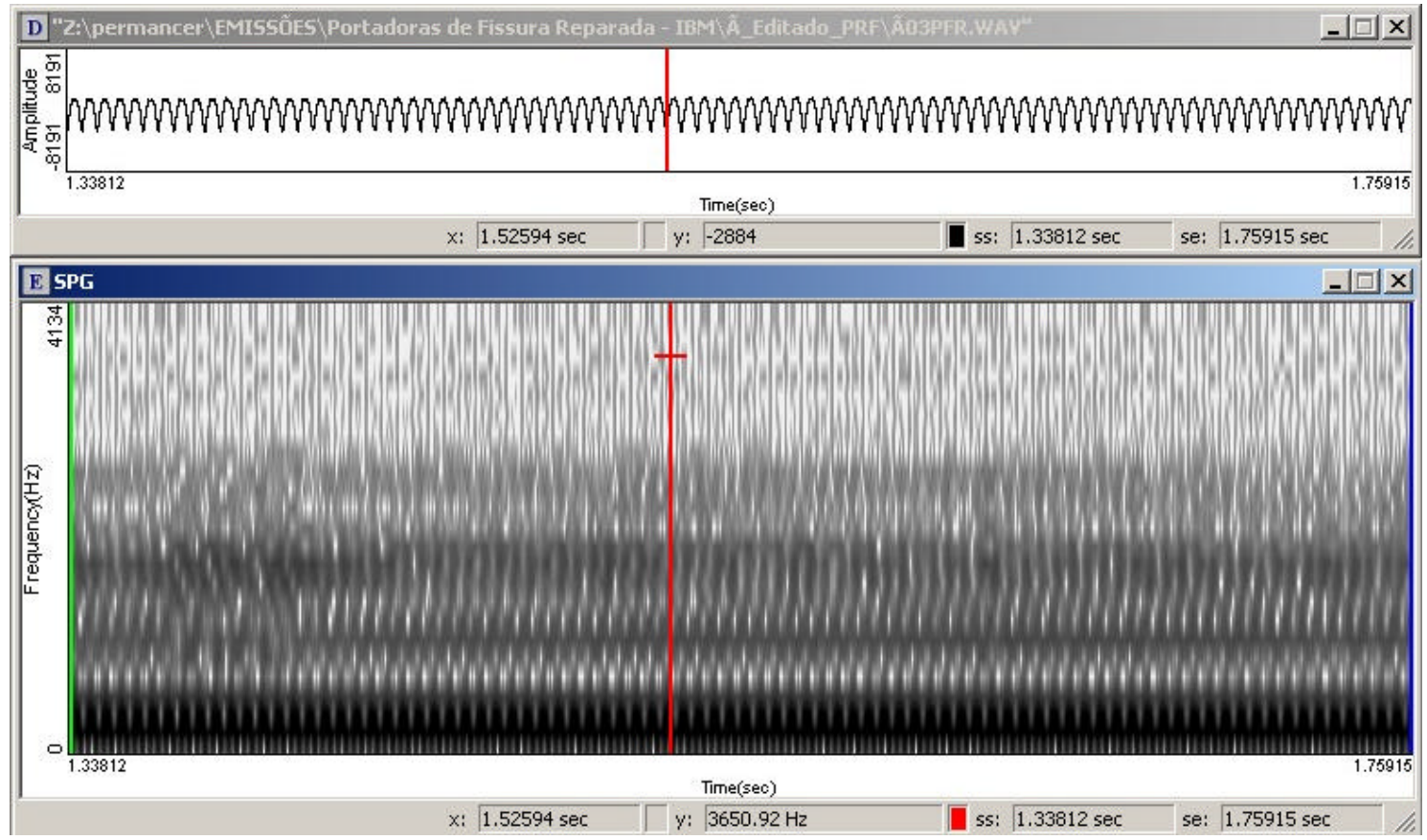

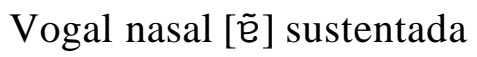


APENNDICE AS - Forma de onda das emissões das vogais [a] e [ẽ ] sustentadas (A) e seu respectivo espectrograma (B) da participante com protocolo número 04 do grupo PFR.

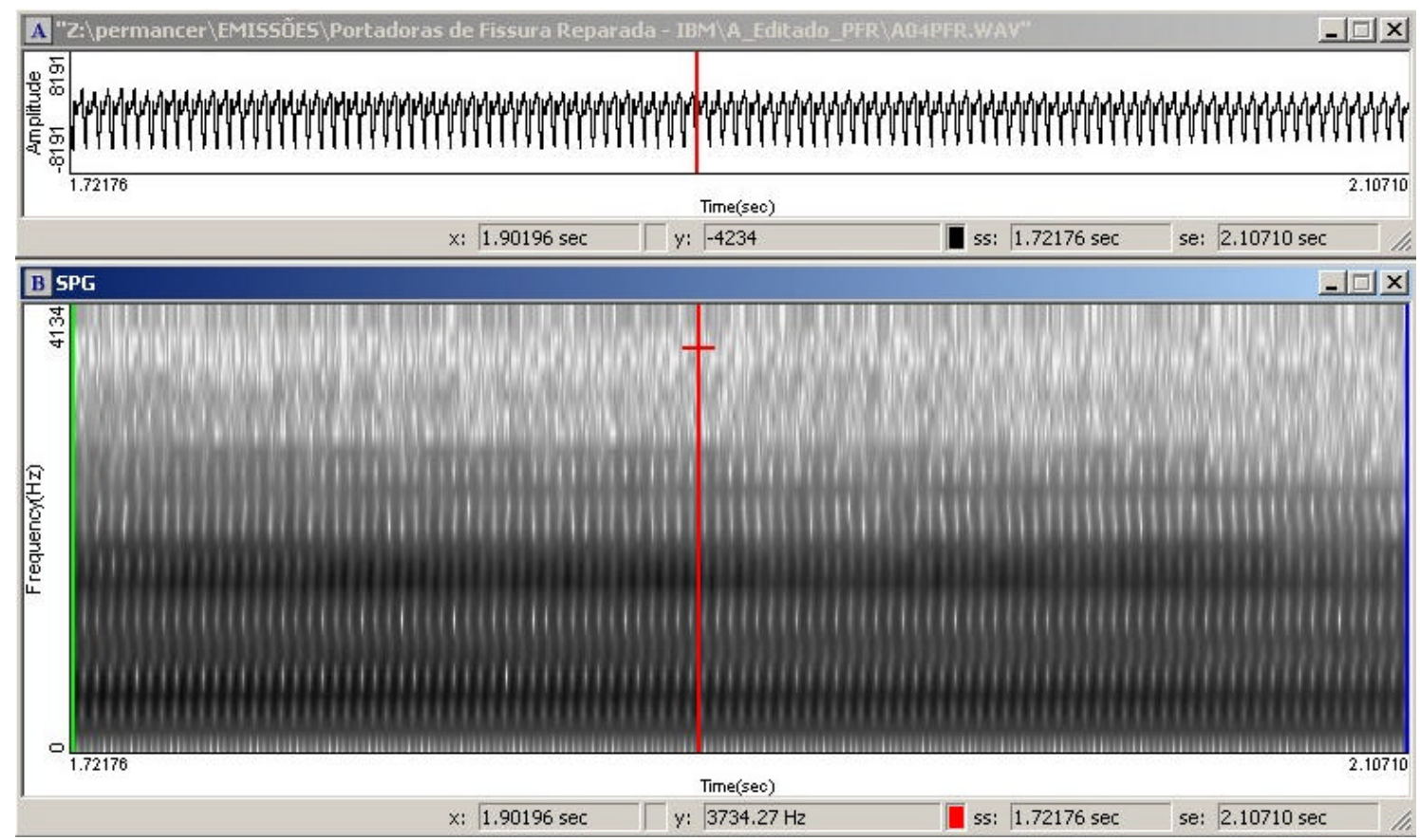

Vogal oral [a] sustentada

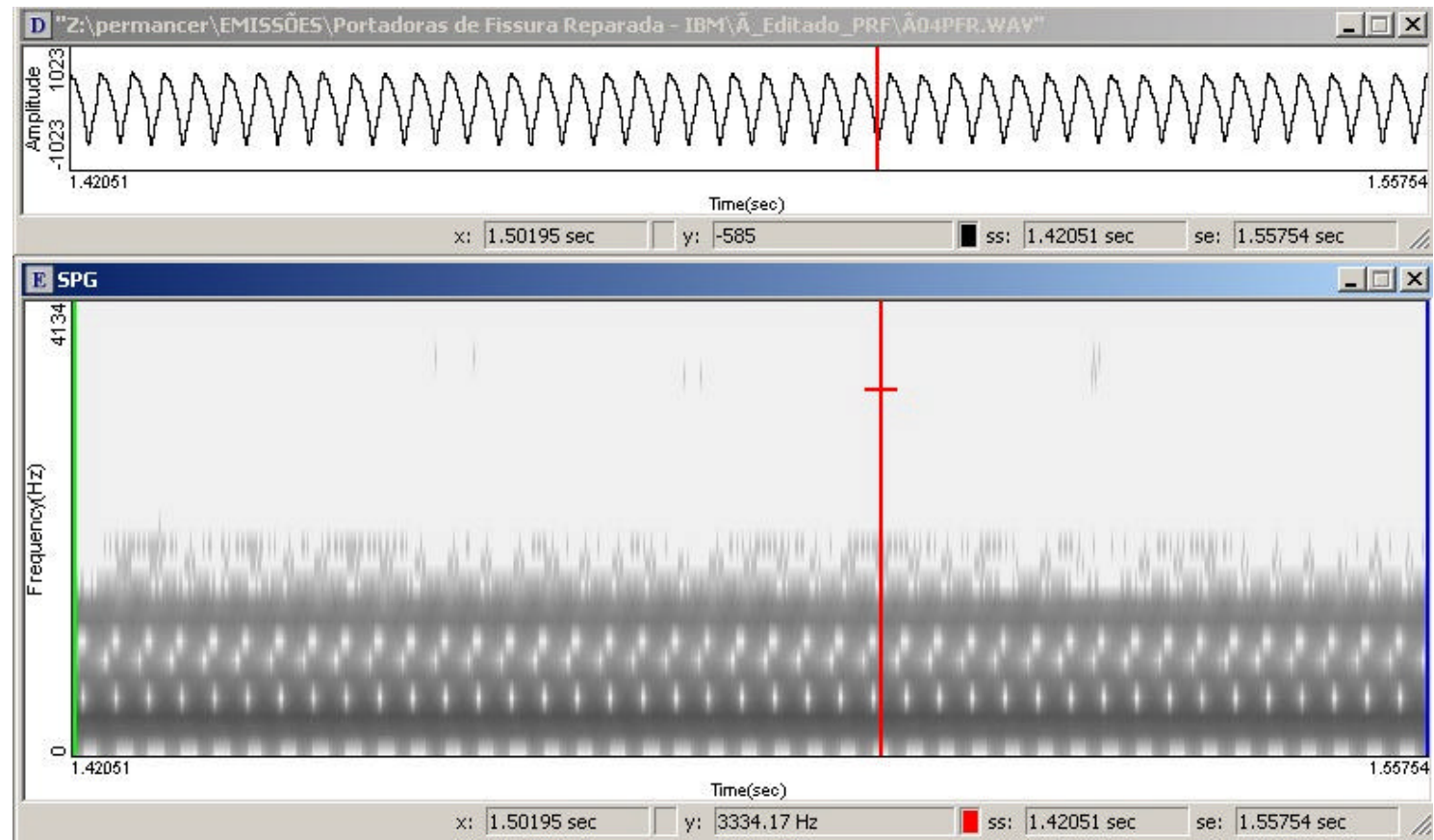

Vogal nasal [ẽe sustentada 
APÊNDICE AT - Forma de onda das emissões das vogais [a] e [ẽe sustentadas (A) e seu respectivo espectrograma (B) da participante com protocolo número 05 do grupo PFR.

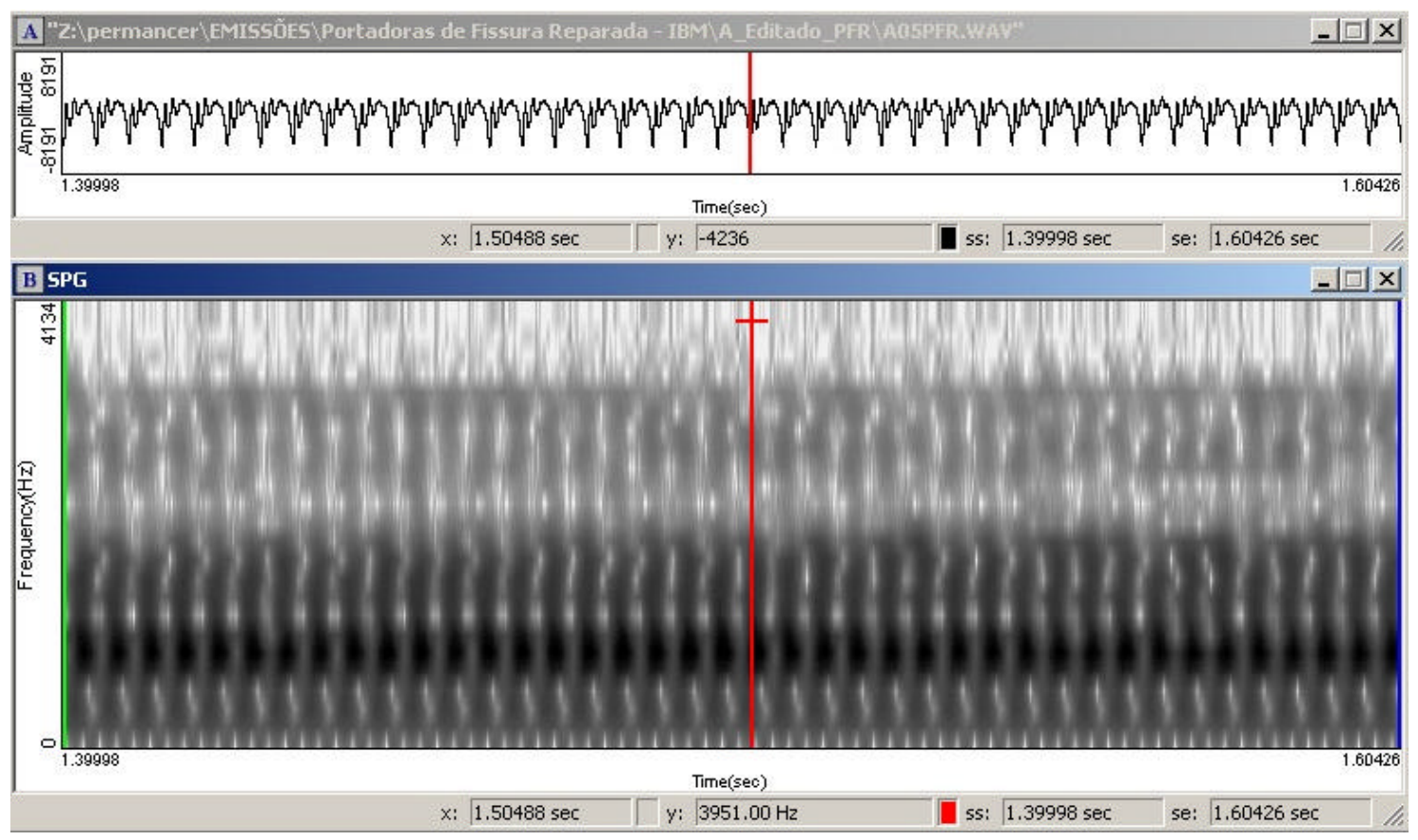

Vogal oral [a] sustentada

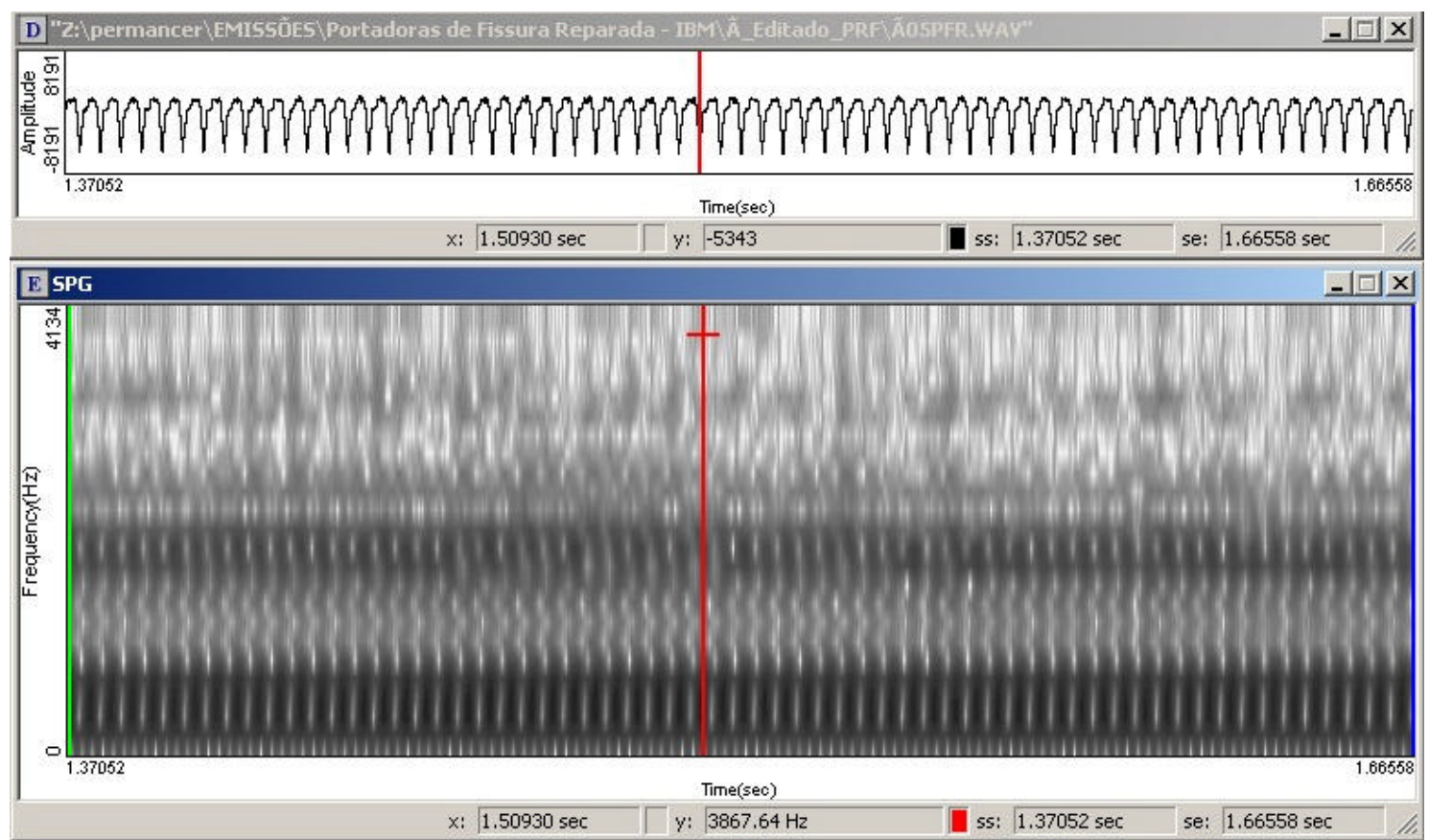

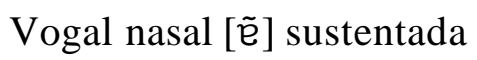


APÊNDICE AU - Forma de onda das emissões das vogais [a] e [ẽ ] sustentadas (A) e seu respectivo espectrograma $(\mathrm{B})$ da participante com protocolo número 06 do grupo PFR.

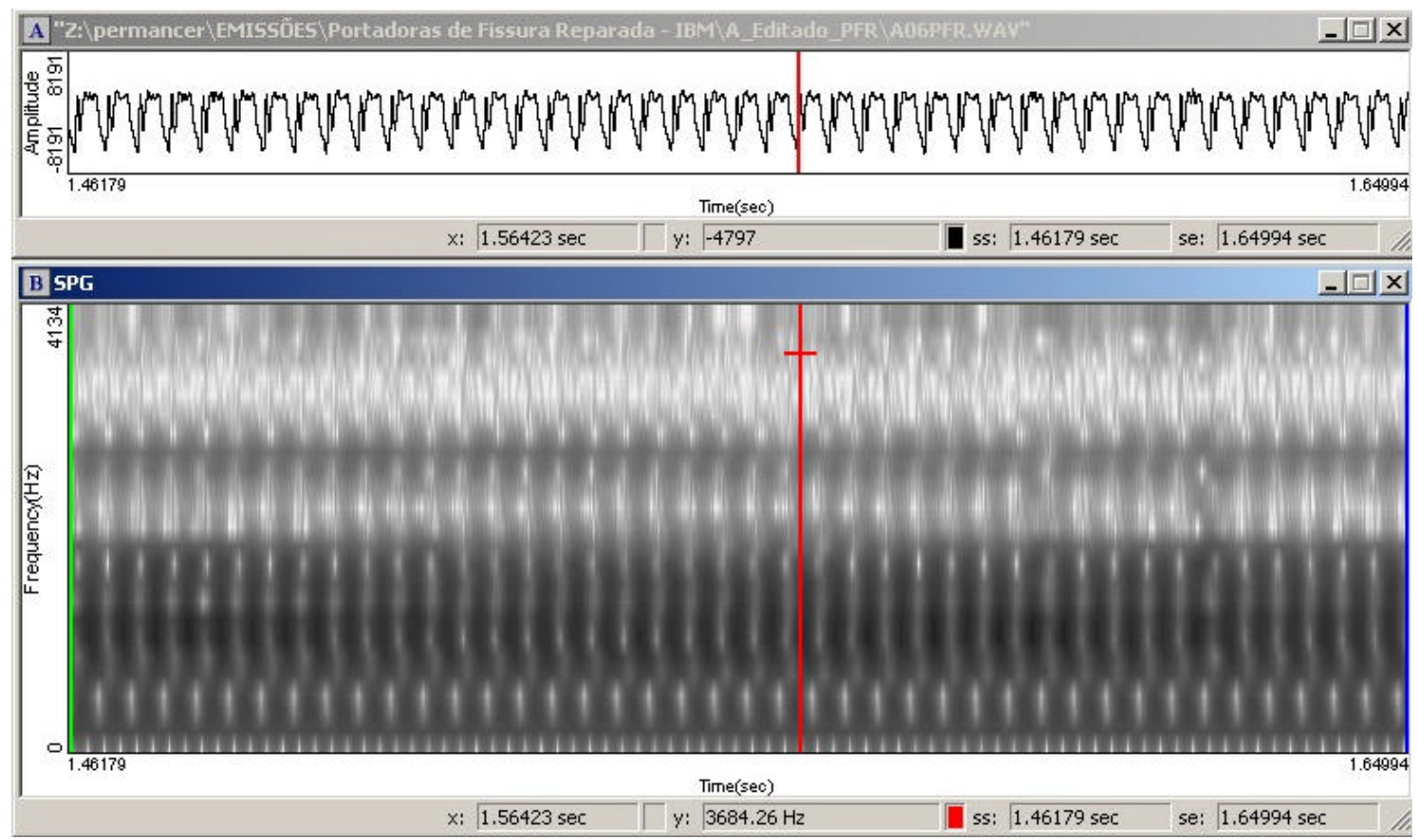

Vogal oral [a] sustentada

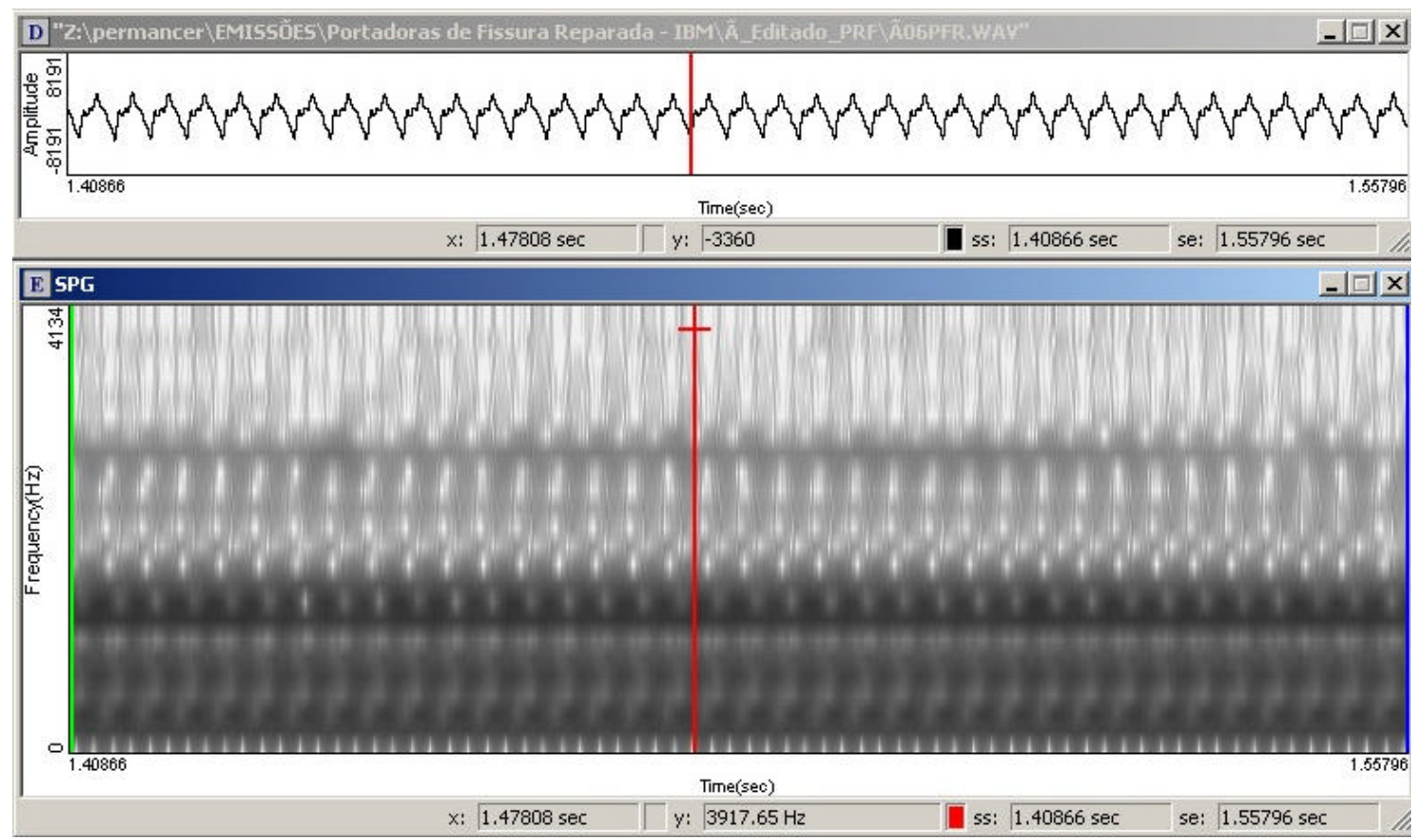

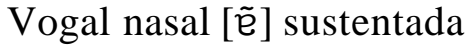


APÊNDICE AV - Forma de onda das emissões das vogais [a] e [ẽe sustentadas (A) e seu respectivo espectrograma $(\mathrm{B})$ da participante com protocolo número 07 do grupo PFR.

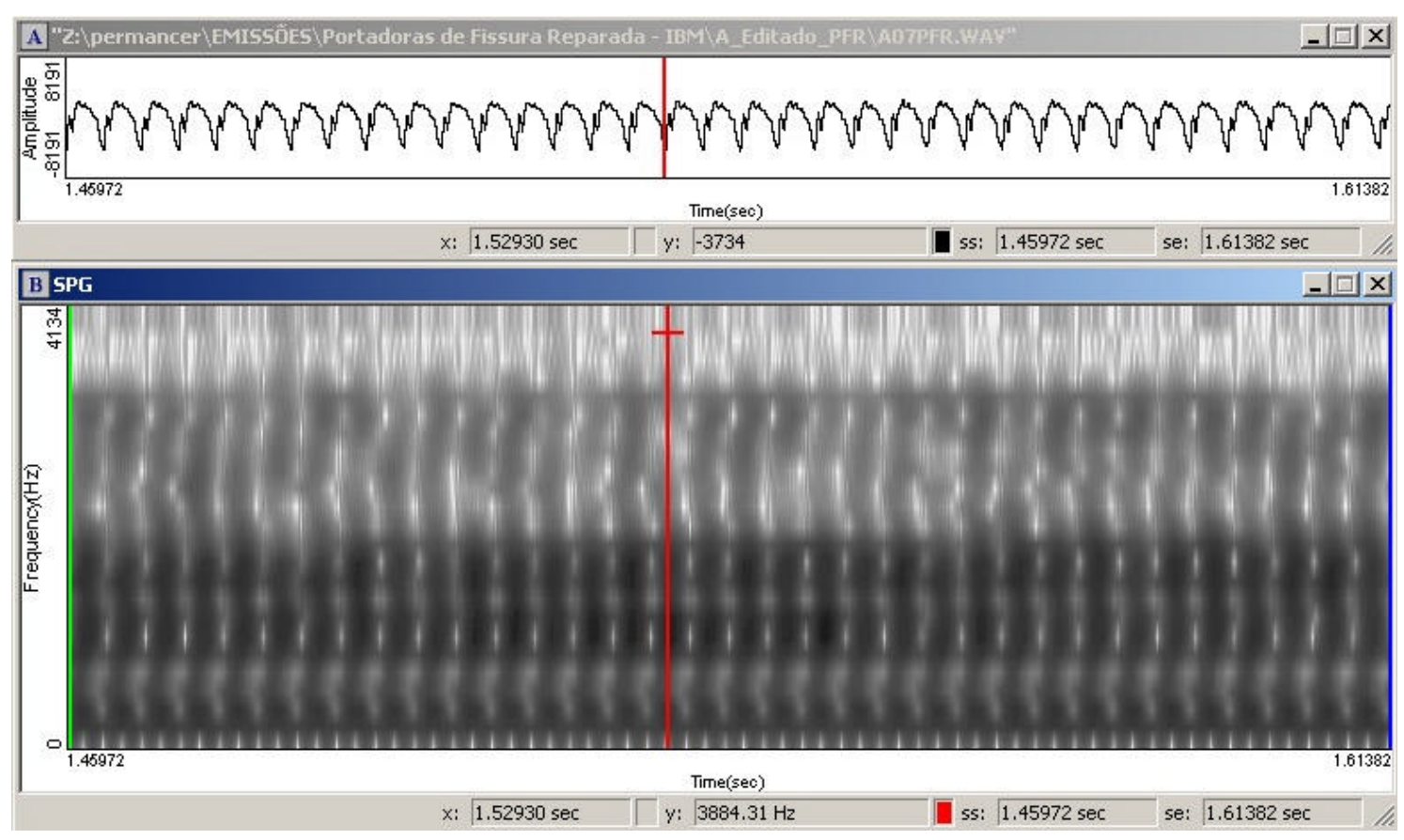

Vogal oral [a] sustentada

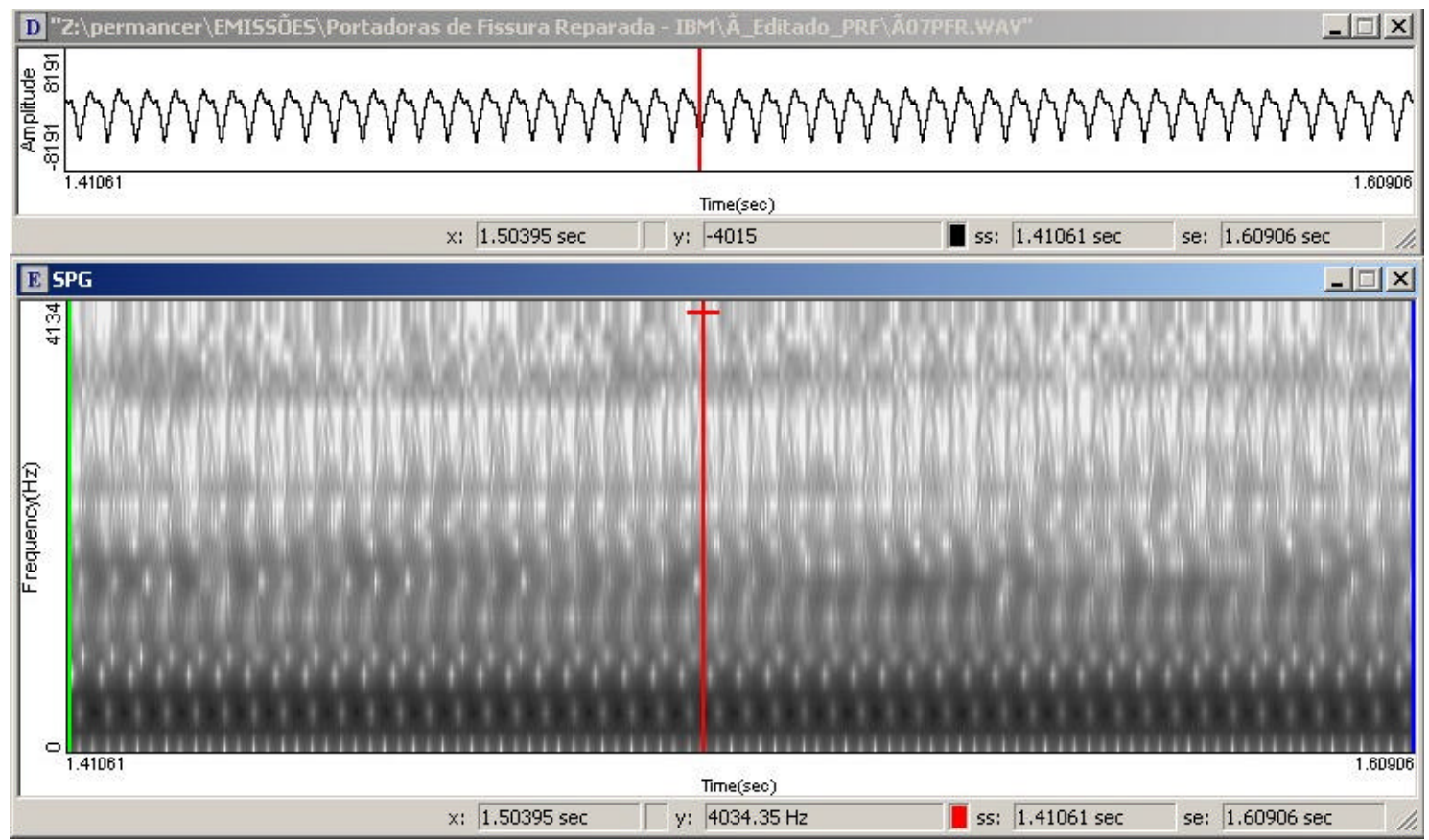

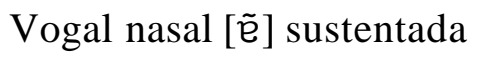


APÊNDICE AW - Forma de onda das emissões das vogais [a] e [ẽ ] sustentadas (A) e seu respectivo espectrograma (B) da participante com protocolo número 08 do grupo PFR.

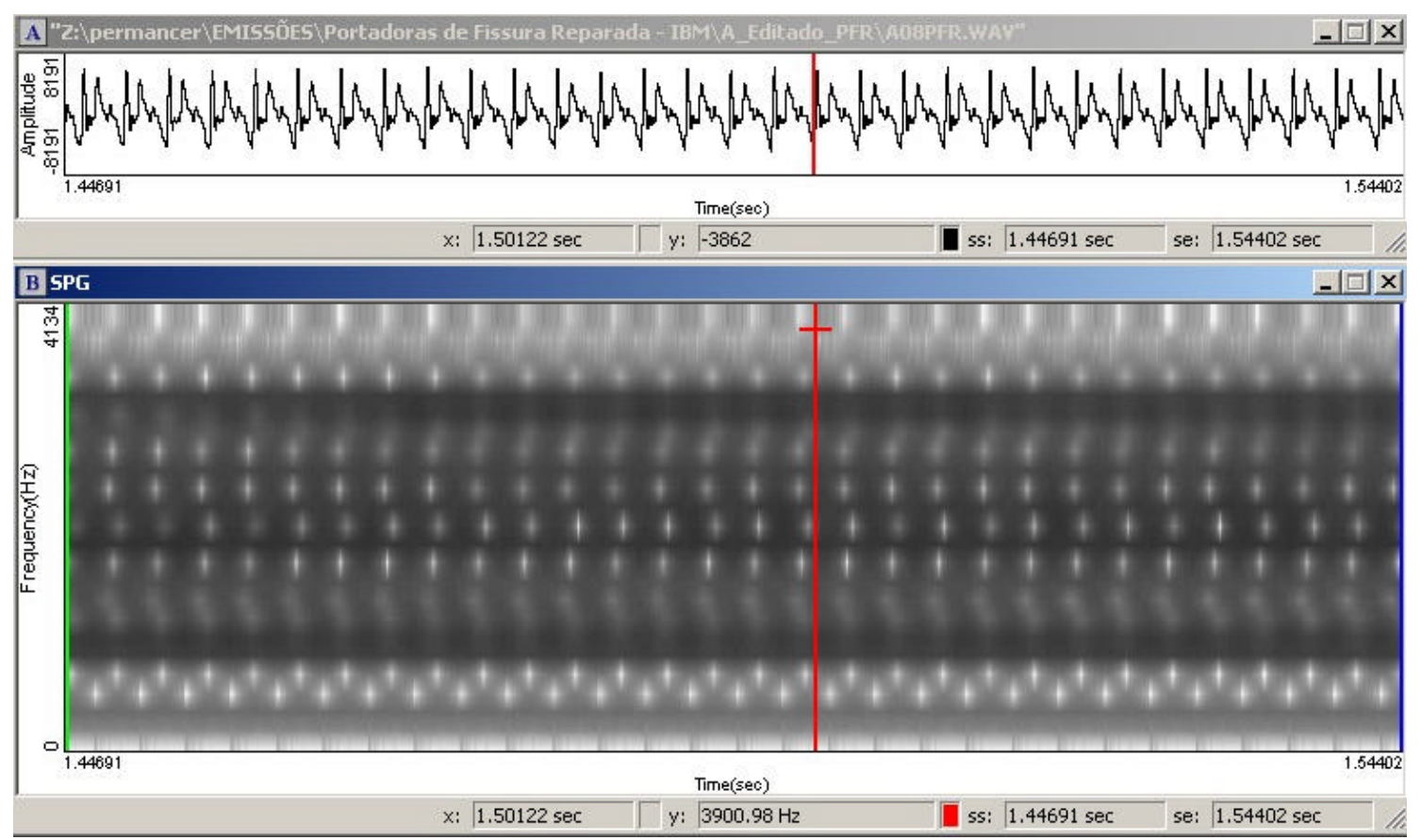

Vogal oral [a] sustentada

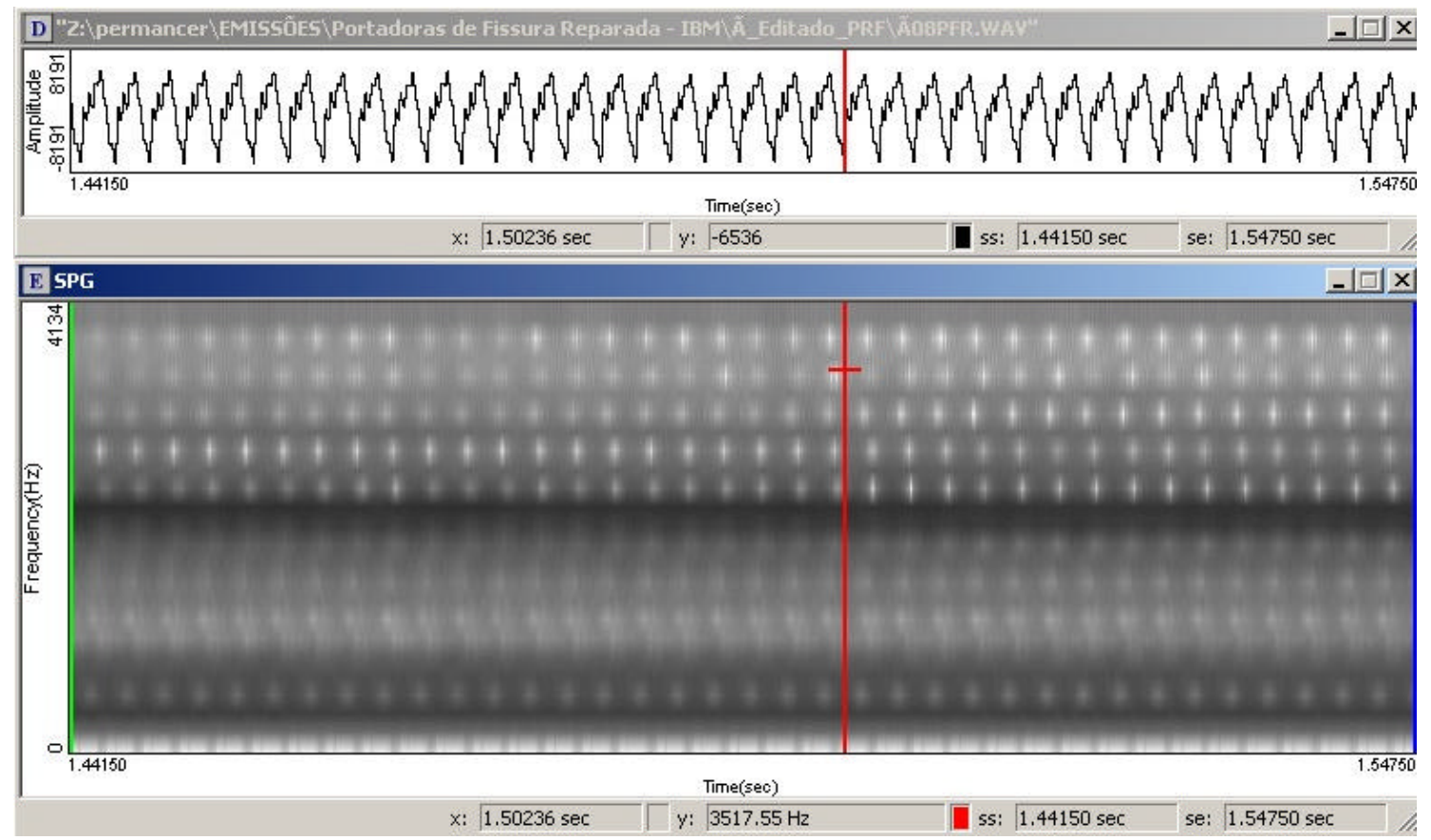

Vogal nasal [ẽ ] sustentada 
APÊNDICE AX - Forma de onda das emissões das vogais [a] e [ẽe sustentadas (A) e seu respectivo espectrograma (B) da participante com protocolo número 09 do grupo PFR.

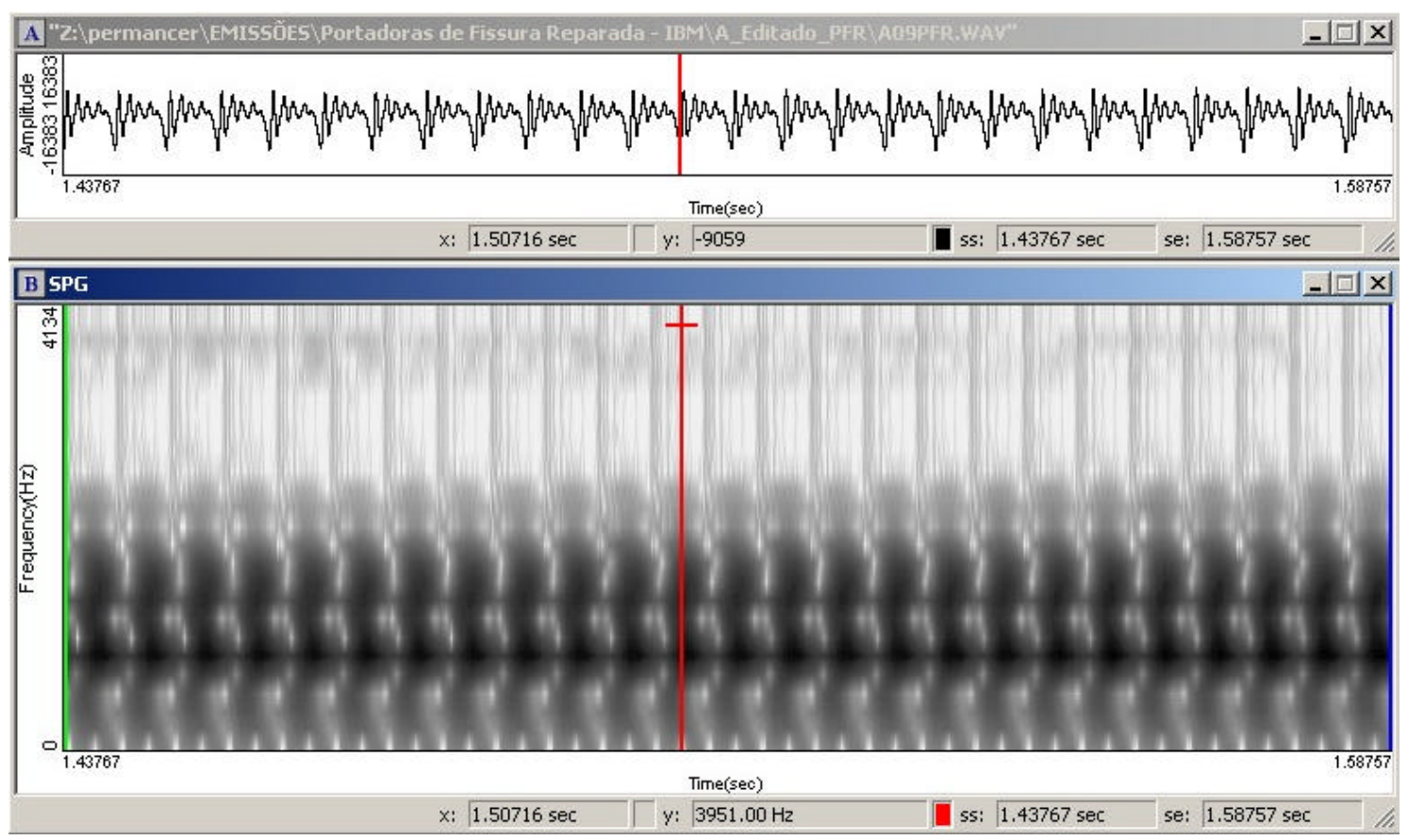

Vogal oral [a] sustentada

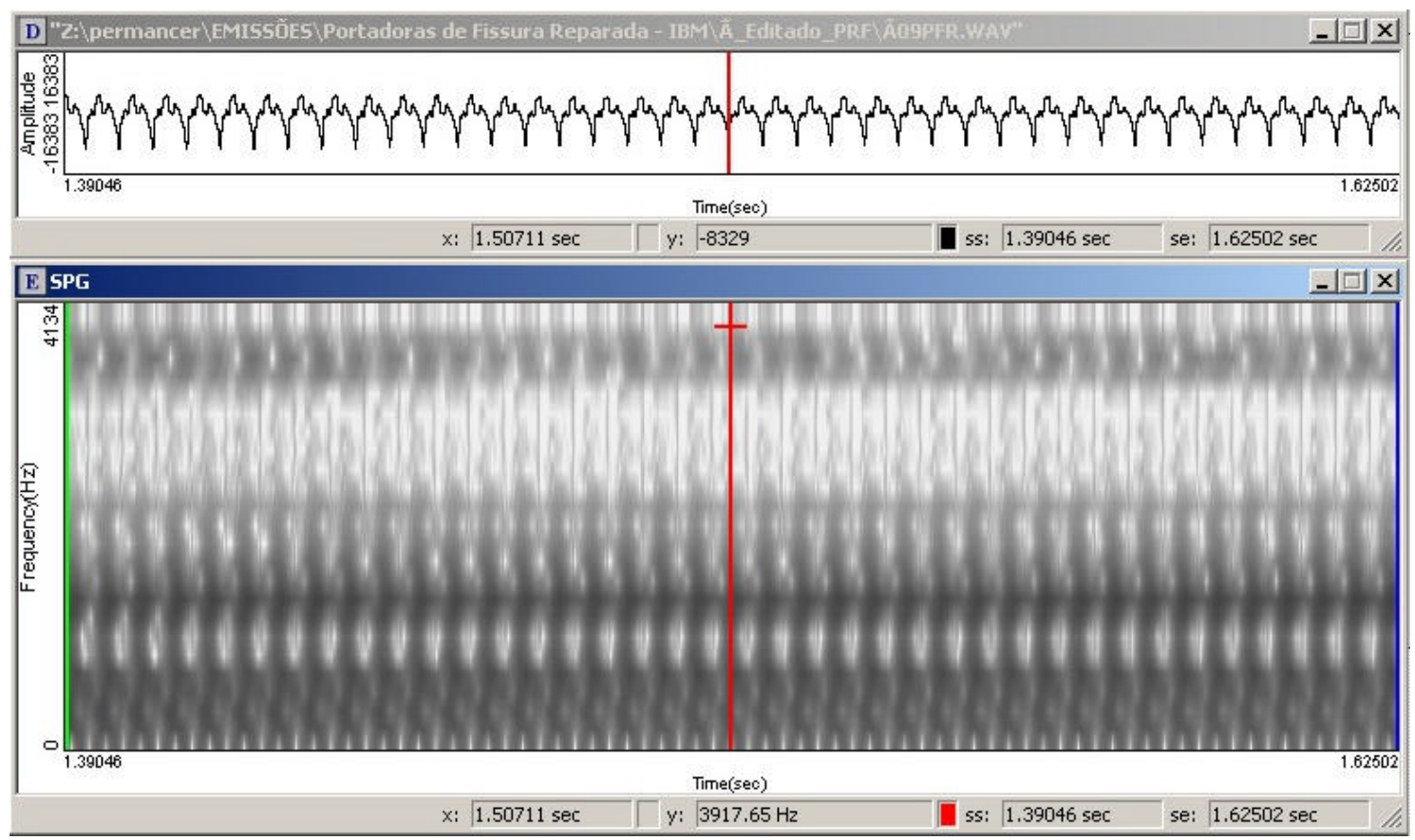

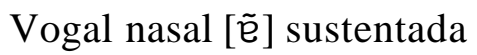


APÊNDICE AY - Forma de onda das emissões das vogais [a] e [ẽ ] sustentadas (A) e seu respectivo espectrograma $(\mathrm{B})$ da participante com protocolo número 10 do grupo PFR.

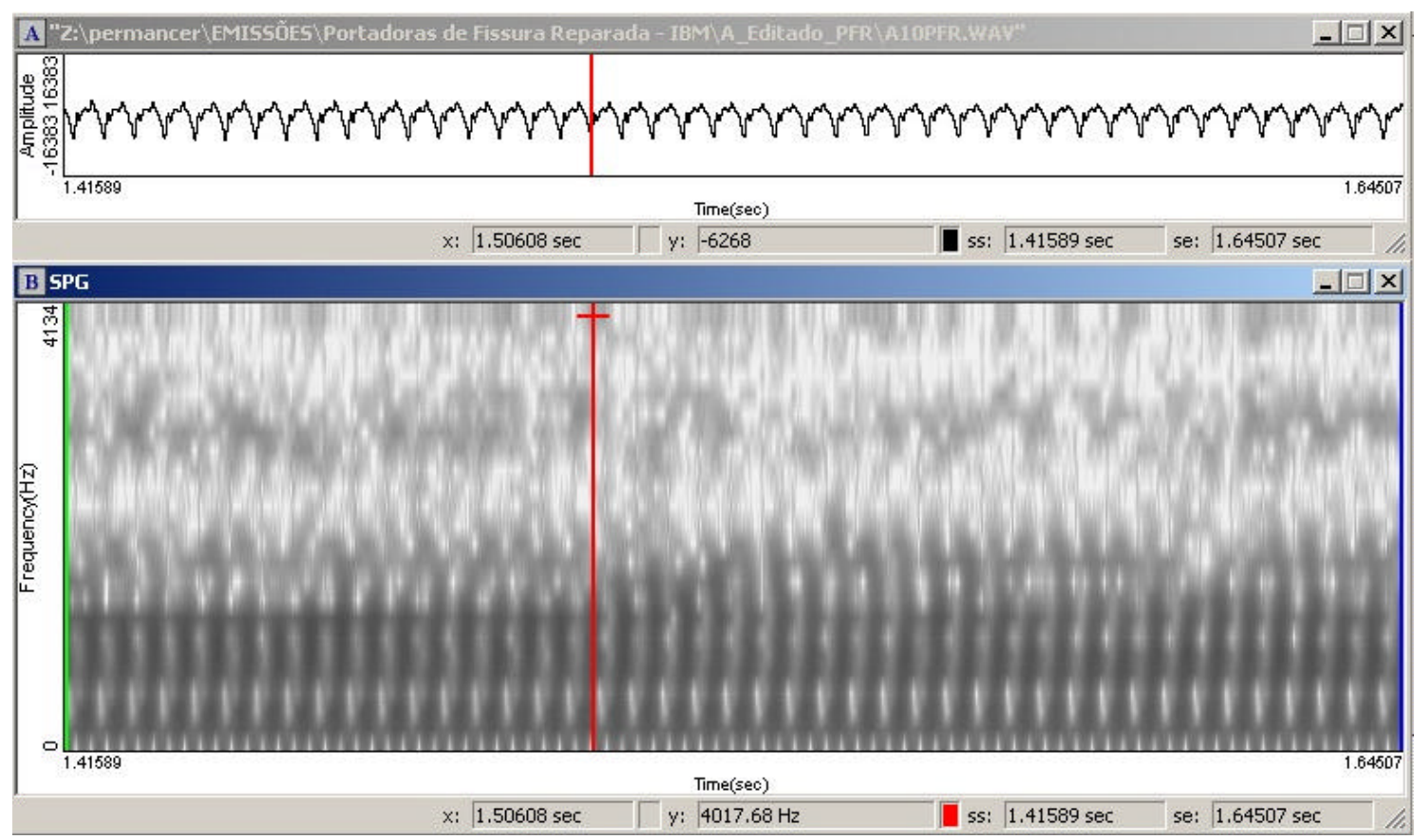

Vogal oral [a] sustentada
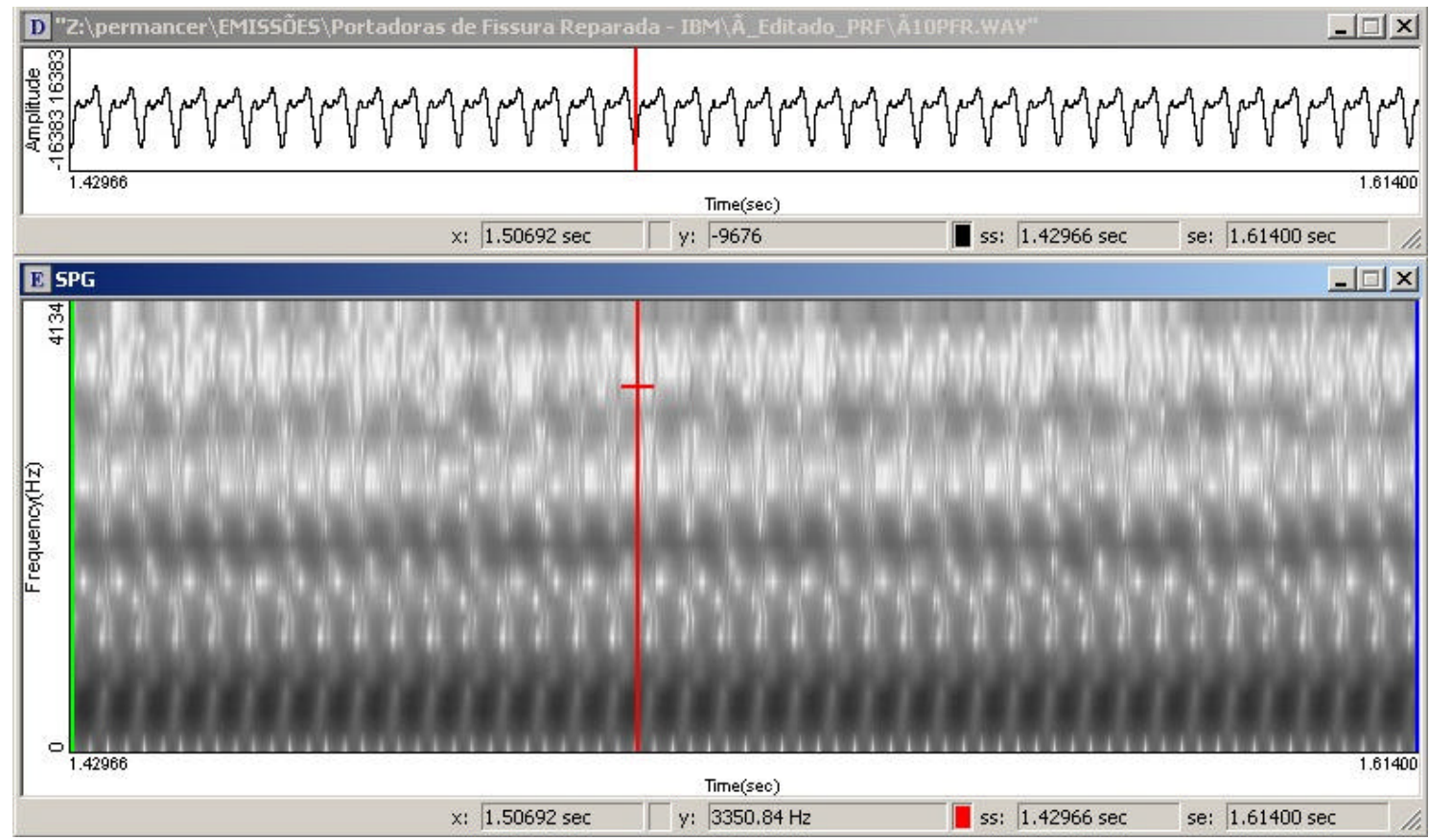

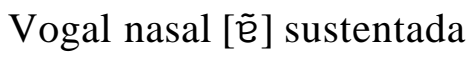


APÊNDICE AZ - Forma de onda das emissões das vogais [a] e [ẽe sustentadas (A) e seu respectivo espectrograma (B) da participante com protocolo número 11 do grupo PFR.

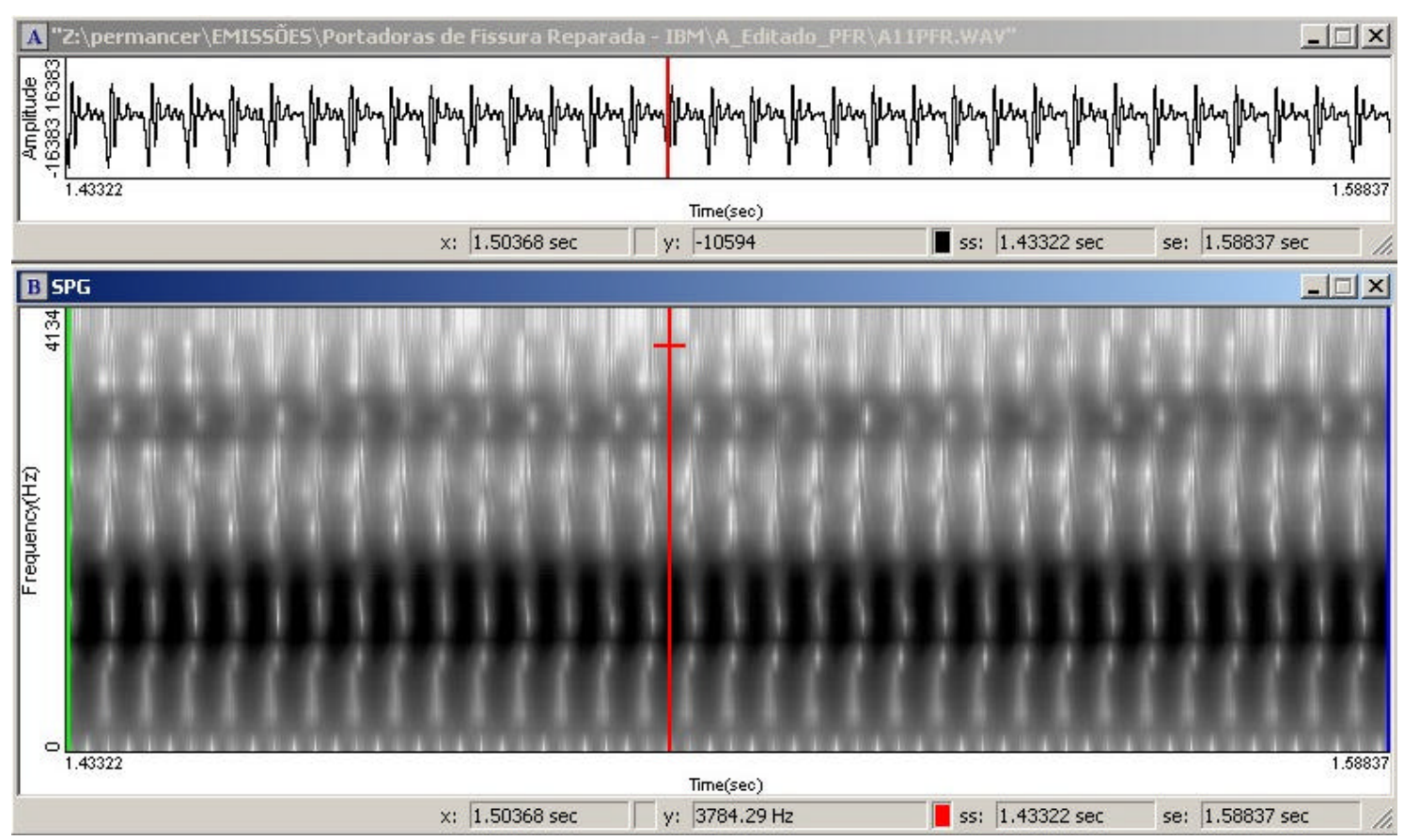

Vogal oral [a] sustentada

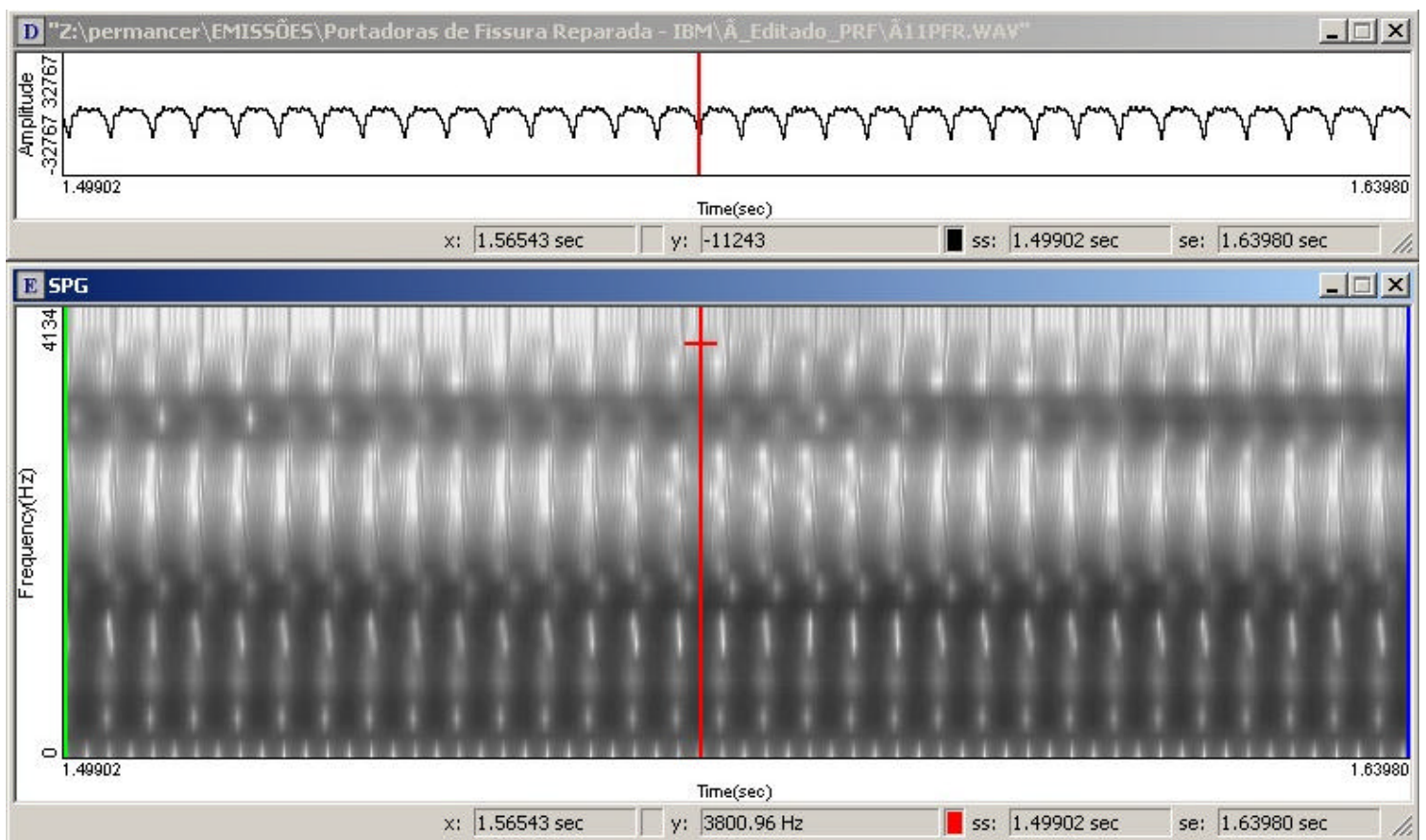

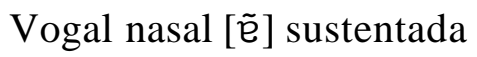


APÊEDICE BA - Forma de onda das emissões das vogais [a] e [ẽ ] sustentadas (A) e seu respectivo espectrograma $(\mathrm{B})$ da participante com protocolo número 12 do grupo PFR.

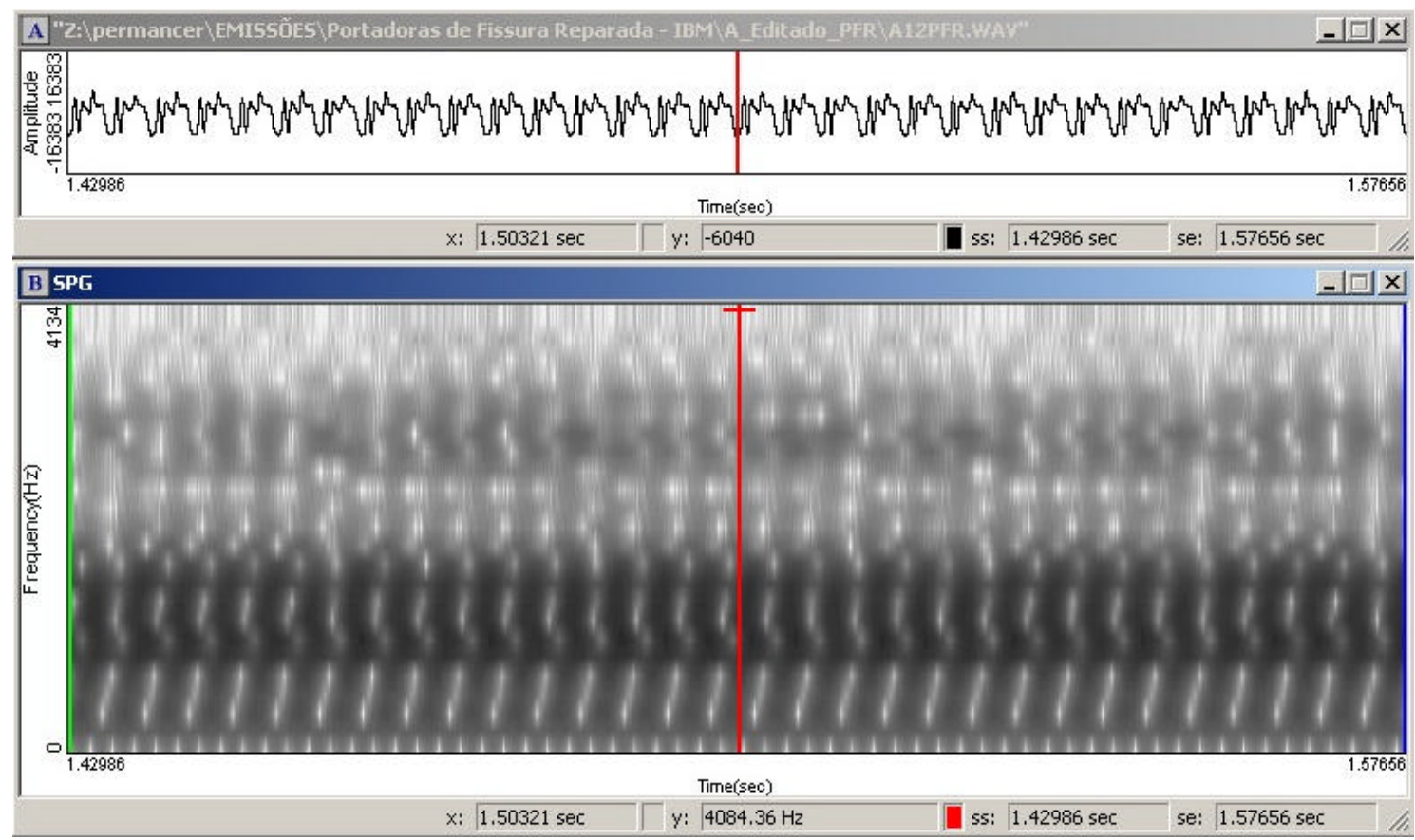

Vogal oral [a] sustentada

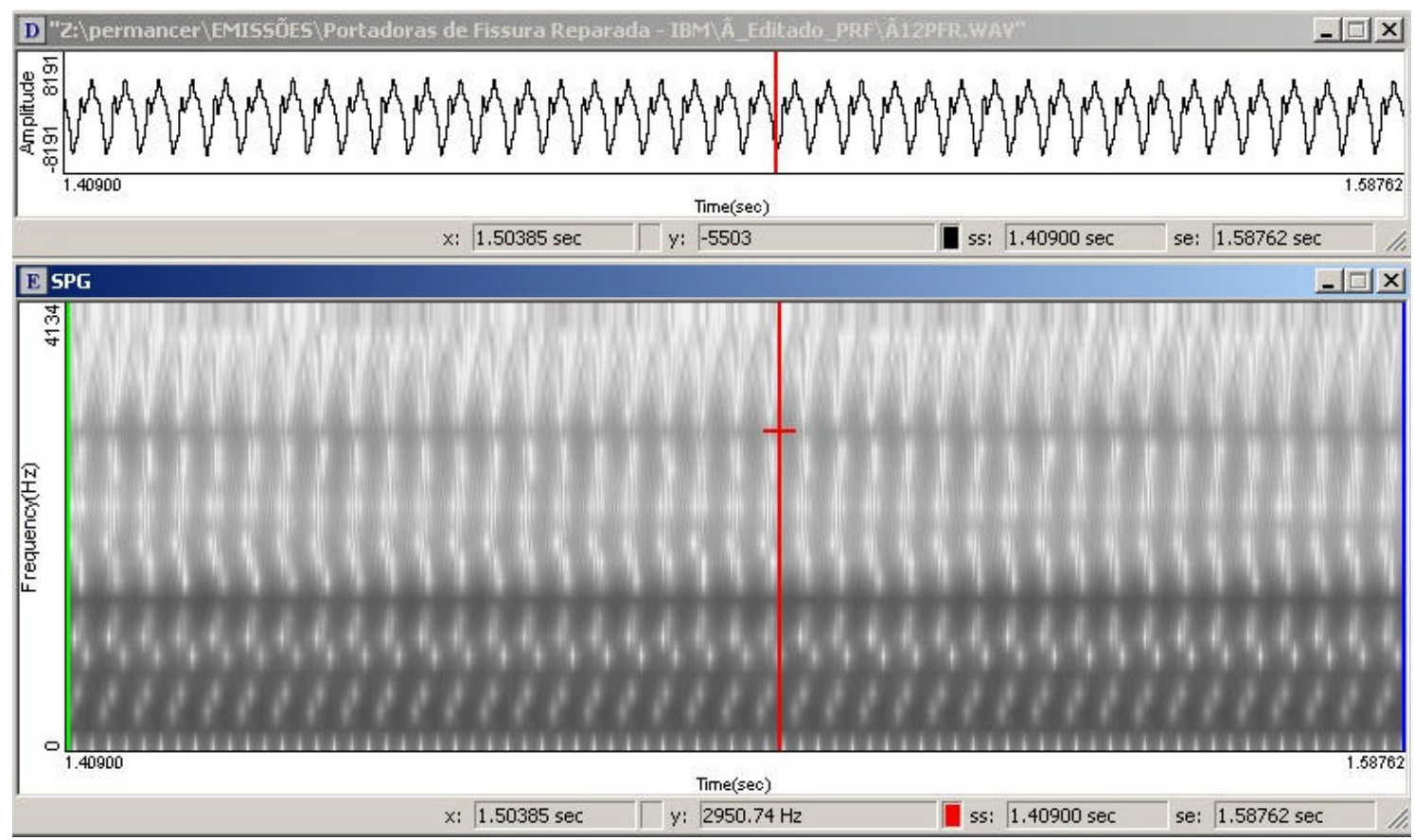

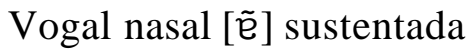


APÊNDICE BB - Forma de onda das emissões das vogais [a] e [ẽe sustentadas (A) e seu respectivo espectrograma (B) da participante com protocolo número 13 do grupo PFR.

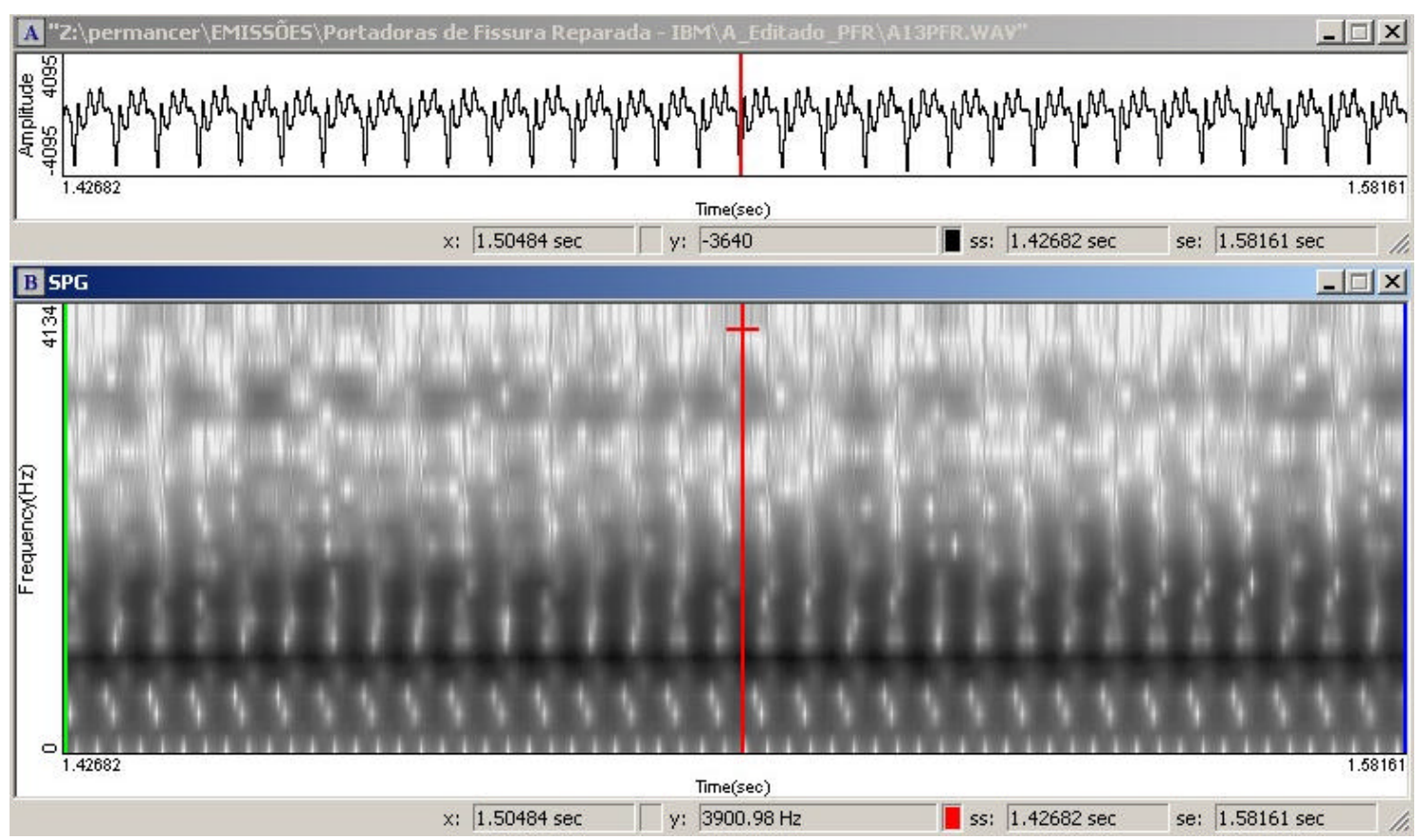

Vogal oral [a] sustentada

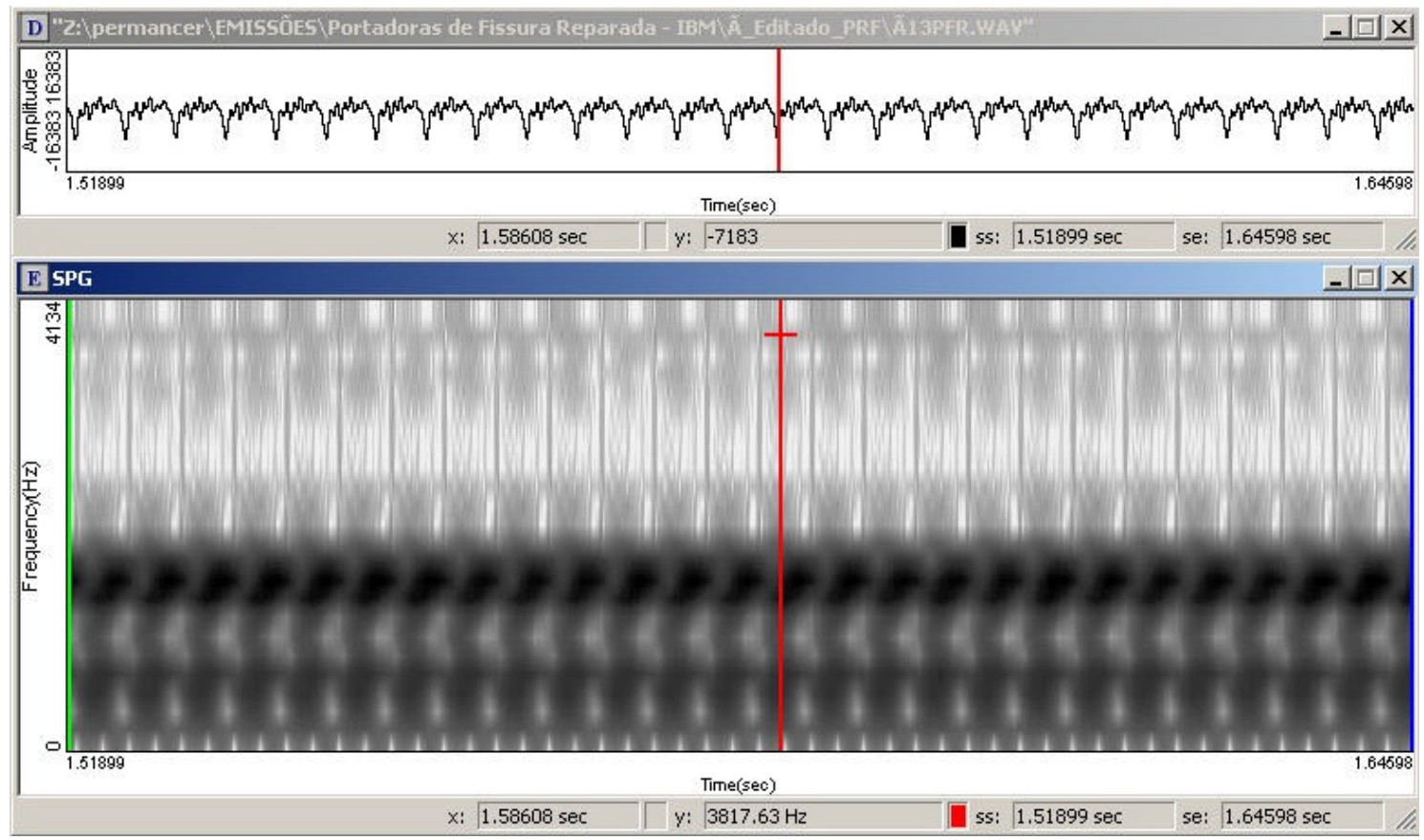

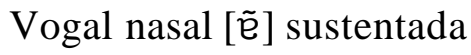


APÊNDICE BC - Forma de onda das emissões das vogais [a] e [ẽ ] sustentadas (A) e seu respectivo espectrograma (B) da participante com protocolo número 14 do grupo PFR.

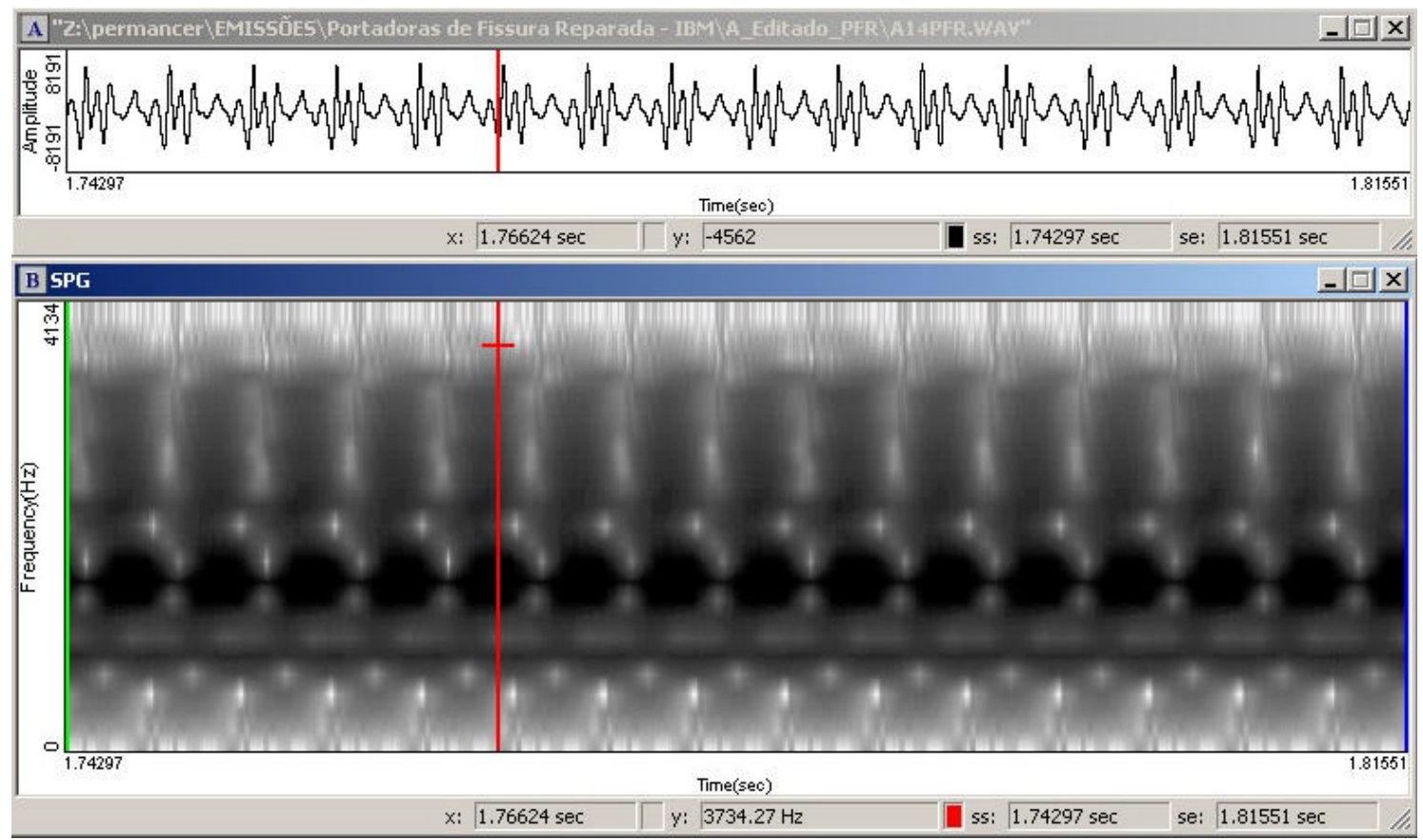

Vogal oral [a] sustentada
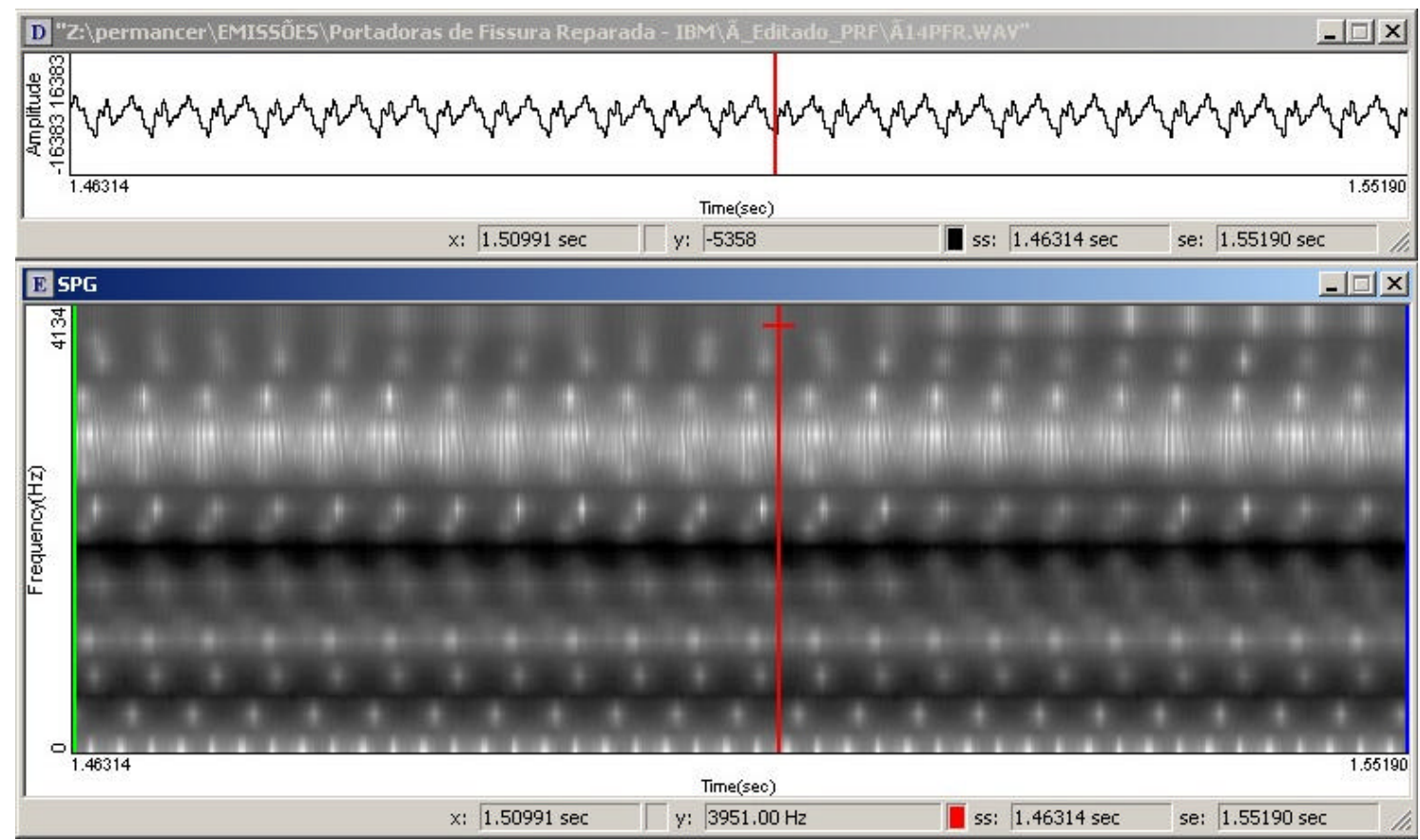

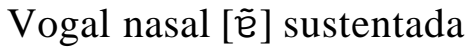


APÊNDICE BD - Forma de onda das emissões das vogais [a] e [ẽ ] sustentadas (A) e seu respectivo espectrograma (B) da participante com protocolo número 15 do grupo PFR.

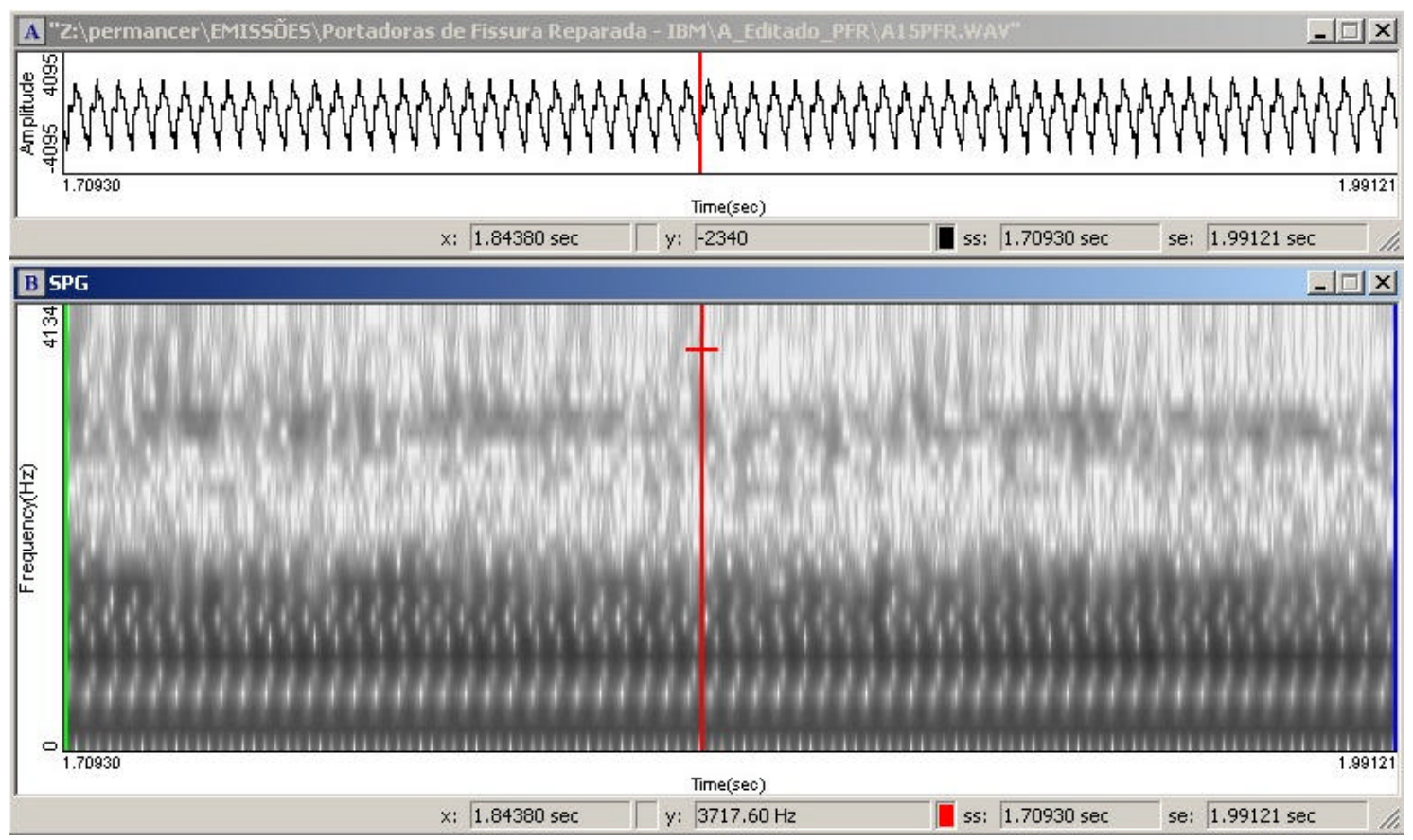

Vogal oral [a] sustentada

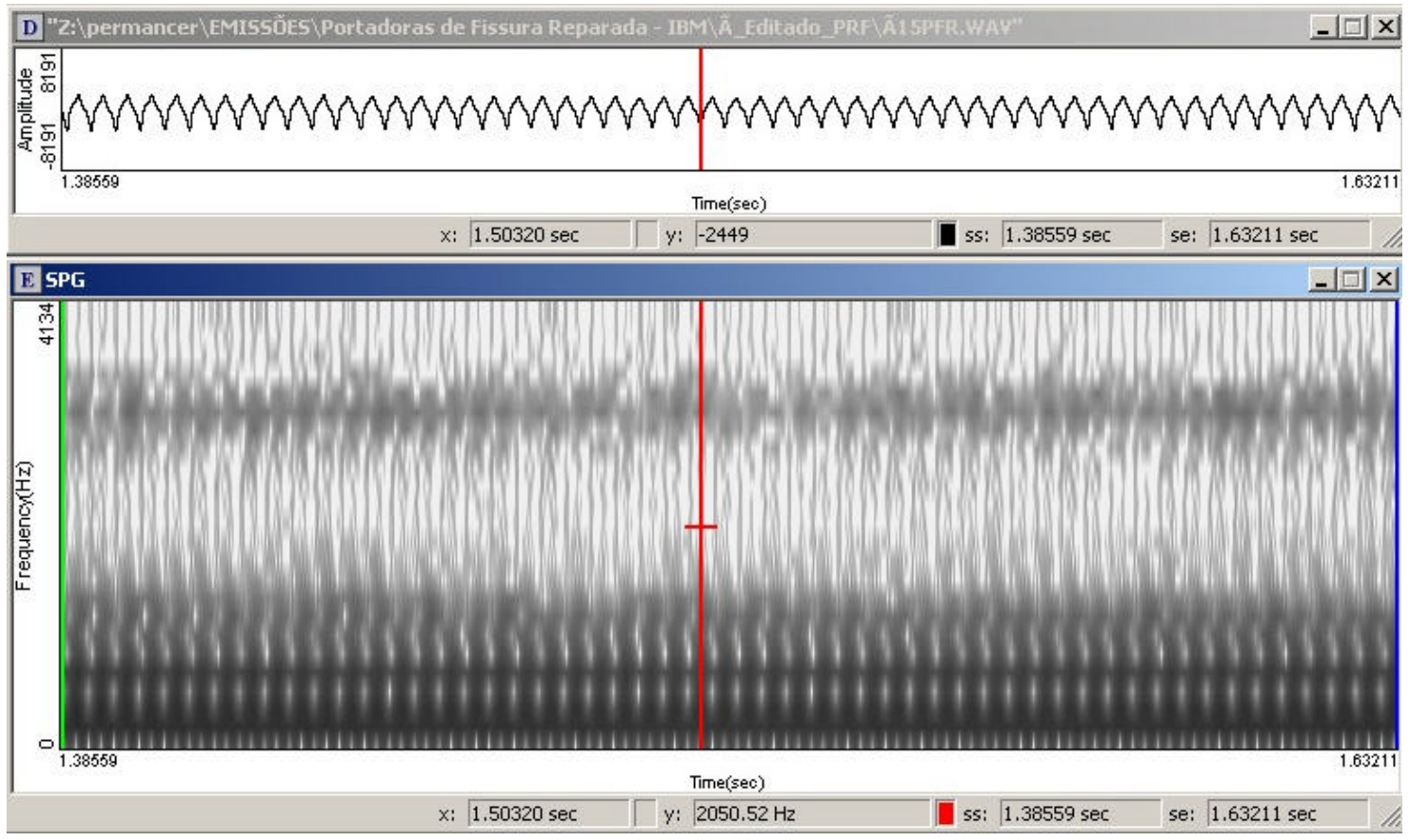

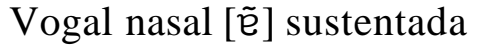


APÊNDICE BE - Forma de onda das emissões das vogais [a] e [ẽ] sustentadas (A) e seu respectivo espectrograma $(\mathrm{B})$ da participante com protocolo número 16 do grupo PFR.

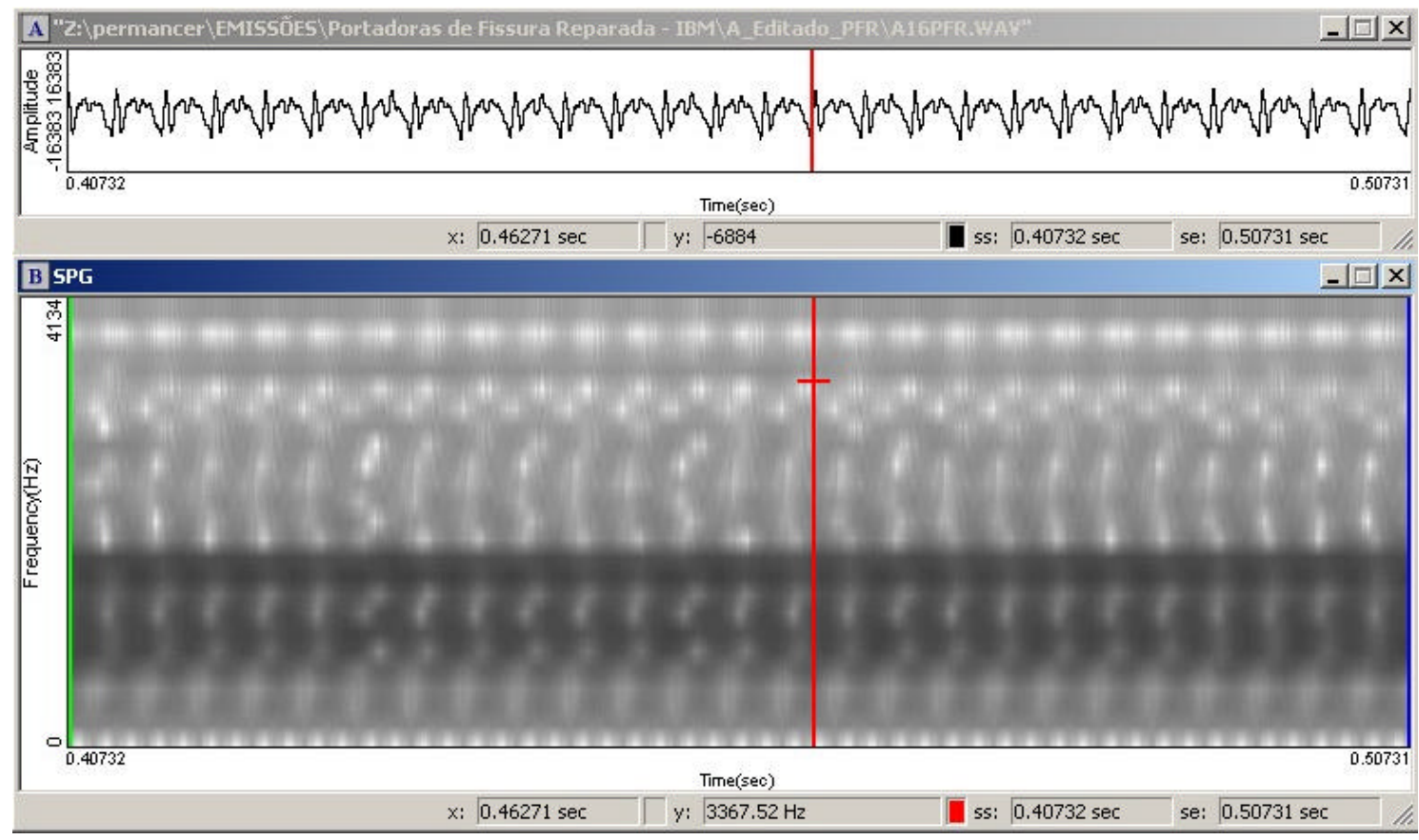

Vogal oral [a] sustentada

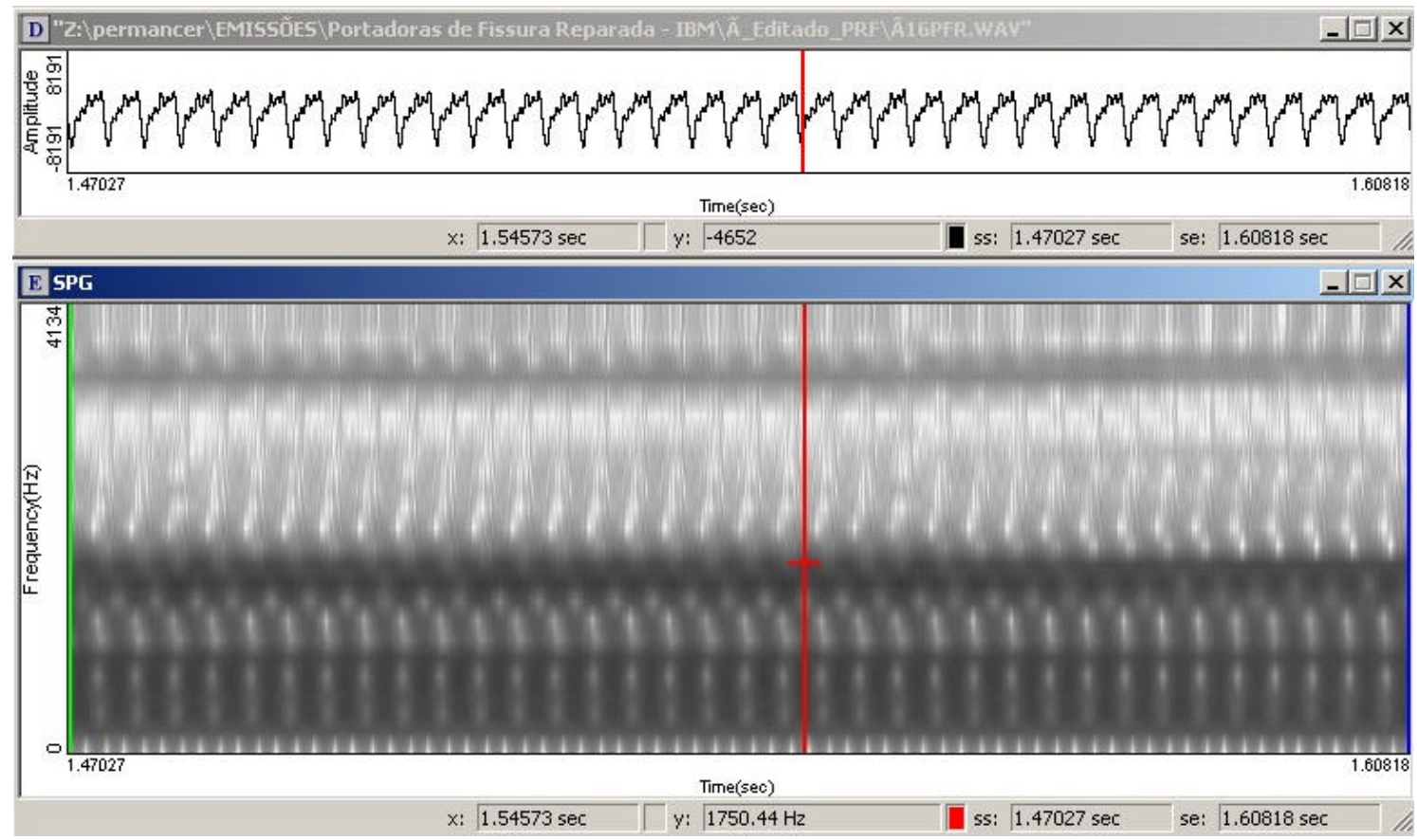

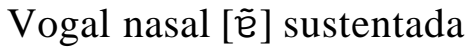


APÊNDICE BF - Forma de onda das emissões das vogais [a] e [ẽe sustentadas (A) e seu respectivo espectrograma (B) da participante com protocolo número 17 do grupo PFR.

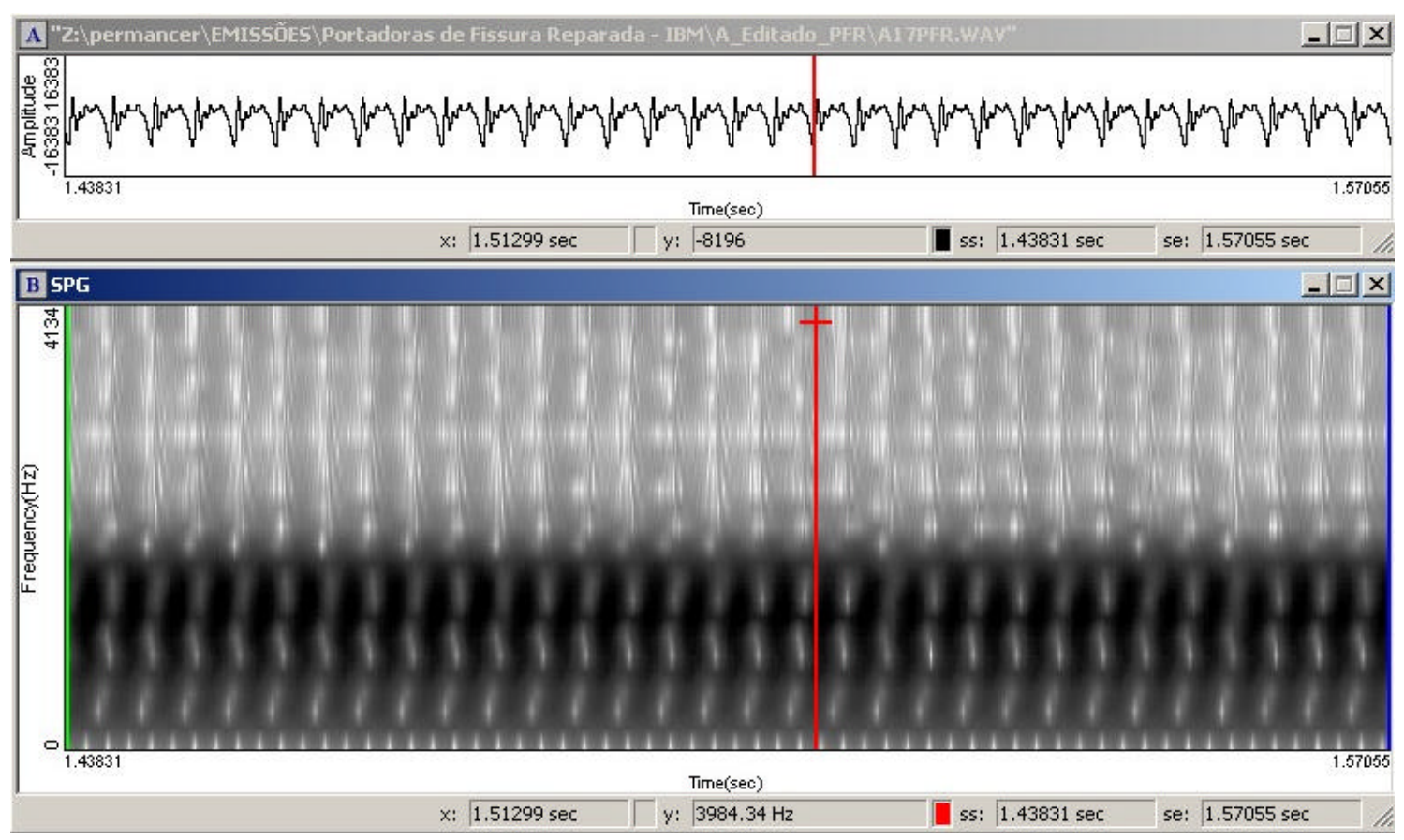

Vogal oral [a] sustentada

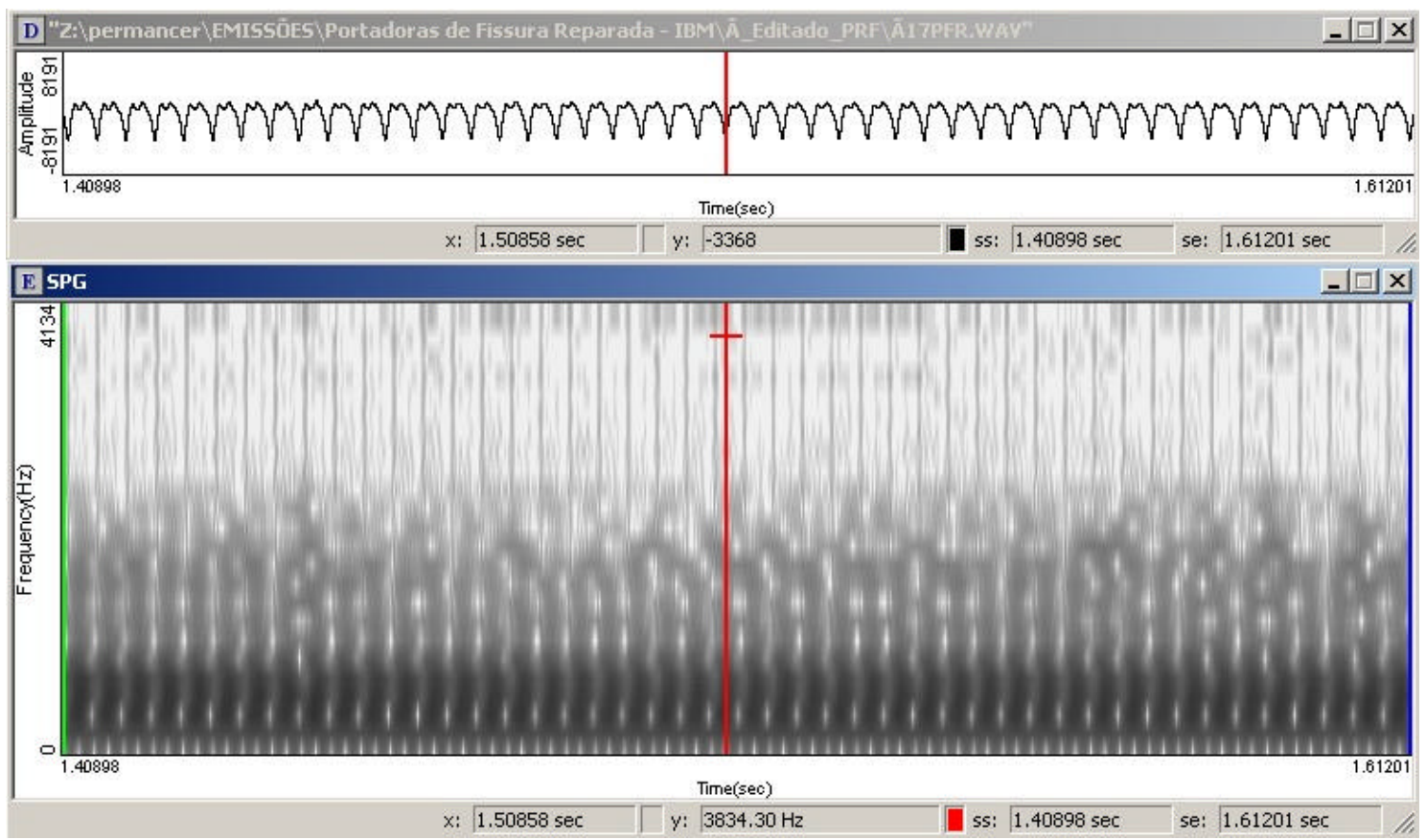

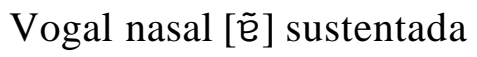


APÊEDICE BG - Forma de onda das emissões das vogais [a] e [ẽ ] sustentadas (A) e seu respectivo espectrograma (B) da participante com protocolo número 18 do grupo PFR.

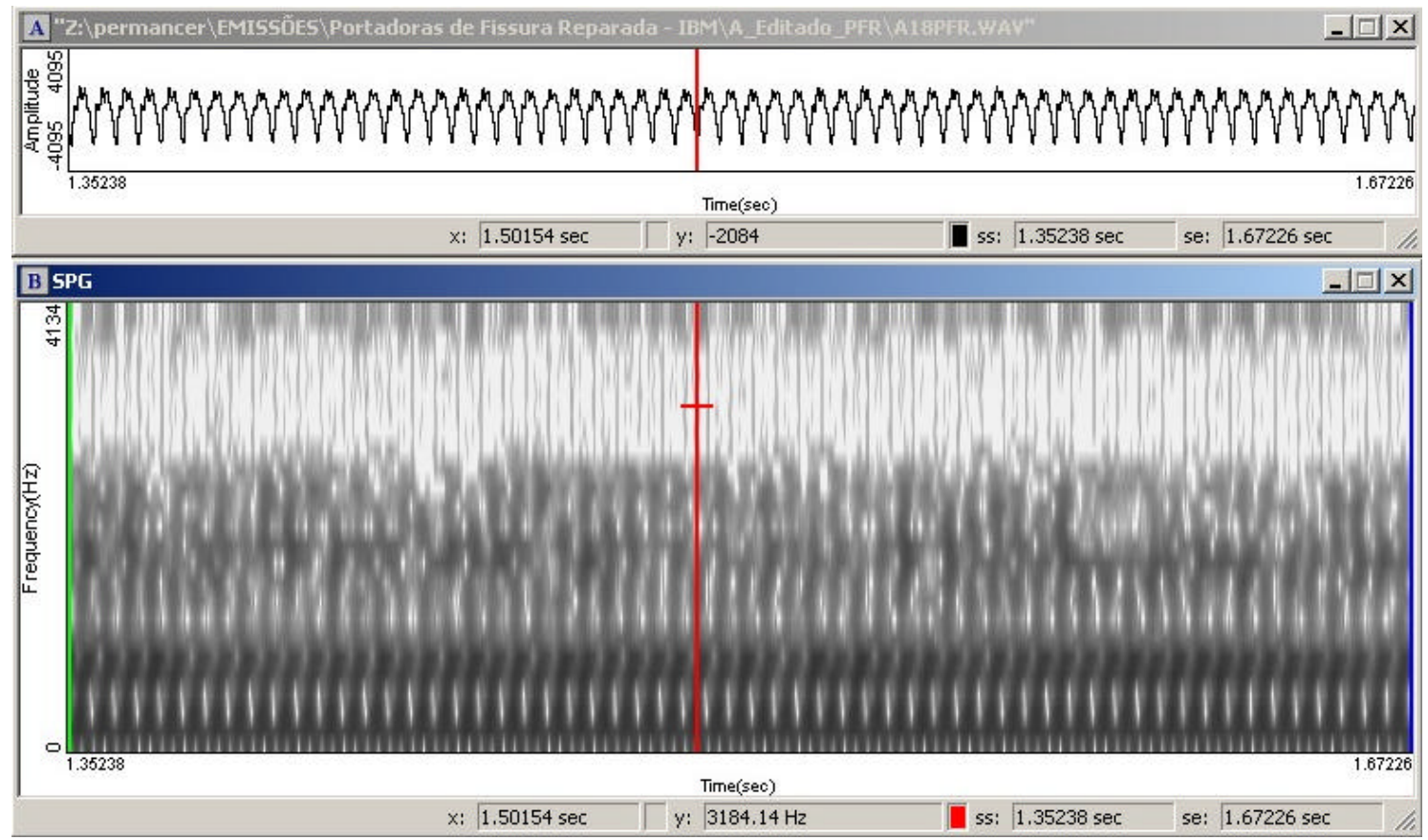

Vogal oral [a] sustentada

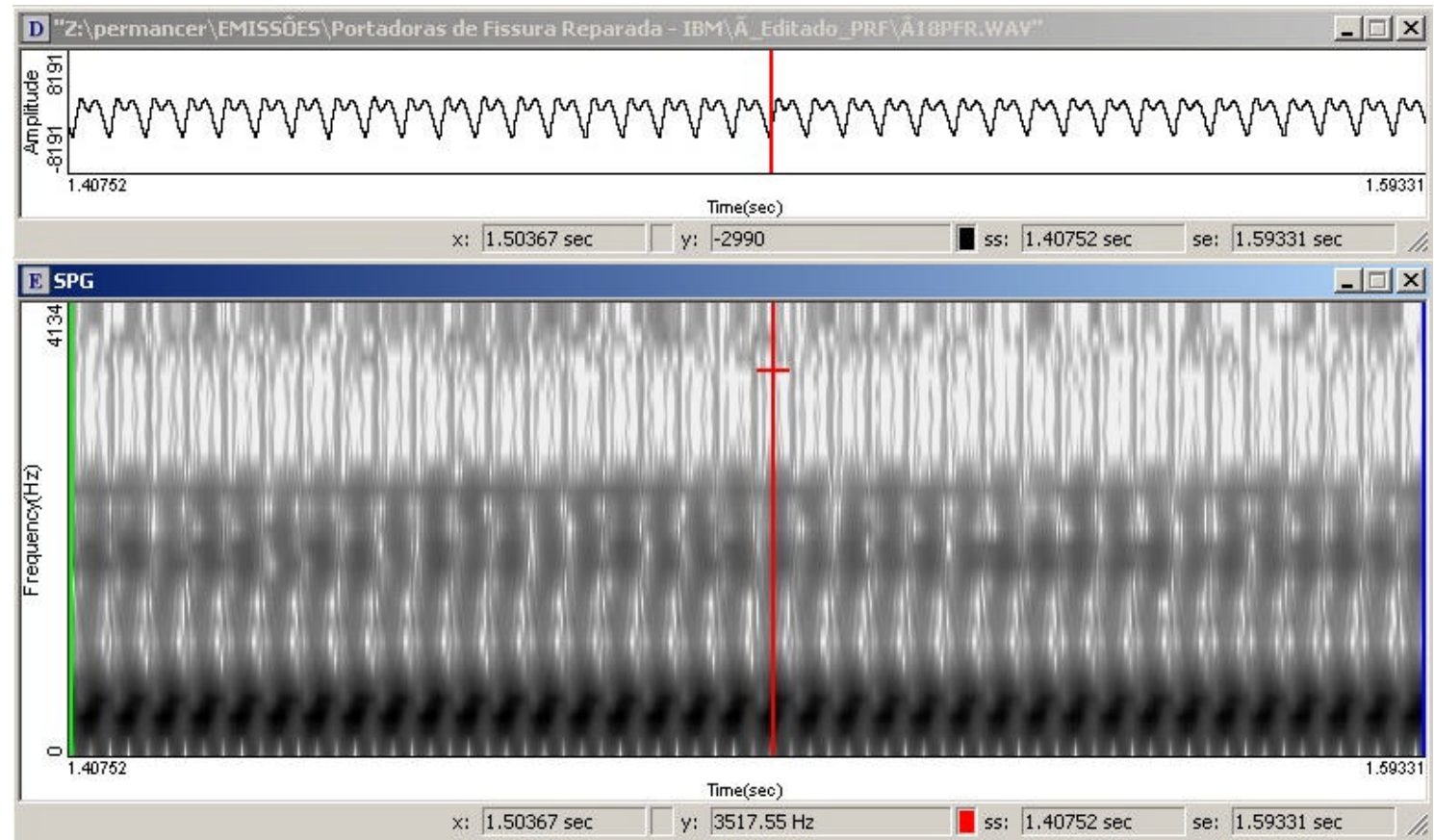

Vogal nasal [ẽ ] sustentada 
APÊNDICE BH - Forma de onda das emissões das vogais [a] e [ẽ ] sustentadas (A) e seu respectivo espectrograma $(\mathrm{B})$ da participante com protocolo número 19 do grupo PFR.

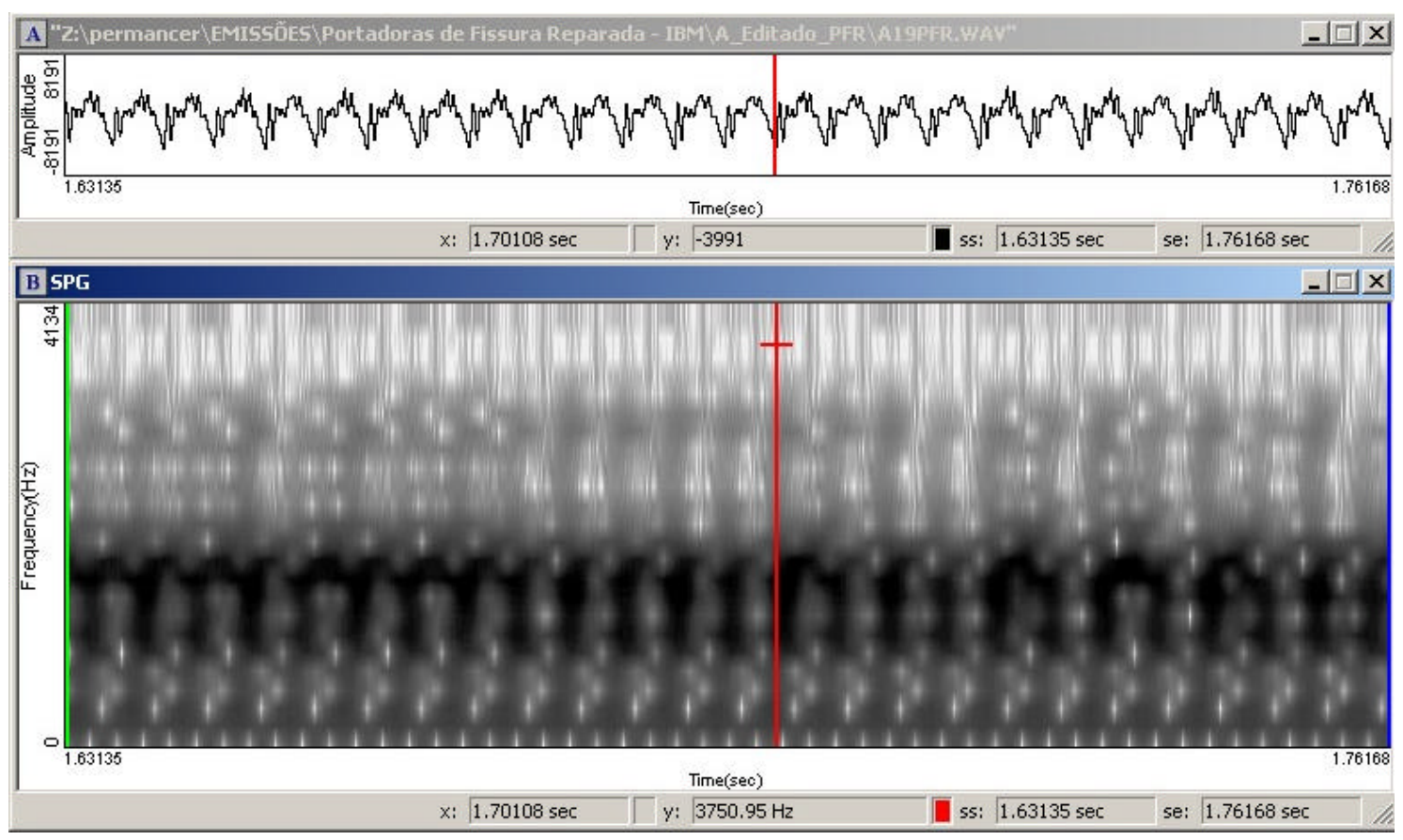

Vogal oral [a] sustentada

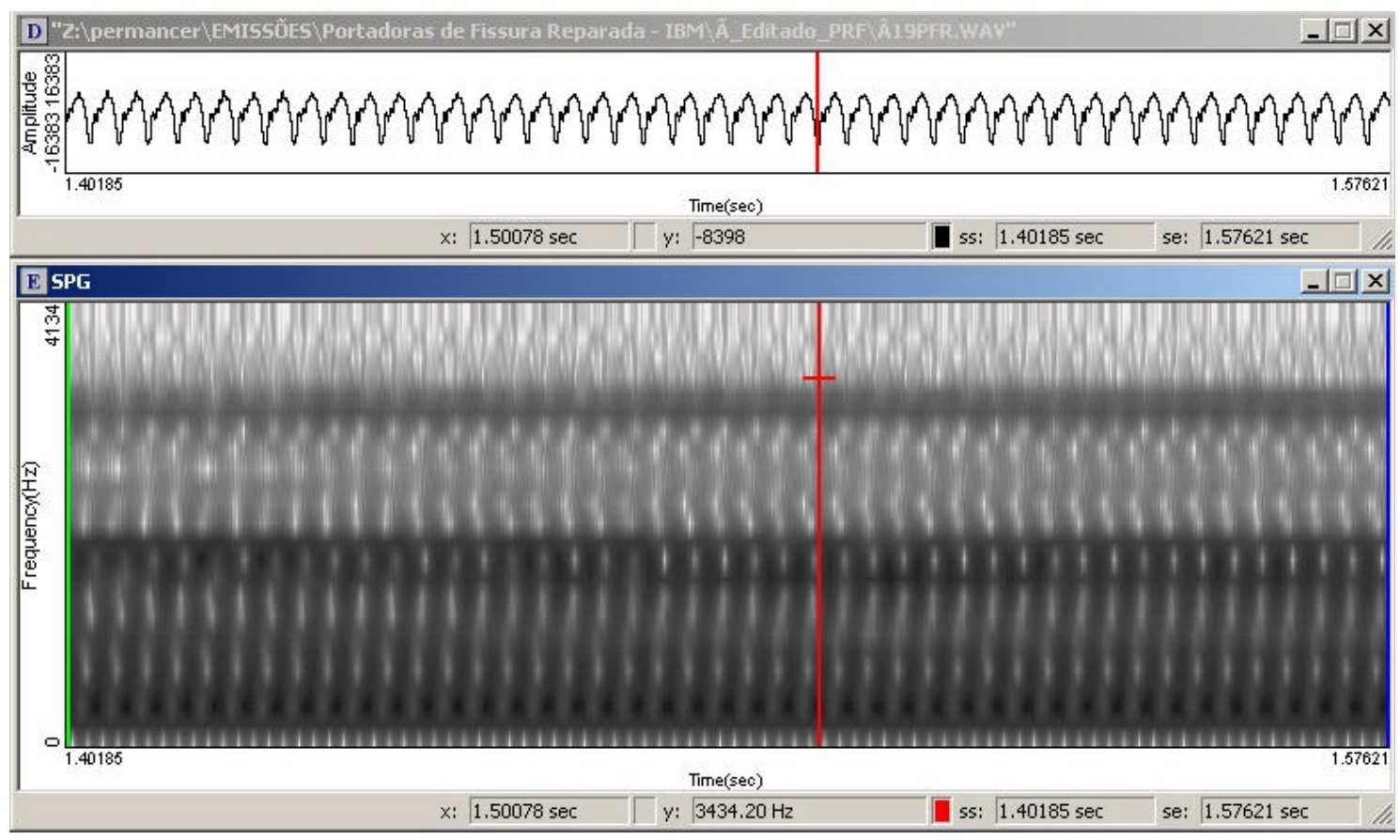

Vogal nasal [ẽ] sustentada 
APÊNDICE BI - Forma de onda das emissões das vogais [a] e [ẽ ] sustentadas (A) e seu respectivo espectrograma (B) da participante com protocolo número 20 do grupo PFR.

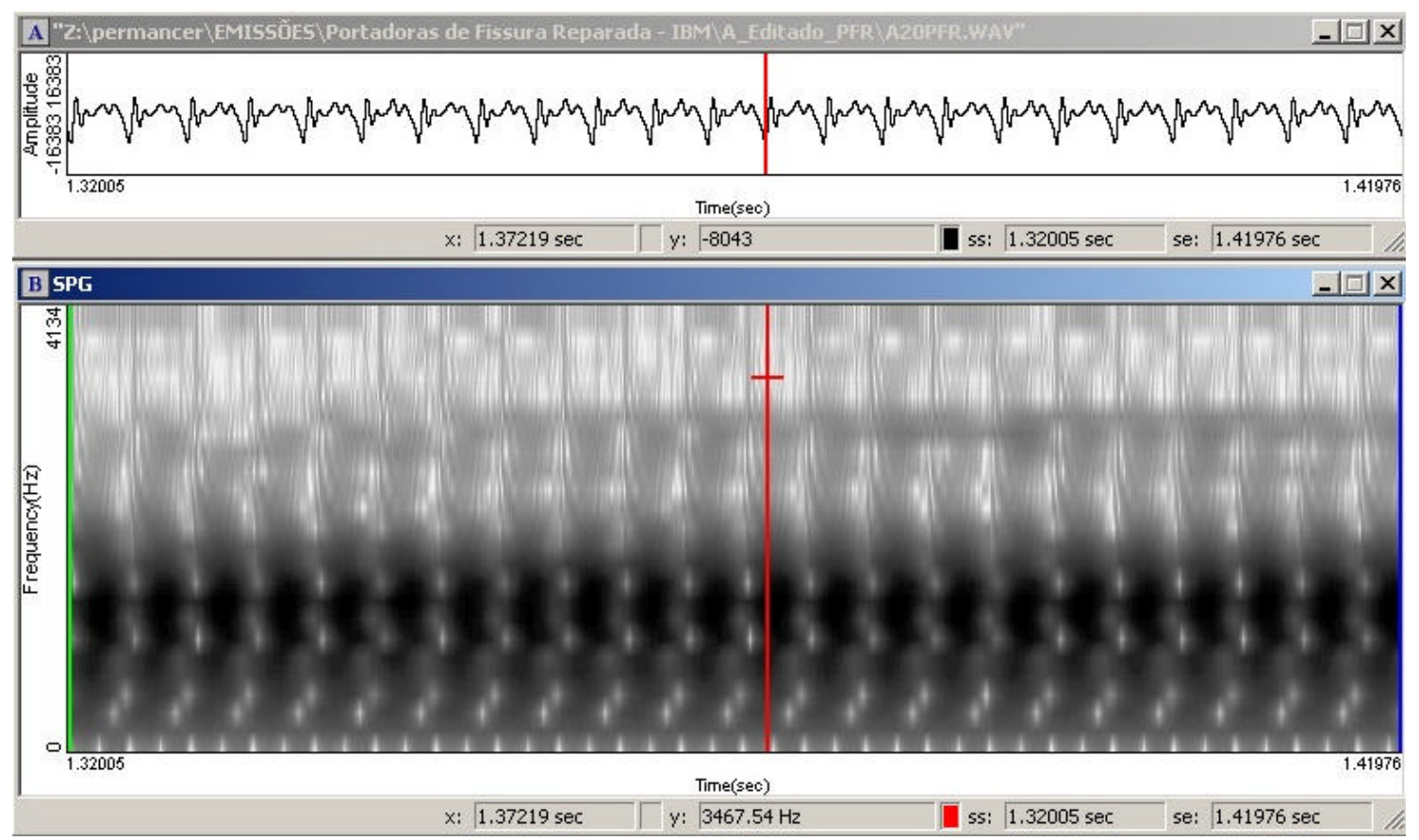

Vogal oral [a] sustentada

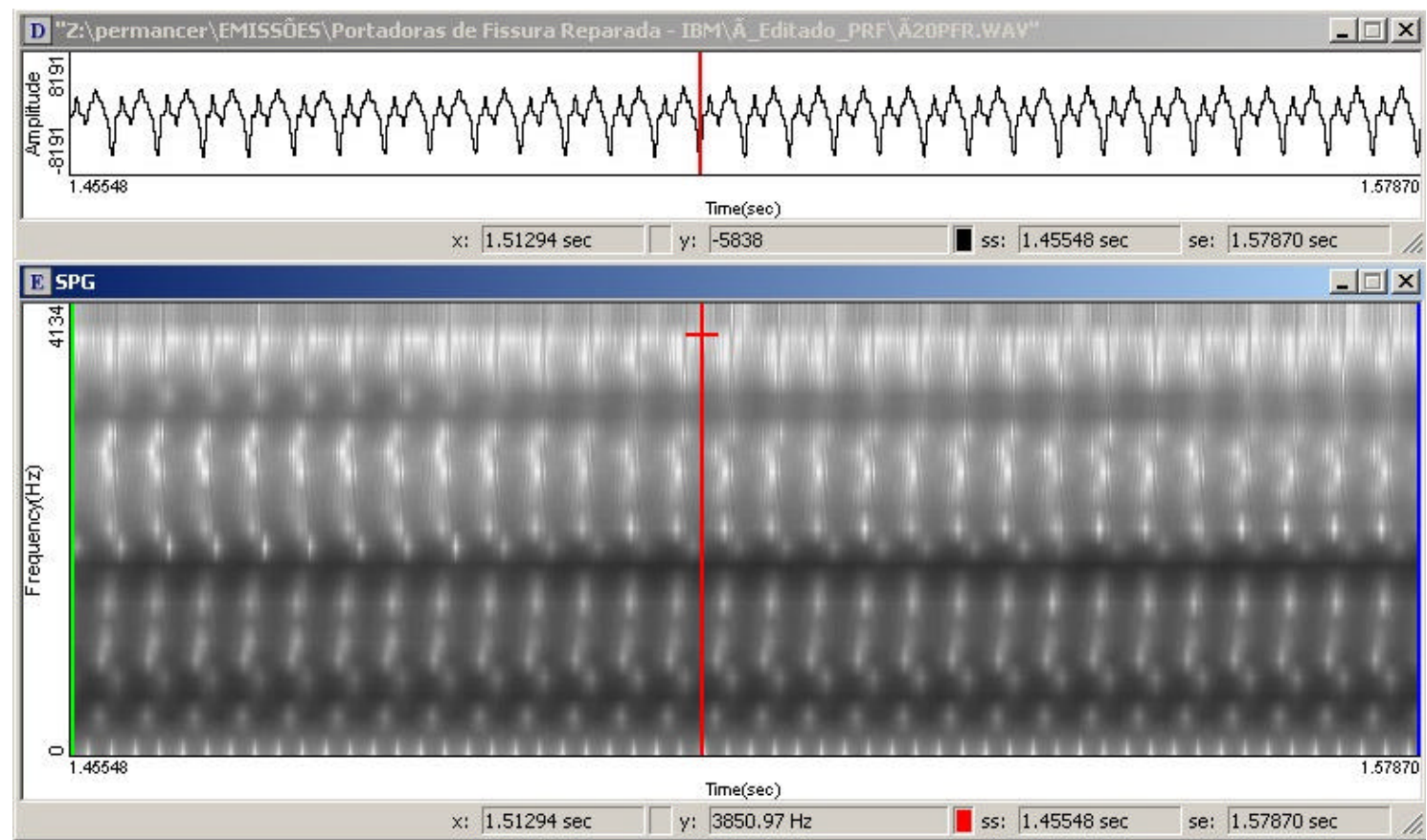

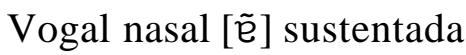


APÊNDICE BJ - Forma de onda das emissões das vogais [a] e [ẽe sustentadas (A) e seu respectivo espectrograma (B) da participante com protocolo número 21 do grupo PFR.

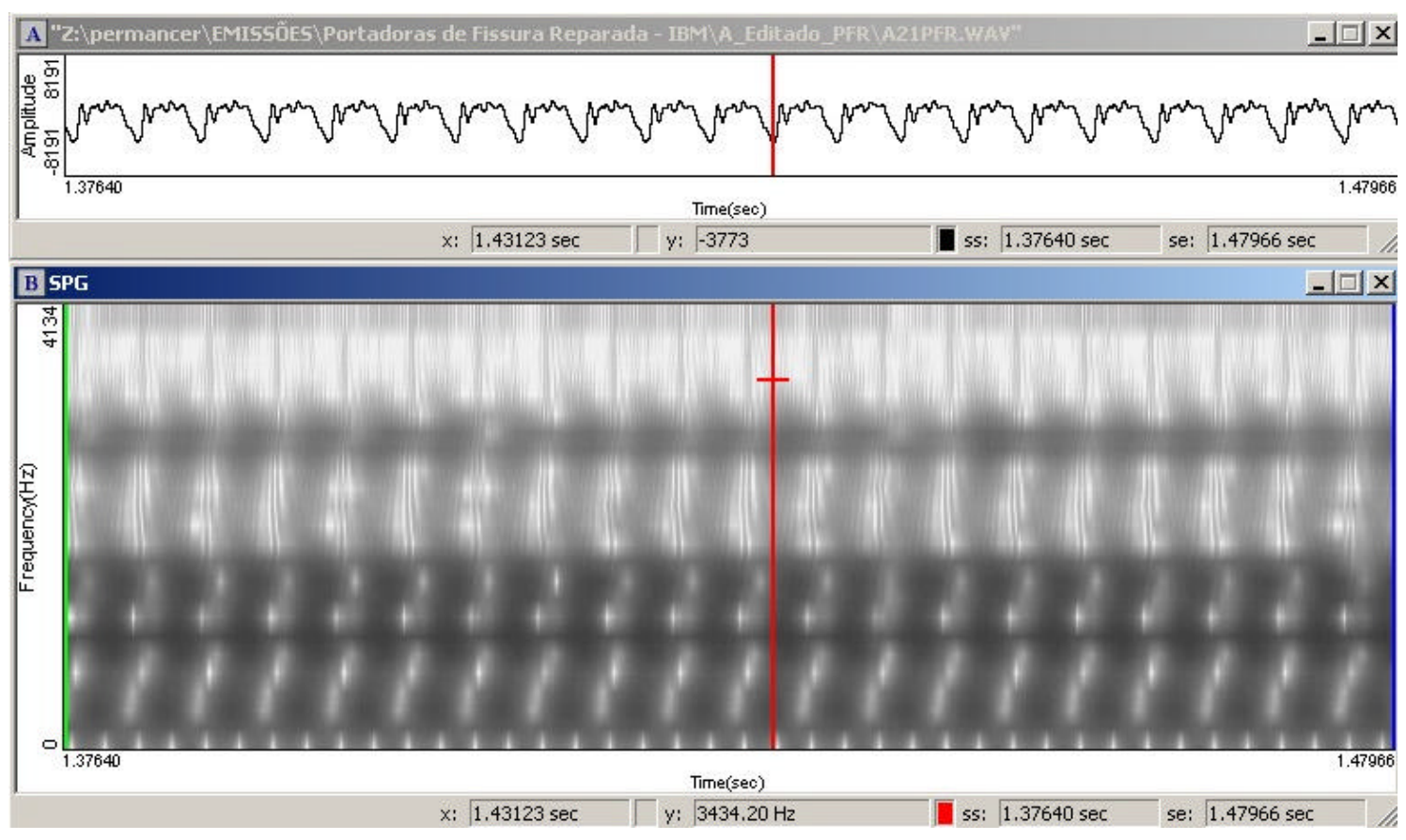

Vogal oral [a] sustentada

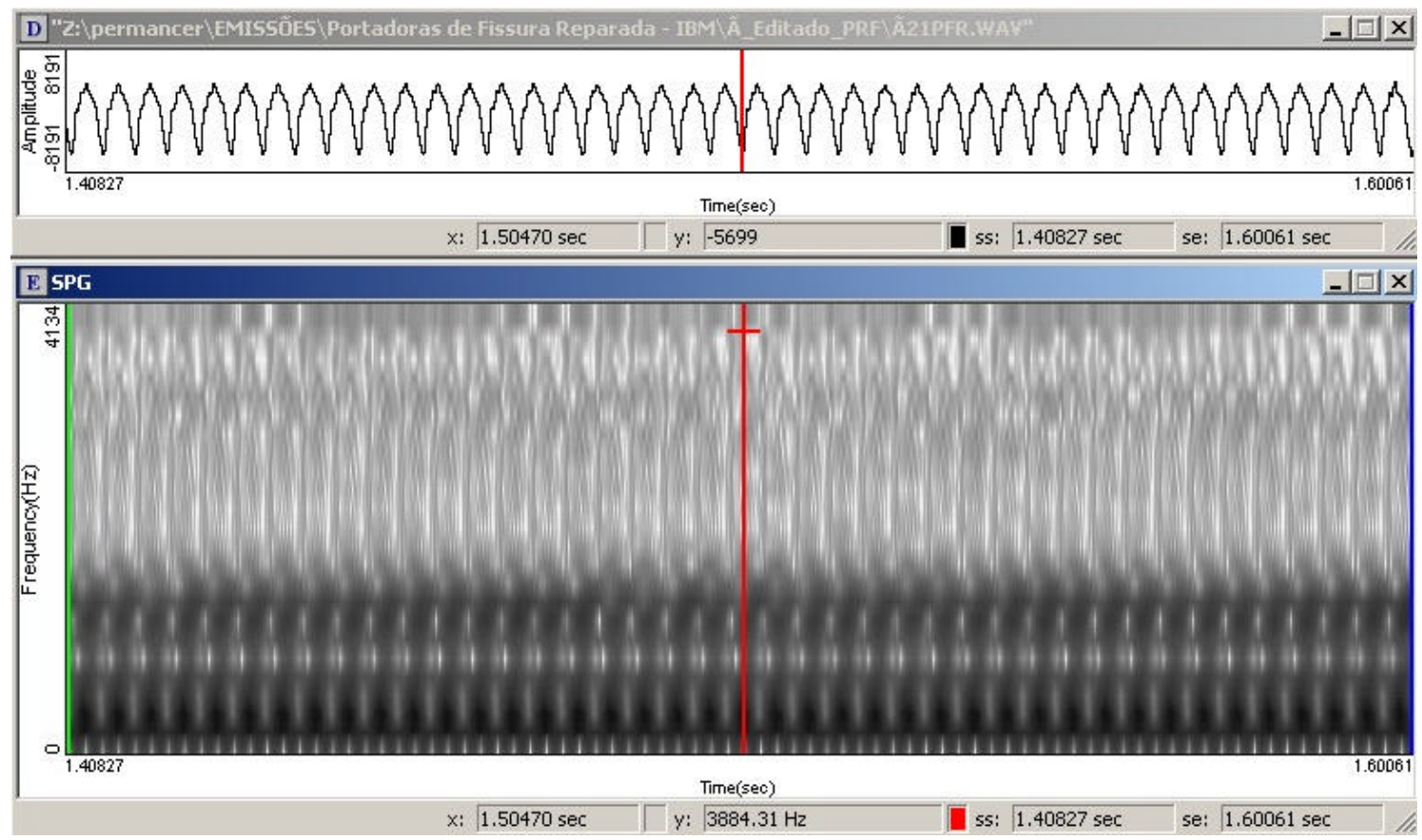

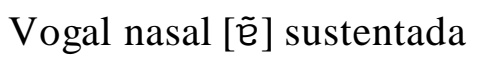


APÊNDICE BK - Análises FFT e LPC das emissões das vogais [a] (linha preta) e [ẽ ] sustentadas (linha vermelha), de participantes do grupo CON.

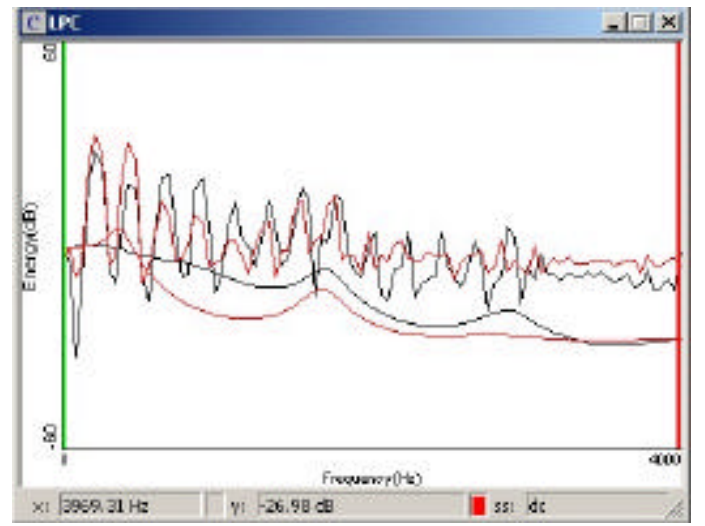

CON01

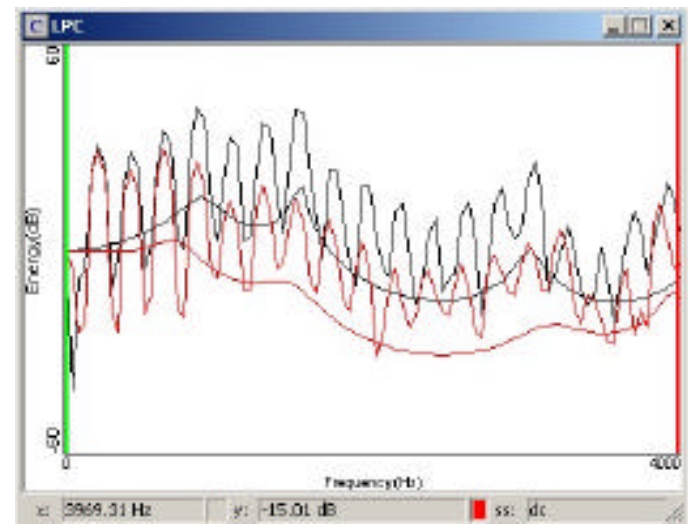

CON02

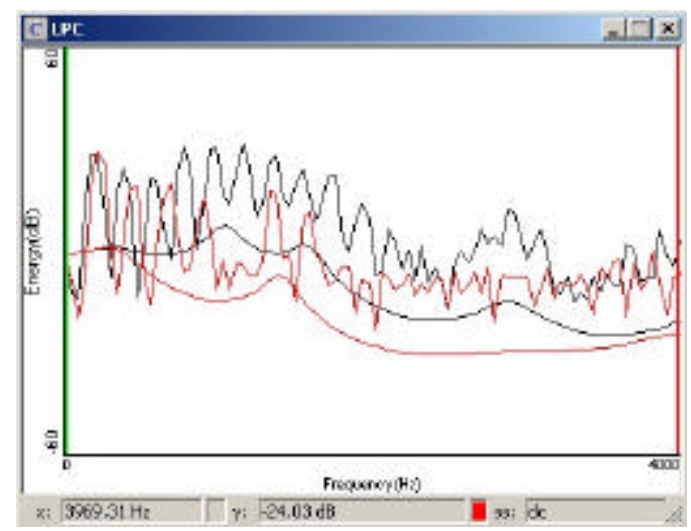

CON03

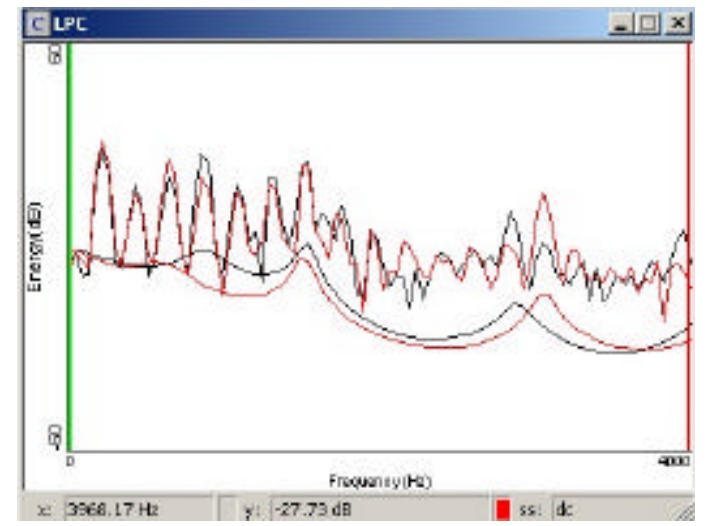

CON04

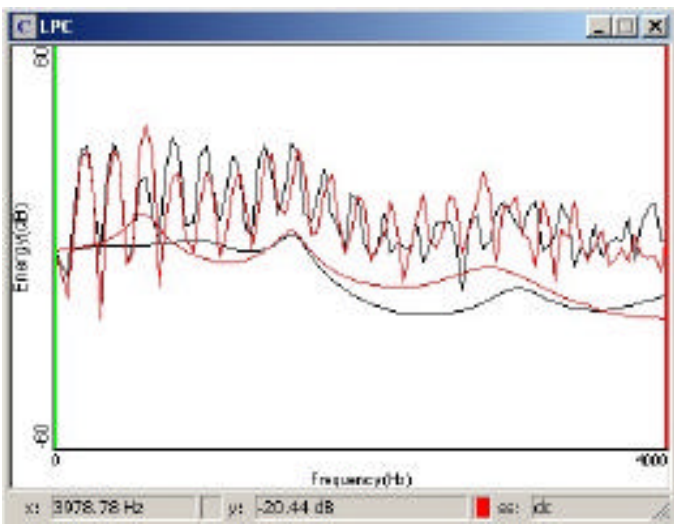

CON05

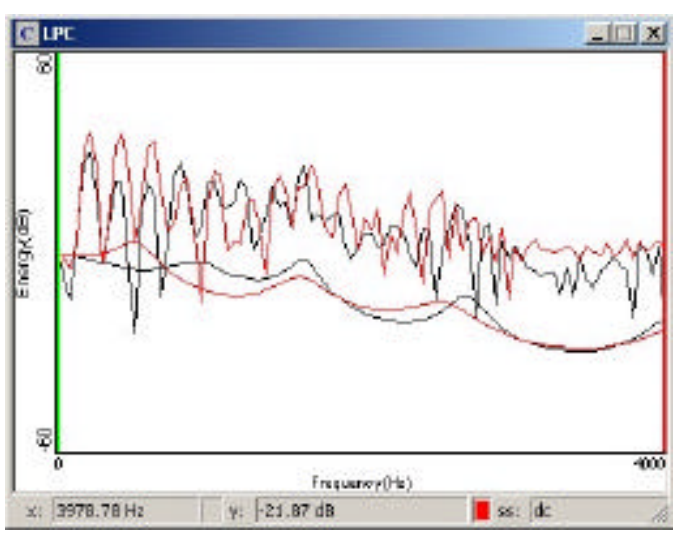

CON06 
APÊNDICE BK - Análises FFT e LPC das emissões das vogais [a] (linha preta) e [ẽ ] sustentadas (linha vermelha), de participantes do grupo CON (Continuação).

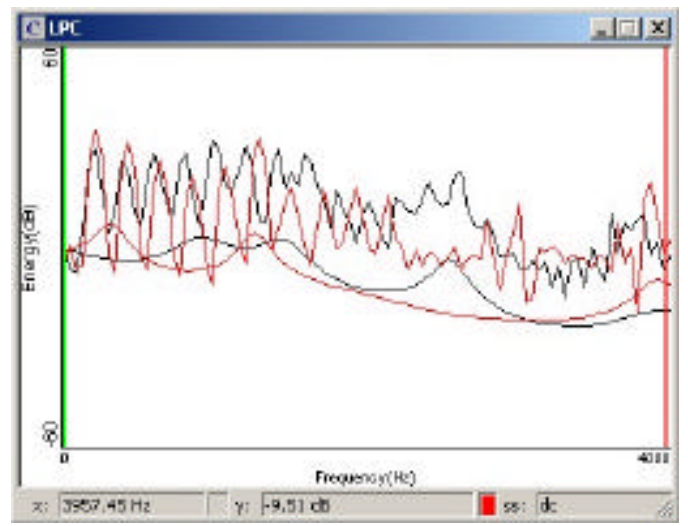

CON07

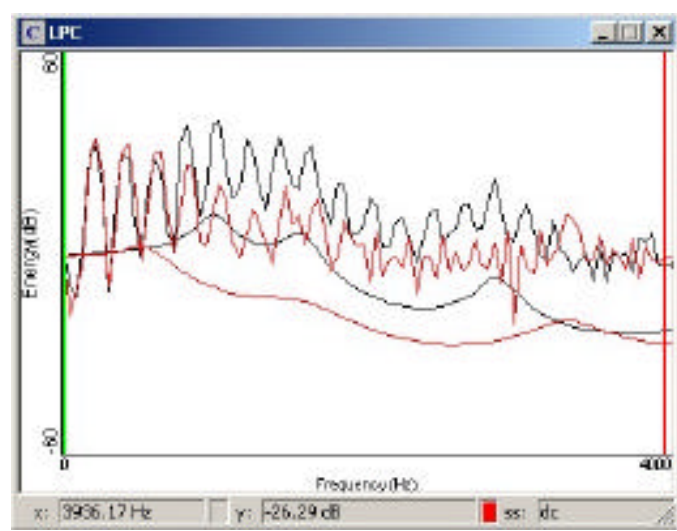

CON08

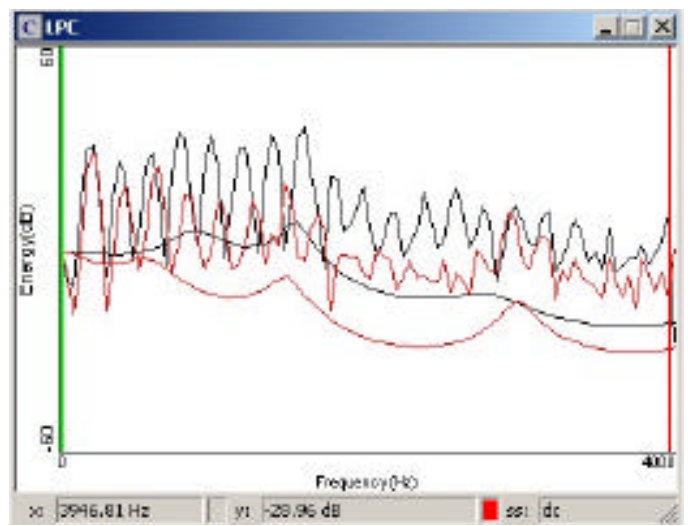

CON09

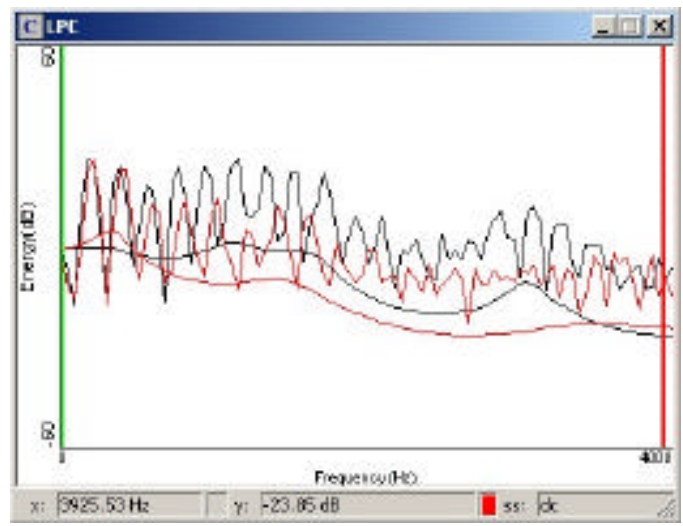

CON10

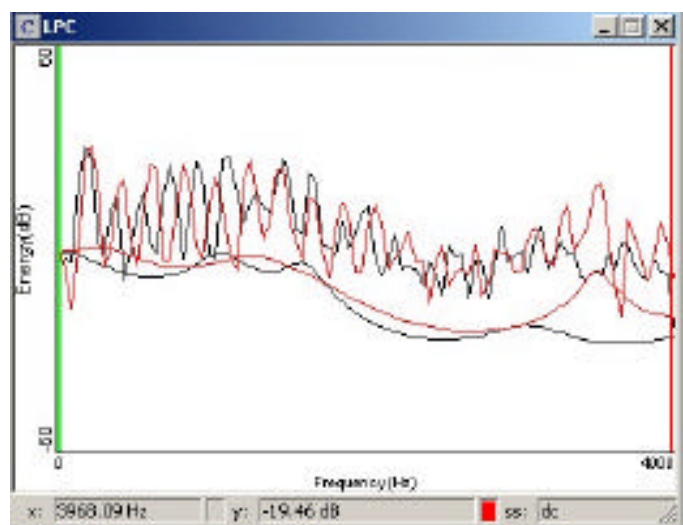

CON11

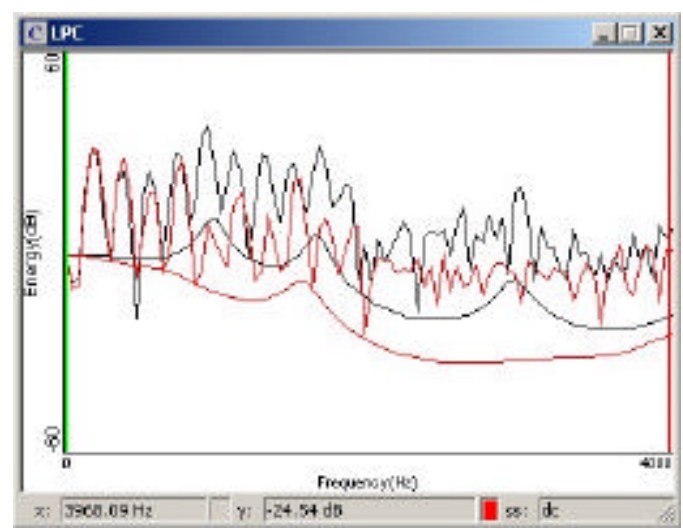

CON12 
APÊNDICE BK - Análises FFT e LPC das emissões das vogais [a] (linha preta) e [ẽ ] sustentadas (linha vermelha), de participantes do grupo CON (Continuação).

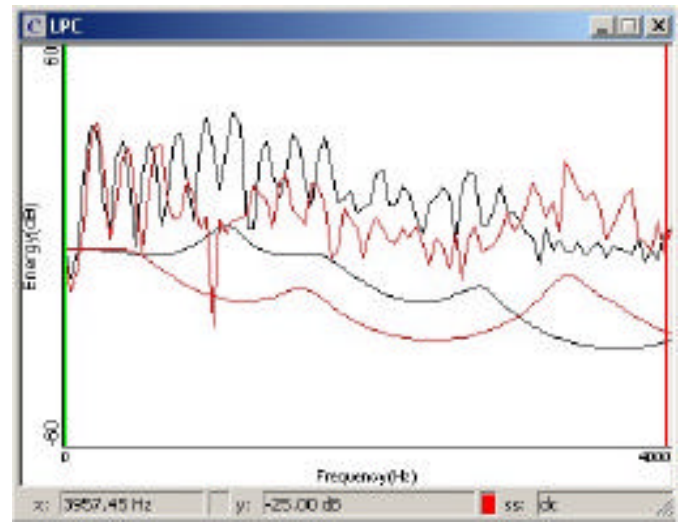

CON13

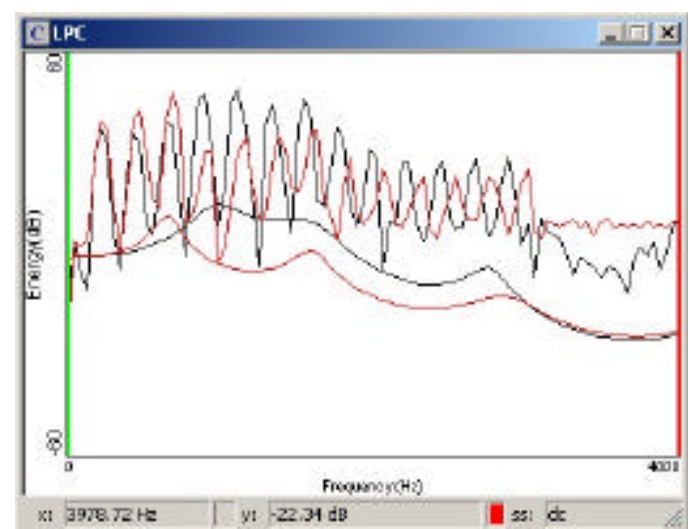

CON14

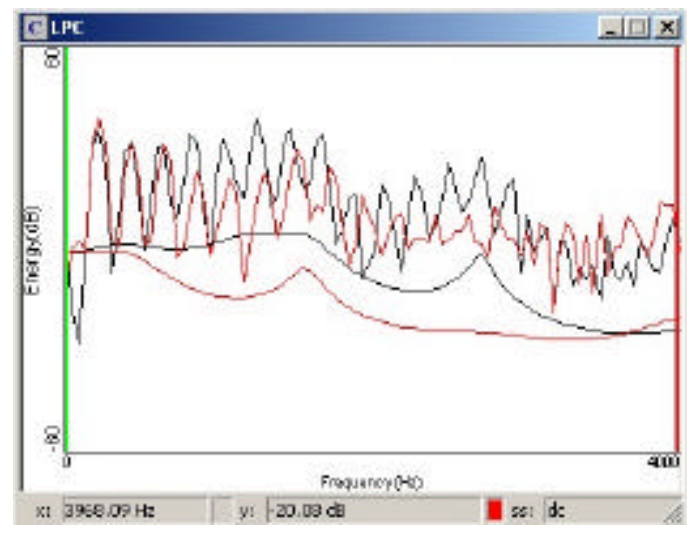

CON15

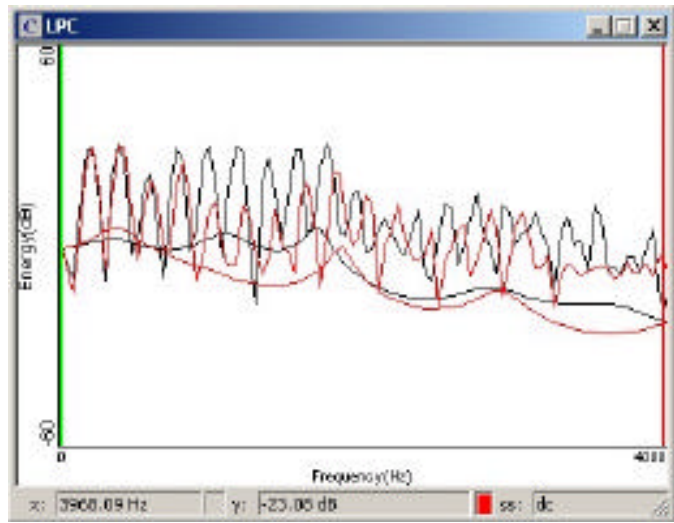

CON16

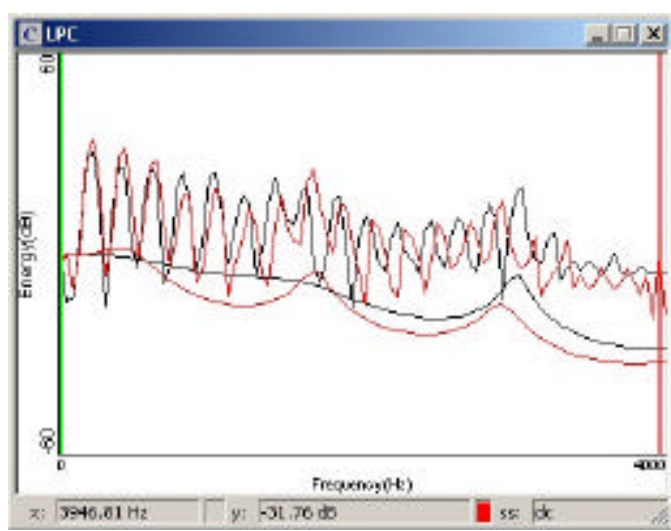

CON17

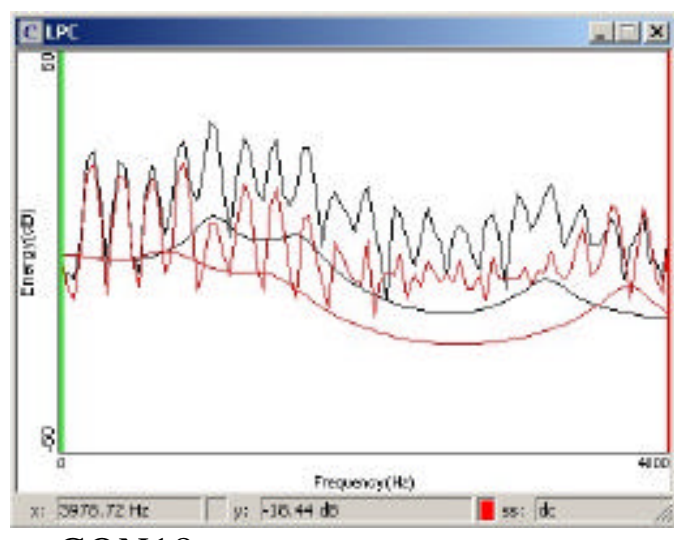

CON18 
APÊNDICE BK - Análises FFT e LPC das emissões das vogais [a] (linha preta) e [ẽ ] sustentadas (linha vermelha), de participantes do grupo CON (Continuação).

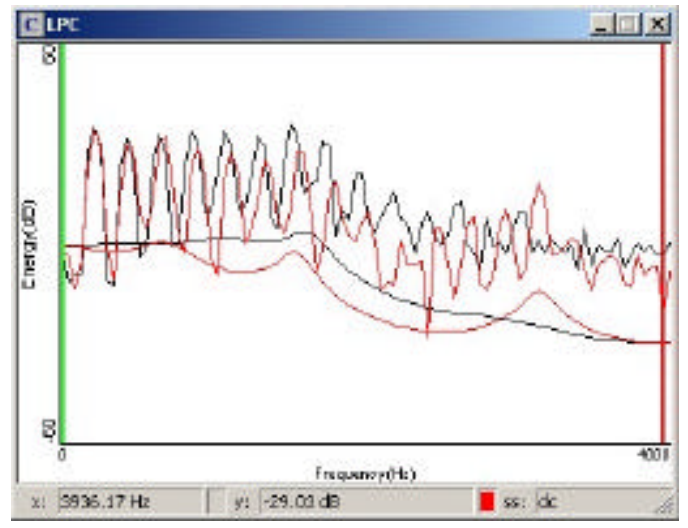

CON19

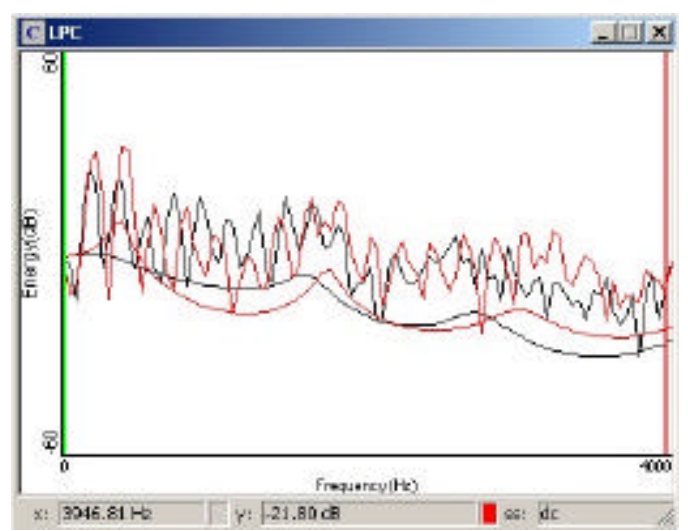

CON20

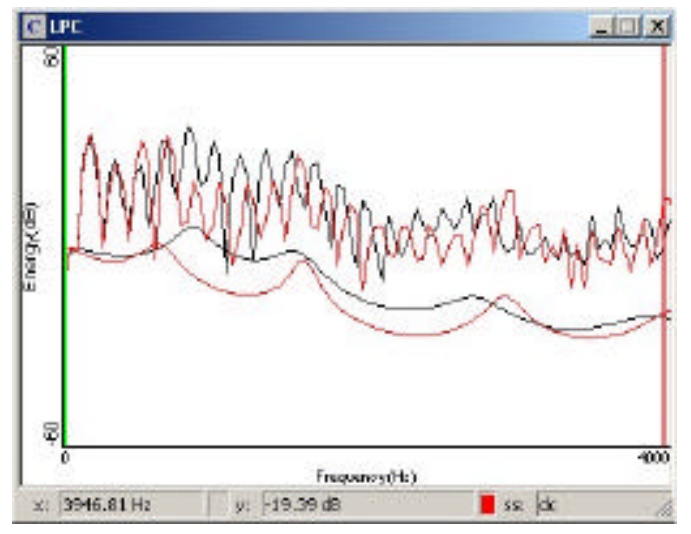

CON21

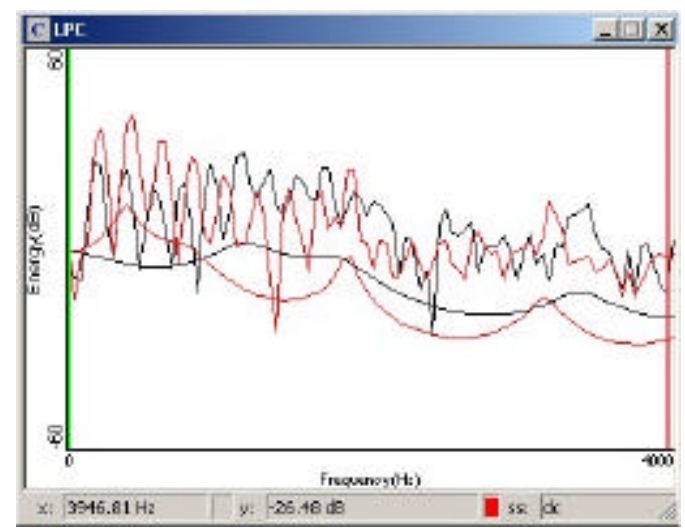

CON22

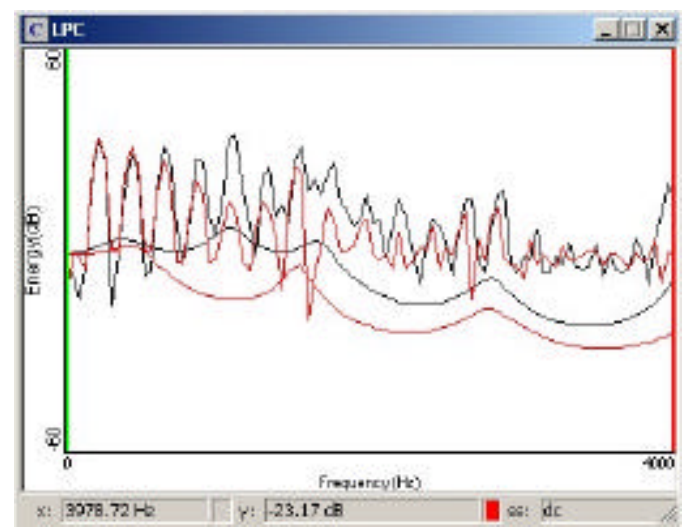

CON23

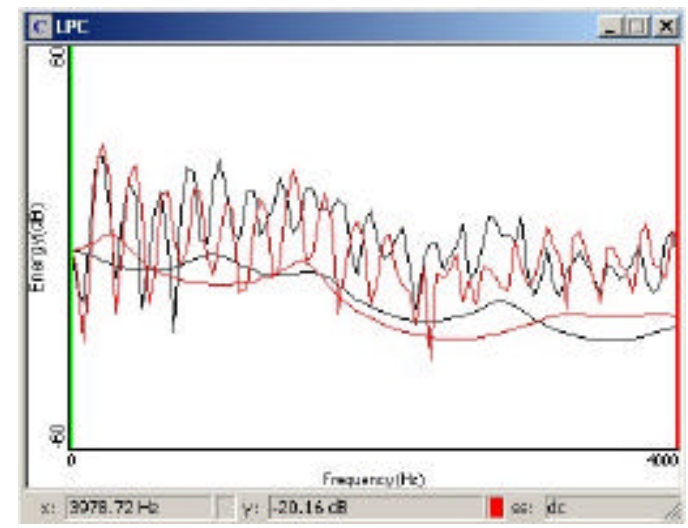

CON24 
APENNDICE BK - Análises FFT e LPC das emissões das vogais [a] (linha preta) e [ẽ ] sustentadas (linha vermelha), de participantes do grupo CON (Continuação).

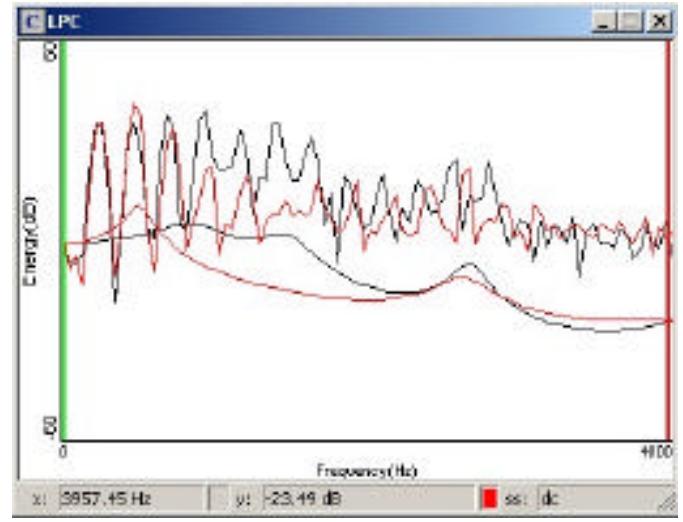

CON25

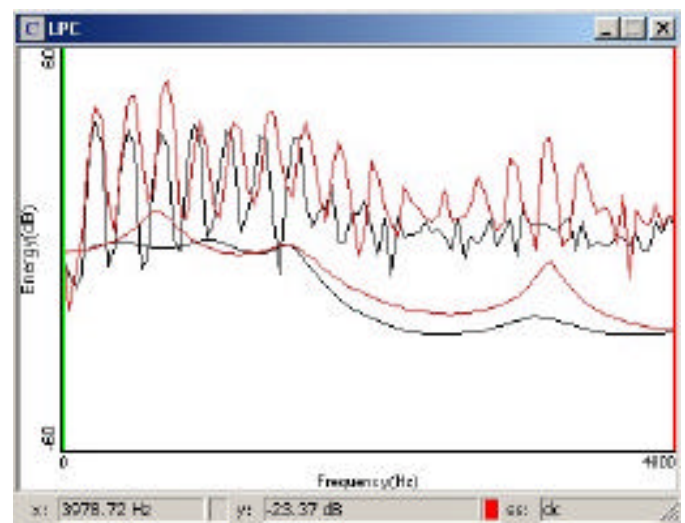

CON26

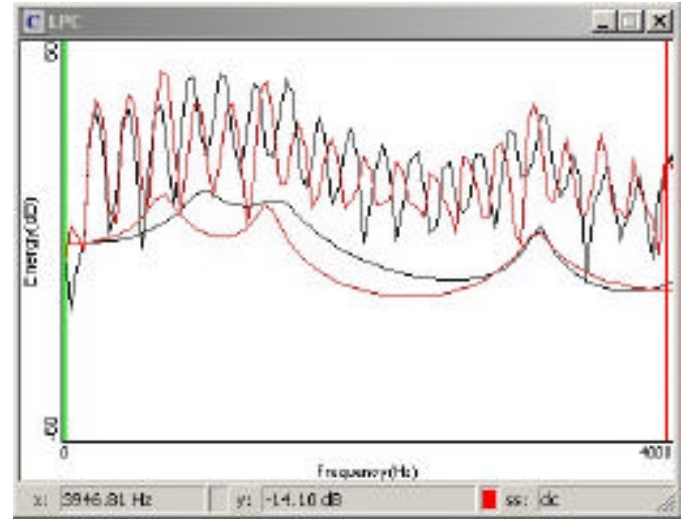

CON27

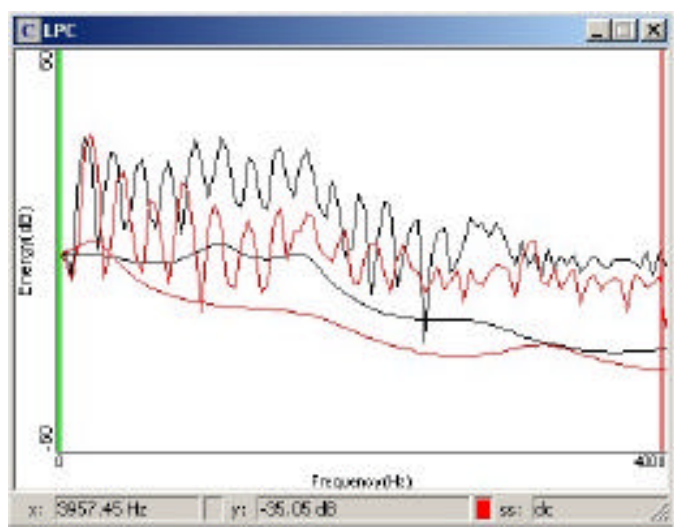

CON28

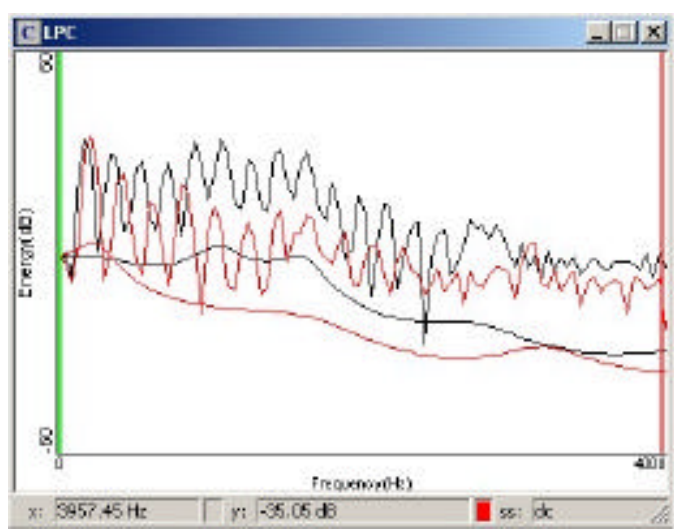

CON29

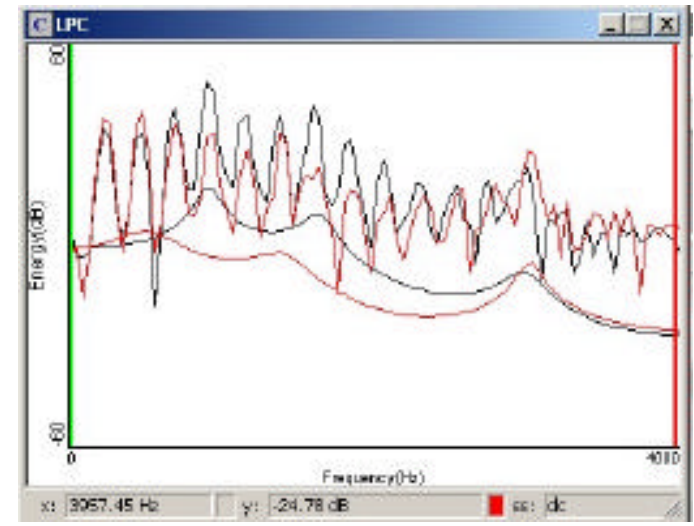

CON30 
APÊNDICE BL - Análises FFT e LPC das emissões das vogais [a] (linha preta) e [ẽ] sustentadas (linha vermelha), de participantes do grupo PFA.

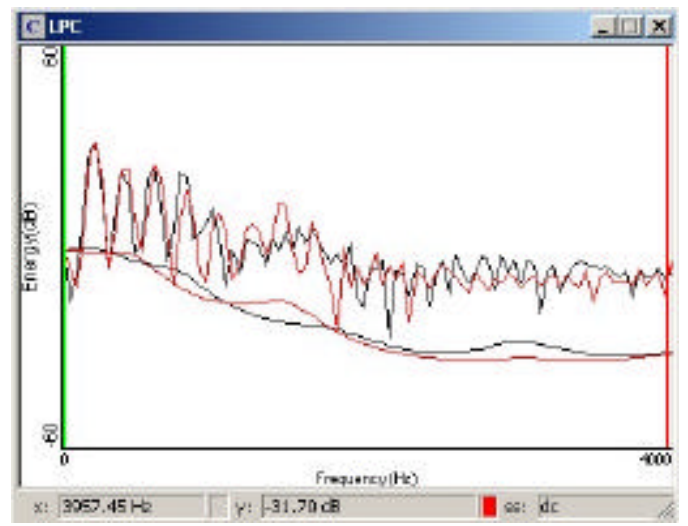

PFA01

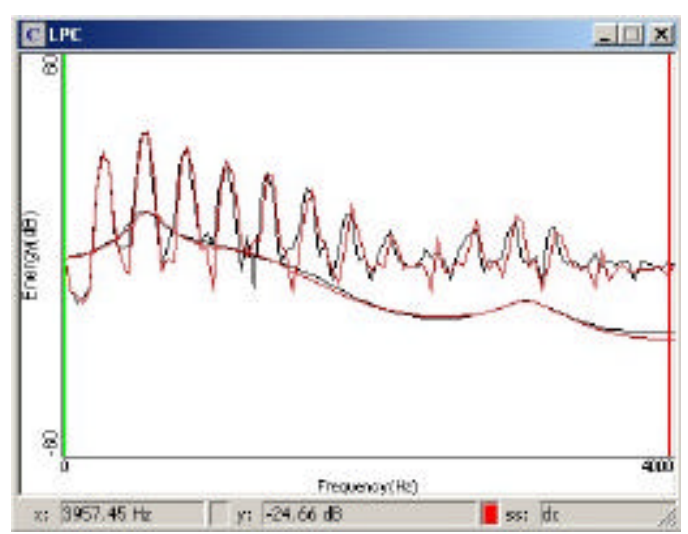

PFA02

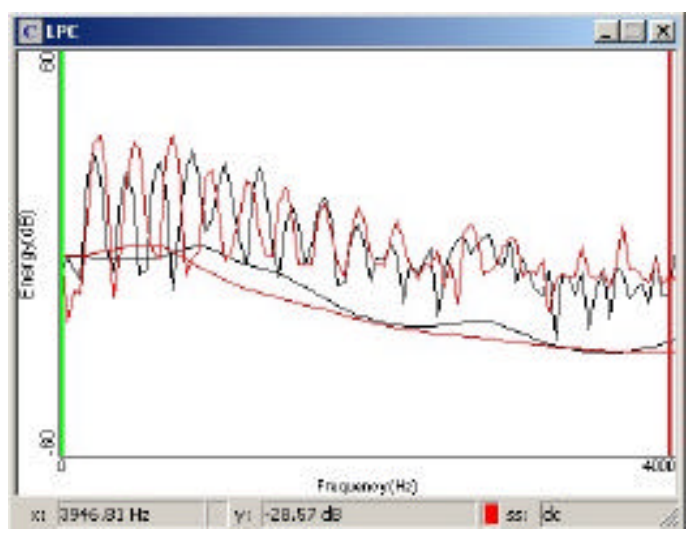

PFA03

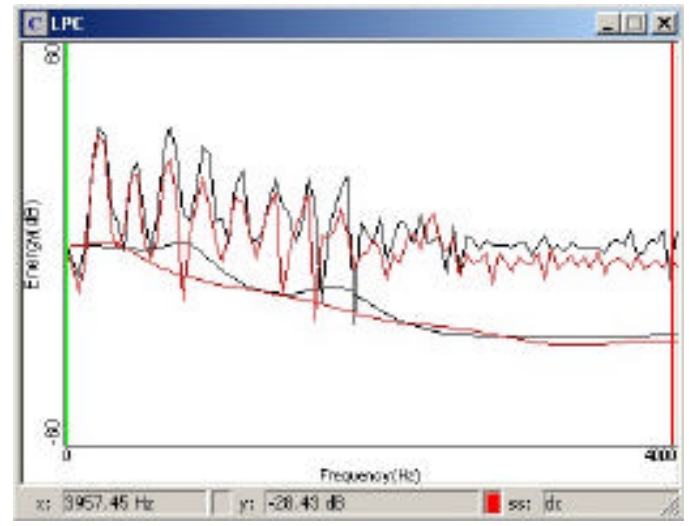

PFA04

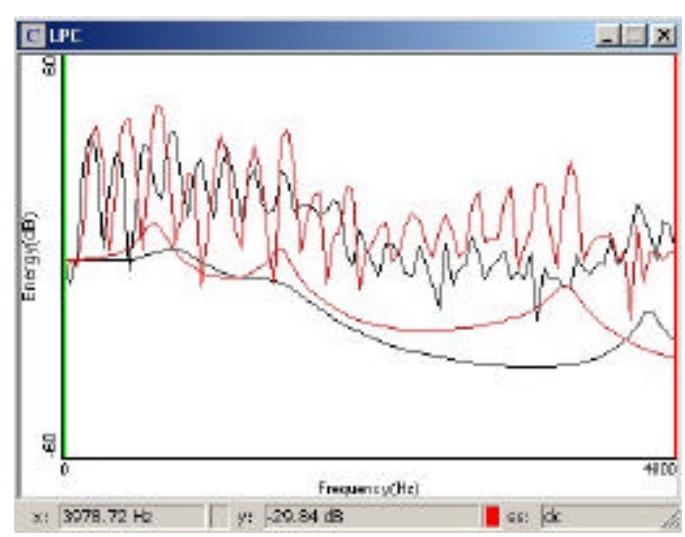

PFA05 
APÊNDICE BM - Análises FFT e LPC das emissões das vogais [a] (linha preta) e [ẽ ] sustentadas (linha vermelha), de participantes do grupo PFR.

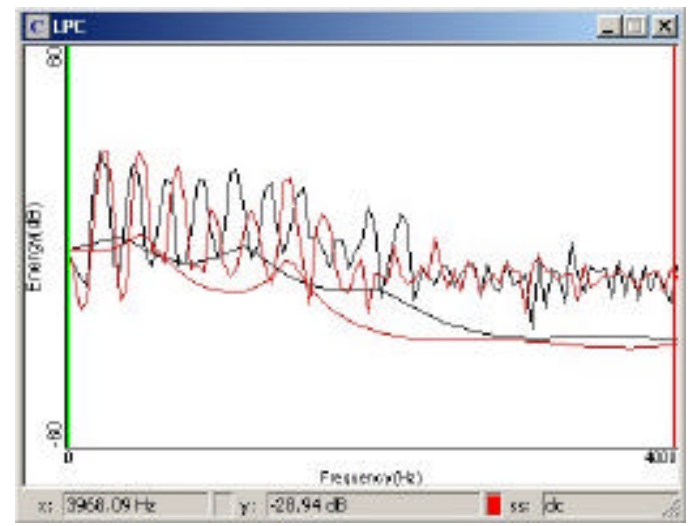

PFR01

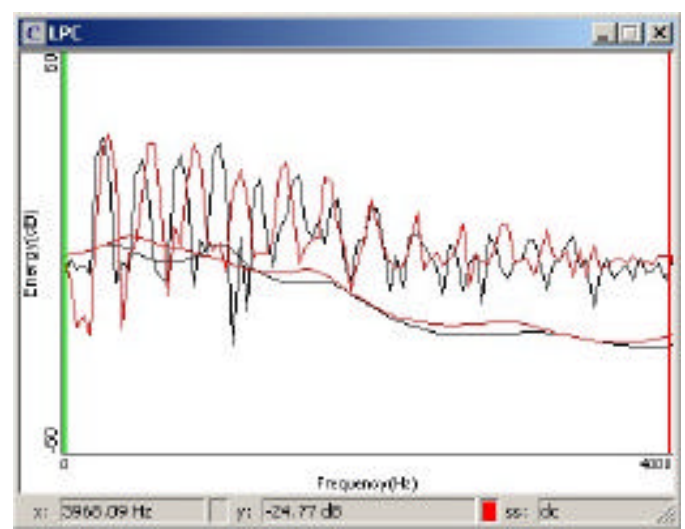

PFR02

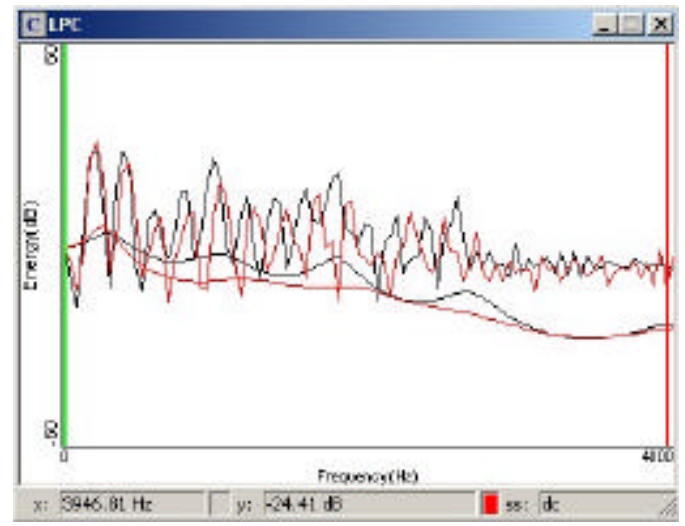

PFR03

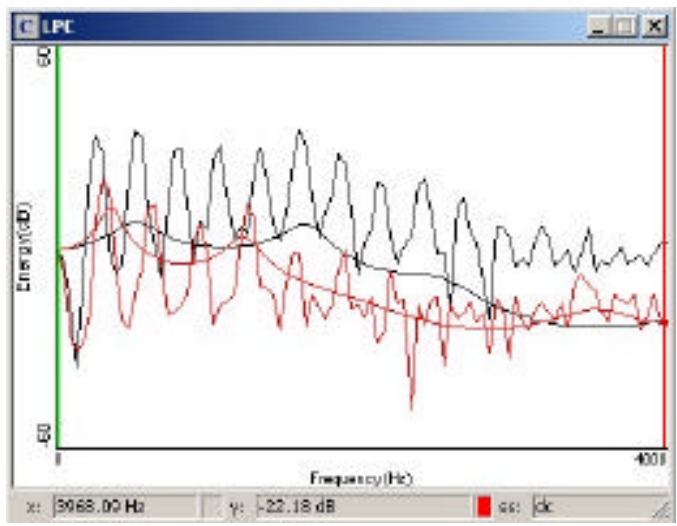

PFR04

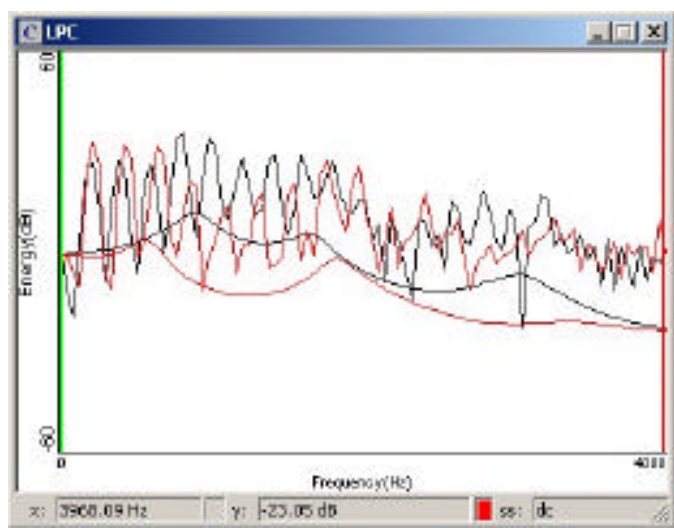

PFR05

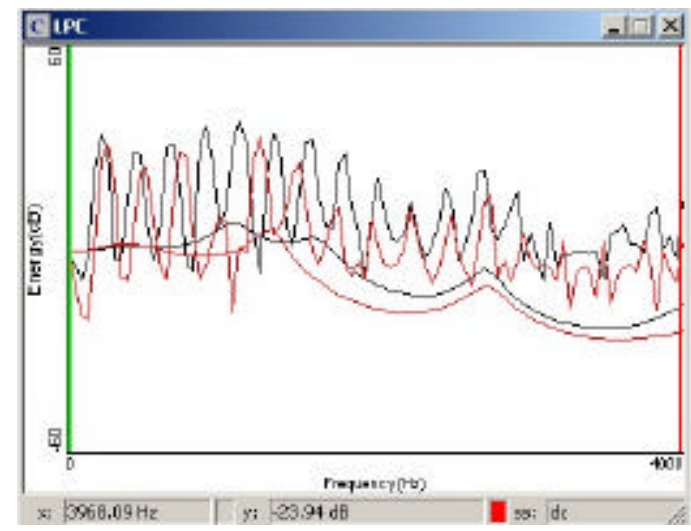

PFR06 
APÊNDICE BM - Análises FFT e LPC das emissões das vogais [a] (linha preta) e [ẽ] sustentadas (linha vermelha), de participantes do grupo PFR (Continuação).

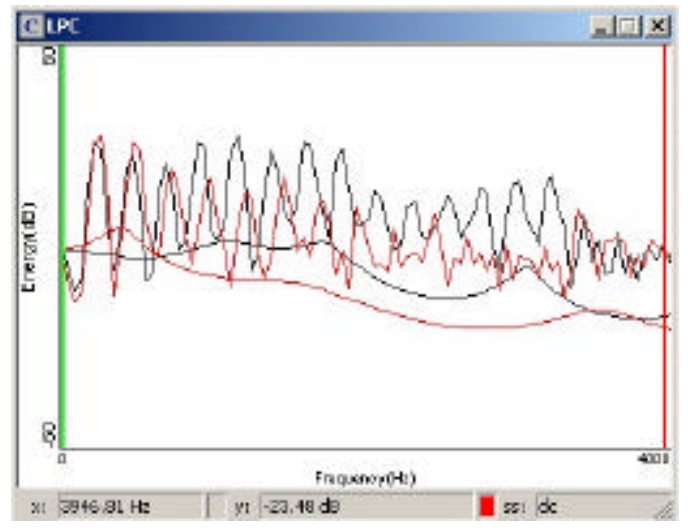

PFR07

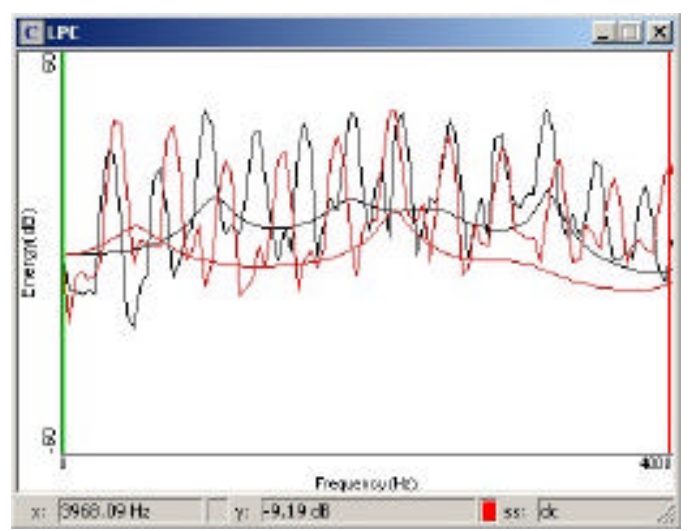

PFR08

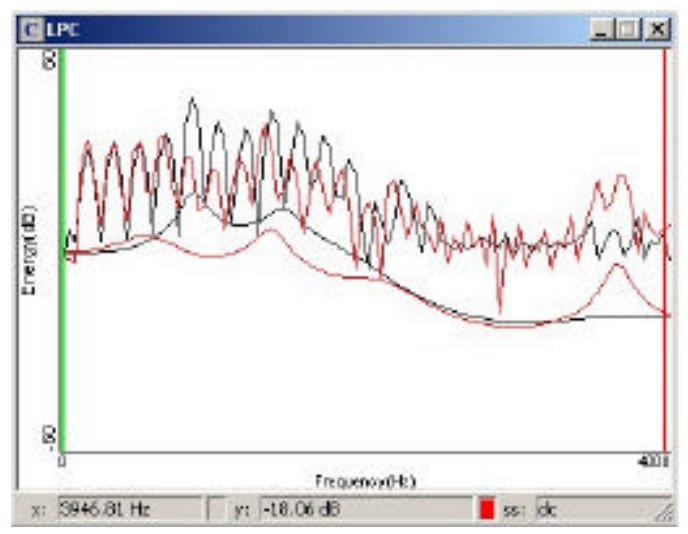

PFR09

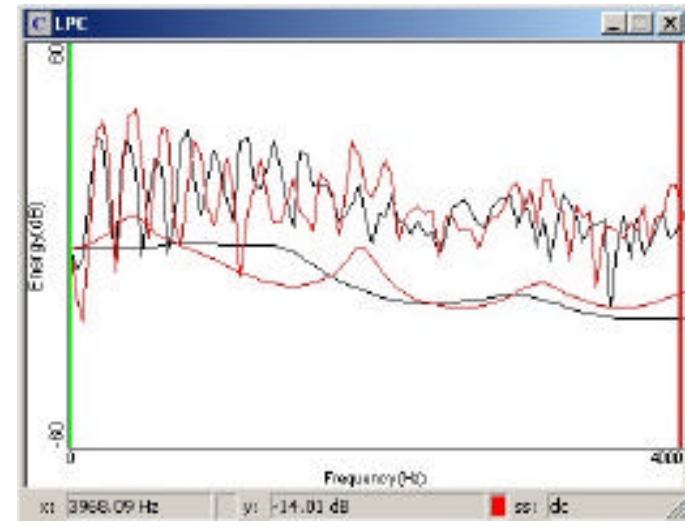

PFR10

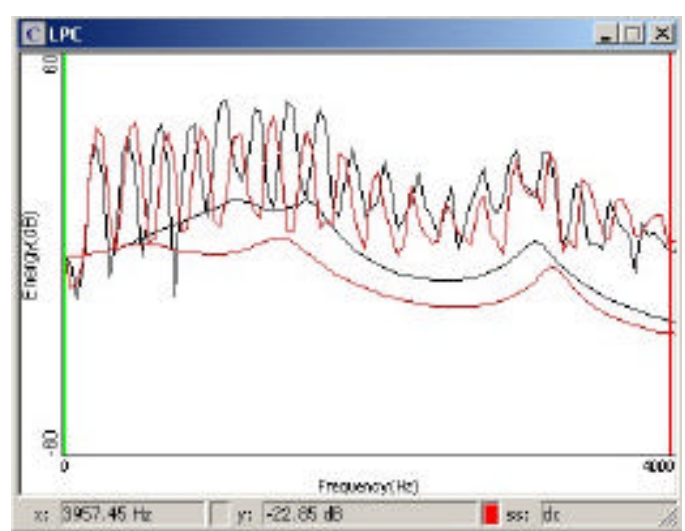

PFR 11

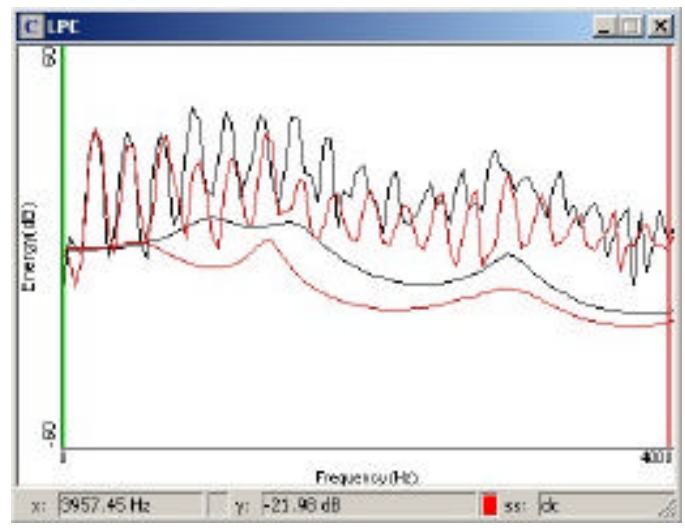

PFR12 
APÊNDICE BM - Análises FFT e LPC das emissões das vogais [a] (linha preta) e [ẽ ] sustentadas (linha vermelha), de participantes do grupo PFR (Continuação).

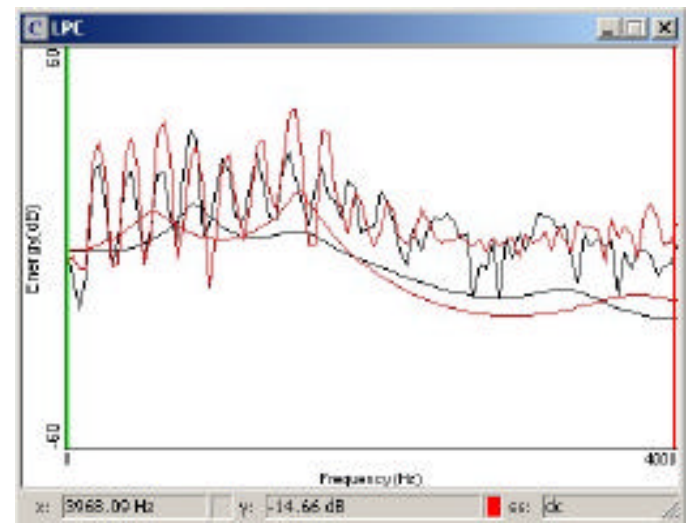

PFR 13

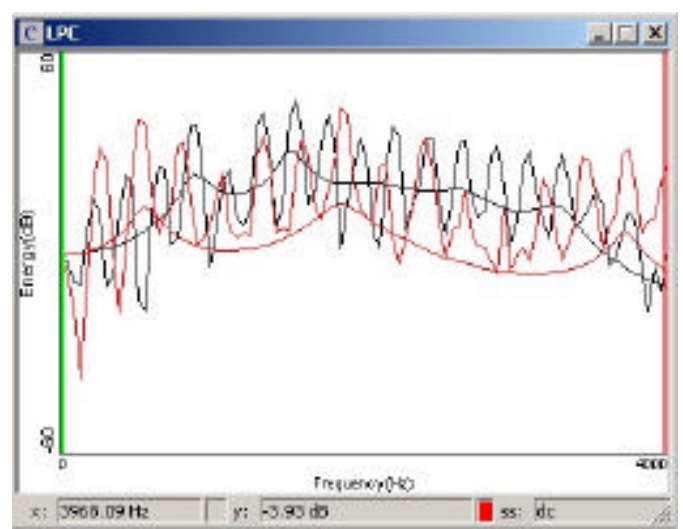

PFR14

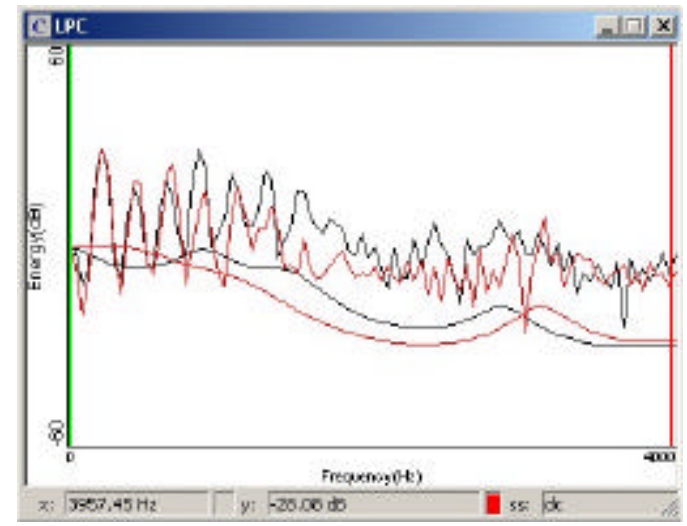

PFR 15

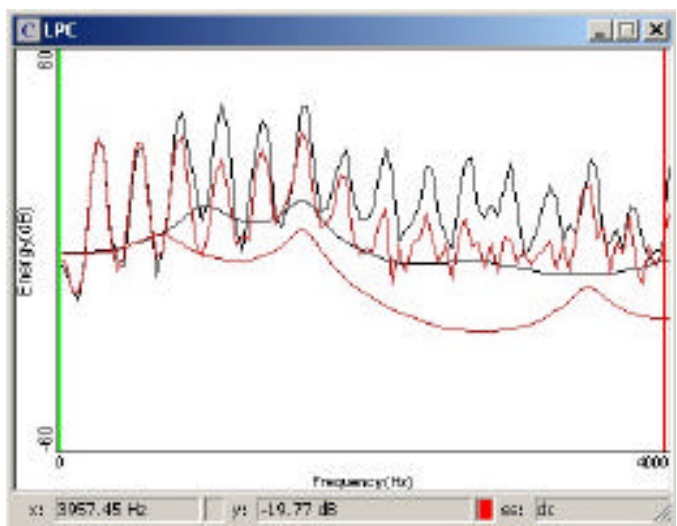

PFR16

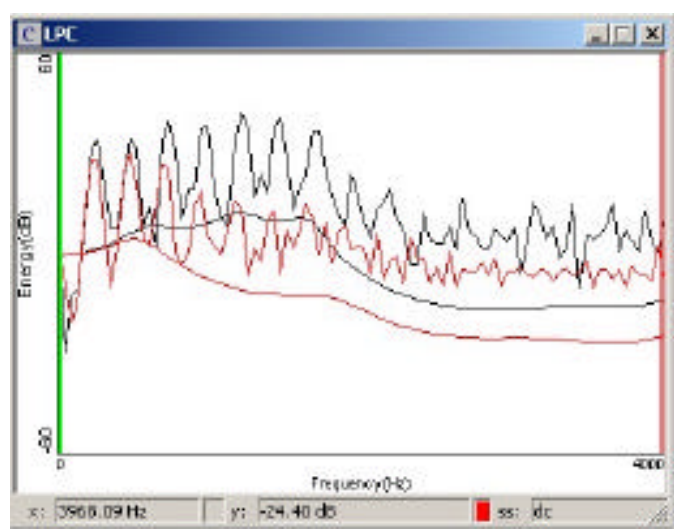

PFR17

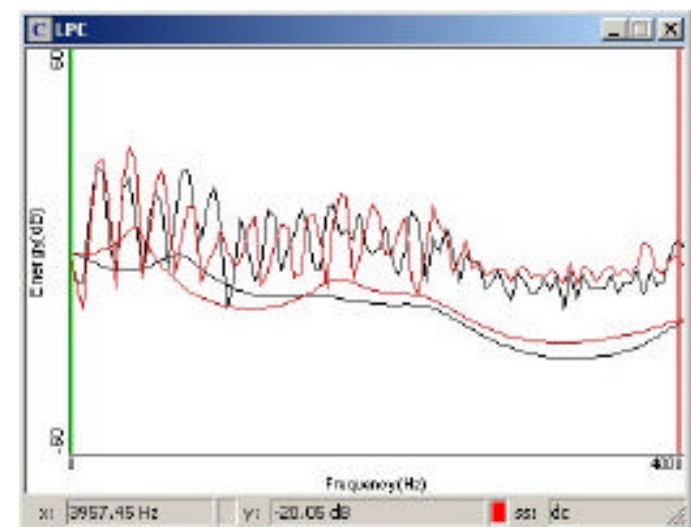

PFR18 
APÊNDICE BM - Análises FFT e LPC das emissões das vogais [a] (linha preta) e [ẽ ] sustentadas (linha vermelha), de participantes do grupo PFR (Continuação).

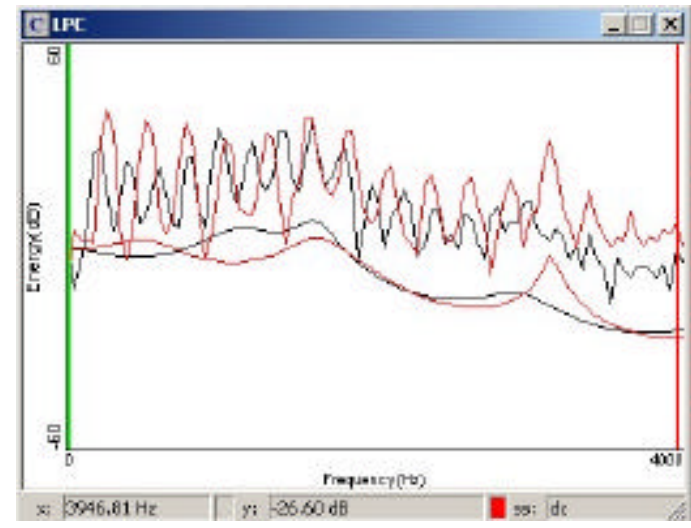

PFR19

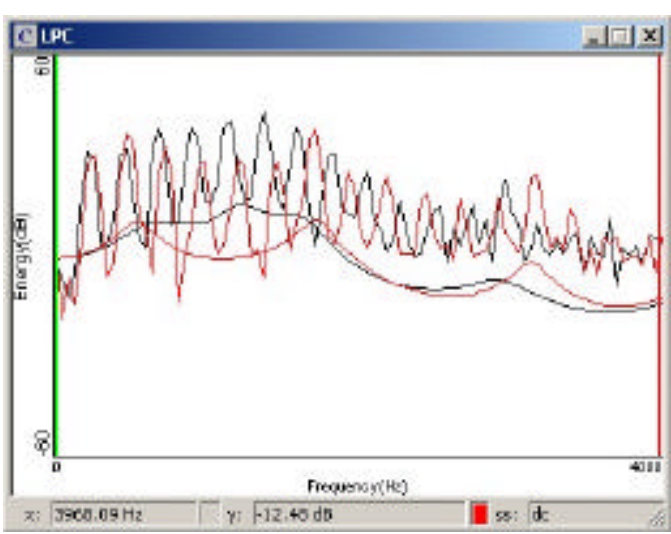

PFR20

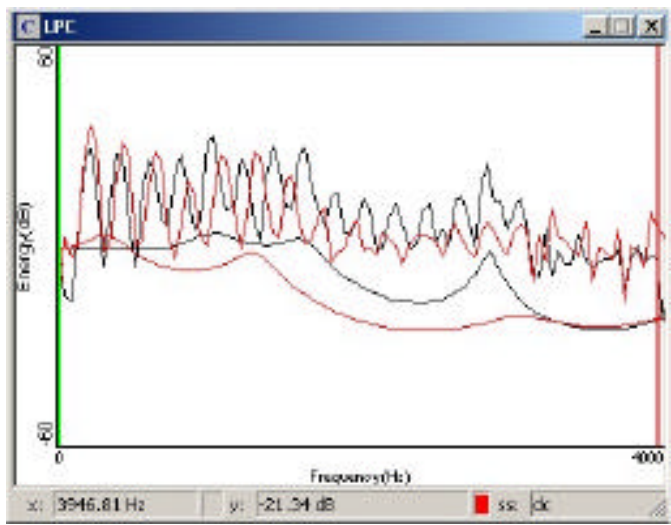

PFR21 
APÊNDICE BN - Tabela comparativa dos resultados entre a avaliação perceptivoauditiva e a análise instrumental na emissão da vogal oral [a] para os 3 grupos estudados.

\begin{tabular}{|c|c|c|c|c|c|c|c|c|}
\hline \multirow[b]{2}{*}{ Grupo } & \multirow[b]{2}{*}{ Hipernasalidade } & \multirow[b]{2}{*}{$\begin{array}{c}\text { Ressonância } \\
\text { nasal/ } \\
\text { Hipernasalidade }\end{array}$} & \multirow[b]{2}{*}{$\begin{array}{c}\text { Nasalância } \\
(\%)\end{array}$} & \multicolumn{5}{|c|}{ Formantes $(\mathrm{Hz})$} \\
\hline & & & & $\mathbf{F}_{1} / \mathbf{f}_{1}$ & $\mathbf{F}_{2} / \mathbf{f}_{2}$ & $\mathbf{F}_{\mathbf{3}} / \mathbf{f}_{\mathbf{3}}$ & $\begin{array}{c}\mathbf{F}_{2}-\mathbf{F}_{1} \\
\text { ou } \\
\mathbf{f}_{2}-\mathbf{f}_{1} \\
\end{array}$ & $\begin{array}{c}\mathbf{F}_{3}-\mathbf{F}_{2} \\
\text { ou } \\
\mathbf{f}_{3}-\mathbf{f}_{2} \\
\end{array}$ \\
\hline CON30 & ausente & normal & 12,40 & 893 & 1553 & 2478 & 660 & 925 \\
\hline CON21 & ausente & normal & 12,48 & 851 & 1531 & 2744 & 680 & 1213 \\
\hline CON28 & ausente & normal & 13,30 & 914 & 1436 & 3117 & 522 & 1681 \\
\hline CON13 & ausente & normal & 15,25 & 1034 & 1690 & 2738 & 656 & 1048 \\
\hline CONO3 & ausente & normal & 16,34 & 1000 & 1583 & 2869 & 583 & 1286 \\
\hline CON31 & ausente & normal & 20,21 & 893 & 1627 & 2946 & 734 & 1319 \\
\hline CON08 & ausente & normal & 23,80 & 960 & 1561 & 2846 & 601 & 1285 \\
\hline CON14 & ausente & normal & 24,47 & 971 & 1589 & 2776 & 618 & 1187 \\
\hline CON06 & ausente & normal & 25,80 & 954 & 1609 & 2678 & 655 & 1069 \\
\hline CON09 & ausente & normal & 30,88 & 897 & 1527 & 2787 & 630 & 1260 \\
\hline CONO2 & ausente & normal & 31,23 & 883 & 1507 & 3002 & 624 & 1495 \\
\hline CON17 & ausente & normal & 31,65 & 648 & 1585 & 3010 & 937 & 1425 \\
\hline CON25 & ausente & normal & 31,96 & 914 & 1627 & 2808 & 713 & 1181 \\
\hline CON26 & ausente & normal & 39,41 & 861 & 1457 & 2670 & 596 & 1213 \\
\hline CON01 & ausente & normal & 40,09 & 831 & 1706 & 2847 & 875 & 1141 \\
\hline CON07 & ausente & normal & 41,31 & 900 & 1441 & 2510 & 541 & 1069 \\
\hline CON24 & ausente & normal & 44,41 & 1042 & 1648 & 2797 & 606 & 1149 \\
\hline CON19 & ausente & normal & 45,19 & 925 & 1574 & 2872 & 649 & 1298 \\
\hline CON12 & ausente & normal & 50,01 & 958 & 1665 & 2927 & 707 & 1262 \\
\hline CON04 & ausente & normal & 51,22 & 876 & 1525 & 2870 & 649 & 1345 \\
\hline CON20 & ausente & normal & 51,44 & 794 & 1563 & 2712 & 769 & 1149 \\
\hline CON05 & ausente & normal & 57,83 & 965 & 1561 & 2984 & 596 & 1423 \\
\hline CON16 & ausente & moderada & 66,18 & 1085 & 1712 & 2893 & 627 & 1181 \\
\hline CON10 & presente & leve & 16,20 & 1084 & 1586 & 2997 & 502 & 1411 \\
\hline CON15 & presente & não avaliada & 31,29 & 1135 & 1577 & 2700 & 442 & 1123 \\
\hline CON18 & presente & moderada & 40,56 & 984 & 1552 & 3154 & 568 & 1602 \\
\hline CON23 & presente & não avaliada & 47,05 & 1148 & 1744 & 3287 & 596 & 1543 \\
\hline CON27 & presente & leve & 49,07 & 925 & 1468 & 3042 & 543 & 1574 \\
\hline CON29 & presente & moderada & 52,40 & 1021 & 1595 & 2840 & 574 & 1245 \\
\hline CON11 & presente & não avaliada & 55,23 & 1042 & 1595 & 3000 & 553 & 1405 \\
\hline PFA03 & ausente & normal & 20,54 & 893 & 1468 & 2712 & 575 & 1244 \\
\hline PFA02 & presente & não avaliada & 26,79 & 531 & & 3021 & & 3021 \\
\hline PFA04 & presente & moderada & 26,82 & 744 & 1787 & & 1043 & \\
\hline PFA05 & presente & severa & 32,41 & 744 & 1404 & 3765 & 660 & 2361 \\
\hline PFA01 & presente & severa & 41,80 & 776 & 1702 & 2978 & 926 & 1276 \\
\hline PFR12 & ausente & normal & 13,47 & 989 & 1521 & 2904 & 532 & 1383 \\
\hline PFR10 & ausente & normal & 28,89 & 1106 & 2861 & & 1755 & \\
\hline PFR21 & ausente & normal & 30,44 & 978 & 1606 & 2840 & 628 & 1234 \\
\hline PFR15 & ausente & normal & 40,35 & 893 & 1478 & 2840 & 585 & 1362 \\
\hline PFR06 & ausente & normal & 41,08 & 1053 & 1627 & 2702 & 574 & 1075 \\
\hline PFR11 & ausente & normal & 47,16 & 1117 & 1606 & 3095 & 489 & 1489 \\
\hline PFR02 & presente & leve & 27,75 & 1000 & 1723 & 3000 & 723 & 1277 \\
\hline PFR18 & presente & moderada & 29,18 & 712 & 1670 & 2340 & 958 & 670 \\
\hline PFR16 & presente & moderada & 29,41 & 989 & 1595 & 2723 & 606 & 1128 \\
\hline PFR17 & presente & moderada & 29,59 & 659 & 1148 & 1659 & 489 & 511 \\
\hline PFR14 & presente & moderada & 29,97 & 882 & 1542 & 2606 & 660 & 1064 \\
\hline PFR01 & presente & não avaliada & 32,35 & 382 & 1148 & 2010 & 766 & 862 \\
\hline PFR19 & presente & moderada & 32,71 & 1031 & 1606 & 2925 & 575 & 1319 \\
\hline PFR20 & presente & moderada & 39,36 & 670 & 1521 & 2893 & 851 & 1372 \\
\hline PFR04 & presente & moderada & 39,73 & 531 & 1627 & 2468 & 1096 & 841 \\
\hline
\end{tabular}


APÊNDICE BN - Tabela comparativa dos resultados entre a avaliação perceptivo auditiva e a análise instrumental na emissão da vogal oral [a] para os 3 grupos estudados (Continuação).

\begin{tabular}{|c|c|c|c|c|c|c|c|c|}
\hline \multirow[b]{2}{*}{ Grupo } & \multirow[b]{2}{*}{ Hipernasalidade } & \multirow[b]{2}{*}{$\begin{array}{c}\text { Ressonância } \\
\text { nasal/ } \\
\text { Hipernasalidade }\end{array}$} & \multirow[b]{2}{*}{$\begin{array}{c}\text { Nasalância } \\
(\%)\end{array}$} & \multicolumn{5}{|c|}{ Formantes (Hz) } \\
\hline & & & & $\mathbf{F}_{1} / \mathbf{f}_{1}$ & $\mathbf{F}_{2} / \mathbf{f}_{2}$ & $\mathbf{F}_{3} / \mathbf{f}_{\mathbf{3}}$ & $\begin{array}{c}\mathbf{F}_{2}-\mathbf{F}_{1} \\
\text { ou } \\
\mathbf{f}_{2}-\mathbf{f}_{1} \\
\end{array}$ & $\begin{array}{r}F_{3}-F_{2} \\
\text { ou } \\
f_{3}-\mathbf{f}_{2} \\
\end{array}$ \\
\hline PFR07 & presente & não avaliada & 40,75 & 1085 & 1765 & 3021 & 680 & 1256 \\
\hline PFR13 & presente & leve & 43,29 & 829 & 1500 & 3212 & 671 & 1712 \\
\hline PFR09 & presente & severa & 44,95 & 861 & 1489 & & 628 & \\
\hline PFR03 & presente & moderada & 55,03 & 989 & 1776 & 2606 & 787 & 830 \\
\hline PFR05 & presente & Leve & 95,68 & 877 & 1634 & 2976 & 757 & 1342 \\
\hline PFR08 & presente & moderada & 95,68 & 989 & 1872 & 2489 & 883 & 617 \\
\hline
\end{tabular}




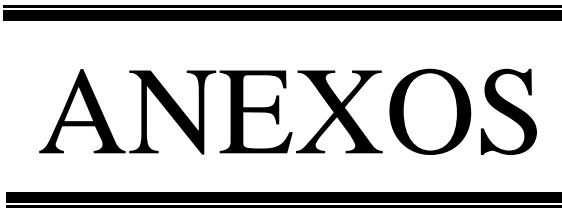


ANEXO A - Ofício no. 072/2002 do Comitê de Ética em Pesquisa (CEP) do HRAC/USP.

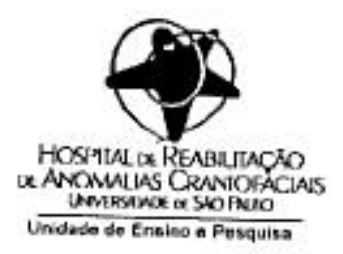

Oficio $n^{\circ}$ 072/2002-UEP-CEP

Bauru, 19 de junho de 2002.

Prezada Senhora

Comunicamos que cm reunião realizada no dia 12 de junho de 2002, pelo Comitê de Ética em Pesquisa, o projeto de pesquisa abaixo de autoria de V.S*, foi aprovado, por este Comitê.

TírULO: Perfil espectográfico da hipernasalidade de fala de mulheres portadoras de fissura palatina

CURSO: Mestrado

Atcnciosamente

$$
\text { Avomi j. AH }
$$

PROF. DR. ANTONIO GABRIEL ATTA

Presidente do Comitê de Ética em Pesquisa do HRAC-USP

$11 \mathrm{~m}^{\mathrm{n}} \mathrm{St} \mathrm{r}^{\mathrm{s}}$

JUSSARA MELO VIEIRA

N/C

Profa. Dra. Maria Inês Pegoraro-Krook

Projeto Flórida - HRAC/USP 
ANEXO B - Classificações da inteligibilidade de fala e da ressonância de fala, segundo Pegoraro-Krook, 1995.

\section{JULGAMENTO DA INTELIGIBILIDADE DE FALA}

\begin{tabular}{cl}
\hline NORMAL & $\begin{array}{l}\text { Inteligibilidade clara, sem nenhuma dificuldade em entender } \\
\text { a fala. }\end{array}$ \\
\hline LEVE & $\begin{array}{l}\text { Inteligibilidade levemente prejudicada, porém foi possível } \\
\text { entender o enunciado e compreender a idéia. }\end{array}$ \\
\hline $\begin{array}{c}\text { LEVE } \\
\text { P/ MODERADA }\end{array}$ & $\begin{array}{l}\text { Houve dificuldade para entender parte do enunciado, mas } \\
\text { sem causar prejuízo na compreensão da idéia. }\end{array}$ \\
\hline MODERADA & $\begin{array}{l}\text { Houve dificuldade para entender parte do enunciado, } \\
\text { causando certo prejuízo na compreensão da idéia. }\end{array}$ \\
\hline $\begin{array}{c}\text { MODERADA } \\
\text { P/SEVERA }\end{array}$ & $\begin{array}{l}\text { Houve grande dificuldade para entender a maior parte do } \\
\text { enunciado, causando grande prejuízo na compreensão da } \\
\text { idéia. }\end{array}$ \\
\hline SEVERA & $\begin{array}{l}\text { Impossível entender o enunciado e a compreensão integral } \\
\text { da idéia. }\end{array}$ \\
\hline
\end{tabular}

\section{JULGAMENTO DA RESSONÂNCIA DE FALA}

(não contém conceituação)

0 - N.A. (não avaliado)

1 - Normal

2 - Mista

3 -Hipernasalidade: $\quad$ ( ) leve ( ) moderada $\quad$ ( ) severa
( ) aberta
( ) fechada
( ) aceitável
( ) não aceitável

4 - Hiponasalidade:

( ) leve

( ) moderada

( ) severa
( ) aberta
( ) fechada
( ) aceitável
( ) não aceitável 
ANEXO C - Visão nasoendoscópica do retalho faríngeo (PRÓTESE DE PALATO/HRAC/USP, 2003).

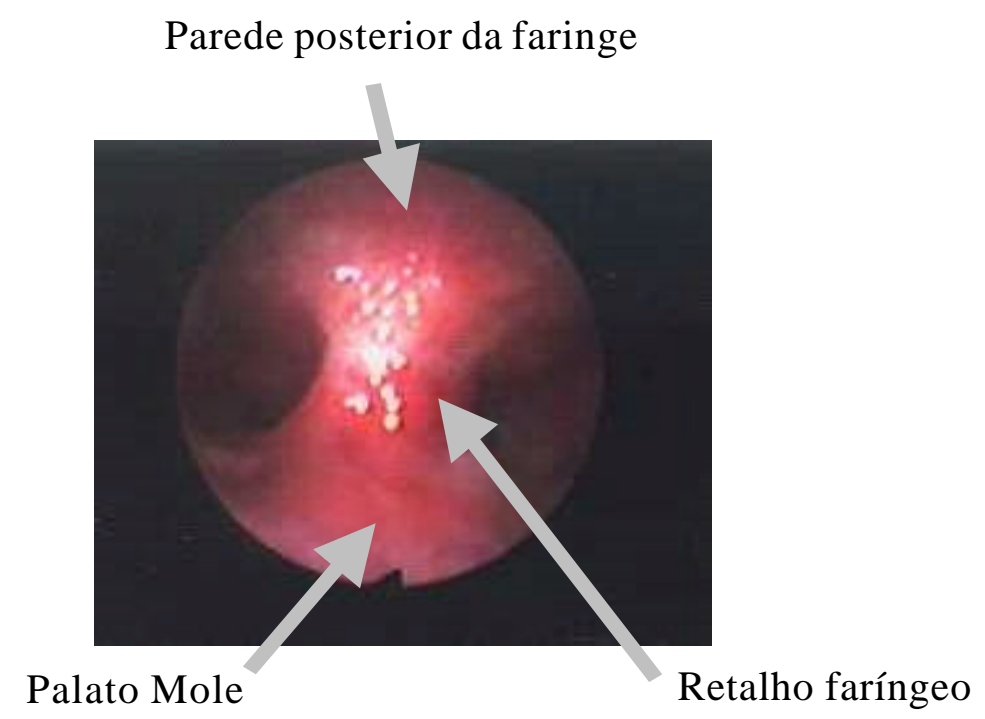

